\title{
Modeling Groundwater Flow and Transport of Radionuclides at Amchitka Island's Underground Nuclear Tests: Milrow, Long Shot, and Cannikin
}

\author{
prepared by \\ submitted to \\ Nevada Operations Office \\ U.S. Department of Energy
}

Ahmed Hassan, Karl Pohlmann and Jenny Chapman

OCTOBER 2002 
Reference herein to any specific commercial product, process, or service by trade name, trademark, manufacturer, or otherwise, does not necessarily constitute or imply its endorsement, recommendation, or favoring by the United States Government or any agency thereof or its contractors or subcontractors. The views and opinions of authors expressed herein do not necessarily state or reflect those of the United States Government or any agency thereof.

This report has been reproduced directly from the best available copy.

Available for sale to the public, in paper, from:

U.S. Department of Commerce

National Technical Information Service

5285 Port Royal Rd.

Springfield, VA 22161

phone: 800.553 .6847

fax: 703.605 .6000

email: order@ntis.fedworld.gov

online ordering: http://www.ntis.gov/ordering.htm

Available electronically at $h t t p: / / w w w . d o e . g o v / b r i d g e$

Available for a processing fee to the U.S. Department of Energy and its contractors, in paper, from:

U.S. Department of Energy

Office of Scientific and Technical Information

P.O. Box 62

Oak Ridge, TN 37831-0062

phone: 423.576 .8401

fax: 423.576 .5728

email: reports@adonis.osti.gov 


\title{
Modeling Groundwater Flow and Transport of Radionuclides at Amchitka Island's Underground Nuclear Tests: Milrow, Long Shot, and Cannikin
}

prepared by

\author{
Ahmed Hassan, Karl Pohlmann and Jenny Chapman \\ Division of Hydrologic Sciences \\ Desert Research Institute \\ University and Community College System of Nevada
}

Publication No. 45172

submitted to

Nevada Operations Office

U.S. Department of Energy

Las Vegas, Nevada

October 2002

The work upon which this report is based was supported by the U.S. Department of Energy under Contract \#DE-AC08-95NV11508. Approved for public release, further dissemination unlimited. 


\section{EXECUTIVE SUMMARY}

The groundwater flow and radionuclide transport at the Amchitka Island underground nuclear tests are modeled using two-dimensional numerical simulations. A multi-parameter uncertainty analysis is adapted and used to address the effects of the uncertainties associated with the definition of the modeled processes and the values of the parameters governing these processes. The nuclear tests performed at Milrow, Long Shot and Cannikin are the focus of this investigation. These tests were detonated on October 2, 1969, October 29, 1965, and November 6, 1971, respectively. The announced yield of these test are approximately one megaton for Milrow, 80 kilotons for Long Shot and less than five megatons for Cannikin.

The flow model is conceptualized to address the problem of density-driven flow where the saltwater intrusion problem is encountered. The multi-parameter uncertainty analysis addresses the effects of the uncertainty associated with four of the parameters governing these processes on the resulting solution. These parameters are the hydraulic conductivity, recharge, fracture porosity and

macrodispersivity. The heat-driven flow and three-dimensional flow features are addressed in a less rigorous manner via a sensitivity analysis. This includes the geothermal heat, the shot-induced heat effects, the chimney geometry, the effects of nearby faults and the effect of the island half-width. All the simulations presented in this report, as well as the sensitivity analyses, are performed using the FEFLOW model of the WASY Institute for Water Resources Planning and Systems Research Ltd.

The conceptual transport model simulates many processes in addition to the advection-dispersion process. The release mechanism and glass dissolution, sorption effects, matrix diffusion and radioactive decay are among the processes modeled. The parametric uncertainty analysis also extends to three of the transport parameters governing the glass dissolution process, the matrix diffusion process and local scale dispersion. The solution of the transport problem is performed using a numerical particle-tracking algorithm and a semi-analytical solution is used for the matrix diffusion studies.

Hydraulic conductivity data collected from six boreholes are analyzed to yield a best estimate for the homogeneous conductivity value and the range of uncertainty associated with this estimate. Temperature logs measured in several of the boreholes on the island are used to estimate groundwater recharge. Measurements of total porosity were made on numerous core samples obtained from four boreholes. There are no measurements for fracture porosity, and therefore, values for this parameter are selected based on reported values from the literature.

Batch sorption experiments were performed using cores collected from the Cannikin emplacement well. Sorption on both basalt and breccia was investigated for strontium, cesium, and lead dissolved in water of basically seawater composition. The high ionic strength of the solution and rock properties resulted in no significant sorption for any ion except lead. The resulting distribution coefficient for lead was used to obtain a surface-based sorption constant for retardation of strongly sorbing radionuclides in fractures. Effective diffusion coefficients were also determined 
for the cores and used to determine the matrix diffusion parameter controlling mass transfer from high-velocity fracture flowpaths into the surrounding matrix. This parameter is also dependent on the fracture half-aperture, estimated as $5 \times 10^{-4} \mathrm{~m}$ from literature values.

A detailed preliminary uncertainty analysis is performed for Milrow to evaluate the impact of uncertainties of individual parameters on transport results. The numerical model is individually calibrated for each test site using site-specific chloride concentration and head data. After calibration, the Milrow configuration is used to perform a parametric uncertainty analysis, where we vary one parameter at a time and evaluate the effects of this change on the results of the transport solutions. This analysis resulted in reducing the list of uncertain parameters to only three significant parameters (recharge, conductivity and porosity) and fixing the rest of the parameters at their best estimate.

The final modeling stage performed for all three shots utilized multiple realizations of the flow field generated by considering random combinations of recharge, conductivity and porosity drawn at random from their respective distributions. All transport parameters were fixed at their best estimate. The ensemble of transport solutions is then analyzed in terms of the mass arrival to the seafloor, the first arrival time and the location and time where peak fluxes and concentrations occur. An additional sensitivity case is also presented for addressing the effect of changing the strength of the matrix diffusion process.

Transport results indicated that the radionuclide movement at Long Shot is much faster than at Milrow and Cannikin. That is due to the location of the cavity being very shallow as compared to the other two tests. The arrival time of the peaks of mass flux and concentration for tritium is in the order of 20 to 30 years for Long Shot and 100 to 125 years for Milrow and Cannikin. This led to higher mass fluxes and concentrations breaking through at Long Shot than at Cannikin or Milrow with the difference depending on the radionuclide's half-life.

In addition to the three uncertain parameters considered (recharge, conductivity and fracture porosity), the results are also very sensitive to the parameters affecting the diffusion of radionuclides into the rock matrix. This sensitivity is greater for radionuclides with short half-lives. Uncertainties primarily in determining the fracture aperture lead to great uncertainty in the matrix diffusion strength. In addition, the semi-analytical solution employed for addressing the matrix diffusion process is based on many simplifying assumptions that are not necessarily satisfied in the field.

A variety of sensitivity studies are presented. With the exception of evaluating matrix diffusion, the alternate scenarios are performed on several realizations selected to be representative of the gamut of flow behavior. As a result, the sensitivity results are not directly comparable to the Monte Carlo results, but do allow identification of the general magnitude of impact that process uncertainty contributes. A variety of numerical solution issues, matrix diffusion, colloid transport, uncertainty in island half-width, sea level changes, and geothermal processes are evaluated using the two-dimensional models. The impact of the two-dimensional simplification, flow in the rubble chimney, Cannikin Lake nuclear heat and flow in fault zones are all evaluated with three-dimensional models. 
The presence of the nuclear chimney, with its high vertical conductivity, is found to dominate many of the other conceptualizations (the chimneys are included in the base-case Monte-Carlo calculations). Numerical solution issues, sea level changes, geothermal processes, the two-dimensional simplification, Cannikin Lake, and fault zones all have relatively limited impact on transport results for the realizations analyzed, or result in significantly less transport than the base case. Matrix diffusion, colloid transport, island half-width, and nuclear heat are potentially more significant. The results of the risk assessment will determine whether the uncertainties identified here are of potential significance or can be tolerated within an acceptable margin of safety. 


\section{ACKNOWLEDGEMENTS}

The authors wish to thank a number of technical reviewers whose comments improved the draft version of this report. This includes Greg Pohll, Roko Andricevic, and Craig Shirley of DRI; the members of the modeling subcommittee of the Underground Test Area Technical Working Group (Andrew Tompson, David Prudic, Rick Waddell, Andrew Wolfsberg, and Vefa Yucel); the Alaska Department of Conservation; and Bruce Crow of Los Alamos National Laboratory. Greg Pohll is also thanked for his valuable contributions to the temperature log analysis for recharge and glass dissolution function. We appreciate Craig Shirley's evaluation of geophysical logs early in the project. We are grateful to Todd Mihevc for the analysis of the many hydraulic tests and for obtaining the core samples and geophysical logs. The experimental sorption and diffusion work of Nicole Brown and Charalambos Papelis is a key contribution to this project and is gratefully acknowledged. Their work was made possible by the core material stored and provided by the U.S. Geological Survey Core Library in Mercury Nevada, which also shared geophysical logs. The authors also appreciate the contributions of David Benson and Bill $\mathrm{Hu}$ to this project in its early stages. Many thanks go to Debi Noack for her highly skillful electronic publishing support. Marjory Jones provided editorial support. Funding was provided by the U.S. Department of Energy, National Nuclear Security Administration, Nevada Operations Office and we are pleased to acknowledge the contributions to this work from Monica Sanchez, Michael Giblin, and Frank Maxwell.

\section{PUBLICATIONS RESULTING FROM THIS WORK}

Hassan, A., K. Pohlmann, and J. Chapman, 2001. Uncertainty Analysis of Radionuclide Transport in a Fractured Coastal Aquifer with Geothermal Effects. Transport in Porous Media 43:107-136.

Pohlmann, K., A. Hassan, and J. Chapman, 2002. Modeling Density-Driven Flow and Radionuclide Transport at an Underground Nuclear Test: Uncertainty Analysis and Effect of Parameter Correlation. Water Resources Research, 38(5), 10.1029/2001WR001047, pp. 17-1 to 17-18.

Chapman, J., A, Hassan, K. Pohlmann, 2002. Resolving Discrepancies Between Hydraulic and Chemical Calibration Data for Seawater Intrusion Groundwater Flow Models by Considering Climate-Driven Sea Level Change. In Sherif, M.M., V.P. Singh, and M. Al-Rashed (eds.), Environmental and Groundwater Pollution, Volume 3, A.A. Balkema Publishers, Lisse, The Netherlands, pp. 379-397.

Hassan, A., J. Chapman, and K. Pohlmann, in press. Uncertainty Analysis of Seawater Intrusion and Implications for Radionuclide Transport at the Amchitka Island's Underground Nuclear Tests. In Chang, A. and D. Ouazar (eds.), Coastal Aquifer Management - Monitoring, Modeling, and Case Studies. CRC Press, Boca Raton, Florida. 


\section{CONTENTS}

EXECUTIVE SUMMARY $\ldots \ldots \ldots \ldots \ldots \ldots \ldots \ldots \ldots \ldots \ldots \ldots \ldots$ ii

ACKNOWLEDGEMENTS $\ldots \ldots \ldots \ldots \ldots \ldots \ldots \ldots \ldots \ldots \ldots \ldots \ldots \ldots$ v

PUBLICATIONS RESULTING FROM THIS WORK $\ldots \ldots \ldots \ldots \ldots \ldots \ldots \ldots \ldots . \mathrm{v}$

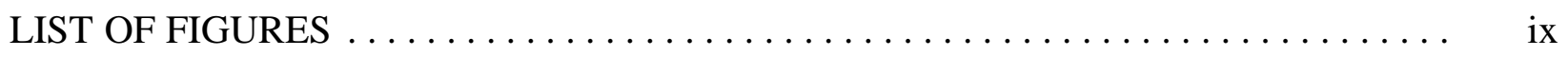

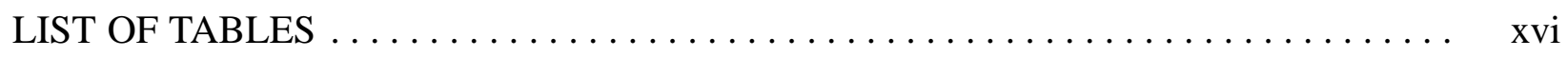

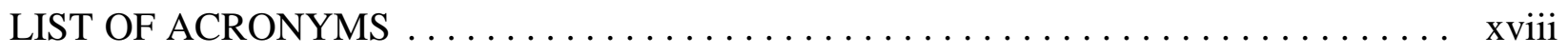

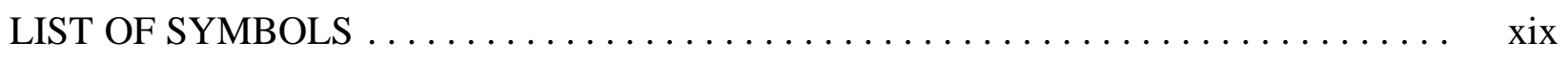

1. INTRODUCTION $\ldots \ldots \ldots \ldots \ldots \ldots \ldots \ldots \ldots \ldots \ldots \ldots \ldots \ldots \ldots \ldots$

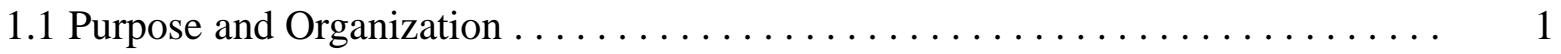

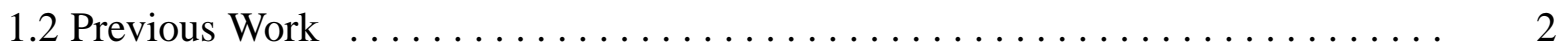

1.3 General Description of Amchitka Island $\ldots \ldots \ldots \ldots \ldots \ldots \ldots \ldots \ldots \ldots \ldots$

1.4 Description of the Underground Nuclear Test Sites $\ldots \ldots \ldots \ldots \ldots \ldots \ldots \ldots$

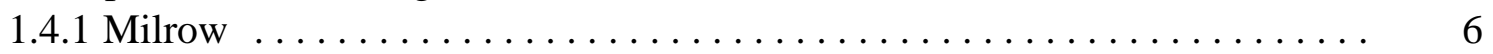

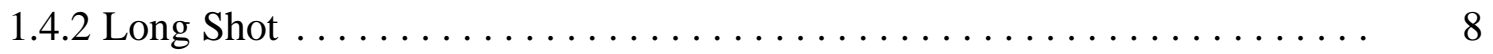

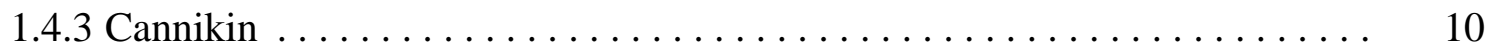

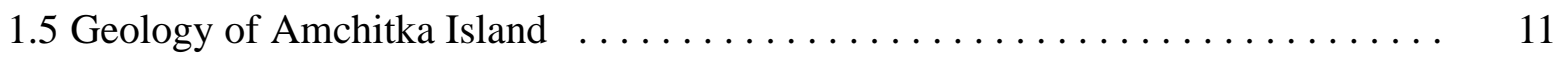

1.5.1 Lithology/Depositional History of Amchitka Island . . . . . . . . . . . 12

1.5.2 Lithology Specific to the Testing Areas . . . . . . . . . . . . . . . . . 15

1.5.3 General Structure of Amchitka Island $\ldots \ldots \ldots \ldots \ldots \ldots \ldots \ldots \ldots \ldots$

1.5.4 Structure Specific to the Testing Areas . . . . . . . . . . . . . . 19

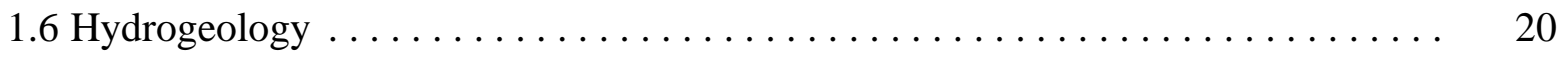

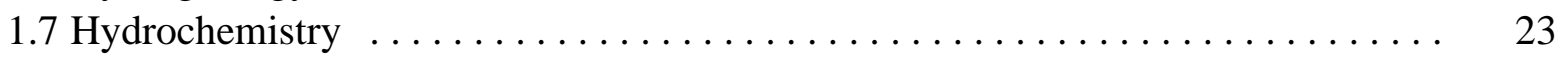

2. CONCEPTUAL FLOW MODEL, PARAMETERS, AND CALIBRATION . . . . . . 29

2.1 Model Components and Assumptions . . . . . . . . . . . . . . . . . . . . 29

2.1.1 Island Hydraulics . . . . . . . . . . . . . . . . . . . . . 29

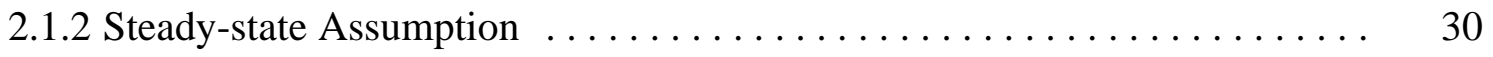

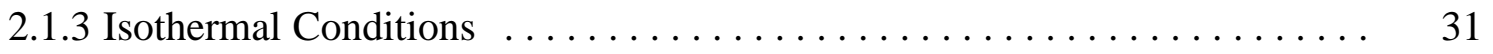

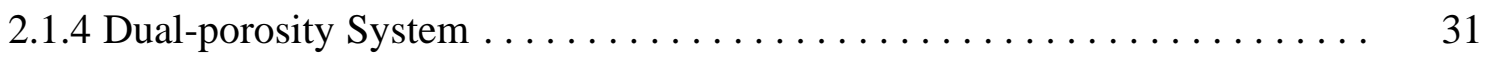

2.1.5 Homogeneity of Hydraulic Properties with Vertical Anisotropy . . . . . . . . 32

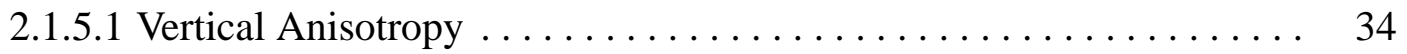

2.1.6 Limited Impact of the Nuclear Tests on the Island Flow Field . . . . . . . . 35

2.1.7 Alternate Conceptual Flow Models . . . . . . . . . . . . . . . . 36

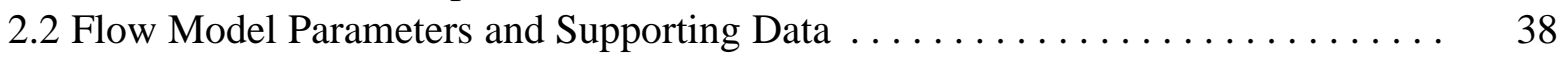

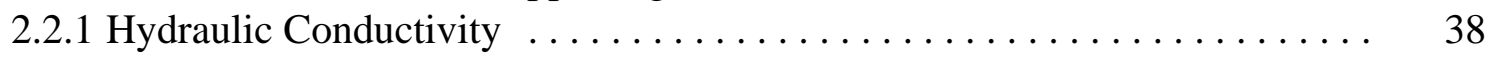

2.2.2 Hydraulic Head . . . . . . . . . . . . . . . . . . . . . . 41

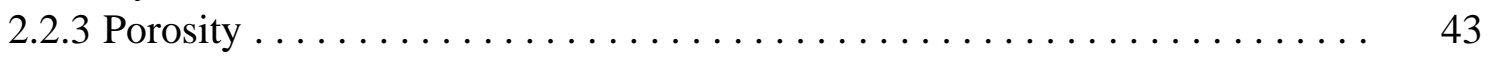

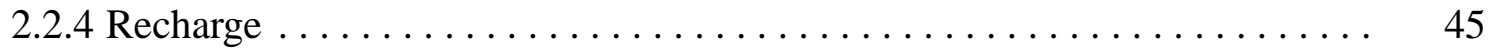

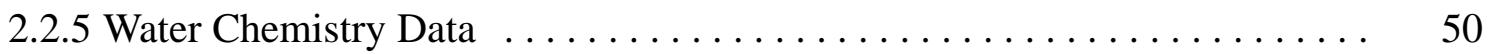

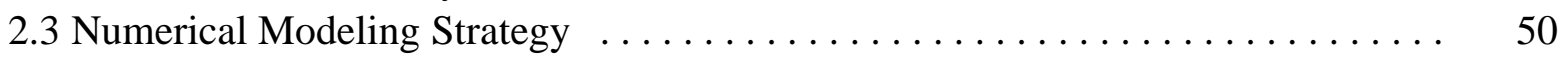

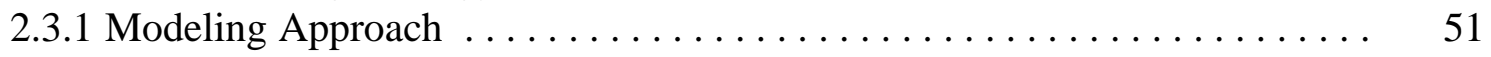

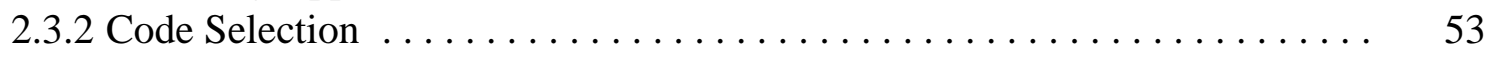


2.4 Flow Model Calibration .............................. 55

2.4.1 Milrow Calibration and Base-case Parameters $\ldots \ldots \ldots \ldots \ldots \ldots \ldots .56$

2.4.2 Long Shot Calibration and Base-case Parameters ............... 66

2.4.3 Cannikin Calibration and Base-case Parameters $\ldots \ldots \ldots \ldots \ldots \ldots .68$

2.4.4 Summary of Calibration Results $\ldots \ldots \ldots \ldots \ldots \ldots \ldots \ldots \ldots \ldots$

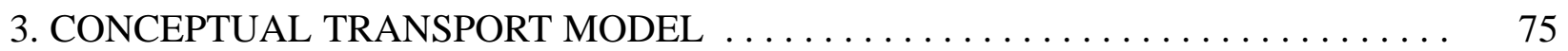

3.1 Source Term and Release Parameters . . . . . . . . . . . . . . . . . . . . 76

3.1.1 Radionuclide Source Term ........................... 76

3.1.1.1 Radioactivity Observed in Cannikin Cavity Water .............. 77

3.1 .2 Release Functions . . . . . . . . . . . . . . . . . . . . . . 78

3.1.2.1 Volume/Surface Mode Designation $\ldots \ldots \ldots \ldots \ldots \ldots \ldots \ldots . \ldots$

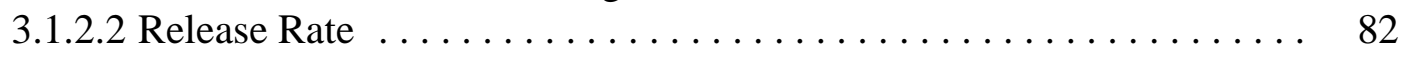

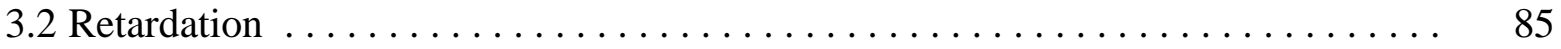

3.2.1 Assignment of Distribution Coefficient ................... 87

3.2.2 Calculation of Retardation Factor $\ldots \ldots \ldots \ldots \ldots \ldots \ldots \ldots \ldots \ldots$

3.2.3 Matrix Diffusion ............................... 89

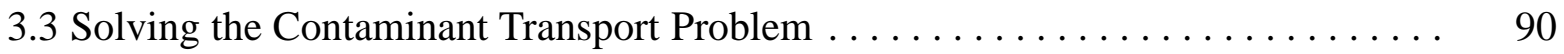

4. PARAMETRIC UNCERTAINTY ANALYSIS . . . . . . . . . . . . . . . . . 97

4.1 Sensitivity/Uncertainty Analysis of Flow Parameters . . . . . . . . . . . . 97

4.1.1 Numerical Approach for the Parametric Uncertainty Analysis . . . . . . . 100

4.1.2 Sensitivity of Concentration and Head Distributions to Flow Parameter

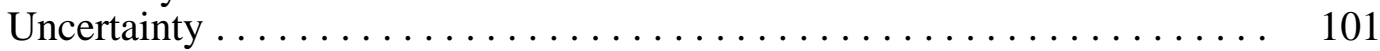

4.2 Sensitivity/Uncertainty Analysis of Transport Parameters $\ldots \ldots \ldots \ldots \ldots . . . \ldots 4$

4.3 Results of the Parametric Uncertainty Analysis . . . . . . . . . . . . . . 111

5. FLOW AND TRANSPORT MODELING RESULTS $\ldots \ldots \ldots \ldots \ldots \ldots \ldots \ldots \ldots$

5.1 Milrow Flow and Transport Results . . . . . . . . . . . . . . . . . 117

5.1 .1 Undecayed Breakthrough Curves ...................... 123

5.1.2 Breakthrough with Radioactive Decay ................... 136

5.1.3 Milrow Summary and Discussion $\ldots \ldots \ldots \ldots \ldots \ldots \ldots \ldots \ldots . \ldots \ldots 14$

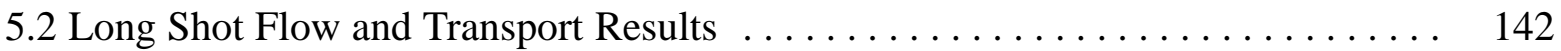

5.2.1 Undecayed Transport Results ......................... 147

5.2.2 Transport Results with Radioactive Decay .................. 150

5.2 .3 Long Shot Summary and Discussion .................... 155

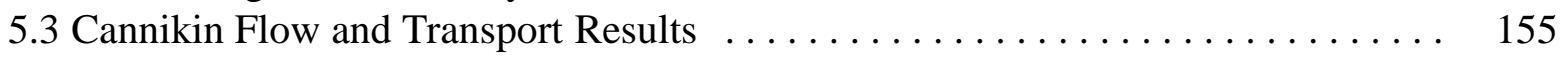

5.3 .1 Undecayed Transport Results ....................... 161

5.3.2 Transport Results with Radioactive Decay $\ldots \ldots \ldots \ldots \ldots \ldots \ldots \ldots . \ldots 164$

5.3 .3 Summary and Discussion ............................ 170

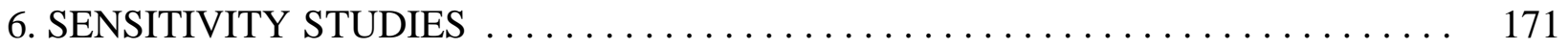

6.1 Two-dimensional Sensitivity Studies $\ldots \ldots \ldots \ldots \ldots \ldots \ldots \ldots \ldots \ldots \ldots \ldots \ldots \ldots \ldots \ldots \ldots \ldots \ldots$

6.1 .1 Numerical Solution Issues $\ldots \ldots \ldots \ldots \ldots \ldots \ldots \ldots \ldots \ldots \ldots \ldots \ldots \ldots$

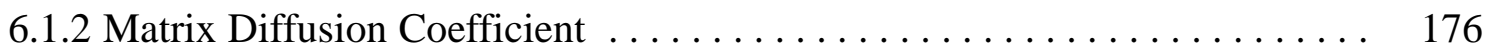

6.1 .3 Colloid Transport .............................. 187

6.1.4 Transient Responses to Sea Level Change .................... 192

6.1 .5 Island Half-Width . . . . . . . . . . . . . . . . . . . . . . . . . . 197 
6.1 .6 Geothermal Heat . . . . . . . . . . . . . . . . . . . . . 201

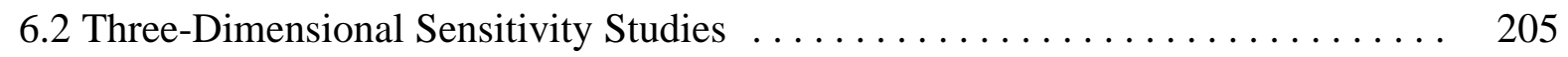

6.2.1 Flow in the Rubble Chimney ........................ 207

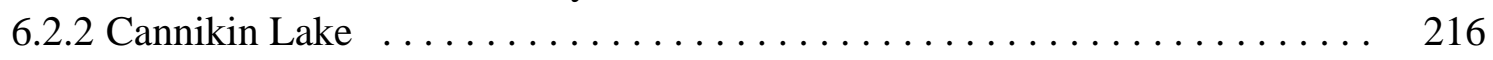

6.2 .3 Heat Derived from Nuclear Test $\ldots \ldots \ldots \ldots \ldots \ldots \ldots \ldots \ldots \ldots .218$

6.2.4 Three-dimensional Formulation - Flow with Fault Zones . . . . . . . . . . . 227

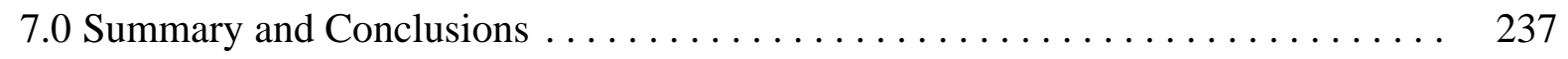

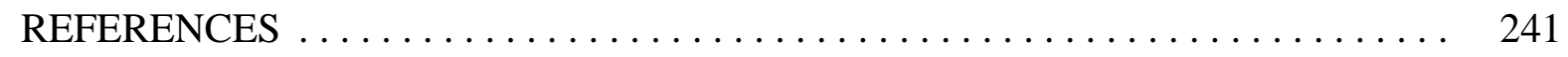

APPENDIX: Modeling the Transport of Reactive and Non-Reactive Solutes in Cores from the Cannikin Test Site, Amchitka Island, Alaska ............ A-1

APPENDIX: Glass Dissolution Solution ........................ B-1

APPENDIX: Modeling the Transport of Reactive and Non-Reactive Solutes in Cores from the Cannikin Test Site, Amchitka Island, Alaska ............. C-1 


\section{LIST OF FIGURES}

1.1. Location map showing Amchitka Island in the Aleutian Island chain. . . . . . . . 4

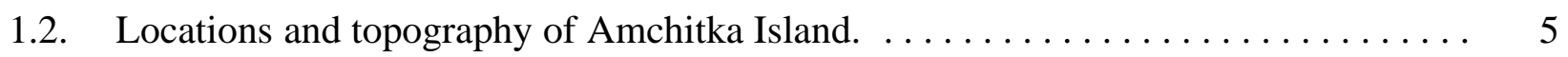

1.3. Average total monthly precipitation at Amchitka Island $\ldots \ldots \ldots \ldots \ldots$

1.4 Location map showing the exploratory locations for the Supplemental Test Site Program (letters B through F) and boreholes $\ldots \ldots \ldots \ldots \ldots \ldots \ldots$

1.5 Schematic cross section of the Milrow test and relevant features,

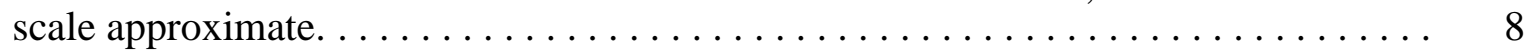

1.6. Location map showing wells and boreholes in the immediate vicinity of Milrow. . . 9

1.7. Schematic cross section of the Long Shot test and pertinent features,

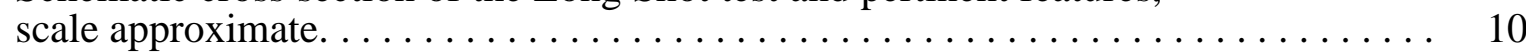

1.8. Location map showing wells and boreholes in the immediate vicinity of

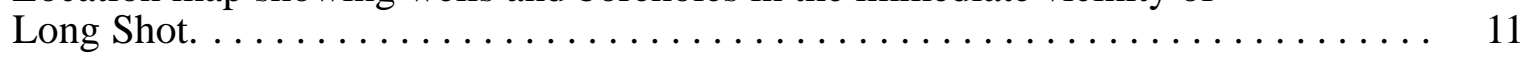

1.9. Schematic cross section of the Cannikin test and relevant features, scale approximate. . . . . . . . . . . . 12

1.10. White Alice Creek drainage basin after the Cannikin test. . . . . . . . . . 13

1.11. Geologic cross section along the long axis of Amchitka Island. . . . . . . . . . 14

1.12. Construction diagram, lithologic log and summary of hydraulic tests, holes UAe-2, UAe-1, EH-2 and EH-5, Amchitka Island, Alaska. . . . . . . . . . . 16

1.13. Stratigraphic section encountered in the exploratory boreholes for the

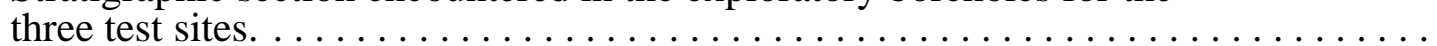

1.14. Schematic map of underground testing areas showing major features and bathymetry.

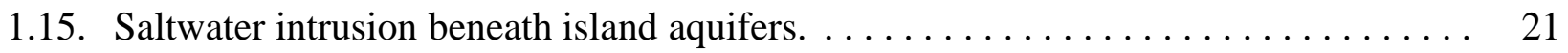

1.16. Head measurements at different wells as a function of elevation. . . . . . . . 22

1.17 Water levels in shallow boreholes at the Long Shot site. . . . . . . . . . . . 22

1.18. Relative ion percentages for water samples from Amchitka. . . . . . . . . . 25

1.19. Chloride content at various depths at Milrow (UAe-2), Long Shot (EH-5),

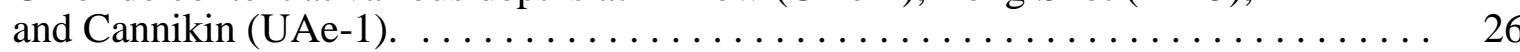

2.1. Distribution of $\log 10$-transformed $\mathrm{K}$ values estimated from straddle packer test data collected from Amchitka boreholes. . . . . . . . . . . . . . . . 41

2.2. Variation with depth of hydraulic conductivity values obtained from packer tests. .. 42

2.3. Variation of total porosity determined from laboratory tests on core samples. . . . . 44

2.4. Plots of temperature profiles simulated using the groundwater recharge model compared to

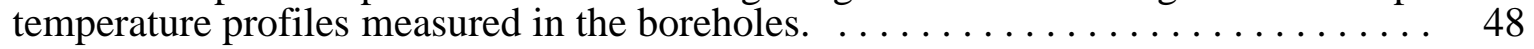

2.5 A lognormal fit to the recharge values obtained by the uncertainty analysis of the temperature

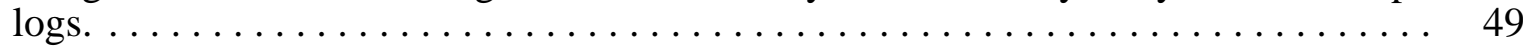


2.6. A finite-element mesh generated by FEFLOW for the modeled domain showing variable element size with fine resolution at the location of the transition zone. ..................................... 54

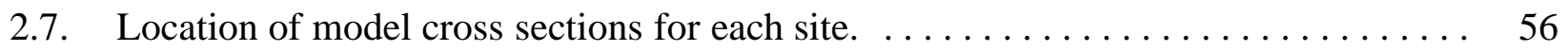

2.8. Finite-element modeling meshes generated for each site model domain. . . . . . 57

2.9. Topographic and bathymetric profiles used for each site-specific model. . . . . . . 58

2.10. Geometry of simulation domain and boundary conditions for the flow problem. . . . 59

2.11. Concentration distribution showing transition zone (top) and velocity field as produced by FEFLOW for one of the Milrow calibration cases tested. .....

2.12. Comparison between simulated and measured heads for eight cases of different conductivity, anisotropy ratio and recharge combinations for Milrow. .....

2.13. Comparison between simulated and measured heads for a Milrow case that leads to a good match for concentrations only. . . . . . . . . . . . . . . . . .

2.14. Comparison between simulated and measured chloride concentrations for a case that gives the best match to Milrow concentration data................

2.15. Comparison between simulated and measured heads for a case that leads to a good match for Milrow heads only. . . . . . . . . . . . . . . . . . . . . .

2.16. Comparison between simulated and measured chloride concentrations at

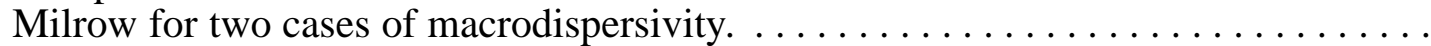

2.17. Long Shot calibration using concentration data at one well and head data at a

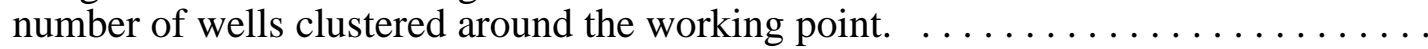

2.18. Calibration results for Cannikin well UAe-1 where head and concentration data are compared to model results. . . . . . . . . . . . . . . . . . . . . 70

2.19. Calibration results for Cannikin wells UA-1 and HTH-1 using head data. ....... 71

2.20. Transition zones modeled for each site using the calibration parameters, expressed by the chloride concentration. . . . . . . . . . . . . . . . . 72

2.21. Velocity vectors for the calibrated flow fields at each site. .............. 74

3.1. Flow chart of the transport model source and processes considered............ 75

3.2. Tritium analyses for three sampling events in the Cannikin post-test hole, UA1-P-1.........................................

3.3. Dissolution function for nuclear melt glass, using the parameters described in the text and various values for the specific surface area. .................

3.4. Release of particles by glass dissolution rate $\ldots \ldots \ldots \ldots \ldots \ldots \ldots \ldots \ldots$

3.5. Conceptualization of the transport processes and computation of mass

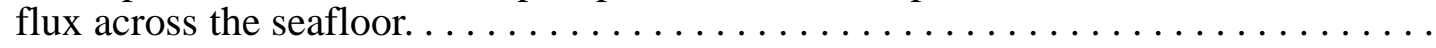

4.1. Randomly generated distributions for the parameters governing the solution

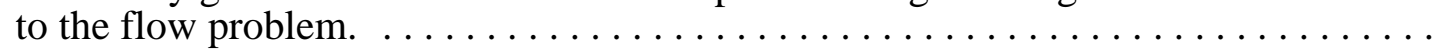

4.2. Finite-element mesh with the upper left half of the domain refined and chimney location highlighted. 
4.3. Sensitivity of UAe-2 concentration and heads to recharge in the first

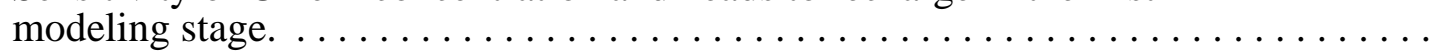

4.4. Sensitivity of UAe-2 concentration and heads to conductivity in the first modeling stage. . . . . . . . . . . . . . . . . . .

4.5. Sensitivity of UAe-2 concentration and heads to porosity in the first modeling stage.

4.6. Sensitivity of UAe-2 concentration and heads to macrodispersivity in the first modeling stage.

4.7. Randomly generated distribution for the glass dissolution rate, $\mathrm{kg}$ (top), and the percentage of mass released as a function of time for the minimum, mean, and maximum $\mathrm{kg}$ (bottom).

4.8. Randomly generated distribution for longitudinal local dispersivity for the first modeling stage.

4.9. Randomly generated distribution for the matrix diffusion parameter, $\mathrm{k}$ (top), and the dependence of the retention function, $\mathrm{g}$, on the value of $\mathrm{k}$ (bottom).

5.1. Expanded view of the upper left portion of each model domain, showing the nuclear chimney included in the flow and transport simulations.

5.2. Randomly generated distributions for Rech, $\mathrm{K}$, and $\mathrm{q}$ in the second modeling

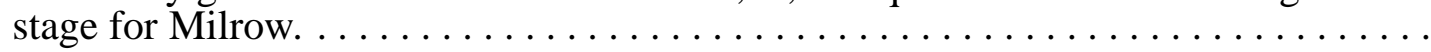

5.3. Comparison of the randomly generated recharge-conductivity ratio and conductivity-porosity ratio in relation to the Milrow base-case values. ........

5.4. Sensitivity of UAe-2 concentrations and heads to the combined uncertainties of Rech, $\mathrm{K}$ and $\mathrm{q}$ in the second Milrow modeling stage. ...............

5.5. Undecayed Milrow breakthrough curves for the first solute class with different matrix diffusion strengths (top) and for the six solute classes with $\mathrm{k}=0.434$ (bottom).

5.6. Histograms of the percentage of Milrow mass that has broken through within 2,200 years.

5.7. Velocity realizations for Milrow showing a circulatory pattern (top) and a non-circulatory pattern (bottom).

5.8. Three snapshots of the particle distribution (plume shape) at different times for Milrow.

5.9. Three snapshots of the particle distribution (plume shape) at different times for Milrow.

5.10. Three snapshots of the particle distribution (plume shape) at different times for Milrow.

5.11. Three snapshots of the particle distribution (plume shape) at different times for Milrow.

5.12. Histograms showing the distribution of first arrival time, last arrival time, and duration of breakthrough for Milrow.

5.13. Histograms showing the distance from groundwater divide to plume edges and plume width for Milrow. 
5.14. Histograms showing the distributions of depths below MSL at which the

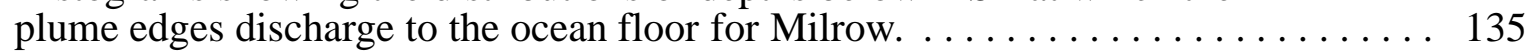

5.15. Statistics of mass flux and concentrations for ${ }^{3} \mathrm{H}$ with $\mathrm{k}=0.434 \ldots \ldots \ldots 138$

5.16. Statistics of mass flux and concentrations for ${ }^{14} \mathrm{C}$ with $\mathrm{k}=0.434 \ldots \ldots \ldots \ldots$

5.17. The effect of the release category (proportion of glass release) on breakthrough. . . 140

5.18. Randomly generated distributions for Rech, $\mathrm{K}$ and $\mathrm{q}$ in the second (final)

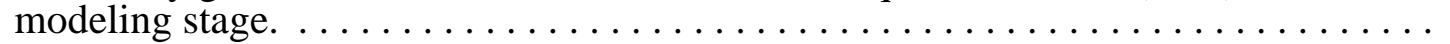

5.19. Comparison of the randomly generated recharge-conductivity and conductivity-porosity ratios relative to the base-case values. . . . . . . . . . . .

5.20. Sensitivity of modeled heads and concentrations to the combined uncertainties of Rech, $\mathrm{K}$ and $\mathrm{q}$ in the second modeling stage at Long Shot.

5.21. Histograms showing the distribution of first arrival time, last arrival time, and duration of breakthrough for Long Shot.

5.22. Histograms showing the distance from groundwater divide to plume edges and plume width for Long Shot.

5.23. Histograms showing the distributions of depths below MSL at which the plume edges discharge to the ocean floor for Long Shot.

5.24. Statistics of mass flux and concentration for ${ }^{3} \mathrm{H}$ from Long Shot with $\mathrm{k}=0.434$. . 153

5.25. Statistics of mass flux and concentration for ${ }^{14} \mathrm{C}$ from Long Shot with $\mathrm{k}=0.434 . \ldots 154$

5.26. Randomly generated distributions for Rech, $\mathrm{K}$ and $\mathrm{q}$ for the final Cannikin

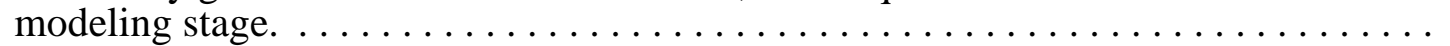

5.27. Comparison of the randomly generated recharge-conductivity and conductivity-porosity ratios relative to the Cannikin base-case values. . . . . . . . . . .

5.28. Sensitivity of UAe-1 modeled concentrations and heads to the combined uncertainties of Rech, $\mathrm{K}$ and $\mathrm{q}$ in the final Cannikin modeling stage. . . . . . . . . .

5.29. Sensitivity of UA-1 and HTH-1 modeled heads to the combined uncertainties of Rech, $\mathrm{K}$ and $\mathrm{q}$ in the final Cannikin modeling stage. . . . . . . . . . . . . .

5.30. Histograms of the percentage of Cannikin mass that has broken through within 2,200 years.

5.31. Histograms showing the distribution of first arrival time, last arrival time, and duration of breakthrough for Cannikin.

5.32. Histograms showing the distance from groundwater divide to plume edges and plume width for Cannikin.

5.33. Histograms showing the distributions of depths below MSL at which the plume edges discharge to the ocean floor for Cannikin.

5.34. Statistics of mass flux and concentration for ${ }^{3} \mathrm{H}$ from Cannikin with $\mathrm{k}=0.434 . \ldots 167$

5.35. Statistics of mass flux and concentration for ${ }^{14} \mathrm{C}$ from Cannikin with $\mathrm{k}=0.434 \ldots$

6.1. Comparison between original velocity streamlines, gridded (or interpolated) velocity streamlines and advective particle trajectory for the entire travel distance and two areas of inset. . . . . . . . . . . . . . . . . . . . . . . . 
6.2. Comparison between original velocity streamlines, gridded (or interpolated) velocity streamlines and advective particle trajectory for the three areas of inset

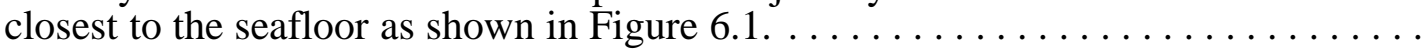

6.3. Comparison between bilinear and inverse-distance interpolation schemes and between these two traditional random walk techniques and the modified method of LaBolle et al. (2000) that avoids computing dispersion and porosity gradient terms.

6.4. Comparison between bilinear and inverse-distance interpolation schemes and between these two traditional random walk techniques and the modified method of LaBolle et al. (2000) that avoids computing dispersion and porosity gradient terms.

6.5. Undecayed breakthrough curves for the first solute class with different matrix diffusion strengths (top) and for the six solute classes with $\mathrm{k}=0.0434$ (bottom).

6.6. Statistics of mass flux and concentration for ${ }^{3} \mathrm{H}$ with $\mathrm{k}=0.0434$ at Milrow. . . . . . 180

6.7. Statistics of mass flux and concentration for ${ }^{14} \mathrm{C}$ with $\mathrm{k}=0.0434$ at Milrow. . . . . . 181

6.8. Statistics of mass flux and concentration for ${ }^{3} \mathrm{H}$ with $\mathrm{k}=0.0434$ at Long Shot. . . . 183

6.9. Statistics of mass flux and concentration for ${ }^{14} \mathrm{C}$ with $\mathrm{k}=0.0434$ at Long Shot. . . . 184

6.10. Statistics of mass flux and concentration for ${ }^{151} \mathrm{Sm}$ with $\mathrm{k}=4.117$ at Long Shot. . . 188

6.11. Statistics of mass flux and concentration for ${ }^{3} \mathrm{H}$ with $\mathrm{k}=0.0434$ at Cannikin. . . . . 189

6.12. Statistics of mass flux and concentration for ${ }^{14} \mathrm{C}$ with $\mathrm{k}=0.0434$ at Cannikin. . . . . 190

6.13. Results of simulating that five percent of the ${ }^{151} \mathrm{Sm}$ travels unretarded, simulating colloid-facilitated migration. . . . . . . . . . . . . . .

6.14. Changes in the concentration and head profiles at the UAe-1 location in response to a rise in sea level from an assumed glacial condition at $30 \mathrm{~m}$ below present sea level.

6.15. Changes in the head profiles at the UA-1 and HTH-1 locations in response to a rise in sea level from an assumed glacial condition at $30 \mathrm{~m}$ below present sea level. ....

6.16. Variation in transition zone configuration for one realization of the Milrow model with the base-case island half-width $(2,062 \mathrm{~m})$ and 200 and $400 \mathrm{~m}$ wider. . . . . . . 198

6.17. Variation in transition zone configuration for one realization of the Milrow model with the base-case island half-width (2,062 m) and 200 and 400 m shorter. . . . . . . 199

6.18. Undecayed, non-retarded breakthrough curves for one realization of the Milrow model under conditions of varying island half-width. The base case is $2,062 \mathrm{~m} \ldots \ldots$. . . 200

6.19. Comparison of profiles of head, concentration and temperature simulated by the isothermal and geothermal models, and values measured at UAe-2. . . . . . . .

6.20. Comparison of velocity profiles along a vertical line through the working point of Milrow for isothermal and geothermal models.

6.21. Comparison of mass breakthrough at the sea floor for non-decayed, unretarded, $\mathrm{s}$ olutes under isothermal conditions and geothermal conditions. . . . . . . . . . . 205

6.22. Selection of realizations for three-dimensional modeling. $\ldots \ldots \ldots \ldots \ldots \ldots$ 
6.23. Salinity in the island groundwater system, expressed as concentration of chloride in $\mathrm{mg} / \mathrm{L}$, for the three realizations identified in Figure 6.22, as calculated in $2-\mathrm{D}$ with the nuclear chimney included. . . . . . . . . . . . . . . . . . . .

6.24. Design of finite-element mesh used for the 3-D model of flow in the Cannikin cavity and rubble chimney. All vertical layers are $100 \mathrm{~m}$ wide.

6.25. Salinity in the island groundwater system, expressed as concentration of chloride in $\mathrm{mg} / \mathrm{L}$, for the three select realizations, for the 3-D model including the nuclear chimney.

6.26. Breakthrough of undecayed, non-retarded particles in 2-D and 3-D domains with both including a nuclear chimney. Each graph represents a different case of recharge/conductivity ratio.

6.27. Salinity in the island groundwater system, expressed as concentration of chloride in $\mathrm{mg} / \mathrm{L}$, for the three sensitivity realizations in 3-D without incorporating

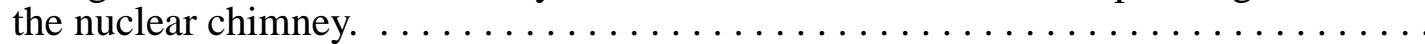

6.28. Particle trajectories for flow in the Cannikin domain with and without the nuclear chimney simulated, for 3-D realization $\# 1$.

6.29. Breakthrough of undecayed, non-retarded, particles in a 3-D isothermal flow field with and without a nuclear chimney simulated.

6.30. Design of finite-element mesh used for the 3-D model incorporating Cannikin Lake.

6.31. Breakthrough of a non-decayed, unretarded, solute using the steady velocity fields generated from isothermal simulations with and without including Cannikin Lake above the chimney.

6.32. Design of finite-element mesh used for the 3-D model incorporating heat derived from the Cannikin nuclear test. All vertical layers are $100 \mathrm{~m}$ wide. . . . . . .

6.33. Variation of temperatures at selected points around the cavity and chimney, following addition of heat derived from the Cannikin test.

6.34. Salinity in the island groundwater system, expressed as concentration of chloride in $\mathrm{mg} / \mathrm{L}$, for the three select realizations, for the 3-D model including the nuclear chimney and heat from the nuclear test. . . . . . . . . . . . . . . . . .

6.35. Particle trajectories from the Cannikin cavity with and without nuclear heat for realization \#2 (cavity within the transition zone).

6.36. Cross section view of particle trajectories from the Cannikin cavity with and without nuclear heat for realization \#1 (transition zone above the cavity).

6.37. Cross-section view of particle trajectories from the Cannikin cavity with and without nuclear heat for realization \#3 (transition zone below the cavity).

6.38. A vertical 2-D view of particle trajectories showing the looping pattern in the

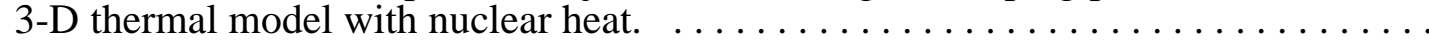

6.39. Breakthrough of undecayed, unretarded mass from a nuclear chimney with and without heat from the nuclear test. . . . . . . . . . . . . . . . . . .

6.40. Design of finite-element mesh used for the the 3-D model incorporating fault zones near Cannikin. 
6.41. Profiles of concentrations and heads along a vertical line through the working point of Cannikin showing the effect of faults with K-ratio of $100 . \ldots 231$

6.42. Profiles of concentrations and heads along a vertical line through the faults (at same $\mathrm{x}$ as the working point) showing the effect of faults with K-ratio of 100. . . 232

6.43. Particle distributions comparing faulted and unfaulted scenarios for Cannikin

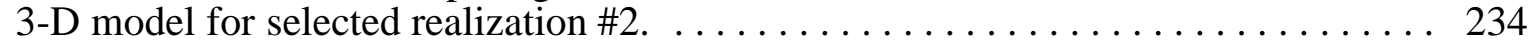

6.44. Plan view of particles' distribution for realization \#3 showing the effects of faults when the transition zone is below the cavity.

6.45. Breakthrough of undecayed, unretarded mass from Cannikin cavity with and without fault zones. Each graph represents a different case of recharge-conductivity

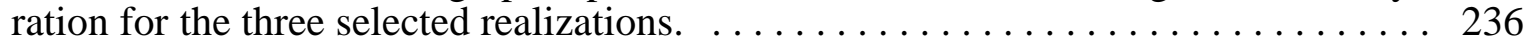

7.1. Cavity location relative to the expected transition zone profile for the three tests. .. 239 


\section{LIST OF TABLES}

1.1. Selected references for island-wide investigations and individual tests. . . . . . . 2

1.2. Representative groundwater chemistry data from the three testing areas ....... 24

1.3 Carbon-14 data for Amchitka groundwater samples. . . . . . . . . . . . . 27

2.1. Summary of hydraulic data from straddle packer tests on Amchitka Island. . . . . . . 39

2.2. Shallow hydraulic head data from the three testing areas. $\ldots \ldots \ldots \ldots \ldots \ldots$

2.3. Boreholes used for estimates of groundwater recharge. . . . . . . . . . . 47

2.4. Parameters used in FEFLOW to solve the isothermal density-driven flow problem. . 60

3.1. List of radionuclides considered for the source term for Milrow, Long Shot,

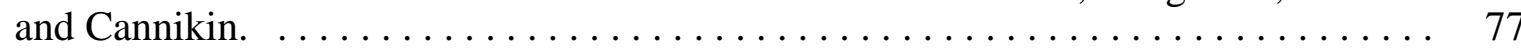

3.2. Release ratios assigned to source term nuclides. $\ldots \ldots \ldots \ldots \ldots \ldots \ldots \ldots \ldots$

3.3. Comparison between chemical composition of natural volcanic glass, nuclear melt glass, and bulk rock composition at the Amchitka testing intervals. . . . . . . . 83

3.4. Linear and Freundlich isotherm parameters for lead sorption. . . . . . . . . . . 87

3.5. Assignment of sorption behavior to radionuclide source elements. . . . . . . . . 87

4.1a. Results of the parametric uncertainty analysis for Milrow comparing the effects of different parameters on plume travel time and transverse location of the

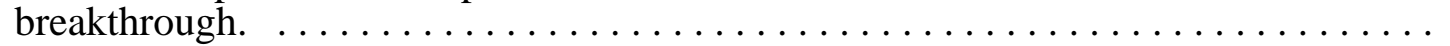

4.1b. Results of the matrix diffusion sensitivity modeling comparing the effects of different parameters on plume travel time and transverse location of the breakthrough when the matrix diffusion parameter, $\mathrm{k}$, is 0.0434 rather than the base-case value of 0.434 .

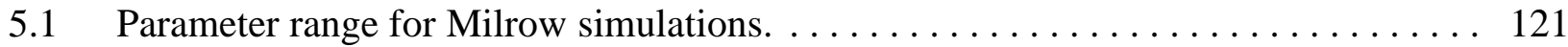

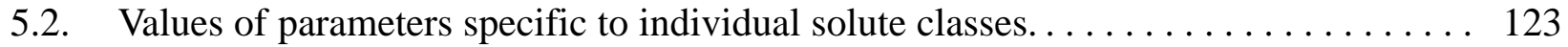

5.3a. Peaks of expected and standard deviation of mass flux and the associated times and locations for radionuclides in the Milrow source term. . . . . . . . . . . .

5.3b. Peaks of expected and standard deviation of concentration and the associated times and locations for radionuclides in the Milrow source term. . . . . . . . . . . 137

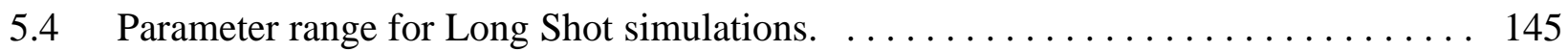

5.5 Values of parameters specific to individual solute classes. . . . . . . . . . . 147

5.6a. Peaks of expected and standard deviation of mass flux and the associated times and locations for radionuclides in the Long Shot source term. . . . . . . . . .

5.6b. Peaks of expected and standard deviation of concentration and the associated times and locations for radionuclides in the Long Shot source term. . . . . . . . . . .

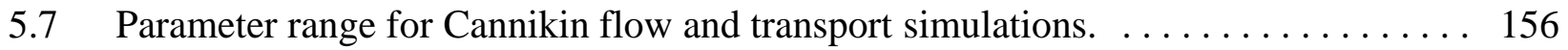

5.8a. Peaks of expected and standard deviation of mass flux and the associated times and locations for radionuclides in the Cannikin source term. . . . . . . . . . 
5.8b. Peaks of expected and standard deviation of concentration and the associated times and locations for radionuclides in the Cannikin source term. . . . . . . . . . .

6.1a. Peaks of expected and standard deviation of mass flux and the associated times and locations for radionuclides in the Milrow source term for the matrix diffusion sensitivity case of $\mathrm{k}=0.0434$.

6.1b. Peaks of expected and standard deviation of concentration and the associated times and locations for radionuclides in the Milrow source term for the matrix diffusion sensitivity case of $\mathrm{k}=0.0434$.

6.2a. Peaks of expected and standard deviation of mass flux and the associated times and locations for radionuclides in the Long Shot source term for the matrix diffusion sensitivity case of $\mathrm{k}=0.0434$.

6.2b. Peaks of expected and standard deviation of concentration and the associated times and locations for radionuclides in the Long Shot source term for the matrix diffusion sensitivity case of $\mathrm{k}=0.0434$.

6.3a. Peaks of expected and standard deviation of mass flux and the associated times and locations for radionuclides in the Cannikin source term for the matrix diffusion sensitivity case of $\mathrm{k}=0.0434$.

6.3b. Peaks of expected and standard deviation of concentration and the associated times and locations for radionuclides in the Cannikin source term for the matrix diffusion sensitivity case of $\mathrm{k}=0.0434$.

6.4. Values of parameters used in FEFLOW for simulations incorporating geothermal heat.

6.5. Values of parameters used in three-dimensional simulations incorporating the rubble chimney.

6.6. Values of parameters used in three-dimensional simulations incorporating heat derived from the Cannikin test. . . . . . . . . . . . . . . . . . . .

6.7. Locations of selected points around the Cannikin cavity and chimney where temperatures are presented in Figure 6.33.

6.8. Values of parameters used in three-dimensional simulations incorporating fault zones. 


\section{LIST OF ACRONYMS}

$\begin{array}{ll}\text { AEC } & \text { Atomic Energy Commission } \\ \text { AMSL } & \text { above mean sea level } \\ \text { DRI } & \text { Desert Resarch Institute } \\ \text { DOE } & \text { Department of Energy } \\ \text { GUI } & \text { graphical user interface } \\ \text { GW } & \text { groundwater } \\ \text { IAEA } & \text { International Atomic Energy Association } \\ \text { MPC } & \text { maximum permissible concentration } \\ \text { MSL } & \text { mean sea level } \\ \text { NTS } & \text { Nevada Test Site } \\ \text { RSC } & \text { relative specific capacity } \\ \text { STS } & \text { Supplemental Test Site } \\ \text { USGS } & \text { U.S. Geological Survey }\end{array}$




\section{LIST OF SYMBOLS}

$\begin{array}{ll}A_{s p} & \text { Specific surface area } \\ A_{L} & \text { Longitudinal macrodispersivity } \\ A_{T} & \text { Transverse macrodispersivity } \\ b & \text { Fracture half aperture } \\ C & \text { Radionuclide concentration } \\ C_{0} & \text { Initial concentration } \\ c_{S} & \text { Specific heat of rock } \\ c_{0} & \text { Specific heat of fluid } \\ D^{*} & \text { Effective diffusion coefficient } \\ D_{m} & \text { Effective diffusion coefficient in the matrix } \\ \text { D } & \text { Local hydrodynamic dispersion tensor } \\ e & \text { Anisotropy ratio } \\ \text { IAP } & \text { Ion activity product } \\ K & \text { Hydraulic conductivity } \\ K_{x x} & \text { Horizontal hydraulic conductivity } \\ K_{z z} & \text { Vertical hydraulic conductivity } \\ K_{T} & \text { Equilibrium constant } \\ K_{d} & \text { Distribution coefficient } \\ K_{a} & \text { Surface-based sorption constant } \\ K_{f} & \text { Freundlich isotherm parameter } \\ k & \text { Thermal conductivity } \\ k_{g} & \text { Glass dissolution rate } \\ k_{l} & \text { Linear rate constant } \\ \kappa & \text { Matrix diffusion parameter } \\ M_{0} & \text { Initial mass of radionuclides } \\ \mathrm{n} & \text { Freundlich isotherm exponent } \\ N P & \text { Number of particles in the random walk simulations } \\ N P_{G}^{t} & \text { Number of particles released via glass dissolution at time t } \\ Q & \text { Total solute mass flux } \\ q & \text { Point solute mass flux } \\ R & \text { Retardation factor in the fracture } \\ R_{c} & \text { Cavity radius } \\ R e c h & \text { Recharge } \\ R_{m} & \text { Retardation factor in the matrix } \\ & \end{array}$




$\begin{array}{ll}S_{S} & \text { Specific storage } \\ t & \text { Time } \\ \mathrm{T} & \text { Temperature } \\ \mathbf{V} & \text { Velocity vector } \\ \alpha_{L} & \text { Longitudinal local dispersivity } \\ \alpha_{T} & \text { Transverse local dispersivity } \\ \beta_{L} & \text { Thermal longitudinal dispersivity } \\ \beta_{T} & \text { Thermal transverse dispersivity } \\ \Delta t & \text { Time step } \\ \Delta x & \text { Spatial grid size } \\ \gamma & \text { Retention function } \\ \lambda & \text { Decay rate } \\ \lambda_{S} & \text { Rock thermal conductivity } \\ \lambda_{0} & \text { Water thermal conductivity } \\ \mu & \text { Undecayed moment } \\ \mu_{d} & \text { Decayed moment } \\ \mu_{0} & \text { Water viscosity } \\ \omega & \text { Radionuclide's half life } \\ \rho_{0} & \text { Fluid density } \\ \sigma & \text { Standard deviation } \\ \theta & \text { Fracture porosity } \\ \theta_{m} & \text { Matrix porosity } \\ z & \text { Mass transfer of a chemical species into aqueous solution per unit surface area } \\ & \end{array}$




\section{INTRODUCTION}

Since 1963, all United States nuclear tests have been conducted underground. A consequence of this testing has been the deposition of large amounts of radioactive material in the subsurface, sometimes in direct contact with groundwater. The majority of this testing occurred on the Nevada Test Site (NTS), but a limited number of experiments were conducted in other locations. One of these locations, Amchitka Island, Alaska is the subject of this report.

Three underground nuclear tests were conducted on Amchitka Island. Long Shot was an 80-kiloton-yield test conducted at a depth of 700 meters (m) on October 29, 1965 (DOE, 2000). Milrow had an announced yield of about 1,000 kilotons, and was detonated at a depth of 1,220 m on October 2, 1969. Cannikin had an announced yield less than 5,000 kilotons, and was conducted at a depth of $1,790 \mathrm{~m}$ on November 6, 1971.

Evaluation of groundwater contamination caused by nuclear testing on Amchitka is being conducted by the U.S. Department of Energy (DOE), in consultation with the State of Alaska Department of Environmental Conservation and the Aleutian/Pribilof Islands Association, Inc.

\subsection{Purpose and Organization}

The purpose of this work is to provide a portion of the information needed to conduct a human-health risk assessment of the potential hazard posed by the three underground nuclear tests on Amchitka Island. Specifically, the focus of this work is the subsurface transport portion, including the release of radionuclides from the underground cavities and their movement through the groundwater system to the point where they seep out of the ocean floor and into the marine environment. This requires a conceptual model of groundwater flow on the island using geologic, hydrologic, and chemical information, a numerical model for groundwater flow, a conceptual model of contaminant release and transport properties from the nuclear test cavities, and a numerical model for contaminant transport.

Needed for the risk assessment are estimates of the quantity of radionuclides (in terms of mass flux) from the underground tests on Amchitka that could discharge to the ocean, the time of possible discharge, and the location in terms of distance from shoreline. The radionuclide data presented here are all reported in terms of normalized masses to avoid presenting classified information. As only linear processes are modeled, the results can be readily scaled by the true classified masses for use in the risk assessment. The modeling timeframe for the risk assessment was set at 1,000 years, though some calculations are extended to 2,000 years.

This first section of the report endeavors to orient the reader with the environment of Amchitka and the specifics of the underground nuclear tests. Of prime importance are the geologic and hydrologic conditions of the subsurface. A conceptual model for groundwater flow beneath the island is then developed and paired with an appropriate numerical modeling approach in section 2 . The parameters needed for the model, supporting data for them, and data uncertainties are discussed at length. The calibration of the three flow models (one for each test) is then presented. At this point the conceptual radionuclide transport model is introduced and its numerical approach described in section 3. Again, the transport parameters and their supporting data and uncertainties are the focus. 
With all of the processes and parameters in place, the first major modeling phase can be discussed in section 4. In this phase, a parametric uncertainty analysis is performed to determine the sensitivity of the transport modeling results to the uncertainties present in the parameters. This analysis is motivated by the recognition of substantial uncertainty in the subsurface conditions on the island and the need to incorporate that uncertainty into the modeling. The conclusion of the first phase determines the parameters to hold as uncertain through the main flow and transport modeling. This second, main phase of modeling is presented in section 5, with the contaminant breakthrough behavior of each test site addressed. This is followed by a sensitivity analysis in section 6 , regarding the importance of additional processes that could not be supported in the main modeling effort due to lack of data. Finally, the results for the individual sites are compared, the sensitivities discussed, and final conclusions presented in section 7.

\subsection{Previous Work}

Amchitka Island was chosen as a Supplemental Test Site (STS) for underground testing of nuclear explosives, a designation which was preceded by thorough characterization of the island geology. Investigations in direct support of Milrow and Cannikin added site-specific data to the island-wide picture. Much of the work supporting these activities is listed in a bibliography of reports by U.S. Geological Survey (USGS) personnel on the geology and hydrology of Amchitka Island (Ohl, 1973). Long Shot actually preceded the STS selection and some of its important references are not in USGS reports. Important references for the island as a whole, and the individual tests, are listed below (Table 1.1). Detailed reports describing geologic and hydrologic data are not included here, but are referenced in appropriate later sections.

Table 1.1. Selected references for island-wide investigations and individual tests.

\begin{tabular}{ll}
\hline \hline Investigation & Scope \\
\hline Selected Island-wide Investigations & \\
Ohl, 1973 & Bibliography of USGS reports on Amchitka \\
U.S. AEC, 1967 & Site-selection report describing geology and hydrology \\
Carr et al., 1969 & Geologic reconnaissance of the island \\
Carr and Quinlivan, 1969 & Updated geologic information \\
von Huene et al., 1971 & Geophysical study of Amchitka \\
Bath et al., 1971 & Gravity survey of Amchitka \\
Anderson, 1971 & Tectonic setting of Amchitka \\
Carr et al., 1971 & Summary paper of stratigraphy, structure, etc. \\
Gates et al., 1954 & Aleutian geology with reference to Amchitka \\
Beetem et al., 1971 & Chemical analyses of water samples \\
Gard, Jr., 1972 & Chemical analyses of rock samples \\
Lee, $1969 a$, b, c, d & Physical rock properties \\
Bath et al., 1972 & Aeromagnetic survey of Amchitka \\
Merritt and Fuller, 1977 & Summary papers on climate, geology, hydrology and biota \\
Wheatcraft, 1995 & Seawater intrusion model of the island \\
\hline \hline
\end{tabular}


Table 1.2. Selected references for island-wide investigations and individual tests (continued).

\begin{tabular}{ll}
\hline \hline Investigation & Scope \\
\hline $\begin{array}{l}\text { Nelected Long Shot Investigations } \\
\text { Gard and Hale, } 1965\end{array}$ & $\begin{array}{l}\text { Groundwater safety analysis } \\
\text { Geology and hydrology }\end{array}$ \\
$\begin{array}{l}\text { U.S. Army Corps of Engineers and } \\
\text { U.S. Geological Survey, 1965 }\end{array}$ & $\begin{array}{l}\text { Geology and hydrology, with hydrologic and core data in } \\
\text { extensive appendices }\end{array}$ \\
\hline Selected Milrow Investigations & \\
U.S. Geological Survey, 1970 & Geologic and hydrologic effects of Milrow \\
Essington et al., 1970 & Radionuclide transport analysis \\
\hline Selected Cannikin Investigations & Summary of subsurface geology \\
Lee and Gard, Jr., 1971 & Hydrologic effects of the test \\
Gonzalez and Wollitz, 1972 & Hydrologic transport of radionuclides \\
Fenske, 1972a, b & Hydraulic effects of the test \\
Gonzalez, 1977 & Near-cavity processes associated with the test \\
Claassen, 1978 & Summary of physical and biologic effects of the test \\
Merritt, 1973 & Geologic and hydrologic effects of the test \\
U.S. Geological Survey, 1972 &
\end{tabular}

\subsection{General Description of Amchitka Island}

Amchitka is the southernmost island of the Rat Island Group of the Aleutian Island chain extending southwestward from mainland Alaska (Figure 1.1). It is located between longitudes $178^{\circ} 37^{\prime} \mathrm{E}$ and $179^{\circ} 29^{\prime} \mathrm{E}$, and between latitudes $51^{\circ} 21^{\prime} \mathrm{N}$ and $51^{\circ} 39^{\prime} \mathrm{N}$. Amchitka is almost half-way from North America to Asia, and is $2,160 \mathrm{~km}$ west-southwest of Anchorage. Amchitka is part of the Aleutian Islands National Wildlife Refuge. It is bounded on the northeast by the Bering Sea and on the southwest by the Pacific Ocean.

The island is about $65 \mathrm{~km}$ long and varies between 2 and $7 \mathrm{~km}$ wide (Merritt, 1977). Elevation varies from sea level at the few beaches to $354 \mathrm{~m}$ above mean sea level (AMSL). Most of the shoreline is rugged and characterized by cliffs up to $30 \mathrm{~m}$ high. Topographically, the island can be divided into three areas (Figure 1.2). The eastern half is a lowland plateau characterized by gently rolling topography below 100 m elevation and many shallow ponds. Low, but abundant, vegetation covers the landscape in this area. The central mountain segment west of Chitka Point is where the maximum elevation of $354 \mathrm{~m}$ is reached. This region has fewer lakes, more integrated drainage, and sparse vegetation. The westernmost end of the island is a high plateau at an elevation of about $240 \mathrm{~m}$, 


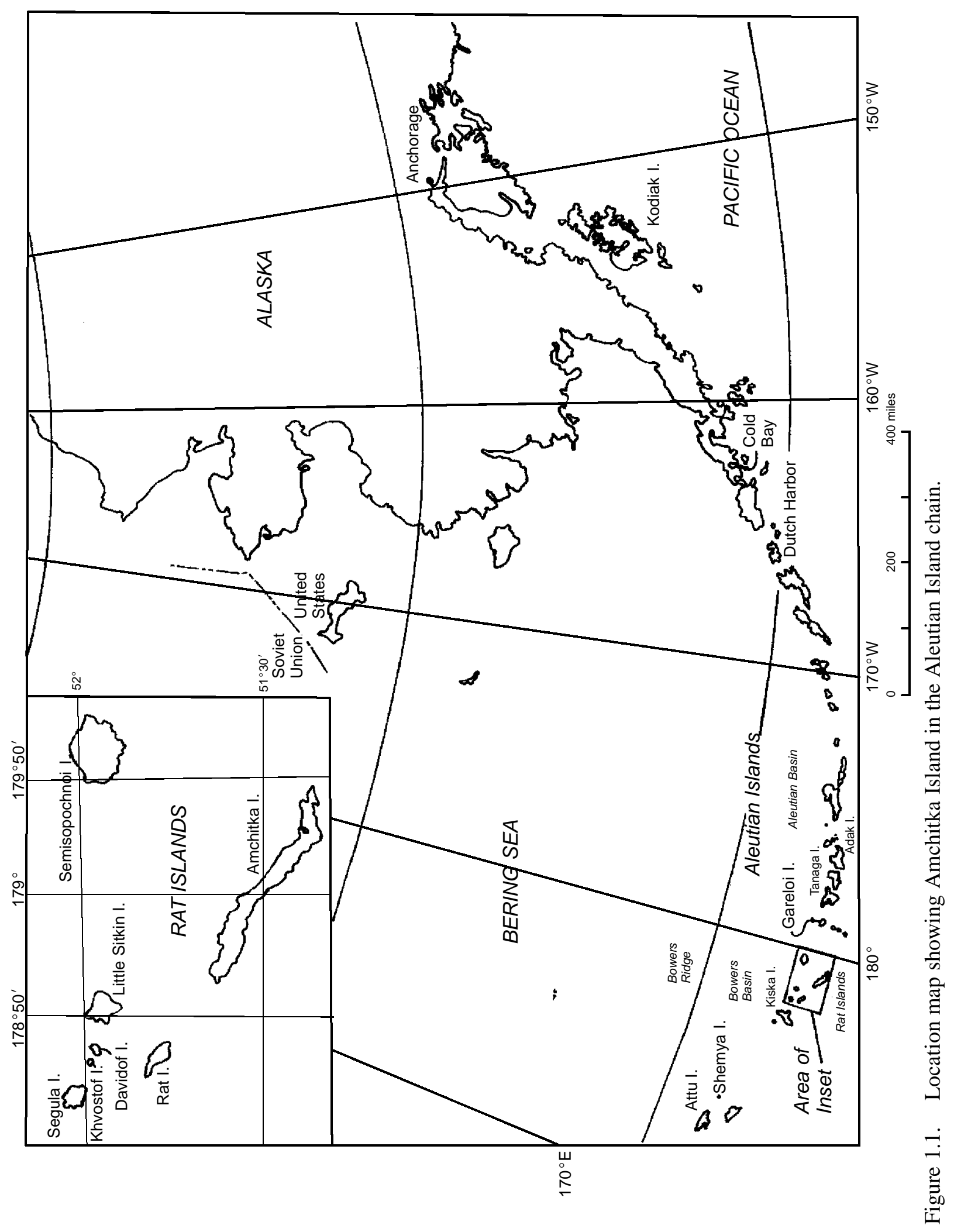




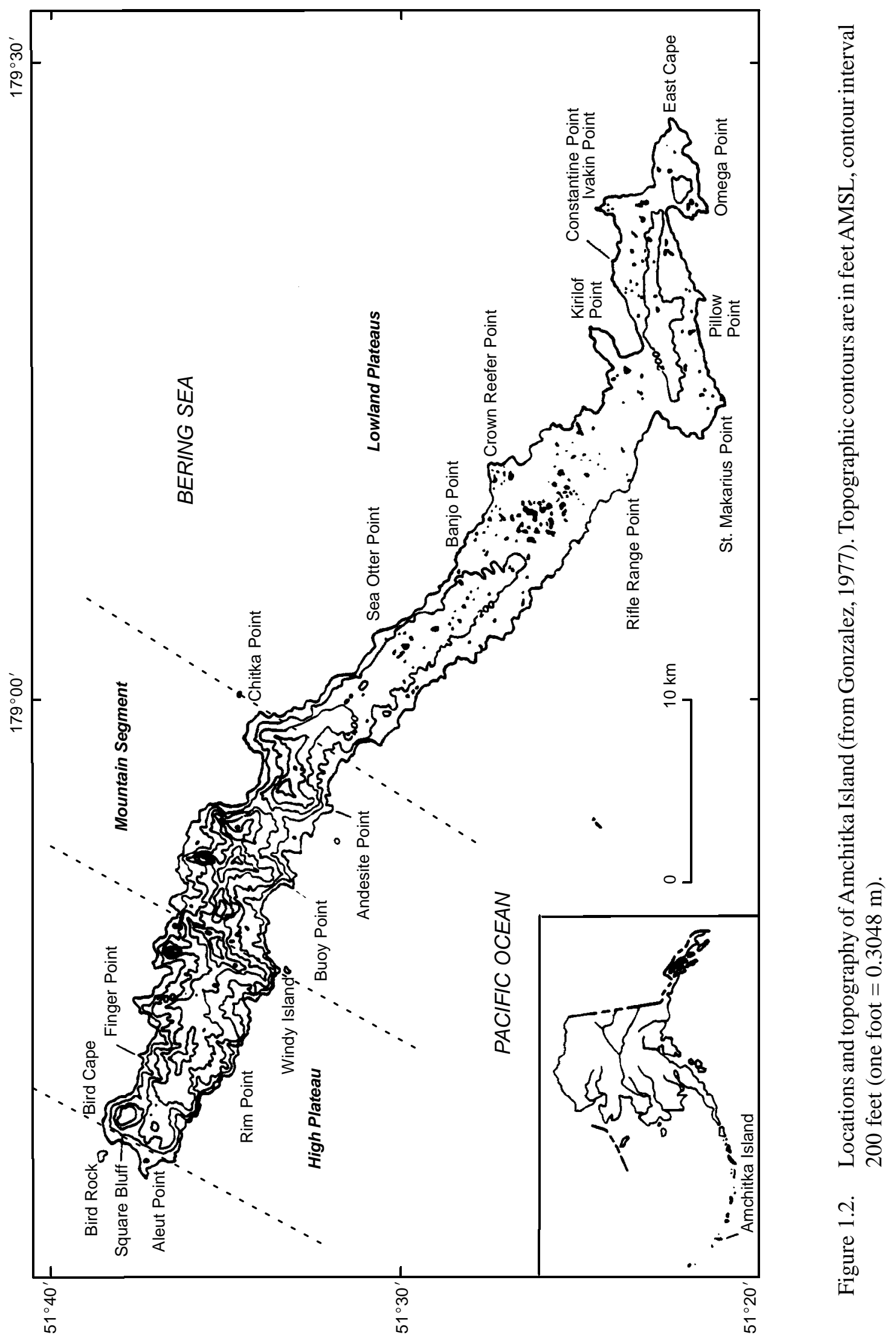


windswept and barren. All of the underground tests, and the majority of detailed investigations, occurred in the Lowland Plateau region.

Amchitka has a maritime climate, being foggy and windswept much of the time. Partial to complete cloud cover occurs 98 percent of the time (Gonzalez, 1977). Aleutian weather results almost entirely from large-scale pressure systems moving along the North Pacific storm track. Climate data are available from the Desert Research Institute's (DRI) Western Regional Climate Center in Reno, Nevada, but reflect only a few years of record in 1949-1950, 1979-1980, and 1988-1993. The moderating influence of the surrounding ocean is evident in the relatively small range in average temperatures: the highest monthly average maximum temperature is $10.8^{\circ} \mathrm{C}$ and occurs in August, while the lowest monthly average minimum is $-2.2^{\circ} \mathrm{C}$ and occurs in February. Average annual precipitation is $94 \mathrm{~cm}$, with lowest amounts in the spring months and greatest precipitation in the late summer (Figure 1.3). Summer is also a time of extensive fog development, with summer fog often persisting for days at a time (Armstrong, 1977). Average snowfall totals 129 $\mathrm{cm}$ per year.

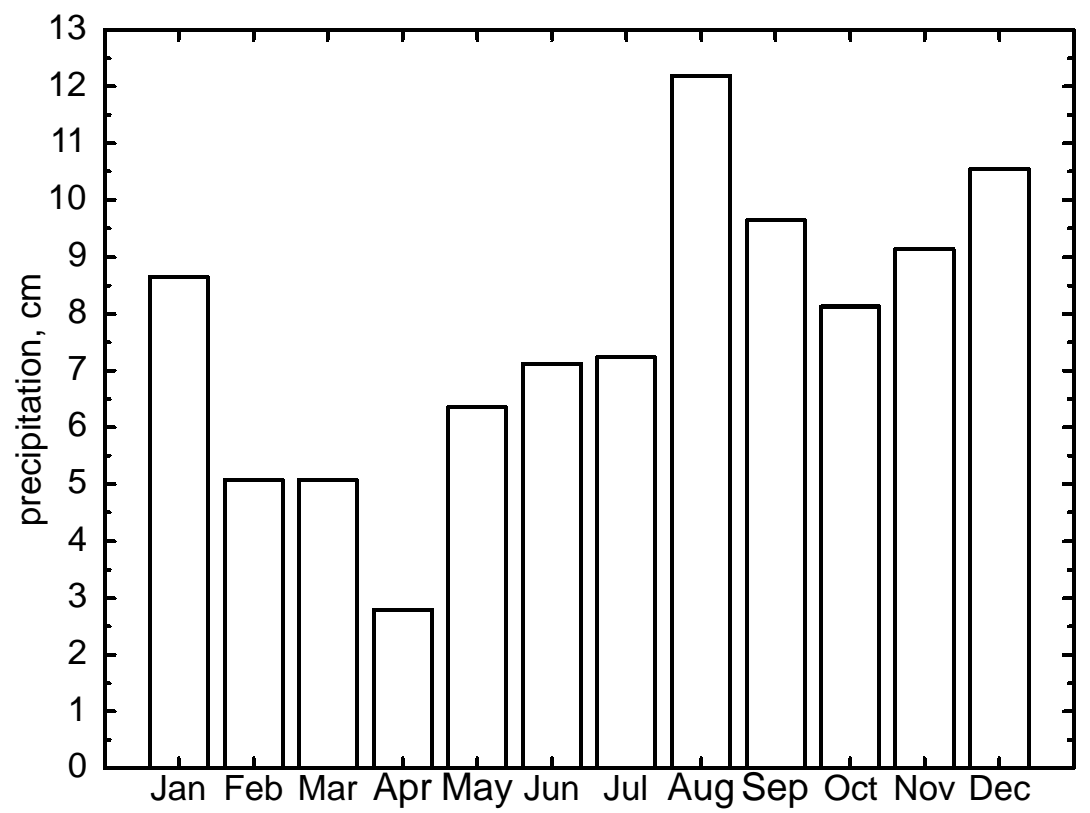

Figure 1.3. Average total monthly precipitation at Amchitka Island (from DRI's Western Regional Climate Center).

\subsection{Description of the Underground Nuclear Test Sites}

The three tests are described below, and throughout this report, in geographic order from the southeast to the northwest. Milrow is first, followed by Long Shot and Cannikin.

\subsubsection{Milrow}

The Milrow test was a "calibration shot," designed to produce a database for extrapolation and prediction of the impact of larger nuclear tests, specifically, as to whether it would be safe to conduct the Cannikin test (Merritt, 1973). The site location is also known as "site B" in much of the earlier literature regarding Amchitka site selection (Figure 1.4). Milrow was fired on October 2, 1969, at 

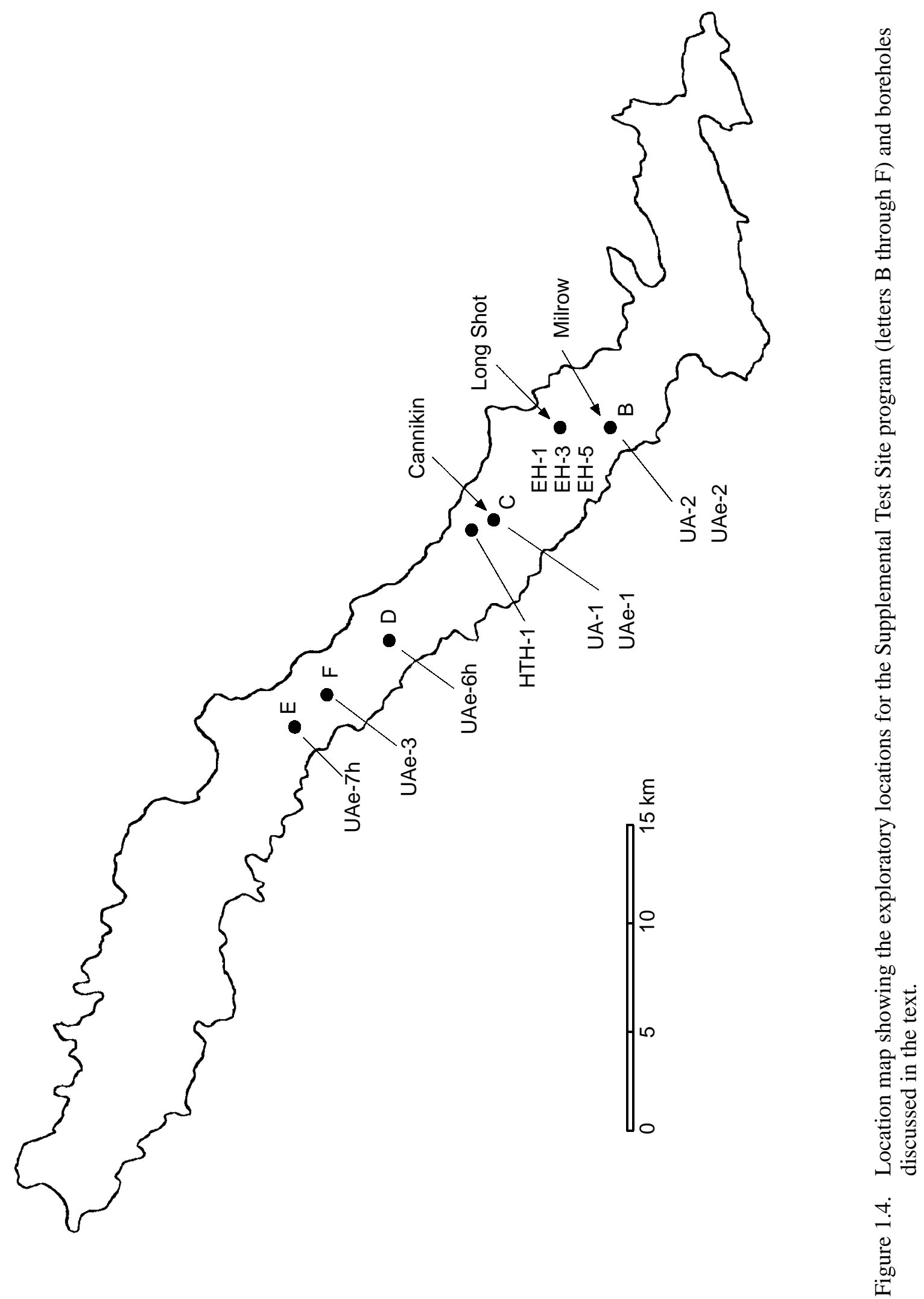
a depth of 1,218 m below land surface, with an announced yield of about one megaton (U.S. DOE, 1994).

Milrow was the only test detonated on the Pacific Ocean side of the island, at UTM coordinates N 5,698,251.49 m, E 651,750.61 m, zone 60 (USGS, 1970). The island half-width is taken as 2,062 $\mathrm{m}$ on the transect from the groundwater divide through Milrow to the coast. Milrow itself is $765 \mathrm{~m}$ from the divide (Figure 1.5). The collar elevation of the emplacement hole was $39.8 \mathrm{~m}$. Using the rough, generic relationships between yield and cavity size, and yield and depth of burial, and cancelling out yield (Glasstone and Dolan, 1977) leads to an estimated cavity radius of $106 \mathrm{~m}$. The collapse of material into the cavity void led to a surface collapse feature (Figure 1.6), and given the uncertainty regarding the degree of fracturing between the rubble-filled chimney (generally only four to six times the cavity radius; Glasstone and Dolan, 1977), the spall zone, and the surface collapse, the entire length from the cavity to land surface is considered disrupted in the model.

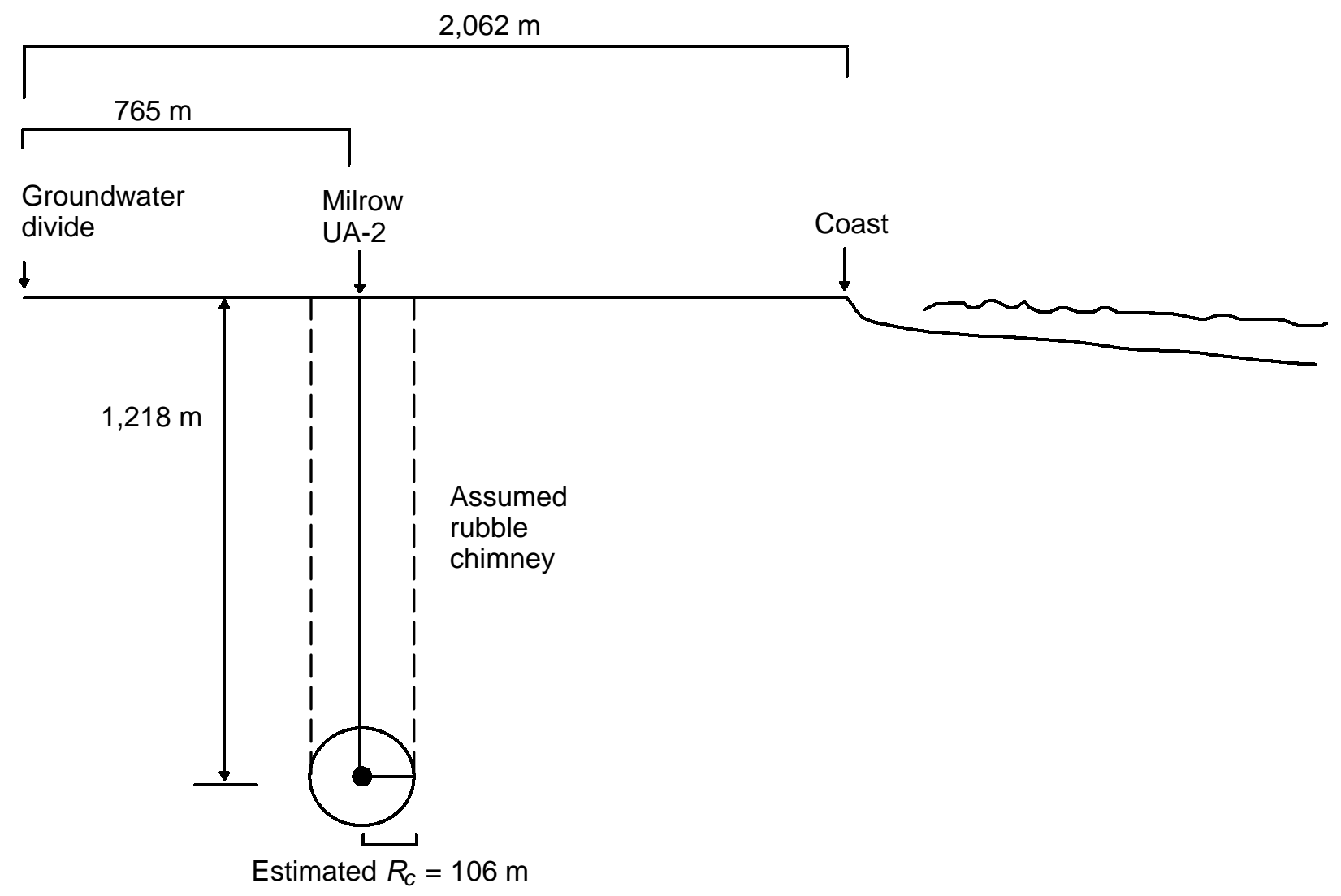

Figure 1.5 Schematic cross section of the Milrow test and relevant features, scale approximate.

\subsubsection{Long Shot}

The Long Shot test was part of the U.S. Department of Defense Vela Uniform program investigating the seismic detection of nuclear tests; specifically, determining location accuracy and seismic wave travel times near island arcs and oceanic trenches. Long Shot was conducted on October 29, 1965, and had an announced yield of 80 kt (U.S. DOE, 2000). 


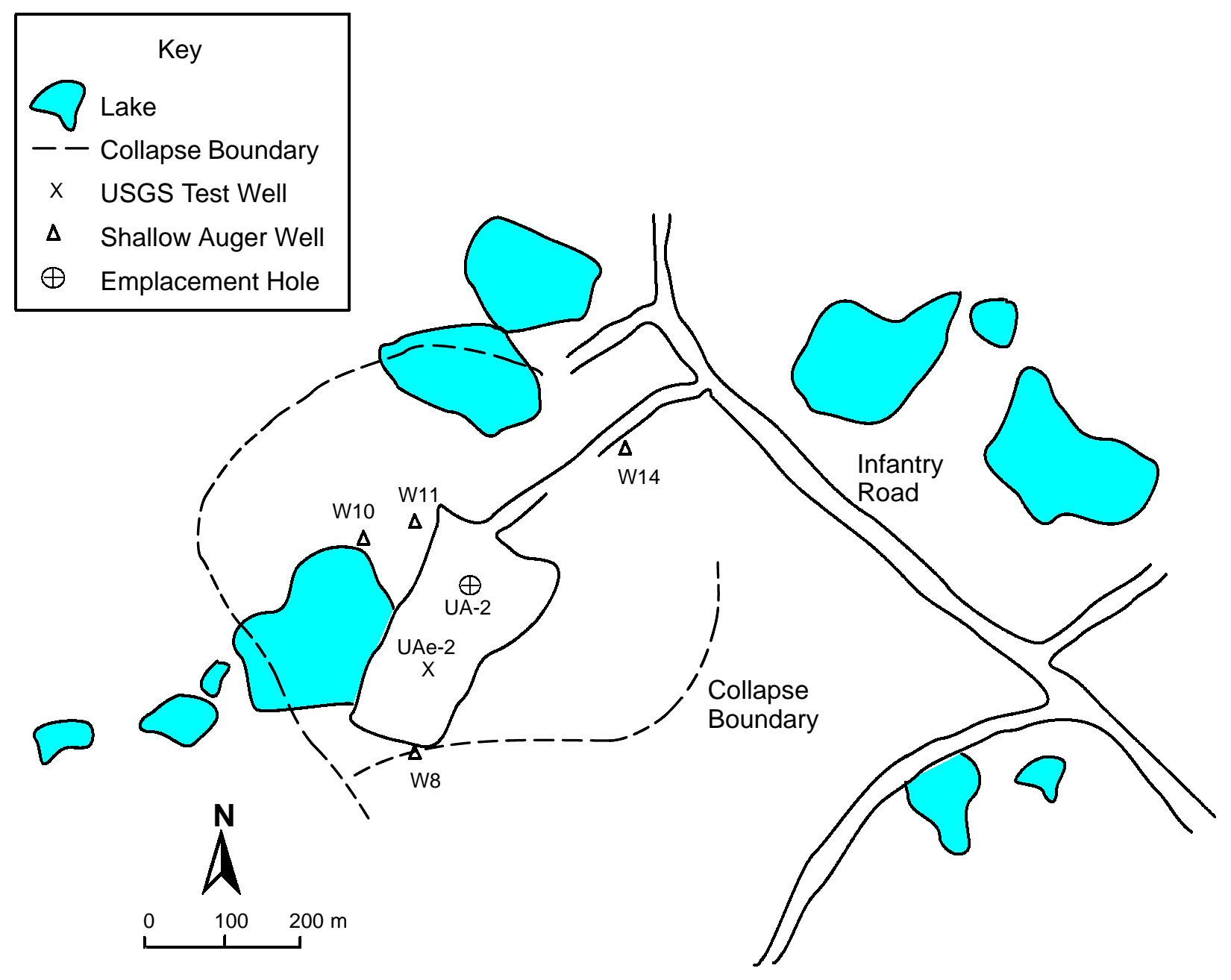

Figure 1.6. Location map showing wells and boreholes in the immediate vicinity of Milrow. The surface collapse area resulting from the test is also shown. Modified from Essington et al. 1971.

The ground zero location was at approximate UTM coordinates N 5,700,585 m, E 651,652 m, zone 60. This is located on the Bering Sea-side of the island, approximately $599 \mathrm{~m}$ from the groundwater divide (Figure 1.7). The island half-width is taken as $2,224 \mathrm{~m}$ on the transect from the divide through Long Shot and to the coast. The land elevation is $42 \mathrm{~m}$. The depth of the device was $701 \mathrm{~m}$ below land surface. The cavity radius is variously estimated as $63 \mathrm{~m}$ (Nork et al., 1965) and $65 \mathrm{~m}$ (McKeown et al., 1967). For consistency with the cavity estimates of the other tests, a value of $61 \mathrm{~m}$ is used here, from a calculation based on the depth of burial (Glasstone and Dolan, 1977). Though the chimney height is likely on the order of $300 \mathrm{~m}$ (five times the cavity radius; Glasstone and Dolan, 1977), the entire zone above the cavity to land surface is considered disrupted in the model.

There is no surface collapse at the Long Shot site. Spalling (fracturing caused by the pressure wave encountering the free-air surface) was predicted to occur between depths of 30 and $150 \mathrm{~m}$ (U.S. Atomic Energy Commission (AEC), 1967). Tritium and krypton were found in surface water ponds 


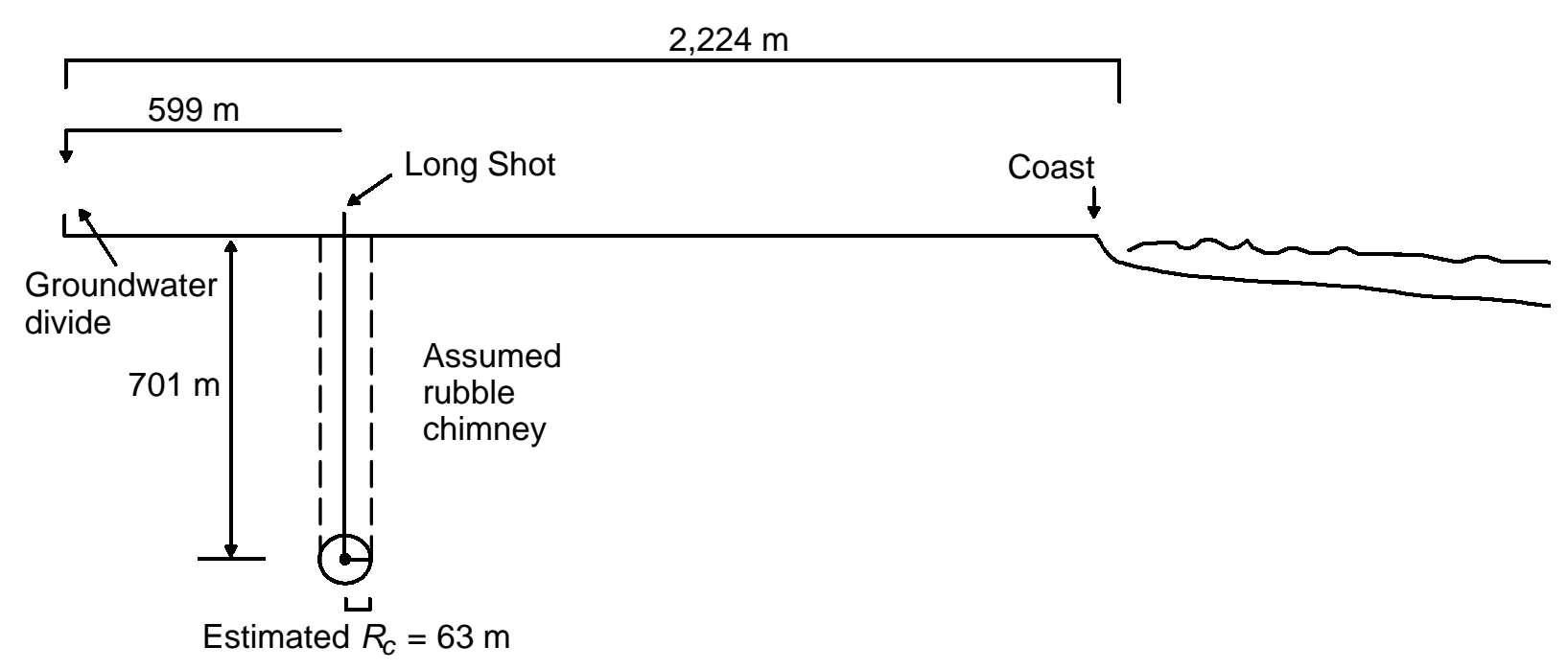

Figure 1.7. Schematic cross section of the Long Shot test and pertinent features, scale approximate.

and mud pits following the test, which led to investigations in several wells. The layout of the site is shown in Figure 1.8. Maximum concentrations occurred in samples collected at depths between 61 and $91 \mathrm{~m}$, and decreased with distance from ground zero. The source was believed to be gases that migrated to the top of the Long Shot chimney in early time. As the chimney filled with water, it is postulated that the gases were pushed upward through stemming material, out into the spall zone, and then dissolved in groundwater (Castagnola, 1969). This spreading upward of the gaseous radionuclide source has not been included in the model. The effect would be to spread the mass through a greater volume, reducing the point mass flux and resultant concentrations. In addition, as there is a strong component of downward vertical flow, the path length for any particles placed higher in the chimney could be longer than that obtained by starting them in the cavity.

\subsubsection{Cannikin}

The Cannikin test was designed to proof-test the Spartan warhead for use in an anti-ballistic missile system (Merritt, 1973). It was detonated on November 6, 1971, and had an announced yield of less than five megatons (U.S. DOE, 1994).

The emplacement well for Cannikin was UA-1 and is located at UTM coordinates N 5,704,185.92 m, E 646,321.59 m, zone 60. The general location is also known as Site "C" in many of the STS characterization reports. Cannikin is located on the Bering Sea side of Amchitka Island. The island half-width, from groundwater divide, through Cannikin, and to the Bering Sea, is estimated as 2,328 m, with UC-1 located $811 \mathrm{~m}$ from the divide (Figure 1.9). The land elevation at the emplacement hole was $63.3 \mathrm{~m}$, but there is land subsidence as a result of the test. The depth of the device was $1,791.9 \mathrm{~m}$ below land surface. The cavity radius used here is based on a generic relationship with depth of burial (Glasstone and Dolan, 1977), and is estimated as $157 \mathrm{~m}$. Claassen 

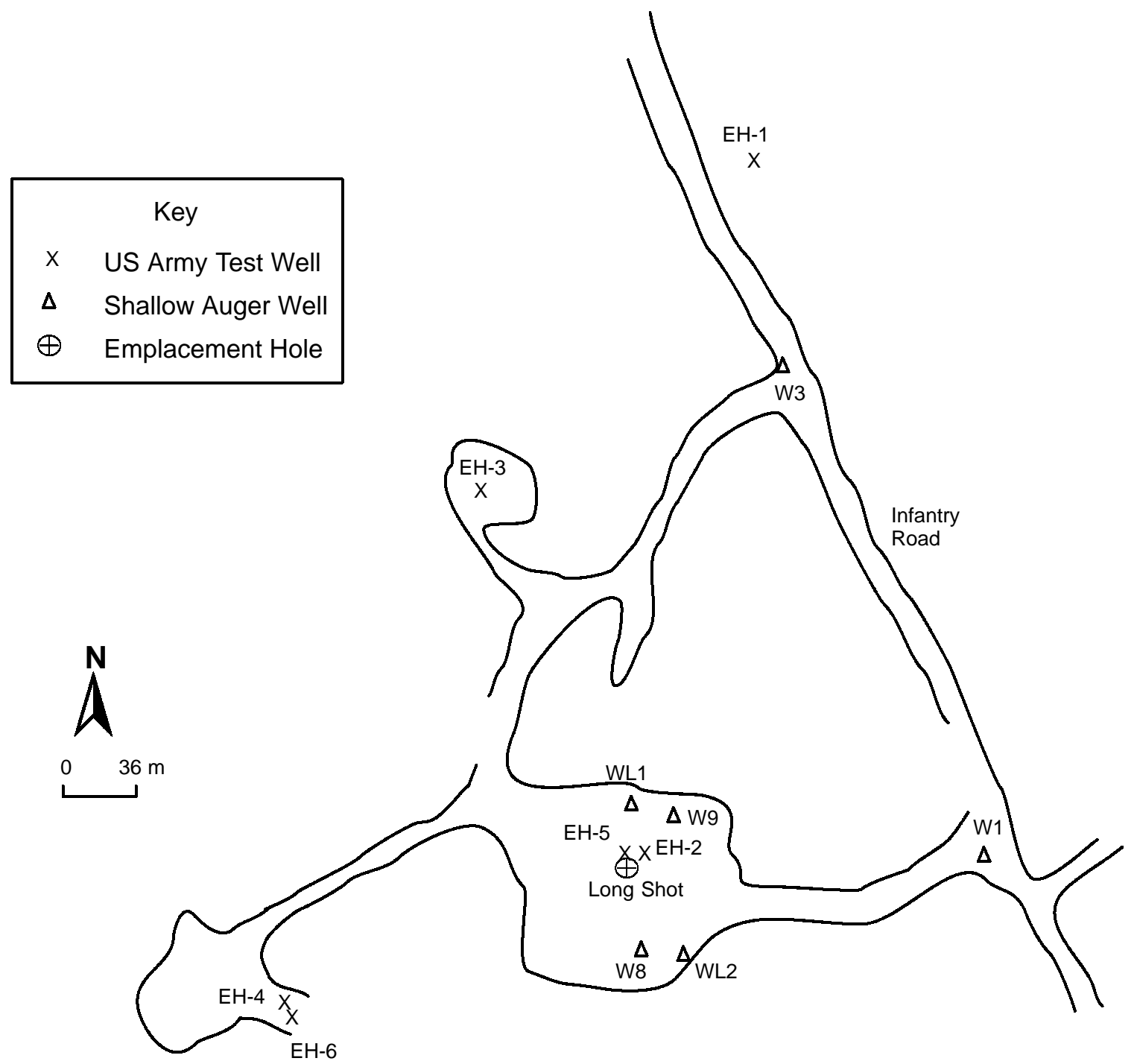

Figure 1.8. Location map showing wells and boreholes in the immediate vicinity of Long Shot. Modified from Fenix and Scisson, 1972.

(1978) estimated a slightly smaller cavity radius of $133 \mathrm{~m}$, using a different approach. As with the other tests, the entire zone above the cavity to land surface is considered disrupted in the model. The collapse into the cavity void resulted in a very irregular subsidence of the land surface. The greatest subsidence, of about $12 \mathrm{~m}$ below pre-test elevation, occurs $400 \mathrm{~m}$ southeast of ground zero. Around it, the subsidence and associated faulting have left an enclosed basin that captured the White Alice Creek drainage and created a new lake, Cannikin Lake (Figure 1.10).

\subsection{Geology of Amchitka Island}

Amchitka Island is an exposure of the predominantly submarine Aleutian Ridge (Anderson, 1971). The Aleutian arc is comprised of the Aleutian Trench, extending from Kamchatka for $3,200 \mathrm{~km}$ east to the Gulf of Alaska, and a topographically high region adjacent to the north of the trench, the western two-thirds of which are known as the Aleutian Ridge. The Ridge is an almost completely 
$2,328 \mathrm{~m}$

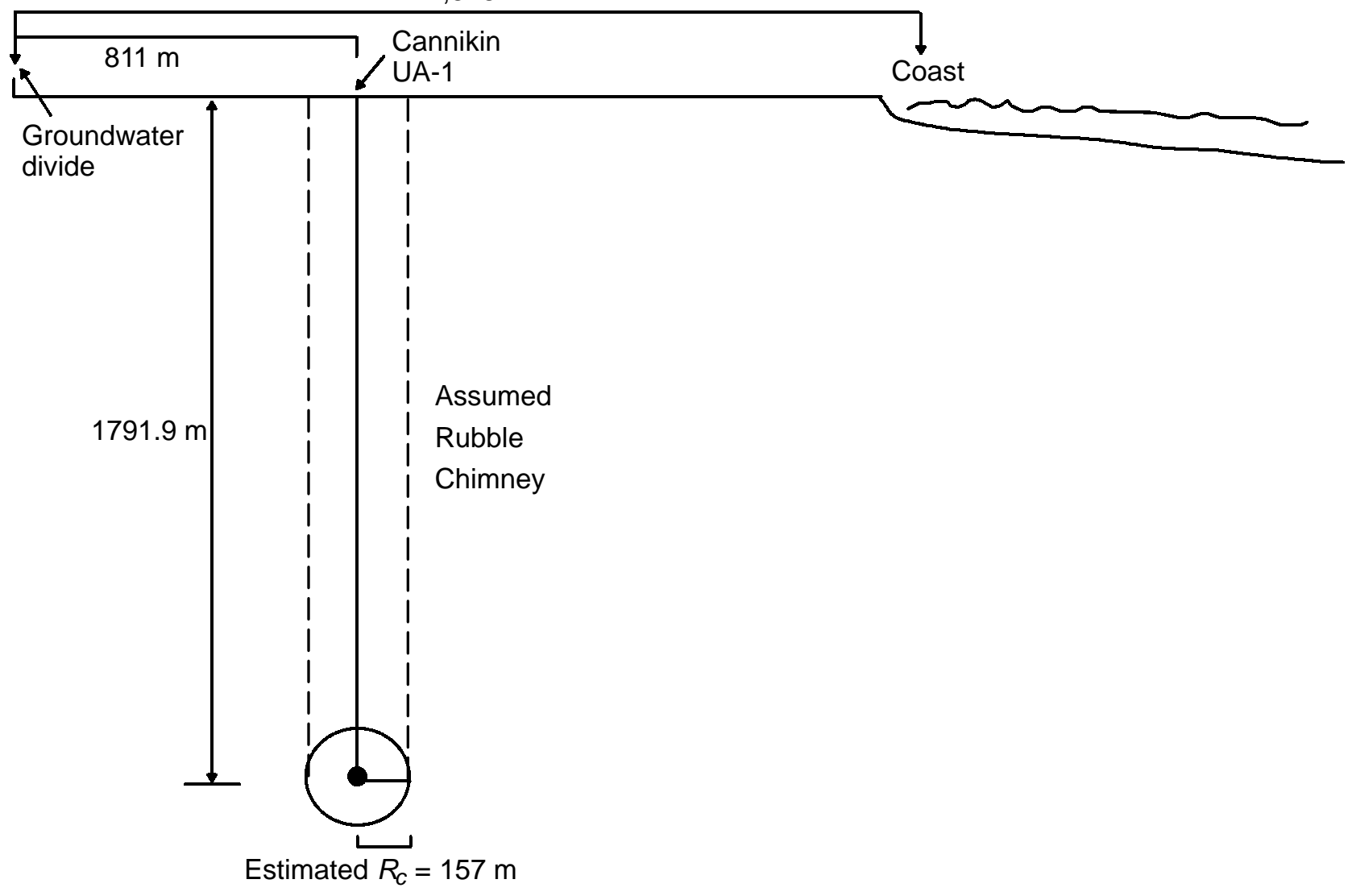

Figure 1.9. Schematic cross section of the Cannikin test and relevant features, scale approximate.

submerged mountain range that rises as much as 19,000 $\mathrm{m}$ above the ocean floor. The Aleutian arc, along with the Kuril and Kamchatka arcs, is the expression of the convergent plate boundary where the Pacific plate runs into the the Eurasian plate. The Aleutian Trench marks the subduction zone where the Pacific plate buckles downward, and the ridge is the crumpled and uplifted overriding continental plate. A prominent feature of the Ridge is the alignment of stratovolcanoes and composite cones, many of which remain active and define a narrow zone of active volcanism. Another characteristic of subduction zones is a concentration of great earthquakes, and the Aleutian arc is one of the world's most active earthquake belts. According to data collected prior to selection of Amchitka for higher-yield underground tests, at least 10 earthquakes of magnitude greater than 4.1 occurred within $100 \mathrm{~km}$ of Amchitka between March 1964 and March 1965 (U.S. AEC, 1967). Two of these were 7.5 in magnitude. Tsunamis commonly result from the earthquake activity, and in 1958, wave height reached $15 \mathrm{~m}$.

\subsubsection{Lithology/Depositional History of Amchitka Island}

Amchitka Island primarily consists of Tertiary-age submarine and subaerially deposited clastic rocks of volcanic material, with lesser amounts of intrusive rocks. Four major stratigraphic units are recognized (Carr and Quinlivan, 1969), from oldest to youngest: 1) older breccias and hornfels, 2) pillow lavas and breccias of Kirilof Point, 3) Banjo Point Formation, and 4) the Chitka Point 


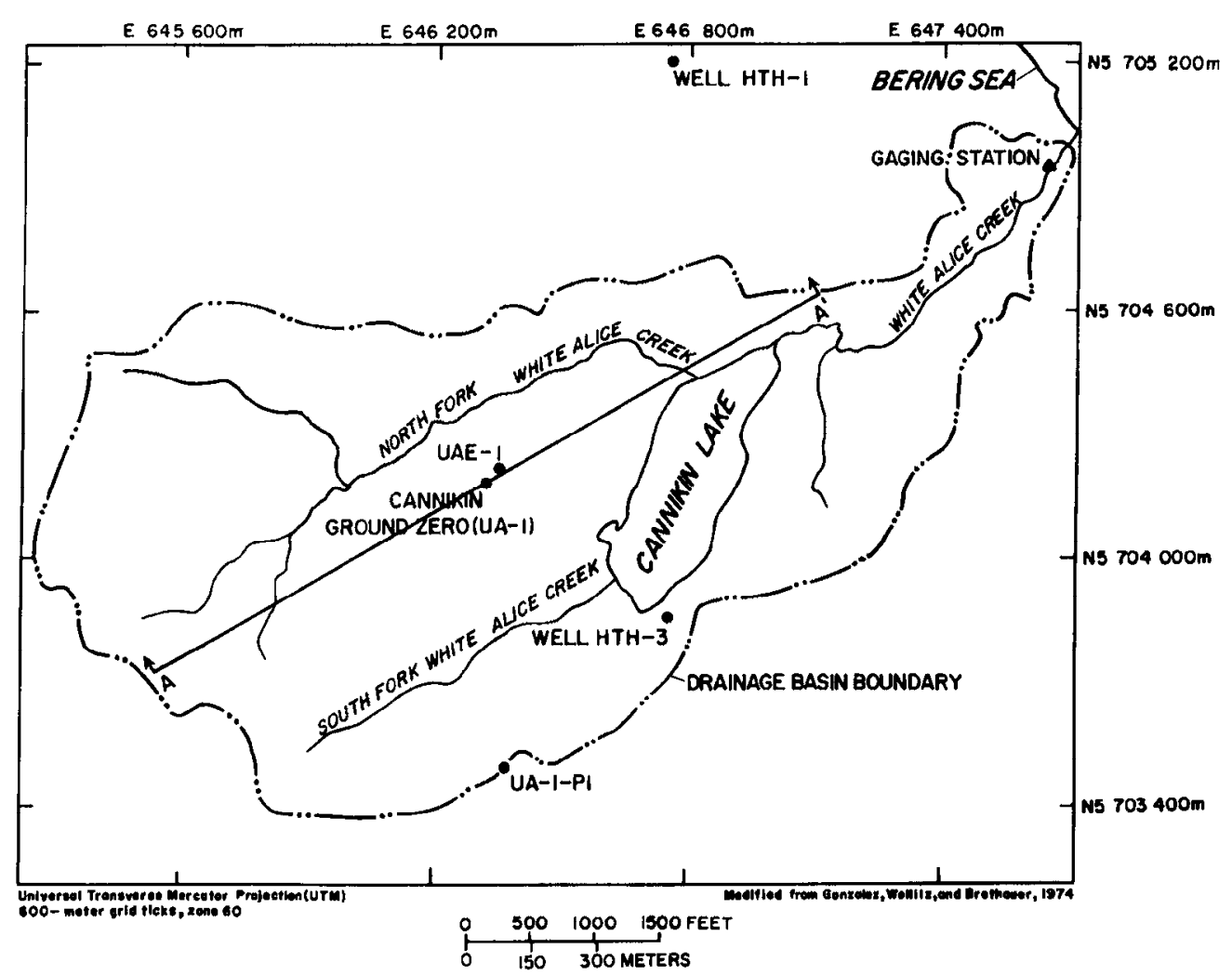

Figure 1.10. White Alice Creek drainage basin after the Cannikin test. From Claassen, 1978.

Formation. The older breccias and Kirilof Point units are sometimes reported as informal units of the Amchitka Formation (Lee and Gard, 1971). The lithology of the island is dominated by breccias and basalts. The following details are primarily from Carr and Quinlivan (1969).

The older breccias and hornfels of the Amchitka Formation, which are interbedded with sedimentary rocks, represent an early episode of submarine volcanic deposition. They are only exposed on the eastern end of the island (Figure 1.11). Lithologically, it consists of fine- to coarse-grained sedimentary breccias with 10 to 20 interest interbedded sandstone, siltstone, and claystone containing volcanic debris. Some alteration is present in the form of quartz, calcite and epidote. The working point for the Cannikin test was located in this unit, in an altered, locally autobrecciated pillow basalt, consisting of about half plagioclase feldspar, 25 percent chlorite, and 15 percent clinopyroxene, with minor calcite (Lee and Gard, 1971).

The pillow lavas and breccias of Kirilof Point are also only exposed on the eastern part of Amchitka and are also interpreted as being primarily of submarine deposition. Exposures reveal a partly glassy, generally monolithic breccia, with fragments generally less than a few centimeters in size. There are at least two pillow lava flows, and minor bedded sedimentary rocks. Rapid chilling is evident through vitric and devitrified glassy matrices, and glassy rinds around pillow structures, and vesiculated glass or pumice is also present. Where not glassy, the Kirilof breccias are yellowish to greenish due to alteration to palagonite, chlorite, nontronite, or green chalcedony. The Milrow working point was located in the pillow lavas and breccias of Kirilof Point (USGS, 1970). 


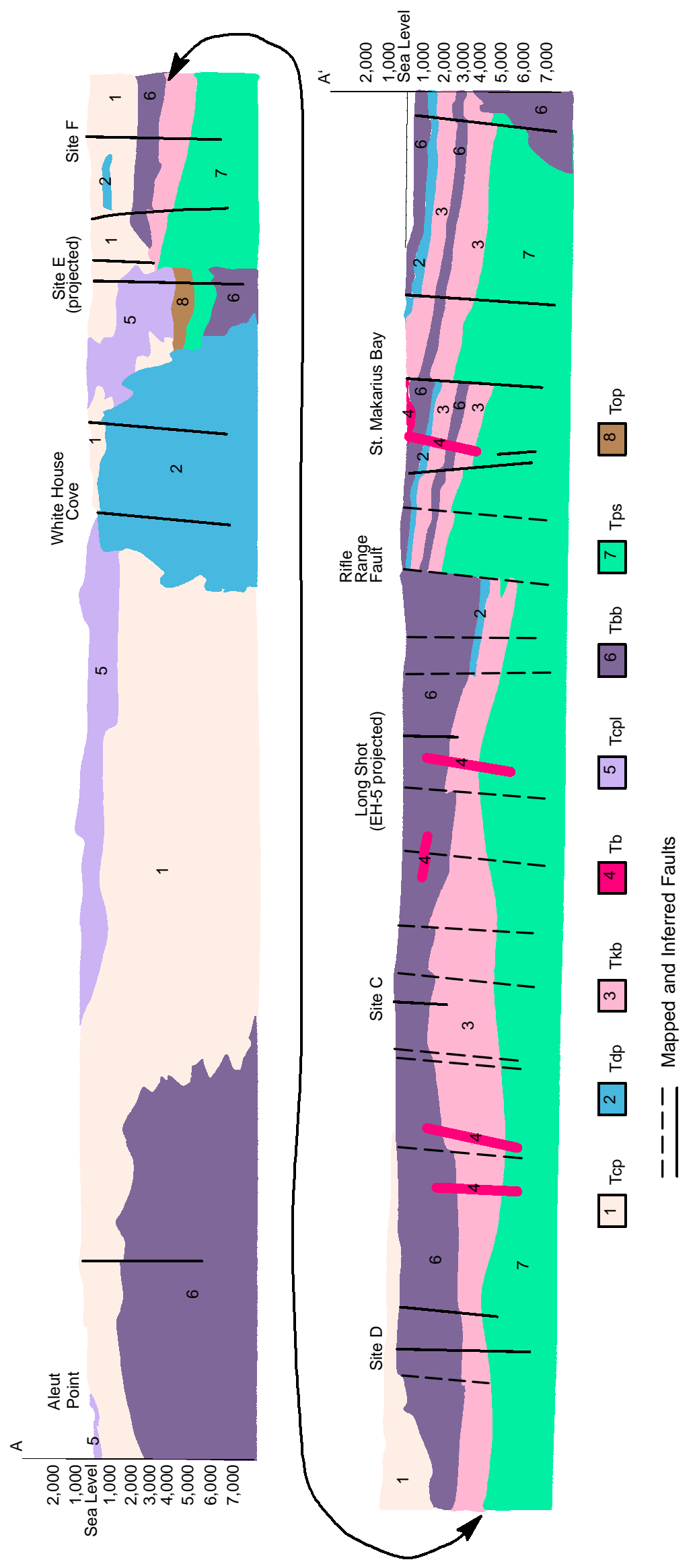

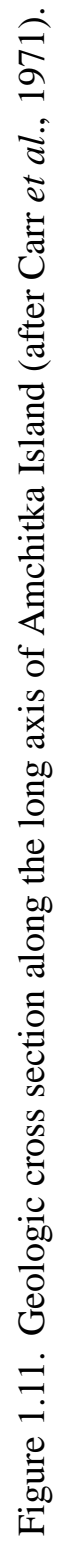


The Banjo Point Formation contains basaltic rocks of submarine deposition. It is a thick series of volcanic breccias, lapilli tuffs, and conglomerates with minor intercalated beds of volcanic sandstone, siltstone, shale, and tuff (U.S. Army Corps of Engineers and USGS, 1965). The volcanic breccias comprise the majority of the formation, and are poorly sorted, unstratified, and irregular in thickness. They are composed of angular basaltic or andesitic rock fragments set in a fine-grained matrix commonly containing fragments of pyroxene crystals. Some rocks contain considerable nontronite and montmorillonite. Marine shell fragments can be found, as well as thin beds of sediment, indicating deposition through submarine landslides and mudflows. Fragments of carbonized organic material, including logs, indicate a nearby landmass. The working point for the Long Shot test was located in the Banjo Point Formation (Nork et al., 1965), in altered pyroclastic rocks of basaltic composition (Gard and Hale, 1964).

The Chitka Point Formation covers almost the entire northwestern half of Amchitka Island and consists almost entirely of subaerially deposited hornblende andesite volcanic rocks (Carr and Quinlivan, 1969). The lower part of the formation consists of varicolored heterogeneous breccia consisting of fragments of hornblende andesite in a tuffaceous matrix, conglomerate with andesite cobbles, a few hornblende andesite lava flows (some with large green pyroxene crystals), and minor sedimentary layers. Much of the Chitka Point Formation has been altered by hydrothermal activity. Weakly altered zones consist of chloritic minerals and pyrite, while the rock in more intensely altered zones is converted to masses of silica, clay zones, iron oxides, pyrite, and chlorite minerals.

A variety of intrusive igneous rocks is present on Amchitka, exposed as dikes and sills, and more voluminous complexes of diorites and andesites. They are exposed on the east and west parts of the island, and strong propylitic alteration and silicification of rocks in the mountainous part of the island suggest the proximity of a large intrusive mass (Carr et al., 1969). Dikes range from olivine-bearing basalts to hornblende and pyroxene andesite to quartz diorite. Quaternary deposits are unconsolidated sands and gravels in fault depressions, beach deposits, and stabilized dunes. Much of the land surface on the southeastern half of the island is covered by a mantle of maritime tundra and peat.

In the part of the island where the nuclear tests were conducted, the stratigraphic section is generally dipping southeastward (Carr and Quinlivan, 1969). Drilling and mapping associated with Long Shot indicated that the Banjo Point Formation strikes $\mathrm{N}^{\circ} 5^{\circ} \mathrm{E}$ and dips from $10^{\circ}$ to $15^{\circ}$ to the southeast (Gard and Hale, 1964).

\subsubsection{Lithology Specific to the Testing Areas}

Six areas were evaluated on Amchitka for the STS program, denoted by the letters A through F (Figure 1.4). Sites B and C became Milrow and Cannikin, respectively, and Long Shot is located between them. The preference for sites $\mathrm{B}$ and $\mathrm{C}$ was largely based on the predictability of the subsurface geology at those sites, due to extrapolations from Long Shot borehole data (U.S. AEC, 1967). In other words, the three tests were sited so that they would encounter similar geologic units. They are discussed below in order from southeast to northwest.

Subsurface data from the Milrow site come primarily from the exploratory borehole UAe-2 (Figure 1.12). This well was located at UTM coordinates of N 5,698,166.48 m, E 651,716.53 m, 
UAe-2 Milrow

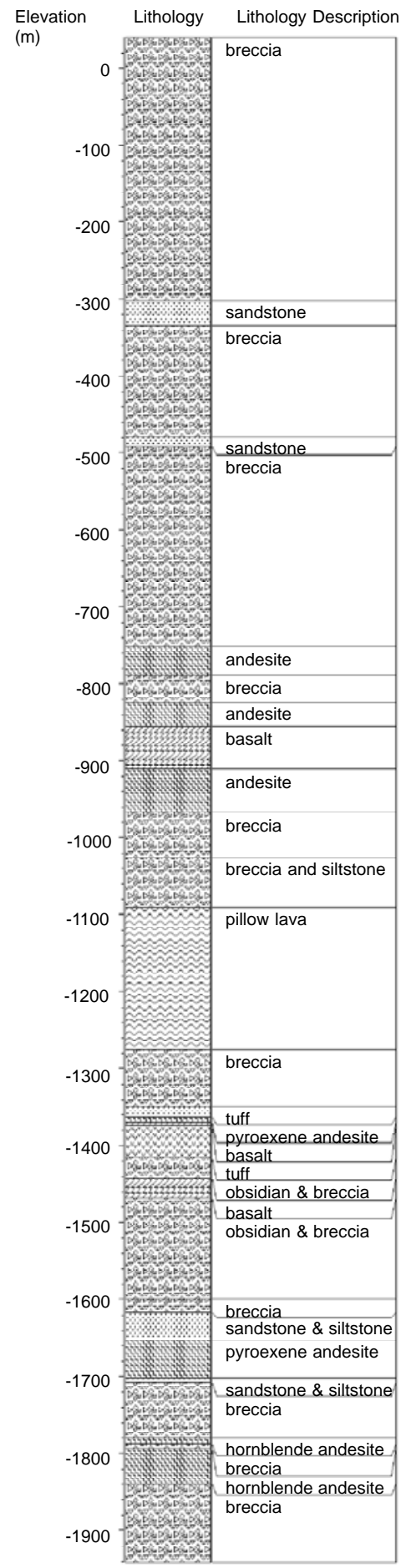

UAe-1 Cannikin

Elevation Lithology Lithology Description $(\mathrm{m})$

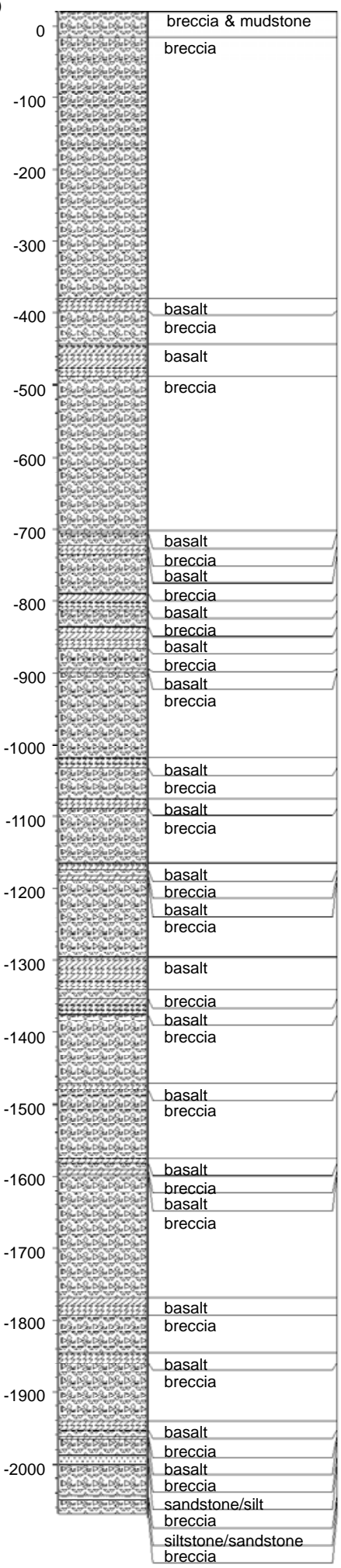

$\mathrm{EH}-2$ \& EH-5 Long Shot

Elevation Lithology Lithology Description $(\mathrm{m})$

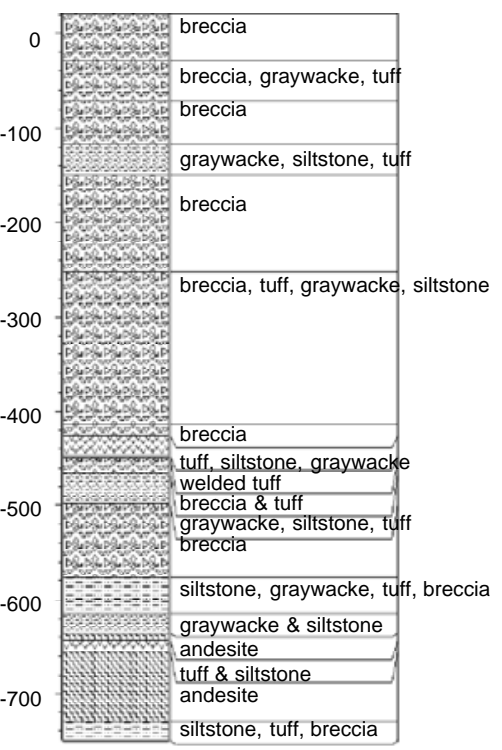

Figure 1.12. Construction diagram, lithologic log and summary of hydraulic tests, holes UAe-2, UAe-1, EH-2 and EH-5, Amchitka Island, Alaska. From Ballance, 1973a,b. 


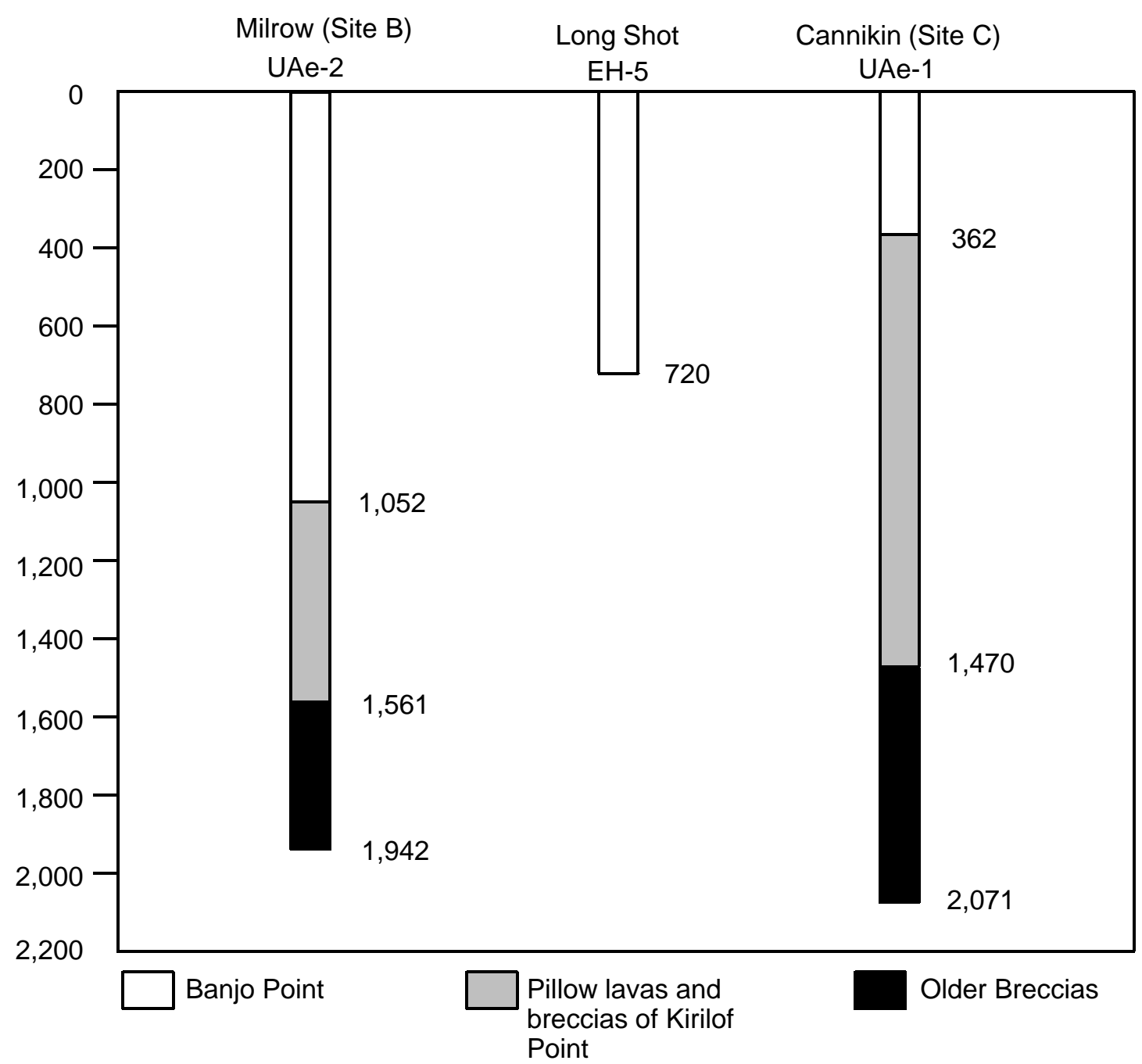

Figure 1.13. Stratigraphic section encountered in the exploratory boreholes for the three test sites (numbers are elevation below sea level).

zone 60 , with a ground elevation of $39.47 \mathrm{~m}$. The hole was drilled to $1,981.2 \mathrm{~m}$. The borehole penetrated the Banjo Point Formation from land surface to a depth of 1,091 m, the pillow lavas and breccias of Kirilof Point from 1,091 to 1,600 m, and bottomed in the Older Breccias (encountered from 1,600 to the total depth of 1,981 m (Figure 1.13, note the figure expresses elevation not depth). The actual working point in borehole UA-2 (the device emplacement hole) was in the pillow lavas and breccias of Kirilof Point. Most of the rock penetrated by UAe-2 is volcanic breccia, andesite, and basalt. Fenske (1972) estimated the geologic section at UAe-2 to be comprised of 60 percent breccia and 32 percent basalt. Lithologic information is detailed by Snyder (1968a), while physical properties of core samples (e.g., porosity and bulk density) are given by Lee (1969a).

Boreholes drilled during Long Shot investigations were contained within the Banjo Point Formation. Volcanic breccia was the primary lithology encountered, with some tuff, sandstone and siltstone containing volcanic rock fragments (Figure 1.12). Two andesite sills were also encountered near the bottom of the boreholes. Boreholes EH-3, -5, and -6 have surface locations within 180 
$\mathrm{m}$ of each other and are angled so as to intersect at depths of about $610 \mathrm{~m}$. Despite this proximity, correlations can only be made in very general terms until the holes are within $30 \mathrm{~m}$ or less of each other. No satisfactory correlations were made with borehole EH-1, located at a distance of about 300 $\mathrm{m}$ from the other holes. Detailed lithologic data and physical property data for Long Shot boreholes can be found in U.S. Army Corps of Engineers and USGS (1965).

The stratigraphic section at Cannikin was investigated in the UAe-1 exploratory borehole (Figure 1.12). This well is at UTM coordinates N 5,704,210 m, E 646,350 m, with a ground elevation of $62.79 \mathrm{~m}$. From land surface to $425 \mathrm{~m}$, the borehole penetrates the breccias, siltstones, and sandstones of the Banjo Point Formation (Lee and Morris, 1968). Glassy breccias and pillow lavas of Kirilof Point were encountered from 425 to $1,533 \mathrm{~m}$ below land surface. Propylitized breccias, basaltic siltstone and sandstones, andesites and basalts, all of the Older Breccias Formation, occur from 1,533 m to the 2,134 m total depth of the hole (Figure 1.13, expressed in elevation). The test chamber in the Cannikin emplacement hole, UC-1, was completed from 1,783 to $1,799 \mathrm{~m}$ in a zeolitic basalt.

\subsubsection{General Structure of Amchitka Island}

There are contradictory interpretations of the regional stress field around Amchitka. Based on the general structural setting of the Aleutian arc, as well as data from Long Shot, McKeown et al. (1967) indicate that the region around Amchitka Island is currently under compression. The arc itself represents the collision of continental and oceanic plates. While acknowledging the crustal foreshortening occurring across the Aleutian arc, Anderson (1971) interprets the geology of Amchitka and regional tectonic features, inferred largely from geophysical data, as providing little evidence for compression. Instead, he suggests that the principal deformation resulted from tensional stress brought on by a rising and spreading core of intrusive igneous rock overlain by a relatively brittle envelope.

There are strongly developed joint and fault systems on the island, indicated by prominent linear topographic features. Near the Long Shot site, the dominant trend of the lineations is $\mathrm{N} 55^{\circ} \mathrm{E}$ to $\mathrm{N} 60^{\circ} \mathrm{E}$, corresponding to the strike of bedding in the area (U.S. Army Corps of Engineers and USGS, 1965). Later work (Carr et al., 1969) concluded that faults are not as abundant as lineaments suggest in the central part of the island, but that the lineaments tend to reflect joints and lithologic contacts, accentuated by erosion.

Approximately a dozen major fault zones were identified in the central part of the island (where the three underground nuclear tests were conducted), a few of which may have a width of up to 1,000 m, and within which the rocks may be highly fractured. Nearly all of these major faults trend about $\mathrm{N} 70^{\circ} \mathrm{E}$, though there is a second direction of structural weakness bearing northwest. The major fault dip is steeply to the northwest at $75^{\circ}-90^{\circ}$. Vertical displacements of at least $300 \mathrm{~m}$ are noted and indications are that the most recent fault movement had a strong lateral component. It is suspected that at least the larger faults are strike-slip. 


\subsubsection{Structure Specific to the Testing Areas}

The underground test locations were sited so as to avoid known fault zones (U.S. AEC, 1967). As a result, all three tests are located approximately midway in structural blocks between known or suspected faults (Figure 1.14).

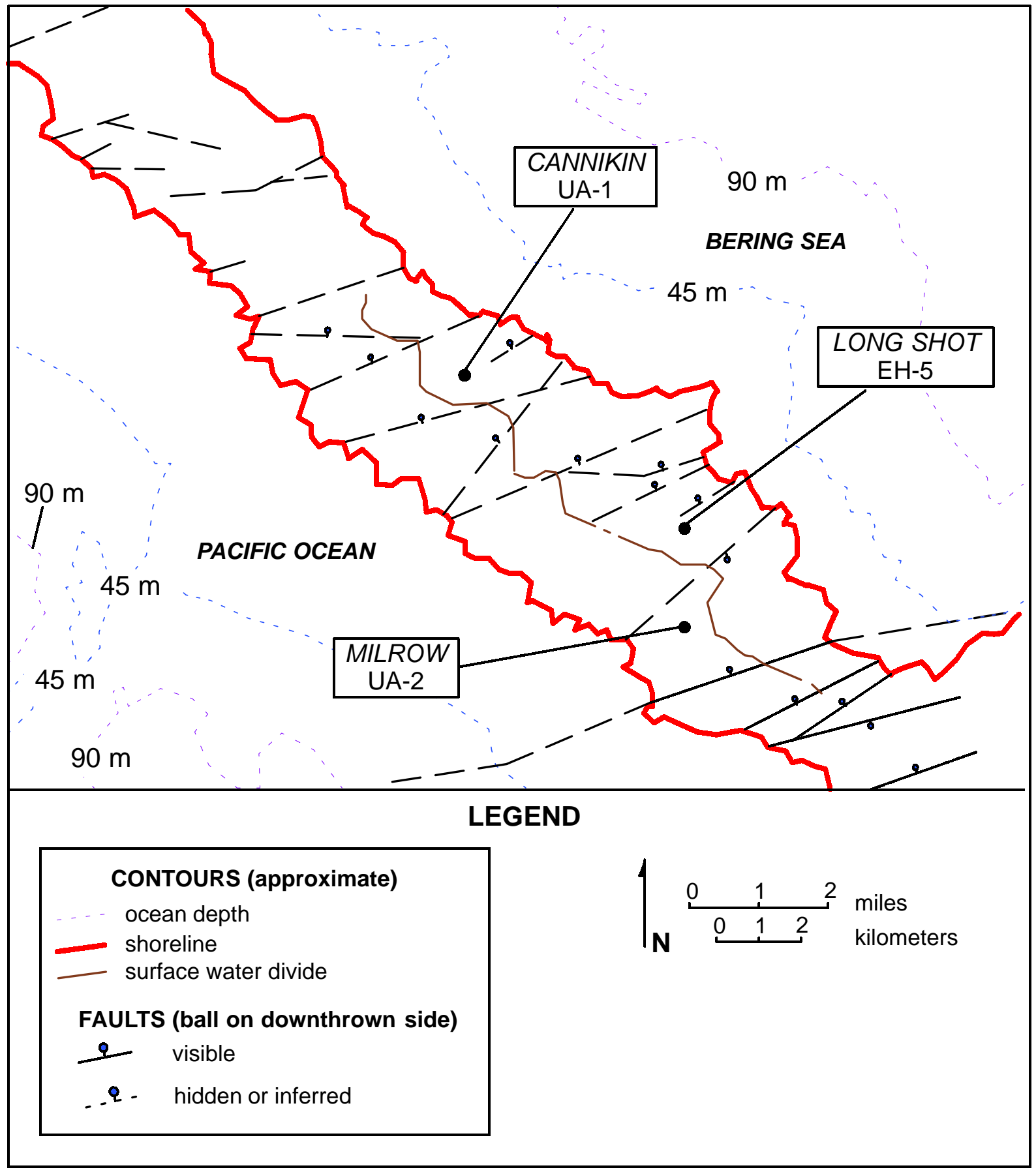

Figure 1.14. Schematic map of underground testing areas showing major features and bathymetry (after von Huene et al., 1971). 
Structurally, Milrow is located in a block between two faults. Milrow is about 1,200 m north of the Rifle Range Fault. This fault trends $\mathrm{N}^{\circ}{ }^{\circ} \mathrm{E}$, has a stratigraphic displacement of 1,220 m, and is thought to be represented by a fracture zone as much as $300 \mathrm{~m}$ wide (Morris and Gard, 1970). The Rifle Range Fault is believed to dip steeply northwest (Carr et al., 1969). Another fault is inferred about 1,000 m north of Milrow (McKeown et al., 1970), trending about N50 ${ }^{\circ} \mathrm{E}$.

Long Shot is bounded on the northwest and southeast by two strong lineaments, believed to be faults striking $\mathrm{N} 55^{\circ} \mathrm{E}$ (Gard and Hale, 1964; McKeown et al., 1967). Though topography suggests the intervening 610-m-wide block is a graben, McKeown et al. (1967) suggest Long Shot is located in a horst. Drillhole EH-1 was located on the bounding fault to the northwest (as indicated by seismic evidence); the hole had to be abandoned at a depth of $490 \mathrm{~m}$ due to lost circulation. During drilling of EH-3, a significant fault was encountered at a depth of $611 \mathrm{~m}$. It was characterized by rock and clay gouge about one meter wide. Most fractures encountered in cores are hairline, with slickensides, and many are cemented by calcium carbonate and zeolites. Several open fractures were encountered in EH-1, one of which had a 1-cm-thick coating of botryoidal calcium carbonate (Gard and Hale, 1964).

Two major northeast-trending faults bound the Cannikin test area (Carr and Quinlivan, 1969). The Teal Creek fault occurs 1,070 m northwest of Cannikin, and an unnamed fault occurs $760 \mathrm{~m}$ south. The Teal Creek Fault strikes approximately $\mathrm{N}^{\circ} 5^{\circ} \mathrm{E}$ and dips $80^{\circ}$ to the northwest (Gard, 1971). The unnamed fault strikes about $N 75^{\circ} \mathrm{E}$ with an unknown dip. A much smaller fault is shown as inferred on a geologic map of the Cannikin area by Gard (1971) and is mapped from the Bering coastline, running about $610 \mathrm{~m}$ in the general direction of the emplacement hole.

\subsection{Hydrogeology}

The hydrogeology beneath the surface at Amchitka is governed by the dynamics of the saltwater intrusion system typical of islands. The groundwater system consists of a freshwater lens floating on seawater. To sustain this lens, there must be active groundwater circulation. Rainfall that infiltrates is fresher, and less dense, than the underlying seawater. Continued recharge results in the buildup of a lens of freshwater floating above the seawater, and the flow of freshwater from the center of the island outward to the ocean. This is analogous to an iceberg in that the majority of the freshwater lens, including the seepage face where discharge occurs, is below sea level. Under non-stressed conditions, such as occur on Amchitka (no pumping of groundwater), a steady-state condition is reached where recharge from rainfall is balanced by discharge along the seepage face

to the ocean. The thickness of the freshwater lens is controlled by the hydraulic conductivity of the aquifer, the recharge flux, the land elevation, dispersion and anisotropy in hydraulic conductivity.

Groundwater flow is generally characterized by recharge along the water table, downward flow in the interior of the island, and upward flow approaching the coast, with freshwater discharge seeps along the seafloor (Figure 1.15). The lateral component of the hydraulic gradient is from the axis of the island to the coasts on either side, though vertical components of flow are important. Although at much lower flux rates than occur in the freshwater lens, there is a cycle of saltwater flow beneath the island as well. The saltwater flow is caused by the diffusion of salt into the overlying freshwater lens in the transition zone. The salt removed by this process is replenished by recharge 


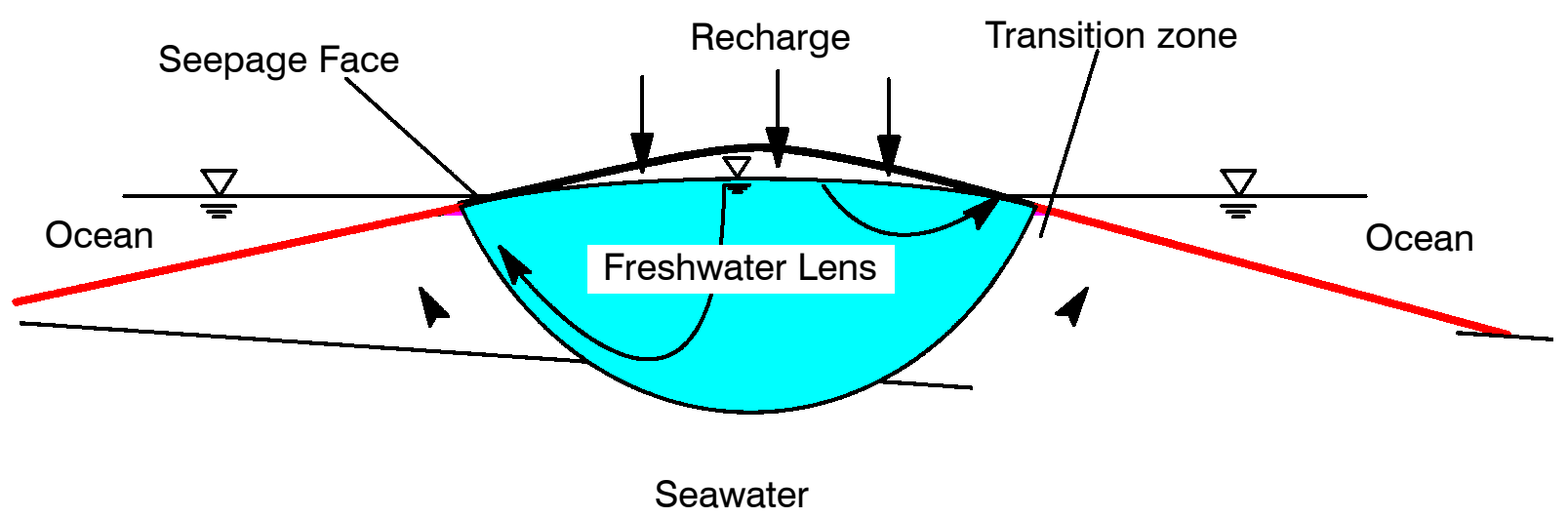

Figure 1.15. Saltwater intrusion beneath island aquifers. Typical flowpaths are indicated by the curved arrows.

of the saline groundwater system through the seafloor at distances greater than the zone of freshwater discharge.

Exclusive of the higher altitude area to the northwest, the water table at Amchitka is very near to land surface. Shallow wells drilled in the testing areas encountered groundwater at depths of essentially zero to several meters below land surface (Essington et al., 1971). Significant runoff of rainfall to ponds and streams occurs (Gonzalez, 1977), consistent with nearly saturated subsurface conditions. Dudley et al. (1977) observed that most precipitation runs off in stream channels.

Hydraulic head measurements with depth (Figure 1.16 and Figure 1.17) demonstrate decreasing head values with increasing depth (Ballance, 1968), consistent with the downward flow expected in the island center. Head data are discussed in more detail in the section on flow parameters (Section 2). Though the hydraulic gradient supports the oceanward movement of groundwater, Dudley et al. (1977) conclude that the hydraulic conductivity in the upper few hundred meters is not high enough for large rates of flow, leading to most groundwater beneath Amchitka moving in very local systems to discharge in lakes and streams.

Lithologic descriptions, the rock physical properties, and geophysical logs indicate that the aquifers on the island occur in fractured rock units (Fenske, 1972) and, generally, most investigators have applied a conceptual model of predominantly fracture flow between matrix blocks of relatively high porosity. By analyzing water level fluctuations in wells as compared to barometric and tidal fluctuations, Fenske (1972) identified two, interconnected components to the Amchitka flow system: 1) a system of high porosity and extremely low hydraulic conductivity, and 2) a system with low porosity and relatively high hydraulic conductivity. Dudley et al. (1977) conclude that hydraulic testing strongly indicates that fractures are the primary avenues of fluid movement. They note that fractures tend to close under greater lithostatic load, implying decreasing hydraulic conductivity 


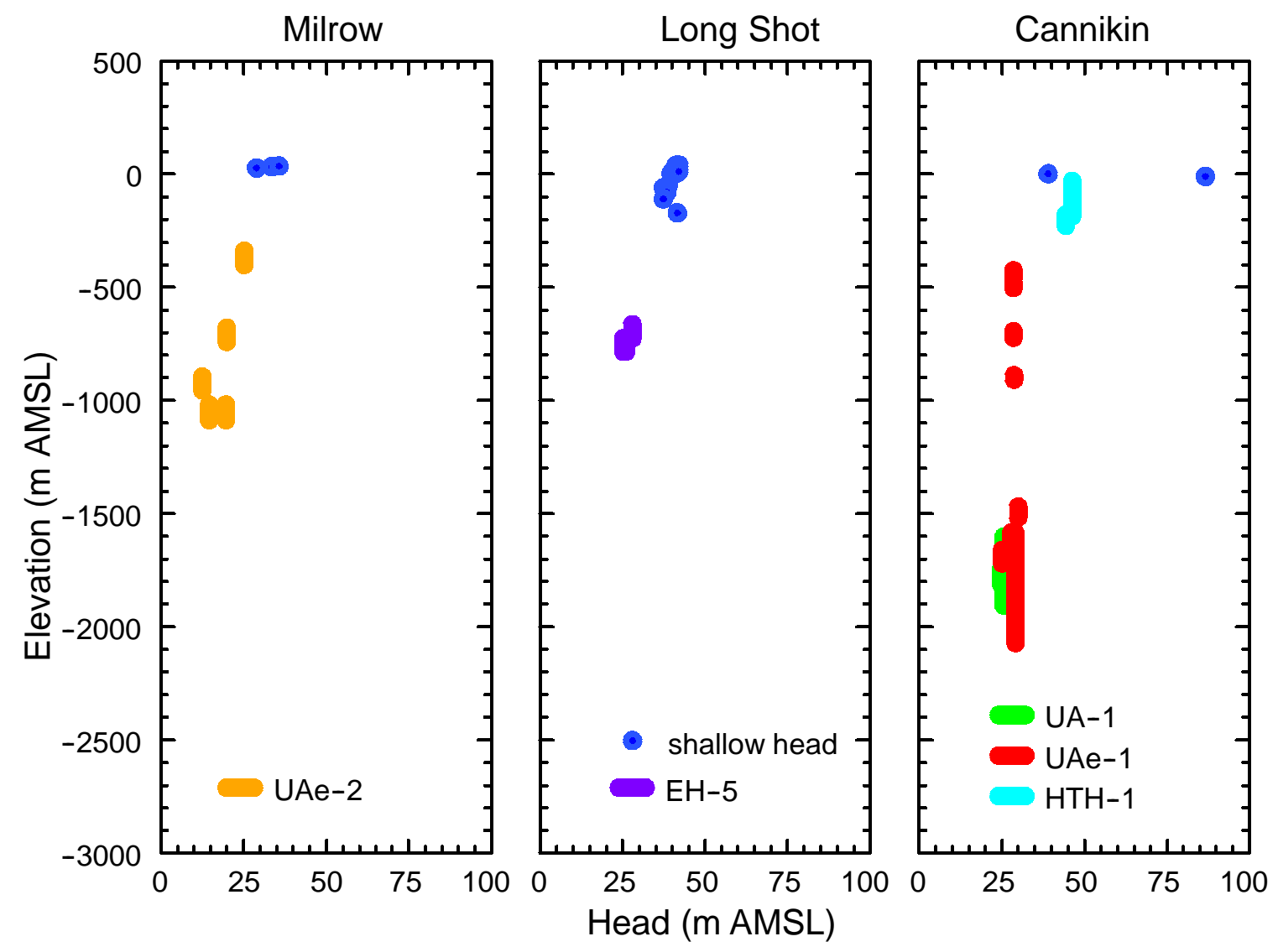

Figure 1.16. Head measurements at different wells as a function of elevation.

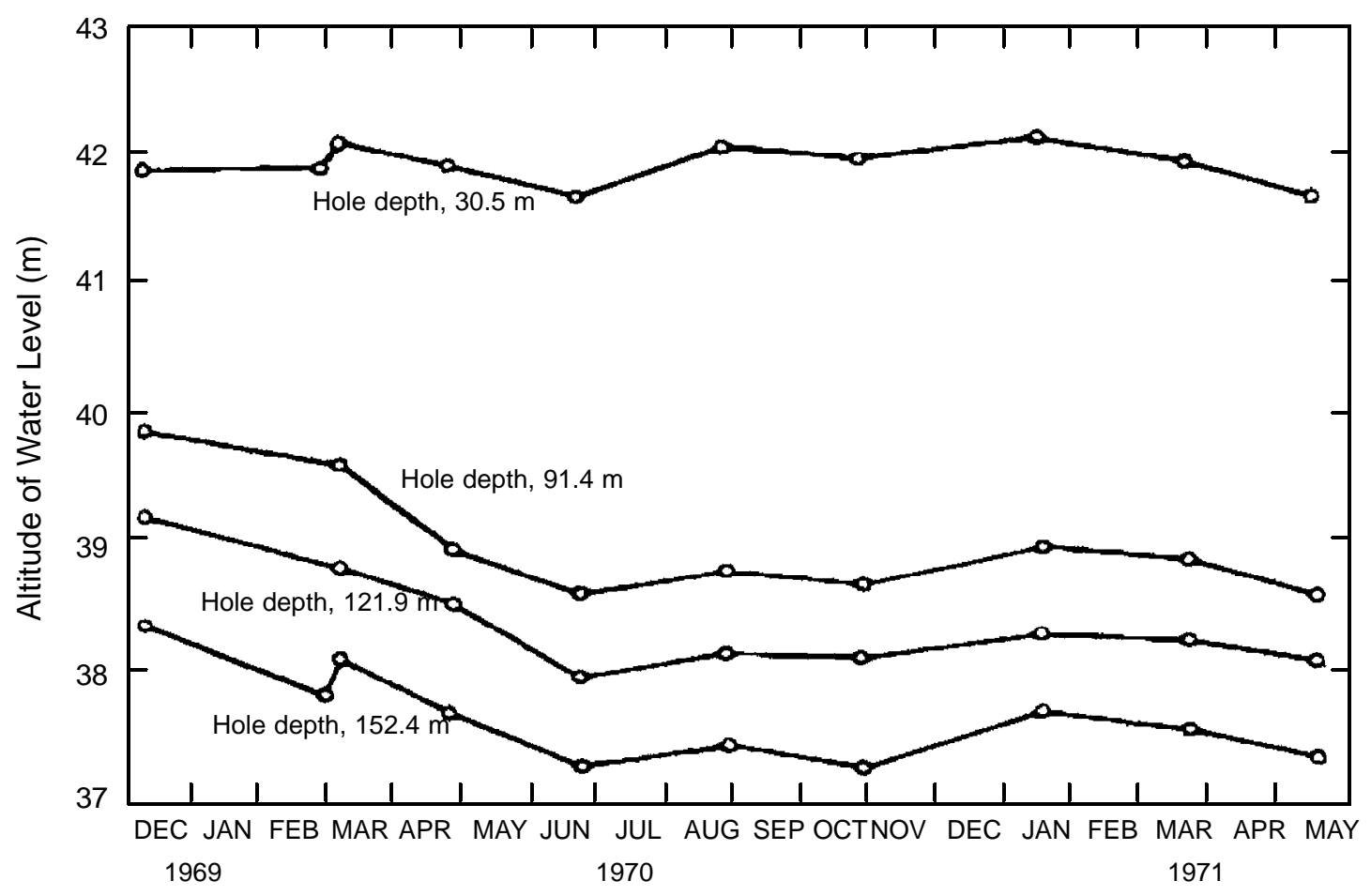

Figure 1.17 Water levels in shallow boreholes at the Long Shot site. From Dudley et al. (1977). 
with depth. The development of zeolites and chlorites in fractures from the alteration of the volcanic rocks further reduces the hydraulic conductivity (Dudley et al., 1977).

The depth of the transition from freshwater to seawater is an important feature in island hydraulic systems, as groundwater velocities are much higher above this transition zone than below it. Based on hydraulic head profiles for the three sites, Fenske (1972) estimated the bottom of the freshwater lens to be $780 \mathrm{~m}$ below sea level at Milrow and about $1120 \mathrm{~m}$ below sea level at Long Shot and Cannikin. Fenske (1972) notes that the results indicate an asymmetry of the freshwater lens. Fenske compared the hydraulic head analysis with the chemical analyses of water samples and found good agreement for Milrow. The relatively shallow depth of the testing at Long Shot did not allow sampling or measurements in the transition zone nor underlying seawater zone. The chemical composition of groundwater samples from the boreholes at Cannikin reveals a much less saline water with depth than encountered at Milrow (as discussed in the following section). After evaluating the drilling methods and hole histories for UAe-1, UAe-2, and UAe-6h, Fenske (1972) concluded that the total dissolved solids content of about one-tenth of the concentration expected below the predicted interface was probably due to injection of drilling fluid during the long and difficult hole construction in UAe-1. Dudley et al. (1977), however, conclude that the data are substantially correct and indicate a freshwater lens extending to an altitude of at least $-1,700 \mathrm{~m}$, based on generally corroborating data from the emplacement hole, UA-1.

\subsection{Hydrochemistry}

Consistent with the island hydraulic system described above, the profile of groundwater salinity with depth beneath an island is expected to reflect low salinity at shallow depths and a salinity consistent with seawater beneath the freshwater lens. The contact between freshwater and seawater cannot be sharp due to mixing caused by diffusion driven by the chemical gradient, and by dispersion caused by hydrogeologic heterogeneity, short-term head fluctuations (e.g., tidal effects), and long-term sea-level changes.

Chemical data for water samples from the island are reported by Beetem et al. (1971), as are their sample collection and analytical procedures. Charge balance checks of their analyses are all less than five percent off balance, with the vast majority being within two percent. Groundwater samples from wells at Long Shot were analyzed and reported by the U.S. Army Corps of Engineers and USGS (1965), though many of their analyses were incomplete in that they did not include all major anions and cations. Selected analyses from these sources are presented in Table 1.2.

The dissolved solids content of seawater collected off Amchitka is reported as 34,700 mg/L for the Bering Sea and 34,800 mg/L for the Pacific Ocean (Beetem et al., 1971). Samples of surface water were collected from lakes and streams on the island and have a mean total dissolved solids (TDS) content of $145 \mathrm{mg} / \mathrm{L}$ and $137 \mathrm{mg} / \mathrm{L}$, respectively (from residue on evaporation, Beetem et al., 1971). Water from springs is similar, with a TDS of $143 \mathrm{mg} / \mathrm{L}$. These relatively high salinities for surface water reflect the influence of the near-coast environment and salt spray. Though $\mathrm{Na}$ dominates the cations, $\mathrm{Ca}$ and $\mathrm{Mg}$ are present in proportions generally similar to seawater (Figure 1.18).

Groundwater samples from boreholes on Amchitka have primarily been collected by swabbing discrete intervals, though a few pumped samples from large intervals have also been collected. 


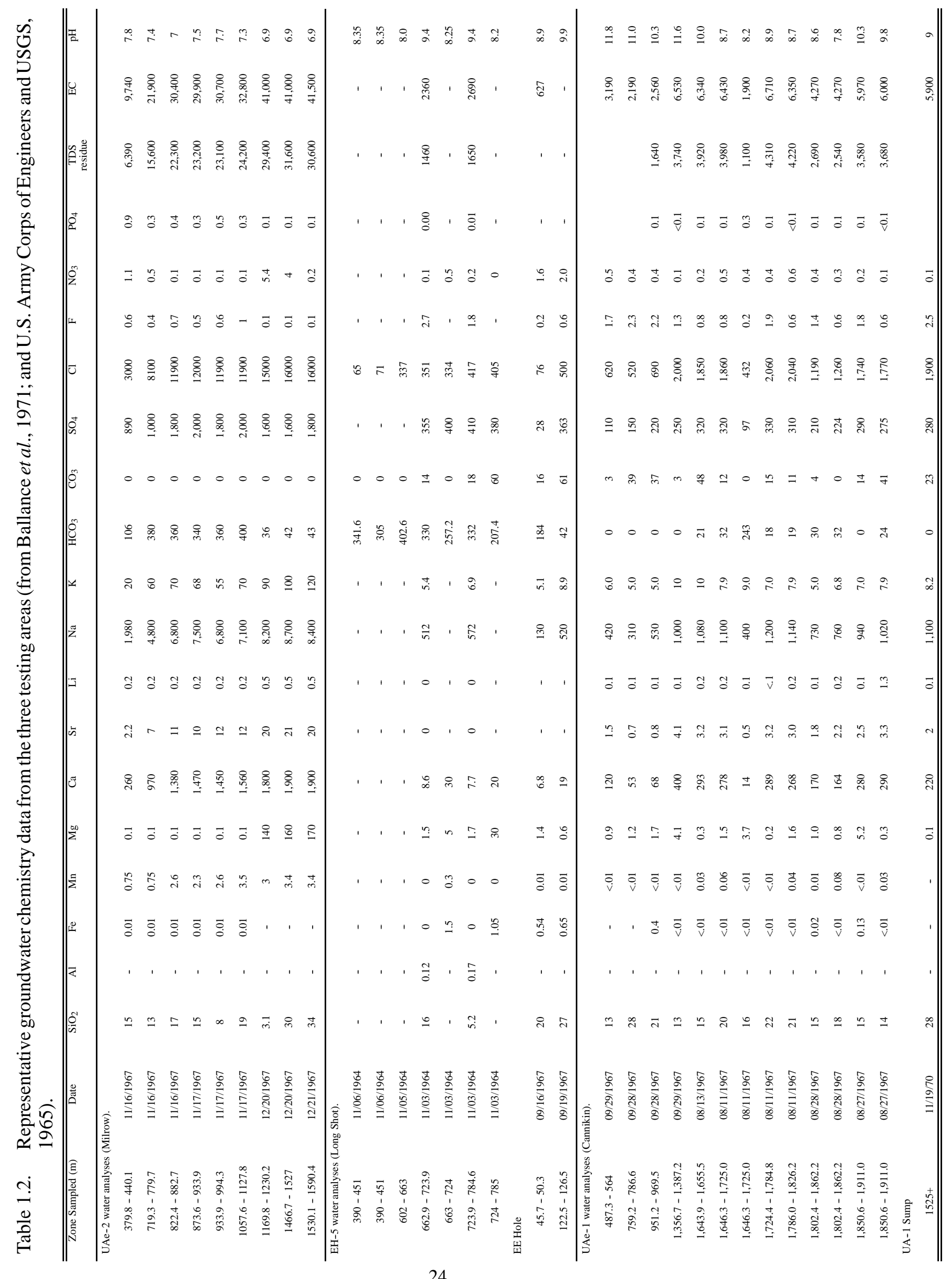




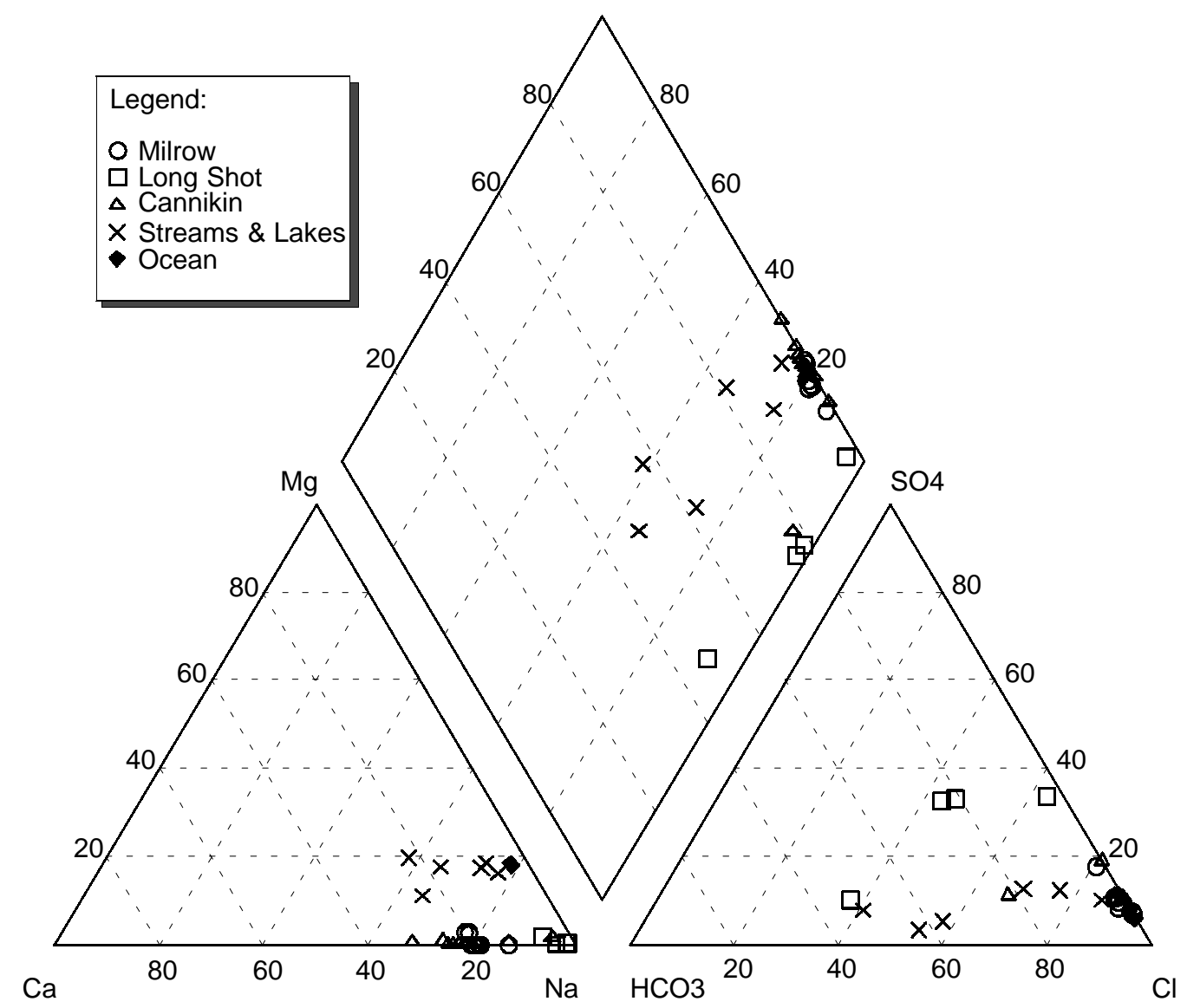

Figure 1.18. Relative ion percentages for water samples from Amchitka.

Collection of samples representative of formation water can be difficult due to the need to purge drilling fluids. High $\mathrm{pH}$ values are reported for some of the groundwater samples, indicating they were affected by contact with cement during grouting operations. The problem of groundwater sample representativeness is discussed further in section 2, regarding model parameter uncertainty.

In terms of major ion percentages, the groundwater at Amchitka is distinguished from the surface water and seawater by the relative absence of $\mathrm{Mg}$. Concentrations of $\mathrm{Ca}$ and $\mathrm{HCO}_{3}$ are highly variable, some of which may be due to cement contamination as indicated by very high $\mathrm{pH}$ values for certain samples. The Long Shot groundwater analyses are atypical of the other groundwater, having a higher proportion of $\mathrm{Na}, \mathrm{HCO}_{3}$, and $\mathrm{SO}_{4}$. The Long Shot holes were drilled with a bentonite mud that was impossible to purge from the holes without collapse, so these chemical differences may reflect residual drilling fluids. One of the Cannikin samples displays a similar chemical character, and the $\mathrm{pH}$ values for all of the Cannikin and Long Shot samples are considerably higher than those measured for the surface water and at Milrow.

The groundwater freshwater lens and underlying saltwater can be identified by samples collected by swabbing packer-isolated zones in well UAe-2. These zones are typically about $60 \mathrm{~m}$ in length and thus the samples represent composites of borehole fluid through that length. The chemical analysis of 
these samples (Table 1.2; Beetem et al., 1971) clearly defines the increase in salinity with depth to near-seawater concentrations. At Long Shot, electrical conductivity measurements led workers to identify "saltwater encroachment" in deeper groundwater samples, but salinities close to seawater were not found in chemical analysis. Groundwater from 670 to $793 \mathrm{~m}$ below land surface at Long Shot contained 350 to $415 \mathrm{ppm}$ chloride and TDS contents of 1460 to $1650 \mathrm{mg} / \mathrm{L}$ (U.S. Army Corps of Engineers and USGS, 1965). Water samples from borehole UAe-1 at the Cannikin site show little relationship between salinity and depth. This scatter has been argued as evidence of drilling fluid contamination by Fenske (1972), though Dudley et al. (1977) argue that the similarity in salinity for sump samples collected during mining the Cannikin cavity is evidence of the samples being representative of groundwater.

Using chloride as a conservative-ion indicator of salinity, the transition zone midpoint can be defined as the depth where the groundwater has a chloride content midway between the surface water value and the seawater value (i.e., 9,025 mg/L, halfway between about 50 and 18,100 mg/L $\mathrm{Cl}$ ). At Milrow, that occurs at an elevation of about $850 \mathrm{~m}$ below sea level (Figure 1.19), and at the other two sites, that salinity is not achieved in water from the sampled intervals.

Four carbon-14 age dates have been reported for Amchitka groundwater (Table 1.3). Two samples from UA-1-HTH-1, seaward of Cannikin, were analyzed for carbon-14. The interval from 183.5 to $234.7 \mathrm{~m}$ gave an apparent age (uncorrected for non-radiogenic carbon, an error expected to be small in a volcanic aquifer) of 8,410 years; the interval from 227.4 to $278.6 \mathrm{~m}$ had an apparent age of 17,880 years (Ballance and Dinwiddie, 1972). A sample from the interval of 679.8 to $740.1 \mathrm{~m}$ below sea level in UAe-2 gave an apparent age of 5,260 years (Fenske, 1972). A deeper sample, from

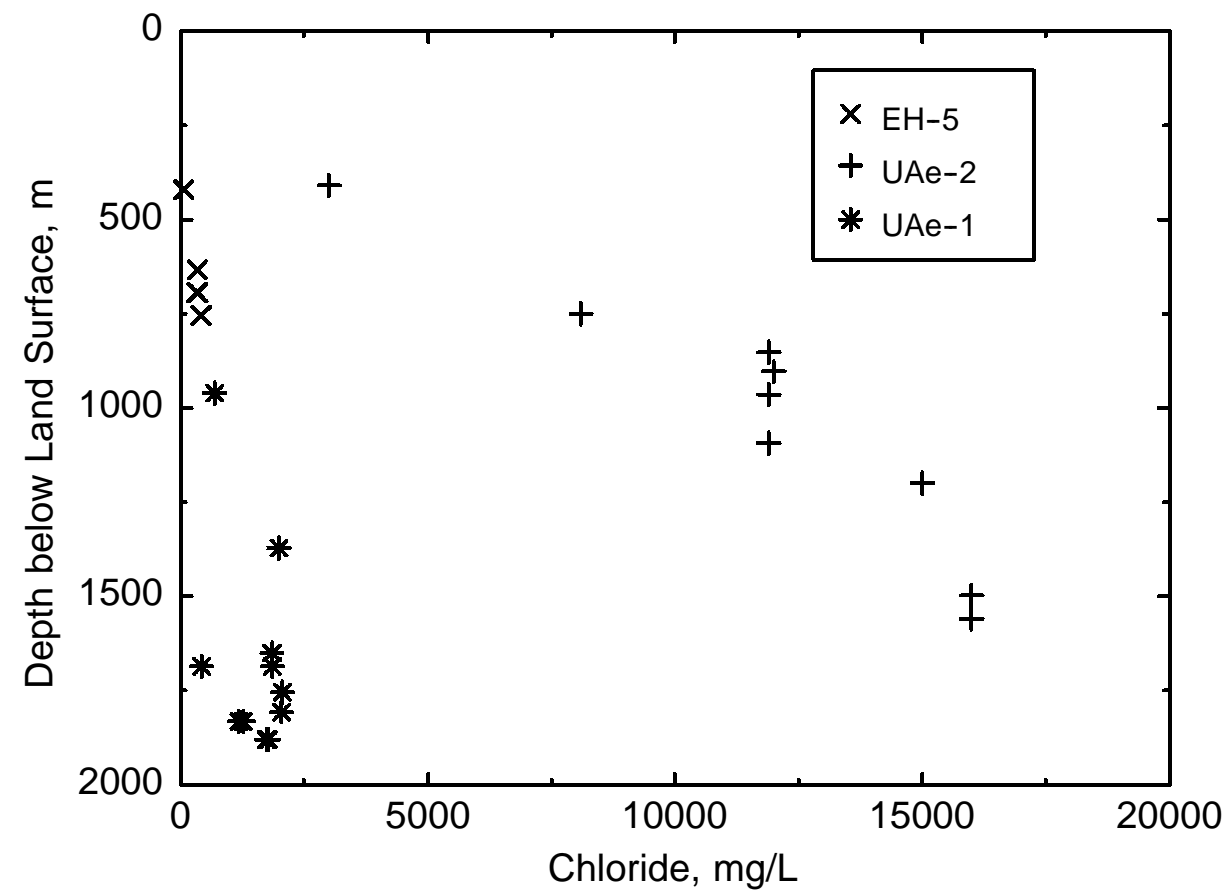

Figure 1.19. Chloride content at various depths at Milrow (UAe-2), Long Shot (EH-5), and Cannikin (UAe-1). 
888.3 to $906.2 \mathrm{~m}$ below sea level, collected from UAe-1, had an apparent age of 11,000 years (Fenske, 1972). Though no consistent trend in age with depth can be discerned from one well location to another, the large increase in age across the 100-m interval in HTH-1 was considered real by Ballance and Dinwiddie (1972). The implication of the carbon-14 data is that even in the shallower, freshwater portion of the island hydraulic system, groundwater residence times are long and overall velocity is low.

Table 1.3 Carbon-14 data for Amchitka groundwater samples. From Fenske (1972) and Ballance and Dinwiddie (1972).

\begin{tabular}{cccc} 
Well & Depth Interval, $\mathrm{m}$ & Conductivity, $\mu$ mhos/cm & Uncorrected C-14 age, yrs \\
\hline HTH-1 & $183.5-234.7$ & 590 & 8410 \\
HTH-1 & $227.4-278.6$ & 800 & 17,880 \\
UAe-2 & $679.8-740.1$ & $\sim 20,000^{*}$ & 5260 \\
UAe-1 & $888.3-906.2$ & $\sim 2400^{*}$ & 11,000 \\
\hline
\end{tabular}

*estimate based on sample from nearest depth interval reported by Beetem et al. (1971) 
THIS PAGE LEFT INTENTIONALLY BLANK 


\section{CONCEPTUAL FLOW MODEL, PARAMETERS, AND CALIBRATION}

The conceptual model of groundwater flow at Amchitka Island has several important components and assumptions, which are listed below and discussed in detail in subsequent sections.

- recharge and discharge characteristics governed by island hydraulics

- steady-state assumption

- isothermal conditions

- dual-porosity system where groundwater flow occurs principally through fractures

- homogeneity of hydraulic properties with vertical anisotropy

- limited impact of the nuclear tests on the island flow field

\subsection{Model Components and Assumptions}

Each of the model components is discussed below, followed by an evaluation of alternate conceptual models for groundwater flow.

\subsubsection{Island Hydraulics}

The fundamental setting of a freshwater lens overlying seawater in an island hydraulic system was described in the previous chapter. Though the basics of such systems were first identified near the turn of the 19th century (known as the Ghyben-Herzberg relationship), the complexity of the seawater intrusion problem has resulted in continued advances in the understanding of the processes into the 21 st century. Despite these complexities, there are also assumptions that acceptance of an island hydraulic system allows in the conceptual model of Amchitka. Some of these assumptions have been corroborated by data collection on the island.

The first assumption is the existence of a freshwater lens beneath the island, sustained by recharge at the land surface. The presence of freshwater has been confirmed by drilling and sampling throughout the island, and the very presence of that lens requires recharge to be taking place. The large amount of runoff observed, numerous lakes, low permeabilities of the aquifer materials, and hydraulic heads near land surface all indicate that actual recharge volumes are low at Amchitka (discussed in more detail in the Data section), but recharge must be occurring nonetheless.

Following from the recharge assumption is the assumption that discharge occurs offshore, along the ocean floor. The presence of this discharge is inferred, and would be difficult to impossible to observe in the high energy environment off the coast of Amchitka. Sustaining the freshwater lens requires active groundwater circulation, however, so it is assumed that discharge does occur. An assumption of steady state (discussed next) requires that the volume of discharge will equal that of the recharge.

With recharge across the entire land surface and discharge in the adjoining sea, a groundwater divide is established in approximately the middle of the island, with flow directed to the sea on either side. Amchitka is elongated, such that the divide is assumed to run along its length, dividing 
groundwater flow to the Pacific Ocean on the southwest, and to the Bering Sea on the northeast. The position of the subsurface divide is assumed to coincide with that of the surface water divide, but even the surface water divide is difficult to discern in the Lowland Plateau area of the tests, as there is minimal topography and numerous lakes. The sensitivity of the groundwater divide assumption is therefore tested in the modeling.

The flow system resulting from the above assumptions is one of predominantly downward flow in the freshwater lens near the island center, arcing outward and finally upward to discharge beneath the ocean. Slower and smaller flux circulation in the seawater lens mirrors the freshwater cycle above. The downward portion of the freshwater flowpath has been confirmed for Amchitka through the measurement of hydraulic head (which decreases with increasing depth) and analysis of temperature logs (which indicate downward movement of cooler water). The upward directed reach of the freshwater flow system has not been measured due to the location of the wells nearer to the island center than to the coast. The saltwater circulation portion has also not been measured at Amchitka.

With flow directed perpendicular from the groundwater divide out to the sea floor, the island hydraulic problem lends itself to analysis in two dimensions. There is no driving force to create gradients along the island axis; flow outside of a plane perpendicular to the axis will only result from heterogeneities in the flow field. The consequence of the two-dimensional simplification, then, is one of underestimating spreading (dispersion) of contaminant plumes simulated in two dimensions.

\subsubsection{Steady-state Assumption}

The complete absence of pumping on Amchitka removes groundwater development as a cause of transient hydrologic responses. Rather, the question of the applicability of steady state conditions to Amchitka arises from temporal variations in natural processes. The processes identified as causing transient effects are tidal fluctuations, short-term variability in recharge, and long-term changes in climate that could affect sea level and possibly recharge rate. Transient responses caused by the nuclear tests themselves are addressed in Section 2.1.6.

With barometric correction, a close correlation was identified between tidal fluctuations at the shore of the Bering Sea and water-level fluctuations in UAe-1 (Fenske, 1972). The period, then, of the hydraulic head response is as rapid as that of the tide, and with a small amplitude (less than a tenth of a meter, plus and minus every day). The effect of this rapidly reversing transient pulse may serve to add dispersion to the contact between the freshwater lens and seawater, but neglecting it in the modeling will not affect the flow directions and velocities.

Short-term variations in recharge could occur due to weather variations from one year to another. Given the island's current condition at flow capacity, wetter years would only serve to increase runoff and thus not impact the groundwater system. A low precipitation year, or series of years, however, could possibly reduce recharge to the groundwater system. If such a reduction was sustained long enough, the depth to the transition zone would eventually be reduced, only to move downward again when average precipitation resumed. The major effect of such variations will again be to disperse the contact between the freshwater and saltwater. 
Climate change involving glacial cycles affects mean sea level, which has a direct impact on the hydrology of an island. As mean sea level falls below current levels, the island's recharge area increases and the head for the saltwater system decreases. The net effect is to increase the depth of the freshwater lens. When sea level rises above current levels, the recharge area decreases, the head in the saltwater system increases, and the freshwater lens shrinks. Sea level varied by several tens of meters at Amchitka during the advances and retreats of Pleistocene glaciers (Gard, 1977). At least four major marine terraces have been mapped above the current island shoreline. The last major interglacial period caused a significant marine transgression at a level 37 to $49 \mathrm{~m}$ above present sea level. This transgression is dated at about 127,000 years before present. The last glacial advance ended about 10,000 years ago, at a sea level about $30 \mathrm{~m}$ below present. Sea level is believed to have been relatively stable at its present level for the past 2,000 to 4,000 years. Dudley et al. (1977) considered that time period long enough to likely allow for head adjustment, but question the response of water chemistry. Flushing of a relict deep freshwater lens will take much longer than head requilibration, especially given the slow velocities beneath the hydraulic transition zone. Dudley et al. (1977) suggest that freshwater circulation beneath Amchitka might have been as deep as 2,500 $\mathrm{m}$ during full glacial conditions, though the evidence of glaciers on the island itself calls into question the amount of recharge possible during the marine regressions.

Given the thousands of years that present sea level has been maintained, the steady-state assumption is considered reasonably valid for hydraulic head. As with the shorter-term processes discussed above, the impact of a glacial climate may principally be to have dispersed the transition zone, perhaps to the degree of leaving a relict, deep freshwater lens (as the last major sea level change was one of regression) that has yet to be displaced by the newer hydraulic regime. The different response times for the chemical and hydraulic systems to sea level changes are an important factor during the model calibration process, because the hydraulic data are considered more likely to represent equilibrium conditions. Given this impact, the relative response times are investigated in a sensitivity analysis.

\subsubsection{Isothermal Conditions}

Isothermal conditions are applied for the flow model, assuming that the flow system is dominated by the freshwater-seawater dynamics and that the effect of including geothermal heat would be relatively small. A significant factor in choosing this assumption is the large increase in computational load required by adding thermal conditions to the density flow solution, an already demanding series of computations as compared to a constant density problem. As discussed elsewhere, multiple realizations of the flow and transport are conducted to accommodate uncertainty. The merits of performing these Monte Carlo simulations were considered to outweigh the geothermal aspects. The error introduced through the isothermal assumption is investigated separately through a sensitivity analysis applying geothermal heat to the Milrow flow domain.

\subsubsection{Dual-porosity System}

Previous workers studying the hydrology of Amchitka Island have all concluded that groundwater flow occurs principally through fractures in the bedrock of the island. This conclusion 
has followed evaluation of geologic evidence gained through mapping and drilling, and analysis of hydraulic information from aquifer tests and cores. Basically, the very low permeability of the unfractured material, coupled with the presence of fractures and joints, leads to the conclusion that flow would be extremely limited other than in fractures.

Regarding the Banjo Point Formation investigated for Long Shot, the U.S. Army Corps of Engineers and USGS (1965) conclude:

The bulk of the rocks of the Banjo Point Formation have a porosity ranging between 4 and 26 percent but seem to have little interstitial permeability. The andesitic sills also have very little interstitial permeability. Rather, most of the permeability of these rock units seems to be in the fractures of the rocks and the permeability of these fractures seems to differ according to rock type and structural features.

The U.S. Geological Survey also investigated the hydrology of the Long Shot area and concluded that the groundwater system consisted of interconnected fractures, based on observations made during drilling, examination of cores, and results of pumping tests (Gard and Hale, 1964). Gard and Hale note that though the rock has high porosity, the effective porosity was only in the fractures.

Fenske (1972) observed that lithologic descriptions, physical property measurements, and geophysical logs indicate that the island aquifer system consists of secondary, fracture-created porosity and hydraulic conductivity superimposed on primary intergranular porosity and hydraulic conductivity. He used fluctuations in the water level at UAe-1 in response to barometric and tidal fluctuations to evaluate the two-component flow system at Cannikin.

Deep exploratory holes, from 1,000 to 2,134 $\mathrm{m}$ in depth, were drilled and tested at Sites B through F. Pumping and slug-recovery tests in zones isolated with straddle packers were performed in the holes. Dudley et al. (1977) report that "Results of the hydraulic testing point strongly to fractures (joints and faults) as the primary avenues for fluid movement."

Based on these assessments and the underlying data, it is assumed here that the groundwater flow system at Amchitka is a dual-porosity system. The primary flow system is considered to be through fractured rock. This characterization is achieved principally through assuming very low effective porosity values, consistent with fractures rather than porous media. Interaction between the fracture flow system and the secondary system found in the high-porosity matrix blocks is allowed only through diffusion during transport (discussed in the conceptual transport model section). The fracture flow conception is considered to be a conservative assumption for the modeling. The use of very low effective porosity values directly relates to faster groundwater velocities. A porous medium assumption, with attendant higher porosity, would result in slower velocities and longer transport times.

\subsubsection{Homogeneity of Hydraulic Properties with Vertical Anisotropy}

Heterogeneity in hydraulic properties is the rule rather than the exception in subsurface geologic units. This heterogeneity, or spatial variability, results from small-scale to large-scale 
variations in geologic properties that in turn control water movement. Examples of features controlling hydrologic spatial variability are clay content in a formation, degree of fracturing, and depositional patterns. Though heterogeneity on some scale is always present, the need to explicitly include it in a numerical model of groundwater flow depends on a number of factors. The primary impact of heterogeneity on a groundwater transport problem is in representing the spreading of a contaminant plume resulting from the tortuous path that water takes due to variations in the flow field caused by the spatial structure of the aquifer. Including heterogeneity in a model increases the amount of data required (to describe the spatial structure), and causes reliance on parameters that are very difficult to determine, such as the correlation scale. The alternative is to consider the hydraulic properties homogeneous and treat the spreading process caused by heterogeneity through a macrodispersivity term in the flow equation (Gelhar and Axness, 1983; Hess et al., 1992).

Identifying the preferred approach is based on the site data. The degree of variability in question needs to be evaluated. Then the availability of data to support a description of the spatial statistics of the hydrologic flow system must be considered.

Groundwater beneath the testing areas occurs in a variety of volcanic and sedimentary rock types, the vast majority of which is breccia, basalt, or a combination thereof. Analysis of hydraulic data from the extensive testing using straddle packers in island boreholes found a range of five orders of magnitude in hydraulic conductivity $(K)$. As discussed in detail in the section on flow parameters, division of the $K$ data into lithologic classes suggests that the mean $K$ of the breccias may be lower than the mean $K$ of the basalts. This difference is only "suggested," due to overlap in the data ranges and the small number of tests involved (only 13 in breccia intervals, 5 in basalt intervals, as the majority of packer seats straddled intervals containing combinations of lithologies).

It is important to note that the hydraulic testing is weighted toward the more permeable units, as these were intentionally singled out for packer isolation. Only about 10 percent of the section in the freshwater lens was considered permeable enough to hydrotest at Cannikin (Fenske, 1972). Zones that appeared to have extremely low $K$ were not tested. Thus, though the range in hydraulic conductivity for the permeable portions of the breccias and basalts may overlap, these portions are interspersed through the subsurface with large sections having much lower $K$. It also follows that there are units of even higher $K$ that may have been missed in the testing, or were included in a packed interval with units of lower $K$ such that a lower averaged value was measured.

The close correlation between hydraulic head in UAe-1 and tidal fluctuations indicates that the aquifer responds with average characteristics rather than as extensive homogeneous layers of differing characteristics (Fenske, 1972). Thus, the layered heterogeneity behaves as an equivalent homogeneous unit. This response is also consistent with flow predominantly through fractures, as lithologic differences would be of lesser importance than structural features. However, Claassen (1978) identified four main zones of different horizontal hydraulic conductivity in the undisturbed subsurface system at Cannikin. These zones are not described or explained in his report, and analysis of the testing from UAe-1 and UA-1 does not suggest these zones. Claassen's study was focused at a smaller scale than the modeling presented here; he was examining flow through the Cannikin 
chimney and post-test hole during infilling that required considering small-scale variations in flow properties.

The small number of wells having hydraulic data, and large spacing between them, precludes spatial analysis at the scale of each site, though Cannikin does have one well between ground zero and the coast (HTH-1). The majority of hydraulic information is available for one borehole at each location. In terms of geologic information, four coreholes were drilled to investigate the subsurface geology at Long Shot. Three of these were drilled with a maximum separation of $183 \mathrm{~m}$, with two directionally drilled (EH-3 and EH-6) to intersect the vertical hole (EH-5). A fourth hole (EH-1) was located $335 \mathrm{~m}$ to the north. Geologists concluded that the holes could only be correlated with each other in very general terms (U.S. Army Corps of Engineers and USGS, 1965). When the holes are within $30 \mathrm{~m}$ or less, several clear-cut correlations can be made. Working upward (and farther apart), several overlying gross units of one predominant lithology (mostly breccia, or mostly clastic) can be identified, but the precise top and bottom cannot be picked with certainty. Many smaller units, to $7.5 \mathrm{~m}$ thick, appear in one hole and nowhere else. No satisfactory correlations could be made across the $335 \mathrm{~m}$ to EH-1. Comparison with outcrop studies of the sea cliffs identified the "extremely irregular deposition of these breccias and fine clastics" (U.S. Army Corps of Engineers and USGS, 1965). It is noted that extreme lenticularity is the rule rather than the exception. The same lithologic types and variations were observed in both cross section and the core holes, with a lack of lateral continuity in both. At Cannikin, the lithology in UAe-1 and the emplacement hole UA-1 correlated well in terms of large-scale stratigraphic units, but the thickness of individual units was found to change drastically in the $90 \mathrm{~m}$ between holes, and some were found to pinch, swell, bifurcate, and even disappear. These lateral changes were not considered unusual for volcanic rocks (Lee and Gard, Jr., 1971).

Given the lack of major differences between the hydraulic conductivity of the rock types in the testing areas, coupled with a lack of ability to confidently project the locations of the units any distance from the boreholes, a homogeneous model was chosen for the numerical flow model. The heterogeneity known to be present is addressed in the model through the use of a macrodispersivity term. The heterogeneity assumption is consistent with the assumption of a dual-porosity flow system, where flow is predominantly through fractures that are distributed through all the lithologies present.

\subsubsection{Vertical Anisotropy}

Though the multitude of layers of varying lithology and varying hydraulic conductivity may be approximated as a single homogeneous unit, the layering results in that system being anisotropic. Flow perpendicular to the layers (vertically) occurs with more head loss than flow parallel to the layers (horizontally). Layered heterogeneity can lead to regional anisotropy values on the order of 100:1 (horizontal to vertical $K$ ), or larger (Freeze and Cherry, 1979). In fractured rocks, the anisotropy can be opposite, with vertical flow favored over horizontal. At Amchitka, the fracture system is overlain on a strongly layered lithologic section, so that the anisotropy is considered to favor flow in the horizontal direction, though not to the degree of a non-fractured sequence of heterogeneous layers. The anisotropy assumed here for Amchitka is 10:1. 
Previous workers have also considered the island to behave anisotropically. Dudley et al. (1977) state that flow in the vertical direction is generally retarded throughout the island. Claassen (1978) studied hydraulic and water quality data from Cannikin and concluded there was a low vertical hydraulic conductivity, with little vertical flow indicated. Though Fenske (1972) contended that the hydrologic system at Cannikin at an elevation below $-400 \mathrm{~m}$ was isotropic, he acknowledged that hydrotest and geological data required anisotropy on a local basis and he included it in a travel time model.

\subsubsection{Limited Impact of the Nuclear Tests on the Island Flow Field}

The underground nuclear tests at Amchitka are assumed to permanently affect the hydrologic environment in the immediate vicinity of each test, but not to affect the flow field at large. Each nuclear test created a cavity, which then collapsed and formed a rubble chimney above. Though there was surface collapse at Milrow and Cannikin, actual chimney formation did not propagate to the surface at any of the sites. Despite this, given the collapse and near-surface spalling, chimney-type properties are assumed to be continuous from the cavity to land surface at all three tests. These properties are increased vertical permeability and increased porosity.

Fracture intensity caused by an underground nuclear test varies with distance from the working point. General relationships are described by Borg et al. (1976) and are as follows: immediately adjacent to the cavity, and in the chimney, a zone of highly crushed rock is found, extending to a distance of about 1.3 cavity radii at the level of the test. A pervasively fractured zone then extends between 2.5 to 4 cavity radii. Beyond this is a region of widely spaced fractures with less frequent interconnection. Generally, at distances between 3.5 and 5.2 cavity radii, the compressive strength of the shock wave is too small to fracture the rock (the limit of shear failure). For many tests, the limit of shear failure coincides with the height of the chimney. Though tensile fracturing may take place beyond the shear failure limit, fractures are typically widely spaced and are considered to contribute little to an increase in overall permeability. Surface observations of nuclear testing effects focus on the impact of spalling. Spalling occurs when the compressional shock wave travels to land surface, causing surface layers to split away (and a temporary rise in land surface elevation), and subsequently slap down when the layers fall. This can result in fracturing of near-surface rock, confined to the upper tens to possibly a hundred meters below land surface, but unconnected to fractures from the cavity.

The International Atomic Energy Association (IAEA) modeled a variety of permeability configurations around a cavity and chimney and compared the results to data from two underground tests (IAEA, 1998). For the larger test (yield of $14.5 \mathrm{kt}$ ), the data were best matched by the models of no fracturing or fracturing only above the chimney. The smaller test (yield of $3.2 \mathrm{kt}$ ) was better simulated by a model of radially decreasing fracturing. This is consistent with observations of testing at the NTS, where larger tests are found to be better contained than smaller ones due to the establishment of a "stress cage" whereby the intense shock wave created by the test itself seals the near-cavity area from surrounding rock. Ultimately, the impact of local increases in $K$ is limited by the hydraulics of the surrounding aquifer (i.e., the water must eventually move into a less conductive area, and this controls the flux through the more conductive zone). 
Nuclear tests also temporarily impact the flow field through transient pressure and temperature gradients. Immediately after the detonation, the vaporization of mass that creates the cavity also desaturates it. This causes hydraulic gradients to be directed toward infilling the cavity and chimney region prior to re-establishing the pre-existing regional gradient. Monitoring of this infill process at Cannikin indicates that it took less than two years to recover. This process could be incorporated into the modeling by preventing contaminant migration from the tests until after hydraulic re-equilibration. Radioactive decay would continue during this time, effectively decreasing the contaminant mass. Neglecting the infill process is therefore a conservative assumption applied here.

The transient temperature gradient is reduced during the infilling process, as groundwater cools the cavity; the thermal impact is greatest during hydraulic equilibration, when the cavity is infilling. Claassen (1978) presents a graph of the temperature history of the Cannikin cavity. A measurement 100 days after the test was about 200 degrees above the ambient pre-detonation temperature; this was reduced to about 25 degrees above ambient after 260 days. Based on vertical sampling in the post-test hole, Claassen concluded that "Large thermal gradients do not appear to have persisted in the Cannikin cavity. It is certainly possible that "hot spots" existed at time of abandonment of the site, but, if randomly distributed, they would contribute little to mixing of the cavity water." Additional examination of radiochemistry of vertically distributed samples in the Cannikin post-test well, led Claassen to observe that "Generalized cavity-wide convection of any magnitude is not apparent from examination of the available data." Based on this analysis, the transient temperature effects are not included in the bulk of the modeling, but are addressed through a sensitivity analysis.

\section{$\underline{\text { 2.1.7 Alternate Conceptual Flow Models }}$}

The conceptual flow model presented above is the basis of the bulk of the numerical modeling presented here. More complex, alternate, models can be imagined but are not supported by the data. In some cases, as noted above, specific alternative models are addressed through a sensitivity analysis.

For the island hydraulic system, the alternate model that could be pursued is in three dimensions rather than two. The basic island model is a two-dimensional problem, but there are variations that do require three dimensions to properly analyze. For the Amchitka testing areas, the impact of fault zones on the flow system, the impact of the chimneys created by the nuclear tests, and the impact of thermal processes, all require three dimensions. These alternate conceptual models are addressed in a sensitivity analysis, following the two-dimensional simulations.

An alternate conceptual model for the steady-state assumption would incorporate the temporal processes described above. Data on tidal fluctuations and long-term sea level changes exist; the magnitude and timing of short-term climate variations are unknown. None of these past processes are included in our modeling because their inclusion would not alter the current groundwater velocity fields (and travel times) calculated here. Forecasting future climate change is highly speculative and not attempted here. If another glacial climate occurred and sea level dropped below its present level, the depth of the freshwater lens would increase and travel times from Milrow and 
Cannikin might decrease. Little impact would occur at Long Shot, as its cavity is already in the freshwater zone. If interglacial conditions of the magnitude indicated by the marine terraces occur, an increase in sea level will shrink the freshwater lens at Amchitka and travel times from all three cavities might increase. Such a change would potentially be most dramatic at Long Shot, if the transition zone rose above the cavity horizon.

Rather than a dual-porosity, fracture flow system, an alternate conceptual model is to consider groundwater flow at Amchitka as strictly in a porous medium. This conception was tested by assigning an effective porosity coincident with the core measurements at Amchitka, keeping the other hydraulic parameters constant. The result (discussed in section 4) is that travel times to the discharge area on the sea floor increase enormously (only 29 out of one hundred realizations showed breakthrough at the sea floor after 5.5 million years). Given this result, the alternate conceptual model of porous media flow is not pursued due to its lack of conservatism. Though not a question of conceptual model so much as a question of implementation of the conceptual model of fracture flow, an equivalent porous medium approximation of fracture flow is used here. This is driven by the scale of the hydraulic data, coincident with that of equivalent blocks rather than discrete fractures, and the many assumptions regarding fracture geometry that are required by a discrete fracture model.

The alternative to a model of homogeneity is a conceptual model of discrete aquifers and/or aquifers with spatially variable hydraulic properties. To implement such conceptual models with a numerical flow model would require numerous assumptions regarding spatial distribution of hydraulic units and properties that cannot be supported by site data. The result would be greater uncertainty in the modeling results due to the introduction of parameters with no supporting data. The disadvantage of the homogeneity assumption is that it neglects known system complexity. For the testing areas, the potential negative consequence of this would be overlooking fast transport pathways. Given the lack of correlation observed at Long Shot, it is doubtful that stratigraphic units would provide direct transport pathways from the test cavities to the ocean floor.

The U.S. Army Corps of Engineers and USGS (1965) present a conceptual model of groundwater flow for the Long Shot site that examines flow through an andesite sill. They consider several variations regarding the relative hydraulic conductivity of the andesite and surrounding units, but key to all the situations is an assumption that the andesite is continuous between the testing area and the discharge point at the sea floor. They conclude that fractures and their distribution are the most important features of the flow system, a conclusion also made by the U.S. Geological Survey, as their description of the Long Shot flow system does not single out the andesite (Gard and Hale, 1964). The possible impact of conductive features of large continuous length is evaluated in a sensitivity analysis regarding the possible effect of faults on the flow system. That analysis can also be applied to conductive stratigraphic features, though they are less likely than fractures in the Amchitka environment.

Another alternative to the assumption of homogeneity is presented by Dudley et al. (1977) in the form of a two compartment hydrologic system on the island. They identify a shallow, moderately permeable, groundwater system that readily accepts recharge and in turn discharges in springs and 
to streams and lakes. This is in contrast to the deep hydrologic system in the consolidated rocks, characterized by low permeability and very slow rates of groundwater movement. They believe that most groundwater beneath Amchitka moves in very local systems to discharge into lakes and streams, and that Amchitka is drained principally by streams that carry direct runoff and sustained base flow derived from discharge of the shallow groundwater system to the streams and lakes. Implementing this conceptual model into a numerical model will result in a dynamic upper hydrologic layer that is essentially de-coupled from the underlying flow system of interest. The upper boundary of the deep system would become a leakage boundary from the shallow system, a subtle difference from the recharge applied in a single-compartment model. The important aspect of the dual-compartment model, that the abundant precipitation at Amchitka is diverted from the deep groundwater system, is captured through a low recharge rate in the single-compartment model. There is no suggestion of an unsaturated zone between the shallow and deep systems (no perching), so that pressure heads can be expected to be continuous. Significant lateral flow in a shallow system might result in somewhat lower heads at the top of the model domain than simulated with the single-compartment model here. The net effect of including a discrete upper layer would be to add complexity and detail in a small portion of the model domain that is not of concern to the modeling objective, and would not result in more rapid contaminant transport than the model pursued here.

\subsection{Flow Model Parameters and Supporting Data}

\subsubsection{Hydraulic Conductivity}

Data from hydraulic tests in exploratory holes on Amchitka Island are presented and analyzed in a series of reports released by the USGS in the late 1960s and early 1970s (Ballance, 1970a, 1970b, 1972a, 1972b, 1972c, 1973b). Most of the tests involved isolating uncased or perforated cased intervals of the boreholes with inflatable straddle packers, and injecting or swabbing known quantities of water. Difficulties in obtaining firm packer seats in cased and uncased portions of some boreholes led to repeated tests in many intervals, and in several intervals the tests could not be completed without packer bypass, as noted by the USGS. The packer intervals ranged in length from 18.3 to $485 \mathrm{~m}$, with an average length of $85 \mathrm{~m}$. The USGS reports present values of relative specific capacity (RSC), rather than transmissivity or hydraulic conductivity, $K$, for most of the tested intervals. As opposed to specific capacity, RSC is derived from a short-duration test of a defined interval (packed interval). The RSC values reported in the USGS reports are generally estimated from injection data.

Unfortunately, the RSC data cannot be used directly in groundwater modeling efforts at Amchitka, which require a description of the hydraulic conductivity of the subsurface. Therefore, an independent analysis of the hydraulic data reported by the USGS was conducted. All of the time-recovery plots presented in the USGS reports were digitized and the data analyzed using the method of Cooper et al. (1967), resulting in estimates of $K$ for 74 intervals in the six available wells. From these results, we selected the 42 values of $K$ estimated from swabbing tests where no packer bypass was noted by the USGS (Table 2.1). Only swabbing test results were included because injection test results can be biased toward lower values of $K$ if pores in the rock become plugged as

water and suspended material move into the formation during the test. All values of $K$ were 
calculated for standard temperature and salinity conditions owing to the lack of consistent reporting of salinity and temperature values in the tubing or packed intervals.

Table 2.1. Summary of hydraulic data from straddle packer tests on Amchitka Island.

\begin{tabular}{|c|c|c|c|c|c|c|}
\hline \multirow[b]{2}{*}{ Well Name } & \multicolumn{3}{|c|}{ "Depth (m below surface measurement point) } & \multirow[b]{2}{*}{$K^{* *}(\mathrm{~m} / \mathrm{d})$} & \multirow[b]{2}{*}{$\log _{10} K$} & \multirow[b]{2}{*}{ Lithology*** } \\
\hline & $\begin{array}{c}\text { Interval } \\
\text { Top }\end{array}$ & $\begin{array}{l}\text { Interval } \\
\text { Bottom }\end{array}$ & $\begin{array}{c}\text { Static Water } \\
\text { Level* }\end{array}$ & & & \\
\hline \multicolumn{7}{|l|}{ "Cannikin Site } \\
\hline UA-1 & 1596.6 & 1647.5 & & $6.0 \mathrm{E}-05$ & -4.2 & Breccia \\
\hline UA-1 & 1651.4 & 1702.9 & & 7.0E-05 & -4.2 & Breccia \\
\hline UA-1 & 1693.5 & 1753.8 & 35.0 & & & \\
\hline UA-1 & 1694.1 & 1769.4 & & $1.2 \mathrm{E}-03$ & -2.9 & Breccia \\
\hline UA-1 & 1745.3 & 1805.6 & & $3.1 \mathrm{E}-04$ & -3.5 & \\
\hline UA-1 & 1755.7 & 1808.1 & & 7.6E-04 & -3.1 & Basalt \\
\hline UA-1 & 1756.8 & 1968.4 & & $1.9 \mathrm{E}-03$ & -2.7 & \\
\hline UA-1 & 1806.3 & 1859.9 & 36.4 & $2.6 \mathrm{E}-03$ & -2.6 & \\
\hline UA-1 & 1813.0 & 1873.3 & 38.7 & & & \\
\hline UA-1 & 1834.9 & 1895.3 & 37.7 & & & \\
\hline UA-1 & 1877 & 1914.5 & & $1.9 \mathrm{E}-03$ & -2.7 & \\
\hline UA-1 & 1896.7 & 1968.4 & 36.4 & $2.8 \mathrm{E}-03$ & -2.6 & \\
\hline UA-1-HTH-1 & 80.5 & 125.0 & 3.9 & & & \\
\hline UA-1-HTH-1 & 128.3 & 179.5 & & $6.5 \mathrm{E}-05$ & -4.2 & Breccia \\
\hline UA-1-HTH-1 & 183.5 & 234.7 & 4.0 & $1.1 \mathrm{E}-01$ & -1.0 & Breccia \\
\hline UA-1-HTH-1 & 227.4 & 278.6 & 5.7 & $8.2 \mathrm{E}-02$ & -1.1 & \\
\hline UAe-1 & 487.7 & 518.2 & 34.4 & $9.0 \mathrm{E}-02$ & -1.1 & Basalt \\
\hline UAe-1 & 542.6 & 563.9 & 34.4 & & & \\
\hline UAe-1 & 951.0 & 969.3 & 34.2 & $5.0 \mathrm{E}-02$ & -1.3 & Basalt \\
\hline UAe-1 & 1531.3 & 1580.1 & 33.1 & $1.1 \mathrm{E}-02$ & -1.9 & \\
\hline UAe-1 & 1645.9 & 1724.6 & 35.1 & $1.2 \mathrm{E}-02$ & -1.9 & \\
\hline UAe-1 & 1648.4 & 2133.6 & 33.9 & $2.4 \mathrm{E}-03$ & -2.6 & \\
\hline UAe-1 & 1724.0 & 1784.3 & 37.7 & 7.6E-03 & -2.1 & Breccia \\
\hline UAe-1 & 1922.1 & 1982.4 & & 4.0E-05 & -4.4 & Breccia \\
\hline UAe-1 & 1966.0 & 2026.3 & & 2.3E-03 & -2.6 & \\
\hline UAe-1 & 2027.6 & 2133.6 & & $1.2 \mathrm{E}-03$ & -2.9 & \\
\hline \multicolumn{7}{|l|}{ Milrow Site } \\
\hline UAe-2 & 379.8 & 440.1 & 14.2 & & & \\
\hline UAe-2 & 933.9 & 994.3 & 27.0 & & & \\
\hline UAe-2 & 719.3 & 779.6 & & 4.6E-02 & -1.3 & \\
\hline UAe-2 & 994.2 & 1054.6 & & $1.8 \mathrm{E}-04$ & -3.7 & \\
\hline UAe-2 & 1057.6 & 1127.8 & 19.7 & $1.3 \mathrm{E}-02$ & -1.9 & \\
\hline UAe-2 & 1057.6 & 1127.8 & 25.0 & & & \\
\hline UAe-2 & 1109.5 & 1169.8 & & $1.8 \mathrm{E}-03$ & -2.7 & \\
\hline UAe-2 & 1164.3 & 1224.7 & & $9.0 \mathrm{E}-04$ & -3.1 & \\
\hline
\end{tabular}


Table 2.1. Summary of hydraulic data from straddle packer tests on Amchitka Island (continued).

\begin{tabular}{|c|c|c|c|c|c|c|}
\hline \multirow[b]{2}{*}{ Well Name } & \multicolumn{3}{|c|}{ Depth (m below surface measurement point) } & \multirow[b]{2}{*}{$K^{* *}(\mathrm{~m} / \mathrm{d})$} & \multirow[b]{2}{*}{$\log _{10} K$} & \multirow[b]{2}{*}{ Lithology*** } \\
\hline & $\begin{array}{l}\text { Interval } \\
\text { Top }\end{array}$ & $\begin{array}{l}\text { Interval } \\
\text { Bottom }\end{array}$ & $\begin{array}{c}\text { Static Water } \\
\text { Level** }\end{array}$ & & & \\
\hline UAe-2 & 1230.2 & 1290.5 & & $9.0 \mathrm{E}-04$ & -3.1 & \\
\hline UAe-2 & 1292.4 & 1352.6 & & $1.2 \mathrm{E}-03$ & -2.9 & Breccia \\
\hline UAe-2 & 1355.8 & 1416.1 & & $1.5 \mathrm{E}-03$ & -2.8 & \\
\hline UAe-2 & 1521.6 & 1581.9 & & $1.2 \mathrm{E}-03$ & -2.9 & Breccia \\
\hline UAe-2 & 1621.5 & 1681.9 & & $4.6 \mathrm{E}-03$ & -2.3 & \\
\hline UAe-2 & 1725.8 & 1786.1 & & $2.0 \mathrm{E}-04$ & -3.7 & Breccia \\
\hline UAe-2 & 1893.1 & 1980.6 & & 8.0E-05 & -4.1 & \\
\hline \multicolumn{7}{|l|}{ Long Shot Site } \\
\hline EH-5 & 663.2 & 724.2 & 14.2 & & & \\
\hline EH-5 & 723.6 & 784.6 & 16 & & & \\
\hline EH-5 & 723.6 & 784.6 & 16.9 & & & \\
\hline \multicolumn{7}{|l|}{ Other Sites } \\
\hline UAe-3 & 216.4 & 276.8 & 31.6 & & & \\
\hline UAe-3 & 318.8 & 357.2 & 32.1 & & & \\
\hline UAe-3 & 527.3 & 587.7 & 32.0 & & & \\
\hline UAe-3 & 1702.6 & 1747.7 & 115.0 & & & \\
\hline UAe-3 & 2032.4 & 2098.0 & & 4.7E-04 & -3.3 & Breccia \\
\hline UAe-6h & 85.0 & 123.8 & 22.9 & & & \\
\hline UAe-6h & 85.0 & 1493.5 & 32.7 & & & \\
\hline UAe-6h & 85.0 & 2133.6 & 41.0 & & & \\
\hline UAe-6h & 1074.1 & 1137.5 & & $2.0 \mathrm{E}-03$ & -2.7 & Basalt \\
\hline UAe-6h & 1236.9 & 1494.8 & & $2.0 \mathrm{E}-03$ & -2.7 & Basalt \\
\hline UAe-6h & 1498.7 & 1589.2 & 71.0 & & & \\
\hline UAe-6h & 1503.3 & 1746.5 & 90.0 & & & \\
\hline UAe-6h & 1560.6 & 1614.8 & & $1.9 \mathrm{E}-03$ & -2.7 & \\
\hline UAe-6h & 1617.9 & 1744.1 & & $2.0 \mathrm{E}-03$ & -2.7 & \\
\hline UAe-6h & 1702.0 & 1771.5 & & 4.7E-03 & -2.3 & \\
\hline UAe-6h & 1774.6 & 1866.6 & & $9.4 \mathrm{E}-03$ & -2.0 & Breccia \\
\hline UAe-6h & 1906.8 & 2116.6 & & $2.7 \mathrm{E}-03$ & -2.6 & \\
\hline UAe-6h & 2019.6 & 2116.6 & & 4.0E-04 & -3.4 & Breccia \\
\hline
\end{tabular}

The distribution of the $\log _{10}$-transformed $K$ values is shown in Figure 2.1 and is notable for both its wide range of variability and for its overall relatively low values. Most of the Amchitka $K$ values are between $1.0 \times 10^{-4}$ and $1.0 \times 10^{-1} \mathrm{~m} / \mathrm{d}$, a range that falls at the lower end of the range of $K$ values reported for fractured rocks by Freeze and Cherry (1979) and volcanic rocks at the NTS by Rehfeldt et al. (1996).

Categorization of the $K$ values into lithologic classes suggests that the mean $K$ of the breccias may be lower than the mean $K$ of the basalts (Figure 2.1). Note that the sum of the number of breccia 


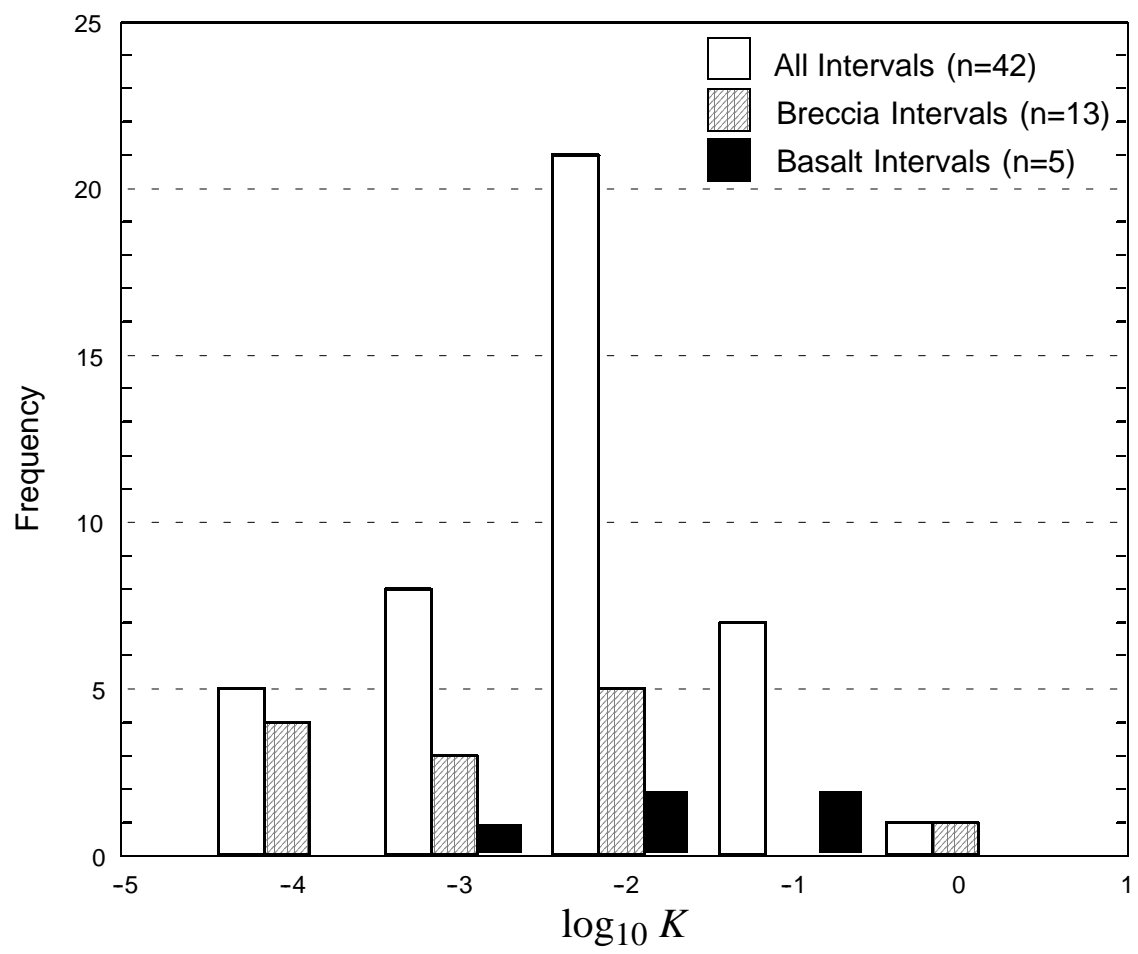

Figure 2.1. Distribution of $\log _{10}$-transformed $K$ values estimated from straddle packer test data collected from Amchitka boreholes. Many intervals contained a mixture of breccia and basalt and could not be assigned to one lithology.

intervals and basalt intervals is less than the total because some intervals contained both, or neither, lithologic units. In any case, the spatial distribution of these lithologic units is very poorly understood, and owing to the lack of appropriate data, this heterogeneity is not directly incorporated in the flow model. The tidal fluctuations and water level responses in UAe-1 are not representative of layers with differing hydraulic characteristics, but rather of an averaged system (Fenske, 1972), supporting this approach. Some variation in $K$ is evident between wells, although the overall ranges of the data far outweigh these differences (Figure 2.2). There appears to be a trend of declining $K$ with increasing depth in two of the wells (UAe-1 and UAe-2), but this is not clear in all of them, due in part to the data distribution. The flow models do not include variation of $K$ with depth, as no consistent quantifiable trends are evident in the data set.

\subsubsection{Hydraulic Head}

Water levels measured during hydraulic testing are used to represent hydraulic heads at the depths of the packed intervals (Table 2.1). Unfortunately, the effects of packer bypass and the incomplete recovery of water levels after swabbing in many tests reduced the number of reliable data available for characterizing the spatial distribution of hydraulic head; many of the values tabulated in the USGS reports are noted as "estimated" or "assumed" based on measurements made under similar conditions in other intervals or other boreholes. Of the data obtained from packer tests, only water levels that clearly indicate static conditions, either prior to an injection test or upon full 

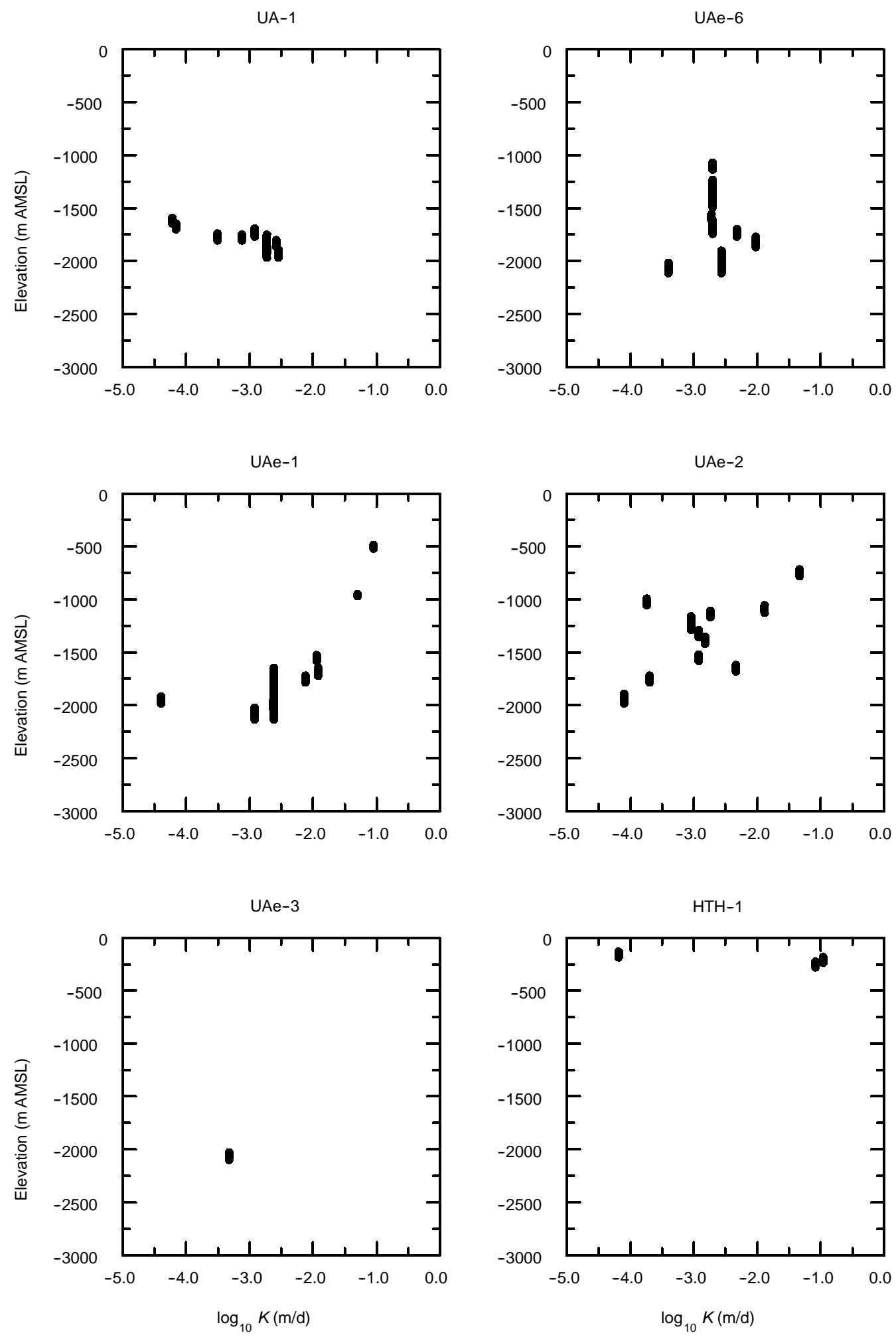

Figure 2.2. Variation with depth of hydraulic conductivity values obtained from packer tests. 
recovery after a swabbing test, are used in the flow model calibrations. These water levels are assumed to represent hydraulic head at the depth of their measurement. The influence of groundwater salinity and temperature on the measurements is unknown because these parameters were not consistently reported with the water level data, thus the measured head values could not be corrected to represent equivalent freshwater heads. This uncertainty increases with increased depth as the salinity and the heat effects on water density increase with depth.

Measurements of static water levels in various shallow observation wells are used to augment the packer test data, which were generally collected at depths greater than $500 \mathrm{~m}$. Construction details and exact locations of many of the shallow wells are not available, but water levels consistently indicate that the water table lies within several meters of ground surface and that heads decline with increasing depth (Table 2.2).

Table 2.2. Shallow hydraulic head data from the three testing areas.

\begin{tabular}{lccccc}
\hline \hline \multicolumn{1}{c}{ Name } & $\begin{array}{c}\text { Elevation } \\
(\mathrm{m})\end{array}$ & $\begin{array}{c}\text { Depth } \\
(\mathrm{m})\end{array}$ & $\begin{array}{c}\text { Bottom Elevation } \\
(\mathrm{m})\end{array}$ & $\begin{array}{c}\text { Water Depth } \\
(\mathrm{m})\end{array}$ & $\begin{array}{c}\text { Water Elevation } \\
(\mathrm{m})\end{array}$ \\
\hline Long Shot Site & & & & & \\
W-1 & 42.1 & 1.1 & 40.9 & 0.0 & 42.1 \\
WL-1 & 42.1 & 2.7 & 39.4 & 0.8 & 41.3 \\
WL-2 & 42.1 & 3.4 & 38.7 & 1.0 & 41.1 \\
Well-1 & 42.1 & 37.8 & 4.3 & 1.7 & 40.4 \\
Well-3 & 42.1 & 37.5 & 4.6 & 2.5 & 39.6 \\
Well-8 & 42.1 & 37.5 & 4.6 & 0.8 & 41.3 \\
Well-9 & 42.1 & 100.9 & -58.8 & 4.7 & 37.4 \\
USGS & 42.1 & 213.3 & -171.3 & 0.6 & 41.5 \\
Dudley \#1 & 42.1 & 30.5 & 11.6 & & $42.0^{*}$ \\
Dudley \#2 & 42.1 & 91.4 & -49.3 & & $38.8^{*}$ \\
Dudley \#3 & 42.1 & 121.9 & -79.8 & & $38.3 *$ \\
Dudley \#4 & 42.1 & 152.4 & -110.3 & & $37.3 *$ \\
Cannikin Site & & & & 1.8 & 86.6 \\
White Alice & 88.4 & 96.3 & -7.9 & 13.5 & 39.0 \\
HTH-3 & 52.5 & 51.2 & 1.3 & & 28.9 \\
Milrow Site & & & & 0.4 & 33.7 \\
W8 & 29.3 & 1.6 & 27.7 & 0.9 & 33.5 \\
W10 & 34.6 & 2.1 & 32.5 & 0.6 & \\
W11 & 34.0 & 1.5 & 32.5 & & \\
W14 & 37.3 & 2.1 & 35.3 & & \\
\hline \hline *estimated from & & & & & \\
& & & & & \\
\end{tabular}

\subsubsection{Porosity}

Measurements of total porosity of rocks undisturbed by nuclear test effects were made on 197 core samples obtained from UAe-1, UAe-2, UAe-3, and UAe-6c (Lee, 1969a,b,c,d), giving an arithmetic mean of 0.14 and a standard deviation of 0.08 for samples from all depths, and a mean 
of 0.12 and standard deviation of 0.06 for rocks from the deeper Kirilof Point and Older Breccias (Figure 2.3). These measurements represent the matrix porosity of blocks of basalt and breccia that occupy the volume between connected fractures, and are likely to overestimate the effective flow porosity in the fracture zones themselves. The U.S. Army Corps of Engineers and USGS (1965) estimated an effective porosity of $1.0 \times 10^{-2}$ from hydraulic testing in $\mathrm{EH}-1$, and $1.0 \times 10^{-3}$ from hydraulic testing in EH-5 (both at the Long Shot site). Nork et al. (1965) assumed a value of $1.0 \mathrm{x}$ $10^{-3}$ for flow in joints in andesite and a value of $1.0 \times 10^{-2}$ for combined fracture and interstitial flow at the Long Shot site. Essington et al. (1970) used effective porosities of $1.5 \times 10^{-3}$ to $2.5 \times 10^{-3}$. By analyzing the response in well UAe-1 to tidal and barometric effects, Fenske (1972) estimated a fracture system porosity of $1 \times 10^{-3}$. Dudley et al. (1977) used estimates of fracture spacing and $K$ data and an empirical relationship developed by Snow (1968) to estimate fracture porosities between $1.9 \times 10^{-5}$ and $6.3 \times 10^{-4}$. Though the hydraulic response estimates have the fewest uncertainties, the lower value of $5.0 \times 10^{-4}$ is selected in the present study to represent the fracture porosity of undisturbed rock at Amchitka to be conservative. This is considered a mean value around which a random distribution is generated and the porosity effects on transport are evaluated.

Direct measurements of porosity are not available for the chimney regions of the Amchitka nuclear tests, but indirect estimates have been made. Using hydraulic properties of the surrounding rock, estimates of chimney infill, chimney dimensions, and measured water level rise, Fenske (1972) calculated the distribution of rubble porosity in the Milrow chimney to be zero (in the puddle glass) at the bottom and 0.14 at the top. Claassen (1978) used many of the same types of data, but a different analytical technique, and estimated the distribution of porosity in the Cannikin chimney

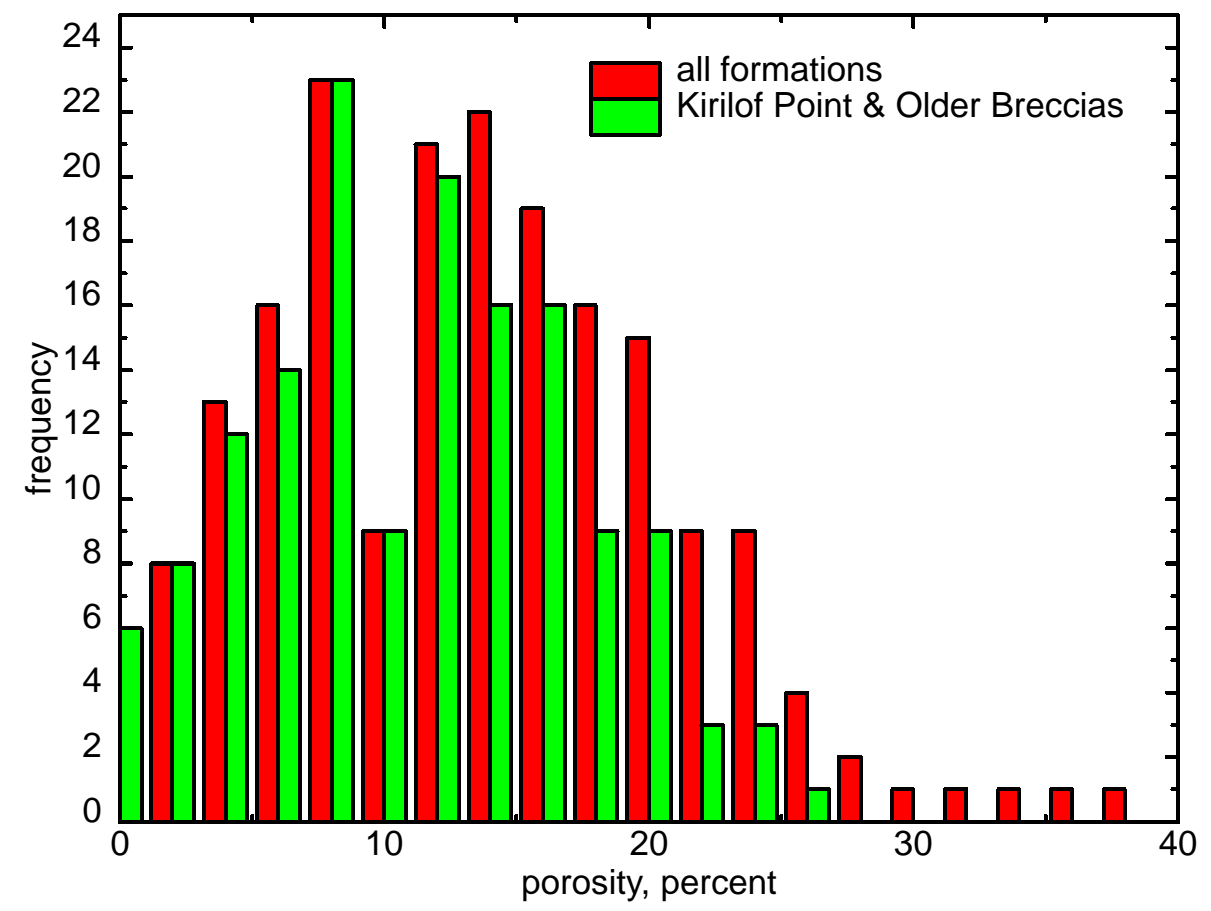

Figure 2.3. Variation of total porosity determined from laboratory tests on core samples. 
to be 0.10 near the bottom and 0.04 near the top. Claassen (1978) provides no explanation for the very different distribution of rubble porosity compared to that of Fenske (1972). Garber (1971) provides an estimate of chimney porosity for the Bilby test at the NTS, which was detonated in saturated zeolitized volcanic tuff. By comparing the volume of water removed during a pumping test with the observed interruption in chimney infill, Garber (1971) estimated the porosity to be about 0.07 at a level $110 \mathrm{~m}$ above the working point, and about 0.02 at a level $175 \mathrm{~m}$ above the working point. A value of 0.07 falls within the range of all these estimates and is selected to represent the rubble porosity for the Milrow chimney.

\subsubsection{Recharge}

Dudley et al. (1977) compared precipitation records and runoff measurements and conclude that most of the precipitation results in surface-water runoff. They note that the water table is at or very near land surface over most of the island, as indicated by the many lakes and streams and water levels in shallow holes. They do note that recharge seems to take place in the months of July and August, following the two months of lower precipitation in May and June (accompanied by water table declines). During this period, there is less correspondence between rainfall and runoff, Dudley et al. (1977) note that the tundra, peat, and fractured and weathered volcanic rock of the shallow subsurface are permeable and "where unsaturated, are capable of accepting recharge readily." They also note that this shallow groundwater system behaves locally, discharging in the lakes and streams. They conclude that recharge from precipitation percolates through the mantle of vegetation and colluvium, flowing downslope along the surface of underlying less permeable volcanic rock to issue as springs.

Gonzalez (1977) also evaluated precipitation and runoff and similarly concluded that most of the precipitation results in surface water runoff. Gonzalez observed that the geologic and hydraulic character is generally the same for all three test sites. He described the situation as follows: "A thick cover of turf ranging from a few centimeters to several meters thick is dominant over the entire area. Annual precipitation of over $90 \mathrm{~cm}$ collects temporarily in an abundant number of lakes and underlying turf before discharging to streams and finally into the oceans. The runoff that occurs within drainage basins almost simultaneously with rainfalls suggests that the rocks underlying the turf and shallow lakes are either low in permeability, or are saturated to land surface." He further notes that "probably only a small amount of precipitation infiltrates into fractures of deeper rocks." Gages in the watersheds surrounding Milrow and Cannikin accounted for 95 and 93 percent, respectively, of precipitation as runoff. The percentage was lower (57 percent) at Long Shot, attributed to difficulties in gaging because of the high number of lakes. He also notes that surface water base flow is sustained by groundwater discharge from thick surficial materials. He states that the bulk of groundwater flow occurs at shallow depths, discharging as seeps, springs and into lakes and streams.

Fenske (1972) used a hydraulic analysis to calculate the recharge rate necessary to sustain the freshwater lens suggested at UAe-1 from the water chemistry data. He believed the resulting estimate of $8 \mathrm{~cm} / \mathrm{yr}$ was high, based on observations of stream discharge. 
Estimates of groundwater recharge are made here using the temperature profiles measured in several Amchitka Island boreholes. Vertical fluid movement can affect the flux of heat within the earth. Stallman (1960) presented the basic equations for the simultaneous transfer of heat and water within the subsurface and suggested that temperature measurements can provide a means of measuring fluid velocity. Stallman (1965) presented a method for near-surface temperature fluctuations, which assumes the transient flow of both heat and fluid. Bredehoeft and Papadopulos (1965) present the steady-state solution for heat and fluid, which is applicable in deeper systems where temporal heat variations become negligible. The differential equation for steady-state, one-dimensional, simultaneous heat and fluid flow through isotropic and homogeneous porous media is given by:

$$
\left(\frac{\partial^{2} \mathrm{~T}}{\partial z^{2}}\right)-\left(\frac{\mathrm{c}_{0} \rho_{0} V_{z}}{\mathrm{k}}\right)\left(\frac{\partial \mathrm{T}}{\partial \mathrm{z}}\right)=0
$$

where $\mathrm{T}$ is the temperature $\left({ }^{\circ} \mathrm{C}\right), \mathrm{z}$ is the vertical Cartesian coordinate (positive downward, $\mathrm{cm}$ ), $\mathrm{c}_{0}$ is the specific heat of the fluid ( $\mathrm{cal} / \mathrm{g}), \varrho_{0}$ is the density of the fluid $\left(\mathrm{gm} / \mathrm{cm}^{3}\right), \mathrm{k}$ is the thermal conductivity of the solid-fluid complex $\left(\mathrm{cal} \mathrm{cm}^{-1} \mathrm{~s}^{-1}{ }^{\circ} \mathrm{C}^{-1}\right)$, and $V_{z}(\mathrm{~cm} / \mathrm{sec})$ is the vertical component of the fluid velocity (cm/s). Equation (2.1) is strictly applicable in an isotropic homogeneous, fully saturated porous media, as $\mathrm{k}$ is a non-linear function of the water content in the vadose zone. Although not all assumptions required by Equation (2.1) are met at Amchitka, the steady-state, low-porosity, and near-saturated conditions provide an approximation to the simultaneous movement of heat and fluid. Bredehoeft and Papadopulos (1965) provide a solution to Equation (2.1) as:

$$
\frac{\left(\mathrm{T}_{\mathrm{Z}}-\mathrm{T}_{0}\right)}{\left(\mathrm{T}_{\mathrm{L}}-\mathrm{T}_{0}\right)}=\frac{\exp \left(\frac{\beta \mathrm{z}}{\mathrm{L}}\right)-1}{\exp (\beta)-1}
$$

where $\mathrm{T}_{0}$ is the temperature at the uppermost elevation $\left({ }^{\circ} \mathrm{C}\right), \mathrm{T}_{\mathrm{L}}$ is the temperature at the lowermost elevation $\left({ }^{\circ} \mathrm{C}\right), \mathrm{T}_{\mathrm{Z}}$ is the temperature at vertical location $\mathrm{z}(\mathrm{cm}), \mathrm{L}$ is the total vertical thickness where thermal data are collected $(\mathrm{cm})$, and $\beta=\mathrm{c}_{0} \varrho_{0} V_{z} \mathrm{~L} / \mathrm{k}$ is a dimensionless parameter that is positive or negative depending on whether $V_{z}$ is downward or upward. The vertical fluid velocity $V_{z}$ is determined by non-linear optimization techniques that search for the value of $V_{z}$ such that there is a minimum difference between the ensemble observed and simulated temperature profiles.

This model is fit to measured temperature profiles in six Amchitka Island boreholes using a value of rock thermal conductivity of $3 \times 10^{-3} \mathrm{cal} \mathrm{cm}^{-1} \mathrm{~s}^{-1}{ }^{\circ} \mathrm{C}^{-1}$, as used by Green (1965) in an analysis of borehole temperatures at the Long Shot site. Measurement error of temperature typically follows a symmetric particle density formation (pdf) (i.e. normal distribution with zero mean) and as such does not have a large impact on the uncertainty of the recharge estimate. This is due to the fact that the recharge estimates are essentially derived from the temperature gradient, which implies that the errors in the temperature measurements tend to cancel if large sample sizes are used in the analysis of recharge. The temperature logs were all measured prior to the nuclear tests, but several months after the completion of drilling (with the exception of EH-3), so they should be reasonably 
representative of natural temperature conditions (Green, 1965; Sass and Moses, 1969). The logs were run primarily in open holes, so there is the possibility of flow in the boreholes, under natural gradients, disturbing the thermal profiles. This flow would be downward, and was noted in some intervals on the logs, and has the effect of causing a potential error for over-predicting the recharge rate using this method.

The model shows good matches to the measured data, particularly in the upper portions of the boreholes (Figure 2.4), using the estimated recharge rates listed in Table 2.3. Note that these estimates are many times lower than recharge rates used by other researchers. For example, Wheatcraft (1995) assumed a value of $10 \mathrm{~cm} / \mathrm{yr}$ in his models of groundwater flow and mass transport at Amchitka Island. Low recharge rates on the island are consistent with the high rates of surface runoff observed during precipitation events (Dudley et al., 1977). The recharge rate estimated for the Milrow site using the UAe-2 temperature profile is $0.62 \mathrm{~cm} / \mathrm{yr}$, Long Shot is 3.39 $\mathrm{cm} / \mathrm{yr}$, and Cannikin is $0.45 \mathrm{~cm} / \mathrm{yr}$. As discussed in the flow modeling section, recharge is adjusted during calibration at each site, and uncertainty in the parameter is retained throughout the modeling process. The minimum, mean, and maximum recharge values used for each site, based on site-specific calibration, are as follows: Milrow 0.319, 2.078, $7.839 \mathrm{~cm} / \mathrm{yr}$; Long Shot 0.809, 3.27, $14.09 \mathrm{~cm} / \mathrm{yr}$; and Cannikin 0.809, 3.62, $18.89 \mathrm{~cm} / \mathrm{yr}$. The mean values for both Milrow and Cannikin are higher than those suggested by the temperature profiles, but within the range estimated by previous workers.

Table 2.3. Boreholes used for estimates of groundwater recharge.

\begin{tabular}{lccc}
\hline \hline & \multicolumn{3}{c}{ Depth Interval } \\
\multicolumn{1}{c}{ Borehole } & Top $(\mathrm{m})$ & Bottom $(\mathrm{m})$ & Recharge Rate $(\mathrm{cm} / \mathrm{yr})$ \\
\hline UAe-1 & 0 & 500 & 0.45 \\
UAe-2 & 0 & 500 & 0.62 \\
UAe-3 & 0 & 500 & 0.75 \\
UAe-6h & 0 & 500 & 2.48 \\
EH-1 & 61 & 305 & 3.39 \\
EH-3* & 61 & 259 & 7.75 \\
\hline \hline
\end{tabular}

*The EH-3 log was run immediately after drilling, with the unstable borehole conditions resulting in greater uncertainty in the representativeness of the $\log$.

An uncertainty analysis was performed on the recharge estimates derived from the thermal gradients, assuming that the errors associated with temperature measurements are symmetrically distributed with a mean of zero. The uncertainty analysis was performed by utilizing the $\beta$ parameter derived from the individual inversions from each well. To allow for additional uncertainty in the inversion process, ranges of $\beta$ were calculated assuming various domain lengths (i.e., shallow and deeper temperature profiles). Next, the ratio of $\beta / \mathrm{L}$ was calculated, which effectively normalized the results from different profiles. These ratios were assumed to follow a uniform distribution spanning the entire range $\left(1.87 \times 10^{-4}\right.$ to $\left.3.34 \times 10^{-3} \mathrm{~cm}^{-2}\right)$ calculated in the inversion process. The 

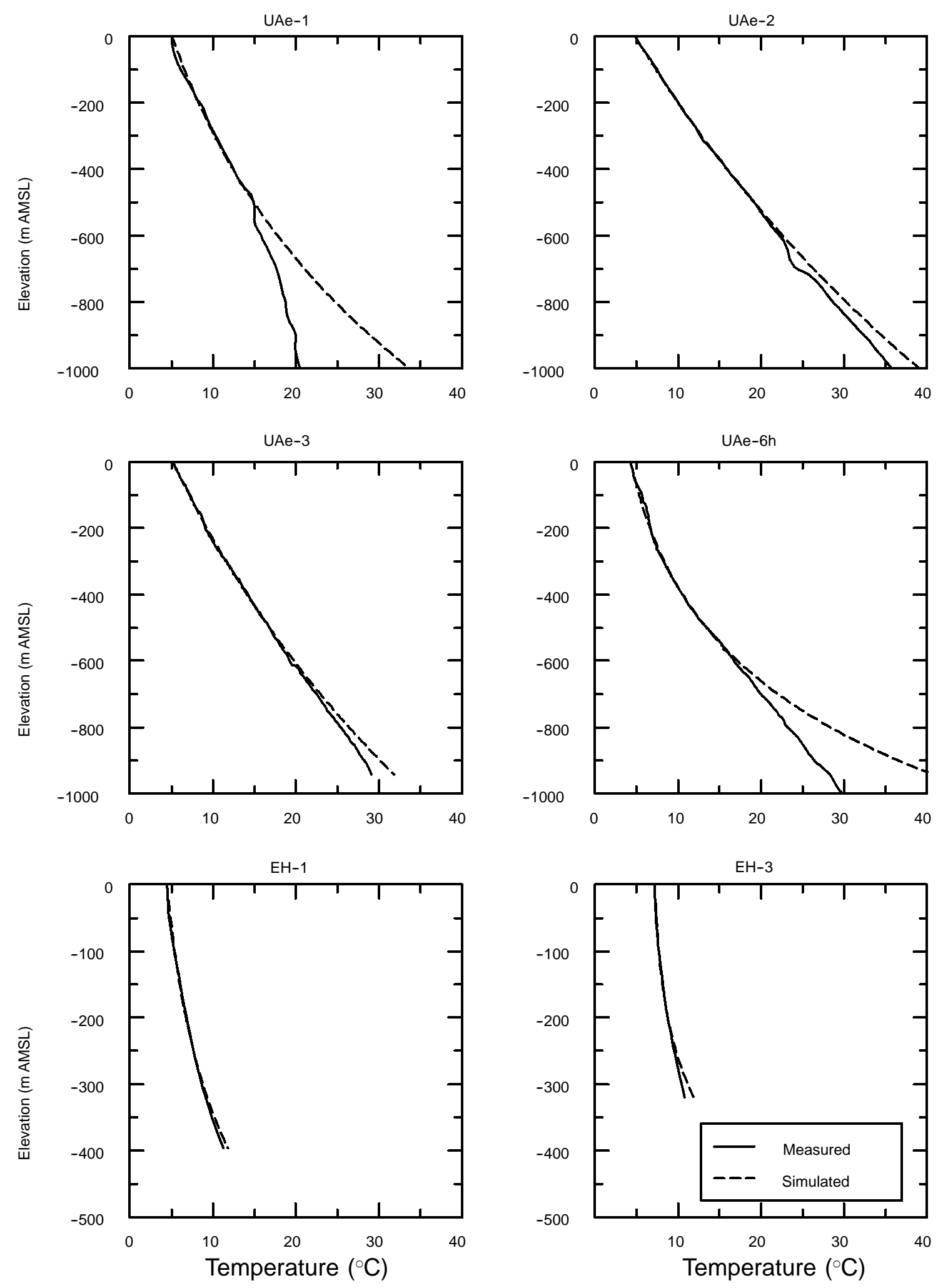

Figure 2.4. Plots of temperature profiles simulated using the groundwater recharge model compared to temperature profiles measured in the boreholes. 
uncertainty associated with the thermal conductivity was assumed to be uniformly distributed with a mean equal to $0.003 \mathrm{cal} \mathrm{cm}^{-1} \mathrm{sec}^{-1}{ }^{\circ} \mathrm{C}^{-1}$ (Green, 1965) and a range of 0.001 to 0.005 . It is important to note that the thermal conductivity used in this analysis is of the solid-fluid complex and the use of measured values as determined by Green (1965) is more representative of local conditions than a more generalized basalt conductivity. The relative range used to represent the uncertainty in the thermal conductivity is similar to the relative range suggested by the reviewer. The uncertainty in the thermal conductivity and the $\beta / \mathrm{L}$ parameters were used in a Monte Carlo framework to calculate the expected uncertainty in the recharge rates. One thousand random independent thermal conductivity and $\beta / \mathrm{L}$ values were drawn from their respective distributions and then fluid velocity was calculated according to:

$$
V_{Z}=\frac{\beta}{L} \frac{K}{c_{0} \rho_{0}}
$$

where $V_{z}$ is the vertical fluid velocity, $\beta$ is the shape parameter used in the inversion process, $L$ is the length of the profile, $K$ is the thermal conductivity, $c_{0}$ is the specific heat of the fluid, and $\rho_{0}$ is the density of the fluid. The resulting probability distribution function is shown in Figure 2.5, with a lognormal fit shown simply to note that the distribution has a certain degree of skew which is caused by the multiplication in the $V_{z}$ calculation. The results suggest that at a 95 percent confidence level, the recharge values should range between 0.3 to $4.8 \mathrm{~cm} / \mathrm{yr}$. The mean and minimum values used in the model for the three sites fall within this range, though the maximum end of the model ranges exceeds it.

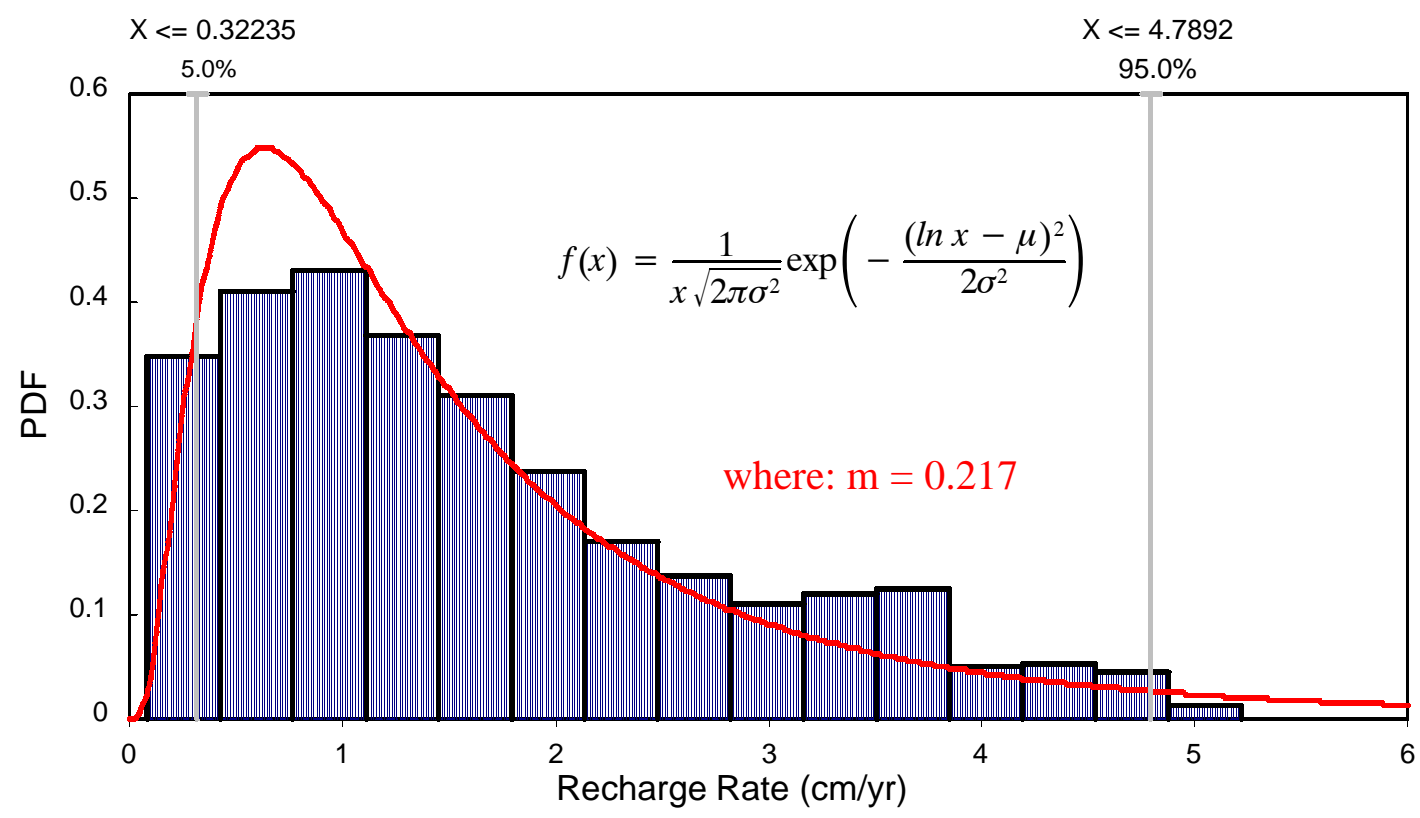

Figure 2.5 A lognormal fit to the recharge values obtained by the uncertainty analysis of the temperature $\log s$. 


\subsubsection{Water Chemistry Data}

Though not literally a parameter used for the numerical modeling, the chemical data from groundwater samples at Amchitka are used for assessing the model calibration. The data are presented in Table 1.2, with a discussion of the salinity profiles for the three locations.

Collection of representative groundwater samples from deep wells during drilling programs is very challenging. Samples from discrete depth intervals were generally collected by swabbing water from a zone isolated by packers. Pumped samples were also collected, but tended to be from very long intervals in the boreholes. The primary problem is the purging of drilling fluids and fluids from zones other than the one being isolated. Significant differences existed in the construction of UAe-1 and UAe-2, and are described in detail by Fenske (1972). UAe-1 was drilled with a water-based mud using normal circulation. UAe-2 was drilled with water using a reverse circulation method that limits pressure against the formation and consequent fluid loss. Drilling and testing of UAe-2 required 105 days, whereas considerable difficulties were encountered in both the drilling and testing of UAe-1, which required 142 days to complete. Fenske notes that the scatter in the UAe-1 chemical data below about 1,400 m below mean sea level suggests contamination. The Long Shot holes were all drilled using a bentonite mud comparable to that used in oil-field operations (U.S. Army Corps of Engineers and USGS, 1965). It is noted that the drilling mud in the hole (left in due to caving problems) and the mud forced into the formation restricted the flow of formation water. "Clear water" was never swabbed from EH-5, leading the workers to conclude that all of the samples collected contained mud.

Given the drilling histories and $\mathrm{pH}$ values of the groundwater samples, the chemical data from UAe-2 are considered to have the highest quality. Water chemistry data from Cannikin and Long Shot contain more uncertainty and are less likely to be representative of in-situ conditions. In addition to the question of the degree of representativeness of the water samples of in-situ conditions, the use of the chemical data for calibration is subject to uncertainty introduced by transient flow processes. Dispersion resulting from short period fluctuations due to tidal and barometric effects can be approximated by adjusting the dispersion term during calibration. However, if there is a significant lag in the response of the chemical system to fluctuations in the transition zone brought about by climate change, the transition zone midpoint and spreading may not coincide with those that would be at equilibrium with the hydraulically defined transition zone. Given that the last major sea level change was in a negative direction (lower sea level due to glaciation), this may have left a deeper freshwater lens relict of the lower sea level condition than would be in equilibrium with the current head configuration.

\subsection{Numerical Modeling Strategy}

Based on previous experience with large-scale flow and radioactive transport modeling, a deterministic approach for flow and transport analyses is not considered to be sufficient for the Amchitka sites. With limited data to support the choice for each individual parameter, the deterministic approach is inadequate in describing the uncertainty of the processes involved. Therefore, a multi-parameter stochastic modeling approach is used, through which the uncertainty 
in the model conceptualization and the flow and transport parameters can be addressed to a certain degree of satisfaction.

The approach used here acknowledges the uncertainty in the parameters and includes it in the analysis. This allows the contaminant breakthrough curves to contain this uncertainty, expressed as a standard deviation around a mean value. Including uncertainty from the flow and transport parameters has been found to be critical to risk assessments, as this source of uncertainty is often quite large and contributes significantly to overall uncertainty in risk (Andricevic et al., 1994; Andricevic and Cvetkovic, 1996). Whether the degree of parametric uncertainty is acceptable or not for the objective of conducting a human-health-risk assessment for Amchitka can be determined from the results of the risk assessment.

The modeling of the island's nuclear tests encompasses two major processes: 1) the flow modeling, which includes density-driven flow, saltwater intrusion, and heat-driven flow, and 2) the transport modeling, which combines radioactive transport and decay, retardation processes, source term and glass dissolution, and matrix diffusion. Modeling each of the two processes is fraught with many uncertainties and difficulties determining the values of the parameters governing these processes. The final modeling approach and results should, therefore, reflect the best of our ability to overcome these difficulties and address these uncertainties. The conceptual model and the modeling strategy that are used to evaluate and address the many uncertainties associated with this analysis are presented in the following sections.

\subsubsection{Modeling Approach}

The modeling approach begins with the flow problem that is coupled with saltwater intrusion and heat effects. One can list the main uncertain parameters that influence the solution of the flow problem for the velocity field. The list includes, but may not be limited to, recharge, hydraulic conductivity, macrodispersivity affecting saltwater dispersion, heat parameters, the island half-width, etc. The impact of any of these parameters is either to change the depth to the freshwater-saltwater interface or transition zone, or to change the width of the transition zone. In either case, the velocity pattern changes significantly, which consequently influences the radionuclide migration from the cavity toward the sea. It is well known (Pohll et al., 1999; Pohlmann et al., 1999) that the most influential parameters are those changing the travel time of the radionuclides from the cavity to the seepage face across the sea floor. However, due to the complexity of the processes involved, it may be difficult to pre-determine those parameters for reducing the above list.

For the transport of radionuclides, many processes have to be considered. Hydraulic versus geochemical release, advection and macrodispersion dictated by the heterogeneous velocity field, local-scale dispersion, matrix diffusion, retardation and decay are important processes that encounter a large number of uncertainties. The uncertain parameters here include effective porosity, glass dissolution rate, retardation factor, local dispersivity, and matrix diffusion coefficient. Only effective porosity and retardation change the travel time; the other factors cause plume spreading, tailing effects and reduction of mass fluxes and concentrations. Again, these parameters are 
computed or assumed with large uncertainties and as such it is important to address the effect of the uncertainty in each parameter on the transport results.

The approach used here is of a stochastic nature and represents an attempt to evaluate the effect of input uncertainties on the associated uncertainties of the output. Since the solution to obtain the velocity field encounters a simultaneous solution to the flow and the advection-dispersion equation, some of the parameters governing transport processes are considered when solving the flow problem. This includes the effective porosity and the macrodispersivity values used for the saltwater intrusion problem.

Consider the four uncertain parameters of the flow model, conductivity, recharge, fracture porosity and macrodispersivity. Based on available data, calibration results, and results of previous studies of Amchitka, a best estimate (mean) for each parameter and an associated degree of uncertainty can be hypothesized. For example, the available hydraulic conductivity data can be analyzed and tied to the calibration results to yield a best estimate (mean value) for a spatially uniform (homogeneous) conductivity and the uncertainty of the estimate. For other parameters, such as macrodispersivity, the mean value can be obtained in the calibration process where an attempt is made to match the measured concentration and/or head values. A certain degree of parameter uncertainty can then be added to the macrodispersivity mean value. For each parameter, a distribution of random values above and below the mean can be generated using the mean and the uncertainty range estimated from data or calibration.

The selection of the parameter distributions is dictated by a number of factors. If data are available, the distribution of a particular parameter should produce the range of values that is indicated by the data. Calibration results set certain limits to the tails of the distribution of some parameters, such as recharge and hydraulic conductivity. Also, when a parameter range covers orders of magnitude, distributions such as uniform or normal are difficult to use for producing this variability range, and a lognormal distribution works better in such cases. In some cases, a normal or a lognormal distribution is used to generate parameter values but the tails of the distribution are truncated to remove the extreme values that are in violation of certain aspects and assumptions of the model.

The first stage of the modeling then becomes the evaluation of the effect of each uncertain parameter on the transport results. Random values of any parameter can be sampled from a hypothetical distribution to form an ensemble of $N$ values with $N=100$ in all cases of the first stage. While fixing all other flow and transport parameters at their mean (best estimate) values, Monte Carlo simulations are performed for flow coupled with saltwater intrusion and radioactive transport coupled with matrix diffusion. By analyzing the ensemble of the resulting plumes, a direct correlation between the parameter uncertainty and that of the results can be established. This procedure is repeated for all the uncertain parameters in the flow and transport lists. This approach seems computationally demanding and time consuming. However, only flow parameters require generating multiple flow realizations. The effect of the uncertainties in transport parameters will be addressed using a single flow realization and multiple transport solutions using the random values of the studied parameter. This realization is selected based on setting all flow and other transport 
parameters to their mean values. The final objective of this first step is to filter out those parameters whose uncertainties have minor effects on the transport results. Another objective is to quantitatively address the effect of the uncertainty of each individual parameter without any overlap with other uncertainties. It should be mentioned here that the first modeling stage is only performed for Milrow. When the list of uncertain parameters is selected for the second modeling stage at Milrow, the same list of parameters will be employed in modeling Cannikin and Long Shot.

Once the set of important parameters is determined, a new set of Monte Carlo simulations is designed for the second stage. The flow set will be generated using values for the influential, uncertain parameters drawn at random from their distributions. That is, for realization $i$, all the values of the flow parameters in the reduced list will be randomly generated based on the distributions used in the first step or new distributions. The new set of $M$ flow realizations, with $M$ between 200 and 300, will be used for the transport simulation such that for realization $i$, each transport parameter in the reduced list (if any) will be selected randomly from its distribution. In this way, all different combinations between flow and transport parameters can be encountered. For example, a case with a very high conductivity, a very low porosity and weak retardation is as likely to be generated as a case with very low conductivity, very high porosity and strong retardation. The set of $M$ transport results will be statistically analyzed for each individual radionuclide to obtain expected mass fluxes, concentrations, and seepage-face location, as well as the associated uncertainties.

The second modeling stage described above will be performed for the three underground nuclear tests. One of the important advantages of the proposed approach is the fact that the first step will give an idea about which parameter uncertainty should be reduced the most to significantly reduce the uncertainty of the results. This will help as a guide in the event that fieldwork is required to collect more data. The important issue to remember here is that the results will be dependent on the initial choice of mean and range for different parameters. Since these mean values themselves encounter large uncertainties as will be seen in the calibration discussion, the results are largely dependent on this choice.

\subsubsection{Code Selection}

A large number of codes are available that can simulate one or more of the processes that have been identified as potentially important to radionuclide transport beneath Amchitka Island. Many of the codes are optimally designed for specific portions of the problem, or have enhanced capabilities that are attractive for some portions of the proposed work. A modeling scheme that will capitalize on the optimal performance of some codes to investigate individual aspects of the flow

and transport processes has been devised. Information gained from the subtasks of the modeling effort will be combined into a final conceptual and numerical simulation of the radionuclide transport. For example, the popular USGS code SUTRA is only available in two-dimensions and does not simultaneously solve for heat and solute transport. An alternative selection is FEFLOW, which is available in three-dimensions and can solve heat and mass transport simultaneously. FEFLOW comes with a graphical user interface and an automatic mesh generator for finite-element discretization. Figure 2.6 shows a finite-element mesh generated using FEFLOW. This figure 


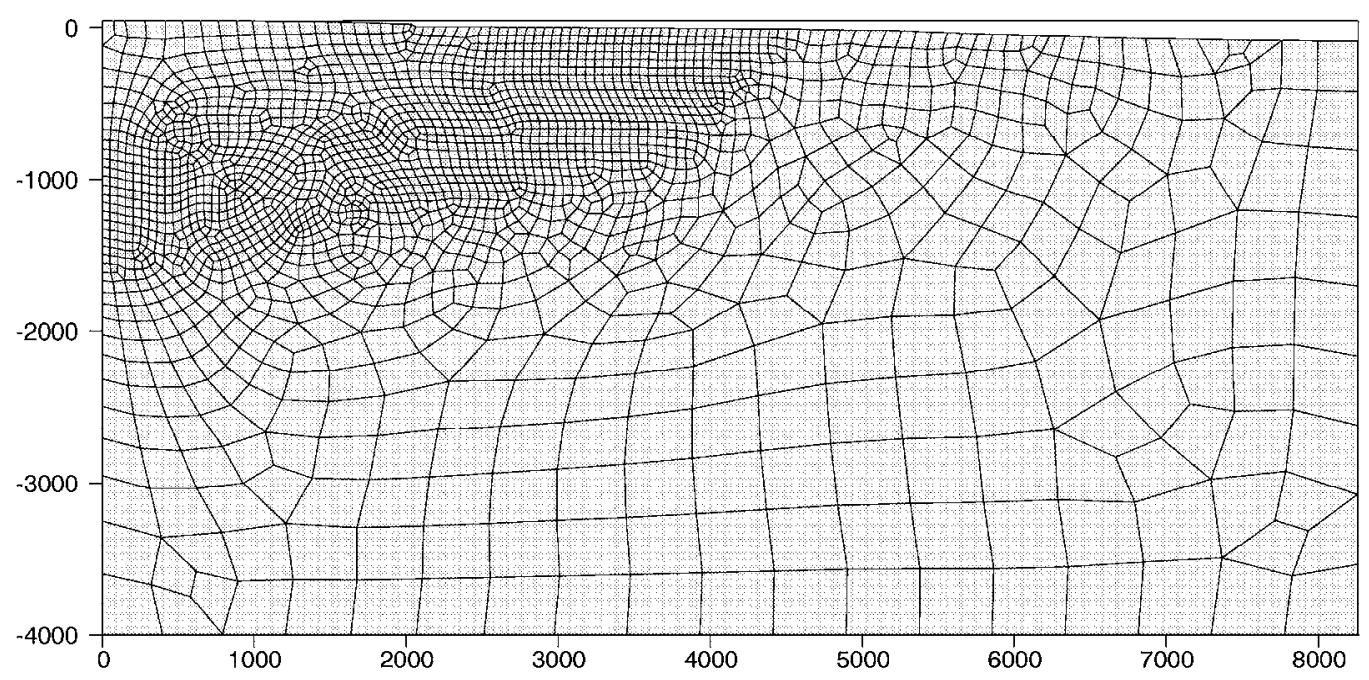

Figure 2.6. A finite-element mesh generated by FEFLOW for the modeled domain showing variable element size with fine resolution at the location of the transition zone.

highlights two points concerning code capability. First, finite-element solutions are vastly more optimized for the seawater intrusion problem because the elements can be made very small throughout the transition zone region without unduly raising the number of elements (and the computational difficulty). Second, the geometry and parameters can be varied almost instantaneously in the graphical user interface (GUI) environment and the results easily compared. For these reasons, the finite-element code FEFLOW is considered the optimal platform for all of the simulations.

The FEFLOW code (Diersch, 1998) is used for the base-case simulations in two dimensions and for addressing issues involving three-dimensional geometry (including the influence on flow patterns of fault zones and rubble chimney configuration) and coupled heat and solute transport (geothermal heat and heat generated by the nuclear explosion). FEFLOW is a finite-element simulation package available from the WASY Institute for Water Resources Planning and Systems Research Ltd. that is developed for two-dimensional and three-dimensional density-dependent flow, mass, and heat transport processes in groundwater, and is generally well-suited for the Amchitka problem.

The groundwater flow problem modeled here requires a description of variable density fluid flow coupled with transport of both salt and heat. The fluid flow is simulated using a form of the Darcy equation generalized for a variable-density fluid. The approach is formulated in terms of the equivalent freshwater head, $h_{\mathrm{f}}$, and the freshwater hydraulic conductivity, $\mathbf{K}_{\mathrm{f}}$, as

$$
h_{f}=\frac{p}{\rho_{0} g}+z
$$

and 


$$
\boldsymbol{K}_{\mathrm{f}}=\frac{\rho_{0} g}{\mu} \boldsymbol{k}
$$

respectively, where $p$ is fluid pressure, $\rho_{0}$ is a reference density of freshwater, $g$ is gravitational acceleration, $z$ is elevation, $\mu$ is fluid viscosity, and $\mathbf{k}$ is the permeability tensor. $K_{f}$ is calculated through Equation (2.5) using actual local concentration and temperature effects on density and viscosity implied by the buoyancy term and the viscosity function, given the appropriate reference temperature and concentration for the $K$ measurements. The flow equation can then be written for Darcy flux as

$$
\boldsymbol{q}=-\boldsymbol{K}_{\mathrm{f}} \cdot\left(\nabla h_{f}-\frac{\rho-\rho_{0}}{\rho_{0}} \nabla_{z}\right)
$$

The density-dependent relations in the coupled transport system employs the extended Boussinesq approximation (Diersch, 1998), where the conservation of fluid mass is described in the generalized form

$$
S_{S} \frac{\partial h}{\partial t}+\nabla \cdot \boldsymbol{q}=Q_{\rho}+Q_{E B}(C, T)
$$

where $S_{\mathrm{s}}$ is the specific storage coefficient (compressibility), $Q_{\rho}$ is the specific source/sink rate of fluid, and $Q_{E B}(C, T)$ is a term of the extended Boussinesq approximation that accounts for temporal changes in concentration and/or temperature and variation in density in directions orthogonal to the direction of flow. The representative equation for mass transport is given as (Diersch, 1998)

$$
R_{d} \frac{\partial C}{\partial t}+\boldsymbol{q} \cdot \nabla C-\nabla \cdot(\boldsymbol{D} \cdot \nabla C)+Q_{p} C=Q_{C}
$$

where $R_{\mathrm{d}}$ is a derivation term of retardation, $\mathbf{D}$ is the tensor of hydrodynamic dispersion, $C$ is concentration, and $Q_{C}$ is the source/sink function of mass. The representative equation for heat transport is given as (Diersch, 1998)

$$
\left[\theta \rho c+(1-\theta) \rho_{s} c_{s}\right] \frac{\partial T}{\partial t}+\rho c \boldsymbol{q} \cdot \nabla T-\nabla\left(\lambda_{s} \cdot \nabla T\right)+\rho c Q_{\rho}\left(T-T_{0}\right)=Q_{T}
$$

where $\theta$ is porosity, $\rho_{\mathrm{s}}$ is density of the solid phase, $c_{\mathrm{s}}$ is specific heat capacity of the solid phase, $T$ is temperature, $\lambda_{\mathrm{s}}$ is thermal conductivity of solid phase, $T_{0}$ is a reference temperature, and $Q_{T}$ is the source/sink function of heat.

\subsection{Flow Model Calibration}

The objective of the calibration process is to select the base-case, uniform (no spatial variability) flow and saltwater intrusion parameters that yield a modeling result as close to reality (if known) as possible. The idea then is to individually quantify the impact of the uncertainty of these parameters and other transport parameters on the movement of radionuclides from the tests to the seafloor. The final result of this uncertainty analysis is a reduced set of uncertain flow and transport 
parameters that significantly influence the transport results (travel times, location of the plume when it crosses the seafloor, etc.). The parameters with little effect (as compared to those with significant influence) will not be considered uncertain in the final stage of uncertainty analysis. In that stage, the values of the selected parameters are chosen at random from the generated distributions. The calibration is then an important step to identify the best estimate of the uncertain flow parameters, upon which all subsequent analysis is based.

Given the distance between the tests, each test site is modeled separately. The locations of the three model cross sections are presented in Figure 2.7. A finite-element mesh is generated for each model domain as shown in Figure 2.8. Finer resolution is needed in the transition zone region. Given that the transition zone can vary substantially in position as a result of different parameter values, the entire upper left-hand half of the domain is given the more detailed mesh. The model domains differ from one another in the topography of the land surface and bathymetry of the seafloor, each being specific for the given location. These differences are most clearly seen using vertical exaggeration (Figure 2.9).

\subsubsection{Milrow Calibration and Base-case Parameters}

Three sets of measured data are used to calibrate the flow model and select the base-case parameters. Chloride concentration data at UAe-2 are used to identify the location and the width of the transition zone. Shallow head measurements that locate the water table from four wells are used

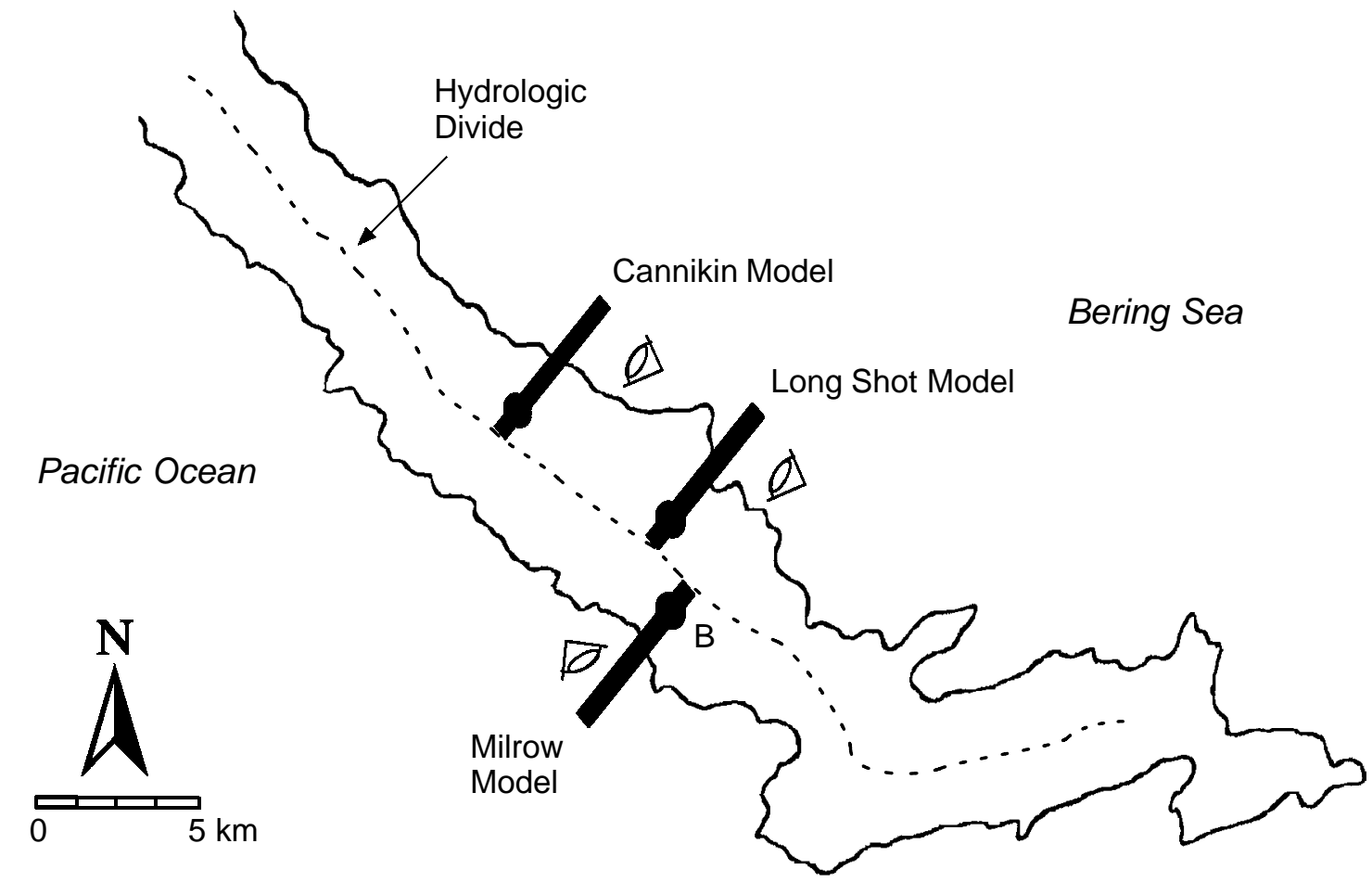

Figure 2.7. Location of model cross sections for each site. The cartoon eye shows the perspective of subsequent figures. 


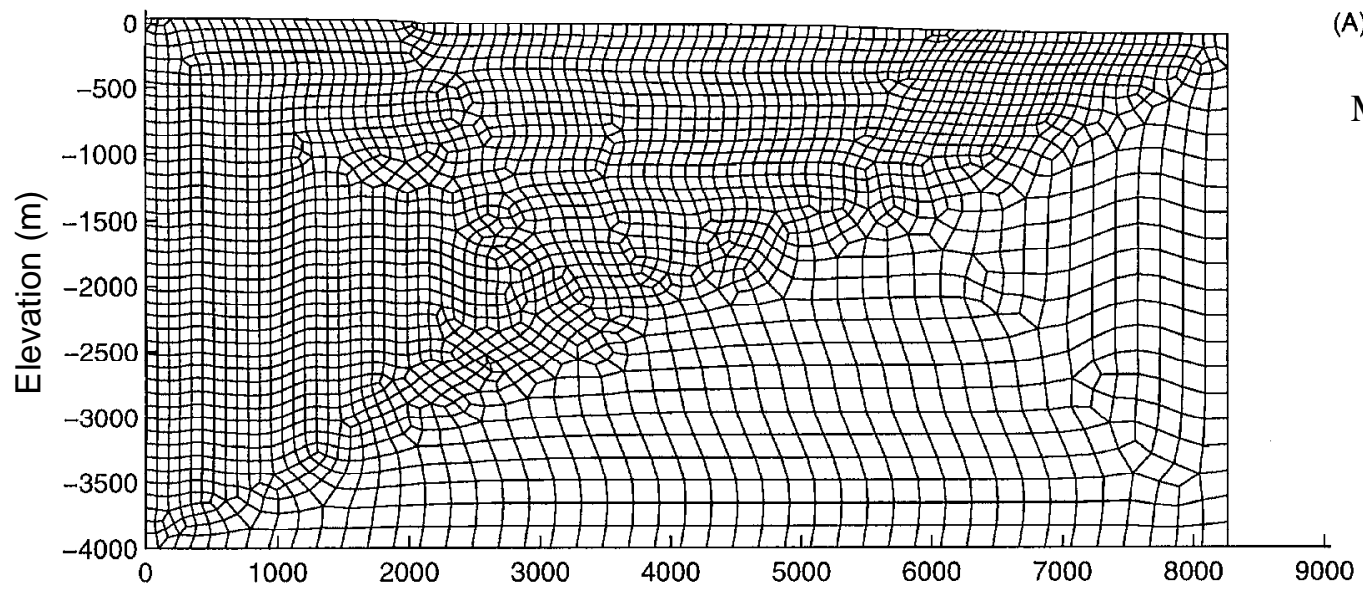

(A)

Milrow

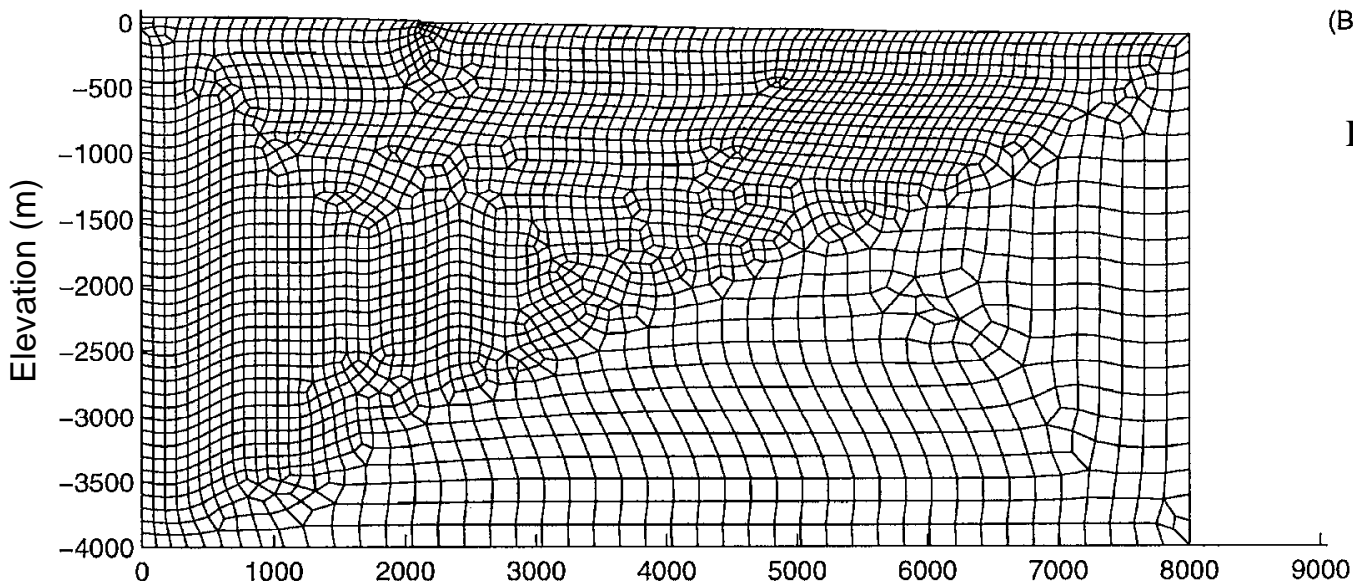

(B)

Long Shot

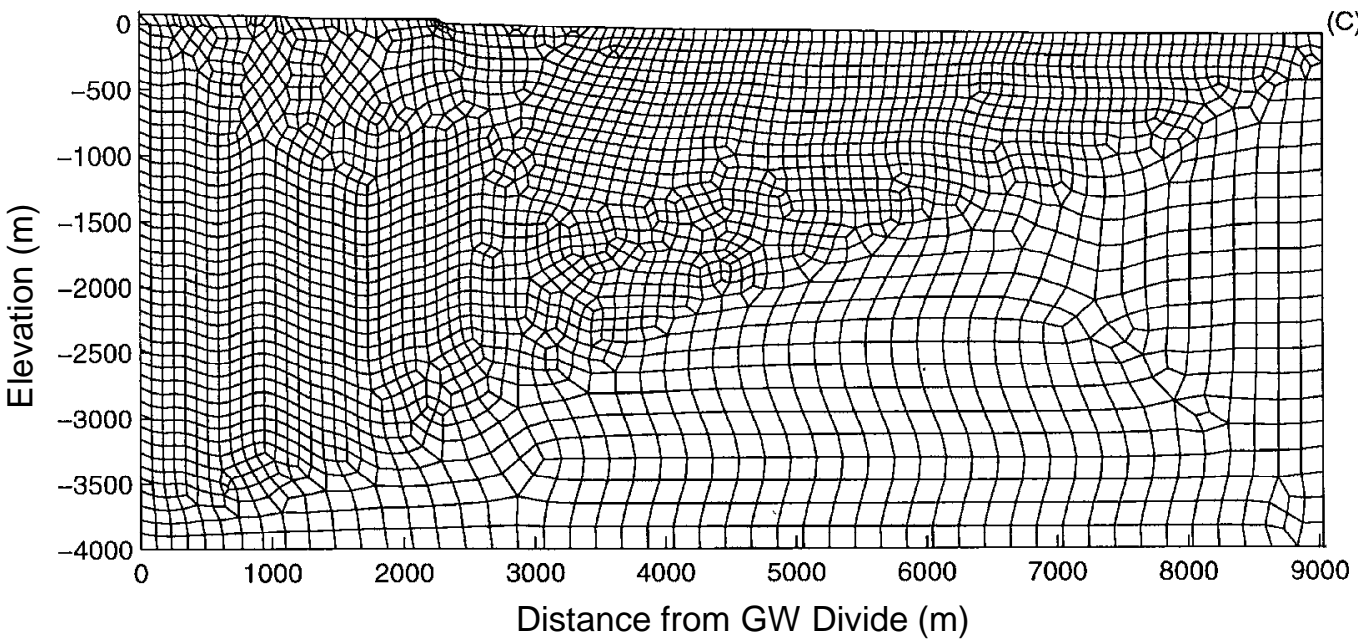

Cannikin

Figure 2.8. Finite-element modeling meshes generated for each site model domain. 

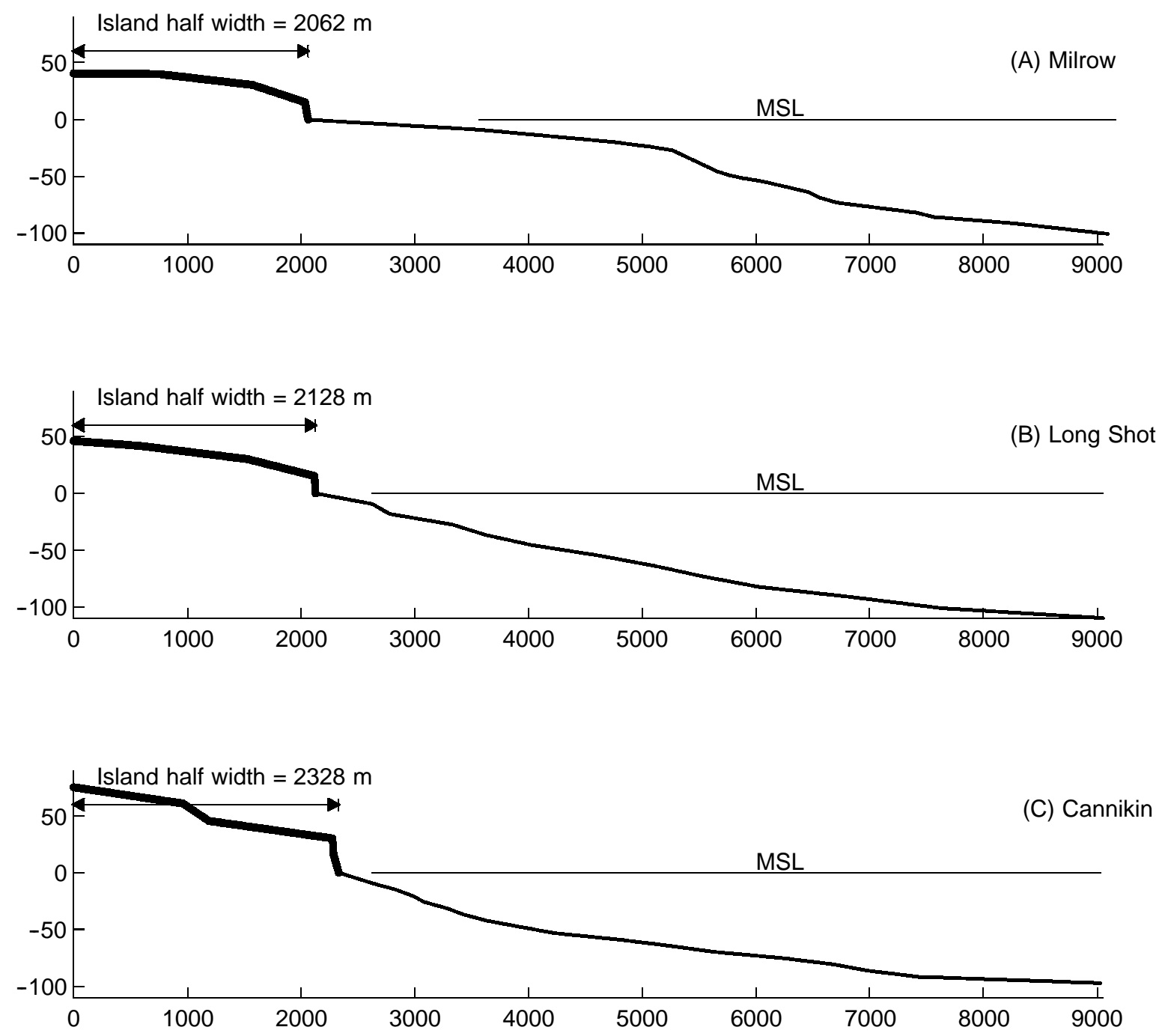

Figure 2.9. Topographic and bathymetric profiles used for each site-specific model. The diagrams use a tenfold vertical exaggeration. 
as a second set of calibration data. The third set is the deep head measurements at UAe-2, which are used to compare with the modeled vertical head profile at the well location.

The geometry of the simulation domain and the boundary conditions are shown in Figure 2.10.

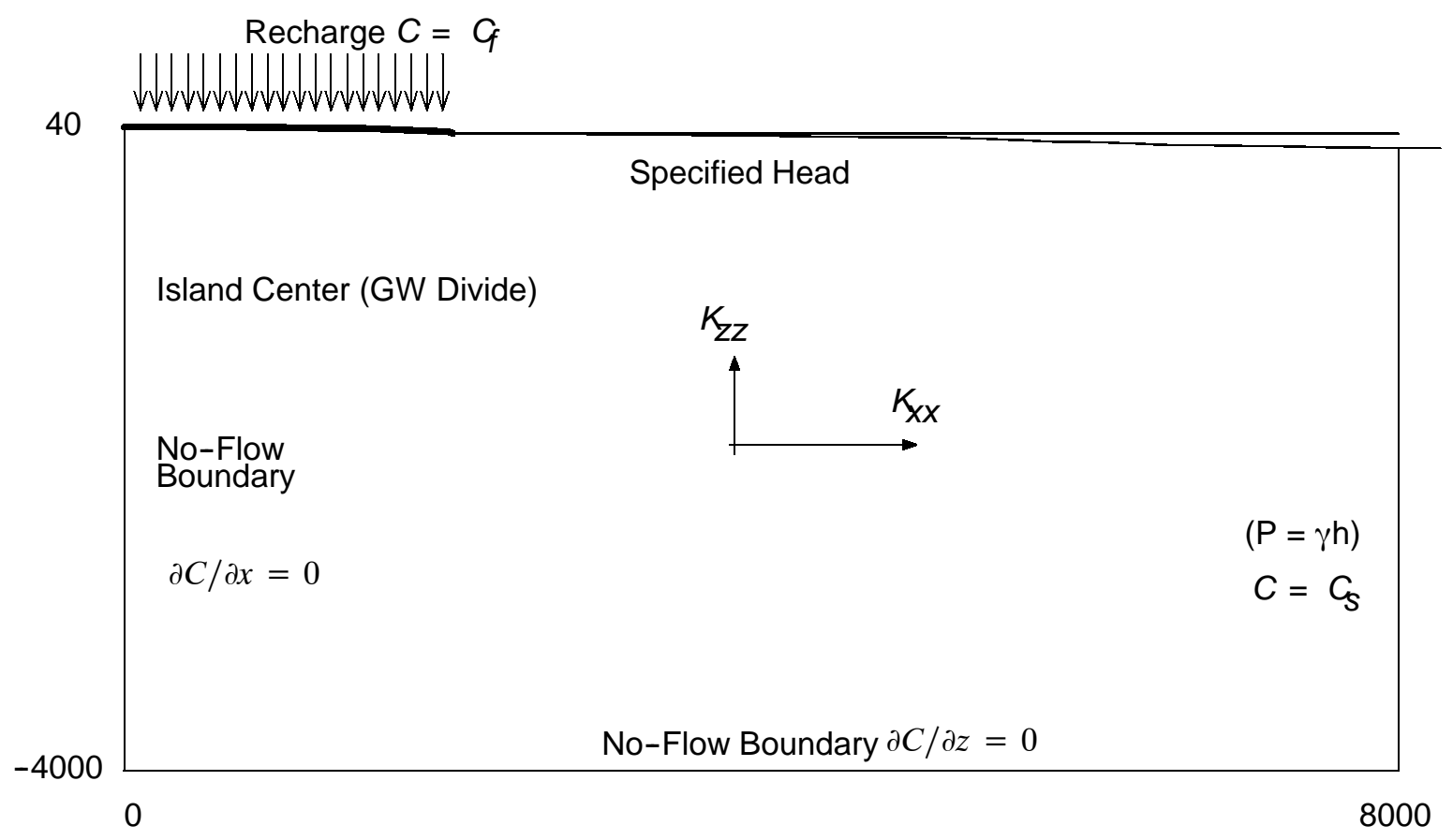

Figure 2.10. Geometry of simulation domain and boundary conditions for the flow problem.

To allow for the sensitivity analysis of uncertain parameters, a domain length of $8,000 \mathrm{~m}$ is assumed, which is about four times the island half-width, and a thickness of 4,000 $\mathrm{m}$ is considered, which is more than three times the thickness of the freshwater lens (inferred from the $\mathrm{Cl}$ data at UAe-2) in the vertical direction. This provides the flexibility to change model parameters, and thus location and width of the transition zone, with no boundary effects influencing the resulting solution. The left-hand boundary is assumed to coincide with the groundwater divide at the island centerline, and as such, is assumed to be a no-flow boundary. The bottom boundary is also assumed to be a no-flow boundary. The right-hand boundary is a specified head and a constant concentration boundary. The top boundary is divided into two segments: a freshwater recharge segment representing the island half-width, and a specified head segment representing the seafloor (bathymetric profile). The bathymetric profile is best seen using vertical exaggeration as on Figure 2.9.

The two-dimensional domain is considered to be anisotropic $\left(K_{x x} \neq K_{z z}\right)$ with anisotropy ratio $e=K_{x x} / K_{z z}$, and homogeneous (no spatial variability). Spatial variability only appears when accounting for the chimney porosity and permeability relative to the surrounding area. However, since calibration data are based on pre-test conditions, uniform conductivity and porosity throughout the domain is assumed at this stage. In a typical groundwater flow system, the spatial variability of hydraulic conductivity leads to a heterogeneous velocity field that exhibits variations at all scales of observation. This randomly changing velocity between blocks of varying conductivity induces an additional mixing process that is usually denoted as dispersion. This large-scale dispersive process can be substituted by 
a macrodispersivity value in a homogeneous conductivity setting. This assumes that dispersion can be considered Fickian and macrodispersivities can be used to mimic the dispersive process caused by spatial variability (e.g., Gelhar and Axness, 1983; Hess et al., 1992). For this reason and for computational convenience, a homogeneous domain with anisotropic conductivity values is assumed. This is also justified by the fact that the density-driven flow pattern is very heterogeneous and adding spatial variabilities in hydraulic conductivity may only slightly change the flow pattern at and near the transition zone, which is the zone of importance for transport modeling. In addition, with hydraulic conductivity data from six wells spaced many kilometers apart on the island, the data abundance and locations will not support analysis of spatial correlations.

A large number of scenarios have been tested using FEFLOW, in which the homogeneous hydraulic conductivity and its anisotropy ratio, the recharge and the macrodispersivity are varied and the results are evaluated and compared to the calibration data. Table 2.4 lists the parameters used in all FEFLOW simulations presented in this study. Porosity does not affect the head distribution nor the location and width of the transition zone; it just speeds up or slows down the convergence of the system to the steady state. The macrodispersivity values are taken as $350 \mathrm{~m}$ and $175 \mathrm{~m}$ in the longitudinal and transverse directions, respectively. These values are chosen very large in an attempt to reproduce the transition-zone dispersion pattern indicated by the chloride data. The initial values of conductivity and recharge are selected based on the analysis of the available data and the variability observed therein, as discussed in Sections 2.2.1 and 2.2.4. The values are then changed based on the behavior of the simulated transition zone and heads in comparison with the measurements. Figure 2.11 shows an example of the FEFLOW output solutions in terms of concentration distribution and transition zone location (top) and velocity field (bottom). From the results of these tests, a single set of parameters to give a good match with all calibration data (shallow and deep heads and concentration data) could not be identified. Some of these cases are shown in Figure 2.12 for the comparison between the simulated and the measured heads. The simulated heads are obtained as freshwater equivalents or as environmental heads. The former is the direct output of FEFLOW, whereas the latter utilizes the actual specific weight that is dependent on the concentration. The measured head values should represent the environmental head provided no dilution occurs during the measurement process.

Table 2.4. Parameters used in FEFLOW to solve the isothermal density-driven flow problem.

\begin{tabular}{lc}
\hline \multicolumn{1}{c}{ Parameter } & Value \\
\hline Freshwater density $\left(\mathrm{kg}_{\text {water }} / \mathrm{m}^{3}\right)$ & 1,000 \\
Saltwater density $\left(\mathrm{kg}_{\text {water }} / \mathrm{m}^{3}\right)$ & 1,025 \\
Freshwater concentration $\left(\mathrm{C} / \mathrm{C}_{\max }\right)$ & $2.67 \times 10^{-3}$ \\
Seawater concentration $\left(\mathrm{C} / \mathrm{C}_{\max }\right)$ & 1.0 \\
Density ratio & 0.025 \\
Diffusivity of solute in fluid $\left(\mathrm{m}^{2} / \mathrm{d}\right)$ & $8.88 \times 10^{-9}$ \\
Specific storage, $\mathrm{Ss}$ & $1.0 \times 10^{-4}$ \\
\hline \hline
\end{tabular}

The concentration distribution in UAe-2 is also compared to the FEFLOW results for the cases considered (the comparison is not shown). Concentrations were measured in water swabbed from 

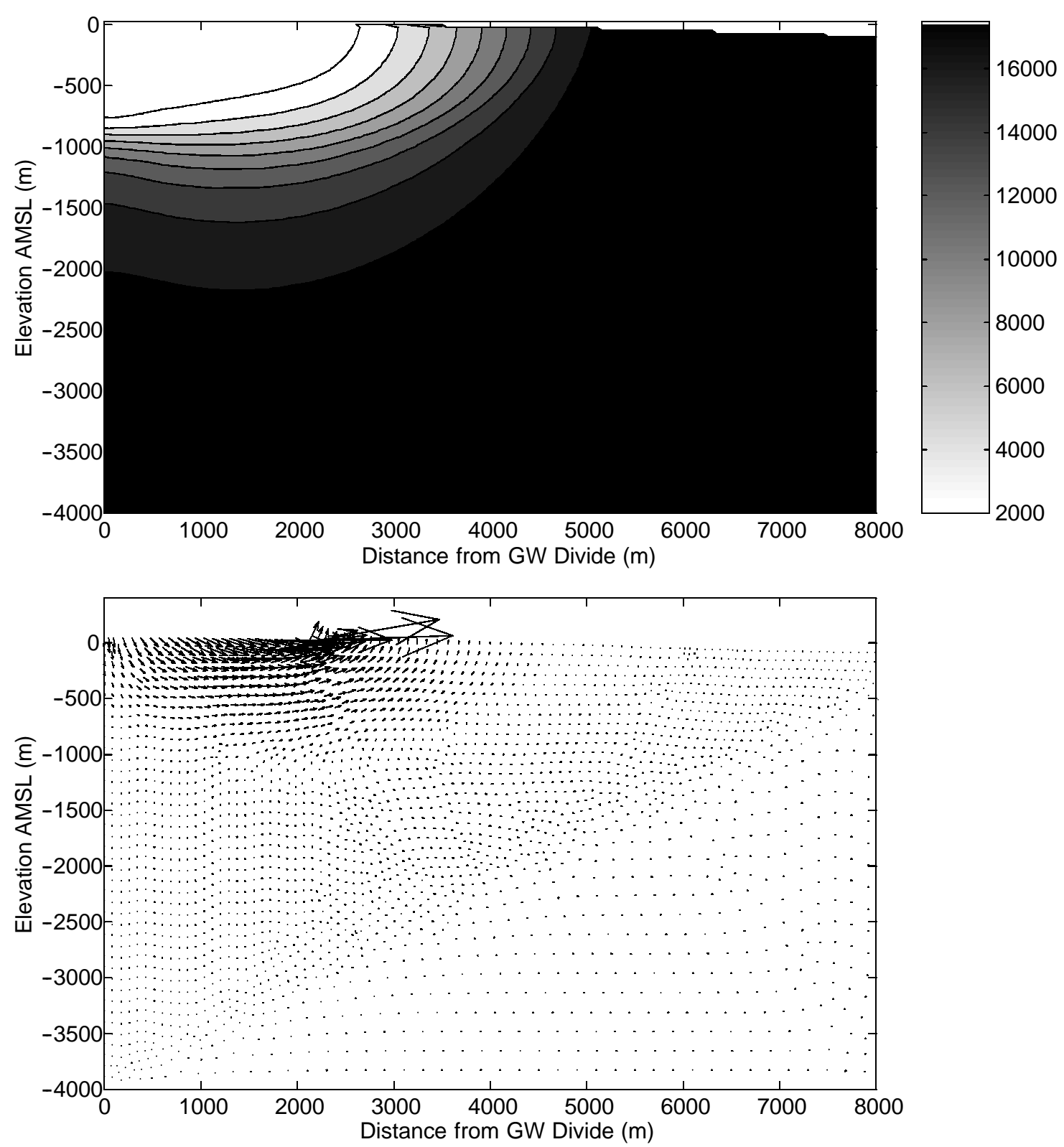

Figure 2.11. Concentration distribution showing transition zone (top) and velocity field as produced by FEFLOW for one of the Milrow calibration cases tested.

60-m packer intervals during hydraulic testing and therefore represent composite values for the entire corresponding intervals, and may also reflect mixing with borehole water originating from other intervals. The comparisons indicate that a certain combination of the input parameters yields a general agreement between simulated and measured concentration data, but simulates head values smaller than measured. The results of this case are shown in Figure 2.13 and Figure 2.14. On the other hand, Figure 2.15 and Figure 2.16 show very good match for the head, both deep and shallow, but result in a thicker freshwater lens than what is indicated by the concentration data. To reduce this thickness, a smaller recharge (or larger conductivity) value is needed, but this results in lower simulated heads than measured. Changing the anisotropy ratio, $e$, plays a role as shown in 

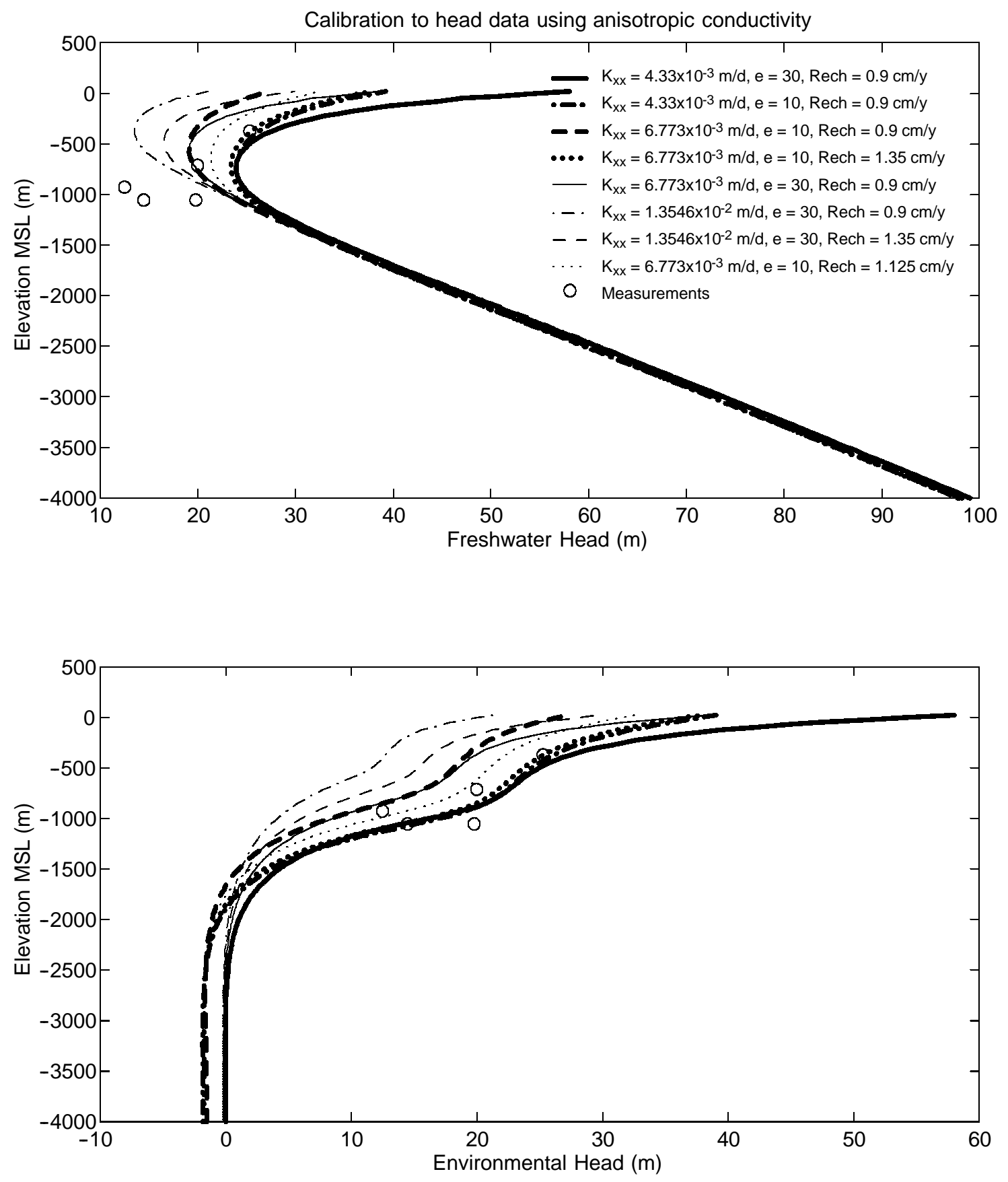

Figure 2.12. Comparison between simulated and measured heads for eight cases of different conductivity, anisotropy ratio and recharge combinations for Milrow. 

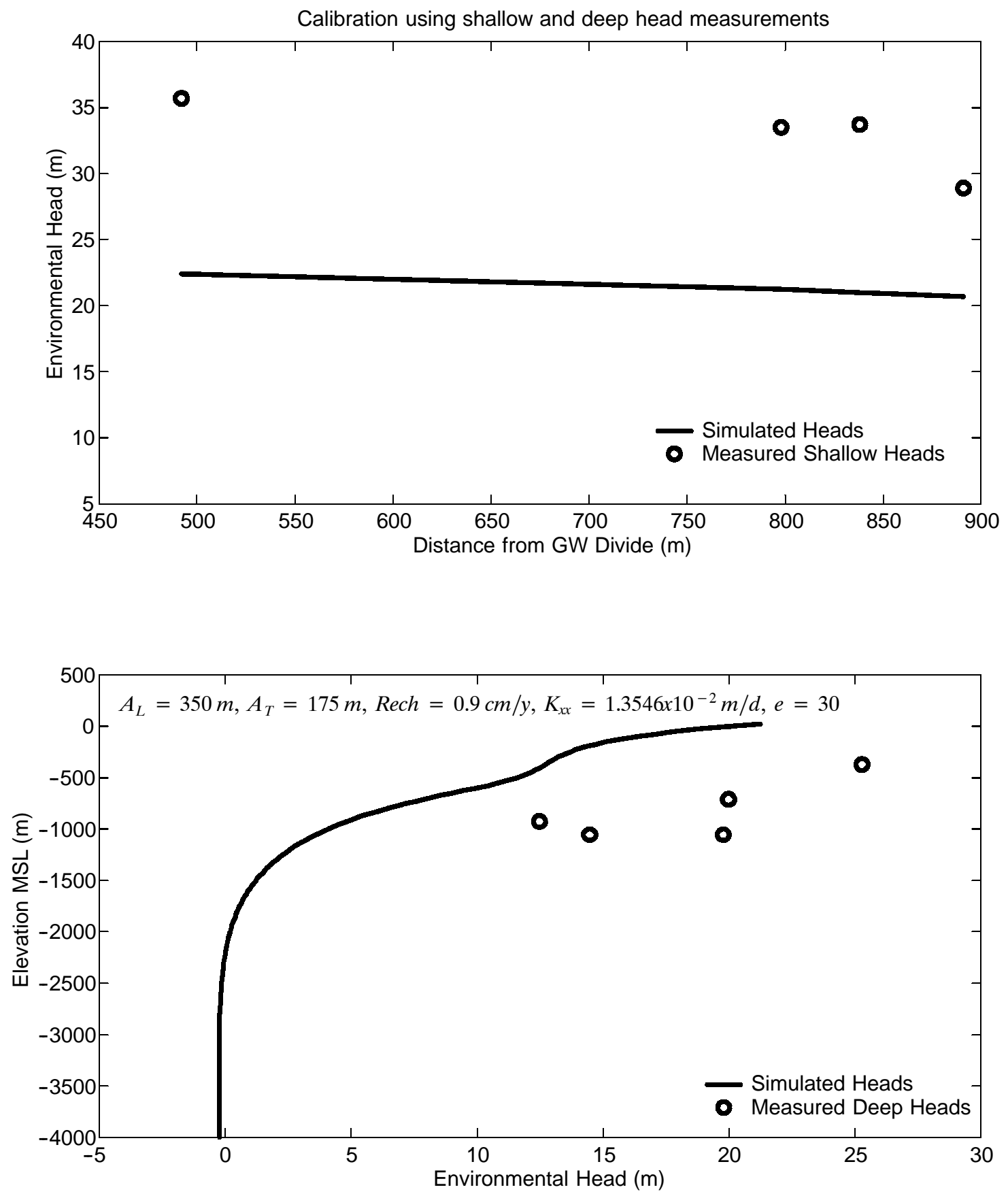

Figure 2.13. Comparison between simulated and measured heads for a Milrow case that leads to a good match for concentrations only. 


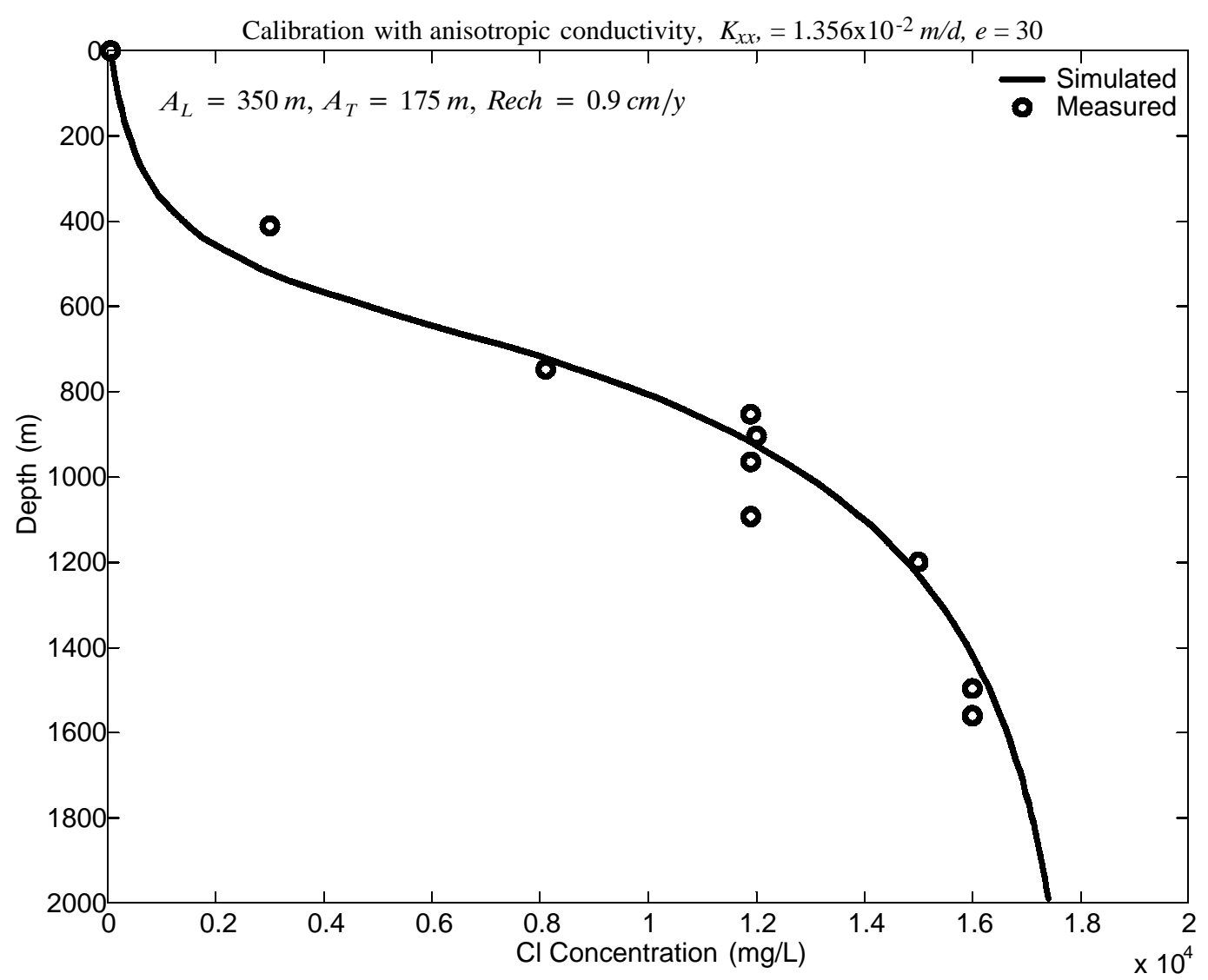

Figure 2.14. Comparison between simulated and measured chloride concentrations for a case that gives the best match to Milrow concentration data.

Figure 2.12, but a parameter combination that would result in matching all the measurements available for calibration could not be identified.

Since the objective of this calibration stage is to select the "mean" values of the parameters of concern, and since the uncertainty analysis will vary these parameters around the "mean" value, it is not crucial to match all the given calibration data. The uncertainty analysis will most likely cover the range of variability that is encountered in the plots of Figure 2.12. That is to say, any one of the combinations shown in Figure 2.12 will definitely be considered in the range of parameters employed for the uncertainty analysis discussed in Section 4. Therefore, the case shown in Figure 2.15 and Figure 2.17represents the base-case scenario, and the parameter values represent the mean values around which the random distributions will be generated. There are two reasons governing the choice of this case (better match of heads) as opposed to the other case where concentration data match better. First, since the concentration data may be affected by temporal changes in seawater level and/or the recharge amount, they may represent a thicker transition zone than represented by the steady-state result of the model. If the transition zone is moving vertically due to these changes, an additional spreading of saltwater will occur, leading to this thick transition zone. Secondly, changing the values of longitudinal and transverse macrodispersivities from 350 and $175 \mathrm{~m}$ to 100 and $10 \mathrm{~m}$ resulted in a transition zone depth (distance from ground surface to the $50 \%$ seawater concentration) close to what is indicated by the concentration data but with a smaller 

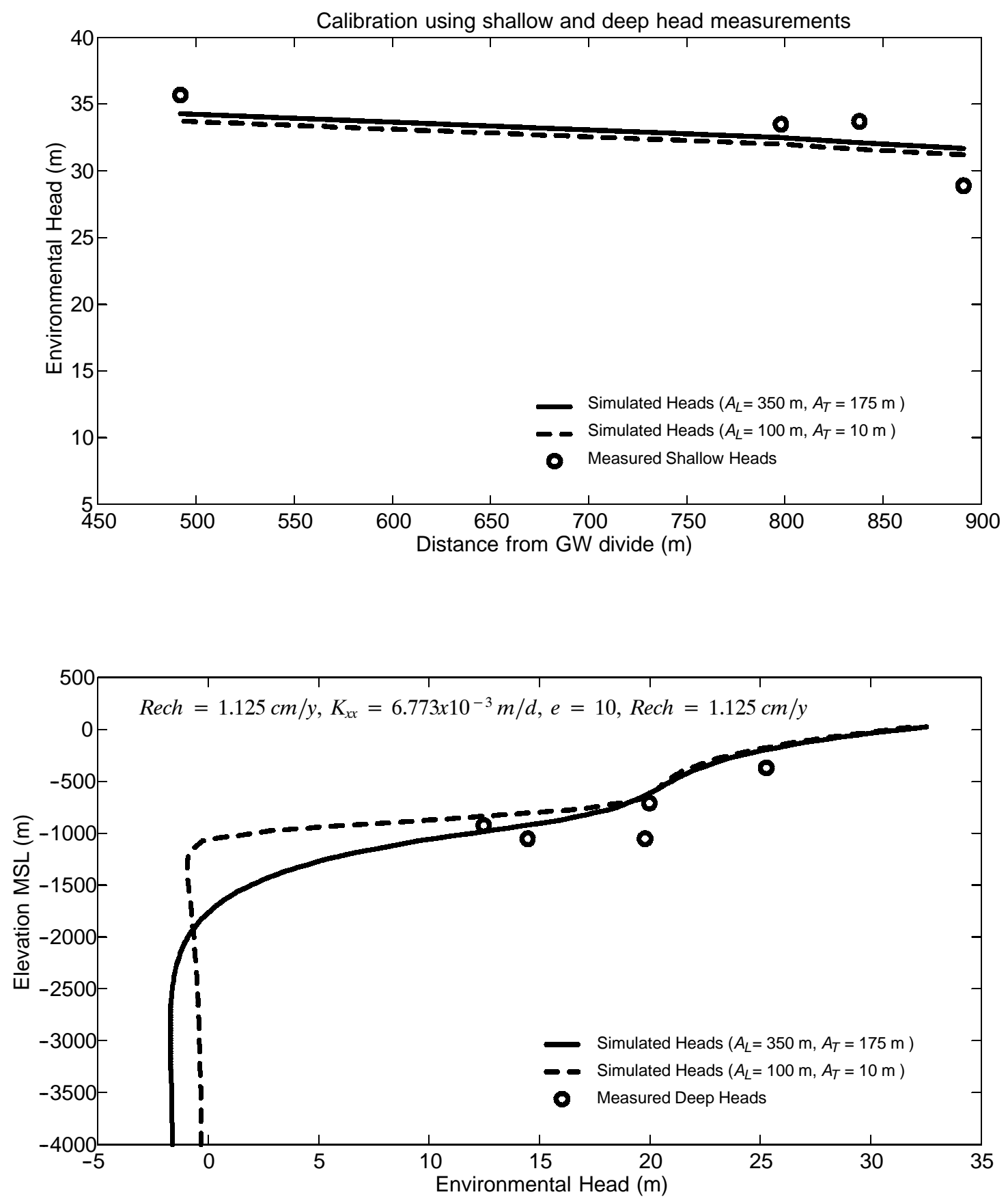

Figure 2.15. Comparison between simulated and measured heads for a case that leads to a good match for Milrow heads only. 


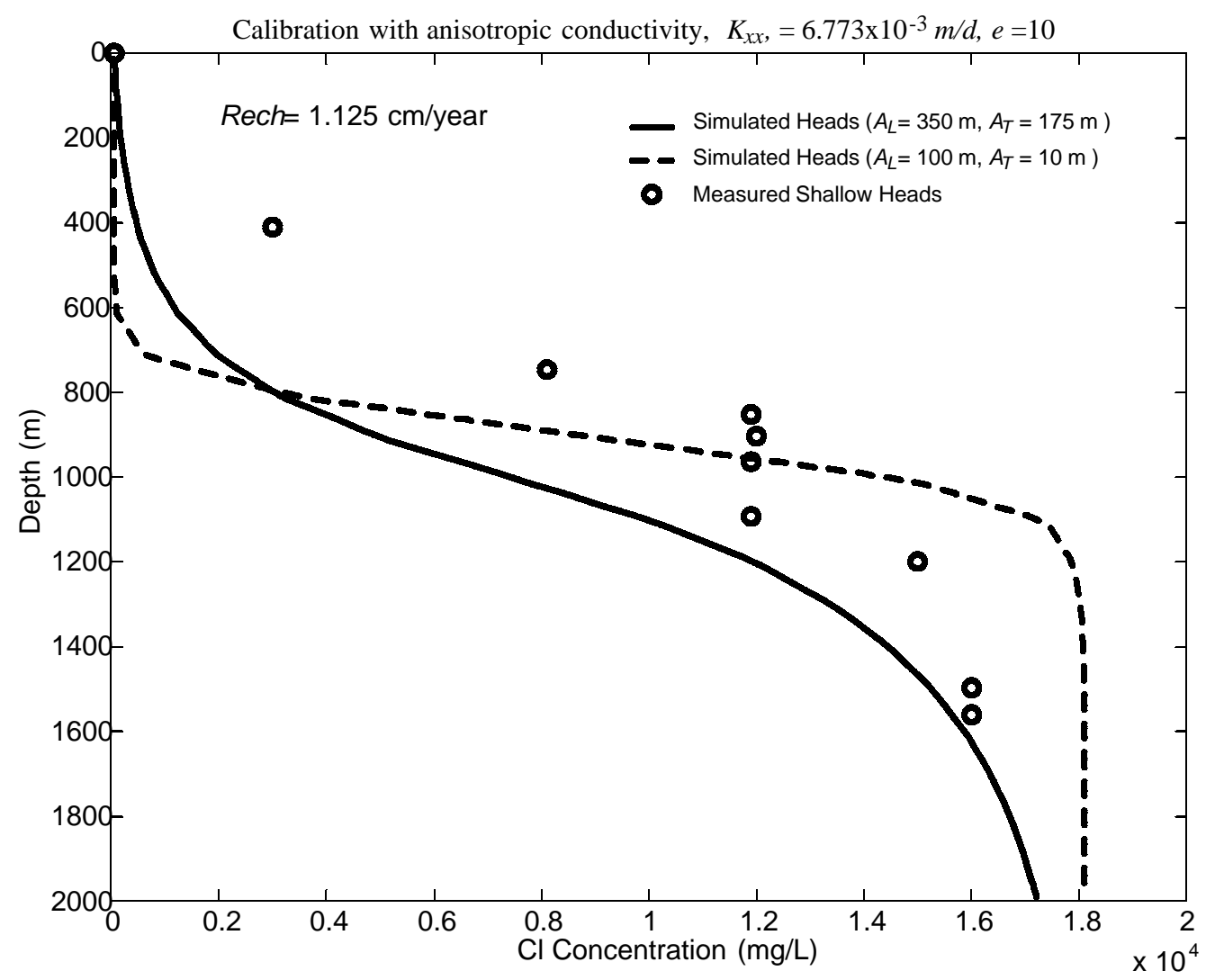

Figure 2.16. Comparison between simulated and measured chloride concentrations at Milrow for two cases of macrodispersivity. The larger values ( 350 and $175 \mathrm{~m}$ ) yield a deep freshwater lens and thick transition zone; the smaller values (100 and $10 \mathrm{~m})$ give a shallower lens and sharper transition from freshwater to seawater concentrations.

thickness (Figure 2.14) and still achieved good match with shallow and deep head measurements (Figure 2.13).

\subsubsection{Long Shot Calibration and Base-case Parameters}

Head data are available at a number of wells located within $100 \mathrm{~m}$ from the working point of Long Shot. Chloride concentration data are estimated from fluid concentrations at EH-5. The data are clustered in a small area around the cavity in such a way that the data points could be compared to a vertical head profile through the ground zero location. The concentration data points are clustered between 400 and $700 \mathrm{~m}$ below ground surface with chloride concentrations below $500 \mathrm{mg} / \mathrm{L}$. These data cannot be used to identify the location and/or depth of the transition zone, but at least can be used as a guide to control the choice of model parameters.

The geometry of the simulation domain and the boundary conditions are similar to Milrow. The only difference is the shape of the upper boundary, which is determined by the topographic and bathymetric profiles (Figure 2.9). The island half-width is about 2,128 $\mathrm{m}$ for Long Shot, which is about $66 \mathrm{~m}$ wider than that of Milrow. The finite-element mesh used to discretize the simulation domain is similar to the other two tests. 

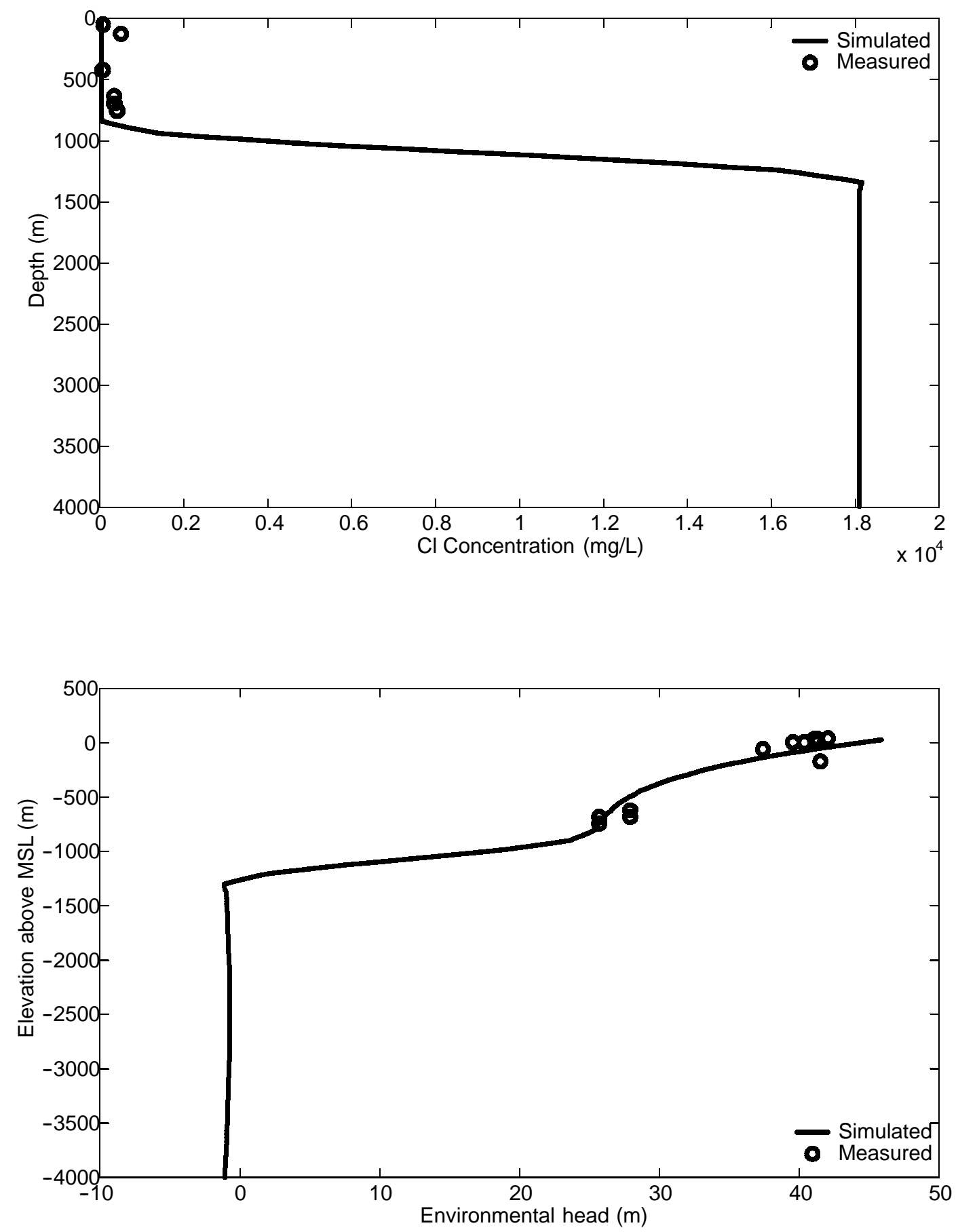

Figure 2.17. Long Shot calibration using concentration data at one well and head data at a number of wells clustered around the working point. 
A number of parameter combinations have been tested, as was done for Milrow, and the response of the model was compared to available head and concentration data. The higher heads at EH-5 as compared to UAe-2 of Milrow indicate that a larger recharge-conductivity ratio is needed for the Long Shot model to match the data. Based on this difference and after running a number of simulations, the Long Shot calibration resulted in a recharge value of $3.65 \mathrm{~cm} /$ year and a conductivity value of $1.58 \times 10^{-2} \mathrm{~m} / \mathrm{d}$, and thus the recharge-conductivity ratio for this calibration is about $6.3 \times 10^{-3}$.

Figure 2.17 depicts the comparison between concentration and head data and the simulation results. The concentration data do not provide sufficient information to delineate the transition zone location. The simulated concentration distribution at the EH-5 location is well matched, though

slightly underestimating some of the measured concentrations. The simulated head profile also closely matches all the data points collected at different depths from different wells. Since these wells are located within one mesh element, and the variations of heads between adjacent elements occur slowly in the horizontal direction, comparing these head data to a vertical profile at a single location is considered reasonable.

\subsubsection{Cannikin Calibration and Base-case Parameters}

Two sets of measured data are available to calibrate the flow model and select the base-case parameters for Cannikin. Chloride concentration data at UAe-1 are used to help identify the location and the width of the transition zone. However, the data are clustered between 1,600 $\mathrm{m}$ and 2,000 $\mathrm{m}$ below ground surface with concentrations below $2,000 \mathrm{mg} / \mathrm{L}$. These data cannot be used to identify the location and/or depth of the transition zone, but at least can be used as a guide to control the choice of model parameters. On the other hand, head measurements are available for three wells, UAe-1, UA-1, and HTH-1, which can be used to compare with the modeled vertical head profiles at the wells' locations.

The geometry of the simulation domain and the boundary conditions are not different from the other sites and are as shown in Figure 2.10. The only difference is the shape of the upper boundary, which is determined by the topographic and bathymetric profiles (Figure 2.9). These profiles for Cannikin are different from those for Milrow and Long Shot. For example, the island half-width is about 2,328 $\mathrm{m}$ for Cannikin, whereas Milrow and Long Shot have an island half-width of about 2,062 and 2,128 m, respectively. The two-dimensional domain is discretized in a manner similar to Milrow, where the upper left half is assigned a mesh size of $100 \mathrm{~m}$ and the other half is assigned a mesh size of $200 \mathrm{~m}$.

A large number of scenarios have been tested using FEFLOW, in which the homogeneous hydraulic conductivity and its anisotropy ratio, the recharge and the macrodispersivity are varied and the results are evaluated and compared to the calibration data. The macrodispersivity values are taken as $100 \mathrm{~m}$ and $10 \mathrm{~m}$ in the longitudinal and transverse directions, respectively. The value of porosity is not important at this stage, as the domain is assigned a uniform porosity and chimney changes are not considered for the pre-test calibration conditions. The initial values of conductivity and recharge are selected similar to those for the Milrow calibration. However, comparing the 
chloride concentration data available for Cannikin and the head values at UAe-1 to those for Milrow and Long Shot indicates that a much deeper transition zone is more likely to be the case for Cannikin. After a number of trials, the values selected for the recharge and conductivity are higher than those for Milrow, and compared to Long Shot, the Cannikin conductivity is slightly lower and the recharge higher. The calibration resulted in a recharge value of $5.48 \mathrm{~cm} /$ year (as compared to $1.125 \mathrm{~cm} /$ year for Milrow and $3.65 \mathrm{~cm} / \mathrm{yr}$ for Long Shot) and a conductivity value of $1.38 \times 10^{-2} \mathrm{~m} / \mathrm{d}$ (as compared to $6.677 \times 10^{-3} \mathrm{~m} / \mathrm{d}$ for Milrow and $1.58 \times 10^{-2} \mathrm{~m} / \mathrm{d}$ for Long Shot). This resulted in a recharge-conductivity ratio of $1.09 \times 10^{-2}$ as opposed to $4.62 \times 10^{-3}$ for Milrow and $6.3 \times 10^{-3}$ for Long Shot, and as such, a deeper transition zone is obtained.

The transition zone is not the only factor controlling the choice of the calibration parameters. The head measurements in the three wells, although not always useful, provide another criterion for calibrating the flow model. In general, the head data for Cannikin wells indicate higher heads than observed at Milrow. To reproduce these higher heads, a higher recharge value is necessary as compared to Milrow. Figure 2.18 shows the comparison between the measurements and the modeling results for the concentration and head data at UAe-1. The concentration profile does not match the data collected below a depth of $1500 \mathrm{~m}$. The head comparison for UAe- 1 shows that the simulated heads pass through the range of the measurements, which do not provide a clear vertical head profile. Figure 2.19 shows the head comparisons for UA-1 and HTH-1. Simulated heads are matching closely the measured heads for UA-1, although positive and negative deviations exist. On the other hand, simulated heads are higher than measured for HTH-1. The two calibration figures indicate that simulations result in a compromise in terms of matching the heads at UAe-1, UA-1, and HTH-1. That is, any increase in the recharge-conductivity ratio will not improve the match for UAe-1, but will increase the existing deviations for HTH-1. Decreasing this ratio, on the other hand, may improve the comparison for HTH-1, but will cause larger head deviations for both UAe-1 and UA-1 and larger concentration deviations for UAe-1. Considering the fact that the quality of the concentration data at UAe-1 has been a source of suspicion in many studies, and the possible violation of the steady state assumption for the chemistry profile, compromising in terms of matching the head data at the three wells is regarded as a reasonable calibration result. In addition, the final modeling stage encounters many realizations that provide a wide range of scenarios and results that encompass most of the data available from the three wells.

\subsubsection{Summary of Calibration Results}

The final calibration values are summarized in Table 2.5 and the corresponding transition zones can be seen on Figure 2.20. The lower recharge-conductivity ratio at Milrow results in a shallower transition zone, consistent with the data. The slightly higher ratio for Long Shot increases the depth to the transition zone, and the much higher recharge-conductivity ratio for Cannikin extends its transition zone deeper still. Again, these different configurations for the freshwater-seawater system are consistent with the data for each site. There may be several contributing factors causing the variation in transition zone depth from one site to another. One contributor is topography, with the higher land elevation at Cannikin (23.5 m higher at the Cannikin emplacement well than at Milrow)

resulting in a corresponding higher elevation of the water table, which is very near ground surface 

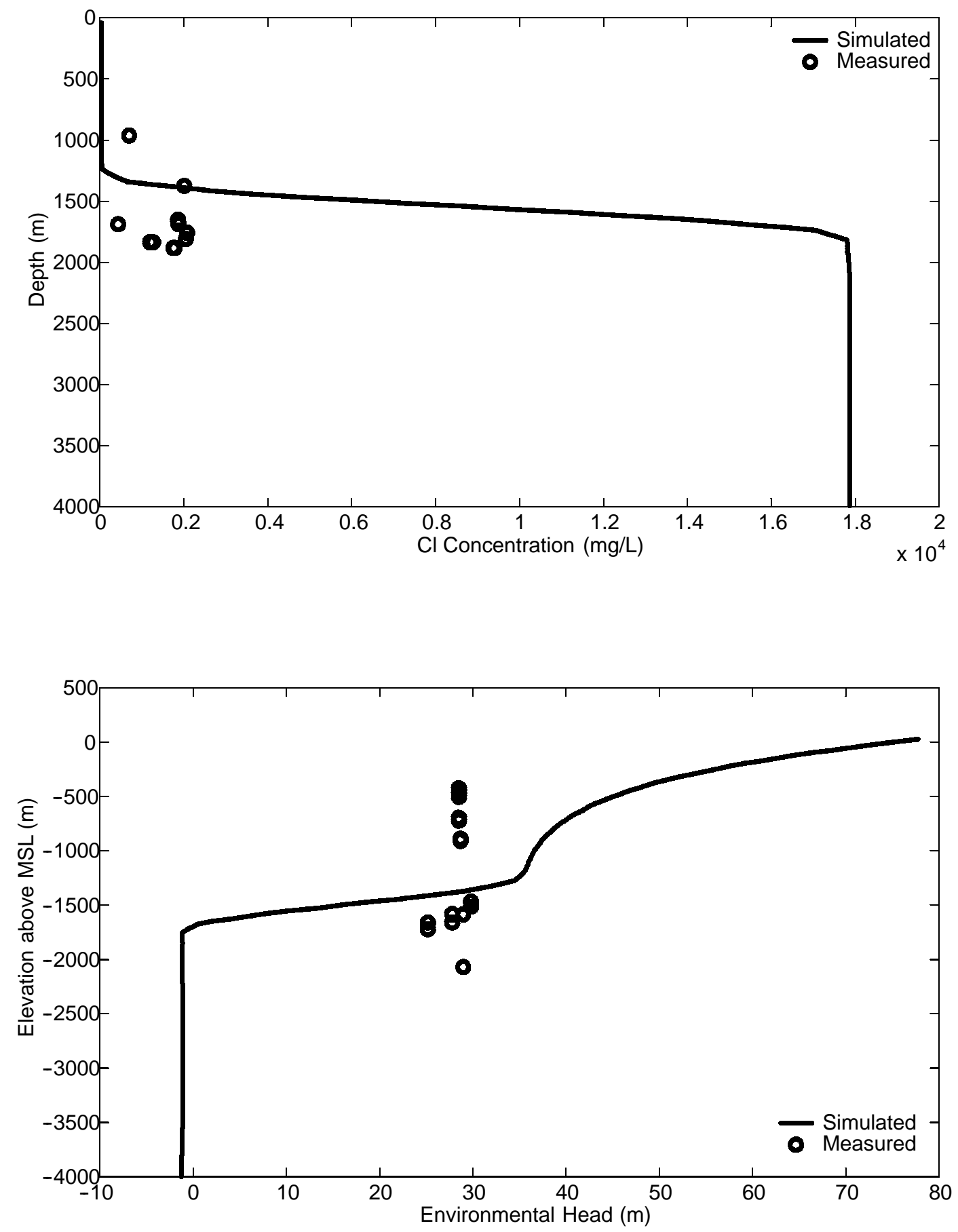

Figure 2.18. Calibration results for Cannikin well UAe-1 where head and concentration data are compared to model results. 

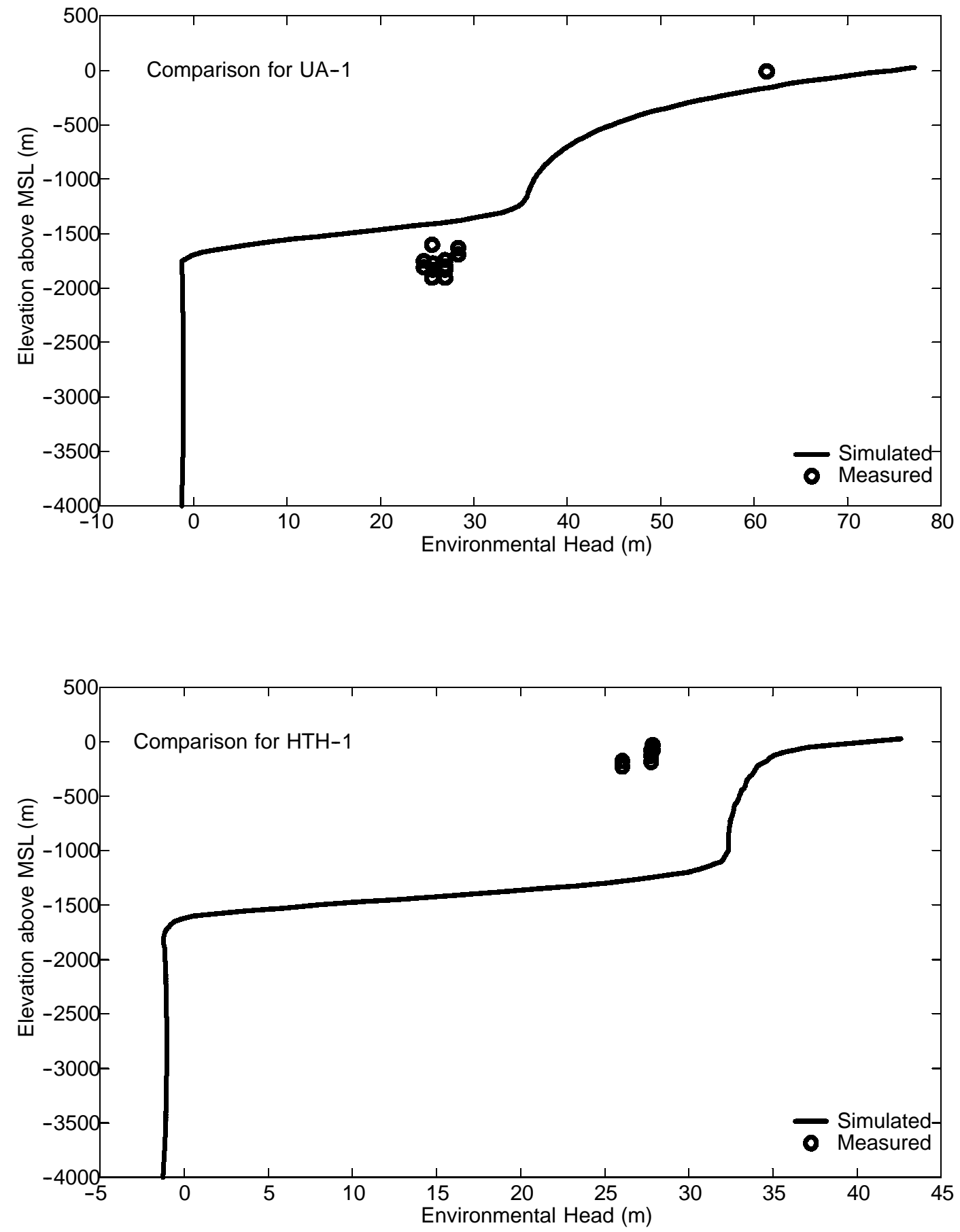

Figure 2.19. Calibration results for Cannikin wells UA-1 and HTH-1 using head data. 

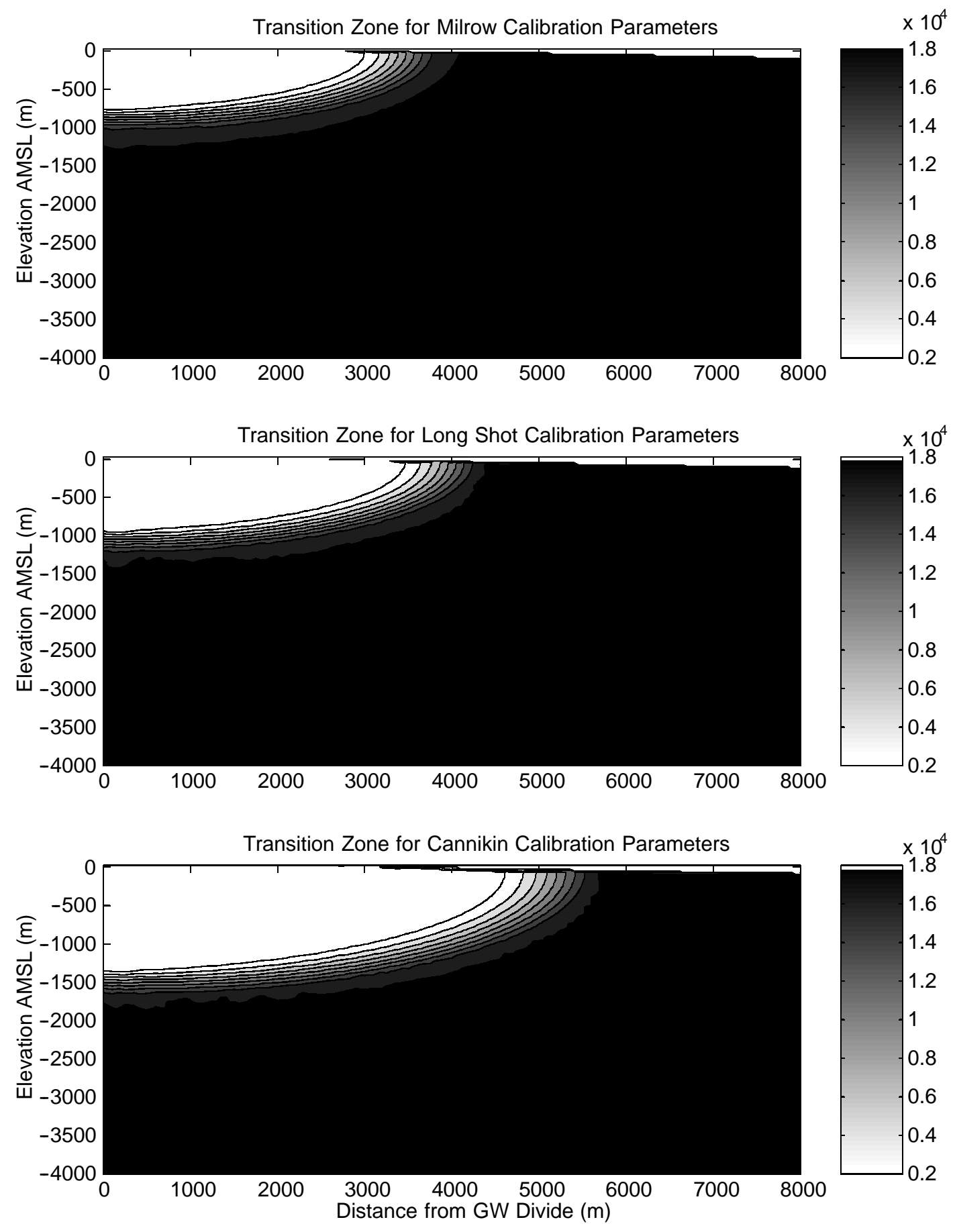

Figure 2.20. Transition zones modeled for each site using the calibration parameters, expressed by the chloride concentration. 
at all locations. Another factor is the tendency toward higher hydraulic conductivity values at Cannikin for a given elevation relative to Milrow (data are presented in Section 2.2.1). Though the availability of recharge is not obviously different from one location to another, the ability of the subsurface to accept and transmit recharge is governed by the hydraulic conductivity.

Table 2.5. Summary of calibration parameters.

\begin{tabular}{lccccc}
\hline \multicolumn{1}{c}{ Test } & $K(\mathrm{~m} / \mathrm{d})$ & $\operatorname{Rech}(\mathrm{cm} / \mathrm{y})$ & $K / \operatorname{Rech}$ & $\mathrm{A}_{\mathrm{L}}(\mathrm{m})$ & $\mathrm{A}_{\mathrm{T}}(\mathrm{m})$ \\
\hline Milrow & $6.773 \times 10^{-3}$ & 1.125 & $4.62 \times 10^{-3}$ & 100 & 10 \\
Long Shot & $1.58 \times 10^{-2}$ & 3.65 & $6.3 \times 10^{-3}$ & 100 & 10 \\
Cannikin & $1.38 \times 10^{-2}$ & 5.48 & $1.09 \times 10^{-2}$ & 100 & 10 \\
\hline
\end{tabular}

An asymmetry to the freshwater lens geometry has been suggested by other researchers, as well as the presence of a deeper freshwater lens at Cannikin (Fenske, 1972a; Dudley et al., 1977). The impact of the transition zone on the groundwater velocity field for each site is shown in Figure 2.21. Given the very low velocities in the seawater portion of the domain, relatively high groundwater velocities at Milrow are confined to a much shallower region than at Long Shot and Cannikin with their deeper transition zones. Not only does the higher velocity transition zone extend deeper in the subsurface, but the reach of sea floor across which freshwater discharges is also extended farther out to sea. Thus, the freshwater lens simulated at Long Shot, and particularly Cannikin, is not only deeper but more laterally extensive than that simulated for Milrow. 

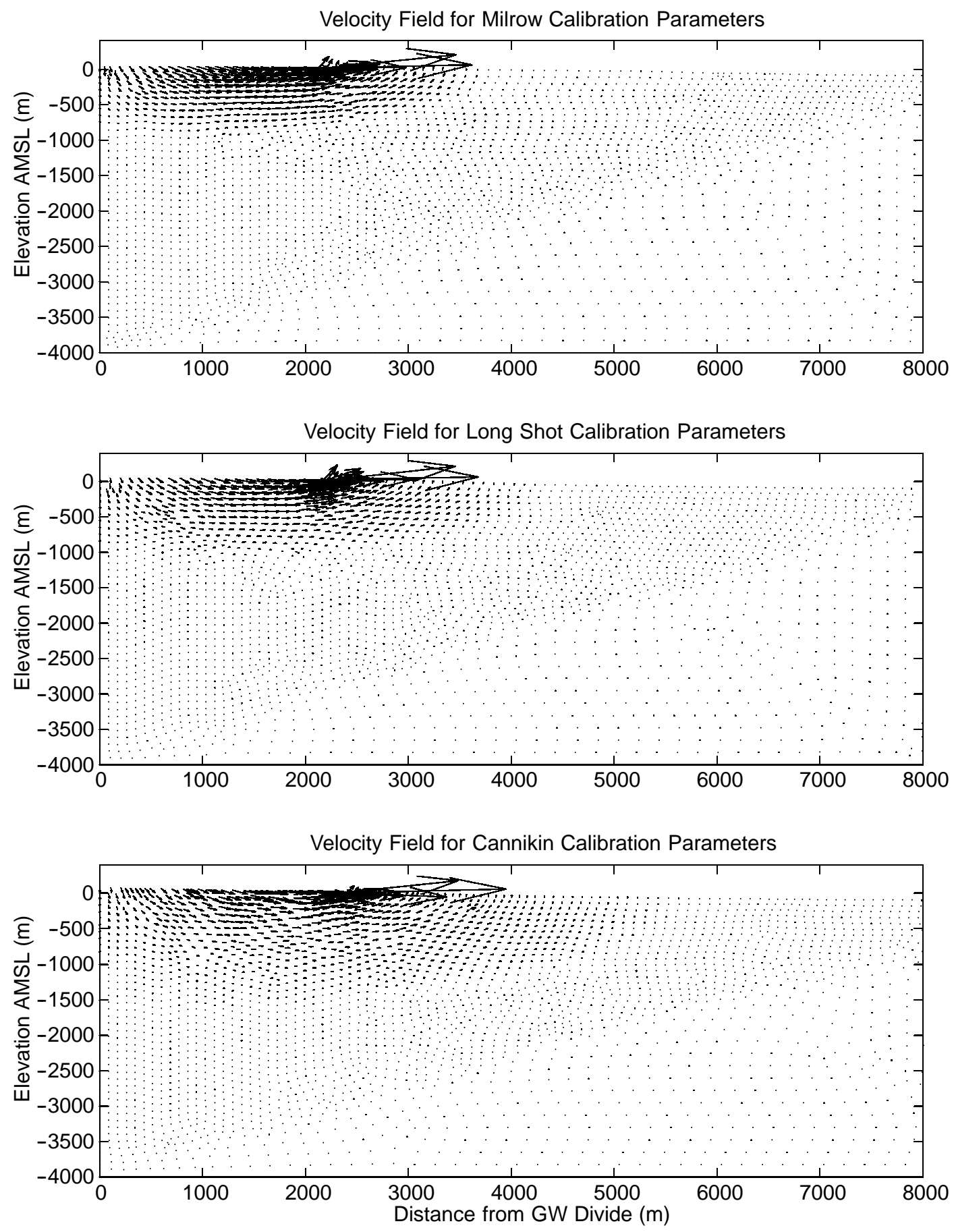

Figure 2.21. Velocity vectors for the calibrated flow fields at each site. 


\section{CONCEPTUAL TRANSPORT MODEL}

The migration of contaminants from the underground nuclear tests at Amchitka involve a complex system of physical and chemical processes. Some of these processes are poorly understood and are the subject of ongoing research conducted by the U.S. Department of Energy. For the analysis of Amchitka, many assumptions were made based on currently available data. A diagrammatic representation of the transport model source and processes considered is shown in Figure 3.1.

The contaminants considered consist of the radionuclides produced by Milrow, Long Shot, and Cannikin and the daughters created by radioactive decay. The nuclides are assumed to all be located within the cavity. Distribution upward through the chimney region was neglected. Sampling in the Cannikin post-test hole confirms that the bulk of radioactivity is contained within the cavity region (Claassen, 1978). In general, the primary effect of spreading the source nuclides through a larger volume is to disperse and dilute the mass, lowering concentrations.

Radionuclides are distributed according to their volatility among surface deposits and volume deposits in nuclear melt glass. Volatile and surface-deposited nuclides are assumed to migrate immediately after the nuclear test, neglecting the time of groundwater infill, when hydraulic gradients are directed toward the cavity. Nuclides within the glass are released according to glass dissolution rates calculated based on volcanic glass dissolution behavior and radionuclide melt glass characteristics. Early time cavity conditions and near-field properties affected by the nuclear tests were not considered in the analysis, presuming that the scale of transport considered here (thousands of meters), renders the calculations insensitive to the near-cavity environment. Residual heat from a test is considered in a sensitivity analysis.

Once released, the nuclides are subjected to retardation processes. Diffusion of contaminants from fractures into surrounding matrix blocks is also considered. Some radionuclides are retarded by reactions with aquifer materials. Retardation factors are calculated from a surface-based sorption

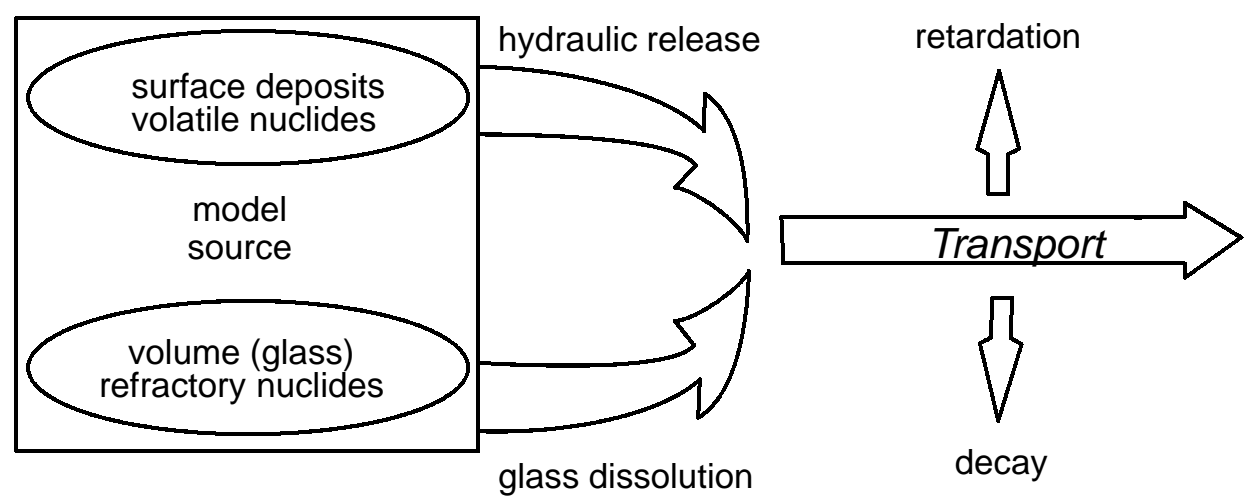

Figure 3.1. Flow chart of the transport model source and processes considered. 
constant for the fractures, based on estimates of fracture aperture and distribution coefficients derived from batch experiments on Amchitka cores. Nuclides were grouped according to assumed general sorptive behavior and assigned the same retardation factor because radionuclide-specific data are not available for many of the contaminants in the Amchitka environment. The effect of colloidal particles on transport behavior was not modeled due to the lack of data to support such calculations and the observations from other sites that the mass actually transported by colloids would necessarily be exceedingly small.

The transport calculations are performed using a particle tracking method. An initial mass is released and its movement tracked through the model domain, with breakthrough at the ocean floor recorded. The mass breaking through is the input needed for a risk assessment model. The effect of radioactive decay was calculated in a post-processing mode. All of the contaminant masses used in the transport modeling are assigned a value of one. The results can then be scaled by the classified masses available in Goishi et al. (1995), or any unclassified estimates available.

\subsection{Source Term and Release Parameters}

\subsubsection{Radionuclide Source Term}

Contaminants from underground nuclear testing can be divided into two broad categories: radionuclides and non-radionuclides. Primary radionuclides can be attributed to three possible origins: 1) residual nuclear material that has not undergone a fission or a thermonuclear reaction, 2) direct products of the nuclear reactions (fission products and tritium), and 3) activation products induced by neutron capture in the immediate vicinity of the explosion (Borg et al., 1976). In addition, radionuclide daughter products are produced by decay of many of the primary radionuclides.

The radionuclide source terms for Milrow, Long Shot, and Cannikin are included in an inventory prepared by Los Alamos and Lawrence Livermore national laboratories for nuclear tests conducted at non-NTS locations (Goishi et al., 1995). This inventory represents the total radionuclide source term, given the following constraint. Radionuclides are excluded from the inventory if they are produced in such low amounts or decayed so rapidly that dissolving the total amount produced during the test into a volume of water equal to the volume of the cavity and allowing decay for 100 years resulted in an aqueous concentration less than one-tenth of the maximum permissible concentration (MPC) (Smith et al., 1995). This effectively eliminates radionuclides with half-lives less than about ten years from the inventory.

A shorter list of radionuclides of significance for remedial investigations at the NTS is compiled considering the 56 radionuclides presented by Goishi et al. (1994) for the NTS, and eight additional radionuclides with half-lives less than ten years that had been encountered in samples of cavity fluids (Smith, 1997). This shorter list is based on the production of a radionuclide in a nuclear test, the relative mobility of the radionuclide determined from historical observations, and the health effects of the radionuclide relative to a total body or organ dose. The source term considered in this work is comprised of the radionuclides common to the Goishi et al. (1995) inventory list and the Smith (1997) list of significant radionuclides. Our source contains a total of 24 nuclides (several are 
stable), including parents and daughters (Table 3.1). These radionuclides cover the gamut of release functions and retardation properties (discussed in following sections) and thus can be considered representative of the full radionuclide source term contained in Goishi et al. (1995).

Table 3.1. List of radionuclides considered for the source-term for Milrow, Long Shot, and Cannikin.

\begin{tabular}{ccc}
\hline \hline Radionuclide & Half-life, years & MPC, pCi/L \\
\hline${ }^{3} \mathrm{H}$ & 12.3 & 20,000 \\
${ }^{14} \mathrm{C}$ & 5730 & 2,000 \\
${ }^{36} \mathrm{Cl}$ & $3.01 \times 10^{5}$ & 700 \\
${ }^{85} \mathrm{Kr}$ & 10.73 & $\mathrm{NA}$ \\
${ }^{90} \mathrm{Sr}$ & 29.1 & 8 \\
${ }^{99} \mathrm{Tc}$ & $2.13 \times 10^{5}$ & 900 \\
${ }^{129} \mathrm{I}$ & $1.57 \times 10^{7}$ & 1 \\
${ }^{137} \mathrm{Cs}$ & 30.17 & 200 \\
${ }^{151} \mathrm{Sm}$ & 90 & 1,000 \\
${ }^{152} \mathrm{Eu}$ & 13.48 & 200 \\
${ }^{234} \mathrm{U}$ & $2.46 \times 10^{5}$ & 90 \\
${ }^{238} \mathrm{U}$ & $4.47 \times 10^{9}$ & 100 \\
${ }^{237} \mathrm{~Np}$ & $2.14 \times 10^{6}$ & 5 \\
${ }^{239} \mathrm{Pu}$ & $2.41 \times 10^{4}$ & 8 \\
${ }^{240} \mathrm{Pu}$ & $6.56 \times 10^{3}$ & 8 \\
${ }^{241} \mathrm{Am}{ }^{*}$ & 432.7 & 10 \\
& & \\
${ }^{85} \mathrm{Rb}$ & stable & \\
${ }^{90} \mathrm{Y}$ & $7.3 \times 10^{-3}$ & \\
${ }^{90} \mathrm{Zr}$ & stable & \\
${ }^{137} \mathrm{Ba}$ & stable & \\
${ }^{151} \mathrm{Eu}$ & stable & \\
${ }^{152} \mathrm{Gd}$ & $1 \times 10^{14}$ & \\
${ }^{236} \mathrm{U}$ & $2.3 \times 10^{7}$ & \\
${ }^{237} \mathrm{~Np}$ & $2.14 \times 10^{6}$ & \\
daughters: & & \\
\hline \hline
\end{tabular}

${ }^{*}$ initial ${ }^{241} \mathrm{Pu}$ will be decayed to ${ }^{241} \mathrm{Am}$ and added to its mass

The initial mass data for the radionuclides produced by the Amchitka tests remain classified (Goishi et al., 1995) and cannot be presented in a public document. The transport calculations presented in this report are performed using a unit value for starting mass. The unit-mass-based transport analyses can be converted to true mass in a classified companion document, when the need arises.

\subsubsection{Radioactivity Observed in Cannikin Cavity Water}

Of the three tests, post-test sampling results are only available for Cannikin. The re-entry hole UA-1-P1 was completed 106 days after the test and subsequently logged, perforated, and sampled. 
The detailed results of investigations in the hole are reported by Claassen (1978). Gamma logging identified high activity spikes in the region of the cavity, coincident with a large increase in temperature. The five perforated intervals span this cavity zone and above, with the uppermost perforation about $200 \mathrm{~m}$ above the cavity size estimated here. Sampling was only performed with thief samplers, plugging of perforations required surging, and significant borehole flow was observed, all requiring great care for interpreting the data. Data collected prior to July 1972 exhibit the impacts of condensed steam prior to cavity infill and are not interpreted by Claassen as being representative of saturated cavity conditions. Claassen points out that samples from the re-entry hole are probably not representative of bulk cavity water, but that they should be representative of the isotopes present, but at lower concentrations due to dilution and mixing.

As expected, elevated tritium concentrations are present in the samples (Figure 3.2). Very little alpha activity was observed in any of the samples. The few exceptions could be accounted for by natural alpha in the drilling fluids used in the hole. Three samples were analyzed specifically for ${ }^{239} \mathrm{Pu},{ }^{240} \mathrm{Pu},{ }^{238} \mathrm{U}$, and ${ }^{235} \mathrm{U}$. No plutonium was detected and the uranium-isotope ratio indicated natural uranium was present in all three. Comparing the gross beta/gamma results for other waters on the island with those from UA-1-P1 finds values elevated one to two orders of magnitude higher in the re-entry well. Some portion of this is due to the associated tritium, as it is a beta emitter, though Claassen (1978) identifies some shorter half-lived components (half-lifes of 50, 66, and 330 days), based on decay of the activity with time. Claassen estimates an average distribution coefficient, $K_{d}$, for the beta/gamma activity of about $2.5 \times 10^{4} \mathrm{ml} / \mathrm{g}$, and a time to attain sorption equilibrium of about 500 days. Claassen cautions that extrapolation of the radiochemical data to estimate the radioactive-source water is not possible. As a result, the source term is defined as described in the previous section, using the classified data, rather than estimated from the UA-1-P1 sampling results.

\section{$\underline{\text { 3.1.2 Release Functions }}$}

Radionuclides produced by an underground nuclear test are present in three basic forms: gases, surface deposits, and volume deposits (Smith et al., 1995), the proportions of which can change with time after the detonation. Immediately after the detonation, essentially all of the radionuclides are part of a superheated, expanding gas (Borg et al., 1976). When the temperature and pressure start to drop, many of the gases condense. The condensation occurs based on the boiling point of the nuclide, with the higher-boiling points (first to condense) referred to as refractory nuclides, and the lower-boiling point species referred to as volatile. A high percentage of the refractory species is trapped in the solidifying melt, much of which collects at the base of the cavity as "puddle glass." These are the volume deposits, whose release is controlled by dissolution of this glass.

Nuclides with somewhat lower boiling points $($ e.g., $\mathrm{Cl}, \mathrm{I})$ remain volatile longer and are able to migrate upward through cracks in the rubble chimney. Some portion of these are included within the solidifying puddle glass, but a portion is also deposited as coatings on chimney rubble surfaces. Nuclides included in these surface deposits can be released by relatively rapid processes such as ion exchange, as well as by dissolution, and thus the surface deposits are more susceptible to leaching than the volume-deposited radionuclides. Ion exchange and dissolution of these surface coatings are 


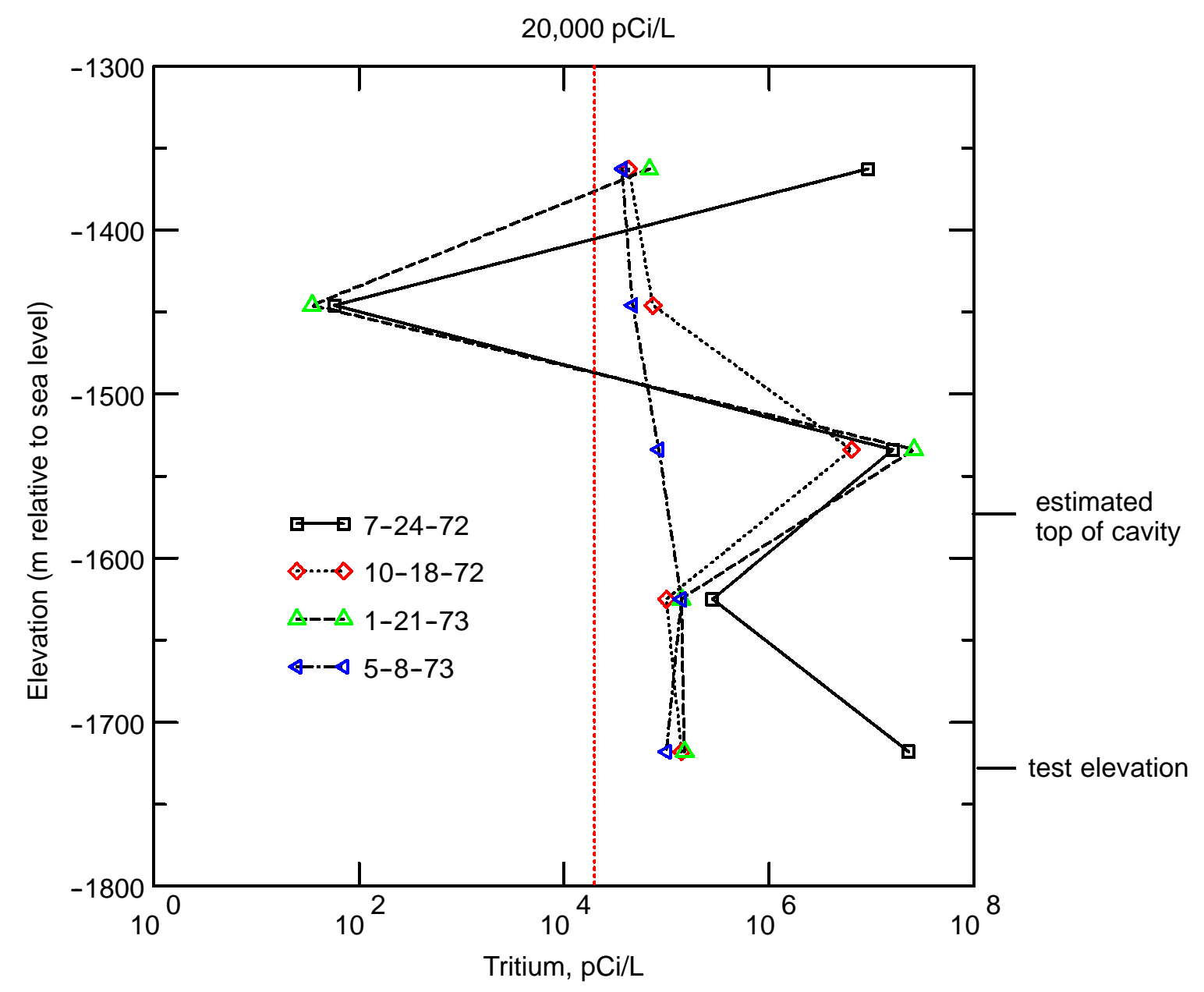

Figure 3.2. Tritium analyses for three sampling events in the Cannikin post-test hole, UA1-P-1. Data from Claassen (1978).

dependent upon the mineralogy of the precipitates and their controlling thermodynamics. The specific form that these surface deposits take at Milrow is unknown, as well as the conditions controlling any dissolution reactions. For these reasons, no attempt is made to formulate a geochemical release function for the surface-deposited radionuclides. Rather, it is assumed that the surface deposits are immediately dissolved upon contact with groundwater and available for migration through the groundwater system. This assumption results in an overestimation of the availability of the surface-deposited radionuclides for transport, as the dissolution and exchange processes described above may be considerably smaller in magnitude and slower in occurrence than modeled. With no geochemical component to the release, the migration from the cavity of the surface-deposited nuclides is governed by the "hydraulic release." The hydraulic release defines the process of re-equilibration of the hydraulic head within the cavity (recovery to static water level from the depressed condition caused by the test), as well as flushing of contaminants from the cavity by the flow-through of groundwater. 
Some of the radionuclides produced remain in gaseous form (e.g., $\mathrm{Kr}$ and $\mathrm{Xe}$ ) and may be trapped in solidifying phases or dissolved in ground water. Other nuclides are gaseous, but then decay to a non-gaseous nuclide. In these cases, the preceding decay-chain behavior is an important control on the distribution and release of daughter nuclides. For example, both ${ }^{137} \mathrm{Cs}$ and ${ }^{90} \mathrm{Sr}$ can be found in surface deposits throughout the chimney, as well as in the puddle glass, because of gaseous precursors. Prompt injection is another release process that may transport gaseous species under early cavity conditions. Gaseous tritium and strontium and cesium precursors may be forced several cavity radii away from the detonation point through explosion-induced fractures arranged radially away from ground zero (Smith, 1995). It is uncertain whether refractory species are transported by prompt injection. At Long Shot, tritium and krypton detected in mud pits and relatively shallow wells are attributed to early-time gas migration upward through the chimney and into the spall zone, where the gas then dissolved in groundwater (Castagnola, 1969). No similar gas migration was detected at Milrow nor Cannikin.

Several of the processes described above require elaboration to understand how they are implemented in the transport analysis. Following are additional discussions of the apportioning of radionuclides between volume and surface deposits, and of the release of radionuclides from the source.

\subsubsection{Volume/Surface Mode Designation}

Refractory and volatile behavior designations are culled from literature references (Borg et al., 1976; Borg, 1975; International Advisory Committee, 1998a; Kersting, 1996; Smith, 1995) whenever possible. For those nuclides with no specific literature reference, volatilities of oxides (Bedford and Jackson, 1965; Krikorian, 1981) and melting point temperatures are used to assign a behavior consistent with the volatilities and melting points of known refractory and volatile nuclides.

A small proportion of nuclear melt glass is not incorporated in the bottom puddle, but is distributed through the collapsing chimney as a result of splashes caused by blocks of rock falling into the puddle, or as fine droplets entrained with escaping cavity gases (Smith, 1995). The exact amount distributed in this way is not known. Based on broad experience at Lawrence Livermore National Laboratory, examining glass samples from underground testing (Borg, 1975) estimates that at most only 2 to 3 percent of refractories are lost from puddle glass. Rabb (1970) found that isotopes other than ${ }^{137} \mathrm{Cs},{ }^{125} \mathrm{Sb},{ }^{95} \mathrm{Zr} /{ }^{95} \mathrm{Nb},{ }^{147} \mathrm{Pm}$, and ${ }^{185} \mathrm{~W}$ were 95 percent or more in the glass with the remainder elsewhere for the Pile Driver test. The international working group charged with evaluating the source term for the French underground nuclear tests on Mururoa and Fangataufa estimated a partioning of 98 percent in melt glass and 2 percent on rubble for plutonium isotopes and other transuranium nuclides, while French studies of the same tests assumed 100 percent in the melt glass (International Advisory Committee, 1998a). Based on these sources, it is assumed here that 5 percent of the total mass of even the refractory species is lost from the puddle glass. Thus, the designated refractory radionuclides have 5 percent of their mass considered surface deposited, with the remaining 95 percent volume deposited (Table 3.2). 
The distribution of ${ }^{90} \mathrm{Sr}$ and ${ }^{137} \mathrm{Cs}$ is assigned based on fractionation data compiled by Borg et al. (1976). They list the fractionation index for several radionuclides from tests in different rock types. The lowest value measured from deeply buried underground tests (neglecting results from shallowly buried tests in alluvium) for incorporation in the glass is applied to the Amchitka evaluation. Thus, it is assumed that 20 percent of the ${ }^{137} \mathrm{Cs}$ is contained within the puddle glass and 80 percent is surface deposited through the cavity and chimney, and 40 percent of the ${ }^{90} \mathrm{Sr}$ is in the puddle glass and 60 percent is surface deposited. The higher proportion of ${ }^{90} \mathrm{Sr}$ in the glass as compared to ${ }^{137} \mathrm{Cs}$ is consistent with the difference in the half-life of their gaseous precursors. The ${ }^{90} \mathrm{Kr}$ half-life is 33 seconds, whereas the ${ }^{137} \mathrm{Xe}$ half-life is 3.9 minutes, allowing more time for migration of the mass-137 chain to migrate out of the puddle glass.

Table 3.2. Release ratios assigned to source term nuclides.

\begin{tabular}{lcc}
\hline \hline \multicolumn{1}{c}{ Element } & Hydraulic Release (\%) & Volume (Glass) Release (\%) \\
\hline H (Hydrogen) & 100 & 0 \\
$\mathrm{C}$ (Carbon) & 100 & 0 \\
$\mathrm{Cl}$ (Chlorine) & 50 & 50 \\
$\mathrm{Kr}$ (Krypton) & 100 & 0 \\
$\mathrm{Sr}$ (Strontium) & 60 & 40 \\
Tc (Technetium) & 20 & 80 \\
$\mathrm{I}$ (Iodine) & 50 & 50 \\
$\mathrm{Cs}$ (Cesium) & 80 & 20 \\
$\mathrm{Sm}$ (Samarium) & 5 & 95 \\
Eu (Europium) & 5 & 95 \\
$\mathrm{U}$ (Uranium) & 5 & 95 \\
$\mathrm{~Np}$ (Neptunium) & 5 & 95 \\
Pu (Plutonium) & 5 & 95 \\
Am (Americium) & 5 & 95 \\
\hline \hline
\end{tabular}

The halogens, ${ }^{36} \mathrm{Cl}$ and ${ }^{129} \mathrm{I}$, can be expected to have volatile behavior in the early time, but there are also natural analogs in the geologic environment whereby halogens are included in volcanic glass (Hampton and Bailey, 1984). As the steam condenses in the cavity, some of the volatiles will be trapped and incorporated in the glass. It is assumed here that 50 percent of the ${ }^{36} \mathrm{Cl}$ and ${ }^{129} \mathrm{I}$ is included in the glass, and the remaining 50 percent is surface deposited. Technetium-99 $\left({ }^{99} \mathrm{Tc}\right)$ is relatively volatile, but has short-lived refractory precursors that are assumed here to trap 80 percent of the mass in the glass (International Advisory Committee, 1998a).

By a similar process, other volatile nuclides are probably entrained in the melt. For example, the French report that more than 50 percent of the available tritium is captured by their glasses (Dupuis, 1970, as reported by Borg, 1975). Borg (1975) reports that only a small (but unquantified) portion of the total tritium produced can be recovered from glasses of tests conducted in saturated alluvium and tuff. At Pile Driver, Borg (1975) estimates that $1.53 \mathrm{gm}$ of a total $1.8 \mathrm{gm}$ produced by activation is contained in the melt, but notes that this is considerably less than the total tritium 
available. Given these uncertainties and the importance of tritium to the transport calculations, no incorporation in the melt glass is assumed here. The size of the carbon dioxide molecule can limit its inclusion in volcanic glasses, (though carbon monoxide may dissolve; Hampton and Bailey, 1984), and krypton is noncondensable, so these nuclides are also considered subject only to the hydraulic release function.

\subsubsection{Release Rate}

It is well established that nuclear cavities and chimneys are dewatered and subsequently refilled, though the process through which the dewatering occurs is largely inferred (Borg et al., 1976). Within the cavity itself, the depressed water levels probably result from thermal and compressional forces generated by the nuclear reaction. Following the desaturation immediately after the test, the cavity and chimney will infill with groundwater flowing radially from the surrounding saturated rock. While hydraulic head within the chimney is depressed below that in the surrounding aquifer, there is no hydraulic force to drive contaminant migration. Given this, radionuclides are not expected to exit the cavity and begin transport through the aquifer until after infilling is completed. At some underground nuclear test sites, the infill process has required decades, and this time has been accounted for in radioactive decay of the source (Pohll et al., 1998; Pohlmann et al., 1999). Estimated cavity infill times for Amchitka are relatively short by comparison, predicted to be 500 days for Milrow based on subsurface hydrologic data (USGS, 1970), and 290 days for Cannikin, based on the time of infilling of Cannikin Lake within the collapse sink (Gonzalez, 1977). Given that the impact of decay over a one- to two-year period is insignificant for the half-lives of the radionuclides considered here, transport is conservatively assumed to begin immediately after the detonation date of each test.

The rock, fission products, and device components that are vaporized by the tremendous heat and pressure of a nuclear reaction quickly begin to condense and coalesce into nuclear melt glass. This glass (a solid with no crystalline structure) contains much of the radioactivity produced by a nuclear test. Radionuclides must be removed from the melt glass to be transported by groundwater. Available data for predicting nuclear melt glass dissolution are presented in a transport analysis performed for the Shoal underground nuclear test (Pohll et al., 1998). The approach selected for that site, and also applied here, is to use dissolution rates based on analogy to the dissolution of volcanic glass. This approach avoids the significant problems inherent in trying to use data from nuclear melt glass leaching experiments, such as data collected during nonequilibrium conditions.

Dissolution of glass in contact with groundwater collected from the depth interval of 1,169.8 to $1,230.2 \mathrm{~m}$ in well UAe-2 (the device emplacement depth was 1,218 $\mathrm{m}$ ) is expected based on thermodynamic considerations. The log of the ion activity product to the equilibrium constant (log $\mathrm{IAP} / \mathrm{K}_{\mathrm{T}}$ ) for amorphous silica is -1.62 . The silica content of this particular sample is comparatively low, but the next higher sampled interval, at a depth range of 1,057.6 to $1,127.8 \mathrm{~m}$, remains undersaturated with respect to amorphous silica, despite a higher dissolved silica content (log $\mathrm{IAP} / \mathrm{K}_{\mathrm{T}}$ of -0.85). The rate equation used to calculate nuclear melt glass dissolution follows a linear rate law (White, 1983): 


$$
\zeta=\zeta_{0}+k_{l} t
$$

where $\zeta$ is the mass transfer of a chemical species into aqueous solution per unit surface area of solid $\left(\mathrm{moles} / \mathrm{cm}^{2}\right), \zeta_{0}$ is the mass transfer at zero time, which is a function of initial surface ion exchange $\left(\mathrm{moles} / \mathrm{cm}^{2}\right), k_{l}$ is the linear rate constant (moles $\left./ \mathrm{cm}^{2} \mathrm{~s}\right)$, and $t$ is the time(s).

The bulk composition of volcanic glass and analyzed nuclear melt glass is similar (Table 3.3). Though there are no analyses of the bulk elemental composition of Amchitka nuclear melt glass, nuclear melt glass tends to resemble the bulk rock composition because there is no appreciable migration of major elements from a cavity region (Schwartz et al., 1984). Chemical analysis of rocks collected from the working points of Long Shot, Milrow, and Cannikin are 49 to 62 percent $\mathrm{SiO}_{2}$ and 15 to 16 percent $\mathrm{Al}_{2} \mathrm{O}_{3}$ (Table 3.3). This composition is closest to that of the trachytic glass used by White (1983) in his dissolution experiments, so that the dissolution constant used here is the one determined from his experiment T-2, at a pH of 6.2 , with a $k_{l}$ of $0.97 \times 10^{-15} \mathrm{moles} / \mathrm{cm}^{2} \mathrm{~s}$ and an initial exchange value, $\xi_{0}$ of $0.34 \times 10^{-9}$ moles $/ \mathrm{cm}^{2}$.

Table 3.3. Comparison between chemical composition of natural volcanic glass, nuclear melt glass, and bulk rock composition at the Amchitka testing intervals. Major and trace element composition in terms of oxides, given as weight percents.

\begin{tabular}{llllllll}
\hline \hline & $\mathrm{SiO}_{2}$ & $\mathrm{Al}_{2} \mathrm{O}_{3}$ & $\mathrm{FeO}$ & $\mathrm{MgO}$ & $\mathrm{CaO}$ & $\mathrm{Na}_{2} \mathrm{O}$ & $\mathrm{K}_{2} \mathrm{O}$ \\
\hline Perlite $^{*}$ & 74.2 & 14.1 & 0.15 & 0.49 & 1.0 & 4.0 & 4.8 \\
Obsidian $^{*}$ & 76.0 & 13.8 & 0.40 & 0.011 & 0.21 & 4.4 & 4.5 \\
Trachytic $^{*}$ & 62.8 & 15.2 & 1.3 & 0.38 & 1.1 & 8.4 & 5.1 \\
$\begin{array}{l}\text { Nuclear Melt } \\
\text { Glass }\end{array}$ & $73.1(4.9)$ & $14.2(2.5)$ & $1.18(1.59)$ & $0.22(0.27)$ & $1.06(0.86)$ & $3.49(1.68)$ & $6.6(4.2)$ \\
$\begin{array}{l}\text { Long Shot, } \\
725 \mathrm{~m}^{\dagger \dagger}\end{array}$ & 53.8 & 15.8 & 4.2 & 4.0 & 5.4 & 3.8 & 2.5 \\
$\begin{array}{l}\text { Milrow, } \\
1,221 \mathrm{~m}{ }^{\dagger \dagger}\end{array}$ & 61.5 & 15.0 & 3.5 & 2.2 & 1.6 & 5.7 & 3.6 \\
$\begin{array}{l}\text { Cannikin, } \\
1,785 \mathrm{~m}{ }^{\dagger \dagger}\end{array}$ & 48.9 & 14.5 & 7.5 & 5.7 & 8.3 & 4.3 & 0.95 \\
\hline \hline
\end{tabular}

*Glassy volcanic rocks, as reported by White (1983)

$\dagger$ Average of six nuclear melt glass samples, as reported by Smith (1995), with standard deviations in parentheses

$\dagger \dagger$ Analyses of rocks from the working points of the respective tests from Gard (1972)

With the dissolution rate constant given on a per unit surface area basis, the specific surface area is a very sensitive term in the dissolution equation. It is also a parameter that is poorly known from experimental work and wholly unknown for in-situ cavity conditions (Pohll et al., 1998). This uncertainty is addressed by considering a distribution of specific surface areas, leading to a distribution of release rates. The mean value used here, $25 \mathrm{~cm}^{2} / \mathrm{gm}$, is equivalent to the value leading to the glass release used in the evaluation of the French underground tests on Mururoa and Fangataufa (International Advisory Committee Working Group 4, 1998). This value is between two extremes evaluated elsewhere for specific surface area of nuclear melt glass. Essington and Sharp (1968) measured specific surface area for larger particle sizes of nuclear melt glass collected from 
the Rainier test and reported a value of $500 \mathrm{~cm}^{2} / \mathrm{gm}$, but concerns have been raised regarding the lower limit of detection of the instrumentation used at that time. This high specific surface area is used to derive the upper bound on the release rate. Recent work evaluating the melt glass produced by the Cambric test (Tompson et al., 1999) applied studies of nuclear waste glass surface area to postulate much lower values of specific surface area (approximately $0.52 \mathrm{~cm}^{2} / \mathrm{gm}$ ). The lower end of the release rate distribution considered here, $4 \mathrm{~cm}^{2} / \mathrm{gm}$, is conservatively an order of magnitude higher than the Cambric value. The range evaluated here ( 4 to $500 \mathrm{~cm}^{2} / \mathrm{gm}$ ) coincides reasonably well with the range of 10 to $100 \mathrm{~cm}^{2} / \mathrm{gm}$ expected as the recommended range for hydrologic source term modeling in recent research into melt glass surface areas (Bourcier et al., in prep).

The total mass of glass available for dissolution is estimated based on a relationship of 700 metric tons of glass produced per kiloton yield (Smith, 1995), and maximum estimates of $80 \mathrm{kt}$, $1,000 \mathrm{kt}$, and 5,000 kt for Long Shot, Milrow, and Cannikin, respectively (U.S. DOE, 2000). The resultant thousands of metric tons of glass are assumed to have a gram formula weight of $60 \mathrm{gm} / \mathrm{mole}$ and density of $2.65 \mathrm{gm} / \mathrm{cm}^{3}$. The dissolution is calculated iteratively to account for the continual reduction in dissolution as the total surface area is reduced. At each time step of one year, the amount of dissolution is calculated. That lost mass (mass transferred from glass to solution) is then subtracted from the initial mass of that time step to determine the new (reduced) total mass and related (reduced) specific surface area necessary to determine the amount of mass lost in the next time step. As the mass and surface area get smaller, less dissolution occurs with each time step, with that reduction expressed as an exponential decline. Particles are released into the flow field according to an exponential function to approximate the glass dissolution process (this is elaborated in Section 3.3). The release coefficient, $k_{g}$, is the product of the specific surface area, the dissolution rate constant, and the gram formula weight. The derivation of $k_{g}$ from Equation 3.1 is given in Appendix B. This approach for handling glass dissolution assumes adequate flow of groundwater such that saturation with amorphous silica is not reached in the water. If this assumption is violated, even slower dissolution of the puddle glass than used here would result.

Using the mean $k_{g}$ value of $2.44 \times 10^{-7}$ days $^{-1}$, about 50 percent of the glass in the Milrow cavity is calculated to be dissolved after approximately 15,000 years (Figure 3.3). More mass is dissolved in early time, with a trailing tail in later years. At the upper end of the release rate distribution (specific surface area of $500 \mathrm{~cm}^{2} / \mathrm{g}$ and $k_{g}$ of $2.5 \times 10^{-6}$ day $^{-1}$ ), 50 percent of the mass has dissolved after about 600 years, while it requires almost 100,000 years to dissolve half the mass at the lower end of the distribution (specific surface area of $4 \mathrm{~cm}^{2} / \mathrm{g}$ and $k_{g}$ of $1.6 \times 10^{-8} \mathrm{day}^{-1}$ ). The other extreme value of $0.52 \mathrm{~cm}^{2} / \mathrm{g}\left(k_{g}=2.6 \times 10^{-9} \mathrm{day}^{-1}\right)$ used by Tompson et al. (1999) requires hundreds of thousands of years to dissolve half the mass; only 9 percent is dissolved at 100,000 years. These calculations neglect rate-reducing processes such as protection of the glass from additional dissolution by the formation of a mantle of reaction products.

Nuclear melt glass dissolution for underground tests in the Pacific, including the French tests in the South Pacific and the tests at Amchitka, was examined by Smith and Bourcier (1999). Though they selected a higher rate constant than used here, their estimate of surface area was much smaller $\left(0.07 \mathrm{~cm}^{2} / \mathrm{g}\right)$, resulting in an estimate of $6.7 \times 10^{6}$ years to dissolve all the melt glass within 
Amchitka. The rate and specific surface area used in the present study result in dissolution of 98 percent of the glass before 100,000 years, for each test (Figure 3.3). For comparison, Smith and Bourcier (1999) estimate a glass dissolution constant of $7.5 \times 10^{7}$ years for Mururoa and Fangataufa, whereas the IAEA use a glass lifetime of 405,000 years.

\subsection{Retardation}

Radionuclides that are dissolved in groundwater and available for transport are subject to a variety of physical and chemical processes that can retard their movement relative to the movement of water. Together, these processes are referred to as retardation and include ion exchange, adsorption, and surface and bulk precipitation. Sorption and matrix diffusion are powerful retardation mechanisms that need to be incorporated in the transport analysis. The data necessary to consider individual reactions are not available for the Amchitka tests; instead, a bulk sorption approach is used to approximate chemical processes. This approach is limited to equilibrium-controlled processes. Kinetic processes, particularly diffusion, can be important in controlling the rate of other retardation processes and may result in additional significant inhibition of radionuclide transport. The supporting data for sorption, and how it is applied to the modeling, are presented first, followed by a discussion of the treatment of matrix diffusion.

The distribution coefficient, $K_{d}$, is a measure of partitioning of an ion between the solution and the solid under equilibrium conditions. Distribution coefficients were presented for a basalt sample

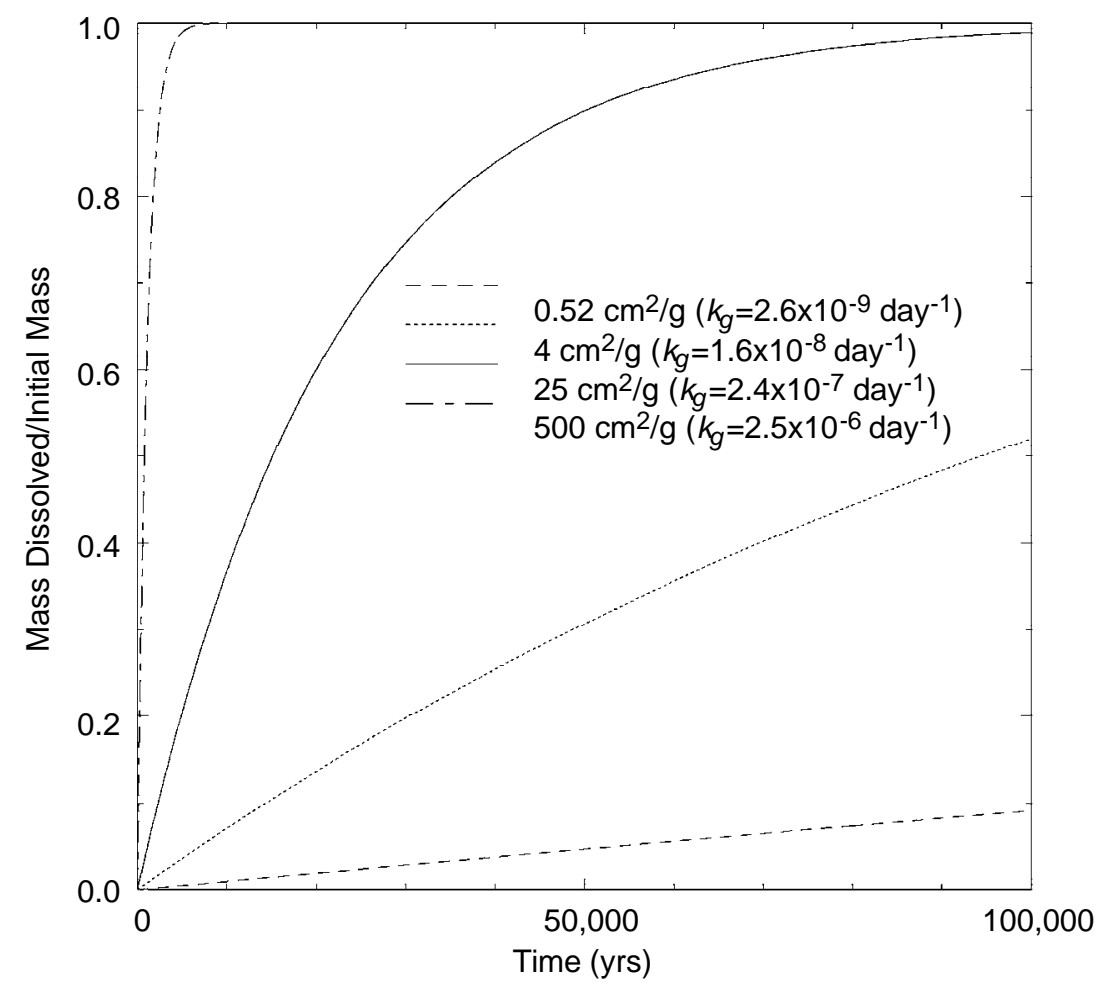

Figure 3.3. Dissolution function for nuclear melt glass, using the parameters described in the text and various values for the specific surface area. 
from Amchitka by Nork and Fenske (1970). They report $K_{d}$ values for $\operatorname{Sr}\left(1.07 \times 10^{-6} \mathrm{~m}^{3} / \mathrm{gm}\right)$ and Cs $\left(6.5 \times 10^{-6} \mathrm{~m}^{3} / \mathrm{gm}\right)$ for the basalt in contact with seawater.

Given the important role such $K_{d}$ values would play in estimating migration, validation and refinement of the sorptive properties of the aquifer matrices of Amchitka are performed through a new series of experiments. The experiments are conducted using cores from Amchitka drillholes with synthetic groundwater based on chemical analyses of groundwater from well UAe-2 from the interval 1,530 to $1,590 \mathrm{~m}$ below land surface. This groundwater is representative of the composition below the transition zone; it is similar to seawater. This is chosen because sorption can be significantly reduced by the competition for reaction sites with higher ionic strength waters, and therefore will result in more conservative (lower) distribution coefficients than experiments with water simulating the freshwater lens. Two aquifer materials are investigated: basalt and breccia. The basalt core is from the Cannikin emplacement well, UA-1, at a depth of 1,819 $\mathrm{m}$. The breccia core is from the same borehole at a depth of $1,885 \mathrm{~m}$.

It is impractical to run individual sorption experiments for all of the elements in the nuclear source term, plus daughter products, especially given the hazardous and controlled nature of many of the elements. Rather, surrogates are identified to approximate the actual source term. Strongly and moderately binding cations (lead and cesium, respectively) are evaluated for their affinity for the different aquifer materials. Previous investigations (Pohll et al., 1998; Pohlmann et al., 1999) also examined anion reactions, but they were found to be relatively insignificant even in freshwater aquifers, so are not included here. Initial work with strontium resulted in dissolution of strontium from the rocks themselves such that it is assumed that no significant sorption would occur and thus no further experiments are performed.

The details of the sorption experiments can be found in Appendix C. In general, the sorptive behavior of the breccia is greater than that of the basalt, consistent with the greater reactive surface area identified in the characterization analyses. Sorption of cesium is essentially non-existent on the basalt material at the high-ionic strength used. Cesium is apparently unable to successfully compete with other cations for exchange sites, consistent with the low sorption reported by Nork and Fenske (1970) for experiments conducted with seawater. Additional scoping experiments at lower ionic strength ( 0.01 molar $\mathrm{NaNO}_{3}$, as opposed to 0.5 molar) confirmed that cesium would sorb under less saline conditions, as would be encountered above the seawater transition zone.

Despite the high ionic strength of the solution, lead is able to sorb onto the aquifer material. The linear and Freundlich isotherm parameters for lead are given in Table 3.4. Non-linearity of the sorption isotherms is not severe, as indicated by the Freundlich parameters, particularly for results in the $\mathrm{pH}$ range of most groundwater samples ( $\mathrm{pH}$ of 7 to 8). Lead sorption is strongly $\mathrm{pH}$ dependent, varying by two orders of magnitude across the $\mathrm{pH}$ range of 6.0 to 9.0. The values of $\mathrm{pH}$ reported for Amchitka groundwater are generally in the range of 6.5 to 9.0 (Beetem et al., 1971). A few groundwater samples have anomalously high $\mathrm{pH}$ measurements, suggestive of contamination during cementing operations. A compilation of data from water samples collected from nuclear cavities and near cavities indicates $\mathrm{pH}$ values near neutral to slightly basic, consistent with regional groundwater in the testing areas (Smith et al., 1997). 
Table 3.4. Linear and Freundlich isotherm parameters for lead sorption. Experimental details and discussion are in Appendix C.

\begin{tabular}{ccccc}
\hline \hline $\mathrm{pH}$ & Rock type & $K_{d}\left(\mathrm{~m}^{3} / \mathrm{gm}\right)$ & $K_{f}(\mathrm{gm} / \mathrm{gm})\left(\mathrm{gm} / \mathrm{m}^{3}\right)^{1 / \mathrm{n}}$ & $1 / \mathrm{n}$ \\
\hline 6.0 & basalt & $2.14 \times 10^{-4}$ & $2.60 \times 10^{-4}$ & 0.77 \\
& breccia & $3.17 \times 10^{-4}$ & $3.19 \times 10^{-4}$ & 0.67 \\
7.0 & basalt & $4.92 \times 10^{-4}$ & $5.75 \times 10^{-4}$ & 0.92 \\
& breccia & $5.87 \times 10^{-4}$ & $5.25 \times 10^{-4}$ & 0.72 \\
\multirow{2}{*}{8.0} & basalt & $1.91 \times 10^{-3}$ & $2.28 \times 10^{-3}$ & 1.06 \\
& breccia & $1.66 \times 10^{-3}$ & $2.09 \times 10^{-3}$ & 0.96 \\
\multirow{2}{*}{9.0} & basalt & $1.59 \times 10^{-2}$ & $8.83 \times 10^{-2}$ & 1.53 \\
& breccia & $1.43 \times 10^{-2}$ & $3.28 \times 10^{-2}$ & 1.32 \\
\hline \hline
\end{tabular}

\subsubsection{Assignment of Distribution Coefficient}

Sorption experiments are only performed for strontium, cesium, and lead. The radionuclide source considered here (Table 3.1) includes many more elements, with the total radionuclide source term even more. Those elements that were not subject to the experiments are assigned $K_{d}$ values by assuming analogous sorptive behavior to those elements with data. This process requires assumptions regarding the likely chemical forms to be found, and obviously includes substantial uncertainty. The resulting sorption assignments are given in Table 3.5.

Table 3.5. Assignment of sorption behavior to radionuclide source elements.

\begin{tabular}{lcc}
\hline \hline Element & No & $\begin{array}{c}\text { Strongly } \\
\text { Sorbing Cation }\end{array}$ \\
\hline $\mathrm{H}$ (Hydrogen) & Sorption & \\
$\mathrm{C}\left(\mathrm{CO}_{3}\right)$ (Carbon) & $\mathrm{X}$ & \\
$\mathrm{Cl}($ Chlorine) & $\mathrm{X}$ & \\
$\mathrm{Kr}$ (Krypton) & $\mathrm{X}$ & \\
$\mathrm{Sr}$ (Strontium) & $\mathrm{X}$ & \\
$\mathrm{Tc}$ (Technetium) & $\mathrm{X}$ & \\
$\mathrm{I}$ (Iodine) & $\mathrm{X}$ & \\
$\mathrm{Cs}$ (Cesium) & $\mathrm{X}$ & $\mathrm{X}$ \\
$\mathrm{Sm}$ (Samarium) & & $\mathrm{X}$ \\
Eu (Europium) & & $\mathrm{X}$ \\
$\mathrm{U}$ (Uranium) & & $\mathrm{X}$ \\
$\mathrm{Np}$ (Neptunium) & & $\mathrm{X}$ \\
Pu (Plutonium) & & $\mathrm{X}$ \\
Am (Americium) & & \\
\hline \hline
\end{tabular}

The laboratory analogue for the strongly sorbing cation is lead. In comparative studies of laboratory sorption data, lead is generally weaker sorbing, often by an order of magnitude, compared to some of the elements assigned here (e.g., U, Pu, Np, Am) (Stenhouse and Pottinger, 1994). 
However, it should be noted that uranium, and to a lesser degree neptunium, had lower sorption affinities under some conditions tested for Yucca Mountain (Triay et al., 1997). The more reduced conditions likely in the deep aquifers at Amchitka can be expected to promote stronger sorption affinity as compared to the oxidized unsaturated zone at Yucca Mountain. No sorption is applied for strontium and cesium, based on the laboratory study, nor for hydrogen (tritium), carbon, chlorine, krypton, technetium, or iodine, based on their characteristics and previous studies.

To follow the in-growth of daughters along decay chains, it is necessary in the modeling process to use the same sorption behavior assigned to the parent for the daughter because radioactive decay (and daughter ingrowth) are handled in post-processing (individual radionuclides are not tracked during transport, only six solute classes as discussed in the modeling section). In one case, this causes a retardation assignment that is contrary to the expected behavior: ${ }^{85} \mathrm{Rb}$ would be expected to be strongly sorbing, but instead is modeled with no retardation due to the behavior of its parent, ${ }^{85} \mathrm{Kr}$. This is a conservative assumption that leads to overestimating the concentrations and fluxes of ${ }^{85} \mathrm{Rb}$.

\subsubsection{Calculation of Retardation Factor}

Despite the relatively large porosity indicated for the Amchitka formations from core data, the conceptualization of the aquifer considers the bulk of the flow to be through fractures. The dimensionless retardation factor $(R)$ in cases of fast reversible adsorption with a linear isotherm can be represented for fracture flow conditions by:

$$
R=1+\frac{K_{a}}{b}
$$

where $K_{a}[\mathrm{~L}]$ is a surface-based sorption constant $\left(K_{a}=K_{d} / A_{s p}\right)$ and $b[\mathrm{~L}]$ is the mean fracture half-aperture (Freeze and Cherry, 1979; Moreno et al., 1988; Frick et al., 1991). Equation (3.2) is only valid for fractured materials in which the porosity of the solid mass between fractures is insignificant (Freeze and Cherry, 1979), an assumption that may well be violated based on the porosity measurements for the core.

Estimating a partitioning coefficient from the lead sorption experiments using basalt and breccia as sorbents under $\mathrm{pH}$ conditions ranging from 6 to 9 , a $K_{d}$ of $1 \times 10^{-3} \mathrm{~m}^{3} / \mathrm{gm}$ and an $A_{s p}$ of $2.4024 \mathrm{~m}^{2} / \mathrm{g}$ are used to calculate a $K_{a}$ of approximately $4 \times 10^{-4} \mathrm{~m}$. No measurements exist for the fracture half-aperture, $b$. Scoping transport calculations for the NTS estimated fracture apertures for permeable tuffs to range from $2 \times 10^{-4}$ to $6 \times 10^{-4} \mathrm{~m}$ (GeoTrans, 1995). Fracture apertures at Yucca Mountain are estimated from $6 \times 10^{-6}$ to $6.7 \times 10^{-5} \mathrm{~m}$ (Peters et al., 1984). Snow (1968) evaluated igneous and metamorphic rocks to $120 \mathrm{~m}$ depth and concluded that openings larger than $4 \times 10^{-5} \mathrm{~m}$ would be unusual. The IAEA used a fracture aperture of $1 \times 10^{-3} \mathrm{~m}$ in the South Pacific work. The same aperture value of $1 \times 10^{-3} \mathrm{~m}$ is used here (half-aperture of $5 \times 10^{-4} \mathrm{~m}$ ). Using these values yielded a retardation coefficient for strongly sorbing cations (lead) of approximately 1.8 .

When retardation occurs within the matrix blocks, it is represented by the following equation (Freeze and Cherry, 1979): 


$$
R_{\mathrm{m}}=1+\frac{\rho_{\mathrm{b}}}{\theta_{m}} K_{d}
$$

where $R_{m}$ is the dimensionless retardation coefficient in the matrix blocks, $K_{d}\left[\mathrm{~L}^{3} / \mathrm{M}\right]$ is the distribution coefficient, $\mathrm{Q}_{\mathrm{b}}$ is the bulk density $\left[\mathrm{M} / \mathrm{L}^{3}\right]$, and $\theta_{m}$ is matrix porosity. A bulk density of $2.3 \mathrm{gm} / \mathrm{cm}^{3}$ is used, based on 99 measurements on core material from UAe-2, UAe-1, UAe-3, and UAe-6 (Lee, 1969a,b,c,d). This value is representative of the bulk density of the breccia formations; the basalt density is higher $\left(2.5 \mathrm{gm} / \mathrm{cm}^{3}\right)$ and would lead to a larger retardation value. The porosity used is also based on core measurements, a value of 0.12 , the mean of 149 core measurements for the deeper Kirilof Point and Older Breccias formations. Given that the matrix retardation formulation leads to high values of $\mathrm{R}$, a partitioning coefficient half of that used in the fracture retardation is applied here, $5 \times 10^{-4} \mathrm{~m}^{3} / \mathrm{gm}$, which is still within the range of experimental results. These parameter values lead to an $R_{m}$ value of approximately 9,000 .

\subsubsection{Matrix Diffusion}

Matrix diffusion is a potentially important mass transfer process by which solutes are removed from high-velocity fracture flowpaths into the surrounding matrix. With the decay of radionuclides, long residence times in the rock matrix actually reduce the mass of contaminant, as well as retard the effective velocity. The numerical approach for simulating matrix diffusion is presented in a later section, while the parameter values are discussed here. The matrix diffusion parameter, $\kappa$, used here is defined as

$$
\kappa=\frac{\theta_{m} \sqrt{D_{m}^{*} R_{m}}}{b}
$$

where $D^{*}{ }_{\mathrm{m}}\left(\mathrm{L}^{2} / \mathrm{T}\right)$ is an effective diffusion coefficient in the rock matrix, $b(\mathrm{~L})$ is the fracture half-aperture, $\theta_{m}\left(\mathrm{~L}^{3} / \mathrm{L}^{3}\right)$ is the rock matrix porosity, and $R_{m}$ is the dimensionless retardation coefficient in the rock matrix. The approach to calculating $R_{m}$ for sorbing radionuclides is described in the previous section. The approach used for estimating $\kappa$ is to derive the best estimate based on available information, then consider conservatively lower values to address both data uncertainty as well as model assumptions (such as an infinite matrix, as discussed in the approach section).

Matrix diffusion can be expected to be a significant transport process through the volcanics at Amchitka because the porosity of the matrix blocks is relatively high. Core measurements on 197 samples from Amchitka boreholes have a mean porosity of 0.14 with a standard deviation of 0.07 , with the deeper units (Kirilof Point and Older Breccias) having an only slightly lower mean at 0.12.

Effective diffusion coefficients are measured on cores from Amchitka, with the details provided in Appendix C. For the conservative ion, bromide, the measurements range from $1.72 \times 10^{-6} \mathrm{~cm}^{2} / \mathrm{s}$ to $9.23 \times 10^{-6} \mathrm{~cm}^{2} / \mathrm{s}$. Diffusion coefficients for basically non-sorbing species in materials from Yucca Mountain and the NTS range from $1.0 \times 10^{-7}$ to $3.5 \times 10^{-6} \mathrm{~cm}^{2} / \mathrm{s}$ (Triay et al., 1993; Walter, 1982). These experiments were conducted with fresh surfaces of various volcanic lithologies and involved matrix porosities between 0.06 and 0.4 . The recent tracer experiments in the fractured lavas at the 
Bullion site on the NTS resulted in estimates of diffusion coefficients of $1.4 \times 10^{-7}$ to $1.9 \times 10^{-7} \mathrm{~cm}^{2} / \mathrm{s}$ (IT Corp., 1998). The diffusion of tritiated water through saturated devitrified tuffs is found to be on the order of $10^{-6} \mathrm{~cm}^{2} / \mathrm{s}$, while large anions that are excluded from tuff pores due to size and charge still record diffusion coefficients on the order of $10^{-7} \mathrm{~cm}^{2} / \mathrm{s}$ (Triay et al., 1997). The IAEA, in its evaluation of radionuclide diffusion into volcanics at the South Pacific French underground testing sites, used a diffusion coefficient of $1 \times 10^{-7} \mathrm{~cm}^{2} / \mathrm{s}$ (IAEA, 1998).

As in the retardation calculation, the fracture half-aperture probably presents the largest uncertainty in the matrix diffusion calculation. Larger fracture apertures are more conservative in the calculation (inhibit matrix diffusion), but are difficult to justify at depths of hundreds of meters due to overburden pressure. A half-aperture of $5 \times 10^{-4} \mathrm{~m}$ is used for the diffusion calculations, implying fracture openings of one millimeter at depths in excess of $1,000 \mathrm{~m}$.

Combining the values described above leads to a matrix diffusion parameter, $\kappa$, of 1.37 day $^{-1 / 2}$ for nonsorbing solutes $\left(\theta_{m}\right.$ of $0.12, D_{\mathrm{m}}^{*}$ of $3.27 \times 10^{-5} \mathrm{~m}^{2} /$ day, $b$ of $\left.5 \times 10^{-4} \mathrm{~m}\right)$, and a $\kappa$ of 130 day $^{-1 / 2}$ for strongly sorbing cations (including the $R_{m}$ of 9,000). The parametric uncertainty analysis of the transport modeling considers a minimum $\kappa$ of $0.0394 \mathrm{day}^{-1 / 2}$, maximum of $1.37 \mathrm{day}^{-1 / 2}$, with a mean of 0.352 day $^{-1 / 2}$ for nonsorbing solutes. The upper end of this range is equivalent to the best estimate derived above, and the lower end is almost two orders of magnitude lower.

In the main transport modeling stage, $\kappa$ is not varied and is assigned the value of 0.434 day $^{-1 / 2}$ for nonsorbing solutes. This is consistent with the parameters above, except the diffusion coefficient is taken an order of magnitude lower $\left(\theta_{m}\right.$ of $0.12, D^{*}{ }_{\mathrm{m}}$ of $3.28 \times 10^{-6} \mathrm{~m}^{2} / \mathrm{day}, b$ of $\left.5.0 \times 10^{-4} \mathrm{~m}\right)$. Strongly sorbing cations are assigned a $\kappa$ value of 41 day $^{-1 / 2}$, consistent with an $R_{m}$ of 9000 . As presented later in the report, a sensitivity scenario was evaluated using a $\kappa$ value for nonsorbing solutes of 0.0434 day $^{-1 / 2}$. In this sensitivity analysis, sorbing solutes are also considered $\left(R_{m}\right.$ of $9000)$, using a $\kappa$ of 4.117 day $^{-1 / 2}$.

\subsection{Solving the Contaminant Transport Problem}

Transport of a nonreactive solute in saturated porous media of constant porosity is described by:

$$
\frac{\partial C(\boldsymbol{X}, t)}{\partial t}+\nabla \cdot[C(\boldsymbol{X}, t) V(\boldsymbol{X})]-\nabla \cdot[\mathbf{D}(\boldsymbol{X}) \nabla C(\boldsymbol{X}, t)]=0
$$

where $C(X, t)$ represents concentration, $\boldsymbol{V}(\boldsymbol{X})$ is the velocity vector at location $\boldsymbol{X}$ and $\mathbf{D}(\boldsymbol{X})$ represents the diagonal of the local hydrodynamic dispersion tensor. The components of $\mathbf{D}(\boldsymbol{X})$ are given as (Bear, 1972)

$$
\mathrm{D}_{i j}=\delta_{i j} \alpha_{T}|V|+\left(\alpha_{L}-\alpha_{T}\right) \frac{V_{i} V_{j}}{|V|}+\delta_{i j} D^{*}
$$

where $\delta_{\mathrm{ij}}$ is the Kroneker delta $\left(\delta_{i j}=1\right.$ for $i=j$ and $\delta_{i j}=0$ for $\left.i \neq j\right), \alpha_{L}$ and $\alpha_{T}$ are the longitudinal and transverse local dispersivities, $|\boldsymbol{V}|$ is the magnitude of velocity, and $D^{*}$ is the effective coefficient of molecular diffusion. 
Several numerical approaches can be used to solve the transport equation, for example, finite differences, finite elements, method of characteristics, and random walk particle-tracking methods. In this study, the random walk method is used to simulate the transport and evolution of radionuclides in the generated random velocity fields. The injected mass is replaced with a large number of particles $N P$ of equal mass $m$ that are tracked in the space-time domain. The initial mass is assumed to be unity and is represented by 20,000 particles in all the transport simulations.

The positions of the particles are updated at each time step according to the random walk equation (Kinzelbach, 1988; Tompson and Gelhar, 1990)

$$
\begin{aligned}
\boldsymbol{X}_{t+\Delta t}= & \boldsymbol{X}_{t}+\left[V\left(\boldsymbol{X}_{t}, t\right)+\nabla \cdot \mathbf{D}\left(V\left(\boldsymbol{X}_{t}, t\right)\right)\right] \Delta t+ \\
& {\left[2 \boldsymbol{D}\left(V\left(\boldsymbol{X}_{t}, t\right)\right) \Delta t\right]^{1 / 2} \cdot \boldsymbol{Z}+\frac{\boldsymbol{D}\left(V\left(\boldsymbol{X}_{t}, t\right)\right)}{\theta} \nabla \theta }
\end{aligned}
$$

where $\boldsymbol{X}_{t+\Delta t}$ is the updated position of the particle that was at $\boldsymbol{X}_{t}$ in the previous time step, $V\left(\boldsymbol{X}_{t}, t\right)$ is the velocity vector at the old position at time $t, \mathbf{D}$ is the local-scale dispersion tensor, $\Delta t$ is the time step, $\theta$ is the spatially varying porosity (between cavity/chimney and the surrounding rock), and $\mathbf{Z}$ is a vector of normally distributed random numbers of zero mean and unit variance. The first term on the right-hand side of Equation (3.7) represents the advective step and the second term adds the effect of the gradients of the dispersion tensor on the particle movement. This latter term is important if sharp fronts exist and whenever the gradient of $\mathbf{D}$ is significant. The term involving the porosity gradient accounts for the porosity variability in the modeled domain. The last term represents the contribution of local-scale dispersion and Brownian diffusion to the movement of the particles.

The need for incorporating the gradient terms for the dispersion coefficient and porosity in Equation (3.7) arises due to the spatial variability of the two parameters within the modeled domain. These gradient terms assume that this variability is sufficiently smooth that one can define these gradients at any point in space. However, when abrupt changes occur in space, as is the case here due to the cavity and chimney formation, these gradients cannot be defined at the interfaces between varying blocks. An alternative to computing these gradient terms was recently proposed by La Bolle et al. (2000), where they developed a stochastic partial differential equation that is valid for discontinuous properties such as dispersion and porosity. They also integrated these equations with the random walk particle-tracking method, which resulted in an algorithm that avoids the computation of gradient terms. We show in Section 6 the details of this modified approach and compare it to the traditional gradient-based approach (Equation 3.7). It was found that the modified approach, which is believed to be more accurate, leads to lower mass flux compared to using Equation (3.7), and as such we remain conservative and use Equation (3.7) throughout this report.

The output velocity fields of the FEFLOW solution are obtained at an irregular finite element mesh. However, for convenience and simplicity in computations, the velocity values are interpolated on a uniform grid. The particle velocities needed in the above equation are then obtained by using a bilinear interpolation scheme using the velocities at the four grid points surrounding the particle location. The numerical issues and accuracies associated with this interpolation are discussed and evaluated in detail in Section 6. 
The nuclides are assumed to all be located within the cavity. In the case of Long Shot, this equates to four grid cells in the cross-sectional model; four at Milrow, and nine at Cannikin. Since the radionuclides are divided among surface deposits that can be released via hydraulic release and volume deposits, which are trapped in a puddle glass, the treatment of particles representing both categories is different. Assume that $p$ is the percentage of mass released hydraulically, and thus 1- $p$ represents the mass in the glass. If the total number of particles is $N P$, then a number of particles equal to $p \times N P$ is released instantaneously (at time 0 , which is equivalent to the test date) into the flow field and is subject to all the processes involved (advection, local dispersion, retardation, etc.). Particles in the glass, (1-p) NP, are released in patches according to the glass release coefficient, $k_{g}$ $\left(\mathrm{T}^{-1}\right)$ (see Appendix B). Therefore, the number of particles released at any time, $t>0$, is obtained from the expression

$$
N P_{G}^{t}=[(1-p) N P] *\left[\left(1-e^{-k_{g} t}\right)-\left(1-e^{-k_{g}(t-\Delta t}\right)\right]
$$

where $N P_{G}^{t}$ is the number of particles released from the puddle glass at time $t>0$. At time $t=0$, no particles are released from glass and only those released via hydraulic equilibrium are allowed to move with the flow field. Figure 3.4 depicts the number of particles released at every time step for a scenario of $95 / 5$ glass/hydraulic release and a total number of particles of 20,000. The value of the glass dissolution rate, $k_{g}$, in this figure is $1.17 \times 10^{-7}$ day $^{-1}$. The top plot of Figure 3.4 shows that the number of particles released at $t=0$ (denoted by the square symbol) is 1,000, which represents the hydraulic release $(0.05 \times 20,000)$. No particles are released from the puddle glass at this time. After one time step (e.g., 40,000 days), an initial patch of particles is released from the glass and is equivalent to about 860 particles. This number decreases exponentially until all the mass is released. As the time progresses, the glass dissolution decreases and thus the number of particles released to the flow field becomes smaller. The lower plot in Figure 3.4 shows the cumulative sum of the particles released at any time. After about 200 time steps (21,900 years), almost all the particles representing the glass were released. However, the transport simulations in the second modeling stage focus on a time scale of about 2,200 years, which is found to encounter the peak mass flux and concentration for most of the cases considered. This implies that only a very small portion of the mass trapped in puddle glass is released to the system and the rest contributes to the mass flux and concentration values at a much later time. Radioactive decay associated with these long times does not allow for a higher peak flux than what occurs within the first 2,200 years.

Using the particle distribution at every time step, three types of information are obtained. First, the total mass-flux breakthrough, $Q(t)$, is obtained for the control plane, which is taken to be the seafloor described by the bathymetric profile. The total mass crossing that boundary is computed at every time step and then normalized by the initial injected mass, $M_{0}$, to yield the total relative mass flux as a function of time. The second type of information represents the normalized point solute flux crossing the seafloor as a function of location and time, $q(x, t)$. Figure 3.5 shows the conceptualization of the transport scenario and the computation of the total and point mass flux. The particles are released from the cavity by either hydraulic release or glass dissolution. They are subjected to advection, dispersion, retardation, matrix diffusion and radioactive decay. When they 

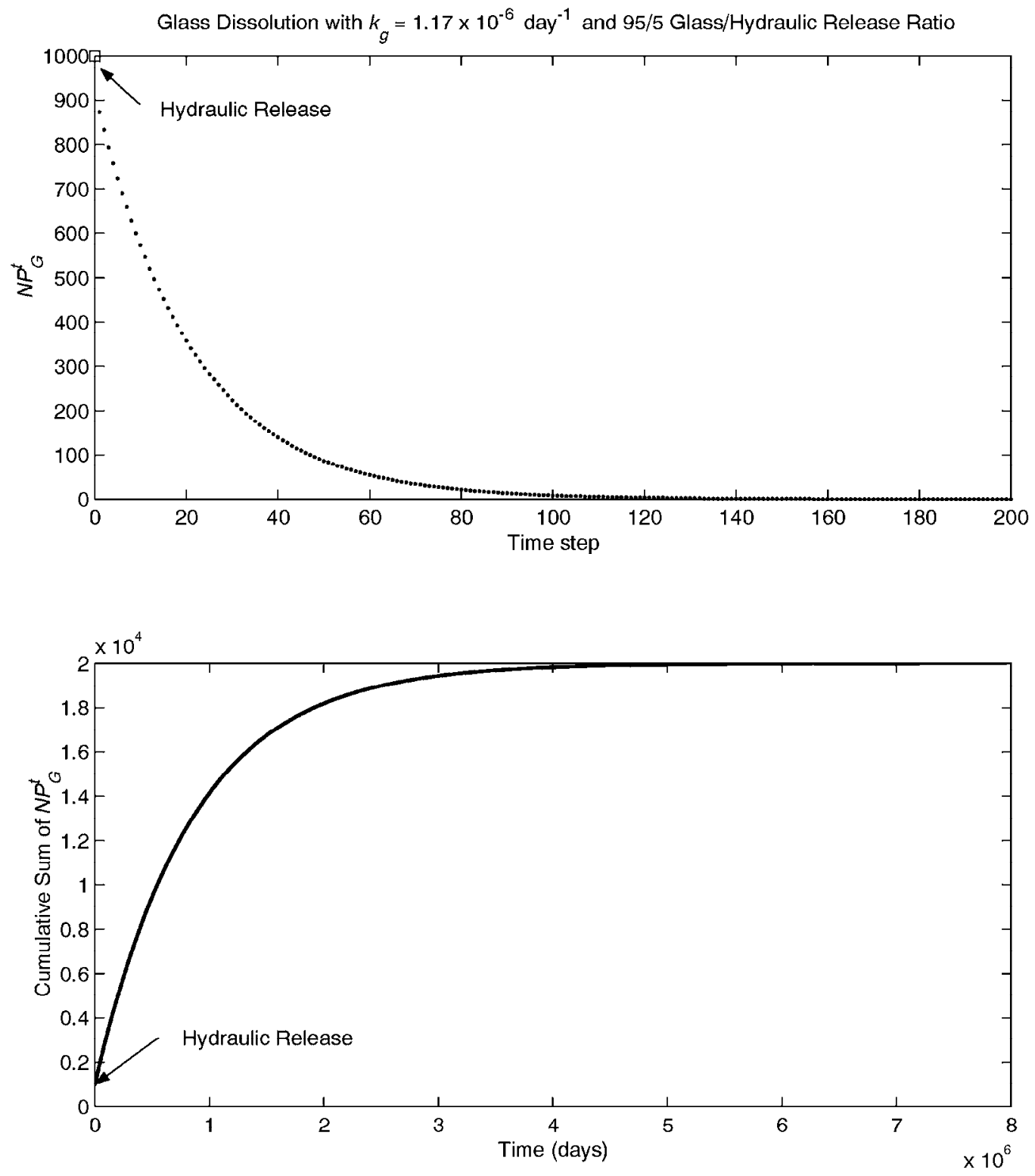

Figure 3.4. Release of particles by glass dissolution rate. The square symbol indicates the number of particles released hydraulically, the top plot indicates the number of particles released at each time step and the bottom plot shows the cumulative sum of the numbers released from time zero to any time $t$.

reach and break through the seafloor, the point solute flux is computed at segments $40 \mathrm{~m}$ in length. Adding all these fluxes at all locations, $x$, along the bathymetric profile gives the total solute flux as a function of time.

The flux-averaged concentration at these segments is also obtained as a third type of information. One only needs to know the groundwater flux at each of these segments to convert the point mass flux to flux-averaged concentration. The point solute flux is related to the flux-averaged 


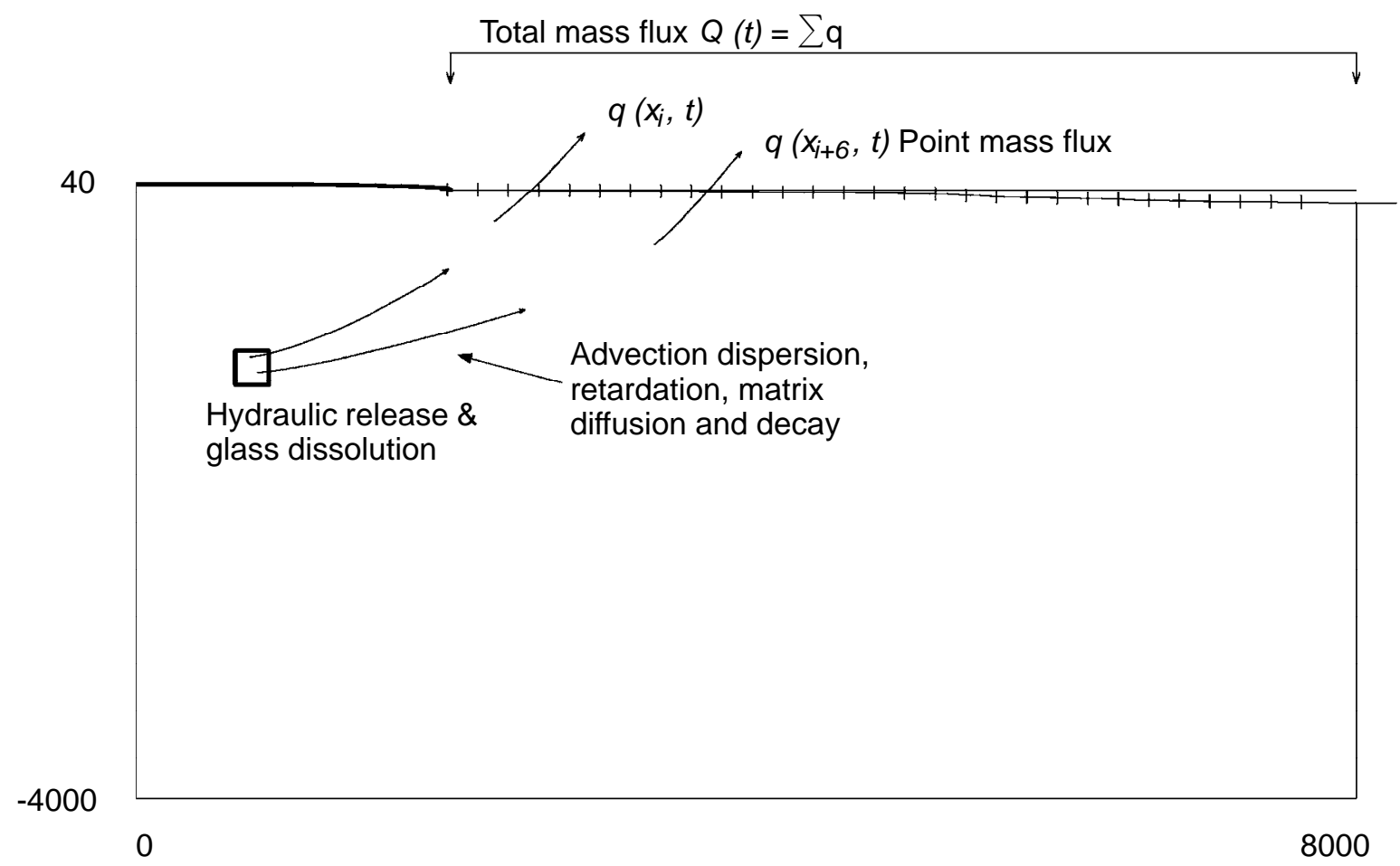

Figure 3.5. Conceptualization of the transport processes and computation of mass flux across the seafloor.

concentration by dividing the former with the groundwater flux (e.g., Kreft and Zuber, 1978; Dagan et al., 1992). The flux-averaged concentration is consistent with common procedures for measuring concentrations in laboratory columns, and in soils, as well as in aquifers (e.g., Kreft and Zuber, 1978; Shapiro and Cvetkovic, 1988). This concentration is then normalized relative to the initial concentration, $C_{0}$. The latter is obtained by dividing the initial unit mass by the water volume within the cavity $\left(\Delta \mathrm{x}_{\text {cavity }}{ }^{*} \Delta \mathrm{y}_{\text {cavity }} * 1.0 * 0.07\right)$, where a unit width along the shoreline is assumed and the 0.07 cavity porosity is employed.

For these temporal and spatial-temporal breakthrough results, the outputs are averaged over the ensemble of realizations and statistically analyzed to obtain the mean and the standard deviation. These results are symbolized as $\left\langle Q(t)>/ M_{0}, \sigma_{Q} / M_{0}\right.$ for the total solute flux, $\left\langle q(x, t)>/ M_{0}, \sigma_{q} / M_{0}\right.$ for the point solute flux, and $\left\langle C(x, t)>/ C_{0}, \sigma_{C} / C_{0}\right.$ for the flux-averaged concentration. These undecayed moments will be the same for all nuclides in a given solute class that represents a particular combination of hydraulic/geochemical release ratios and retardation factors. The moments are subsequently decayed for individual nuclides based on their half-lives using the formula

$$
\left[\mu_{d}(t)\right]_{i}=[\mu(t)] e^{-(\ln 2) t / \omega_{i}}
$$

where $\left[\mu_{d}(t)\right]_{i}$ is the decayed moment (mean or standard deviation) for nuclide $i$ at time $t,[\mu(t)]$ is the undecayed moment for the scenario to which nuclide $i$ belongs, $\omega_{i}$ is the half-life of nuclide $i$ in days, and $t$ is the time at which moment is computed in days. 
For the general case of the decay of a parent isotope $\left(\mathrm{N}_{1}\right)$ to a radioactive daughter $\left(\mathrm{N}_{2}\right)$, which decays to a second daughter $\left(\mathrm{N}_{3}\right)$ through the final daughter $\left(\mathrm{N}_{\mathrm{n}}\right), \mathrm{N}_{1} \rightarrow \mathrm{N}_{2} \rightarrow \mathrm{N}_{3} \ldots \mathrm{N}_{\mathrm{n}}$, the solution giving the number of atoms of any member of the decay series as a function of time and assuming zero initial mass for the daughters $\left(\mathrm{N}_{2}{ }^{0}=\mathrm{N}_{3}{ }^{0}=\ldots \mathrm{N}_{\mathrm{n}}{ }^{0}=0\right)$ has the form (Faure, 1977):

$$
\mathrm{N}_{\mathrm{n}}=\epsilon_{1} \mathrm{e}^{-\lambda_{1} \mathrm{t}}+\epsilon_{2} \mathrm{e}^{-\lambda_{2} \mathrm{t}} \ldots+\epsilon_{\mathrm{n}} \mathrm{e}^{-\lambda_{\mathrm{n}} \mathrm{t}}
$$

where the coefficients $\left(\epsilon_{\mathrm{n}}\right)$ are defined as:

$$
\begin{aligned}
& \epsilon_{1}=\frac{\lambda_{1} \lambda_{2} \ldots \lambda_{\mathrm{n}-1} \mathrm{~N}_{1}^{0}}{\left(\lambda_{2}-\lambda_{1}\right)\left(\lambda_{3}-\lambda_{1}\right) \ldots\left(\lambda_{\mathrm{n}}-\lambda_{1}\right)} \\
& \epsilon_{2}=\frac{\lambda_{1} \lambda_{2} \ldots \lambda_{\mathrm{n}-1} \mathrm{~N}_{1}^{0}}{\left(\lambda_{1}-\lambda_{2}\right)\left(\lambda_{3}-\lambda_{2}\right) \ldots\left(\lambda_{\mathrm{n}}-\lambda_{2}\right)}
\end{aligned}
$$

and $\lambda_{n}$ is the decay rate for radionuclide $N_{n}$. In a case where the initial mass of the daughter radionuclide is not zero (i.e., the radionuclide is also present in the original source), the source mass and the daughter's mass are calculated separately and summed afterward.

The above description of transport modeling applies for the porous medium approach. As discussed earlier in Section 2.1.7, the flow system is conceptualized as a fracture flow system with high velocity in the fractures that separate adjacent porous blocks. The approach we employ is a continuum approach in the sense that discrete fractures are not considered in space, but instead, effective fracture properties (high conductivity and low porosity) are assigned to the discretized domain blocks. Therefore, particles are tracked in space in the same manner as for a porous medium, but they experience the very high fracture velocity within each block. Therefore, for the analysis of transport in a fractured system, the same undecayed moments (mass flux and concentration mean and standard deviation) are obtained. However, before applying the decay analysis to these moments, matrix diffusion is accounted for using the solute flux analytical solution presented by Cvetkovic and Dagan (1994) and Cvetkovic et al. (1999). The breakthrough curves for total mass flux with matrix-diffusion effect can be obtained from

$$
Q_{m d}(t)=\int_{0}^{\infty} \gamma(t, \tau) Q(\tau) d \tau
$$

where $Q(\tau)$ is the undecayed mass flux at time $\tau, Q_{m d}(t)$ is the mass flux after accounting for matrix diffusion, and $\gamma(t, \tau)$ is the retention function that incorporates the effect of mass transfer between the fracture and the rock matrix. This retention function is given as (Cvetkovic and Dagan, 1994; Cvetkovic et al., 1999)

$$
\gamma(t, \tau)=H(t-\tau) \frac{\kappa \tau}{2 \sqrt{\pi}(t-\tau)^{3 / 2}} e^{-\frac{(\kappa \tau)^{2}}{4(t-\tau)}}
$$

where $H$ is the dimensionless Heaviside function, $\tau$ is the particle travel time (days), $t$ is the time (days) at which the flux is obtained after accounting for matrix diffusion, and $\kappa$ is the matrix 
diffusion parameter $\left(\right.$ days $\left.^{-1 / 2}\right)$ defined as $\kappa=\frac{\theta_{m} \sqrt{D_{m}^{*} R_{m}}}{b}$. Here $\theta_{m}$ is the matrix porosity, $b$ is the effective half aperture $(\mathrm{m}), D_{m}^{*}$ is the effective diffusion coefficient in the rock matrix $\left(\mathrm{m}^{2} /\right.$ day) and $R_{m}$ is the dimensionless retardation coefficient in the rock matrix. The main assumptions underlying the derivation of the above analytical retention function are a constant aperture along the streamtube, diffusion only perpendicular to the fracture plane, well-mixed conditions over the cross-sectional area of the fracture, and homogeneous, infinite rock matrix with no advection. The radioactive decay can also be incorporated in the retention function. To do so, an additional term, $\exp (-t \ln 2 / \omega)$ should be multiplied by the right-hand side of the $\gamma$ expression, with $\omega$ being the half-life.

In summary, a non-decayed breakthrough curve is obtained by the random walk particle tracking method and then convoluted with a retention function that accounts for matrix diffusion (e.g., Cvetkovic and Dagan, 1994; Cvetkovic et al., 1999). This approach treats the fractured system as a stochastic continuum. The retention function, however, is derived for discrete fractures. There is, therefore, some inconsistency in this analysis as the discrete and continuum approaches are mixed. However, this is not unreasonable and it has been used in many European studies dealing with safety analysis and risk assessment (e.g., NAGRA, 1994; Cvetkovic, personal communication).

A crucial assumption underlying this analysis relates to the availability of the rock matrix and the rate of diffusion from the fractures into the rock matrix. It is usually assumed that the rock matrix availability for diffusion is unlimited and that the diffusion rate is constant at all times. In other words, the semi-analytical solution employed here does not allow for rock saturation and ceasing of matrix diffusion. The matrix diffusion continues for as long as there are contaminants moving through the fractures. That may not be true for the actual field situation. Depending on the intensity of fractures, the rock matrix may have a limited capacity to absorb contaminants from the fractures and may reach a level of saturation that prevents any further diffusion into it. There is, therefore, the concern that the transport predictions may overestimate the diffusion into the matrix and thus give lower fluxes and concentrations than what might be the case in the field. Three factors alleviate this concern. First, the matrix diffusion values used to produce the transport results are at least one order of magnitude lower than the best estimate. Secondly, radioactive decay will remove mass from the matrix blocks, particularly for shorter-lived nuclides. Thirdly, the conceptualization of fracture flow at depths exceeding 1,000 m below ground surface may represent an overestimation of the flow velocities at that depth. Fractures tend to close up at large depths due to the overburden pressure and this then may change the flow system from a fractured to a continuum porous medium. For porous medium flow with a porosity three orders of magnitude larger than the fracture porosity, residence times become very long and radioactive decay inhibits breakthrough of most radionuclides with short and moderate half-lives. 


\section{PARAMETRIC UNCERTAINTY ANALYSIS}

The purpose of the parametric uncertainty analysis is to identify which parameters are important to treat as uncertain in the flow and transport modeling. As previously discussed, uncertainty in parameter values and the need to include that uncertainty in the risk assessment prohibit a deterministic approach to the modeling. Despite this, if uncertainty in a given parameter has a minimal impact on the results, the value of including it in the Monte Carlo process is outweighed by the additional computational effort. To optimize the modeling process, a parametric uncertainty analysis was performed to identify which parameters to carry forward as uncertain and which to set as constant, best estimate, values. This analysis was performed for the Milrow site. Though the different locations of the three test cavities relative to the transition zone might be expected to lead to somewhat different results, the final parameters identified as important for Milrow coincide with those expected to be most important based on hydrogeologic principles.

The processes evaluated through their flow and transport parameters include recharge, saltwater intrusion, radionuclide transport, glass dissolution, and matrix diffusion. The end result of this analysis is a relative comparison of the effect of uncertainty of each individual parameter on the final transport results in terms of the arrival time of mass of radionuclides crossing the seafloor. First to be considered is the density-driven flow problem associated with saltwater intrusion, and the parameters affecting this process are denoted as the flow parameters. Second is the radioactive transport problem, where the movement of radionuclides from the test cavity to the seafloor is studied and the parameters of concern in this process are denoted as transport parameters.

\subsection{Sensitivity/Uncertainty Analysis of Flow Parameters}

The parameters of concern here are the hydraulic conductivity, $K$, the recharge, Rech, and the longitudinal and transverse macrodispersivities, $A_{L}$ and $A_{T}$. Since the saltwater intrusion problem encounters a density-driven flow, the macrodispersivities are considered as flow parameters. In addition, the porosity is also considered at this stage as the spatial variability of porosity between the chimney and the surrounding area affects the solution of the saltwater intrusion problem. In all cases, the flow and the advection-dispersion equations are solved simultaneously until a steady-state condition is reached. The solution provides the groundwater velocities and the concentration distribution that can be used to identify the location and thickness of the transition zone. For each of the four parameters, a random distribution of 100 values below and above a "mean" value close to the calibration result is generated. Figure 4.1 shows the histograms for Rech, $K, \theta$, and $A_{L}$. The transverse macrodispersivity, $A_{T}$, is taken as $A_{L} / 10$, as is commonly assumed in transport modeling. As can be seen from the figure, the distribution of random recharge values covers a range of values extending from one-fourth the calibrated value to about double that value. A lognormal distribution was used to generate the recharge values and the distribution was truncated such that the upper and lower limits lead to reasonable transition zone movement around the location indicated by the chemistry data. From the 100 random values, the minimum recharge value is about $0.328 \mathrm{~cm} / \mathrm{year}$ and the maximum is about $2.205 \mathrm{~cm} / \mathrm{year}$. This range lies within the recharge estimates obtained using temperature logs as discussed in Section 2.6.1. 

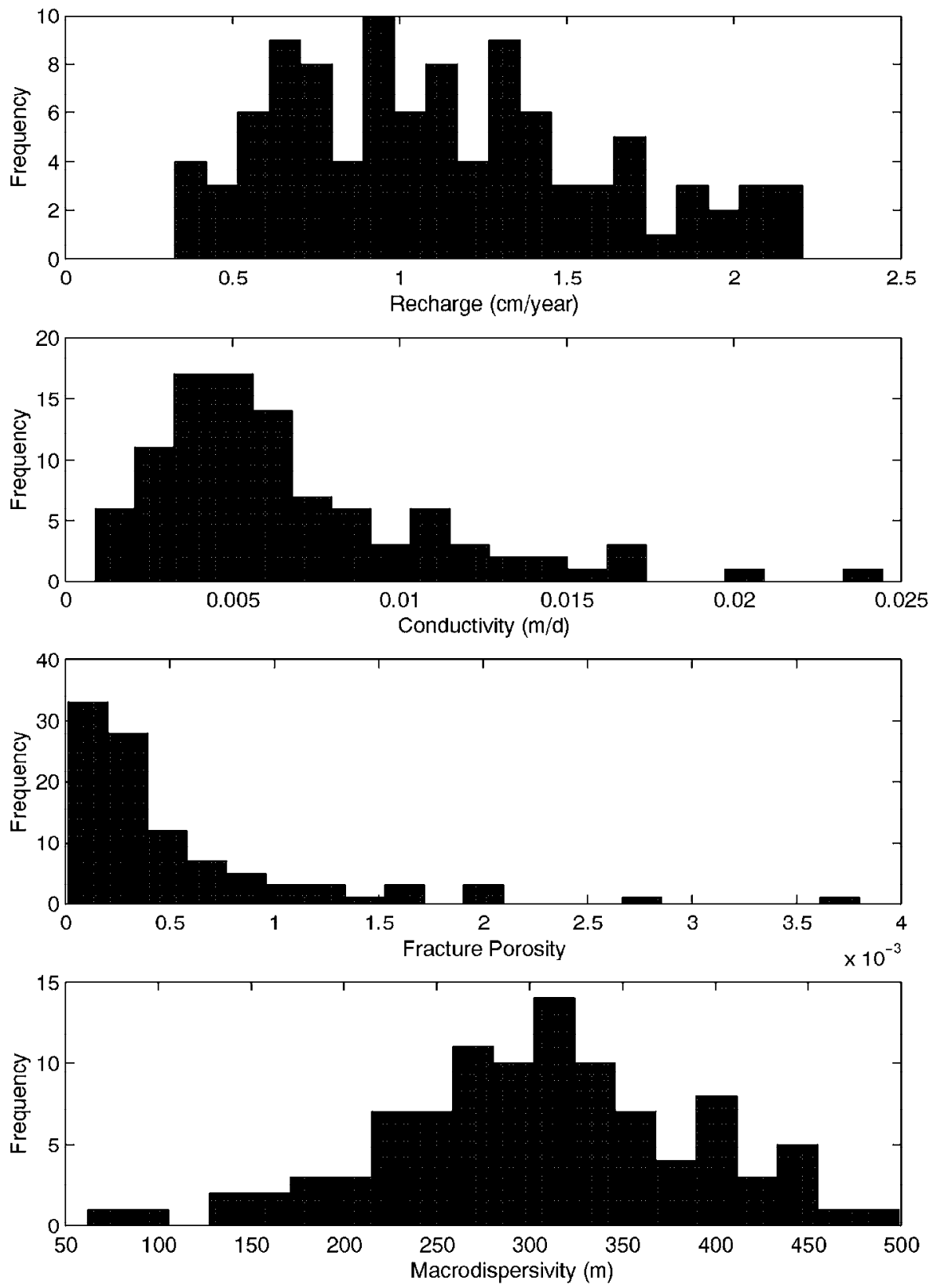

Figure 4.1. Randomly generated distributions for the parameters governing the solution to the flow problem. These distributions are used for the individual-parameter uncertainty analysis. 
The uncertain conductivity values are generated from a lognormal distribution and have a mean value of $6.773 \times 10^{-3} \mathrm{~m} / \mathrm{day}$, which is equivalent to the Milrow calibration value and it also lies between the geometric and arithmetic means of the conductivity data. These means for the full data set are $1.862 \times 10^{-3}$ and $1.137 \times 10^{-2} \mathrm{~m} /$ day, respectively. If an average value is computed for each of the six wells, these mean values become $1.9953 \times 10^{-3}$ and $1.575 \times 10^{-2} \mathrm{~m} /$ day. In both cases, the mean of the generated random distribution lies between the geometric and the arithmetic means. The maximum conductivity value among the generated 100 values is $2.445 \times 10^{-2} \mathrm{~m} /$ day, whereas the minimum value is $1.5 \times 10^{-3} \mathrm{~m} /$ day. This range is considered sufficient to yield realistic results. That is, by changing the uniform $K$ value applied to the whole domain based on this distribution and keeping all the other parameters fixed, the resulting transition zone lies within the simulation domain. It should be mentioned here that values of conductivity beyond this range yield transition zones far from the one identified from the chemical data. For example, any conductivity value smaller than $1.5 \times 10^{-3} \mathrm{~m} /$ day (with all other parameters fixed at their calibrated values) yields a transition zone depth greater than $2,000 \mathrm{~m}$, which is more than double the depth indicated by the data (about $850 \mathrm{~m}$ ).

From these conductivity limits and those of the recharge, the recharge-conductivity ratio is changing from $1.26 \times 10^{-3}$ to $2.05 \times 10^{-2}$ for the conductivity sensitivity values, and from $1.35 \times 10^{-3}$ to $9.05 \times 10^{-3}$ for the recharge sensitivity case. In both cases, the range of this ratio encompasses the estimate of $6.88 \times 10^{-3}$ obtained by Wheatcraft (1995). However, the recharge and conductivity values considered in that study were about one order of magnitude larger than the values used here. It should be mentioned here that the recharge-conductivity ratio is the factor that controls the location of the transition zone, but the magnitude of the velocity depends on the recharge and conductivity values.

The large macrodispersivity values are considered to account for the additional mixing resulting from spatial variability that is not considered in the model. Although the base-case value chosen for longitudinal macrodispersivity is about $100 \mathrm{~m}$, the mean of the distribution shown in Figure 4.1 is $300 \mathrm{~m}$. This is done mainly to avoid violation of the Peclet number when small macrodispersivity values are used. Based on the distribution shown, the macrodispersivity values are taken between a minimum of $60 \mathrm{~m}$ and a maximum of $500 \mathrm{~m}$. As mentioned earlier, the macrodispersivity changes the width of the transition zone, which affects the flow pattern and the location of the converging flow towards the seafloor.

Porosity in the cavity and chimney is assumed to be higher than the rest of the simulation domain. For all cases considered in this study, the chimney and cavity porosity is set to a fixed value of 0.07 as discussed earlier. The rest of the domain is assigned a fracture porosity value that is obtained from the random distribution generated for the fracture porosity. The random distribution of the porosity gives a minimum value of about $1.294 \times 10^{-5}$ and a maximum value of $3.8 \times 10^{-3}$. The mean of the 100-value random distribution is about $5.2 \times 10^{-4}$. 


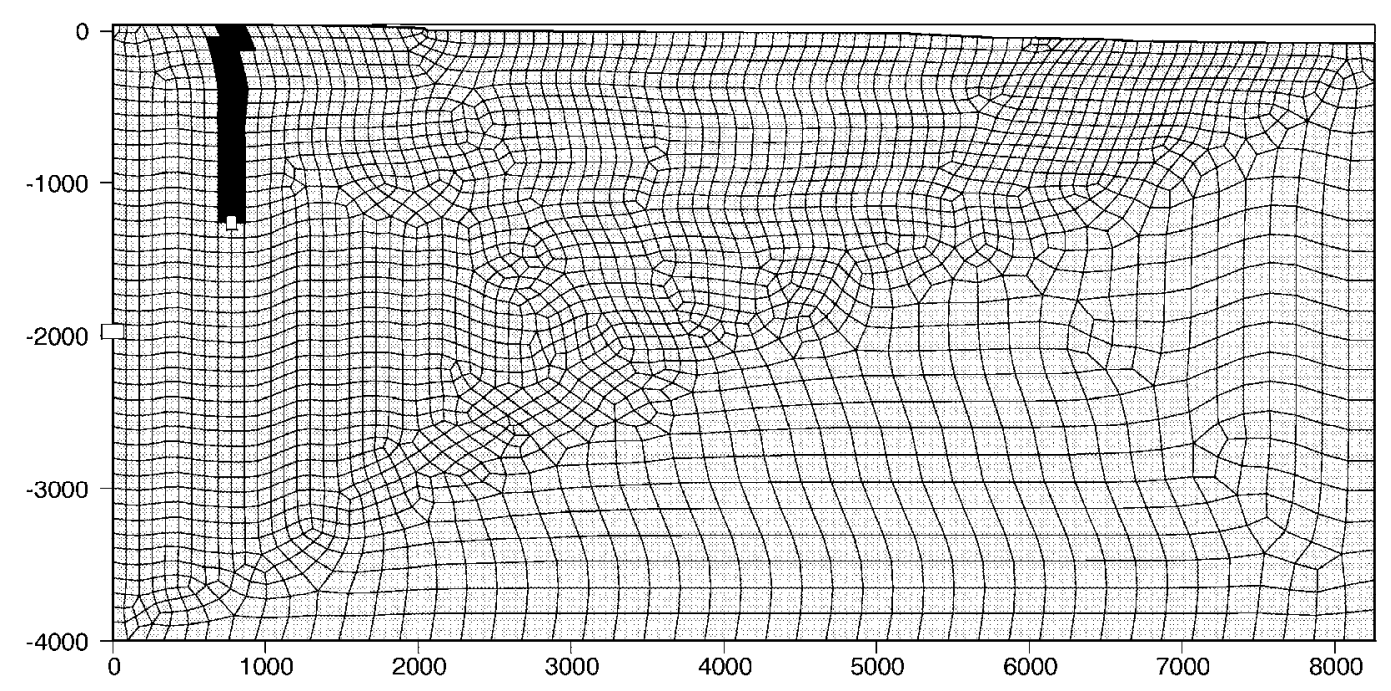

Figure 4.2. Finite-element mesh with the upper left half of the domain refined and chimney location highlighted.

\subsubsection{Numerical Approach for the Parametric Uncertainty Analysis}

Having generated these individual random distributions for each of the parameters considered, the variable-fluid-density groundwater flow problem is solved using FEFLOW. A new mesh is generated that is different from the one shown in Figure 2.8. The mesh remains refined in the entire left upper triangle of the simulation domain since the transition zone varies a lot with the random parameters selected. Therefore, a grid size of about $100 \mathrm{~m}$ is used in the upper left half of the domain and a 200-m grid is used in the lower right half (Figure 4.2). The 100-m grid size is consistent with the scale of the hydraulic and chemistry data, which were collected from straddle-packed intervals having an average length of $85 \mathrm{~m}$. Figure 4.2 also shows the location of the cavity and chimney. The chimney is assumed to extend all the way up to ground surface, to account for near-surface fractures due to spalling and disruption from the surface collapse. Porosity and conductivity in the cavity and chimney are different from the rest of the domain as mentioned earlier.

The FEFLOW code deals with the flow and saltwater transport problems simultaneously in a transient mode. The transient solution continues for a certain number of time steps determined by the user. In simulations, a steady-state velocity distribution is assumed, and as such FEFLOW runs for a large number of time steps to reach steady state. A very large simulation time is implemented for all realizations considered. However, FEFLOW has an automatic time step configuration algorithm that allows for increasing the size of the time step when the changes in the flow solution are slow and the system is approaching steady state. At the beginning of the simulation, the size of the time step is very small, but it gradually increases as the solution approaches steady state. For each individual realization, the head and concentration values are monitored at a number of points within and around the transition zone as a function of time. If at the end of the simulation time the head and 
concentration do not reach constant values, the simulation is repeated with a longer time until steady state is reached. This guarantees that all the runs reach steady state and that the obtained solution is stable and representative of the equilibrium state of the system.

\subsubsection{Sensitivity of Concentration and Head Distributions to Flow Parameter Uncertainty}

For each one of the four parameters considered, a set of 100 velocity and concentration distributions is obtained that corresponds to the 100 random input values. For the simulated head and concentration values at UAe-2, the mean of the 100 realizations as well as the standard deviation of the result are computed. Figure 4.3 through Figure 4.6 show the sensitivity of the concentration and head to the recharge, conductivity, porosity and macrodispersivity. In each figure, the mean of the Monte Carlo runs, the mean \pm one standard deviation, the base-case (all parameters take their mean values) result, and the data points are plotted. Figure 4.3 shows the sensitivity of concentration and head profiles to changes in the recharge values. The one standard deviation confidence interval around the mean captures most of the data points for concentration and for head measurements. The conductivity case (Figure 4.4) covers the high concentration data (saltwater side) but gives lower concentrations than the data for the freshwater side of the transition zone. The head sensitivity to conductivity variability shown in Figure 4.4 indicates that the confidence interval encompasses all the head data at UAe-2.

It should be mentioned here that the base-case results are different than those shown in Figure 2.15 and Figure 2.16 of the calibration results (the dashed lines on those figures). This is due to adding the chimney effect, which is not present in the pre-test calibration analysis. It is assumed that the cavity and chimney are isotropic, which means that the vertical conductivity is 10 times larger than the surrounding area. In addition, the porosity in the cavity and chimney is kept in all realizations at a value of 0.07 , even when the fracture porosity is drawn randomly from its assumed distribution. This leads to a base-case result that is different from the one established from calibration. The other aspect to discuss here is the use of the pre-test data for this comparison. It is evident that incorporating the cavity and chimney conditions only slightly changes the head and concentration profiles at UAe-2. Therefore, the pre-test data can still be considered as providing guidelines for choosing the model parameters and controlling the range of variability around the base-case values. The assumptions employed in this analysis are that the short-term effects of the nuclear test are neglected as the long-term behavior of the radionuclides is controlled by the steady-state conditions of the island. The only long-term effects considered are the porosity and conductivity changes in the cavity and chimney.

Figure 4.5 shows the effect of the fracture porosity parametric uncertainty on the resulting heads and concentrations at UAe-2. As expected, the porosity does not affect the solution of the flow problem even with the chimney having a different porosity. The porosity only influences the speed at which the system converges to steady state and as such, simulated heads and concentrations at UAe-2 do not show any sensitivity to the fracture porosity value outside the chimney. It should be remembered that the fracture porosity outside the chimney and cavity area will have a dramatic

effect on travel times and radioactive decay of mass released from the cavity and migrating toward 

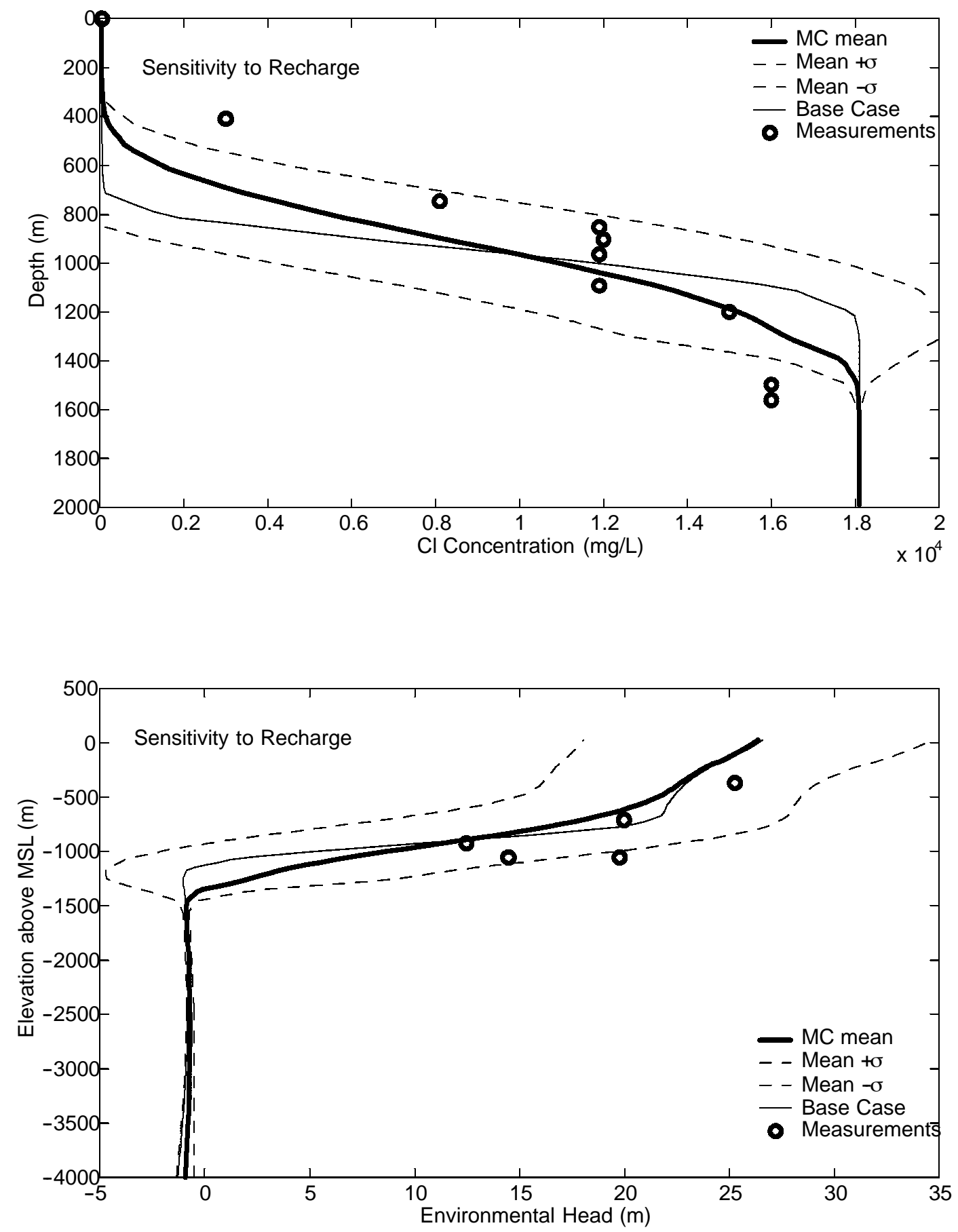

Figure 4.3. Sensitivity of UAe-2 concentration and heads to recharge in the first modeling stage. 

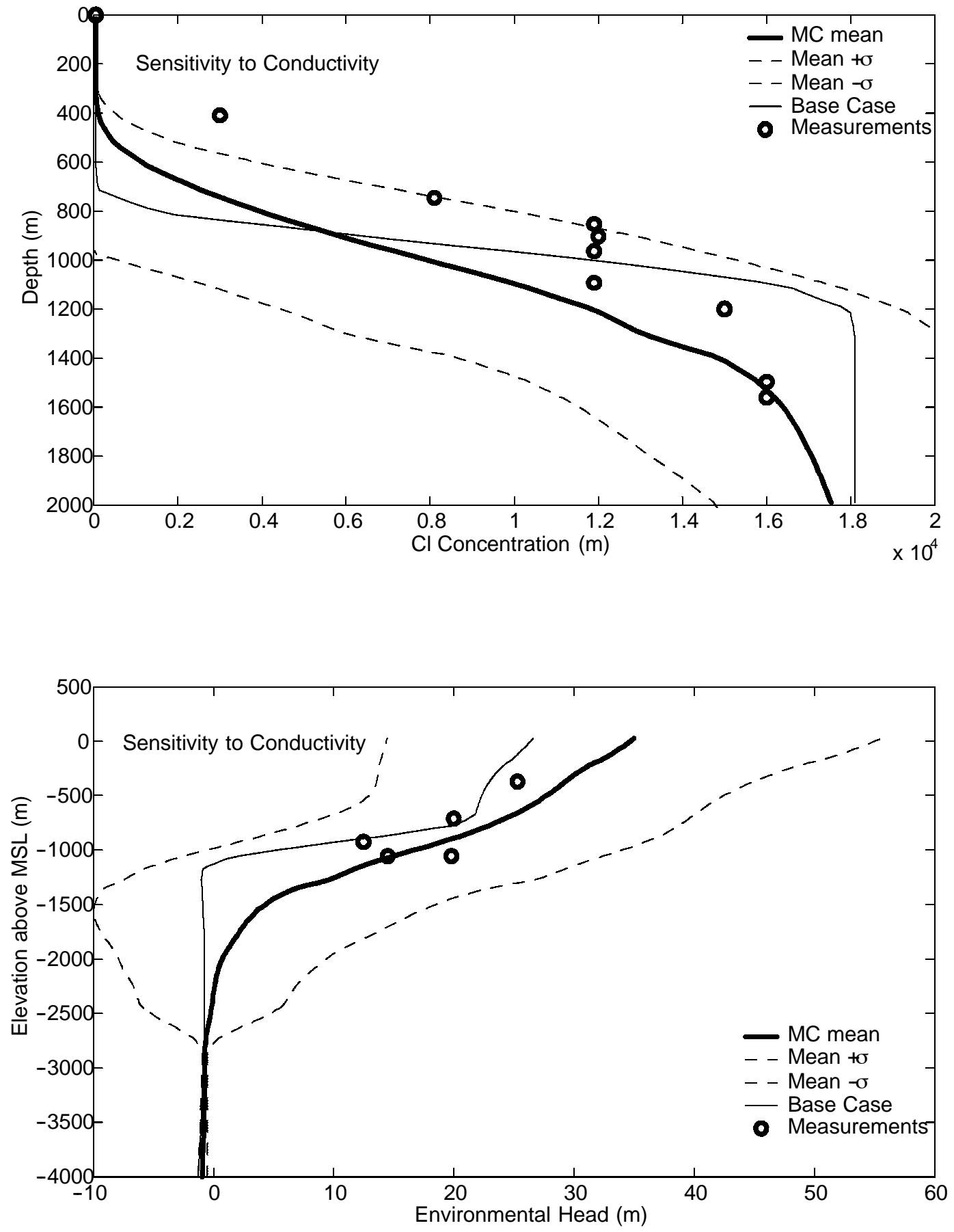

Figure 4.4. Sensitivity of UAe-2 concentration and heads to conductivity in the first modeling stage. 
the seafloor. This will be demonstrated later when the effect of these parameters on travel times is analyzed.

The macrodispersivity effect is displayed in Figure 4.6. The macrodispersivity range of $60 \mathrm{~m}$ to $500 \mathrm{~m}$ considered in this sensitivity case has a minor effect on the head and concentration at UAe-2, especially at the center of the transition zone. This is to be expected since macrodispersivity leads to more or less dispersion around the center of the transition zone. Again, the final decision as to whether the changes in macrodispersivity would be important to include in the final modeling stage cannot be determined from these results. The criterion for selecting the most influential parameters is determined by analyzing the transport results in terms of travel times from the cavity to the seafloor and location where breakthrough occurs. The set of figures discussed here indicates that the simulated heads and concentrations at UAe- 2 are most sensitive to conductivity and recharge and least sensitive to fracture porosity outside the chimney and macrodispersivity. This picture may be confirmed or changed by analyzing the travel time statistics for particles originating from the cavity and breaking through the seafloor.

The output of this stage is a set of 100 velocity realizations for each of the four parameters considered. These velocity realizations are used to model the radionuclide transport from the cavity toward the seafloor. The transport parameters are kept fixed at their means while addressing the effect of the four parameters that change the flow regime. When the effect of transport parameters, such as matrix diffusion coefficient, glass dissolution rate, etc., is studied, a single velocity realization with the flow parameters fixed at the calibration values is used. The following section presents the uncertainty analysis for the transport parameters. Following that discussion, the results of the parametric uncertainty analysis for both the flow and transport parameters are presented.

\subsection{Sensitivity/Uncertainty Analysis of Transport Parameters}

In transport simulations where the radionuclides are divided among surface-deposited nuclides and volume-deposited nuclides trapped in puddle glass, the dissolution rate, $k_{g}$, becomes an important factor affecting transport results. However, there exists a large degree of uncertainty in estimating this parameter, which leads to a couple of orders of magnitude range for the release rate. To analyze the effect of this uncertainty on transport results, a 100-value random distribution of variability for $k_{g}$ ranging from $1.56 \times 10^{-8}$ days $^{-1}$ to $2.54 \times 10^{-6}$ days $^{-1}$ with a mean of about 2.44 $\mathrm{x} 10^{-7}$ days $^{-1}$ is generated from a lognormal distribution. Figure 4.7 shows a histogram of the random distribution used in the sensitivity analysis (top) and how the release of nuclides from the puddle glass is influenced by this range of variability (bottom). This analysis is performed using a single flow realization and the transport simulations are performed for 100 different $\mathrm{kg}$ values.

A similar analysis is performed to analyze the effect of the local dispersivity, $\alpha_{L}$. An important point here is that the macro/local dispersivity is used in both the flow and transport simulations. Since flow simulations involved solving the saltwater intrusion problem, the macrodispersivity values were used in the analysis of flow parameters. However, these macrodispersivity values were chosen to be very large for a number of reasons. First, FEFLOW solves the flow and transport equations using a finite-element technique. A Peclet number criterion has to be met for a stable 

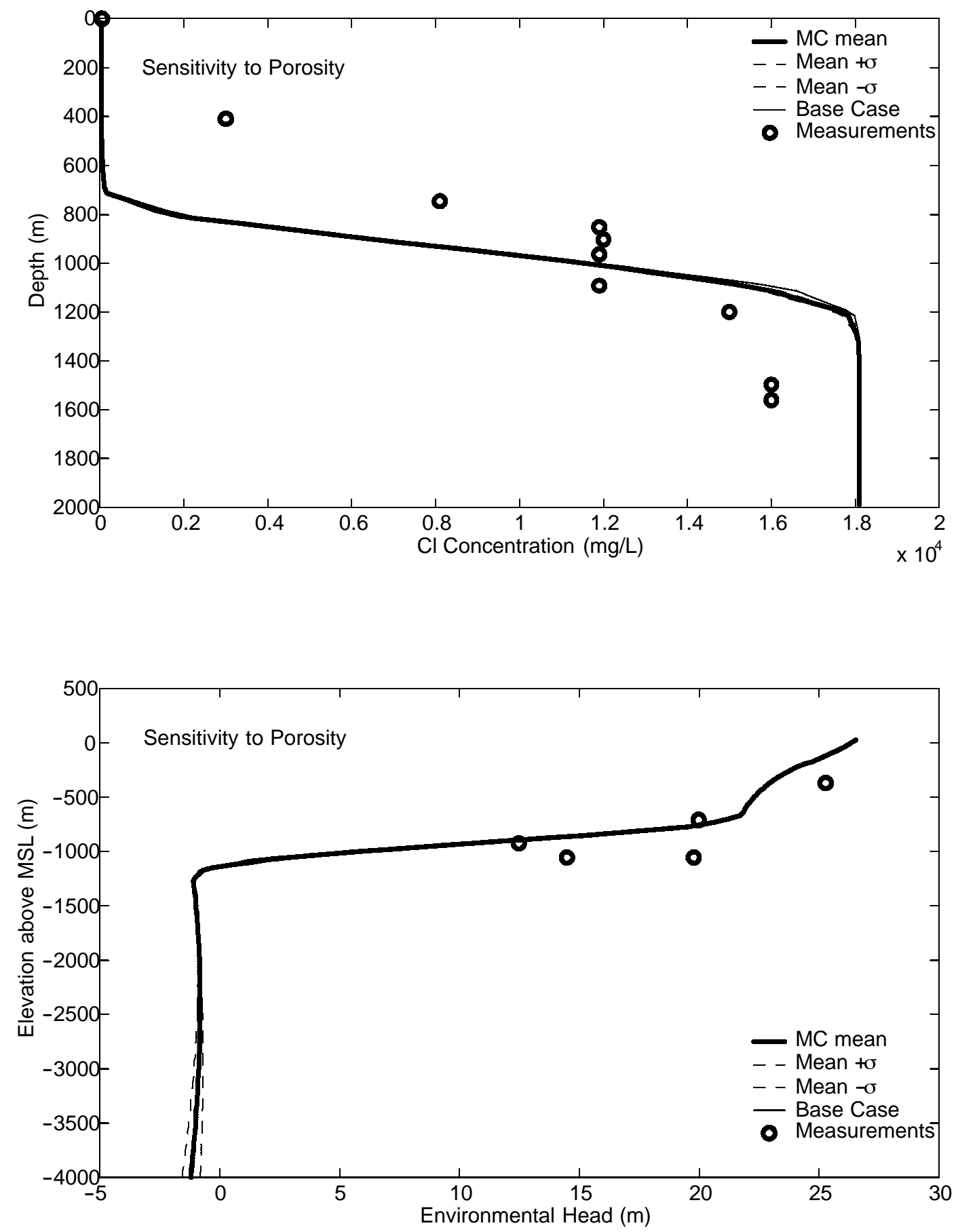

Figure 4.5. Sensitivity of UAe-2 concentration and heads to porosity in the first modeling stage. 

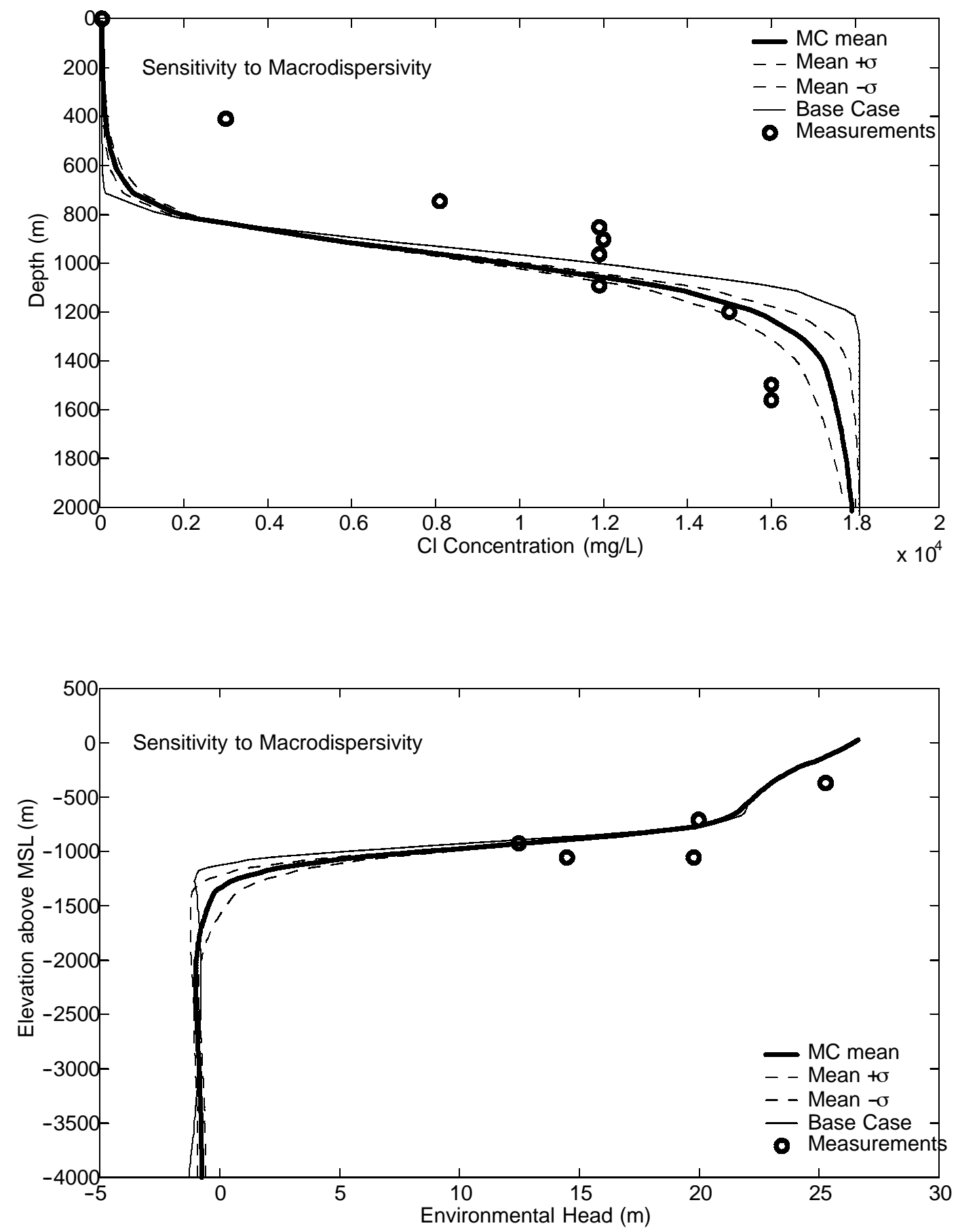

Figure 4.6. Sensitivity of UAe-2 concentration and heads to macrodispersivity in the first modeling stage. 

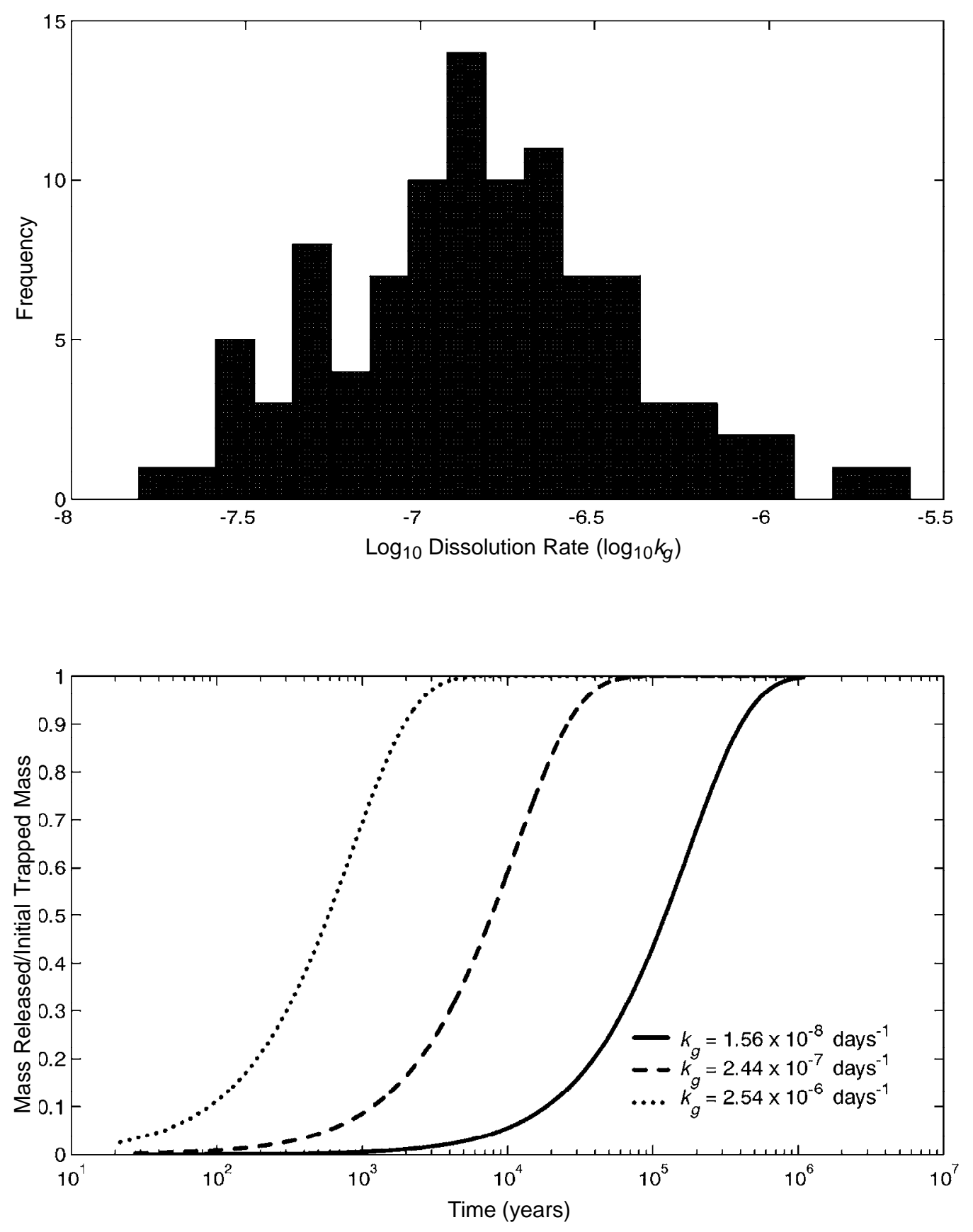

Figure 4.7. Randomly generated distribution for the glass dissolution rate, $\mathrm{kg}$ (top), and the percentage of mass released as a function of time for the minimum, mean, and maximum $\mathrm{kg}$ (bottom). 
finite-element solution. The Peclet number, $P_{e}$, associated with the finite-element solutions to the advection-dispersion equation can be approximated by the ratio $(V \Delta x) /\left(A_{L} V\right)=(\Delta x) /\left(A_{L}\right)$. To obtain a stable solution when using an implicit finite-element scheme, the Peclet number should be kept less than unity and thus a very fine grid would be needed for small values of longitudinal macrodispersivity $A_{L}$. This becomes prohibitive in terms of storage and CPU time due to the large extent of the simulation domain $(8,000 \mathrm{~m} \mathrm{x} \mathrm{4,000} \mathrm{m).} \mathrm{Therefore,} \mathrm{the} \mathrm{longitudinal} \mathrm{macrodispersivity}$ is chosen very large to ensure a stable solution over a grid of an average size of about $100 \mathrm{~m}$. The second reason for choosing such large macrodispersivities in the flow simulations is the fact that chemistry data show a largely dispersed transition zone which we tried to reproduce during calibration. It is also important to remember that no spatial variability is included in the medium conductivity, which usually adds a macro-dispersion effect to the transition zone spreading. A large macrodispersivity value may be used as a surrogate to spatial variability in hydraulic conductivity (e.g., Gelhar and Axness, 1983; Hess et al., 1992). For all these reasons, a large asymptotic macrodispersivity is used in flow simulations with a range extending from $60 \mathrm{~m}$ to $500 \mathrm{~m}$ as discussed earlier.

Although the dispersivity is a porous medium property, the dispersivity values used in transport simulations are chosen much smaller than those used in the saltwater intrusion problem. The reason for that choice is twofold. First, it is more conservative to select a small dispersivity value that reduces dispersion and leads to a higher flux and concentration peaks. Second, the strong variability of the velocity field at and around the transition zone dominates the dispersion process rendering the local-scale dispersion effect very minor. In addition, the macrodispersivity used for the saltwater intrusion problem introduces an artificial dispersion process that compensates for neglecting the spatial variability of hydraulic conductivity.

The calibrated flow model at a grid scale of about $100 \mathrm{~m}$ is used to perform random walk particle-tracking experiments for which there is no lower limit for the local dispersivity value that can be used. The longitudinal local dispersivity, $\alpha_{L}$, is thus changed from a minimum of about $0.56 \mathrm{~m}$ to a maximum of $19.5 \mathrm{~m}$. The 100-value distribution that is generated from a lognormal distribution has a mean of about $5.0 \mathrm{~m}$ and is shown in Figure 4.8. Transverse local dispersivity, $\alpha_{T}$, is taken as one tenth of the longitudinal value. Again, these 100 simulations are performed using a single FEFLOW output for the purpose of analyzing the effect of local dispersivity alone.

The last parameter to be analyzed within transport simulations is the matrix diffusion parameter, $\kappa$. Based on the discussion of Section 3.2.3, a best estimate for $\kappa$ of 1.37 day $^{-1 / 2}$ was derived (consistent with $\theta_{m}$ of $0.12, b$ of $5.0 \times 10^{-4}$ and $D_{m} *$ of $3.2745 \times 10^{-5} \mathrm{~m}^{2} /$ day). This value leads to a very strong diffusion into the matrix, which significantly delays the mass arrival to the seafloor, producing no mass breakthrough at the seafloor within the selected time frame of about 27,400 years of this first modeling stage. As there is a large degree of uncertainty in determining this parameter manifested in the uncertainty in $b$ and $D_{m}{ }^{*}$, and there is uncertainty derived by the conceptual model assumptions for diffusion (e.g., assumption of an infinite matrix), values for $\kappa$ that are smaller than the best estimate of 1.37 were chosen. A random distribution of 100 values is generated for $\kappa$ with a minimum of 0.0394 , a maximum of 1.372 and a mean of 0.352 . This mean 


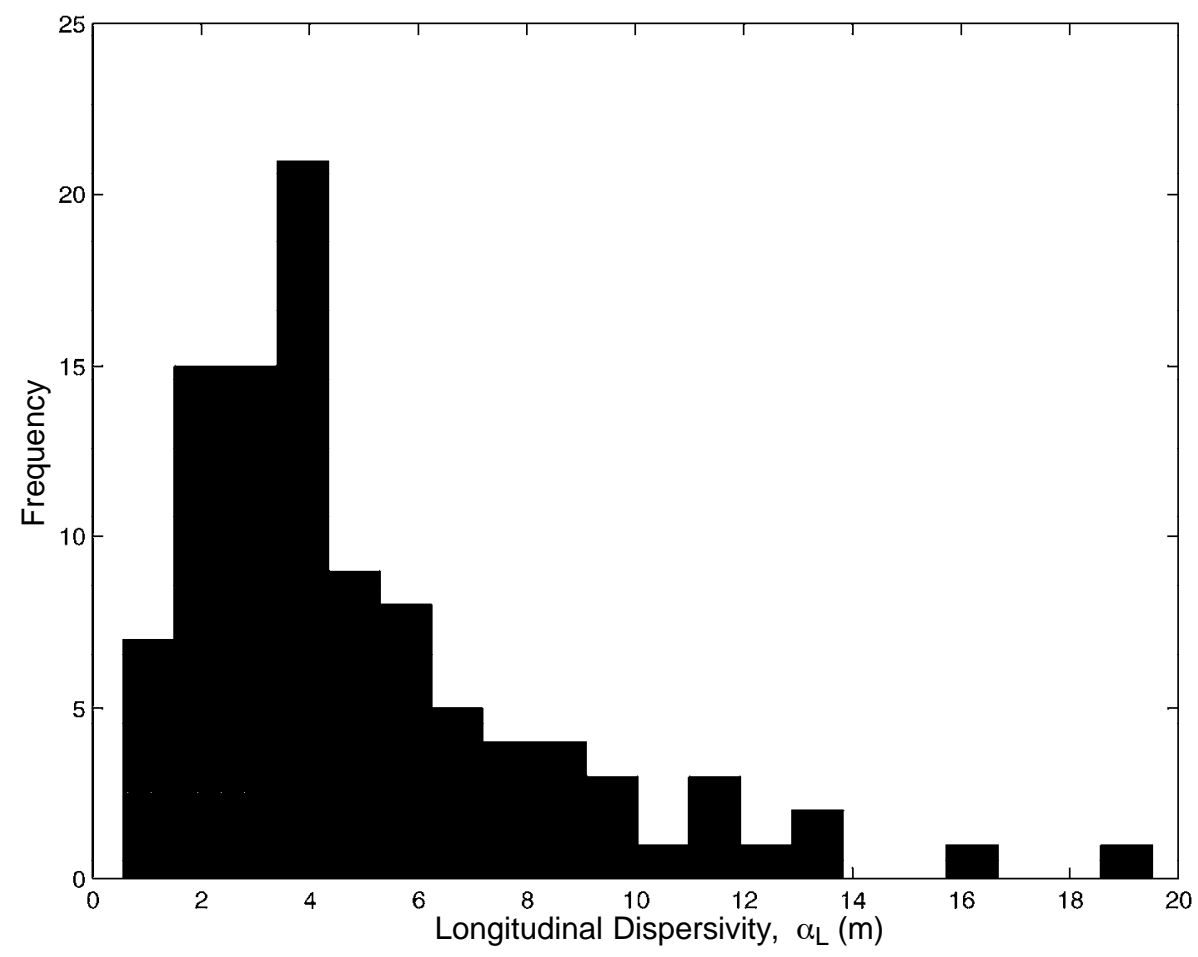

Figure 4.8. Randomly generated distribution for longitudinal local dispersivity for the first modeling stage.

is close to the $\kappa$ value of 0.434 that is obtained from the same parameters described above for its best estimate, but using an order-of-magnitude-lower diffusion coefficient. The lower end of the distribution is yet another order-of-magnitude-lower $\kappa$. Figure 4.9 shows the distribution of these values and the effect on the retention function, $\gamma(t, \tau)$, that is used for matrix diffusion computation. The distribution shown in Figure 4.9 is generated from a lognormal distribution with a standard deviation adjusted to a minimum and a maximum value close to the ones specified above. The difference between these two extremes is very significant as depicted by the lower plot of Figure 4.9. This plot shows how the retention function behaves with different $\kappa$ values. As can be seen, the function has a lower peak and a much longer tail for higher values of $\kappa$. This function indicates that if there is a single pulse of conservative (and no matrix diffusion) mass flux crossing the seafloor at time $\tau=1,000$ days within a time step of $\Delta t$ and with unit value, the mass flux after including the matrix diffusion effect is given by $\gamma(t, \tau) \times \Delta t$. This implies that $\int_{0}^{\infty} \gamma(t, \tau) d t=1.0$ for any value of $\tau$.

The analysis here is performed using a single flow realization and a single particle-tracking realization with the mean values of transport parameters $\left(\alpha_{L}=5.0 \mathrm{~m}\right.$ and $\left.k_{g}=1.26 \times 10^{-7} \mathrm{days}^{-1}\right)$. The conservative breakthrough of this realization is convoluted with the $\gamma$ function (Equation 3.14) for 100 realizations of the parameter $\kappa$ that are generated as discussed above. The resulting 100 

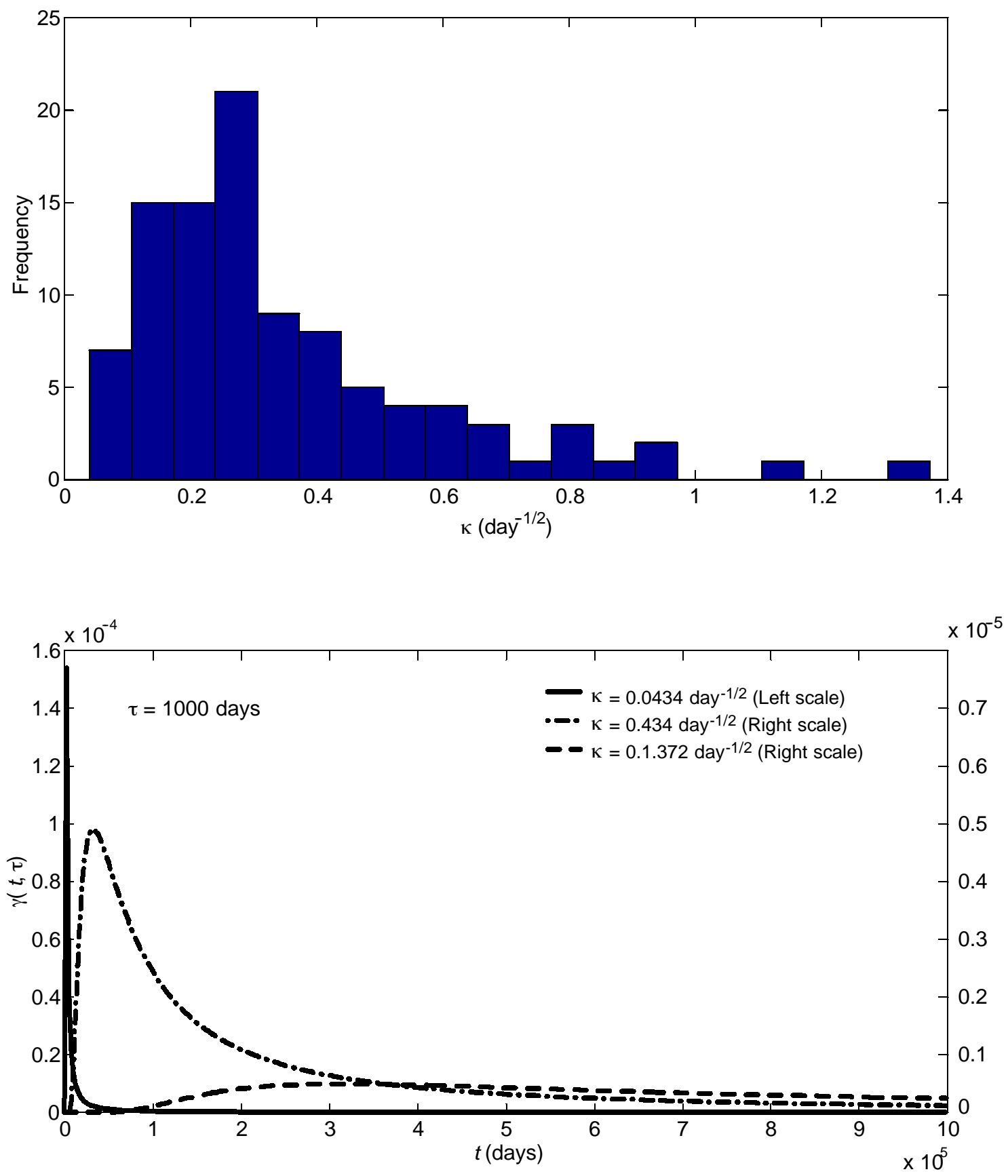

Figure 4.9. Randomly generated distribution for the matrix diffusion parameter, $\kappa$ (top), and the dependence of the retention function, $\gamma$, on the value of $\kappa$ (bottom). 
breakthrough curves are analyzed for arrival time and location of the breakthrough with respect to the bathymetric profile.

\subsection{Results of the Parametric Uncertainty Analysis}

The transport modeling described in the previous section is applied to the four cases dealing with flow parameters, and the results of the 100 Monte Carlo realizations for each parameter are analyzed in terms of mean arrival time and location of breakthrough. For all these cases, the particle-tracking experiments are performed with a time step of 100 days and for a total simulation time of $10^{7}$ days (27,400 years). Transport parameters such as glass dissolution, local dispersivity and matrix diffusion parameter are kept unchanged in all these cases. Longitudinal and transverse local dispersivities, $\alpha_{L}$ and $\alpha_{T}$, are taken as $5.0 \mathrm{~m}$ and $0.5 \mathrm{~m}$, respectively, and matrix diffusion parameter, $\kappa$, is fixed at 0.434 and 0.0434 days $^{-1 / 2}$. In each case, 100 conservative, total mass flux, $Q(t)$, breakthrough curves are obtained and then convoluted with the matrix-diffusion gamma function of Equation (3.14) to yield the undecayed breakthrough curves for a $100 \%$ hydraulic release scenario. Due to the matrix diffusion effect, the mass that breaks through within the time frame of 27,400 years is far less than $100 \%$ of the total mass released within the cavity. Therefore, the breakthrough curves are analyzed in terms of the mean arrival time of the mass that breaks through within this time frame and the location of this breakthrough along the bathymetric profile. Recall that the purpose of this analysis is to select the parameters for which the associated uncertainty has the most significant effect on transport results expressed in terms of uncertainty of travel time to the seafloor and the location where breakthrough occurs. By doing so, the parameters for which the uncertainty only slightly affects the uncertainty in travel time and transverse location of the breakthrough can be identified, and as such these parameters are fixed at their best estimate and only those with significant effects are varied.

In addition to the four parameters discussed here $\left(\operatorname{Rech}, K, \theta, A_{L}\right)$, the results using the case with randomly chosen conductivity but with a porous medium porosity of 0.12 are also presented. This porosity value is the average of all the core measurements for the Kirilof Point and Older Breccias formations. The objective is to compare a case with a very low fracture porosity and matrix diffusion to a case with a continuum porous medium that has no matrix diffusion, but a large porosity value. In the porous medium case, the whole domain including the cavity and chimney is assigned a uniform porosity of 0.12 . The 100 conservative breakthrough curves are then analyzed in a manner similar to the other cases described above.

The results of the sensitivity analysis performed for the seven parameters, $K, \operatorname{Rech}, \theta, A_{L}$ (in saltwater intrusion), $k_{g}, \alpha_{L}$ (in radionuclide transport modeling) and $\kappa$ are summarized in Table 4.1a and Table 4.1b. The difference between the tables is that the matrix diffusion parameter, $\kappa$, is assigned the base-case value of $0.434 \mathrm{day}^{-1 / 2}$ in Table $4.1 \mathrm{a}$ and the sensitivity value of $0.0434 \mathrm{day}^{-1 / 2}$ in Table 4.1b. In addition, the random conductivity case with porous medium porosity is also presented in Table 4.1a. For each case, the table presents the range of values of the input parameter (minimum, maximum and mean), the standard deviation, and the coefficient of variation. On the output side, the results are presented in terms of the statistics of travel time and transverse location 


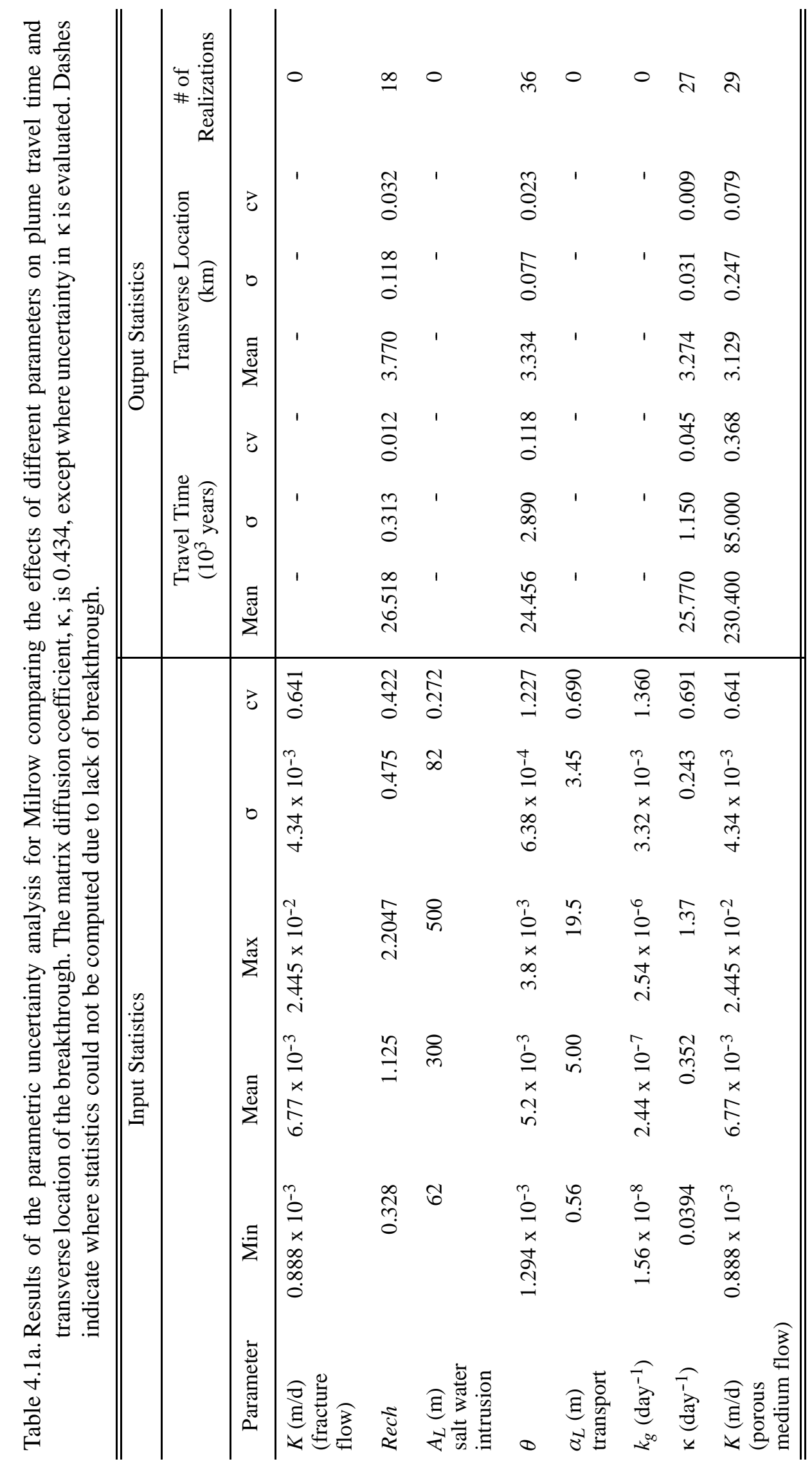




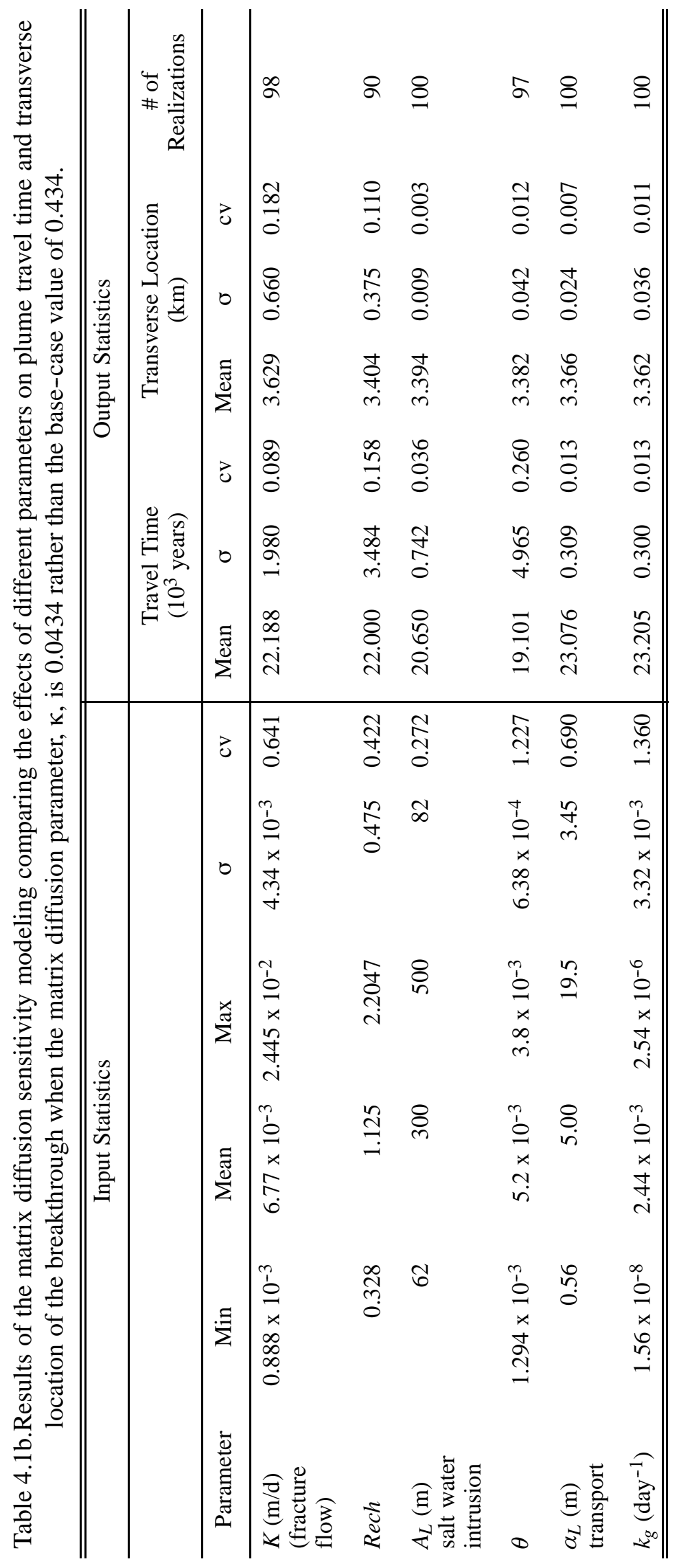


where breakthrough occurs. For each single realization of the radionuclide transport, the mean arrival time and mean transverse location of the mass that has crossed the seafloor within 27,400 years are recorded. This time frame is used for all cases except the porous medium (no fracture flow) scenario, where the simulation time is about 5,480,000 years. The resulting ensemble of these values is used to compute the mean, standard deviation and coefficient of variation of the travel time and location. These values are presented in Table 4.1a and Table 4.1b along with the number of realizations (out of 100) that show mass breakthrough within the above-mentioned time frames. The mean arrival time for the case of $K$ in porous medium flow is significantly larger than the other cases due to the longer simulation times considered for this case.

To facilitate the comparison between different cases, one would compare the values of the coefficient of variation on both input and output sides. The case of random conductivity but with a porous medium conceptualization shown in Table 4.1 a is only presented for comparison purposes. Comparing this case to the similar fracture flow case where matrix diffusion is added $(\kappa=0.0434$, Table 4.1b) indicates that the addition of matrix diffusion reduces some of the variability in the plume arrival time. Although the simulation time for the porous medium scenario is about 5.5 million years, only 29 realizations show some mass breakthrough. This is attributed to the very small flow velocities when using a uniform porous medium porosity of 0.12 . The porous medium scenario will not be considered in any further analysis.

Table 4.1a shows that none of the 100 realizations considered showed any breakthrough with $\kappa=0.434 \mathrm{day}^{-1 / 2}$ for the cases addressing uncertainty in $K, A_{L}, \alpha_{L}$, and $k_{g}$. This is essentially due to the strong effect of matrix diffusion with $\kappa=0.434$ day $^{-1 / 2}$. Recharge uncertainty leads to some uncertainty in arrival times, which is the least compared to $\theta$ and $\kappa$ uncertainty cases (Table 4.1a). To avoid the complete elimination of mass by matrix diffusion, which hinders the statistical analysis of arrival times, we present the uncertainty effects using $\kappa=0.0434$ day $^{-1 / 2}$ in Table $4.1 \mathrm{~b}$.

Among the six cases in Table 4.1b, the two cases encountering variability in the macro/local dispersivity value lead to very small uncertainty in the travel time and the transverse location in comparison to other parameters. Although the coefficient of variation of $\alpha_{L}$ in radionuclide transport simulations is higher than that of conductivity and recharge, the resulting coefficients of variation for travel time and transverse location are much smaller. The glass dissolution coefficient, $k_{g}$, encounters the largest variability (coefficient of variation is 1.36), yet the effect on travel time and transverse location is minor as compared to conductivity and recharge. Therefore, it can be argued that the uncertainty in these three parameters may be neglected as their variabilities slightly influence transport results when compared to other parameters. This leaves the four parameters, $K$, $\operatorname{Rech}, \theta$, and $\kappa$. The fracture porosity variability with the highest coefficient of variation among these four parameters leads to the highest variability in mean arrival time. The conductivity on the other hand leads to the highest variability in transverse location. The first three parameters of this reduced list influence the solution of the flow problem and thus require multiple realizations of the flow field. The matrix diffusion parameter is a transport parameter that does not require multiple flow realizations. 
The final choices for the uncertain parameters for the second modeling stage are the three flow parameters. The uncertainty of the matrix diffusion parameter will be assessed in a less rigorous manner within a simple sensitivity analysis. This choice is motivated by the fact that we only have data pertinent to the solution of the flow problem, which can be used to guide the generation of the random distributions in the second stage. Head and chloride concentration data can be used as criteria for determining whether the combined random distributions lead to realistic flow solutions or not. Given that using the same random distribution for $\kappa$ as in the first stage or skewing it towards higher or lower values cannot be judged or tested against data, the transport results using a different $\kappa$ value are compared in the sensitivity section. 
THIS PAGE LEFT INTENTIONALLY BLANK 


\section{FLOW AND TRANSPORT MODELING RESULTS}

For the primary flow and transport modeling for the sites, using the significant uncertain parameters identified in the parametric uncertainty analysis $(K, \operatorname{Rech}$, and $\theta)$, the same model meshes employed in the parametric uncertainty analysis of Section 4 are used. Again, these meshes differ from those used in the calibration (Figure 2.8) because the chimneys created by collapse into the nuclear cavities are included. These features were not used during calibration because the calibration data for each site were obtained prior to each test. It is assumed that the hydrologic impact of the chimneys is an enhancement in vertical conductivity; as a result, no anisotropy is applied in those model cells, resulting in an increase in vertical hydrologic conductivity of ten times over the rest of the domain. Figure 5.1 shows the upper left portion of the simulation domain for the three tests with the chimney location highlighted.

\subsection{Milrow Flow and Transport Results}

Three new random distributions are generated for the conductivity, recharge and fracture porosity. The same distributions generated in the first stage are not used for two reasons. First, the new distributions have 500 values of each parameter as opposed to only 100 values in the first stage. Second, an upper and a lower limit for the recharge-conductivity ratio are specified to ensure that the transition zone is within the depths identified by the chloride data. This is intended to reduce the uncertainty in the location of the transition zone and to guarantee a converging solution with no boundary effects. Therefore, 500 random $K$ values and a similar number for Rech are generated with no correlation among the generated values. The cases that satisfy the condition $0.0013 \leq \operatorname{Rech} / K \leq 0.0347$ are then selected, which yields 300 realizations of the random values. These limits are chosen based on the individual results of the first stage and the location of the transition zone relative to the chloride concentration data. The minimum, mean and maximum values of $K$ are $2.2 \times 10^{-3}, 1.69 \times 10^{-2}$, and $6.24 \times 10^{-2} \mathrm{~m} /$ day, respectively. For the recharge, these limits are $0.319,2.066$, and $6.65 \mathrm{~cm} / \mathrm{year}$, respectively. Independently of these values, 300 random porosity values with a minimum of $1.057 \times 10^{-5}$, a mean of $4.4 \times 10^{-4}$, and a maximum of $6.2 \times 10^{-3}$ are generated. Figure 5.2 displays the histograms of these three distributions. In comparing these distributions to those used in stage one, it is found that recharge and conductivity distributions have higher means in this stage. Porosity distribution on the other hand shows a lower mean than in the first modeling stage, which is toward the conservative side.

It is interesting to compare the recharge-conductivity ratio and the conductivity-porosity ratio for the new distributions to the base-case values. Recall that in the base case, $K=6.773 \times 10^{-3} \mathrm{~m} / \mathrm{day}$, $R e c h=1.125 \times 10^{-4} \mathrm{~cm} / \mathrm{year}$, and $\theta=5.0 \times 10^{-4}$. The plots in Figure 5.3 illustrate how the two ratios $(R e c h / K$ and $K / \theta$ ) vary among the 300 realizations around the base-case ratios. As can be seen in the figure, $R e c h / K$ varies from a minimum that is four times smaller than the base case to a maximum that is six times larger. More realizations lie below the base-case line than above it, which indicates some skewness towards the high conductivity values. The conductivity-porosity ratio varies from ten times smaller to about 160 times larger than the base-case value. As will be seen later, this distribution represents conservative $K$-Rech combinations since the critical combinations are those having a large recharge-conducitivty ratio. The figure also shows that more realizations lie in the high $K /$ low $\theta$ region 


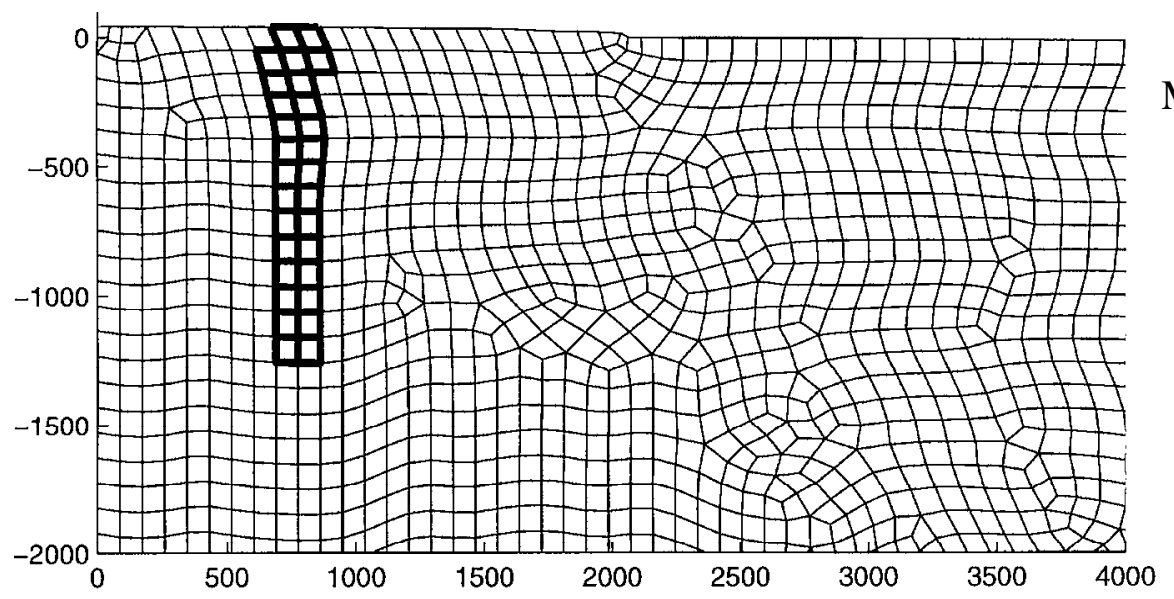

(A) Milrow
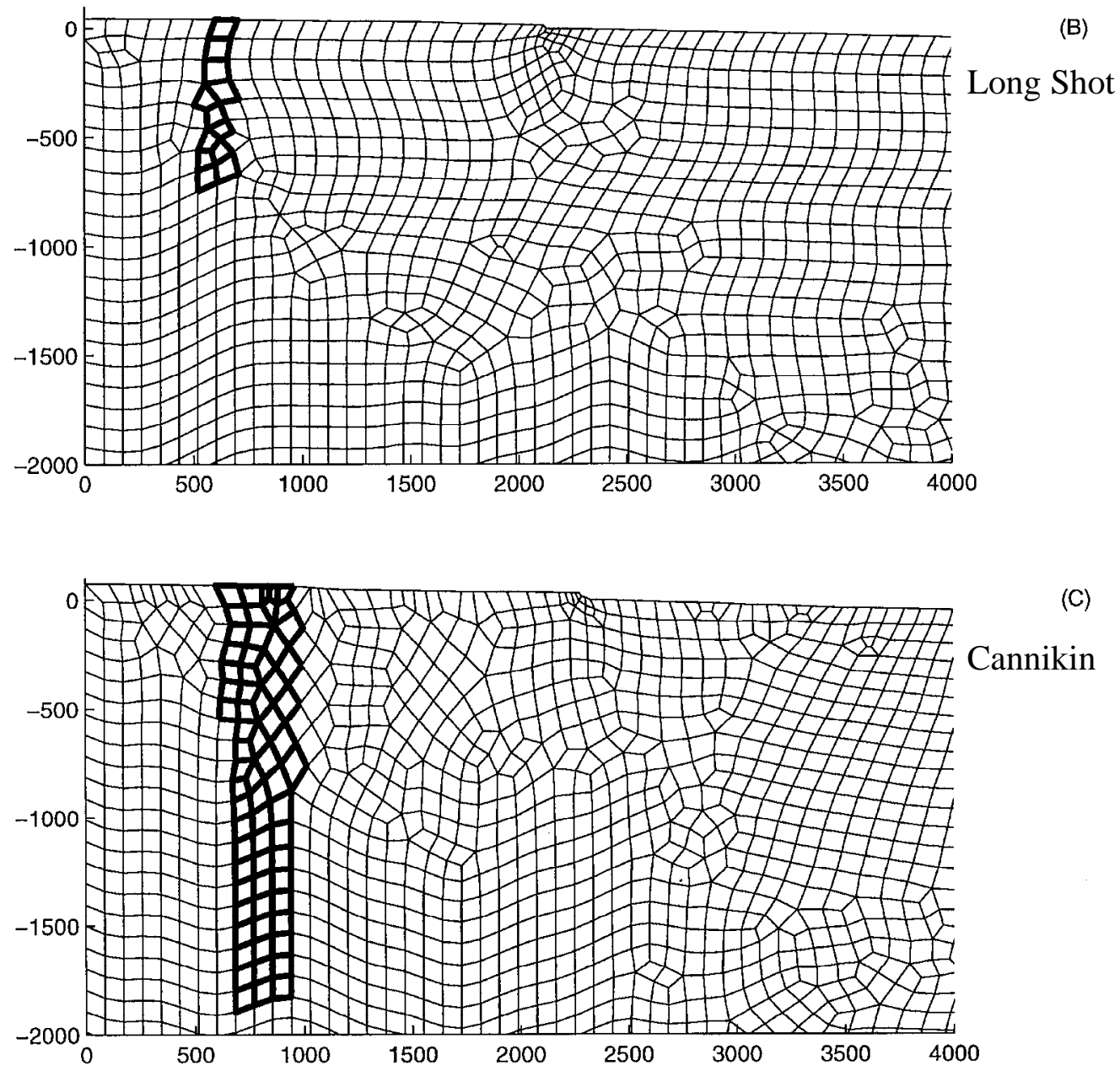

Figure 5.1. Expanded view of the upper left portion of each model domain, showing the nuclear chimney included in the flow and transport simulations. 

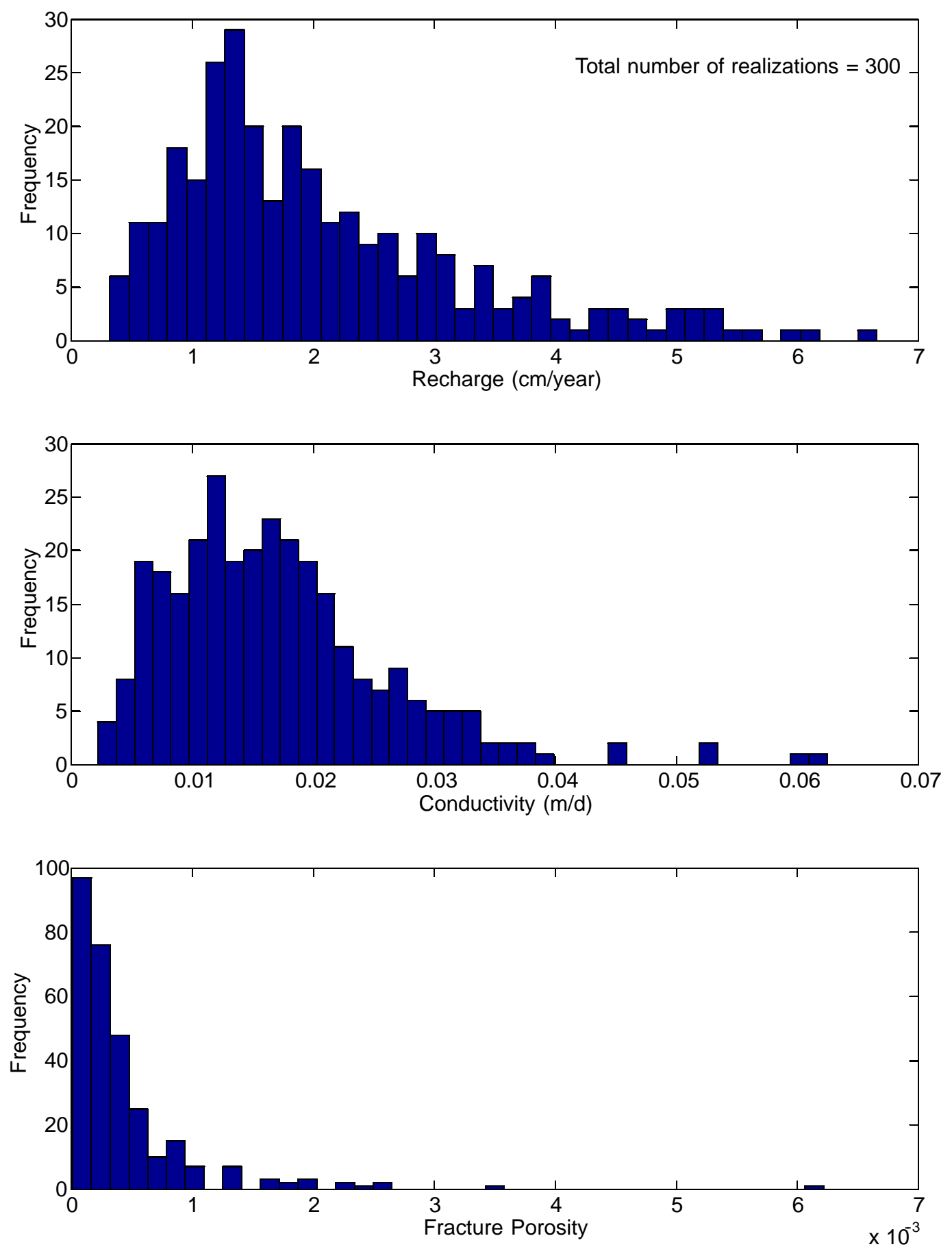

Figure 5.2. Randomly generated distributions for Rech, $K$, and $\theta$ in the second modeling stage for Milrow. 

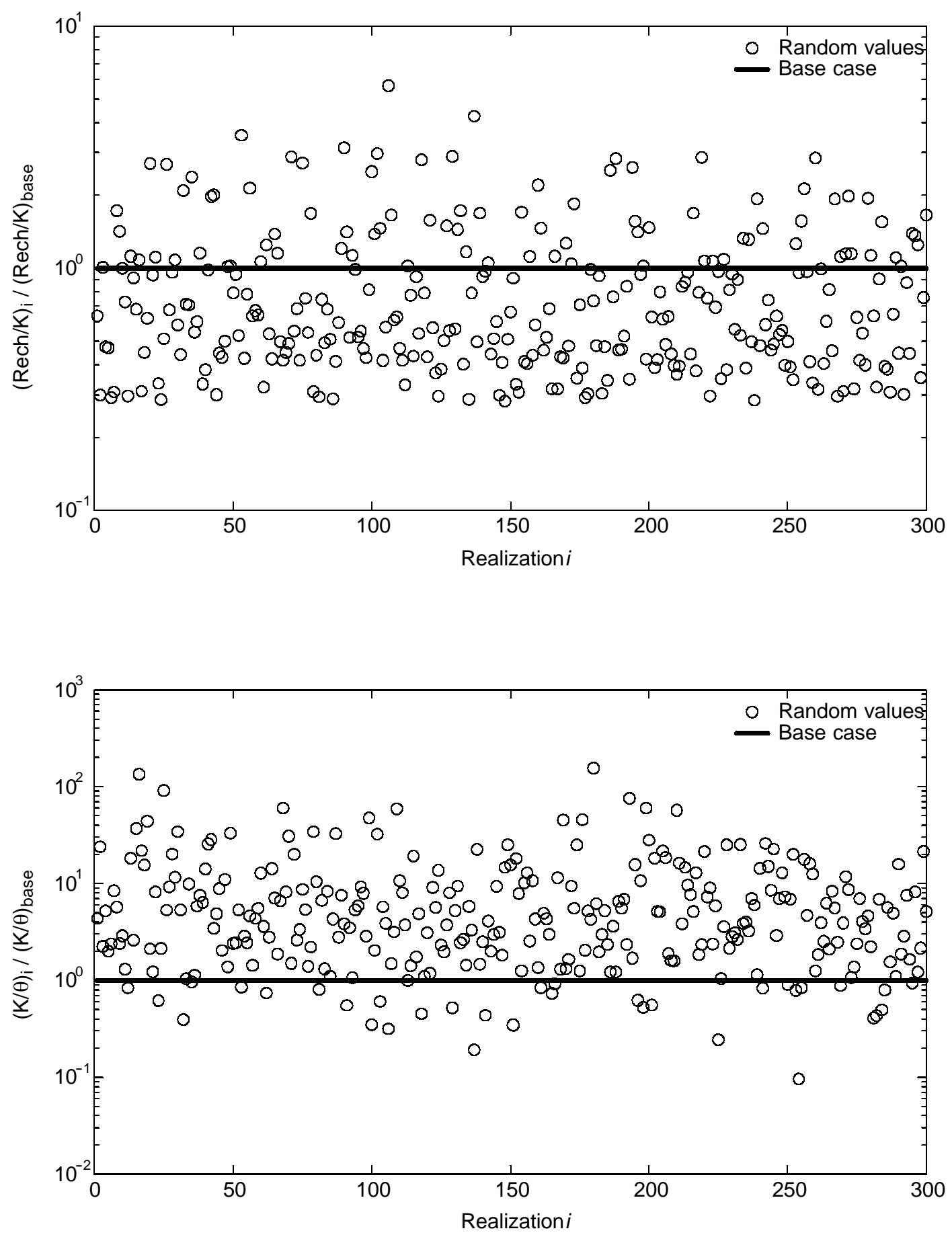

Figure 5.3. Comparison of the randomly generated recharge-conductivity ratio and conductivity-porosity ratio in relation to the Milrow base-case values. 
than in the opposite region. This is again on the conservative side, as more realizations are produced with very high velocities than with low velocities.

The solution of the flow problem in this stage is performed similarly to the first stage, with the parameters summarized in Table 5.1. FEFLOW is used to solve the density-driven flow problem for 300 realizations with the recharge, conductivity, and porosity values already generated. Macrodispersivity values are fixed at $100 \mathrm{~m}$ and $10 \mathrm{~m}$ in the longitudinal and transverse directions, respectively. Domain geometry and boundary conditions remain unchanged. To assess the choice of the combined random values used in this analysis, the results of these realizations are analyzed at the UAe-2 location. Figure 5.4 displays the simulated concentration and head profiles in UAe-2 in terms of the mean of the 300 realizations, the mean \pm one standard deviation, the base-case result and the measured data. The first observation in this figure is that the mean of the MC realizations is closer to the data points than any of the individual cases investigated in the first stage (e.g., Figure 4.3 through Figure 4.6). Furthermore, the one standard deviation confidence interval encompasses all the data points for the chloride concentration. The confidence interval also encompasses all head data, although the mean of the MC runs gives lower heads than the measurements. The overall result is that the ranges of variabilities considered encounter a large number of possible combinations that cover a wide range of uncertainty in the flow parameters.

Table 5.1. Parameter range for Milrow simulations.

\begin{tabular}{lccccc}
\hline \multicolumn{1}{c}{ Parameter } & Minimum & Mean & Maximum & $\sigma$ & Distribution \\
\hline$K$ & $2.2 \times 10^{-3}$ & $1.69 \times 10^{-2}$ & $6.24 \times 10^{-2}$ & $9.3 \times 10^{-3}$ & $\sim$ lognormal \\
Rech & 0.319 & 2.066 & 6.65 & 1.24 & $\sim$ lognormal \\
$\theta$ & $1.057 \times 10^{-5}$ & $4.4 \times 10^{-4}$ & $6.2 \times 10^{-3}$ & $5.92 \times 10^{-4}$ & $\sim$ lognormal \\
$A_{L}$ & - & 100 & - & - & - \\
$A_{T}$ & - & 10 & - & - & - \\
$\alpha_{L}$ & - & 5.0 & - & - & - \\
$\alpha_{T}$ & - & 0.5 & - & - & - \\
$\kappa$ & - & 0.434 & - & - & - \\
$K_{g}$ & - & $1.26 \times 10^{-7}$ & - & - & - \\
\hline
\end{tabular}

Radionuclide transport simulations are also performed in a manner similar to the first stage described in Section 4. All transport parameters are kept constant in all realizations. Glass dissolution rate, $k_{g}$, is taken as $1.26 \times 10^{-7} \mathrm{day}^{-1}$, local dispersivities are fixed at 5.0 and $0.5 \mathrm{~m}$, and the matrix diffusion parameter is assigned a value of 0.434 (consistent with a $\theta_{m}$ of 0.12 , a $b$ of 5.0 $\mathrm{x} 10^{-4} \mathrm{~m}$ and $D_{\mathrm{m}}^{*}$ of $3.28 \times 10^{-6} \mathrm{~m}^{2} /$ day).

The particle-tracking transport simulations are performed for six cases with different release ratios and retardation behavior. The 24 radionuclides (parents and daughters) chosen for investigation are grouped into six solute classes based on their ratio of hydraulic release to geochemical release and retardation factor, and are listed in Table 5.2. The transport of the radionuclides in each solute class is simulated as a group, followed by application of the radioactive 

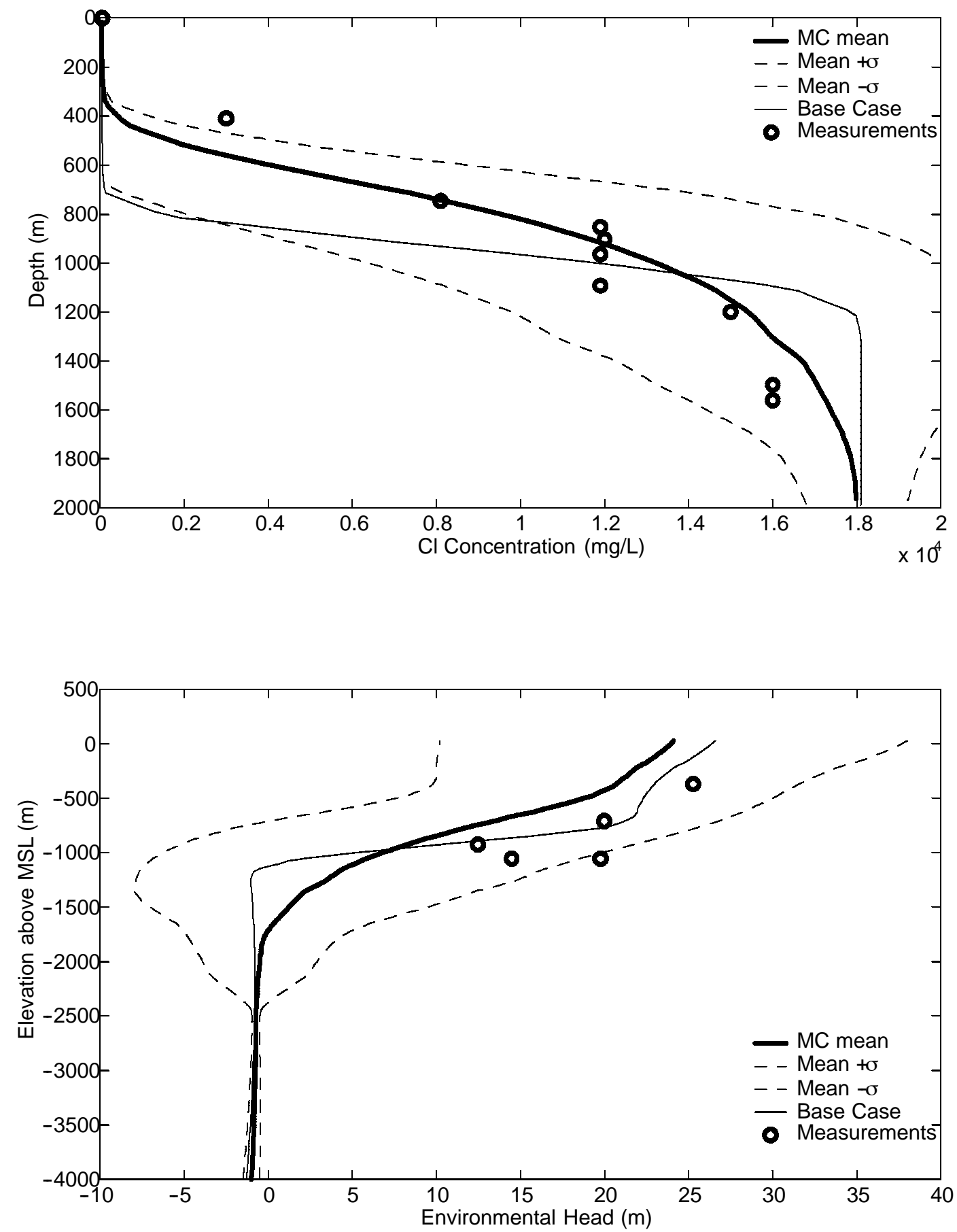

Figure 5.4. Sensitivity of UAe-2 concentrations and heads to the combined uncertainties of Rech, $K$ and $\theta$ in the second Milrow modeling stage. 
decay rate appropriate to each individual radionuclide. The total simulation time and the time step are scaled for each class using the appropriate retardation factor in such a way that the same average length is traversed by particles as for the cases with no retardation. Among the six cases, only Case 6 has a retardation factor of about 1.8 in the fractured system, and thus the simulation time and the time step are scaled with a factor of 2.0. The results of Monte Carlo simulations are presented in terms of the mean and standard deviation of the total solute flux, $Q(t)$, the point solute flux, $q(x, t)$, and the flux-averaged concentration, $C(x, t)$, where $x$ is the distance from the groundwater divide (island center) to the bathymetric segment at which $q$ and $C$ are computed.

Table 5.2. Values of Parameters Specific to Individual Solute Classes.

\begin{tabular}{|c|c|c|c|c|c|c|}
\hline Parameter & $\overline{\text { Case } 1}$ & Case 2 & Case 3 & $\overline{\text { Case } 4}$ & $\overline{\text { Case } 5}$ & Case 6 \\
\hline Total Time (years) & 2191 & 2191 & 2191 & 2191 & 2191 & 4382 \\
\hline Time Step, $\Delta t$ (days) & 100 & 100 & 100 & 100 & 100 & 200 \\
\hline $\begin{array}{l}\text { Release Ratio (\%), } \\
\text { Hydraulic Release / } \\
\text { Geochemical Release }\end{array}$ & $100 / 0$ & $50 / 50$ & $60 / 40$ & $20 / 80$ & $80 / 20$ & $5 / 95$ \\
\hline Retardation Factor & 1 & 1 & 1 & 1 & 1 & 1.8 \\
\hline $\begin{array}{l}\text { Geochemical Release } \\
\text { Coefficient } k g\left(\text { day }^{-1}\right)\end{array}$ & NA & $1.26 \times 10^{-7}$ & $1.26 \times 10^{-7}$ & $1.26 \times 10^{-7}$ & $1.26 \times 10^{-7}$ & $1.26 \times 10^{-7}$ \\
\hline
\end{tabular}

\subsubsection{Undecayed Breakthrough Curves}

The effects of the hydraulic/geochemical release ratio, the retardation, and the glass dissolution coefficient of the six solute classes are most effectively examined without the effects of radioactive decay. This is because the widely differing decay rates of the individual radionuclides conceal the general release and retardation behavior. It is also of interest to present the undecayed breakthrough curves with and without the inclusion of matrix diffusion to capture the effect of the matrix diffusion process.

Figure 5.5 (top) shows the undecayed breakthrough curves for the first solute class (100 percent hydraulic release) with and without matrix diffusion. Without matrix diffusion, a very early breakthrough is observed where the first mass arrival occurs at about five years after the test. As will be shown later, this early breakthrough is mainly controlled by a few realizations that have very high velocities (due to certain combinations of $\operatorname{Rech}, K$ and $\theta$ ). When adding matrix diffusion $(\kappa=0.0434$ and 0.434 ), a significant reduction in the mass flux values is obtained and a significant delay in mass arrival time. A typical feature of the matrix diffusion effect is to delay the arrival of mass to the breakthrough boundary, reduce the peak and induce a tailing effect. The shape and length of the tailing effect depends on the parameters governing the diffusion into the rock matrix, which are lumped into the $\kappa$ parameter. The effect of $\kappa$ will be addressed in the sensitivity analysis (Section 6.1.2).

The lower plot of Figure 5.5 shows the undecayed mass flux for the six solute classes with $\kappa=0.434$. It is clear that the shapes of the first five curves are similar with the difference caused 

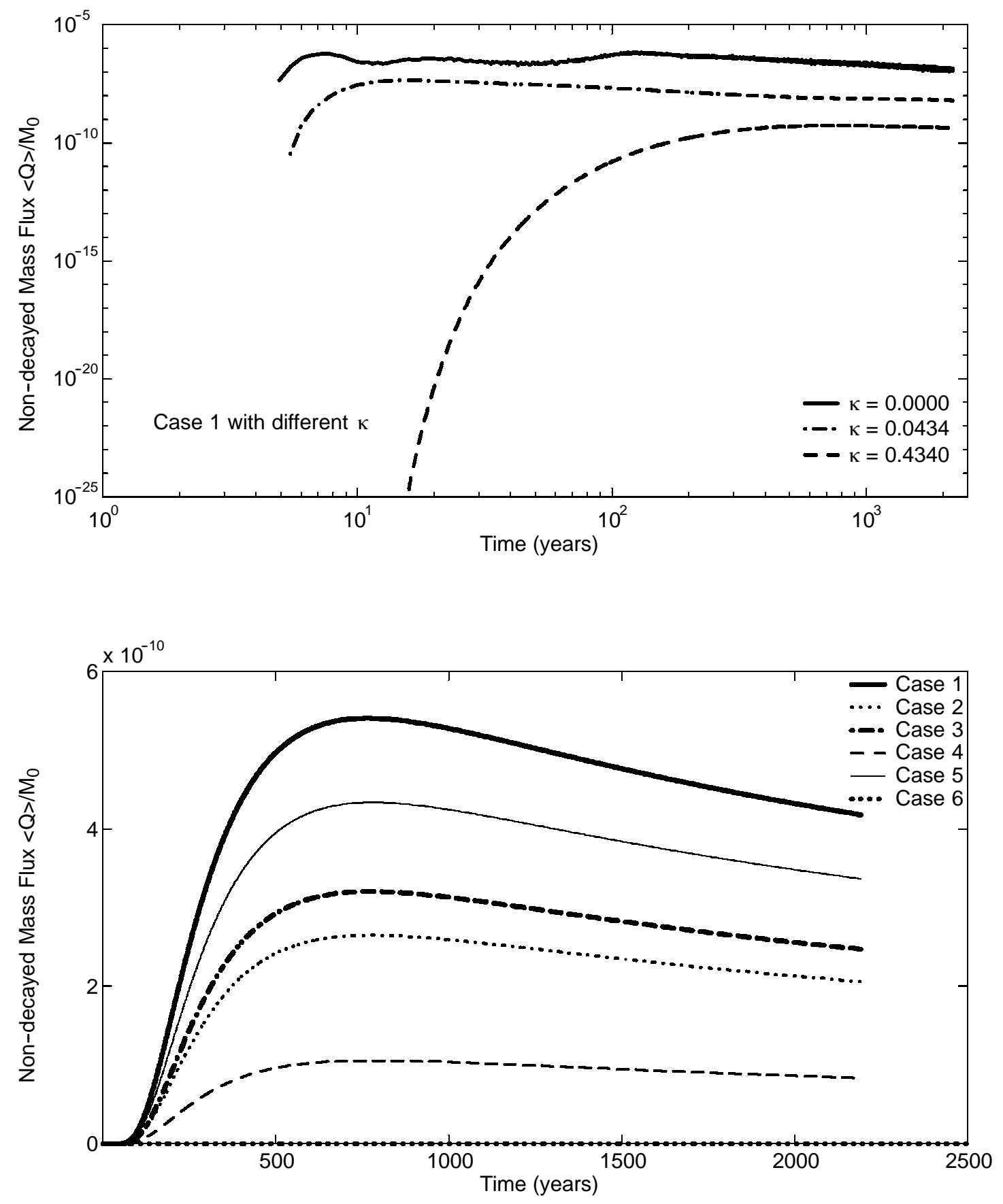

Figure 5.5. Undecayed Milrow breakthrough curves for the first solute class with different matrix diffusion strengths (top) and for the six solute classes with $\kappa=0.434$ (bottom). 
by the differing hydraulic/geochemical release ratio. Case 6 shows no significant mass flux due to the large retardation into the rock matrix. As Table 5.2 indicates, the first five classes differ only in the hydraulic/geochemical release ratio. This ratio has a major effect on the resulting mass flux and breakthrough curves because of the fact that travel time to the seafloor is much smaller than the time scale within which all glass mass is dissolved and released to the domain. That is to say that the mass flux within the short time scale of 2,200 years is mainly caused by the portion of mass subjected to hydraulic release that is assumed to occur instantaneously.

To shed more light on the early mass arrival to the seafloor and the individual realizations' results, the conservative breakthrough results (without matrix diffusion) are studied for Case 1 . The 300 realizations are analyzed in terms of the percentage of mass that breaks through within 2,200 years, the first arrival time, the duration of breakthrough, the location of the plume edges with respect to the bathymetric profile and the depths below MSL where breakthrough occurs. Figure 5.6 shows the distribution of the mass percentage that reaches the seafloor within the 2,200-year time frame. About 100 realizations show less than 1 percent of the total mass reaching the breakthrough boundary. Out of these realizations, 25 do not show any mass breakthrough. A total number of about 150 realizations have less than 5 percent of the total mass out within that time frame, 165 have less than 10 percent of the mass out and only about 13 realizations have above 90 percent of the mass out. It should be mentioned, however, that those realizations showing a very small percentage of mass breaking through may in fact contribute more to the peak mass flux and the early arrival of mass. That is to say that a realization with only 5 percent of mass out may contribute significantly to the peak flux and concentration if this portion of the mass arrives very early at the boundary.

To explain why some realizations do not show any breakthrough within the selected time frame, we plot in Figure 5.7 particle trajectories (advective-dispersive) in two realizations with the top plot showing a no-mass-breakthrough realization and the bottom one showing a realization with $>90$ percent mass breakthrough. The trajectories shown are for a particle released at the lower left corner of the cavity. The figure also shows the velocity field in both cases. Due to the location of the cavity below the transition zone in the first case, most (if not all) particles move either toward the island center or vertically in the chimney before they change direction and move toward the seafloor. In addition to this longer path, the velocities encountered below the transition zone are much smaller than above it, as indicated by the relative sizes of the velocity vectors shown in the figure. The other realization, with the cavity located above the transition zone, shows a direct movement for the same particle from the cavity to the seafloor direction. The different flow patterns in these realizations are dependent upon the random combination of the recharge, conductivity and fracture porosity values, while keeping the cavity and chimney porosity fixed at 0.07 . The main difference between the two realizations is that in the first one, the transition zone is shallow due to a small recharge-conductivity ratio $\left(\operatorname{Rech} / K=2.94 \times 10^{-3}\right)$ and the cavity location is at the lower edge of the transition zone. The other realization is having a much deeper transition zone $((\operatorname{Rech} / \mathrm{K}$ $=7.97 \times 10^{-3}$ ) and the cavity comes closer to the freshwater zone where velocity pattern is more or less uniformly oriented towards the seafloor. 

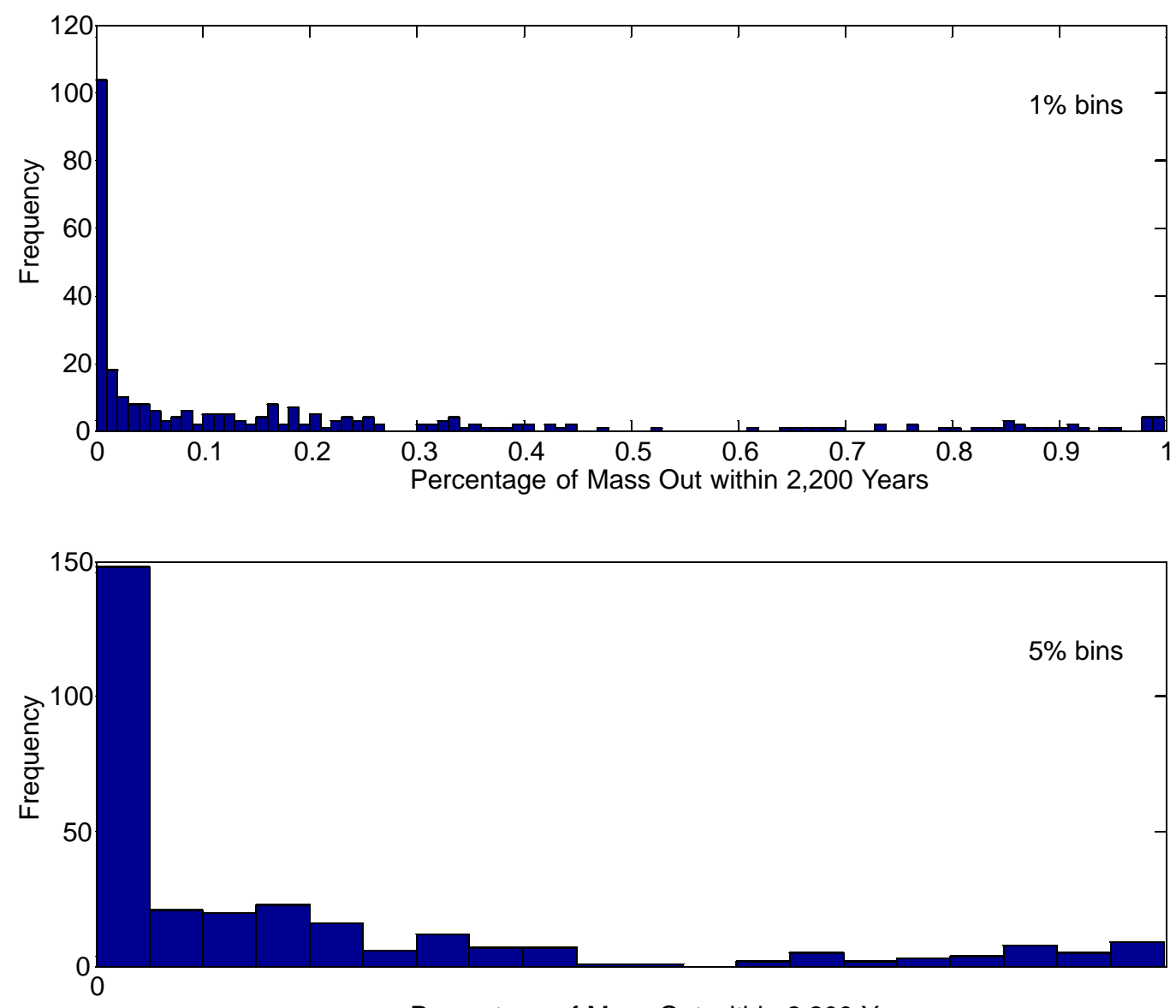

Percentage of Mass Out within 2,200 Years

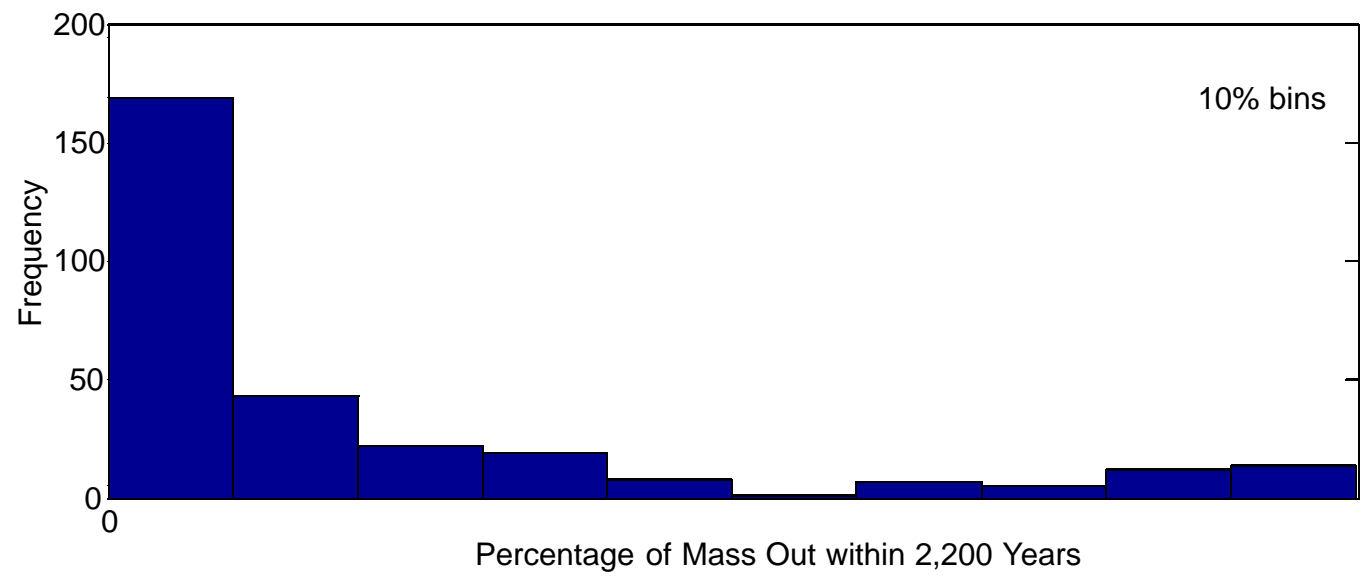

Figure 5.6. Histograms of the percentage of Milrow mass that has broken through within 2,200 years. 


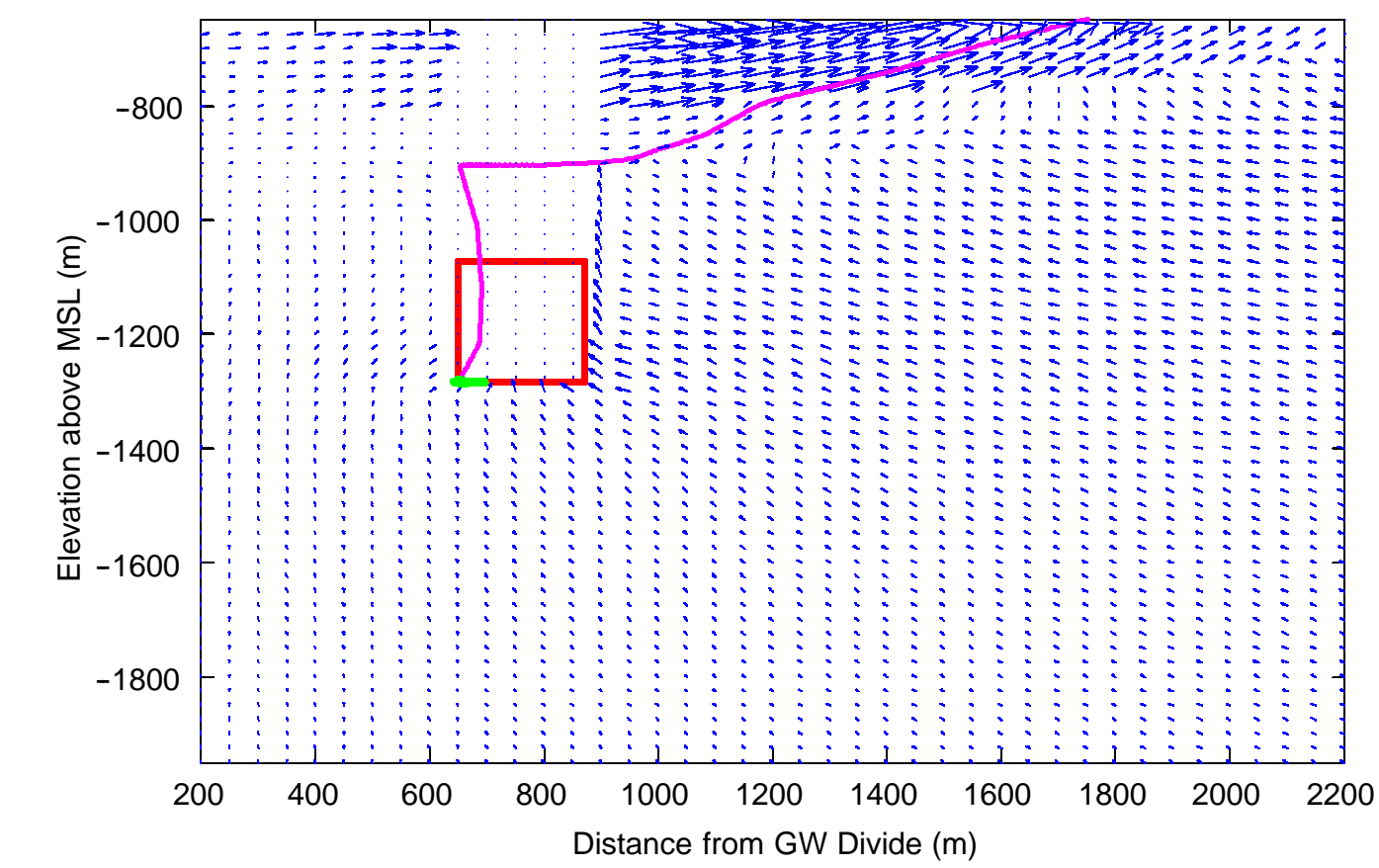

Test Cavity

- Particle Trajectory

Streamline

Velocity Field

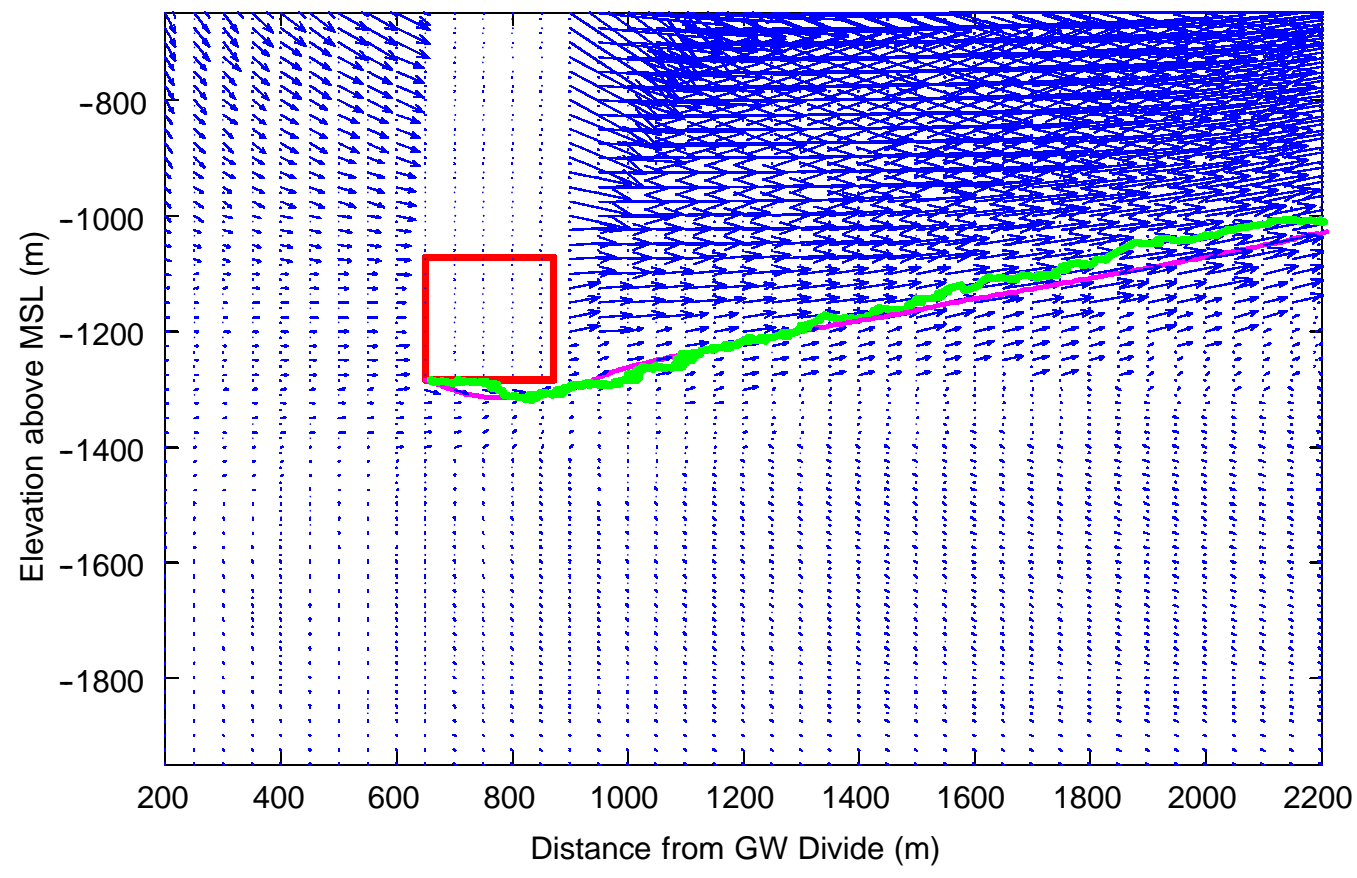

Figure 5.7. Velocity realizations for Milrow showing a circulatory pattern (top) and a non-circulatory pattern (bottom). 
To show how the particles travel from the cavity to the seafloor (breakthrough plane), a single realization showing about 100 percent mass breakthrough during the simulation time $(2,200$ years) is selected for analysis and visualization. The realization is assigned a $K$ value of $4.583 \times 10^{-3} \mathrm{~m} / \mathrm{d}$, a Rech value of $4.317 \mathrm{~cm} /$ year, a porosity value of $1.067 \times 10^{-3}$, and a recharge-conductivity ratio of $2.58 \times 10^{-2}$. The particles location at different times are reported and used to visualize the plume shape and movement. Figure 5.8 through Figure 5.11 show 12 snapshots of the particles' distribution at different times with the percentage mass reaching the seafloor computed and presented on the figures. No particles reach the seafloor within the first 100 years after the detonation. At 140 years, the leading edge of the plume starts to arrive at the seafloor. Larger numbers of particles arrive between 140 and 180 years, with a total of 1.2 percent of the initial mass reaching the seafloor by 180 years. About 55 percent of the total mass arrives at the seafloor between 200 and 500 years (Figure 5.9), and about an additional 17 percent arrives between 500 and 700 years (Figure 5.10). By 1,000 years after detonation, 90 percent of the mass reaches the seafloor and the rest of the mass arrives very slowly over the remaining 1,200 years of simulation (Figure 5.11).

To continue the analysis of individual realizations, Figure 5.12 presents the distributions of the first arrival time (whether it is for one particle or a thousand particles), the last arrival and the duration of breakthrough. The figure illustrates that about 58 realizations show a first mass arrival less than 60 years. Only a few realizations show a last arrival within the 2,200-year simulation time. This is also evident for the histogram of the breakthrough duration, where only about 20 realizations show ceasing of breakthrough in 500 years or less. This ceasing does not necessarily mean full breakthrough, but means that no particles arrive at the seafloor after the last arrival. Figure 5.13 shows the distribution of the location of the plume edges relative to the groundwater divide and the distribution of the plume width before and after accounting for matrix diffusion. The location of the left (first) edge of the plume is concentrated around 3,000 $\mathrm{m}$ from the island centerline, while the right (second) edge of the plume is located around 4,000 $\mathrm{m}$ in a large number of realizations. These results indicate that the plume before accounting for matrix diffusion is mainly spread over a length less than one kilometer along the bathymetric profile in most of the realizations. The other quantity that is very essential for risk assessment is the depth below MSL where breakthrough occurs, which is shown in Figure 5.14. This shows that the left edge of the plume exists at a depth of 2 to $10 \mathrm{~m}$, whereas the right edge exists at a depth of 5 to $30 \mathrm{~m}$ below MSL. As mentioned earlier, 25 realizations out of 300 did not show any breakthrough within the simulation time of 2,200 years. 

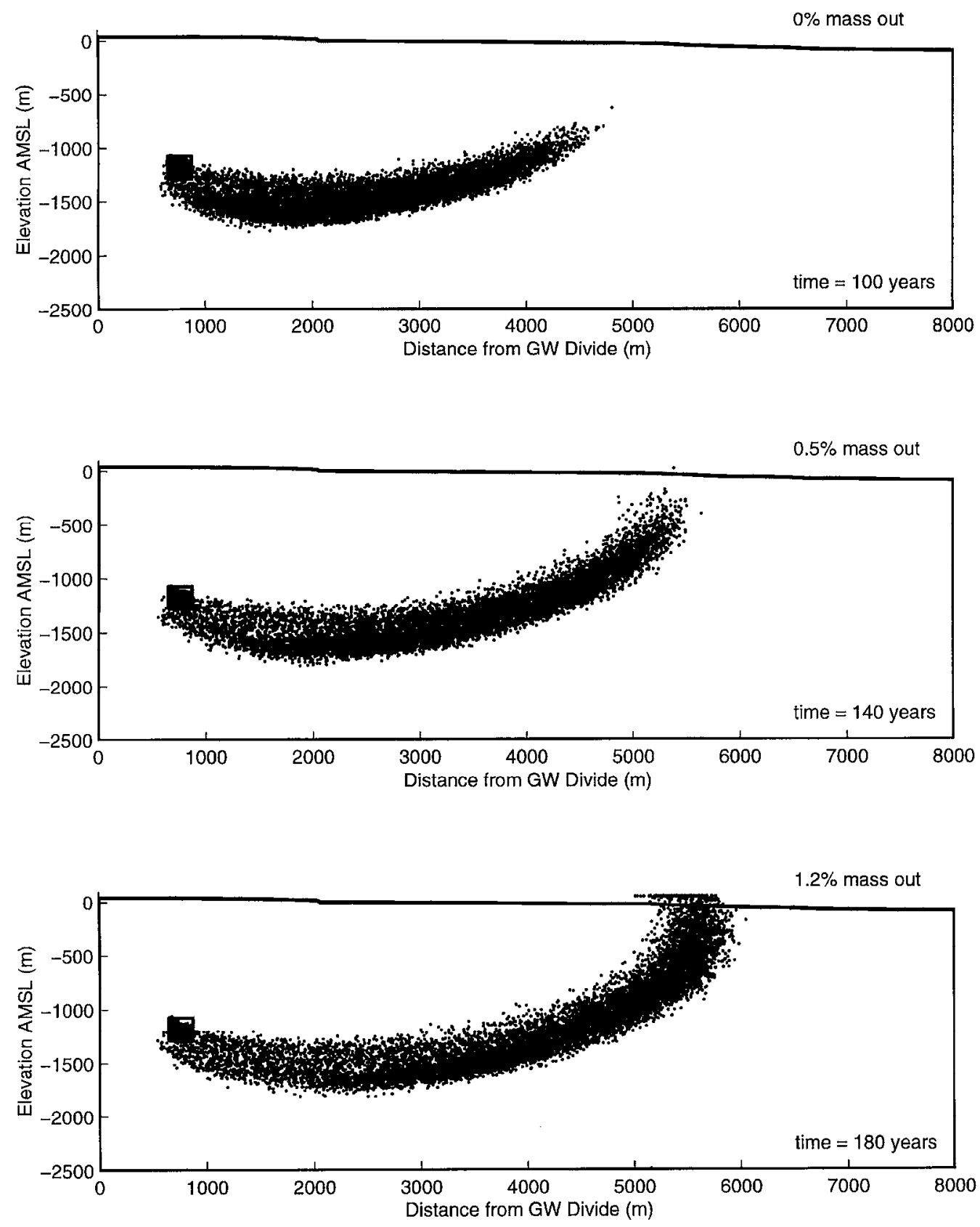

Figure 5.8. Three snapshots of the particle distribution (plume shape) at different times for Milrow. 

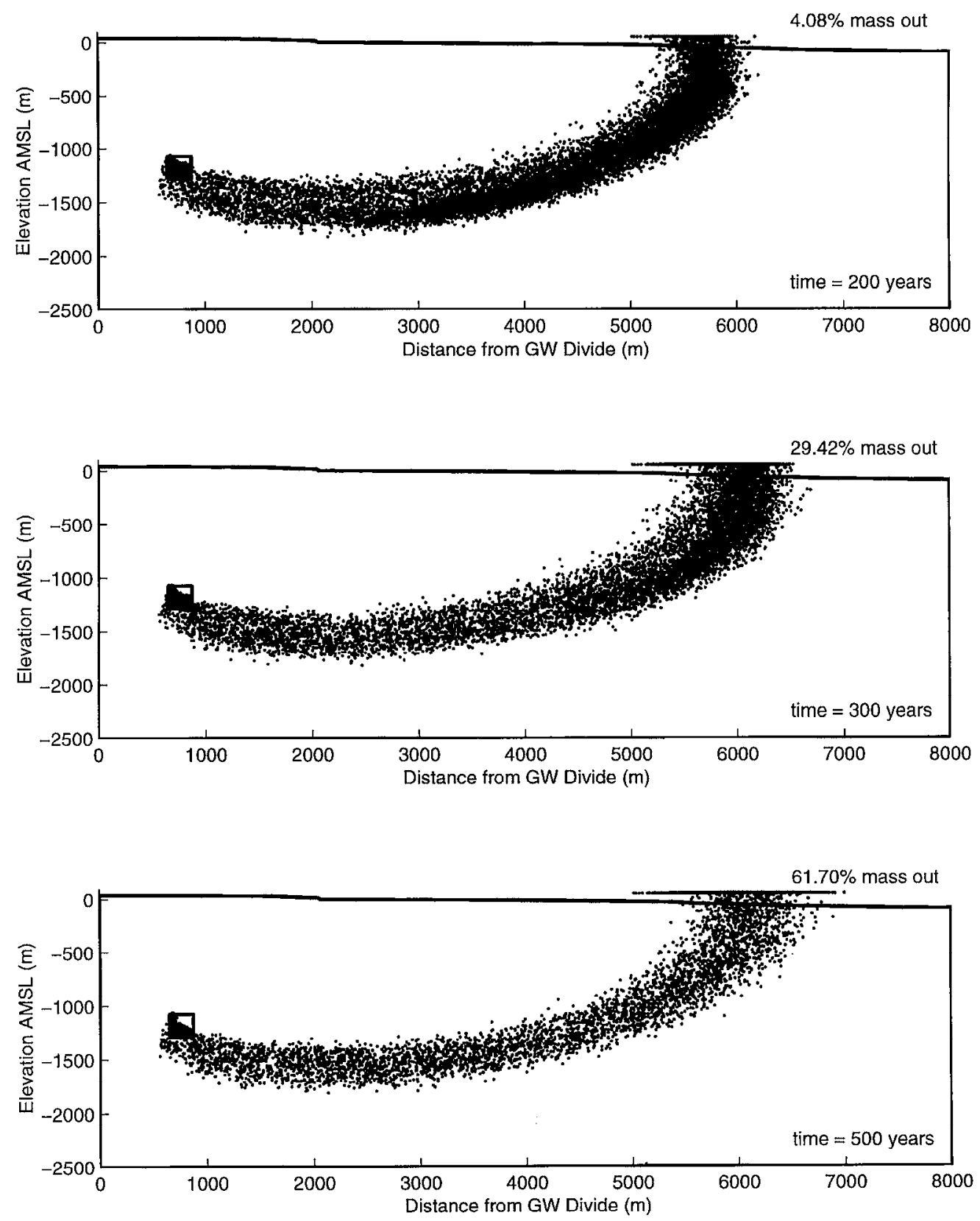

Figure 5.9. Three snapshots of the particle distribution (plume shape) at different times for Milrow. 

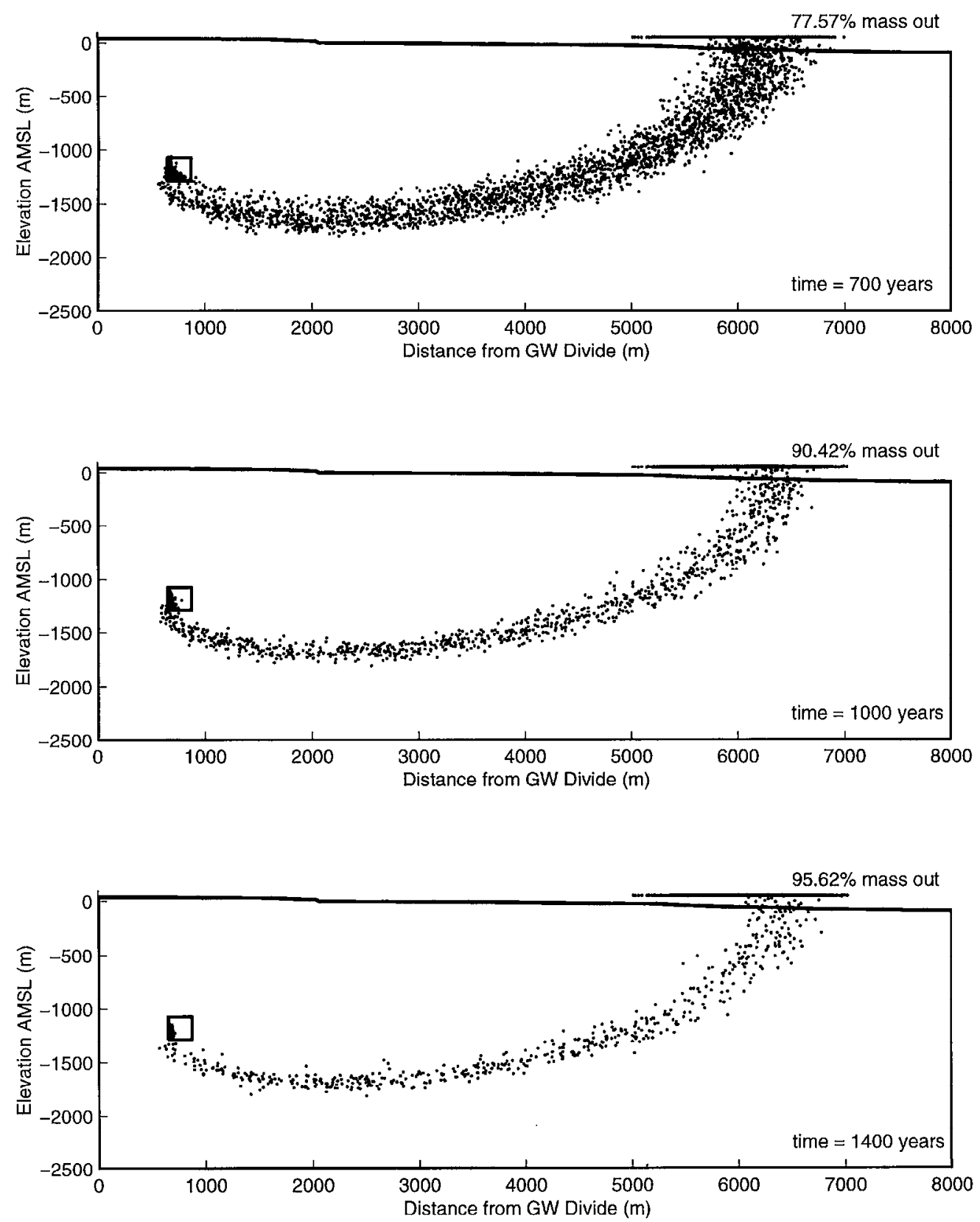

Figure 5.10. Three snapshots of the particle distribution (plume shape) at different times for Milrow. 

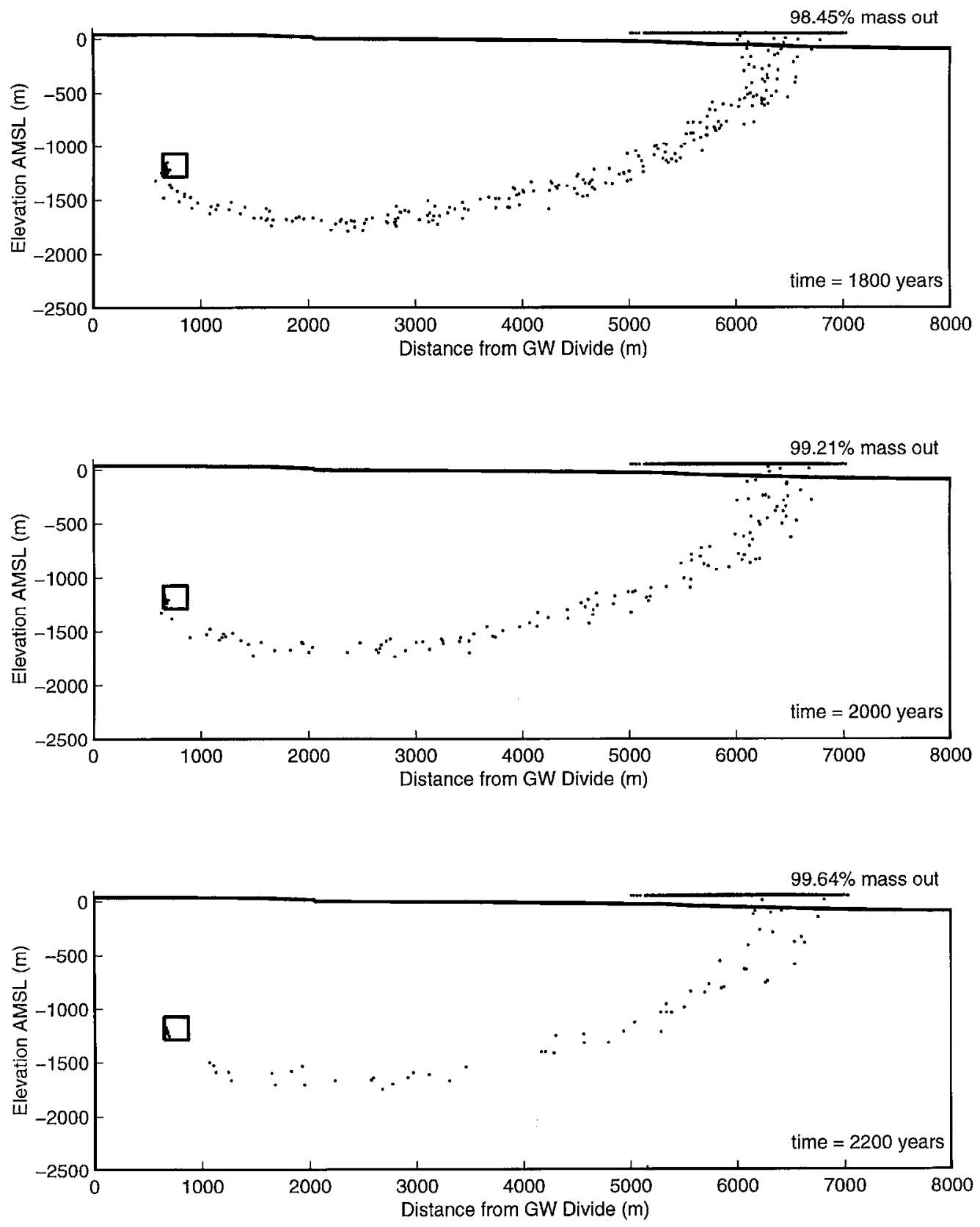

Figure 5.11. Three snapshots of the particle distribution (plume shape) at different times for Milrow. 

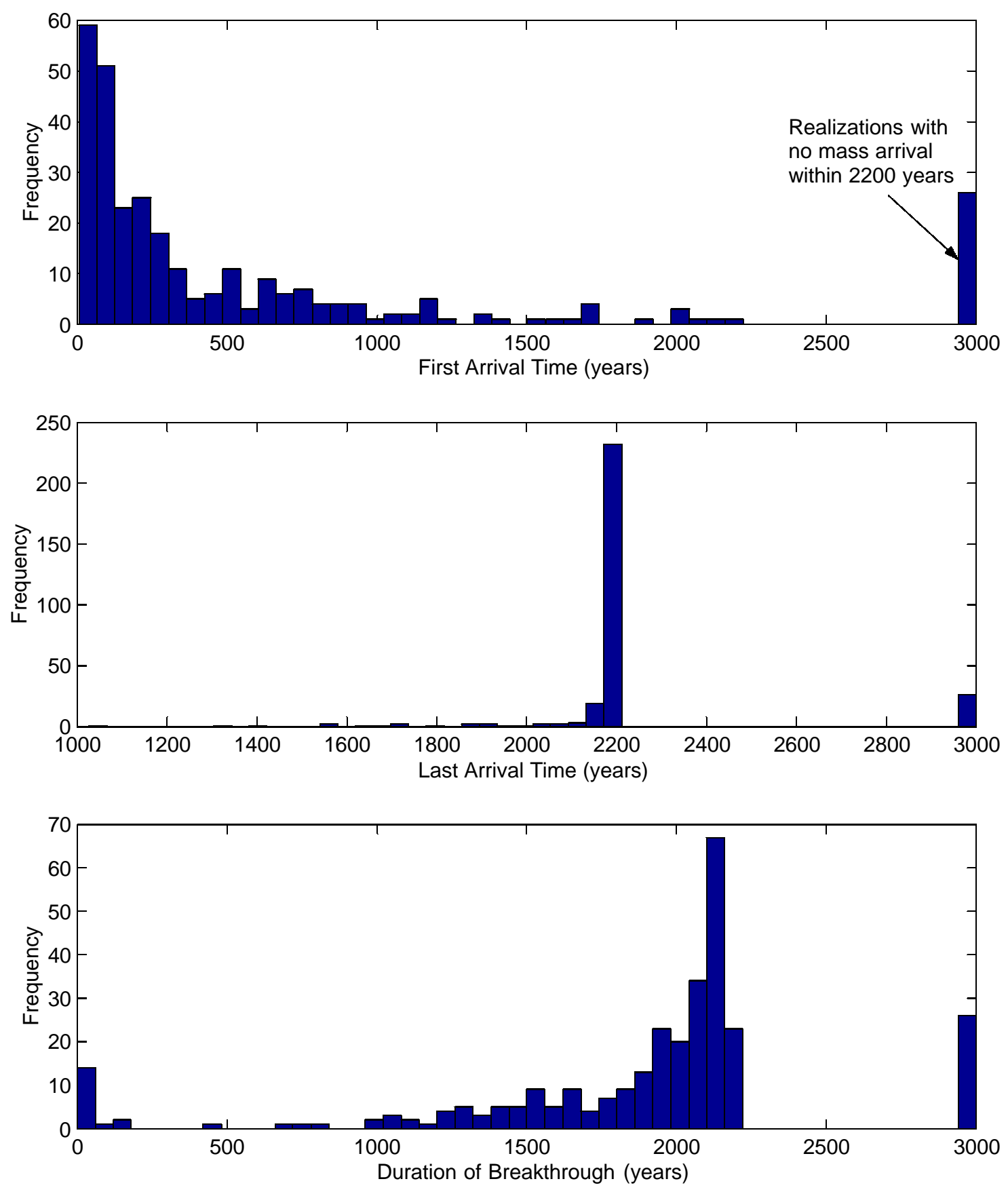

Figure 5.12. Histograms showing the distribution of first arrival time, last arrival time, and duration of breakthrough for Milrow. 

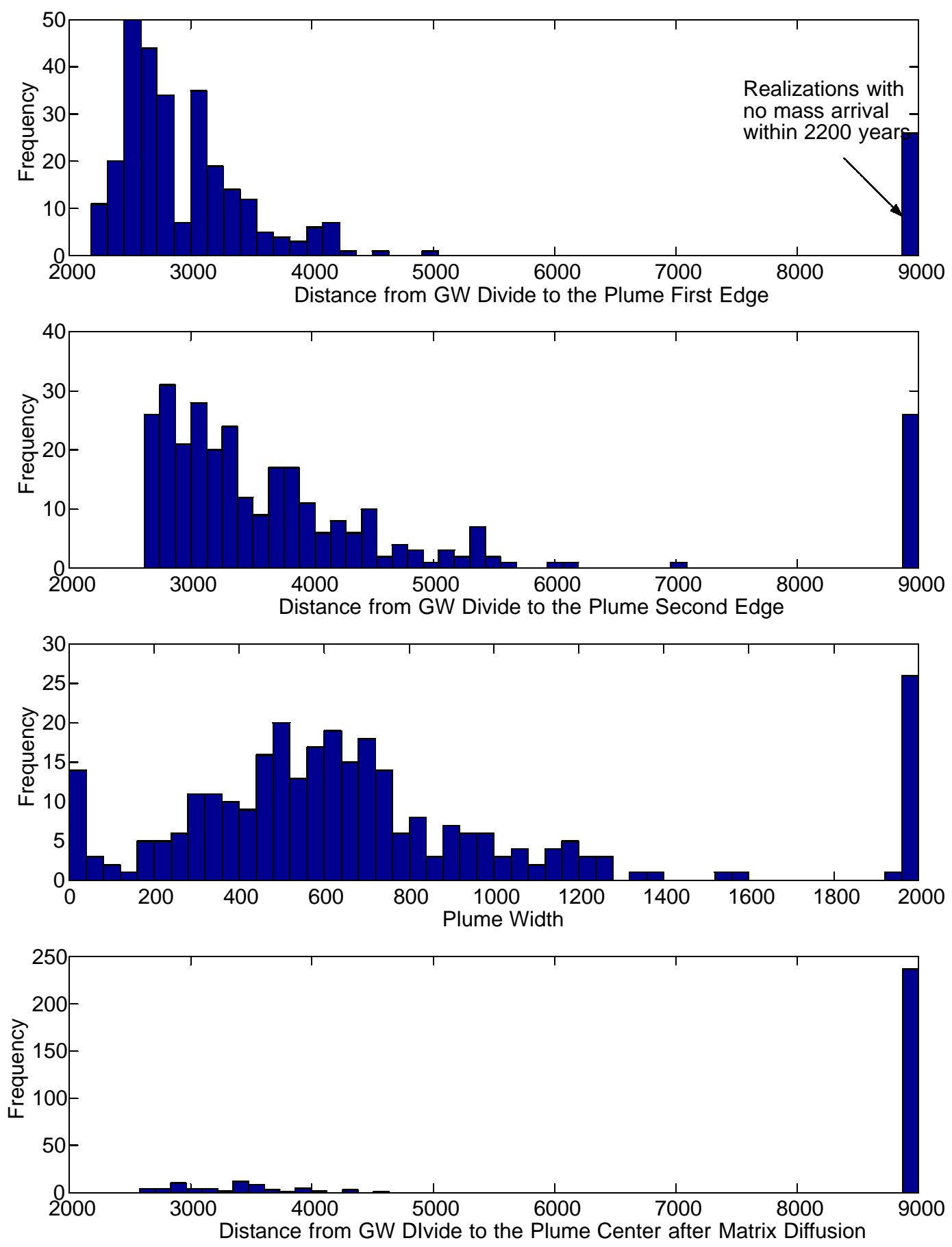

Figure 5.13. Histograms showing the distance from groundwater divide to plume edges and plume width for Milrow. 

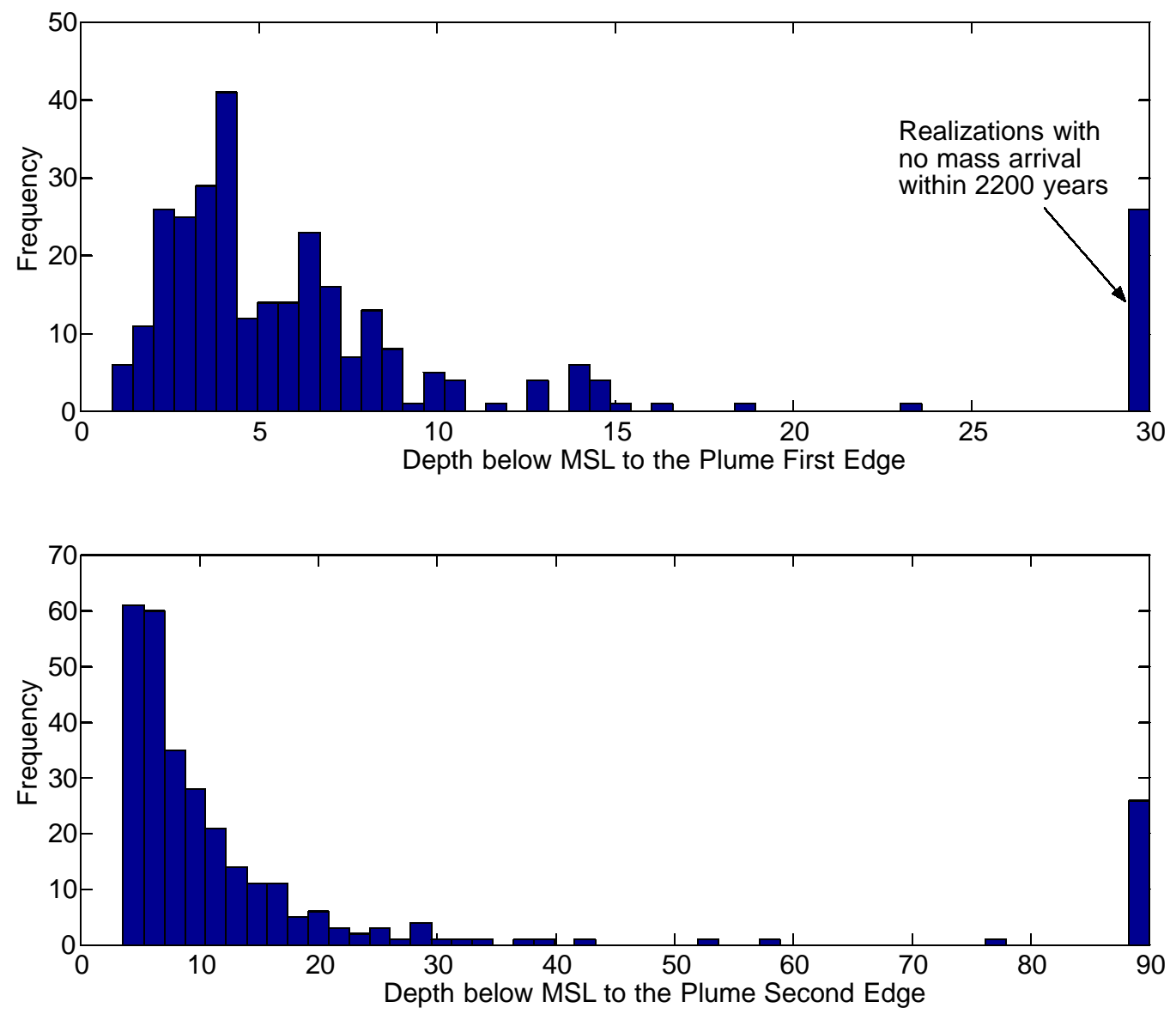

Figure 5.14. Histograms showing the distributions of depths below MSL at which the plume edges discharge to the ocean floor for Milrow. 


\subsubsection{Breakthrough with Radioactive Decay}

For all 12 radionuclides representing the first five cases, the results for flow and transport are tabulated in Table 5.3. The normalized peaks of expected mass flux and concentration $\left(\langle Q\rangle_{\max }\right.$, $\langle q\rangle_{\max }$, and $\left.\langle C\rangle_{\max }\right)$ at the seafloor, and the peaks of the standard deviations $\left(\left(\sigma_{Q}\right)_{\max },\left(\sigma_{q}\right)_{\max }\right.$, and $\left.\left(\sigma_{C}\right)_{\max }\right)$ are listed in the table. Also the times and locations at which these peaks occur are presented. Table 5.3a displays the statistics related to $Q(t)$ and $q(x, t)$, whereas Table 5.3b shows the statistics of the concentration $C(x, t)$. In addition, the uncertainties associated with arrival times and locations are given in the last two columns of Table 5.3b. The flux and concentration values include radioactive decay and are based on unit mass at the source. Radionuclides in Case 1 have no retardation and 100 percent hydraulic release, which means that all particles are released to the flow field and allowed to move at the same time. Figure 5.15 gives the flux and concentration results for tritium, ${ }^{3} \mathrm{H}$, which is an element in Case 1 . The short travel times (without matrix diffusion effect) to the seafloor result in essentially little decay (if any) even with the short half-life of ${ }^{3} \mathrm{H}$. However, adding the matrix diffusion effect yields a delayed arrival and allows for more radioactive decay. Figure 5.15 shows that the mean concentration distribution has a peak value of about $1.6 \times 10^{-8}$ times the initial source concentration, $C_{0}$. Adding one standard deviation to this value leads to a normalized peak of about $3.0 \times 10^{-7}$. This peak occurs roughly 110 years after the test and at about $4,500 \mathrm{~m}$ from the island center (about 2,440 $\mathrm{m}$ from the shoreline).

As alluded to earlier, matrix diffusion leads to delayed arrival of mass and lower mass fluxes. This delayed arrival encounters significant decay for short-lived nuclides. The effect of this parameter is much less dramatic for radionuclides with long half-lives. Carbon-14, with a half-life about three orders of magnitude longer than tritium, shows significant mass flux and peak concentration as compared to ${ }^{3} \mathrm{H}$ with $\mathrm{\kappa}=0.434$. The normalized peak of the mean concentration is found to be about $1.4 \times 10^{-4}$, as shown in Figure 5.16, and occurs at about 700 years and the same location as for ${ }^{3} \mathrm{H}$.

Classes 2 to 5 include a portion of slow release due to glass dissolution with different ratios of hydraulic/geochemical release. To show the effect of the slow release ratio, the results for an element in Class 1 (with 100 percent hydraulic release) are compared to those of an element in Class 3 with 60 percent hydraulic release and 40 percent slow release via glass dissolution. Figure 5.17 compares the total mass flux decayed breakthrough curves $(\langle Q(t)\rangle)$ for ${ }^{85} \mathrm{Rb}$ from Class 1 and ${ }^{90} \mathrm{Zr}$ from Class 3. These two elements are selected because they both are stable daughters and thus the effect of different half-lives can be removed. The top plot of Figure 5.16 is for $\kappa=0.434$ and the lower plot is for $\kappa=0.0434$. As is clear from the figure, the different values of mass flux are the result of releasing all the mass instantaneously in the case of ${ }^{85} \mathrm{Rb}$ but releasing only 60 percent of the mass and holding 40 percent in glass puddle in the case of ${ }^{90} \mathrm{Zr}$. The figure also exhibits the effect of changing the matrix diffusion parameter $\kappa$ by an order of magnitude. That change results in a two-orders-of-magnitude change in the resulting mass flux for both elements presented in the figure. Again, a thorough sensitivity analysis for the effect of $\kappa$ is presented in Section 6.1.2. 


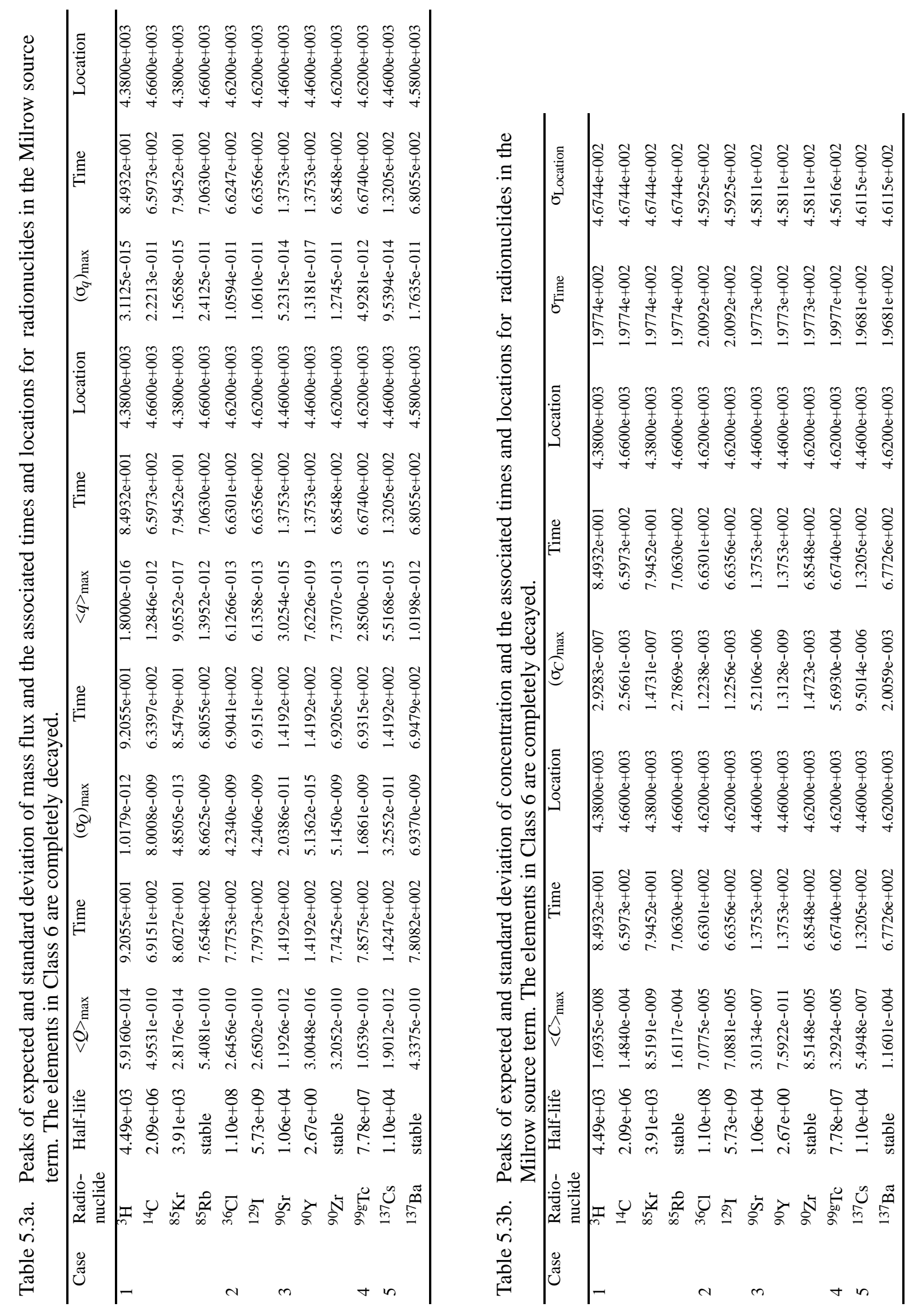



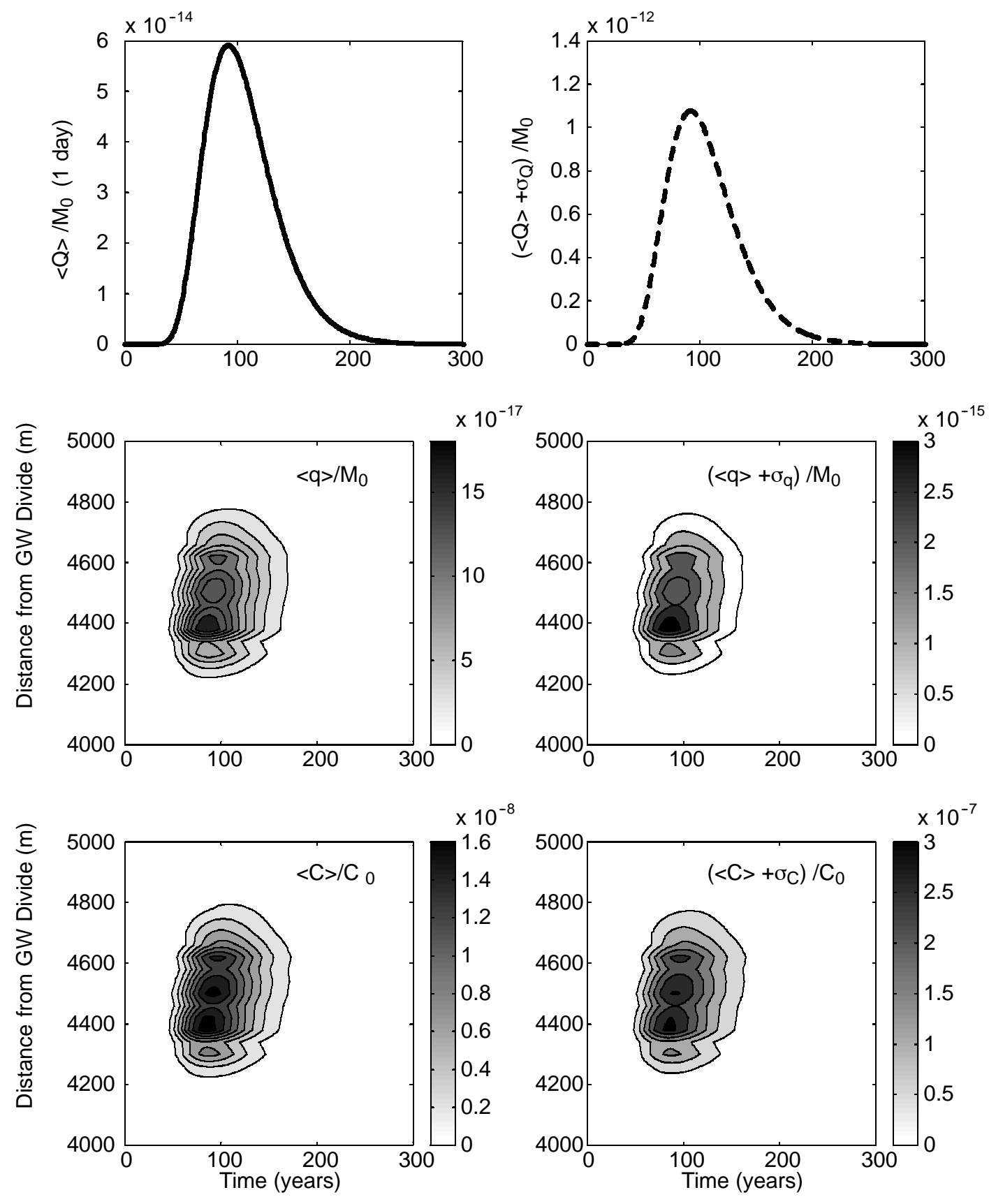

Figure 5.15. Statistics of mass flux and concentrations for ${ }^{3} \mathrm{H}$ with $\kappa=0.434$. 

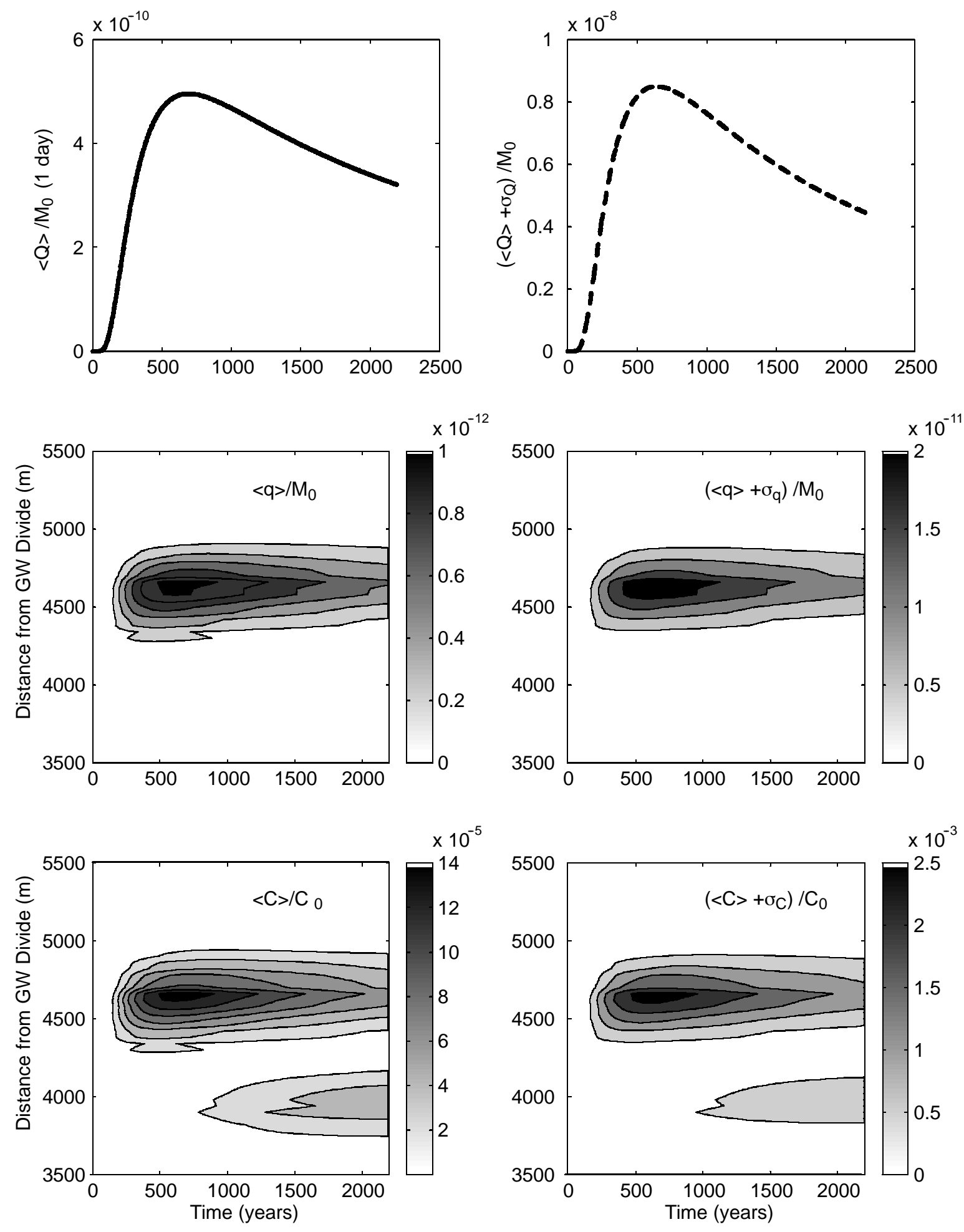

Figure 5.16. Statistics of mass flux and concentrations for ${ }^{14} \mathrm{C}$ with $\kappa=0.434$. 

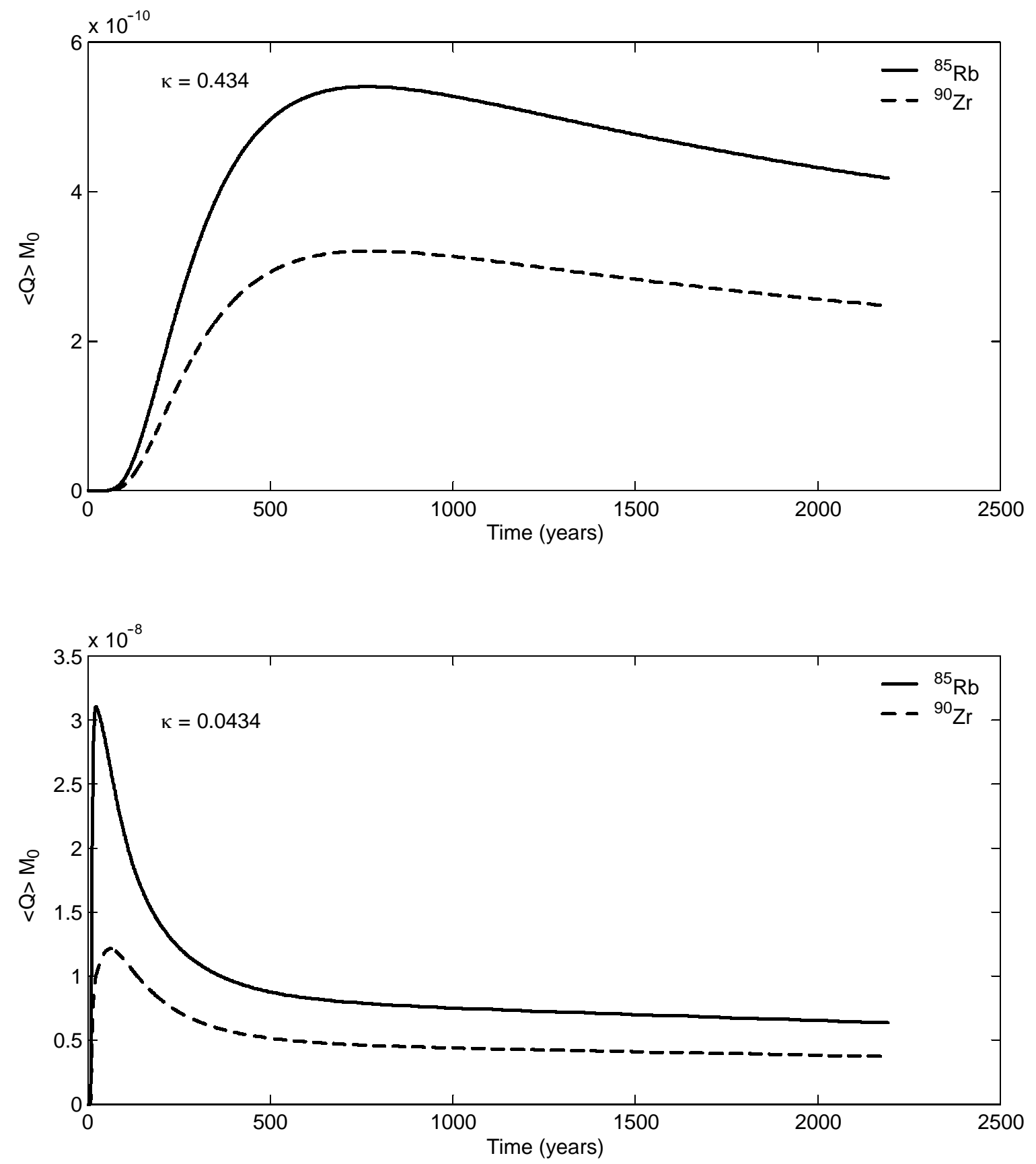

Figure 5.17. The effect of the release category (proportion of glass release) on breakthrough. 


\subsubsection{Milrow Summary and Discussion}

A three-step modeling scheme is adapted for Milrow where a calibration analysis is followed by a multi-parameter sensitivity analysis for many flow and transport parameters, and finally the combined effect of a few random parameters is addressed in the third step of modeling. Data available from the Milrow site are used to identify the location of the transition zone and the vertical distribution of groundwater heads near the test. The existence of these two sets of data constrains the model calibration. Many combinations of the parameters governing the density-driven flow modeling are tested with no single parameter-combination producing results that match the two data sets. A calibration case is then selected and used in the second step which entailed studying the sensitivity of transport results to the uncertainty associated with the flow and transport parameters. The result of this sensitivity analysis is the reduction of the number of uncertain parameters from seven to only three. Uncertainties of recharge, conductivity and fracture porosity are found to have the most significant effect on travel times and transverse locations where the plume hits the seafloor.

Three random distributions are then generated for these parameters and used in the final modeling stage where each realization utilizes randomly generated recharge, conductivity and porosity values. The combined distributions for these three parameters produce a wide range of variability around the base-case mean values. The recharge-conductivity ratio changes by more than one order of magnitude (the maximum ratio is roughly 25 times the minimum ratio). The conductivity-porosity ratio also changes by about three orders of magnitude. This wide range of variability in the input parameters leads to a large degree of variability in arrival time of radionuclides. This arrival time is mainly affected by the conductivity-porosity ratio, which changes significantly between realizations.

The final results show that the radionuclides could start to arrive at the seafloor within 10 years of release from the cavity. However, the distribution of first arrival time covers a very long time scale, extending from 10 years to 2,200 years and beyond. About 8 percent of the total realizations do not show any breakthrough within 2,200 years. The early arrival is mainly controlled by a few realizations in which the transition zone is below the cavity. This allows for the direct and quick migration of radionuclides from the cavity to the seafloor. The important fact is that the portion of mass that arrives early, even if very small, contributes to the peak flux and concentration more than the rest of the mass arriving at a later time due to radioactive decay. This is particularly true for short-lived radionuclides such as ${ }^{3} \mathrm{H}$.

As with any radioactive transport simulation, the most influential parameters are those changing the travel time. Uncertainty in estimating such parameters leads to great uncertainty in transport results, which is magnified by the radioactive decay that is a function of the residence time. The analysis performed for Milrow (and the other tests, as will be seen later) reveals the very crucial aspect of selecting the value of the fracture porosity. With lack of data, a very small fracture porosity is used and the porosity value is varied by two orders of magnitude. These choices are very crucial and have critical consequences when it comes to travel times and radioactive decay. Increasing the porosity values by only an order of magnitude may lead to a significant reduction in mass flux and concentrations especially for short-lived nuclides. 
The uncertainty associated with determining the hydraulic conductivity value is not as crucial as that of the porosity since a significant amount of conductivity data exists that gives a good idea about the range of conductivity values at the island. Of course, both uncertainties are equally important for travel time, but there are sufficient data to alleviate major concerns about the range of values selected for the hydraulic conductivity, while no data exist for the fracture porosity.

\subsection{Long Shot Flow and Transport Results}

The calibration process is repeated for Long Shot, with the same objective of selecting base-case flow and saltwater intrusion parameters that provide a modeling result as close to reality as possible. Though Long Shot has the same types of calibration data used at Milrow (chloride concentrations, and deep heads), the quantity of data is smaller. Specifically, the chloride profiles do not extend into the transition zone so they cannot be used to identify the location and width of the transition zone at Long Shot. Similarly, the deep hydraulic head measurements are restricted to shallower depths than at the other sites.

Three random distributions are generated for the conductivity, recharge and fracture porosity. Distributions with 500 values of conductivity and recharge are generated. An upper and a lower limit for the recharge-conductivity ratio are specified to ensure that the transition zone is consistent with the available data and information at Long Shot and the other sites. The thickness of the freshwater lens is considered possibly larger than that at Milrow, based on limited information at Cannikin, suggesting that the freshwater lens is assymmetric between the Bering and Pacific sides of the island (Fenske, 1972). Therefore, the 500 values for the recharge conductivity ratio are computed and the realizations that satisfy the condition $0.0047 \leq \operatorname{Rech} / K \leq 0.019$ are selected, which yielded 240 realizations of the random values. It should be mentioned that the lower limit is about four times the one used for Milrow but the upper limit is smaller (0.0347 for Milrow). This is to eliminate those realizations with very shallow transition zones, which are unlikely to occur at Long Shot. The minimum, mean and maximum values of $K$ are $2.3 \times 10^{-3}, 1.21 \times 10^{-2}$, and $4.44 \times 10^{-2} \mathrm{~m} /$ day, respectively. For the recharge, these limits are 0.809, 3.416, and $14.09 \mathrm{~cm} /$ year, respectively. Independently of these values, 240 random porosity values are generated with a minimum of 1.024 $\times 10^{-5}$, a mean of $4.11 \times 10^{-4}$, and a maximum of $5.2 \times 10^{-3}$. Figure 5.18 displays the histograms of these three distributions. In comparing these distributions to those used in Milrow, it is found that recharge has a higher mean but conductivity has a lower mean. This is to be expected, as it is an attempt to reproduce a deeper transition zone as compared to Milrow. Porosity values, on the other hand, show a similar distribution as for Milrow.

Figure 5.19 compares the recharge-conductivity ratio and the conductivity-porosity ratio for the generated distributions to the base-case values. Recall that in the base case, $K=1.58 \times 10^{-2} \mathrm{~m} /$ day, Rech $=3.65 \mathrm{~cm} /$ year, and $\theta=5.0 \times 10^{-4}$. The plots in Figure 5.19 illustrate how the two ratios (Rech/K and $K / \theta$ ) vary among the 240 realizations around the base-case ratios. As can be seen in the figure, $\operatorname{Rech} / K$ varies from a minimum that is about 0.7 times the base-case ratio to a maximum that is about three times larger. More realizations lie above the base-case line than below it, which indicates some skewness towards the high recharge range that is necessary to drive the transition zone downwards. The conductivity-porosity ratio varies from ten times smaller to about 50 times 

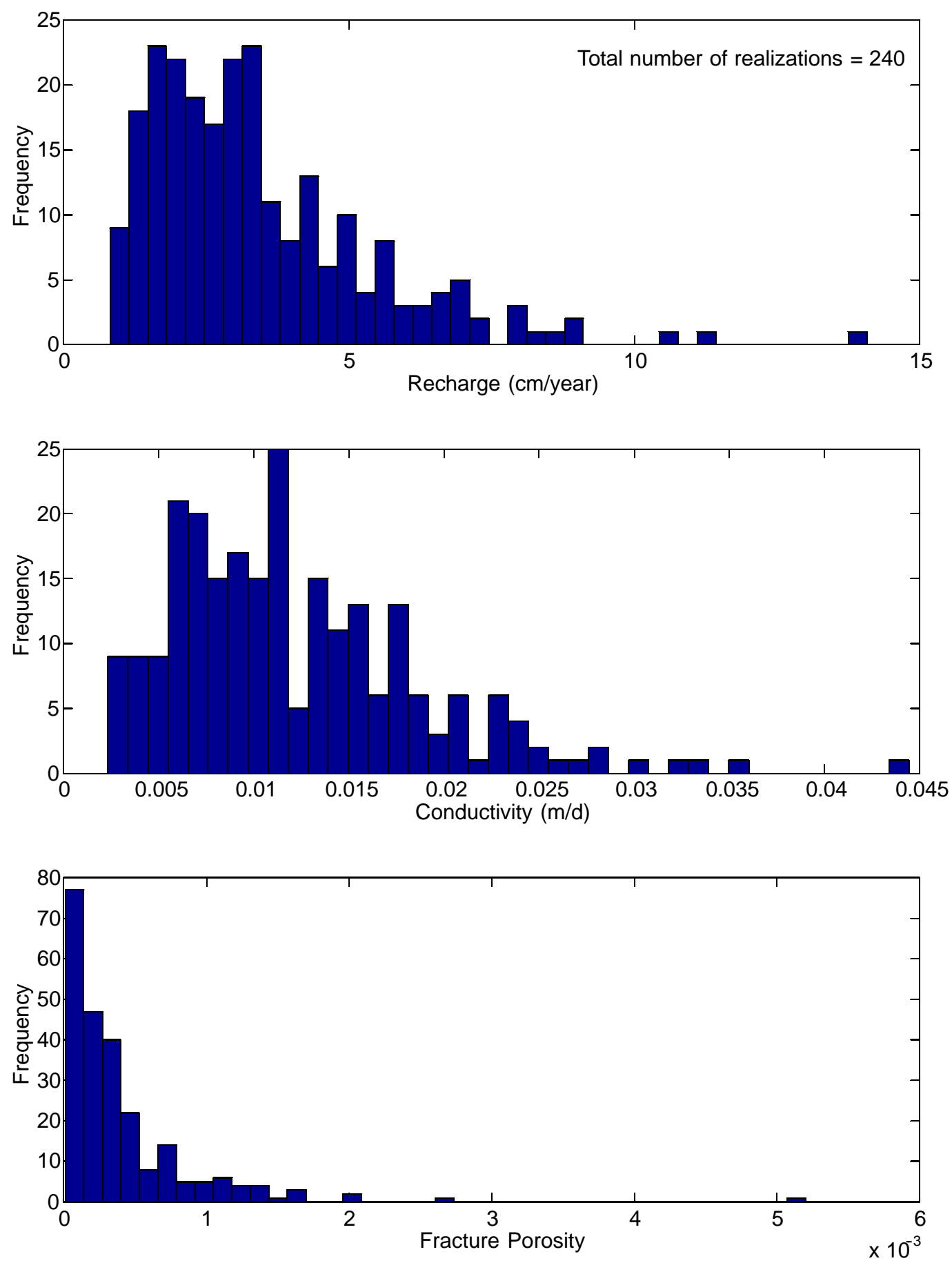

Figure 5.18. Randomly generated distributions for Rech, $K$ and $\theta$ in the second (final) modeling stage. 

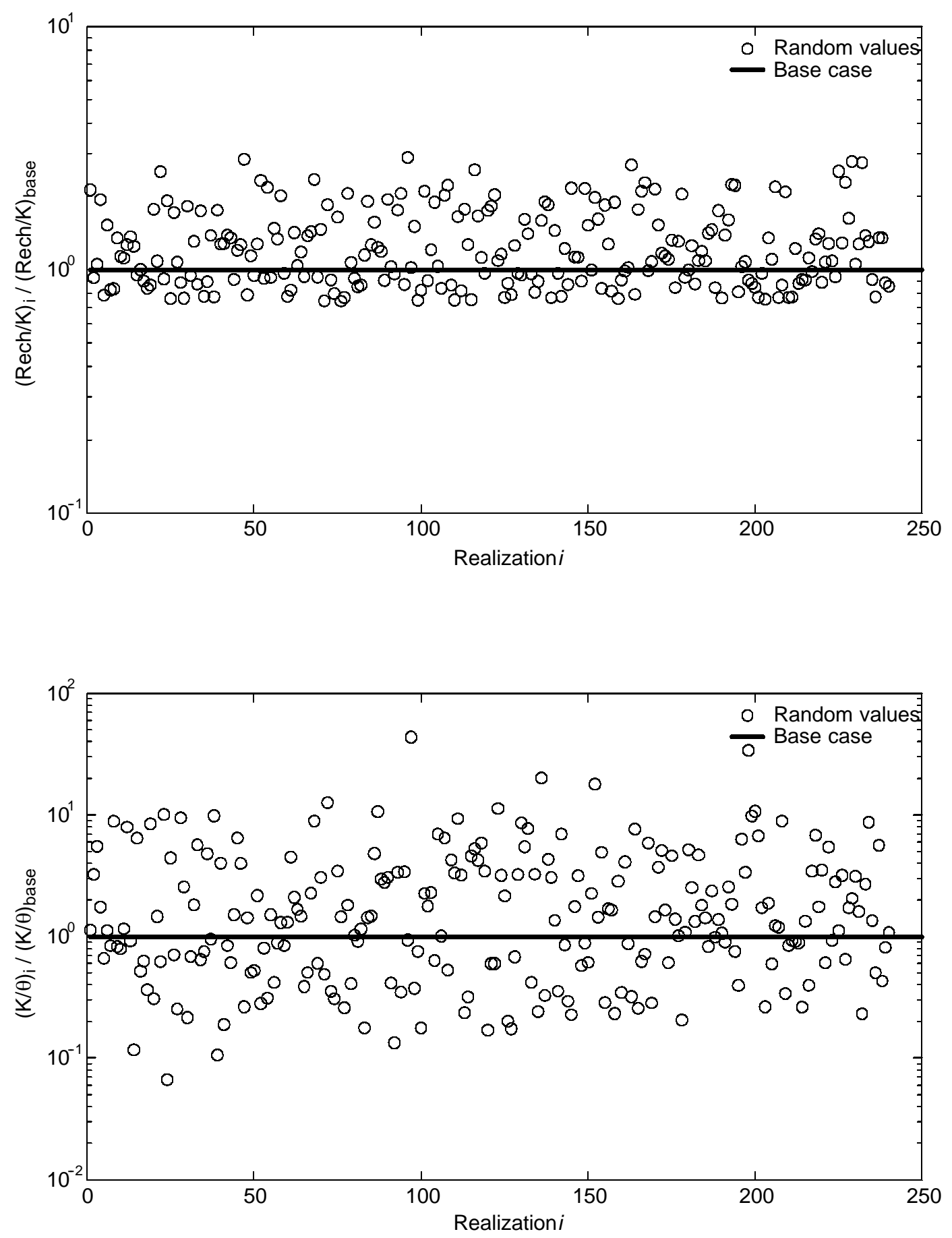

Figure 5.19. Comparison of the randomly generated recharge-conductivity and conductivity-porosity ratios relative to the base-case values. 
larger than the base-case value. This ratio is more or less evenly distributed around the base-case value. The flow and transport parameters used for Long Shot are summarized in Table 5.4.

Table 5.4. Parameter range for Long Shot simulations.

\begin{tabular}{lccccc}
\hline \multicolumn{1}{c}{ Parameter } & Minimum & Mean & Maximum & $\sigma$ & Distribution \\
\hline$K$ & $2.3 \times 10^{-3}$ & $1.21 \times 10^{-2}$ & $4.44 \times 10^{-2}$ & $6.66 \times 10^{-3}$ & $\sim$ lognormal \\
Rech & 0.809 & 3.416 & 14.09 & 2.01 & $\sim$ lognormal \\
$\theta$ & $1.024 \times 10^{-5}$ & $4.11 \times 10^{-4}$ & $5.2 \times 10^{-3}$ & $5.19 \times 10^{-4}$ & $\sim$ lognormal \\
$A_{L}$ & - & 100 & - & - & - \\
$A_{T}$ & - & 10 & - & - & - \\
$\alpha_{L}$ & - & 5.0 & - & - & - \\
$\alpha_{T}$ & - & 0.5 & - & - & - \\
$\kappa$ & - & 0.434 & - & - & - \\
$K_{g}$ & - & $1.26 \times 10^{-7}$ & - & - & - \\
\hline
\end{tabular}

FEFLOW is used to solve the density-driven flow problem for 240 realizations with the recharge, conductivity, and porosity values already generated. Macrodispersivity values are fixed at $100 \mathrm{~m}$ and $10 \mathrm{~m}$ in the longitudinal and transverse directions, respectively. Domain geometry and boundary conditions remain unchanged as compared to the analysis in Section 4 . To assess the choice of the combined random values used in this analysis, the results of these realizations at location EH-5 are analyzed and compared to the measured heads and concentrations. Figure 5.20 illustrates this comparison. In addition to the data points, the mean of the 240 realizations, the mean \pm one standard deviation, and the base-case result are plotted. The variabilities in the input parameters resulted in a mean concentration profile that reasonably matches the concentration data, though slightly underpredicting the salinity observed above the transition zone. The head data are well bounded by the one standard deviation interval. The mean of MC realizations provides higher heads than indicated by the data, but similar gradients.

Radionuclide transport simulations are also performed in a manner similar to Milrow. All transport parameters are kept constant in all realizations. Glass dissolution rate, $k_{g}$, is taken as 1.26 $\mathrm{x} 10^{-7}$ day $^{-1}$, local dispersivities are fixed at 5.0 and $0.5 \mathrm{~m}$, and the matrix diffusion parameter is 0.434 , as discussed earlier. The particle-tracking simulations are performed for the six cases shown in Table 5.5 with different time steps than used in Milrow. This is due to the fact that the Long Shot cavity is very shallow as compared to Milrow, and as such, particles released in the cavity experience the high velocity region in the freshwater lens above the transition zone for many of the realizations considered. The selection of the time step size for the three sites is determined by analyzing the velocity magnitude at the seepage face for all individual realizations. The maximum value of the velocity at the seepage face is determined for each realization and then the absolute maximum of all these maxima is used to compute the time step such that when multiplied together, they result in a step size smaller than the grid size $(100 \mathrm{~m})$. The non-decayed transport results are discussed first, followed by the final decayed results for a selected number of radionuclides. 

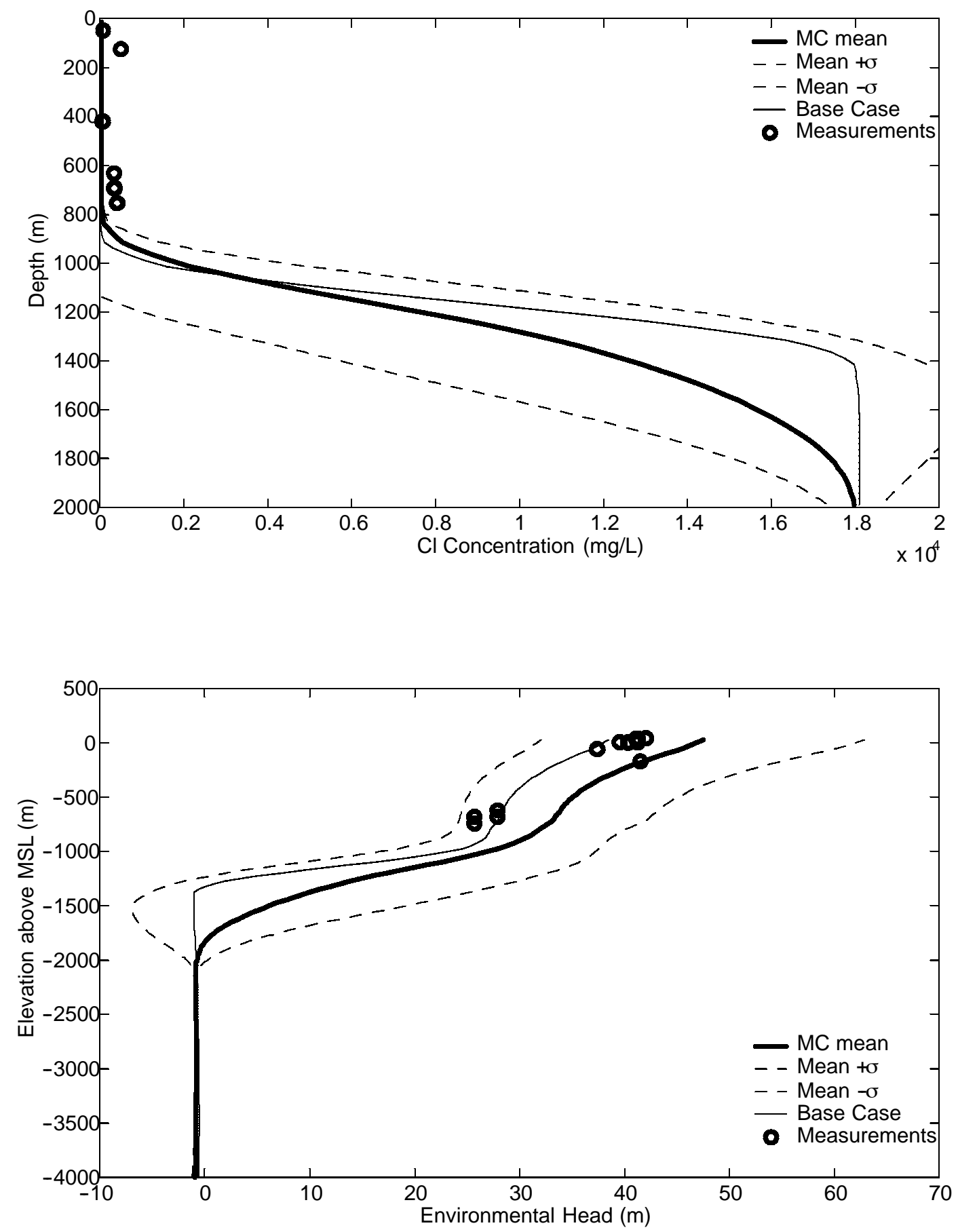

Figure 5.20. Sensitivity of modeled heads and concentrations to the combined uncertainties of Rech, $K$ and $\theta$ in the second modeling stage at Long Shot. 
Table 5.5 Values of parameters specific to individual solute classes.

\begin{tabular}{|c|c|c|c|c|c|c|}
\hline Parameter & Case 1 & Case 2 & Case 3 & Case 4 & Case 5 & Case 6 \\
\hline Total Time, $t$ (years) & 2,191 & 2,191 & 2,191 & 2,191 & 2,191 & 4,382 \\
\hline Time Step, $\Delta t$ (days) & 25 & 25 & 25 & 25 & 25 & 50 \\
\hline $\begin{array}{l}\text { Release Ratio }(\%), \\
\text { Hydraulic Release / } \\
\text { Geochemical Release }\end{array}$ & $100 / 0$ & $50 / 50$ & $60 / 40$ & $20 / 80$ & $80 / 20$ & $5 / 95$ \\
\hline Retardation Factor & 1 & 1 & 1 & 1 & 1 & 1.8 \\
\hline $\begin{array}{l}\text { Geochemical Release } \\
\text { Coefficient } k_{g}\left(\text { day }^{-1}\right)\end{array}$ & NA & $1.26 \times 10^{-7}$ & $1.26 \times 10^{-7}$ & $1.26 \times 10^{-7}$ & $1.26 \times 10^{-7}$ & $1.26 \times 10^{-7}$ \\
\hline
\end{tabular}

\subsubsection{Undecayed Transport Results}

The results of the first arrival time and the location and depth of the breakthrough are analyzed for the first class with 100 percent hydraulic release and no retardation. Also, no matrix diffusion or decay computations are included in this analysis unless stated otherwise. Similar to the analysis of Milrow, the 240 realizations are analyzed in terms of the percentage of mass that breaks through within 2,200 years, the first and last arrival times, the duration of breakthrough, the location of the plume edges with respect to the bathymetric profile, the plume width and the depths below MSL where breakthrough occurs. Since the Long Shot cavity is very shallow as compared to the other two tests, almost all realizations show 100 percent mass breakthrough within 2,200 years. Only six realizations out of 240 show less than 95 percent but greater than 85 percent mass breakthrough within this time frame.

Figure 5.21 displays the distributions of the first arrival time (whether it is for one particle or a thousand particles), the last arrival time and the duration of breakthrough. The figure shows that about 55 realizations (out of 240) show a first mass arrival within 10 years. Most of the realizations show a first arrival time less than 300 years. The figure also shows that about 45 realizations require a last arrival time beyond 2,200 years. Many of these realizations have about 99 percent of the mass arriving at the seafloor within the simulation time and the remaining one percent in the simulation domain is what requires the last arrival to be beyond the 2,200-year simulation time. Figure 5.22 displays the distributions of the locations of the plume edges on the bathymetric profile, the plume width, and the distance from the groundwater divide to the center of the plume that is obtained after accounting for matrix diffusion effect. The location of the left (first) edge of the plume is concentrated between $2,800 \mathrm{~m}$ and 3,600 $\mathrm{m}$ from the island centerline, while the right (second) edge of the plume is located within the range of $3,600 \mathrm{~m}$ to $5,500 \mathrm{~m}$. The location of the right edge of the plume shows more spread than the left edge. Comparing these results to those of Milrow reveals that the breakthrough at Long Shot is spread over a shorter length than at Milrow. One reason for this result is the fact that the initial source size (cavity) at Long Shot is much smaller than the Milrow cavity (and also much smaller than at Cannikin). The Long Shot cavity is about $122 \times 122 \mathrm{~m}$, whereas Milrow and Cannikin have 212 × $212 \mathrm{~m}$ and 354 × $354 \mathrm{~m}$, respectively. In addition to the cavity size, the location of the cavity relative to the varying transition zone location plays a significant role in 

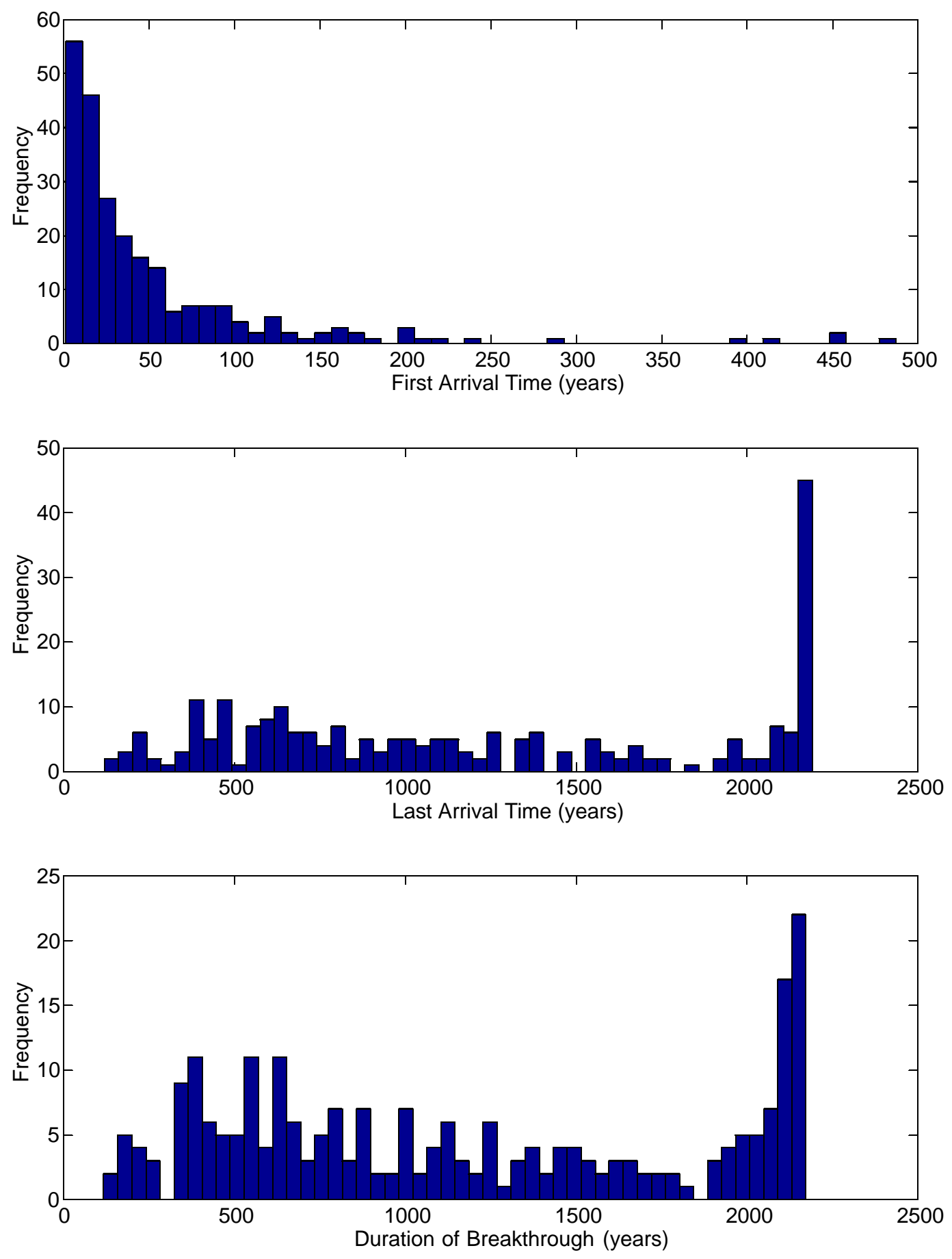

Figure 5.21. Histograms showing the distribution of first arrival time, last arrival time, and duration of breakthrough for Long Shot. 

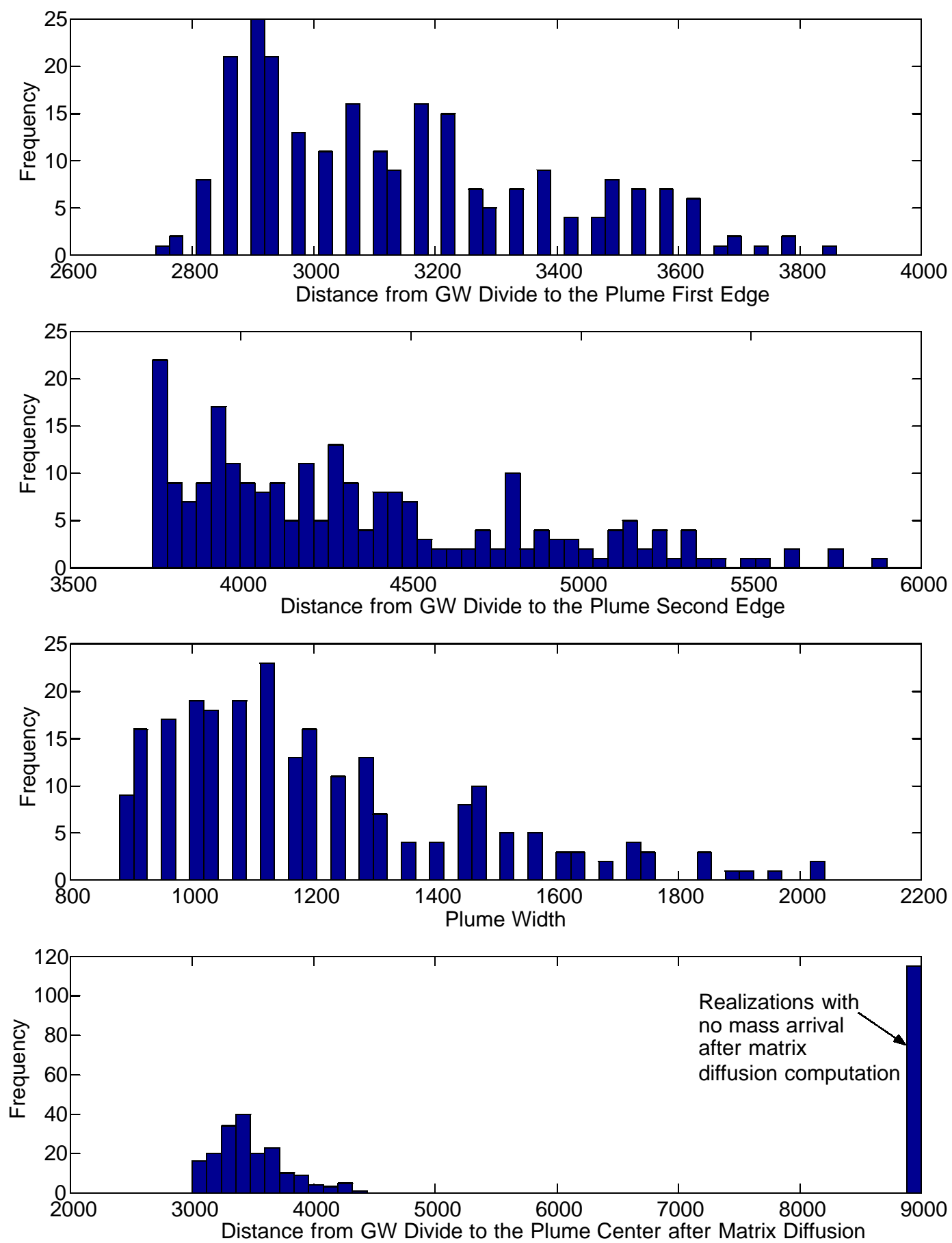

Figure 5.22. Histograms showing the distance from groundwater divide to plume edges and plume width for Long Shot. 
transport results. The Long Shot cavity is always located at the fresh water lens and as such the radionuclides have a uniform path towards the seepage face in almost all realizations.

In addition to the location of the plume edges, Figure 5.22 also shows that the plume is much wider than at Milrow. The plume width varies between $900 \mathrm{~m}$ to about 2,000 m with many realizations having the width between 900 and 1,300 $\mathrm{m}$. At Milrow, the plume had a width mainly less than $1,000 \mathrm{~m}$. This can be attributed to the fact that at Milrow, many realizations showed a very small percentage of mass arriving at the seafloor, which breaks through within a narrow length along the bathymetric profile leading to the small plume width as compared to Long Shot, where all realizations show above 85 percent mass breakthrough. The last quantity in Figure 5.24 is the distance from the divide to the plume center. When accounting for matrix diffusion, about 117 realizations (out of 240) did not contribute to the final breakthrough results at Long Shot. This number is to be compared to 240 (out of 300) at Milrow. These realizations have late arrival and slow groundwater velocities, which increase the residence time of the mass in the fractured system and allow for more diffusion into the matrix as opposed to the realizations with early arrival and high velocities.

Figure 5.23 shows the distribution of the depth below MSL of the plume edges where breakthrough occurs. This information is very important for risk assessment studies as it helps determine the nature of the currents that disperse the flowing mass and the type of sea creatures living at these depths. The figure shows that the left edge of the plume exists at a depth of 20 to $40 \mathrm{~m}$, whereas the right edge exists at a depth of 40 to $80 \mathrm{~m}$ below MSL. Breakthrough at Milrow occurs at depths ranging from $2 \mathrm{~m}$ to about $25 \mathrm{~m}$. The deeper locations at Long Shot are a result of the different bathymetric profile as compared to Milrow, Figure 2.9.

\subsubsection{Transport Results with Radioactive Decay}

For all 12 radionuclides representing the first five cases, the results are tabulated in Table 5.6. No breakthrough occurred for radionuclides in Case 6 (though the sensitivity analysis of the matrix diffusion parameter did result in breakthrough for Case 6, as discussed later in Section 6). The structure of the table is similar to that of Table 5.3 presented earlier for Milrow. Figure 5.24 depicts the flux and concentration results for tritium, ${ }^{3} \mathrm{H}$, which is an element in Case 1, with a matrix diffusion parameter value of 0.434 . The normalized mean concentration distribution has a peak value of about $1.8 \times 10^{-4}$, which is the highest value among the three tests. Recall that this value for Milrow was $1.6 \times 10^{-8}$. Adding one standard deviation to the Long Shot value leads to a normalized ${ }^{3} \mathrm{H}$ peak mean concentration of about $2.5 \times 10^{-3}$. This peak occurs roughly at 25 to 30 years after the test and at about 3,500 $\mathrm{m}$ from the island center (about 1,370 $\mathrm{m}$ from the shoreline). These normalized concentrations are about four orders of magnitude larger than the result at Milrow. The arrival time at Long Shot is 40 to 75 years earlier than Milrow. This is to be expected, as the shallow cavity location leads to shorter travel distances to the seepage face. Furthermore, the location of the cavity within the freshwater lens with very high velocities leads to shorter travel times as compared to Milrow. The results for ${ }^{14} \mathrm{C}$, shown in Figure 5.25, show that the mass flux and peak concentration are about an order of magnitude higher than those of ${ }^{3} \mathrm{H}$ with $\kappa=0.434$. The normalized peak of 

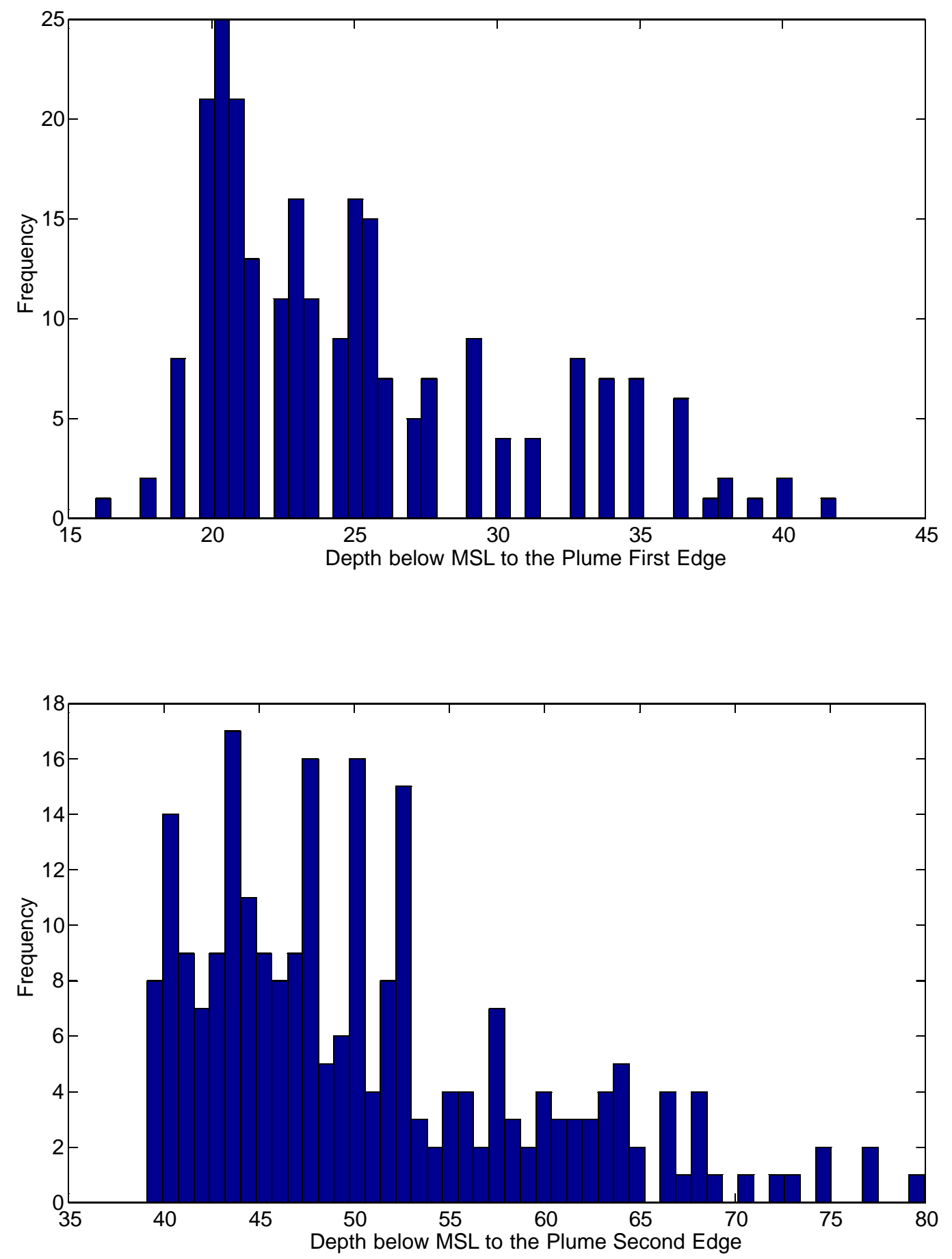

Figure 5.23. Histograms showing the distributions of depths below MSL at which the plume edges discharge to the ocean floor for Long Shot. 

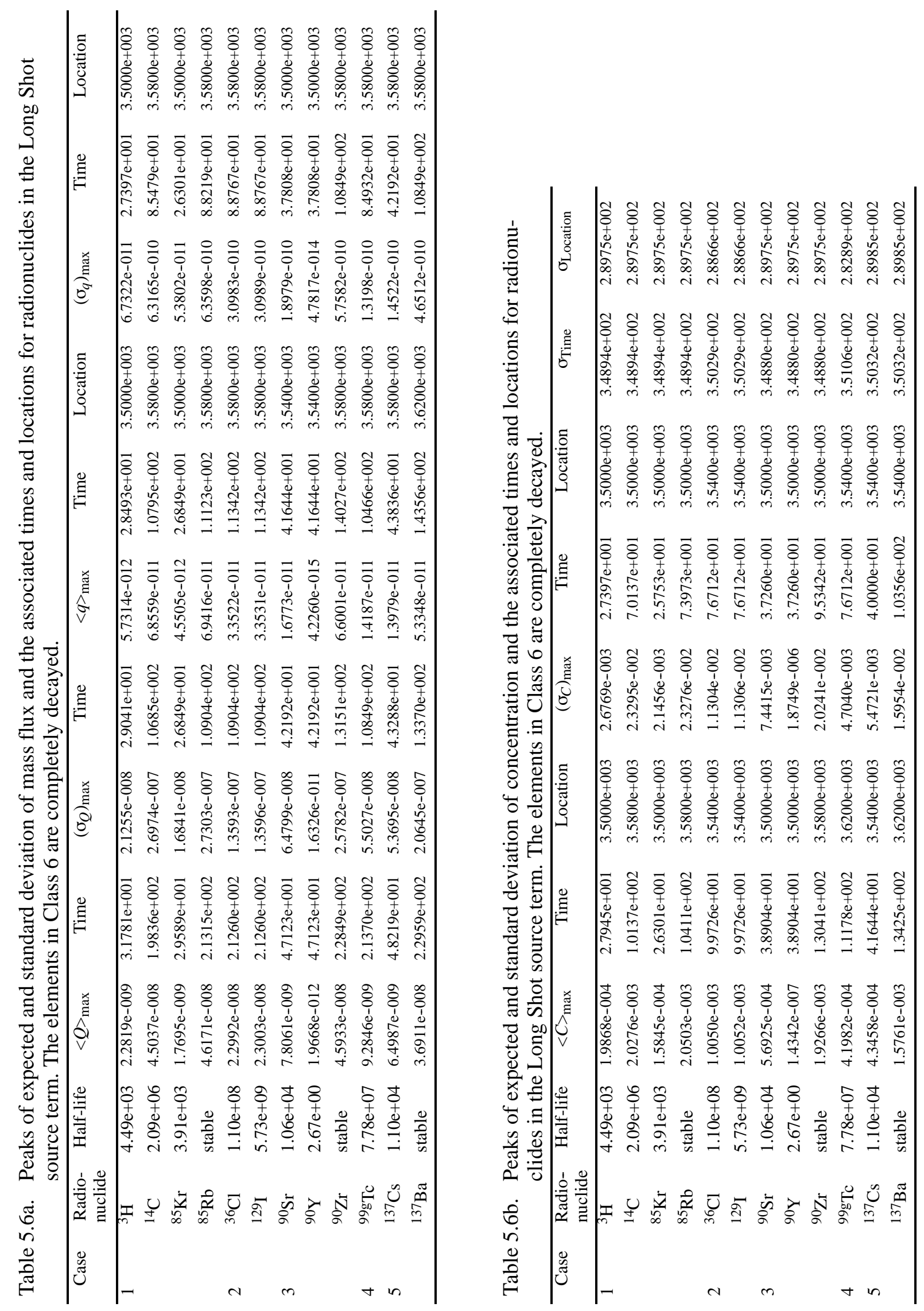

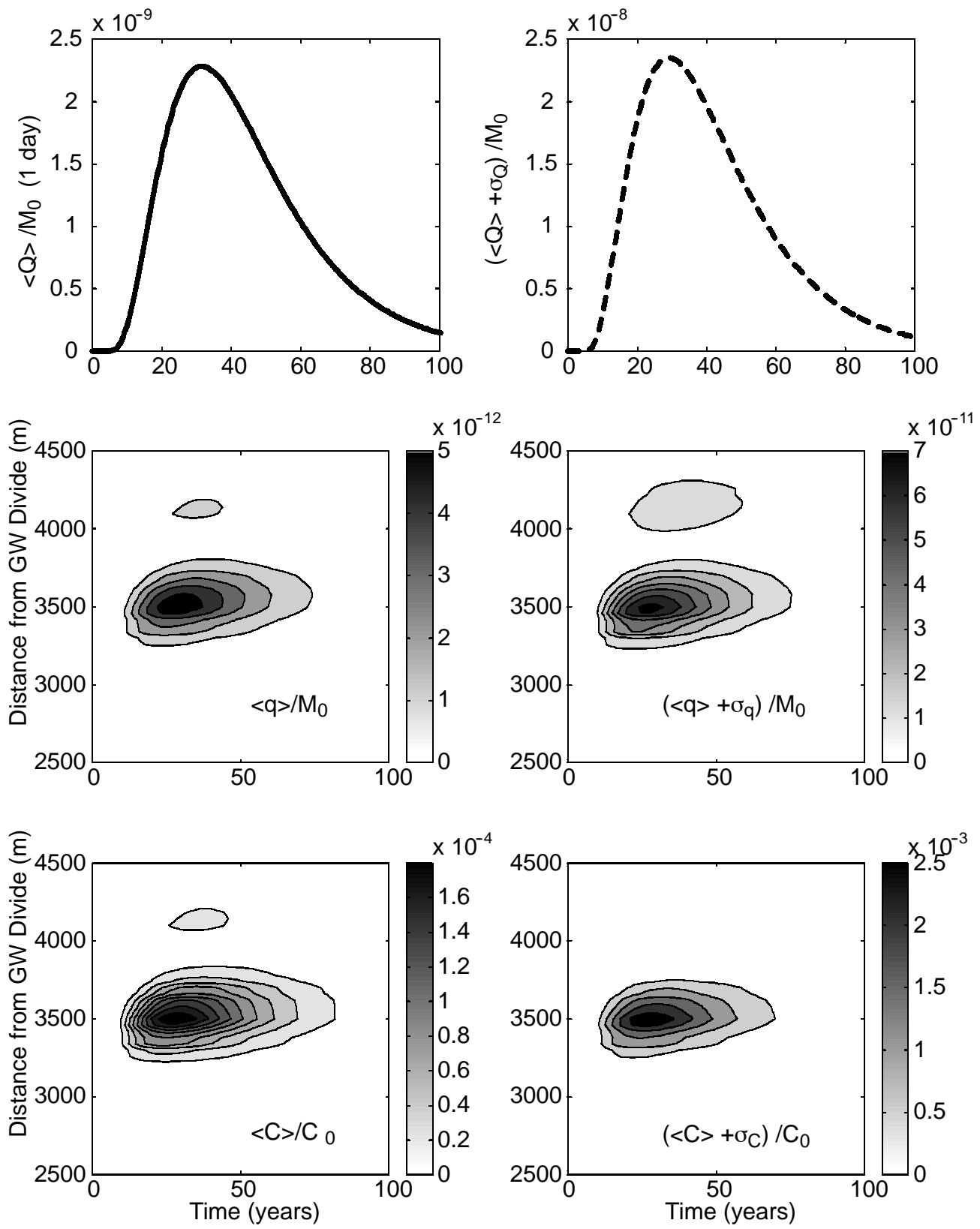

Figure 5.24. Statistics of mass flux and concentration for ${ }^{3} \mathrm{H}$ from Long Shot with $\kappa=0.434$. 

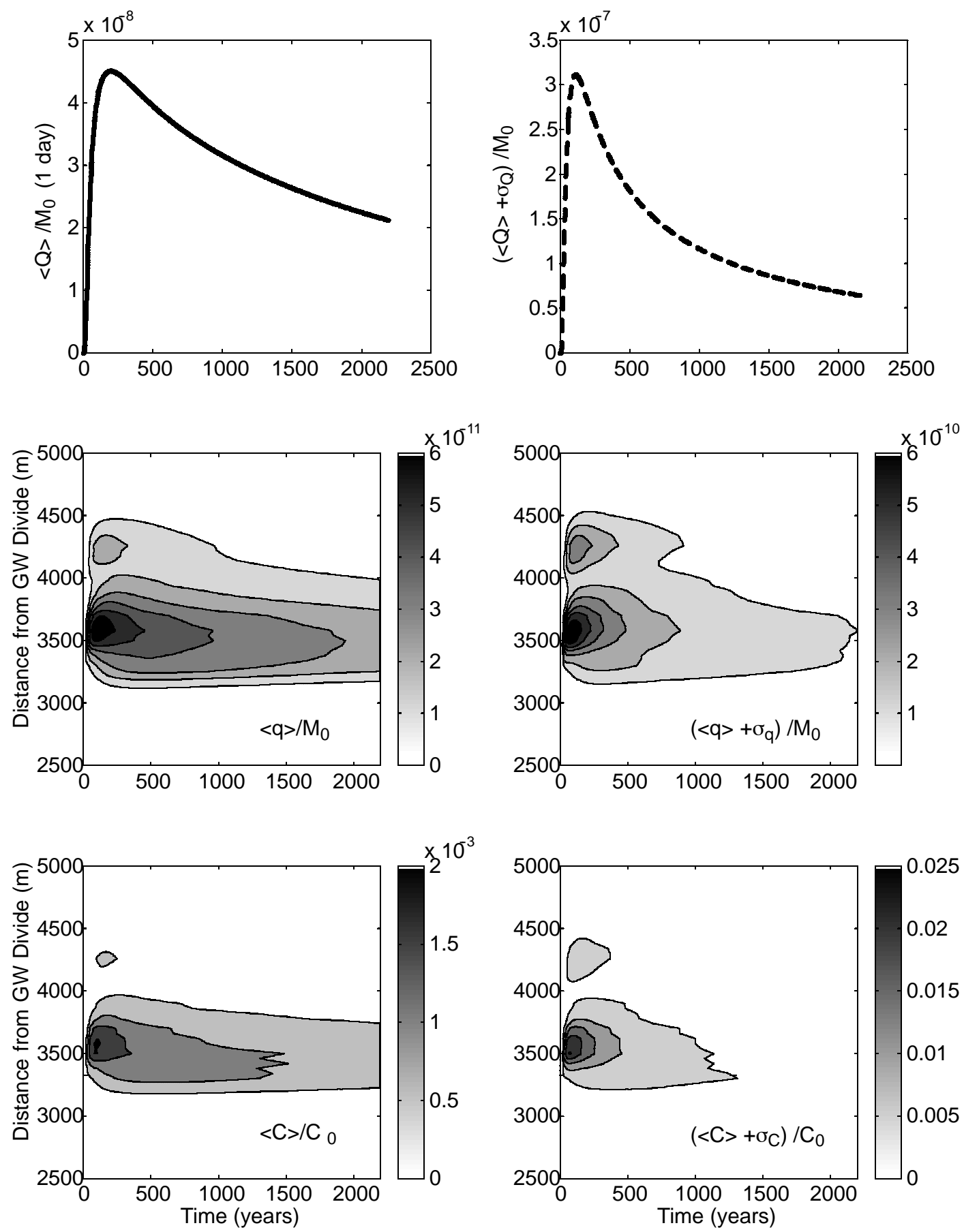

Figure 5.25. Statistics of mass flux and concentration for ${ }^{14} \mathrm{C}$ from Long Shot with $\kappa=0.434$. 
the mean concentration is found to be about $2.0 \times 10^{-3}$, and occurs at about 100 years and at 3,500 m from the groundwater divide.

\subsubsection{Long Shot Summary and Discussion}

The numerical modeling for groundwater flow and radionuclide movement at Long Shot is performed in two stages: a calibration stage and a final modeling stage. The calibration utilized chloride concentration data from one well (EH-5) and head data from a number of wells clustered around the working point of Long Shot. As the quality of the chemical data was questionable due to possible mixing with drilling fluids, a close match to the head data was the target regardless of how the simulated concentrations compare to the measurements. The flow model was successfully calibrated using higher recharge and conductivity than used at Milrow. Calibration indicated that the heads at Long Shot are higher than at Milrow. In addition, the random distributions generated for the final modeling stage were different than Milrow. The final modeling resulted in a confidence interval around the mean that encompasses all head data and part of the concentration data.

The main feature that distinguishes Long Shot from Milrow (and Cannikin) is the location of the cavity, which is very shallow in comparison. Due to this shallow location, all the generated flow realizations encountered a transition zone that lies below the cavity. Therefore, the cavity is always located within the freshwater lens and radionuclide migration occurs through the recharge water moving down and along the transition zone towards the seafloor. This resulted in a 100 percent breakthrough for about 90 percent of the realizations within the selected time frame. The cavity location also has the implication that the travel distances from the test to the seafloor are much smaller than in the other two tests and as such, breakthrough occurs earlier with higher mass fluxes and concentrations. Mean concentrations are, in general, one to a couple of orders of magnitude higher than the other two tests depending on the radionuclide's half-life.

\subsection{Cannikin Flow and Transport Results}

Three random distributions are generated for the conductivity, recharge and fracture porosity. Distributions with 500 values of conductivity and recharge are generated. An upper and a lower limit for the recharge-conductivity ratio are specified to ensure that the transition zone is within the depths that are thought to encompass the transition zone. The thickness of the freshwater lens is considered much larger than that at Milrow. Therefore, 500 random $K$ values and a similar number for Rech are generated with no correlation among the generated values. The cases that satisfy the condition $0.0047 \leq R e c h / K \leq 0.0349$ are selected, which yielded 260 realizations of the random values. These limits are chosen based on the individual results of the location of the transition zone relative to the chloride concentration data. It should be mentioned that the lower limit is about four times the one used for Milrow but the upper limit is the same. The minimum, mean and maximum values of $K$ are $2.17 \times 10^{-3}, 1.19 \times 10^{-2}$, and $4.44 \times 10^{-2} \mathrm{~m} /$ day, respectively. For the recharge, these limits are 0.809 , 3.62 , and $18.89 \mathrm{~cm} /$ year, respectively. Independently of these values, 260 random porosity values are generated with a minimum of $1.0 \times 10^{-5}$, a mean of $4.31 \times 10^{-4}$, and a maximum of $5.2 \times 10^{-3}$. 
Table 5.7 summarizes these values as well as the standard deviation and the type of the distribution used to generate the parameter values. Figure 5.26 displays the histograms of these three distributions. In comparing these distributions to those used in Milrow, it is found that recharge has a higher mean but conductivity has a lower mean. Also, the Cannikin recharge mean is slightly higher than Long Shot, and the conductivity mean is slightly lower than at Long Shot. This is done as an attempt to reproduce a deeper transition zone as compared to Milrow and Long Shot. Porosity values, on the other hand, show a similar distribution as for the other two sites.

Table 5.7. Parameter range for Cannikin flow and transport simulations.

\begin{tabular}{lccccc}
\hline \multicolumn{1}{c}{ Parameter } & Minimum & Mean & Maximum & $\sigma$ & Distribution \\
\hline$K$ & $2.17 \times 10^{-3}$ & $1.19 \times 10^{-2}$ & $4.44 \times 10^{-2}$ & $6.65 \times 10^{-3}$ & $\sim$ lognormal \\
Rech & 0.808 & 3.62 & 18.89 & 2.32 & $\sim$ lognormal \\
$\theta$ & $1.0 \times 10^{-5}$ & $4.31 \times 10^{-4}$ & $5.2 \times 10^{-3}$ & $5.4 \times 10^{-4}$ & $\sim$ lognormal \\
$A_{L}$ & - & 100 & - & - & - \\
$A_{T}$ & - & 10 & - & - & - \\
$\alpha_{L}$ & - & 5.0 & - & - & - \\
$\alpha_{T}$ & - & 0.5 & - & - & - \\
$\kappa$ & - & 0.434 & - & - & - \\
$K_{g}$ & - & $1.26 \times 10^{-7}$ & - & - & - \\
\hline
\end{tabular}

Figure 5.27 compares the recharge-conductivity ratio and the conductivity-porosity ratio for the generated distributions to the base-case values. Recall that in the base case, $K=1.38 \times 10^{-2} \mathrm{~m} /$ day, Rech $=5.48 \mathrm{~cm} /$ year, and $\theta=5.0 \times 10^{-4}$. The plots in Figure 5.27 illustrate how the two ratios (Rech/K and $K / \theta$ ) vary among the 260 realizations around the base-case ratios. As can be seen in the figure, $R e c h / K$ varies from a minimum that is about 0.4 times the base-case ratio to a maximum that is about three times larger. The conductivity-porosity ratio varies from about 0.0 times the base-case value to about 50 times larger than the base-case value. More realizations lie above the base-case lines, which is a conservative selection, as the high $K / \theta$ ratios lend to earlier arrival of mass and less mass diffusion and decay.

FEFLOW is used to solve the density-driven flow problem for 260 realizations with the recharge, conductivity, and porosity values already generated. Macrodispersivity values are fixed at $100 \mathrm{~m}$ and $10 \mathrm{~m}$ in the longitudinal and transverse directions, respectively. Domain geometry and boundary conditions remain unchanged and are similar to the one used in Section 4. To assess the choice of the combined random values used in this analysis, the results of these realizations at locations of UAe-1, UA-1, and HTH-1 are analyzed. Figure 5.28 is a plot of the concentration and head profiles in UAe- 1 in terms of the mean of the 260 realizations, the mean \pm one standard deviation, the base-case result and the measured data. The first observation in this figure is that the mean of the MC realizations predicts a higher transition zone than the base case (recall that the base case is different than the calibration case in the sense that chimney changes in porosity and conductivity are not incorporated in the calibration). The one standard deviation confidence interval encompasses all but one of the data points for the head at UAe-1, but is still above the clustered chloride concentration data at depths in excess of 1,600 m. The head data at UA-1 and HTH-1 are plotted against the simulation results in Figure 5.29. Again, the confidence interval in the figure 

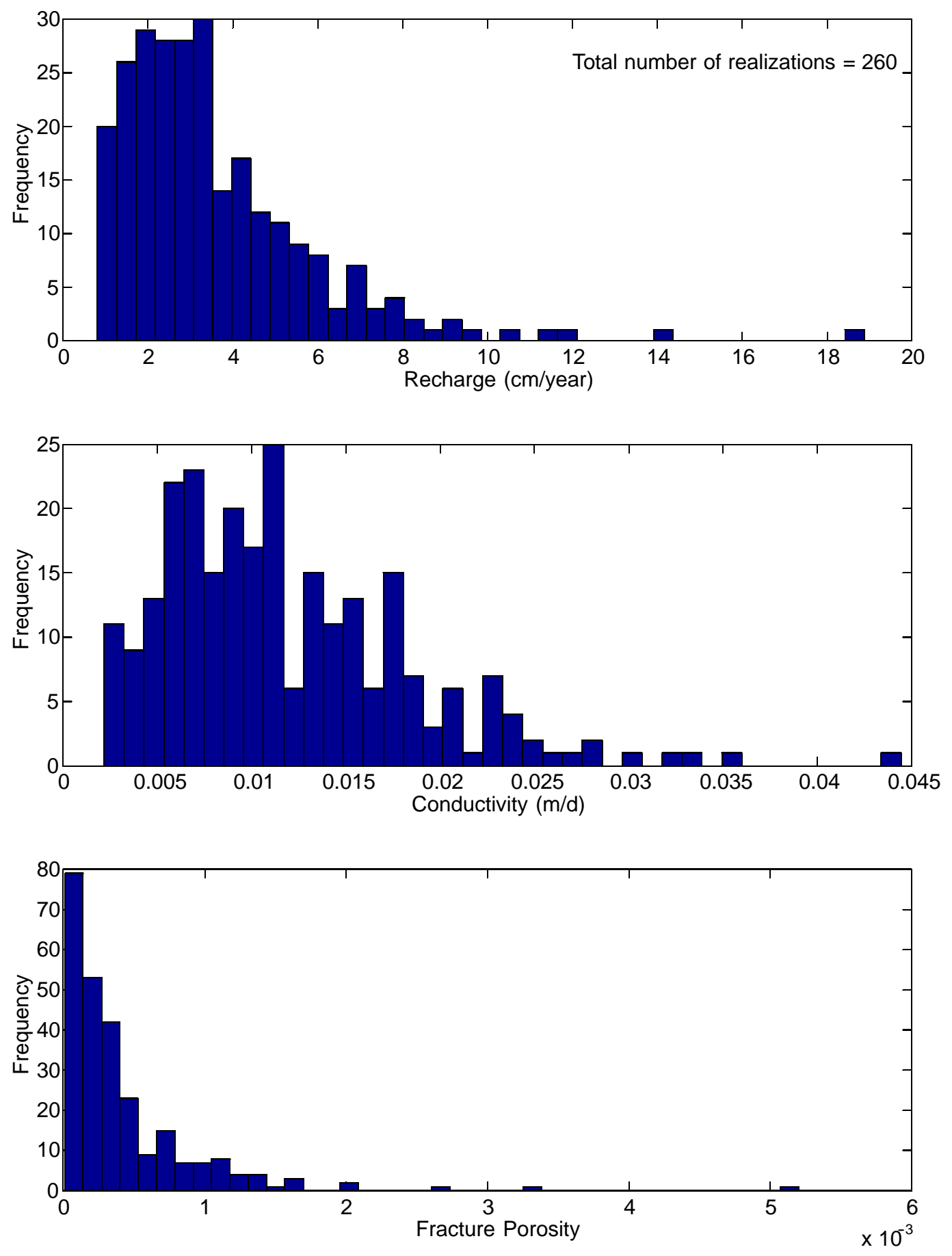

Figure 5.26. Randomly generated distributions for Rech, $K$ and $\theta$ for the final Cannikin modeling stage. 

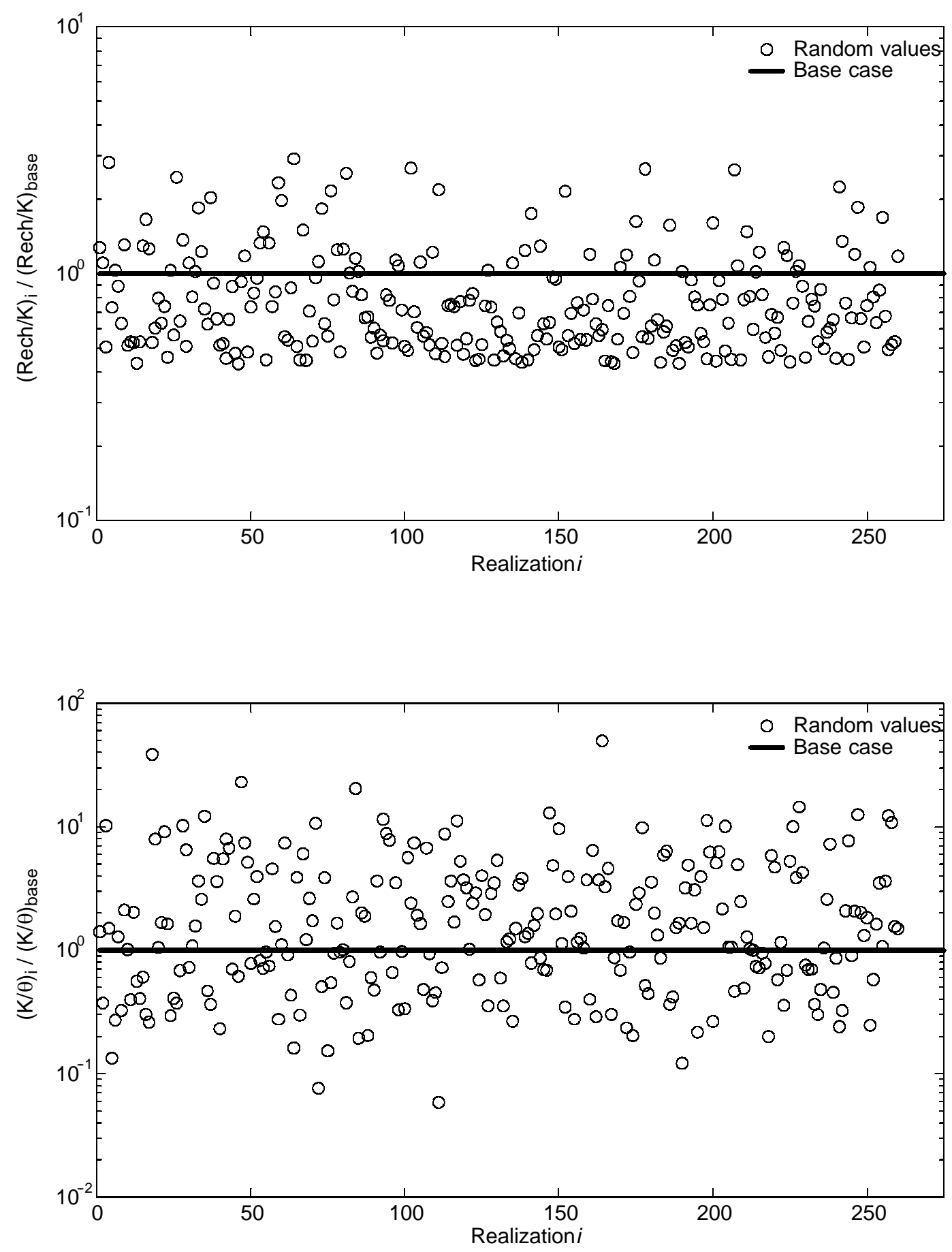

Figure 5.27. Comparison of the randomly generated recharge-conductivity and conductivity-porosity ratios relative to the Cannikin base-case values. 

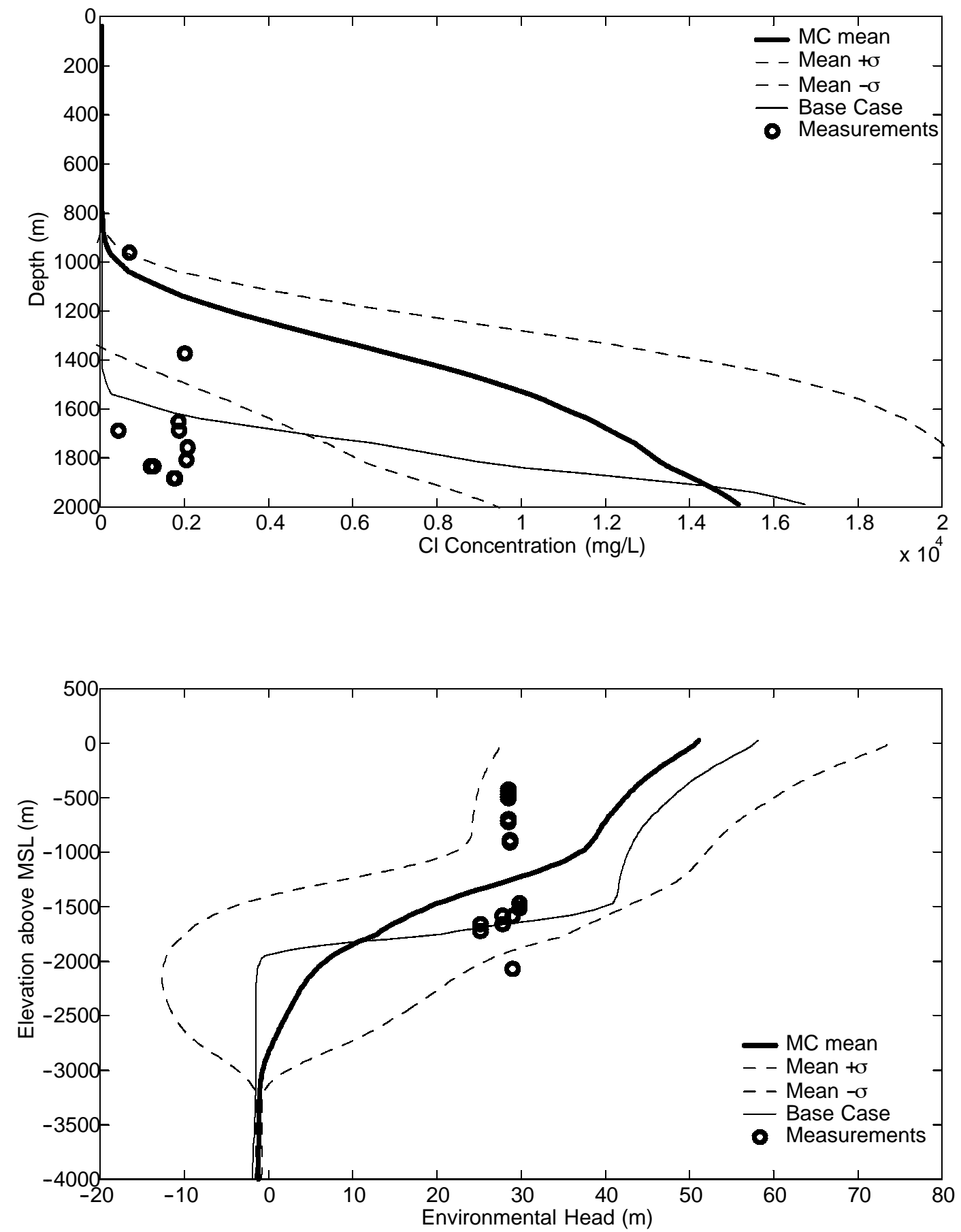

Figure 5.28. Sensitivity of UAe-1 modeled concentrations and heads to the combined uncertainties of Rech, $K$ and $\theta$ in the final Cannikin modeling stage. 

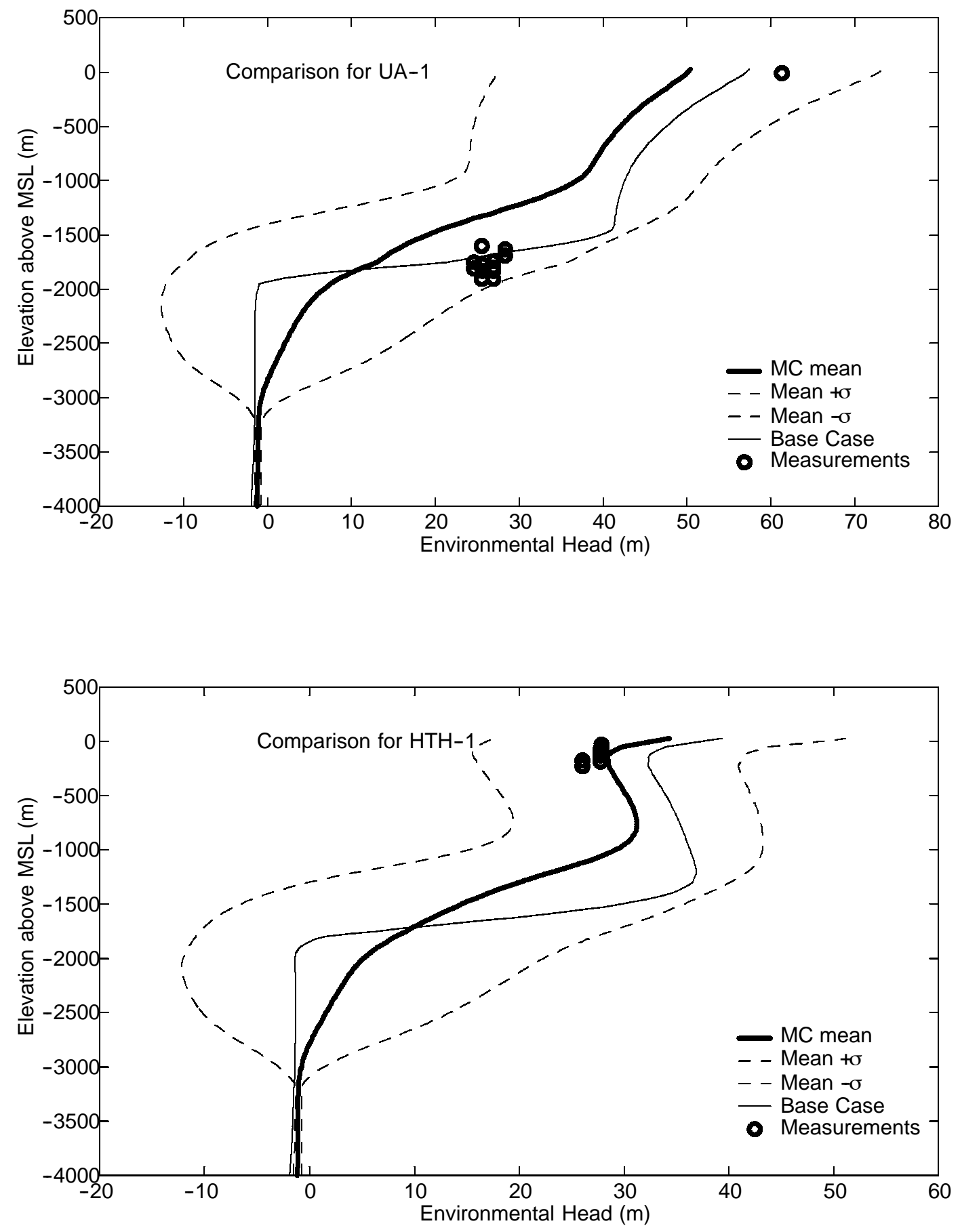

Figure 5.29. Sensitivity of UA-1 and HTH-1 modeled heads to the combined uncertainties of Rech, $K$ and $\theta$ in the final Cannikin modeling stage. 
encompasses all the head data at the two wells. The mean of the Monte Carlo simulations predicts a lower head at UA-1 and is a poorer match to the data than the base case, but it matches the HTH-1 head better than the base case. These comparisons indicate that the selected distributions of recharge, conductivity and porosity lead to a set of results with mean head distribution close to the wells' data and range of variability bounding all but one available data point. Again, since the quality of the concentration data is considered more questionable than that of the head data, and the concentration profile is more likely to violate the steady-state assumption, not matching the chemical data is tolerated for the modeling scenario for Cannikin.

Radionuclide transport simulations are also performed in a manner similar to Milrow and Long Shot. All transport parameters are kept constant in all realizations. Glass dissolution rate, $k_{g}$, is taken as $1.26 \times 10^{-7} \mathrm{day}^{-1}$, local dispersivities are fixed at 5.0 and $0.5 \mathrm{~m}$, and the matrix diffusion parameter is assigned a value of 0.434 as discussed earlier. The particle-tracking simulations are performed for the same six cases and the same parameter values shown in Table 5.2. As was done for Milrow, the non-decayed transport results are discussed and the final decayed results are shown for a selected number of radionuclides.

\section{$\underline{\text { 5.3.1 Undecayed Transport Results }}$}

The undecayed breakthrough curves for the six solute classes with and without matrix diffusion are more or less similar to those presented for Milrow in Section 5.1. Therefore, there is no need to repeat the plot and the corresponding discussion here. The results that are of interest and importance to risk assessment studies are those related to the first arrival time and the location of the breakthrough. Similar to the analysis of Milrow, the 260 realizations are analyzed in terms of the percentage of mass that breaks through within 2,200 years, the first arrival time, the last arrival time, the duration of breakthrough, the location of the plume edges with respect to the bathymetric profile, the plume width, the location of the plume center after matrix diffusion computation, and the depths below MSL where breakthrough occurs. Figure 5.30 shows the distribution of the mass percentage that reaches the seafloor within the 2,200-year time frame. About 139 realizations out of 260 show less than 1 percent of the total mass reaching the breakthrough boundary. Out of these realizations, about 85 do not show any mass breakthrough. A total number of 157 realizations have less than 5 percent of the total mass out within that time frame, 175 have less than 10 percent of the mass out and only about 5 realizations have above 90 percent of the mass out.

Figure 5.31 displays the distributions of the first arrival time (whether it is for one particle or a thousand particles), the last arrival time and the duration of breakthrough. The figure shows that about 32 realizations (out of 260) show a first mass arrival within 60 years. Many realizations show a first arrival time less than 1,000 years. Again, about 85 realizations do not show any mass arrival within the simulation time. The figure also shows that about 140 realizations require a last arrival time beyond 2,200 years. For the breakthrough duration, most of the realizations that show a breakthrough have duration between 1,000 and 2,200 years. Figure 5.32 displays the distributions of the locations of the plume edges on the bathymetric profile, the plume width, and the distance from the groundwater divide to the center of the plume that is obtained after accounting for matrix diffusion effect. The location of the left (first) edge of the plume in many realizations is concentrated 

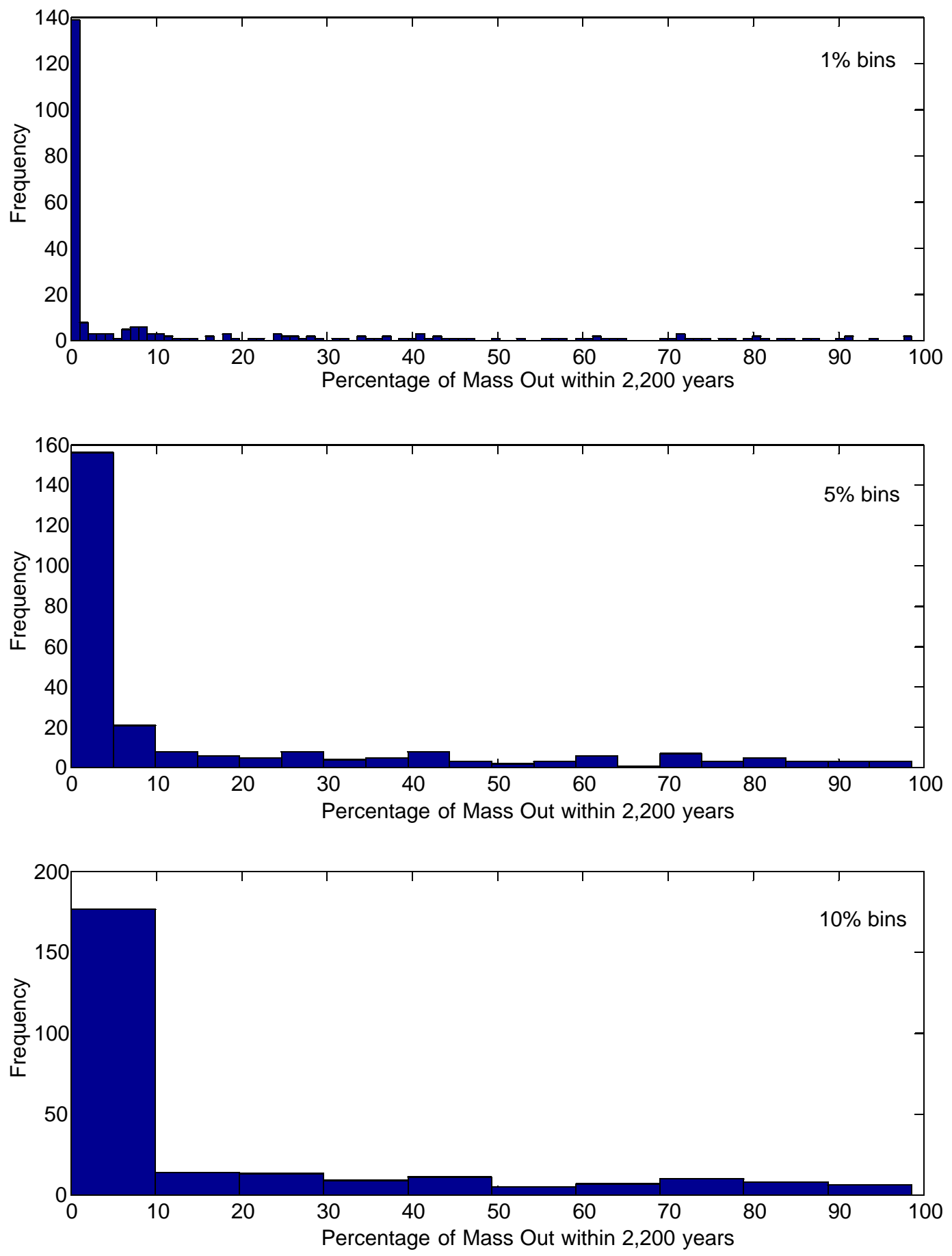

Figure 5.30. Histograms of the percentage of Cannikin mass that has broken through within 2,200 years. 

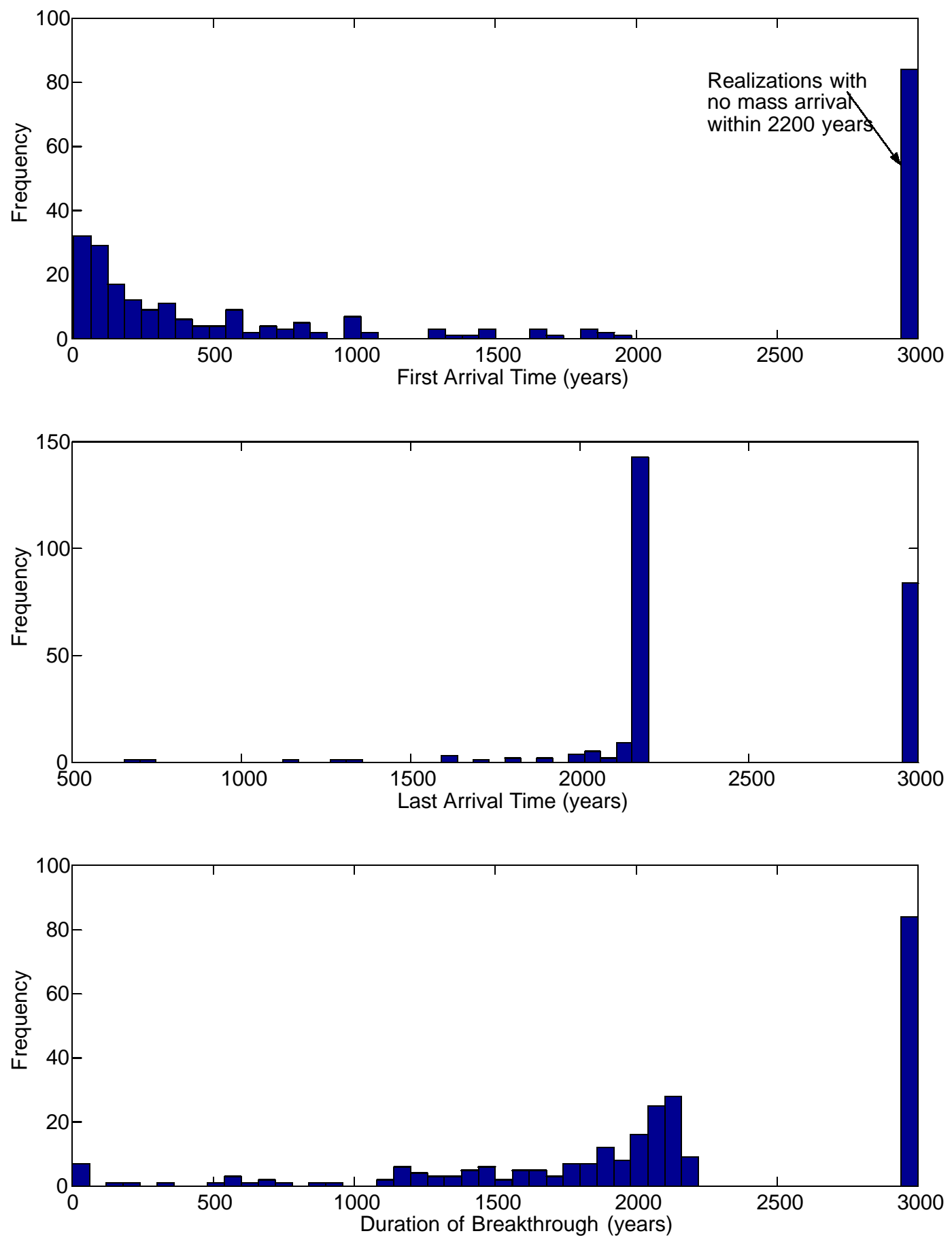

Figure 5.31. Histograms showing the distribution of first arrival time, last arrival time, and duration of breakthrough for Cannikin. 
between 4,000 $\mathrm{m}$ and 5,000 $\mathrm{m}$ from the island centerline, while the right (second) edge of the plume is located within the range 4,600 $\mathrm{m}$ to $6,000 \mathrm{~m}$. The location of the right edge of the plume shows more spread than the left edge. The breakthrough at Cannikin is spread over a length that varies from $200 \mathrm{~m}$ to about $1,800 \mathrm{~m}$ with no tendency toward certain width, whereas at Milrow many realizations showed a plume width between 400 and $800 \mathrm{~m}$ and at Long Shot the distribution of the plume width has peaks between 1,000 and 1,200 $\mathrm{m}$.

The last quantity in Figure 5.32 is the distance from the divide to the plume center. When accounting for matrix diffusion, about 225 realizations (out of 260) did not contribute to the final breakthrough results at Cannikin. This number is to be compared to 240 (out of 300) at Milrow and 117 (out of 240) at Long Shot. These realizations have late arrival and slow groundwater velocities, which increase the residence time of the mass in the fractured system and allow for more diffusion into the matrix as opposed to the realizations with early arrival and high velocities. These latter realizations are only 35 in Cannikin and as such one would expect the Cannikin breakthrough results to have the lowest mass flux and concentration values.

Figure 5.33 shows the distribution of the depth below MSL of the plume edges where breakthrough occurs. This information is very important for risk assessment studies as it helps determine the nature of the currents that disperse the flowing mass and the type of sea creatures living at these depths. The figure shows that the left edge of the plume exists at a depth of 45 to $75 \mathrm{~m}$, whereas the right edge exists at a depth of 50 to $80 \mathrm{~m}$ below MSL. Breakthrough at Milrow occurs at depths ranging from 2 to about $25 \mathrm{~m}$ and at Long Shot it occurs at depths between 20 to $70 \mathrm{~m}$. The different depths at the three tests are a result of the different bathymetric profiles as can be seen from Figure 2.9.

\subsubsection{Transport Results with Radioactive Decay}

For all 12 radionuclides representing the first five cases, the transport results are tabulated in Tables 5.8a and 5.8b. The tables are similar to Tables 5.3a and 5.3b presented earlier for Milrow. Figure 5.34 depicts the flux and concentration results for tritium, ${ }^{3} \mathrm{H}$, which is an element in Case 1 , with a matrix diffusion parameter value of 0.434 . The mean concentration distribution has a peak value of about $1.9 \times 10^{-9}$ times the initial source concentration, $C_{0}$. Adding one standard deviation to this value leads to a normalized peak of about $3.0 \times 10^{-8}$. This peak occurs roughly at 100 years after the test and about 5,300 $\mathrm{m}$ from the island center (about 2,970 $\mathrm{m}$ from the shoreline). These normalized concentrations are about one order of magnitude lower than those for Milrow. A ten-year later arrival time and a more spreading of mass cause this concentration reduction in comparison with Milrow. In comparison to Long Shot, Cannikin fluxes and concentrations for ${ }^{3} \mathrm{H}$ are about five to six orders of magnitude lower. The results for ${ }^{14} \mathrm{C}$, shown in Figure 5.35, show significant mass flux and peak concentration as compared to ${ }^{3} \mathrm{H}$ with $\kappa=0.434$. The normalized peak of the mean concentration is found to be about $9.0 \times 10^{-5}$, and occurs at about 1,200 to 1,500 years and at 5,500 m from the groundwater divide. These values are less than an order of magnitude lower than at Milrow and about two orders of magnitude lower than at Long Shot. 

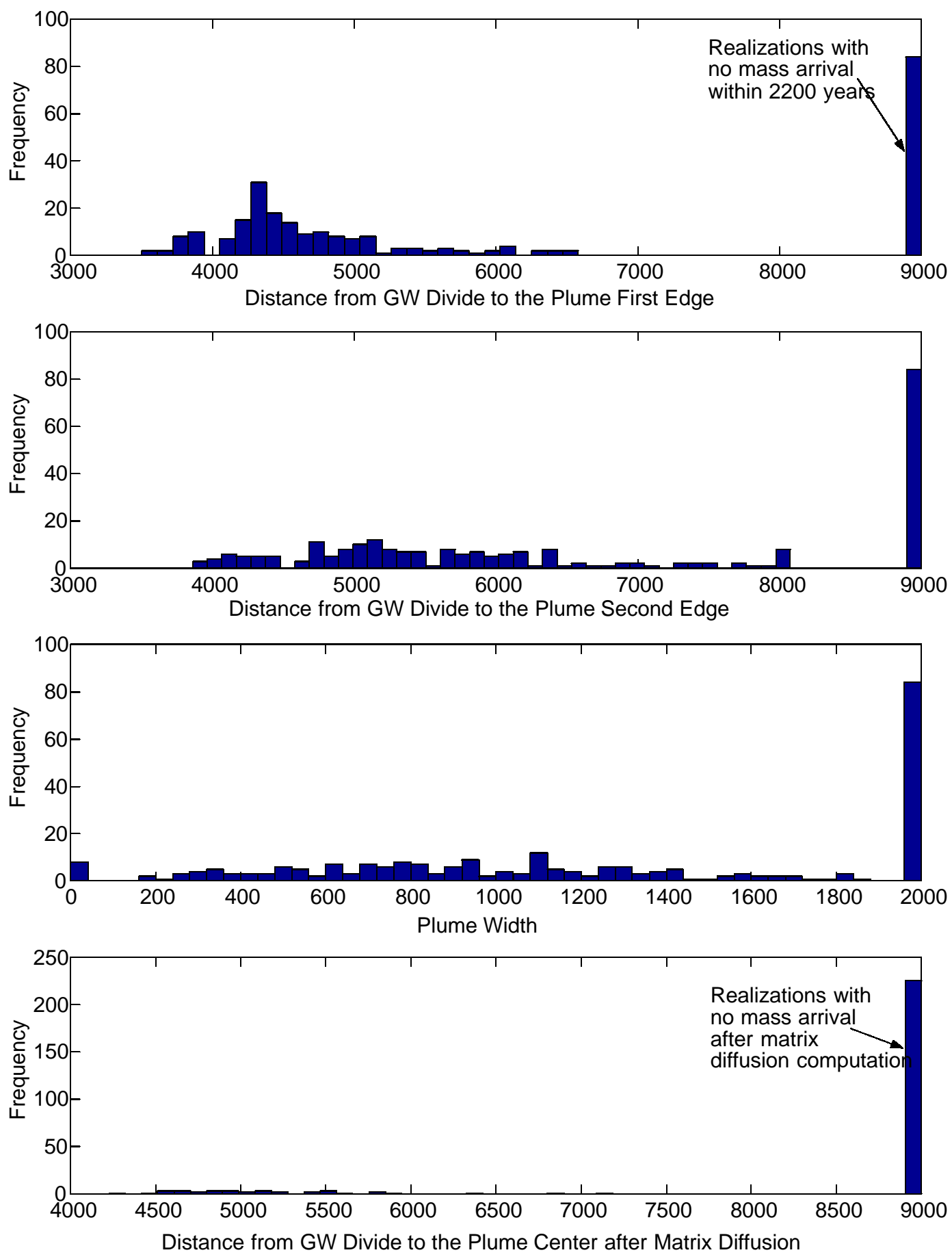

Figure 5.32. Histograms showing the distance from groundwater divide to plume edges and plume width for Cannikin. 

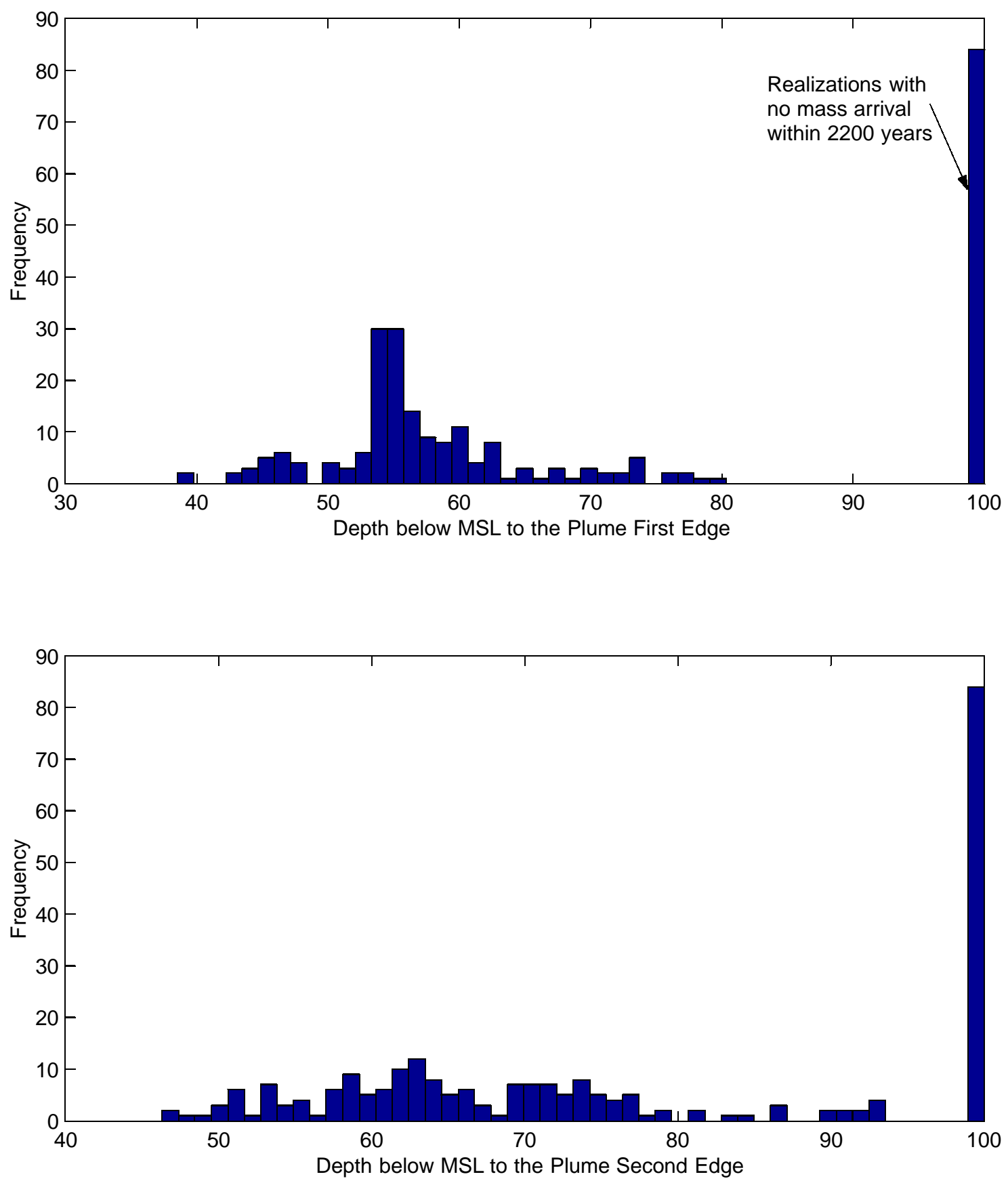

Figure 5.33. Histograms showing the distributions of depths below MSL at which the plume edges discharge to the ocean floor for Cannikin. 

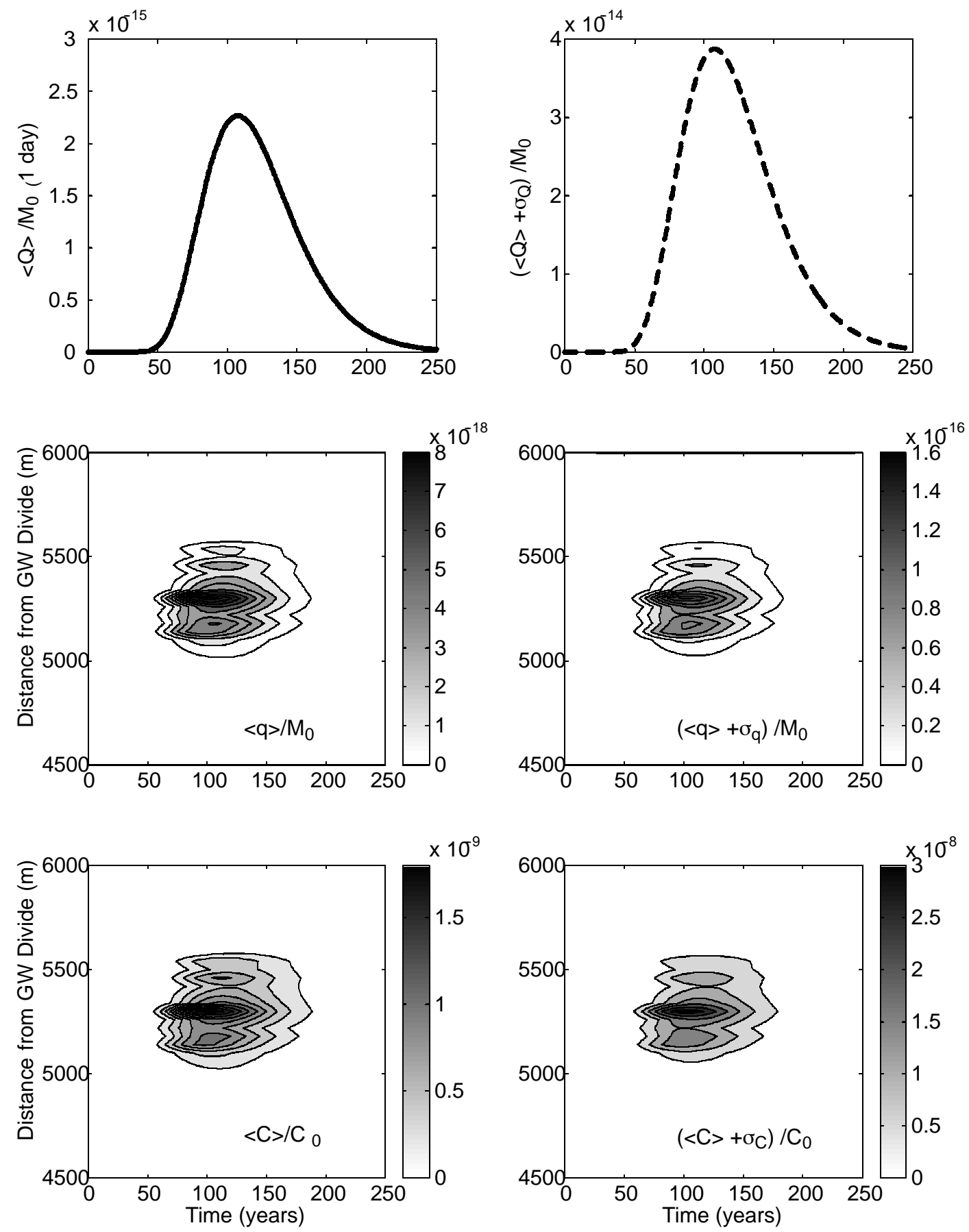

Figure 5.34. Statistics of mass flux and concentration for ${ }^{3} \mathrm{H}$ from Cannikin with $\kappa=0.434$. 

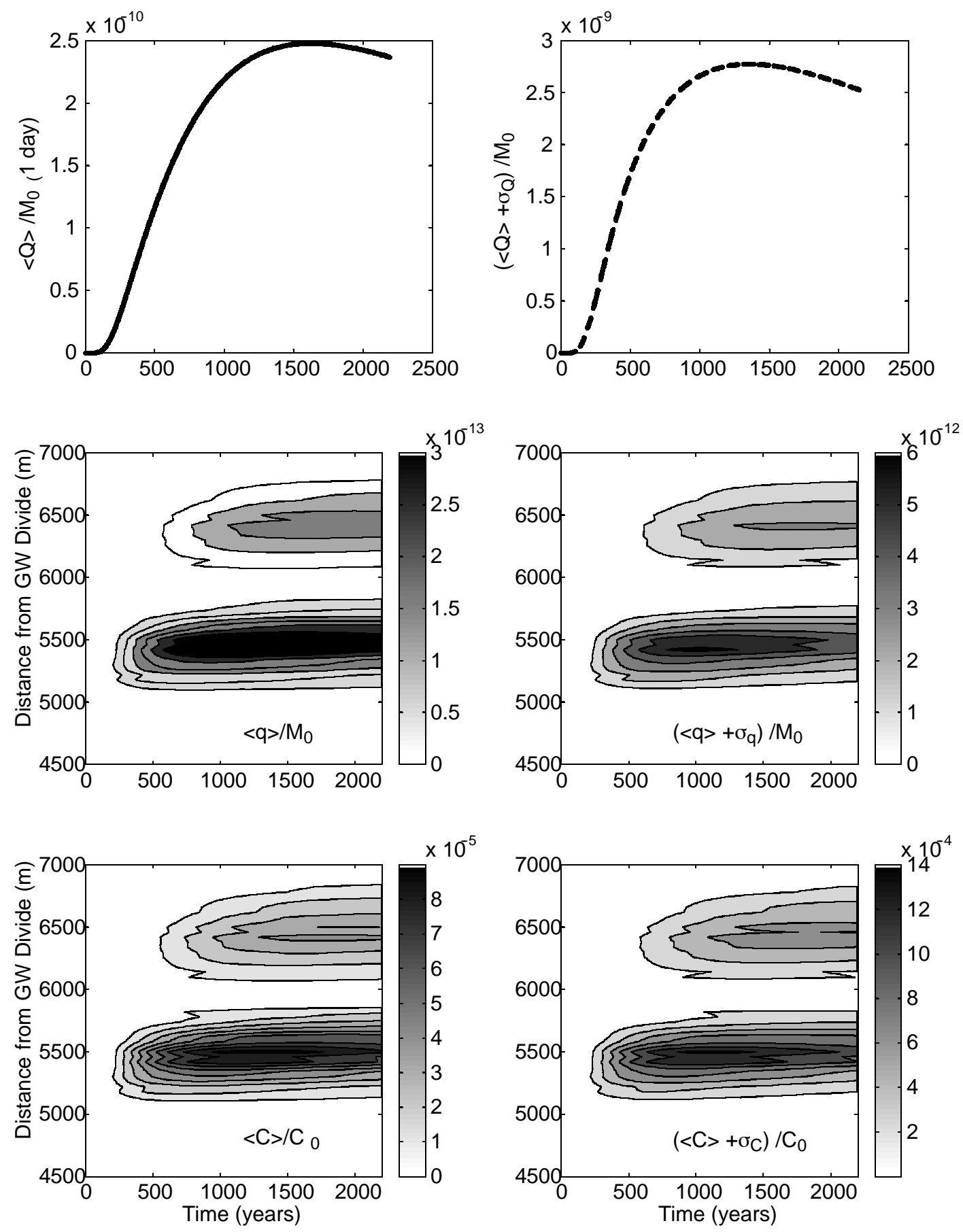

Figure 5.35. Statistics of mass flux and concentration for ${ }^{14} \mathrm{C}$ from Cannikin with $\kappa=0.434$. 


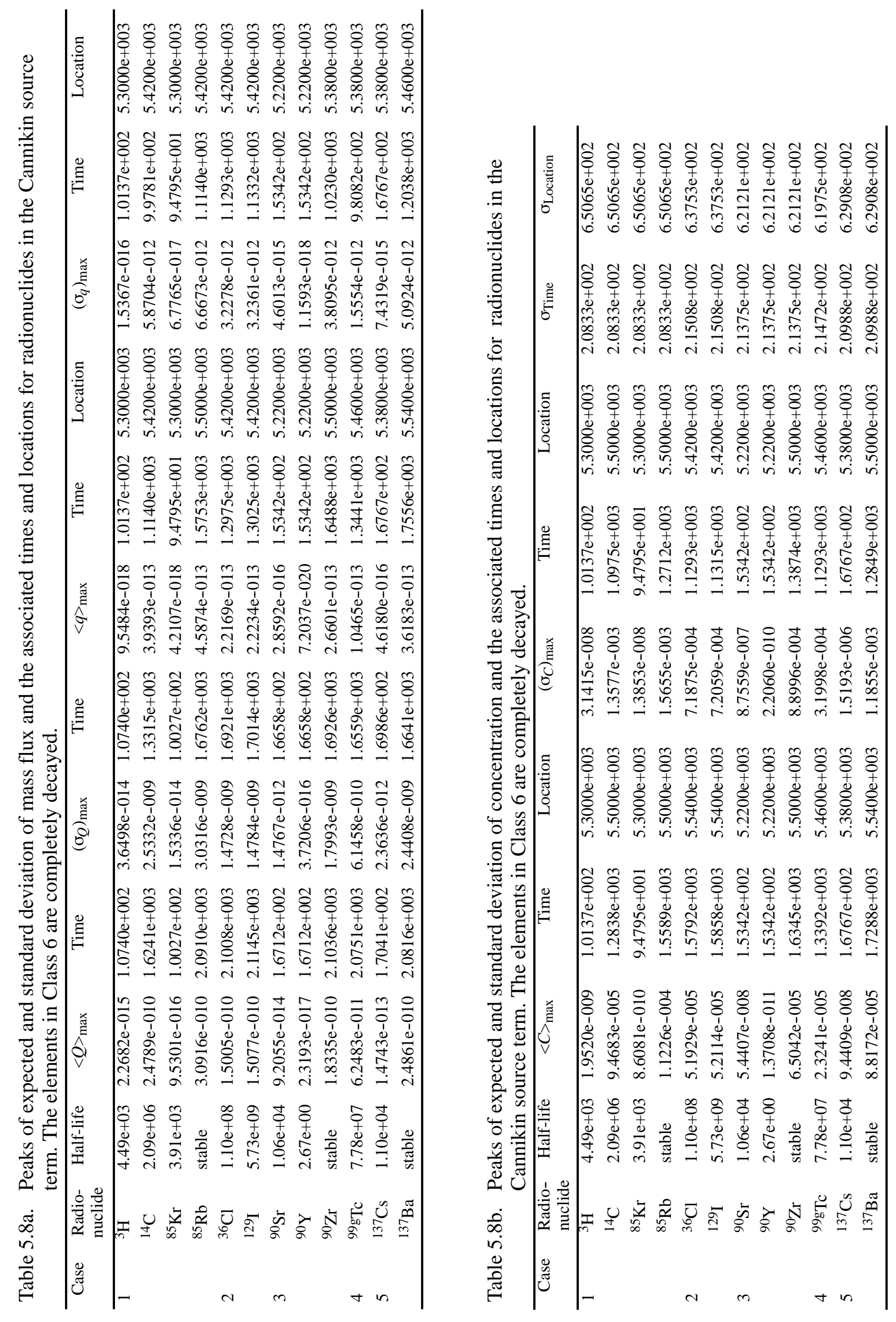




\subsubsection{Summary and Discussion}

The numerical modeling for the test at Cannikin is performed in two stages: a calibration stage and a final modeling stage. The calibration utilized chloride concentration data from one well and head data from three wells. As the quality of the concentration data was questionable, a focus was placed on getting a close match to the head data regardless of how the simulated concentrations compare to the measurements. Calibration indicated that the heads at Cannikin are higher than at Milrow and Long Shot, and the transition zone should therefore be deeper. This resulted in recharge and conductivity values higher than those used for the base case at Milrow. The final modeling resulted in a mean head distribution closer to the data than the base case and the calibration case at the same locations, but more deviating at other locations. The confidence interval around that mean encompasses all the head data for the three wells.

Transport results indicated that the radionuclides' movement at Cannikin is only slightly slower than Milrow (on average). That may be attributed to the location and size of the cavity. The Milrow cavity extends for $212 \mathrm{~m}$ in the two directions, whereas the Cannikin cavity is about $355 \mathrm{~m}$ on a side. Also, the working point at Milrow is located at about 1,218 $\mathrm{m}$ and that of Cannikin is at about 1,791 $\mathrm{m}$ below ground surface. This leads to longer travel distances in the case of Cannikin, which leads to a later arrival of mass to the breakthrough boundary as compared to Milrow. The flux and concentration values at Cannikin change from less than an order of magnitude to about an order of magnitude lower than Milrow, and from two to about five orders of magnitude lower than Long Shot results. 


\section{SENSITIVITY STUDIES}

As in every numerical simulation of a groundwater system, the modeling of Amchitka Island is conducted in the face of significant uncertainties. Where data allowed, uncertainty in critical parameter values was incorporated directly in the modeling process. Performing the modeling with mean values and distributions of important parameters allows the uncertainty in those parameters to be accounted for and carried into the subsequent risk assessment through a standard deviation in the breakthrough curves. However, some uncertainties cannot be addressed through that process, either due to a lack of data from which to derive means and distributions (as in the case of the matrix diffusion parameter), or because the uncertainty is in the underlying conceptual model or numerical approach. A variety of sensitivity analyses are presented now to address some of these issues. The first set of sensitivity problems can be addressed using the two-dimensional model formulation presented in the previous section. The second set requires expanding the model into the third dimension.

\subsection{Two-dimensional Sensitivity Studies}

The two-dimensional FEFLOW formulation of the three sites is used to evaluate the following topics: issues related to the numerical solution of the transport problem, the sensitivity of transport results to the matrix diffusion coefficient, the possibility of transport by colloids, the impact of the island half-width on the model, and finally, the possible system response to sea level change.

\section{$\underline{6.1 .1 ~ N u m e r i c a l ~ S o l u t i o n ~ I s s u e s ~}$}

The density variations due to the saltwater intrusion problem lead to a spatially varying velocity field as shown in Figure 6.1 and Figure 6.2. The velocity values are only known at specific points according to the finite-element solution of the flow problem. These points do not form a uniform grid, as would be the case in the finite difference models. For computational convenience, we grid the non-uniformly spaced velocity vectors using nearest-neighbor interpolation and obtain the velocity vectors at a uniformly-spaced two-dimensional grid. This facilitates the interpolation of the velocity needed for determining particle velocity for radionuclide transport simulations. Particle velocity needs to be interpolated from the surrounding known velocity values. A number of studies dealt with the velocity interpolation and presented different alternatives for computing particle velocity in purely advective transport regimes. These include, but are not limited to, Pollock (1988), Goode (1990), Schafer-Perini and Wilson (1991) and LaBolle et al. (1996). The common result of these approaches is that for heterogeneous media, the linear and bilinear interpolation schemes yield similar results [e.g., Goode (1990, Fig. 17) and LaBolle et al. (1996, Figs. 12-14)]. Although we do not consider medium heterogeneity, the salinity variability leads to heterogeneous velocity distribution for which the interpolation schemes need to be evaluated.

First, we check the aspects of the velocity gridding and interpolation. The accuracy of the conversion of the non-uniformly spaced velocity vectors into uniform grid values is evaluated in Figures 6.1 and 6.2. In these figures, we compare the original velocity vectors obtained from FEFLOW on the finite-element mesh to the interpolated-velocity (or the gridded-velocity) streamlines. As can be seen from different insets in the figures, the streamlines obtained from the 

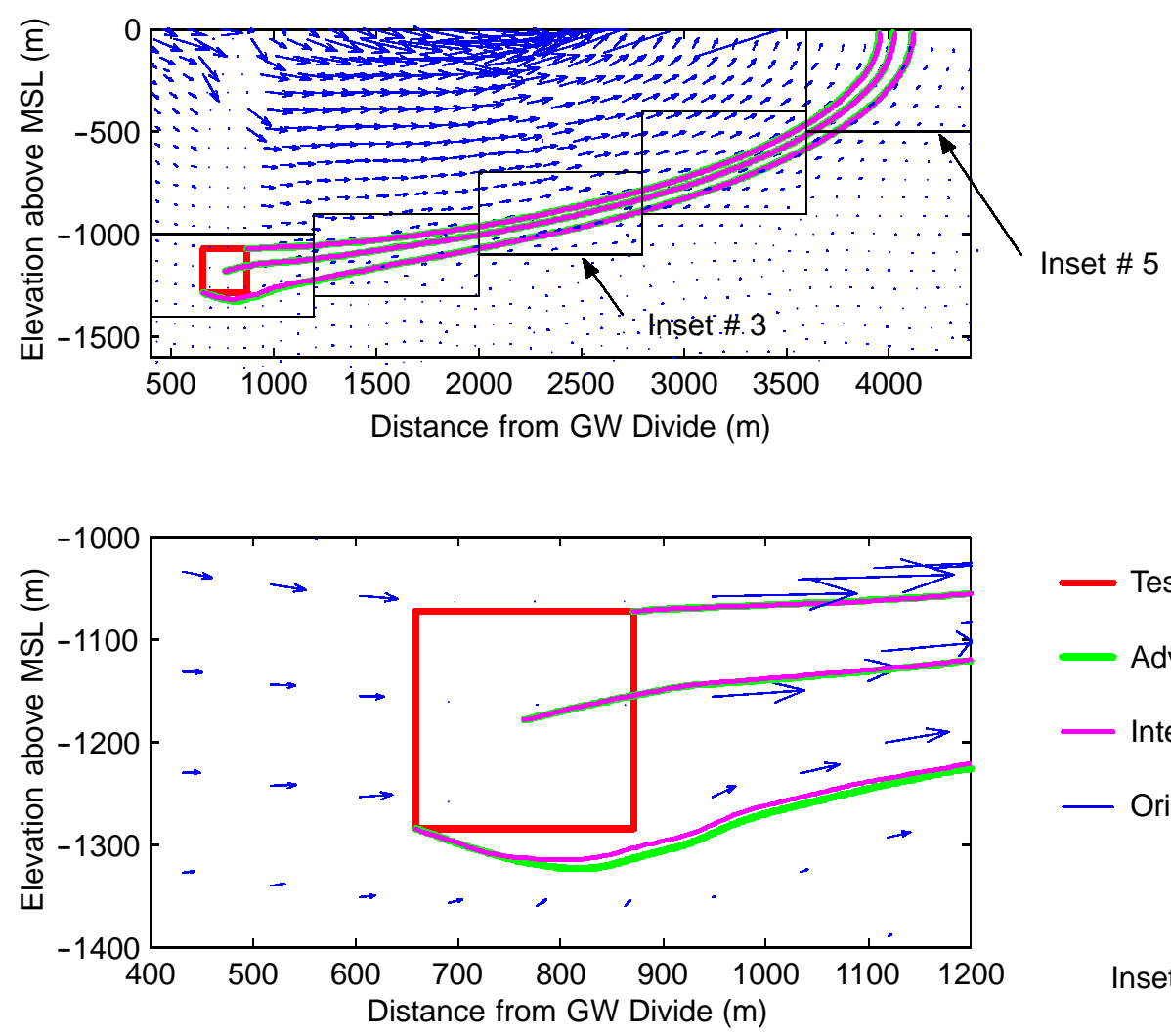

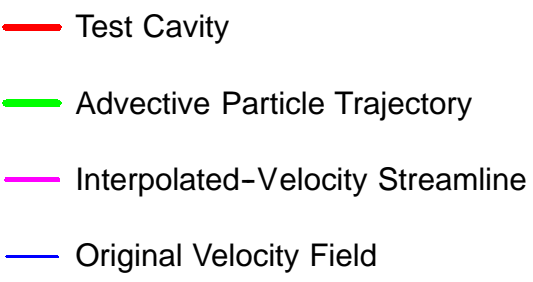

Inset \# 1

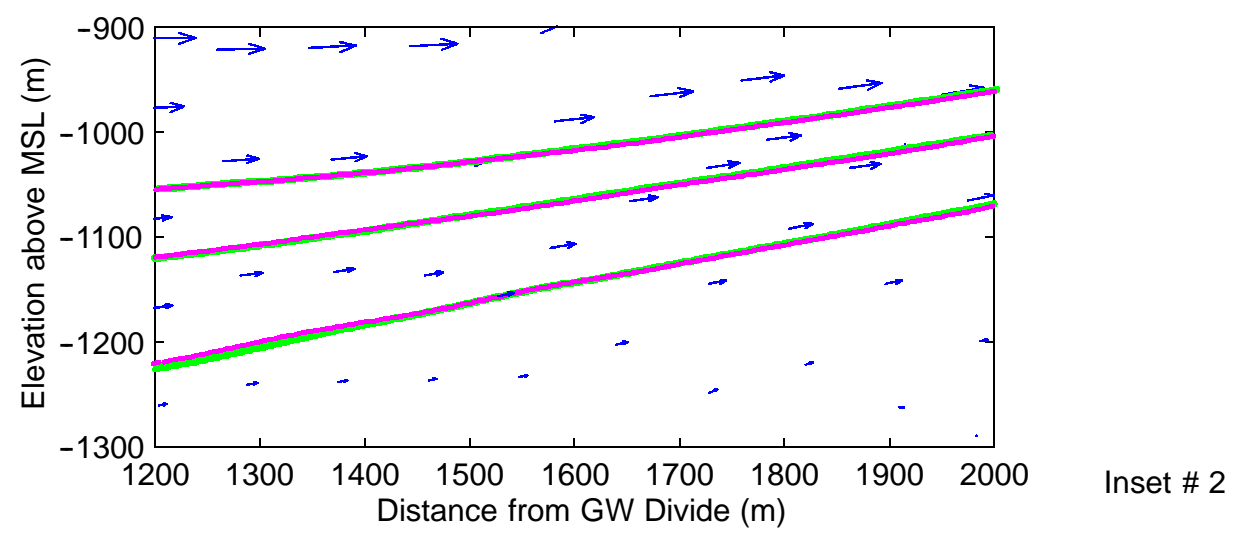

Figure 6.1. Comparison between original velocity streamlines, gridded (or interpolated) velocity streamlines and advective particle trajectory for the entire travel distance and two areas of inset. 

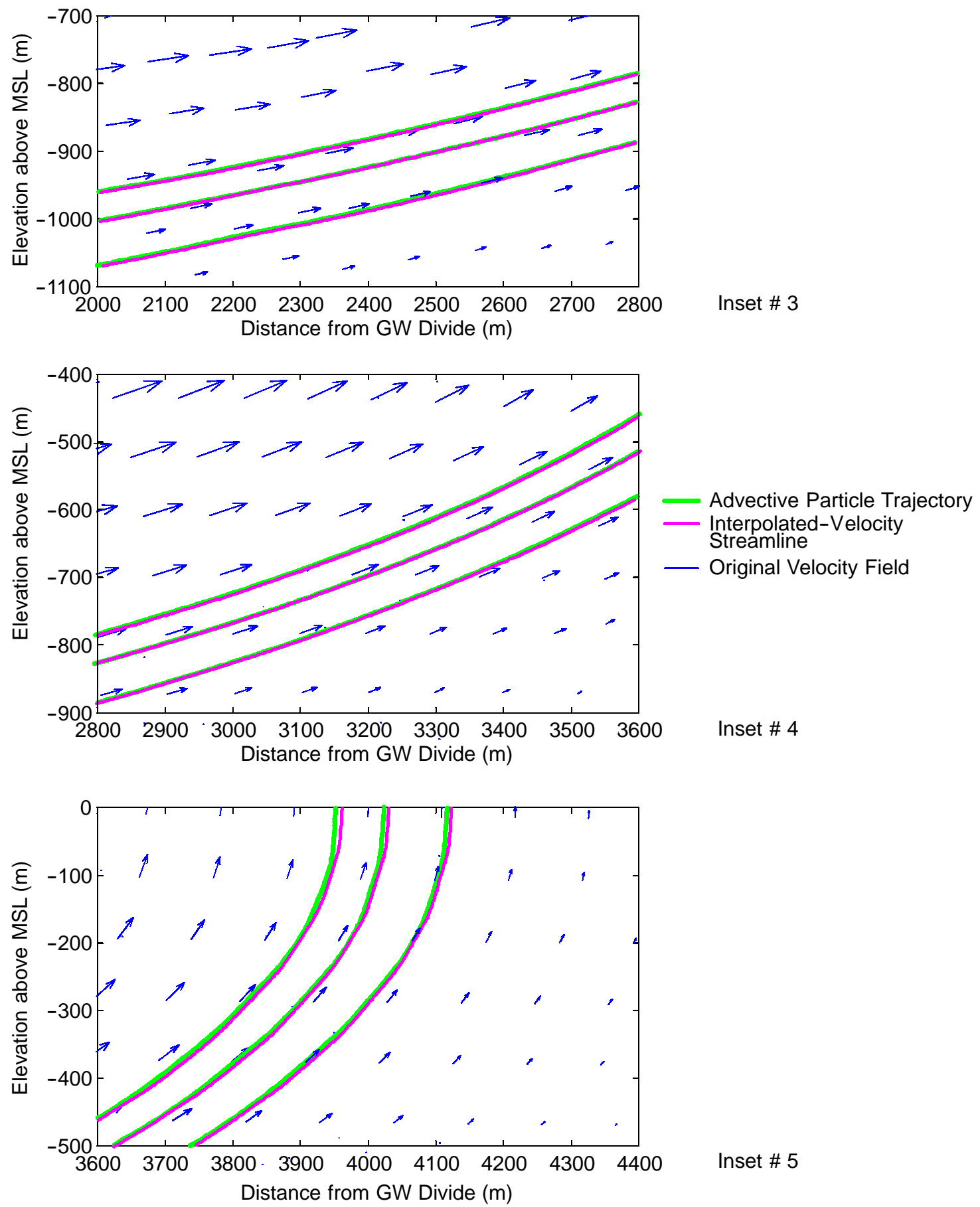

Figure 6.2. Comparison between original velocity streamlines, gridded (or interpolated) velocity streamlines and advective particle trajectory for the three areas of inset closest to the seafloor as shown in Figure 6.1. 
interpolated velocity (magenta lines) are following very closely the original velocity vectors (blue arrows) of the non-uniform grid. The velocity vectors run parallel to these streamlines and show very good correspondence starting from the cavity location and ending at the seepage face across the seafloor.

The other aspect we check is the accuracy of the interpolation of the gridded velocity to obtain particle velocity. The colored figures discussed above also show the advective particle trajectories (green lines), which match very closely the original velocity vectors and the streamlines of the gridded velocity. This qualitative evaluation indicates that the gridded velocity and the particle interpolation scheme employed in our simulations are sufficient for obtaining accurate estimates. One should also remember that the actual simulations are performed with local-scale dispersion, which is implemented by adding random steps to the particle movement. These random steps change the streamline the particle follows in a random manner such that any errors in the particle velocity interpolation may be smeared out by the addition of these random steps.

To check the sensitivity of the results of the random walk transport simulations to the velocity interpolation scheme, we employ a bilinear and an inverse distance interpolation scheme and compare the breakthrough results for the first scenario of the Milrow settings. Figure 6.3 shows the non-decayed mean and standard deviation of the total mass flux crossing the seafloor as a function of time using both bilinear and inverse-distance interpolation schemes. The third subplot in the figure is a magnification of the $\sigma_{Q}$ profile for a time frame of 200 years. The results show that the two interpolation schemes yield similar peak value and arrival time for both the mean and the standard deviation of the mass flux. The differences that exist between the two interpolation schemes are very minor, indicating that any of the two schemes would lead to the same exact final result (after applying matrix diffusion and decays computations).

Standard random walk methods (represented by Equation 3.7) usually rely on the assumption that medium properties such as porosity, $\theta$, and dispersion coefficient, $D$, are sufficiently smooth. Discontinuities in effective subsurface transport properties that may arise in discrete velocity fields of numerical groundwater flow models violate this smoothness assumption (LaBolle et al., 2000). Therefore, when either $\theta$ or $D$ are discontinuous (e.g., step functions, as is the case between the cavity and the surrounding domain), these standard methods fail (LaBolle et al., 1996) because the gradient terms of $D$ and/or $\theta$ cannot be formally defined. LaBolle et al. (2000) developed generalized stochastic differential equations applicable to the case of discontinuous coefficients (e.g., dispersion coefficients) and developed a new random walk method that numerically integrates these equations. That method is applicable for cases of abrupt changes in transport parameters and velocity values. The new random-walk equations proposed by LaBolle et al. (2000) can be written as

$$
\boldsymbol{X}_{t+\Delta t}=\boldsymbol{X}_{t}+\boldsymbol{V}_{x}\left(\boldsymbol{X}_{t}, t\right) \Delta t+\left(2 \boldsymbol{D}\left(\boldsymbol{V}\left(\boldsymbol{X}_{t}+\delta, t\right)\right) \Delta t\right)^{1 / 2} \cdot \boldsymbol{Z}
$$

where the displacement vector $\delta$ is defined as 

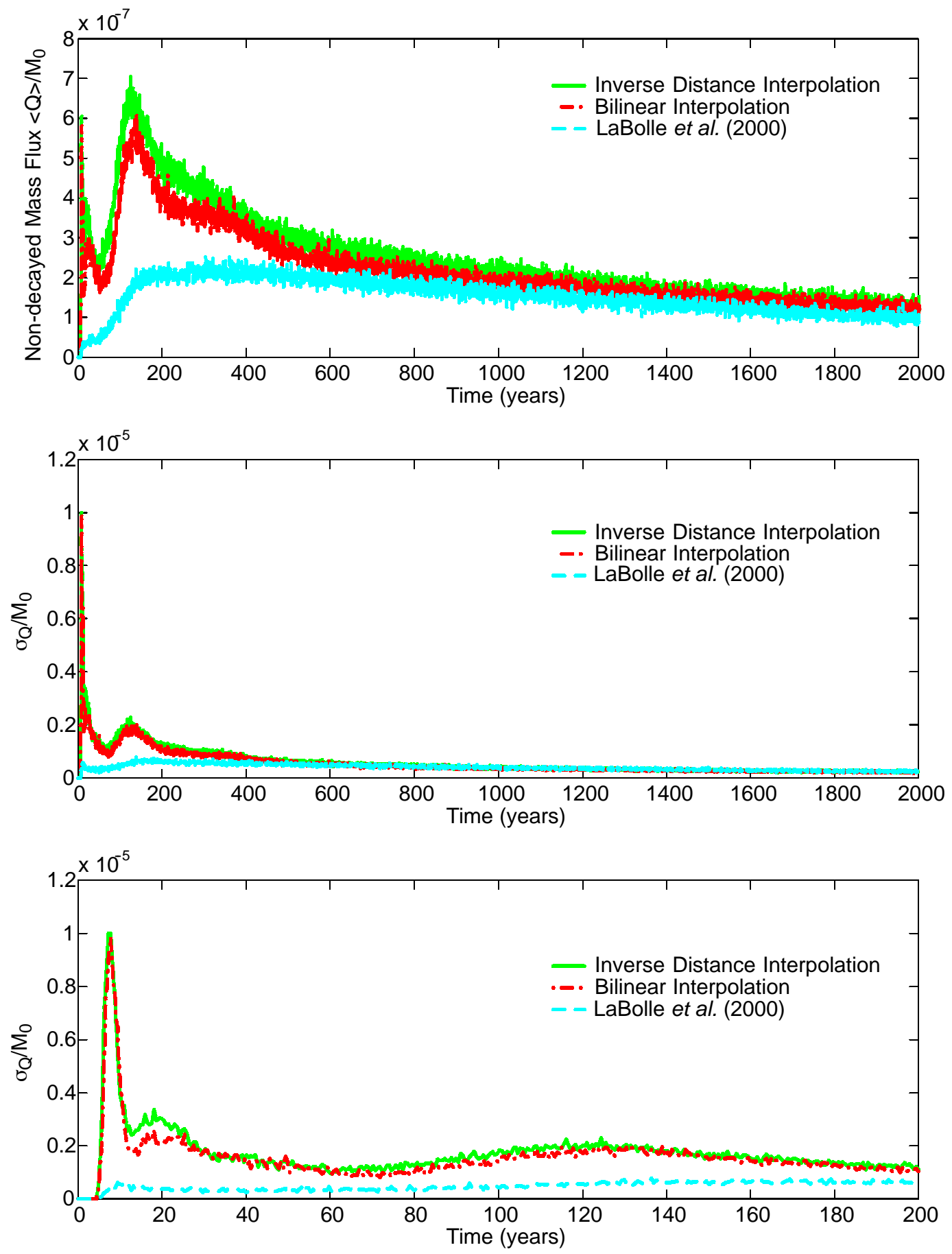

Figure 6.3. Comparison between bilinear and inverse-distance interpolation schemes and between these two traditional random walk techniques and the modified method of LaBolle et al. (2000) that avoids computing dispersion and porosity gradient terms. 


$$
\boldsymbol{\delta}=\left(2 \boldsymbol{D}\left(\boldsymbol{V}\left(\boldsymbol{X}_{t}, t\right)\right) \Delta t\right)^{1 / 2} \cdot \boldsymbol{Z}
$$

The idea in this approach is to evaluate the advective step of the particle using the velocity at the current position of the particle $\left(\boldsymbol{X}_{t}\right)$, and at time $t$. The dispersive step is performed using dispersion coefficients evaluated at an intermediate location, $\left(\boldsymbol{X}_{t}+\delta\right)$, where the increments vector $\delta$ represents dispersive steps from the current location, $\boldsymbol{X}_{t}$, to the intermediate location, $\boldsymbol{X}_{t}+\delta$. Comparing Equations (6.1) and (6.2) to Equation (3.7), one can see that the dispersion gradients (which are not defined at interfaces between domain blocks) are not needed in LaBolle et al.'s (2000) approach.

It is of interest to compare the performance of this modified approach with the traditional random walk method in one of the three tests. We plot in Figure 6.3 the mean and standard deviation of the mass flux crossing the seafloor for Milrow. These results do not account for matrix diffusion or for radioactive decay. The figure compares the traditional random walk method (which relies on computing gradient terms) using bilinear and inverse square-distance interpolation schemes for particle velocity to the modified approach of LaBolle et al. (2000). As mentioned earlier, the traditional approach is not very sensitive to the particle velocity interpolation scheme. The modified approach of LaBolle et al. (2000) results in much lower values for both $\langle Q\rangle$ and $\sigma_{Q}$ at all times. We, however, performed all simulations using the inverse square-distance interpolation scheme, which yields the highest mass flux values and earliest arrival. If one agrees that LaBolle et al.'s (2000) approach is more accurate than the traditional approach, our results can be viewed as conservative estimates of the radionuclide arrival to the seafloor.

In terms of the spatial-temporal distribution of the point mass flux, $q\left(x_{i}, t\right)$, crossing the seafloor, Figure 6.4 shows a comparison similar to that presented for $Q(t)$, but including the matrix diffusion effect. The same conclusion can be drawn from this figure that the inverse distance scheme used in our simulations is the most conservative one and thus the modified approach of LaBolle et al. (2000), though may be more accurate, is not implemented for our simulations.

\subsubsection{Matrix Diffusion Coefficient}

The parametric uncertainty analysis identified the matrix diffusion parameter, $\kappa$, as a sensitive parameter in the transport analysis. Despite this, matrix diffusion was not selected as an uncertain parameter for the final modeling stage because few data are available to guide the generation of the random distributions of $\kappa$. Instead, a sensitivity approach is used to understand the impact of uncertainty in matrix diffusion. In addition to the base-case value used earlier ( $\kappa$ of 0.434), an order-of-magnitude lower $\kappa$ is evaluated here to assess the sensitivity of the transport results to the uncertainty associated with this parameter. Recall that the value of 0.434 itself already allows less diffusion than the best estimate of $\kappa$ of 1.37 day $^{-1 / 2}$. This particular sensitivity analysis is performed using all of the flow realizations generated for the three sites and includes parameter uncertainty as used in the base-case models presented in Section 5, with the only difference being the lower $\kappa$ of 0.0434 day $^{-1 / 2}$. 

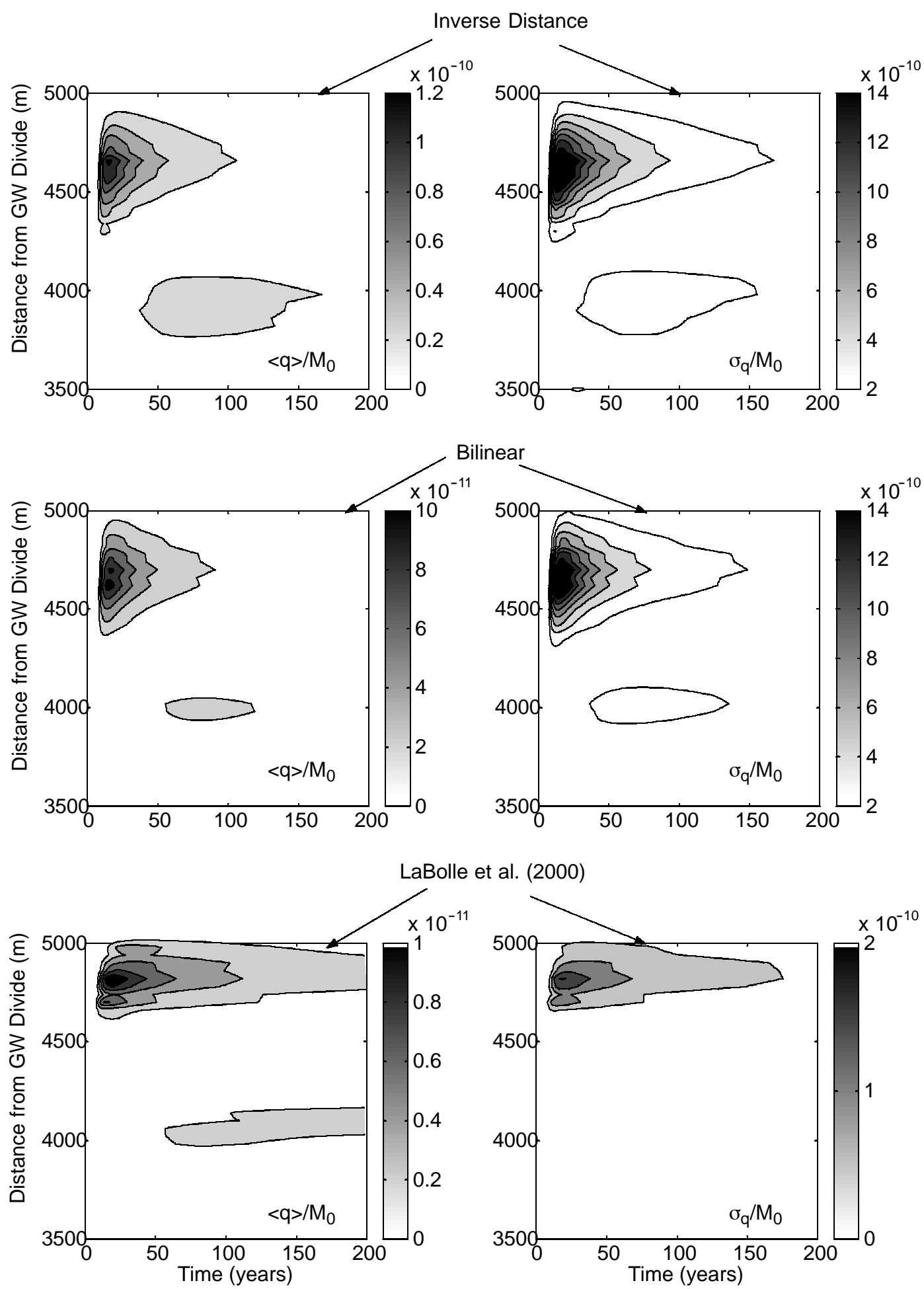

Figure 6.4. Comparison between bilinear and inverse-distance interpolation schemes and between these two traditional random walk techniques and the modified method of LaBolle et al. (2000) that avoids computing dispersion and porosity gradient terms. 
Figure 6.5 (top) shows the undecayed breakthrough curves for the first solute class (100 percent hydraulic release) at Milrow with and without matrix diffusion. The two cases for the matrix diffusion parameter are plotted in the figure. Without any matrix diffusion, a very early breakthrough is observed where the first mass arrival occurs at about five years after the test. When adding matrix diffusion with $\kappa=0.434$ (the base case), a significant reduction in the mass flux values is obtained and there is a significant delay in mass arrival. A typical feature of the matrix diffusion effect is to delay the arrival of mass to the breakthrough boundary, reduce the peak and induce a tailing effect. The shape and length of the tailing effect depends on the parameters governing the diffusion into the rock matrix, which are represented by $\kappa$. The results with $\kappa=0.0434$ also show a significant reduction (two orders of magnitude at least) in mass flux, but less delay in mass arrival time.

The results for each of the sites show a great sensitivity to matrix diffusion. At Milrow, the peak ${ }^{3} \mathrm{H}$ flux is increased about five to six orders of magnitude and occurs earlier (at about 15 years) than the higher matrix diffusion base case (Figure 6.6 and Figure 5.14). The short half-life of ${ }^{3} \mathrm{H}$ magnifies the effect of this parameter. As alluded to earlier, the higher values of $\kappa$ lead to delayed arrival of mass and lower mass fluxes. This delayed arrival encounters significant decay for short-lived nuclides. The effect of this parameter is much less dramatic for radionuclides with long half-lives. For example, for ${ }^{14} \mathrm{C}$, the normalized peak of the mean concentration increases by one to two orders of magnitude and occurs at about 250 years (Figure 6.7 and Figure 5.15). The peak of the total mass flux is increased two orders of magnitude by decreasing the matrix diffusion parameter. The effect of this parameter is less dramatic than it was for ${ }^{3} \mathrm{H}$. Other radionuclides show similar sensitivities to the matrix diffusion parameter as shown in Table 6.1a and Table 6.1b and in comparison with Tables 5.3a and 5.3b, with the effect essentially dependent on the radionuclide's half-life.

The results of the transport simulations for Long Shot show less sensitivity (as compared to the other two tests) to the value of the matrix diffusion parameter even for the short-lived nuclides. This is attributed to the short arrival times encountered at Long Shot. The peak for ${ }^{3} \mathrm{H}$ is increased about three orders of magnitude and occurs at about seven years (as opposed to 30 years in the base case; compare Figure 6.8 and Figure 5.23). For ${ }^{14} \mathrm{C}$, the normalized peak of the mean concentration increases by two orders of magnitude and occurs at about four years, when $\kappa$ is decreased to 0.0434 (compare Figure 6.9 and Figure 5.24). Other radionuclides show similar sensitivities to the matrix diffusion parameter as shown in Table 6.2a and Table 6.2b, with the effect being less dependent on the radionuclide's half-life as compared to Milrow due to the very short arrival times.

At the Long Shot site, the lower matrix diffusion value results in breakthrough of some radionuclides where none occurred in the base case. The radionuclides in Class 6, which did not survive the base-case transport scenarios for any of the sites, showed detectable amounts of mass flux and concentration for the Long Shot case with the smaller matrix diffusion. With the short arrival times and the smaller value of the matrix diffusion parameter, the elements in that category break through but with much lower concentrations and mass fluxes as compared to elements in the first five classes. Since Class 6 survived the scenario with the small matrix diffusion $(\kappa=$ 

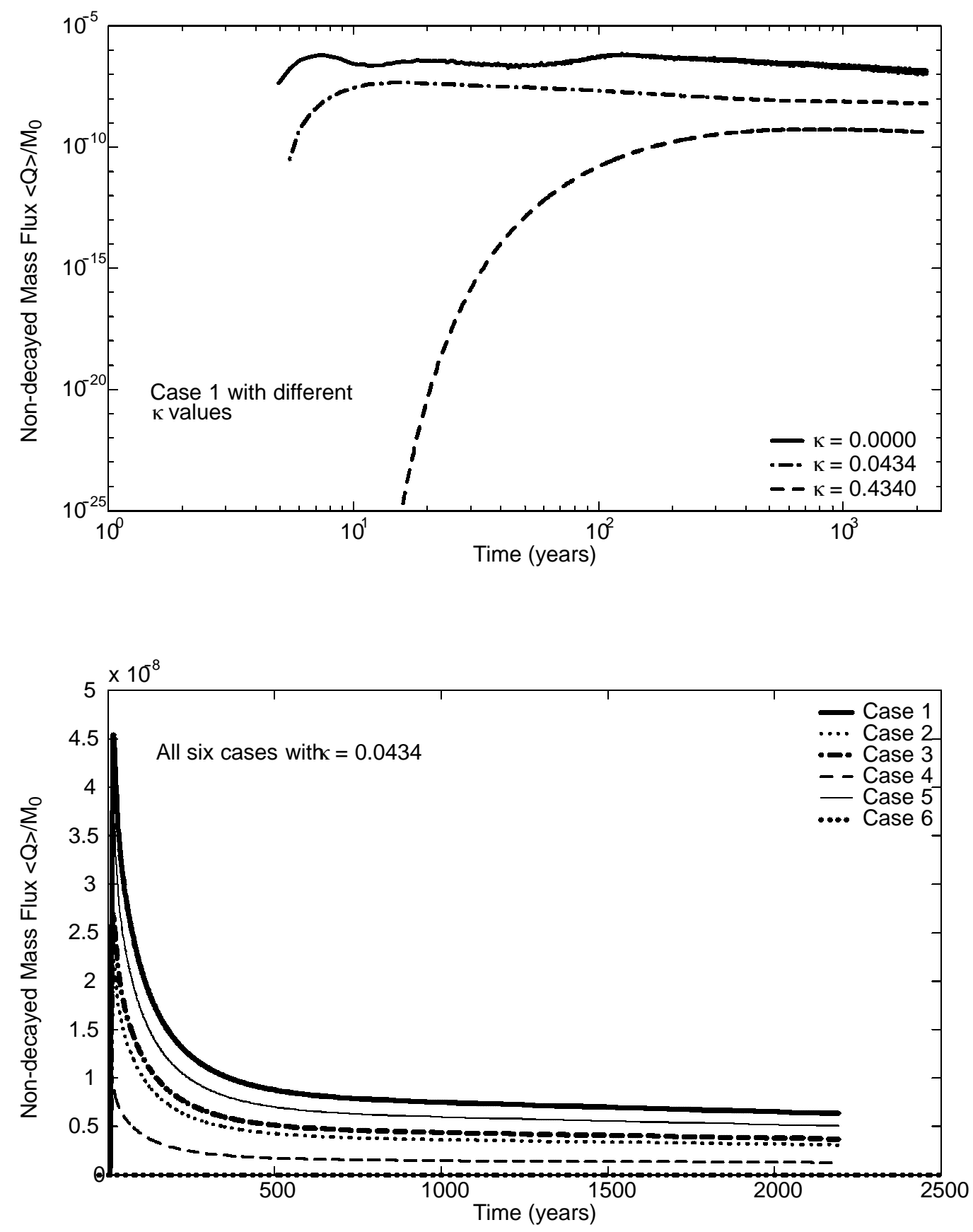

Figure 6.5. Undecayed breakthrough curves for the first solute class with different matrix diffusion strengths (top) and for the six solute classes with $\kappa=0.0434$ (bottom). 

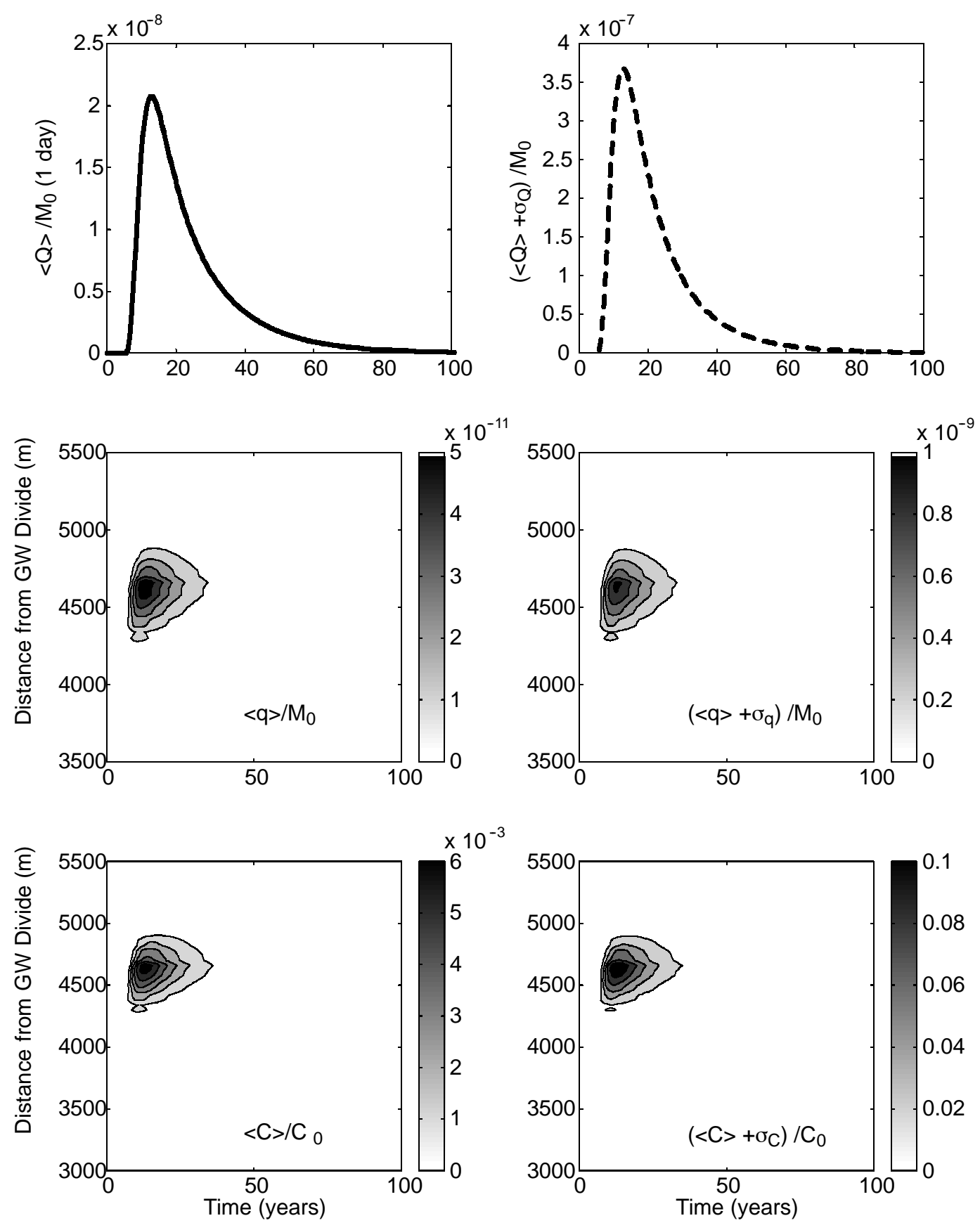

Figure 6.6. Statistics of mass flux and concentration for ${ }^{3} \mathrm{H}$ with $\kappa=0.0434$ at Milrow. 

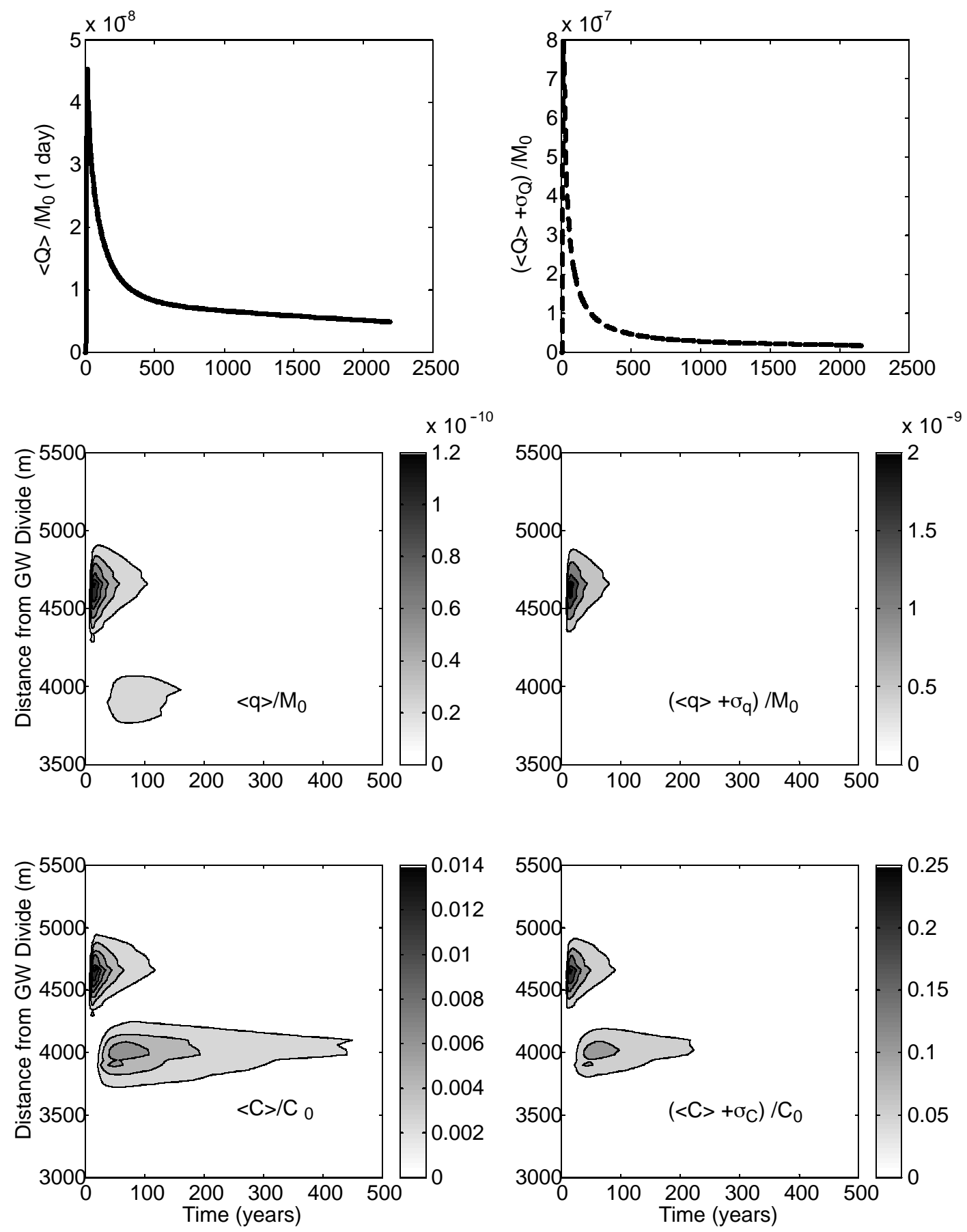

Figure 6.7. Statistics of mass flux and concentration for ${ }^{14} \mathrm{C}$ with $\kappa=0.0434$ at Milrow. 

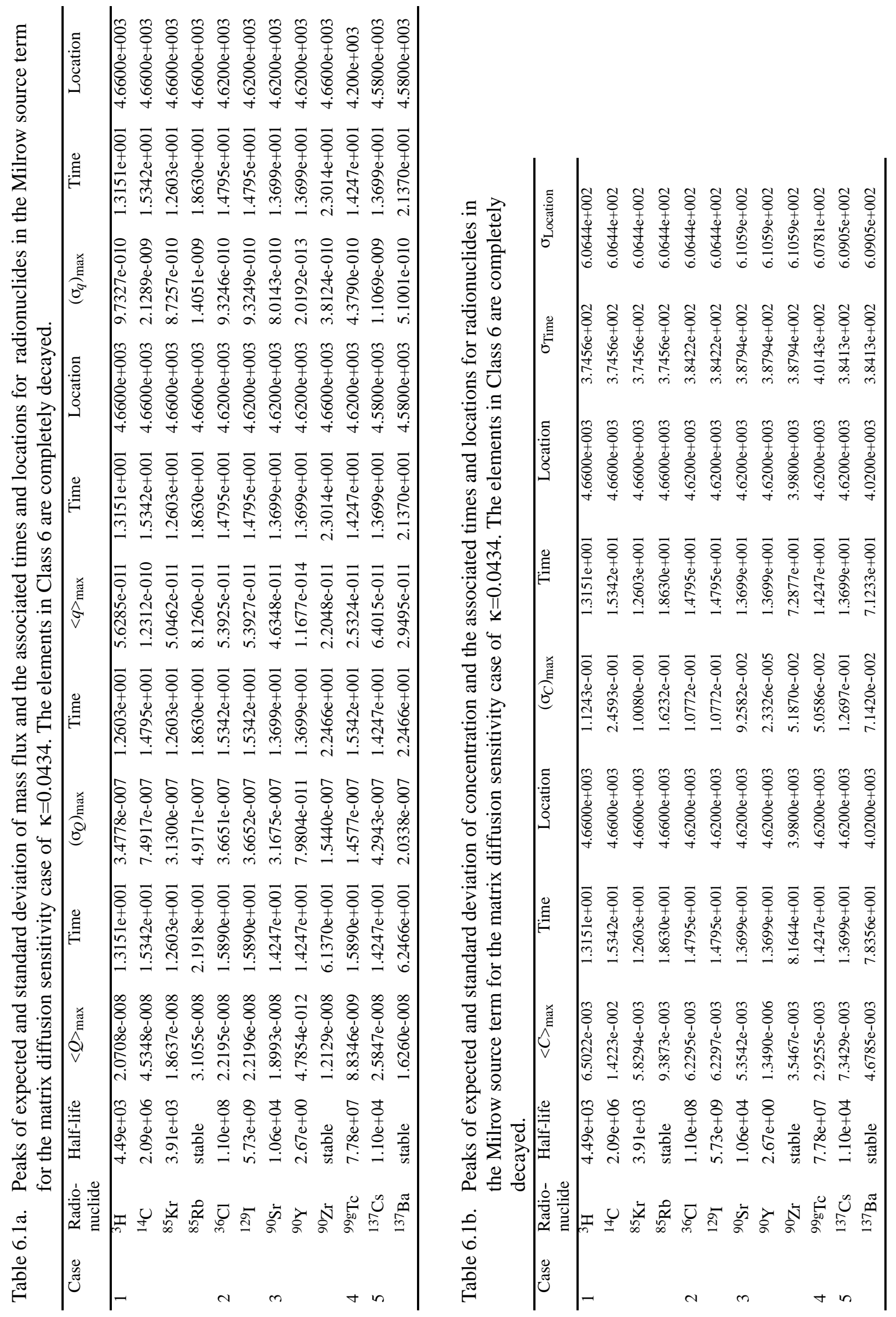

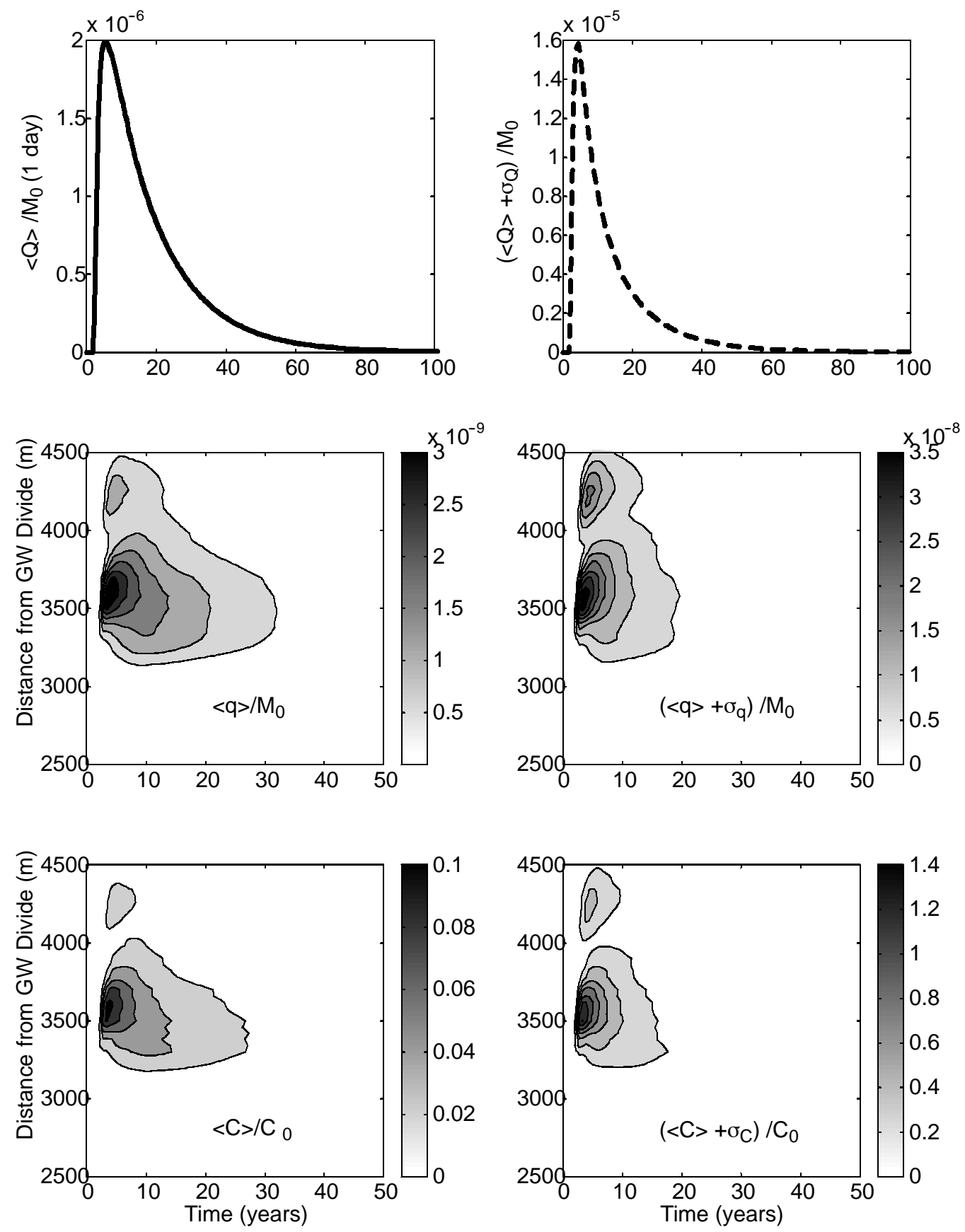

Figure 6.8. Statistics of mass flux and concentration for ${ }^{3} \mathrm{H}$ with $\kappa=0.0434$ at Long Shot. 

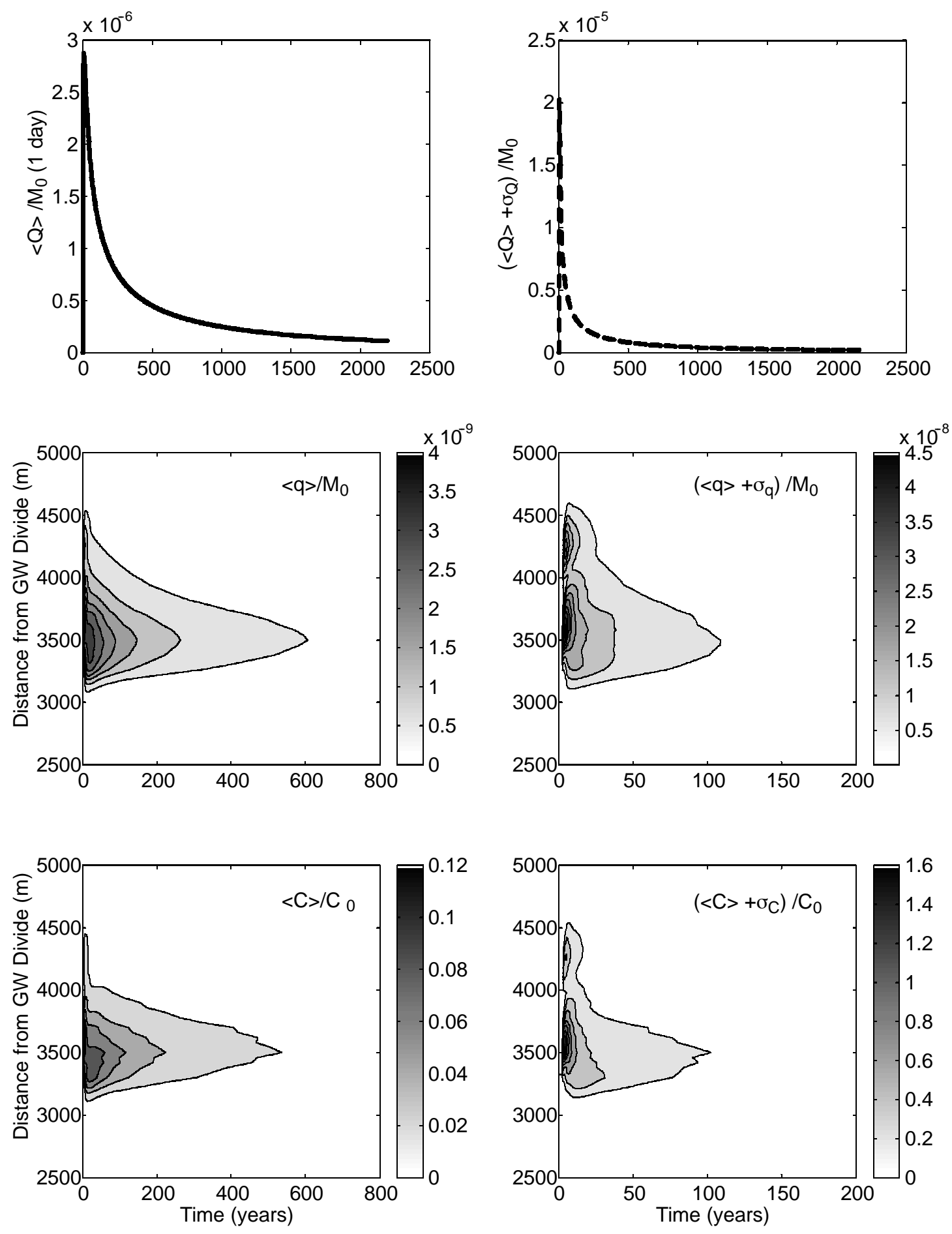

Figure 6.9. Statistics of mass flux and concentration for ${ }^{14} \mathrm{C}$ with $\kappa=0.0434$ at Long Shot. 


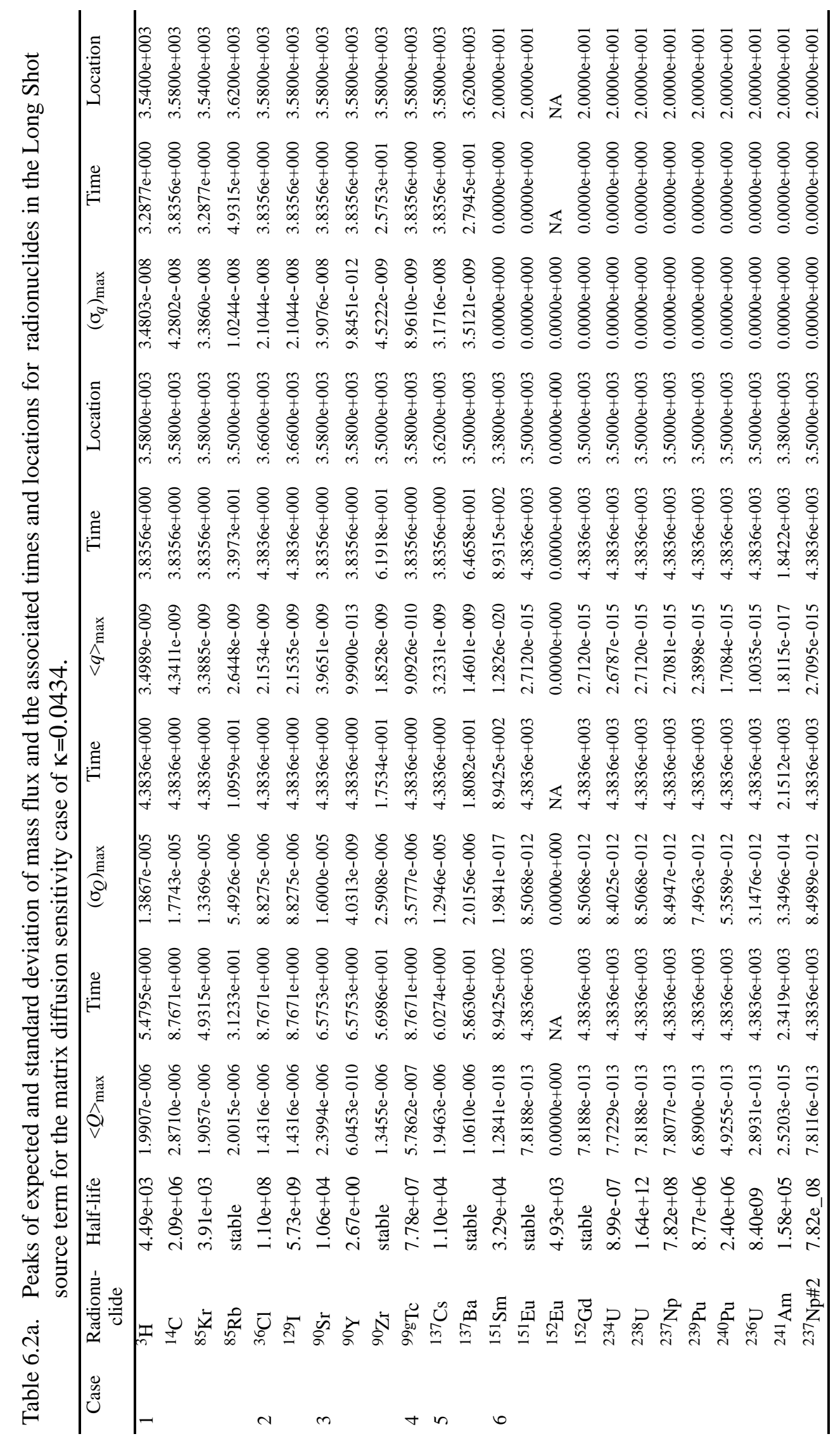




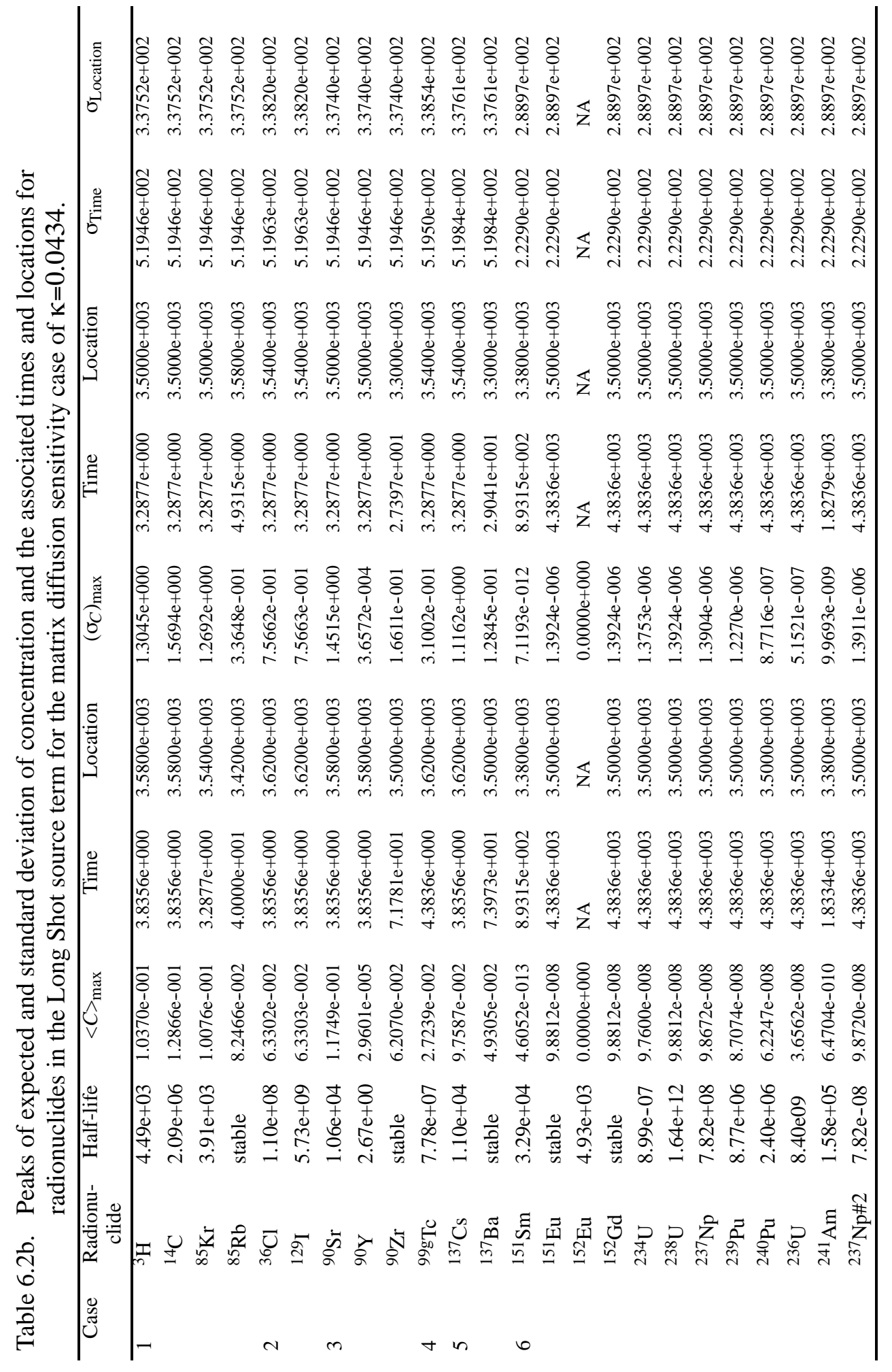


$0.0434 \sqrt{9,000}=4.117$ ), Figure 6.10 presents the mass flux and concentration plots for ${ }^{151} \mathrm{Sm}$ with a half-life of 3,290 days. ${ }^{151} \mathrm{Sm}$ is a rare-earth element with a high boiling point, low solubility and high $K_{d}$ for clays and zeolites, and thus has a behavior analogous to that of the actinides. The results show very small concentration and mass flux values as compared to ${ }^{3} \mathrm{H}$ and ${ }^{14} \mathrm{C}$. The normalized peak of the mean plus one standard deviation of concentration is about $7.0 \times 10^{-12}$ and occurs at about 900 years and 1,400 $\mathrm{m}$ from the divide. Table $6.2 \mathrm{~b}$ shows some higher concentrations for other elements in Case 6 due to longer half-lives.

More similar to Milrow, the results for Cannikin show a great sensitivity to the matrix diffusion parameter. For tritium, the peak is increased about six orders of magnitude and occurs much earlier (at about 20 years) than in the base case (compare Figure 6.11 and Figure 5.33). As mentioned earlier, the short half-life of ${ }^{3} \mathrm{H}$ magnifies the effect of this parameter. For ${ }^{14} \mathrm{C}$, the normalized peak of the mean concentration increases by two orders of magnitude and occurs at about 30 years in this sensitivity case (compare Figure 6.12 and Figure 5.34). The effect of this parameter is less dramatic than it was for ${ }^{3} \mathrm{H}$. Other radionuclides show similar sensitivities to the matrix diffusion parameter as shown in Table 6.3a and Table 6.3b, with the effect being dependent on the radionulclide's half-life.

\section{$\underline{6.1 .3 \text { Colloid Transport }}$}

The most extreme sensitivity case regarding matrix diffusion is to consider no diffusion at all. Given the high porosity measured for rocks from Amchitka, this is physically reasonable only if the conceptual model is one of porous medium flow, rather than fracture flow. This scenario was evaluated during the parametric uncertainty analysis and transport times were much longer for porous medium flow with no matrix diffusion than for fracture flow with matrix diffusion. However, there is one transport mechanism within the conceptual model of fracture flow that could allow for unretarded transport, and that is transport via colloids.

Colloids are submicrometer-size suspended particles that can be mobile in groundwater and have the potential to enhance transport of non-soluble contaminants through sorption. Buddemeier and Hunt (1988) demonstrated that colloids can play a role in moving relatively insoluble radionuclides (particularly rare-earth fission products such as ${ }^{151} \mathrm{Sm}$ ) away from underground nuclear tests. This transport process has been proposed to explain the occurrence of very low concentrations of plutonium $(\mathrm{Pu}) 1.3 \mathrm{~km}$ from an underground nuclear test on the NTS (Kersting et al., 1999). The ability of colloids to migrate significant distances and move significant mass is questionable, particularly under the geochemical conditions of a saltwater intrusion environment. Of particular concern are the reversibility of radionuclide sorption onto colloids, attachment of colloids to fracture walls, and aggregation with resultant filtering of colloids. These processes and experiments studying them are described by Triay et al. (1997).

The IAEA evaluated the issue of fast plutonium transport via natural colloids as one extreme of their $K_{d}$ model. They assumed that 10 percent of the plutonium did not undergo sorption, but they only applied this scenario to the 12 "CRTV" tests (tests where the cavity breached the volcanic cover and was in direct contact with highly permeable carbonates). The readily anticipated result was rapid breakthrough of plutonium into the adjacent lagoon, leading to the conclusion that if colloids 

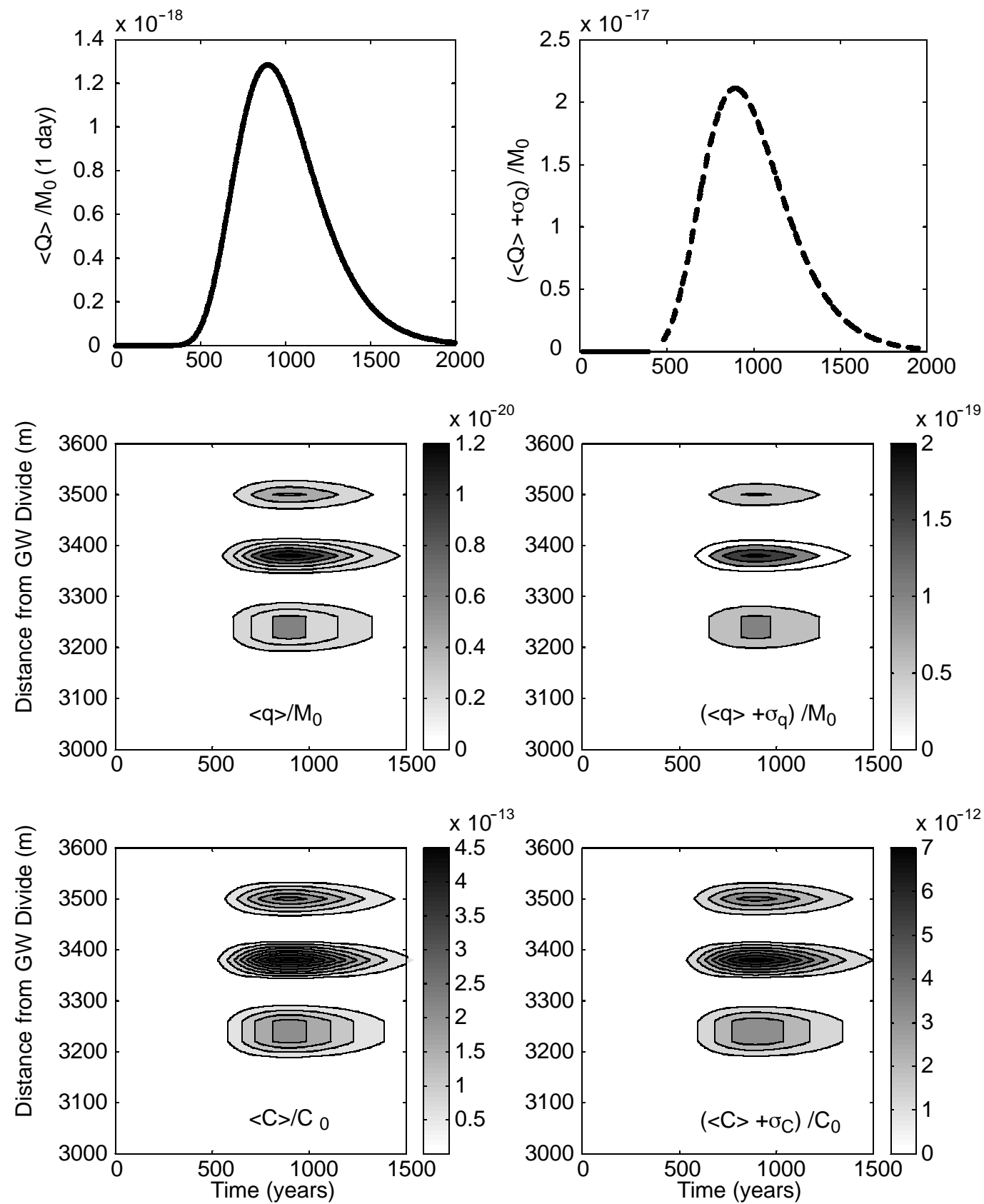

Figure 6.10. Statistics of mass flux and concentration for ${ }^{151} \mathrm{Sm}$ with $\kappa=4.117$ at Long Shot. 

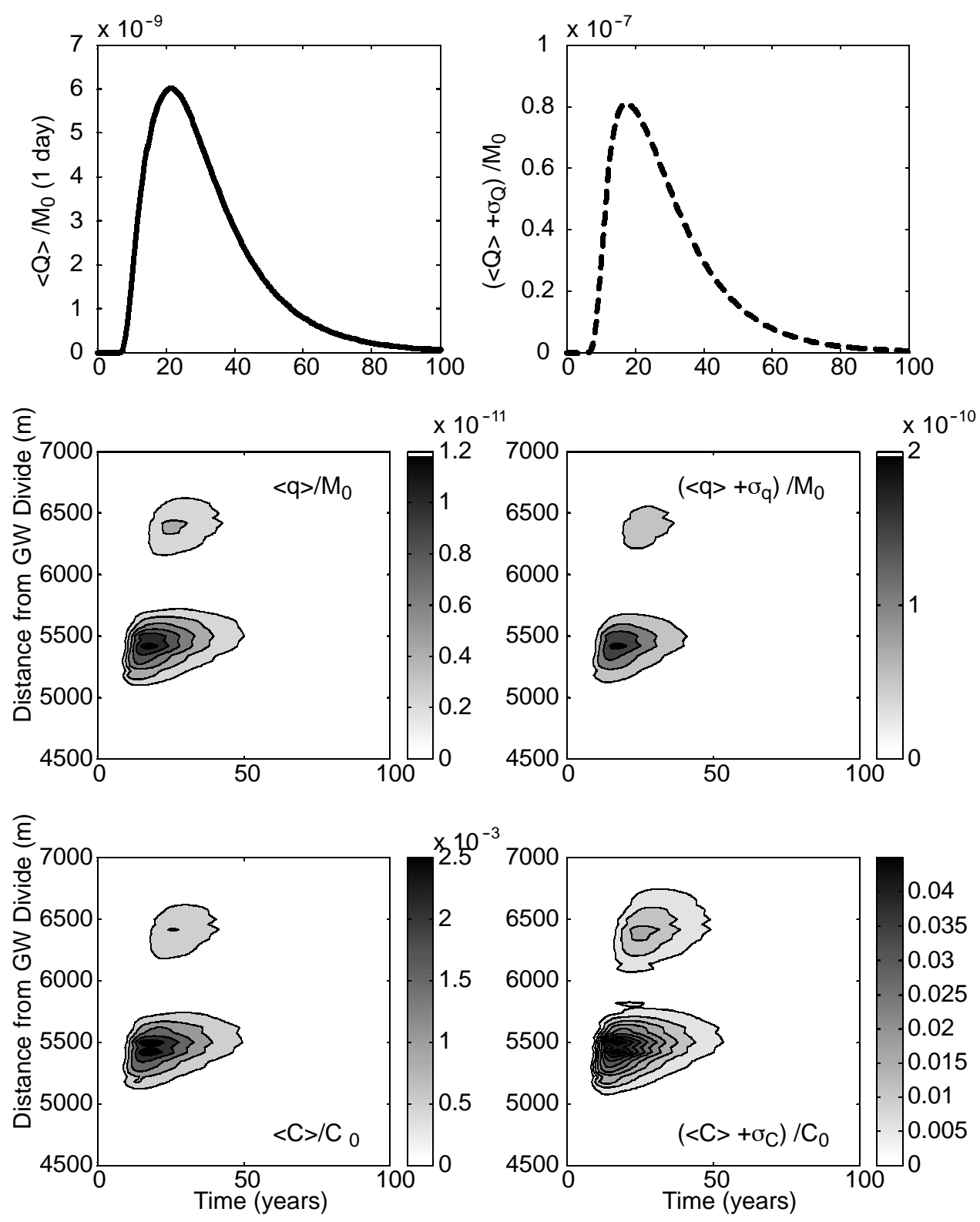

Figure 6.11. Statistics of mass flux and concentration for ${ }^{3} \mathrm{H}$ with $\kappa=0.0434$ at Cannikin. 

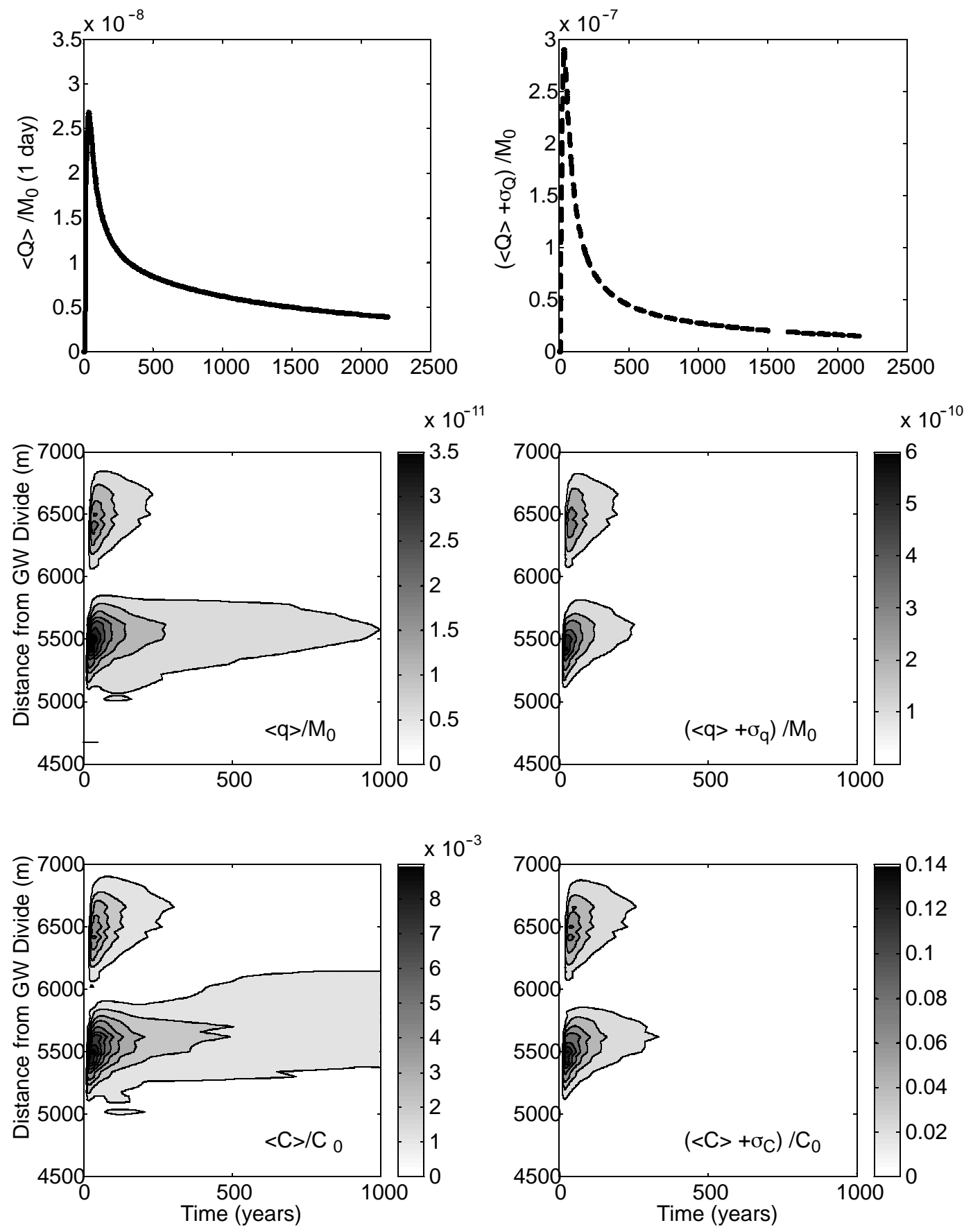

Figure 6.12. Statistics of mass flux and concentration for ${ }^{14} \mathrm{C}$ with $\kappa=0.0434$ at Cannikin. 

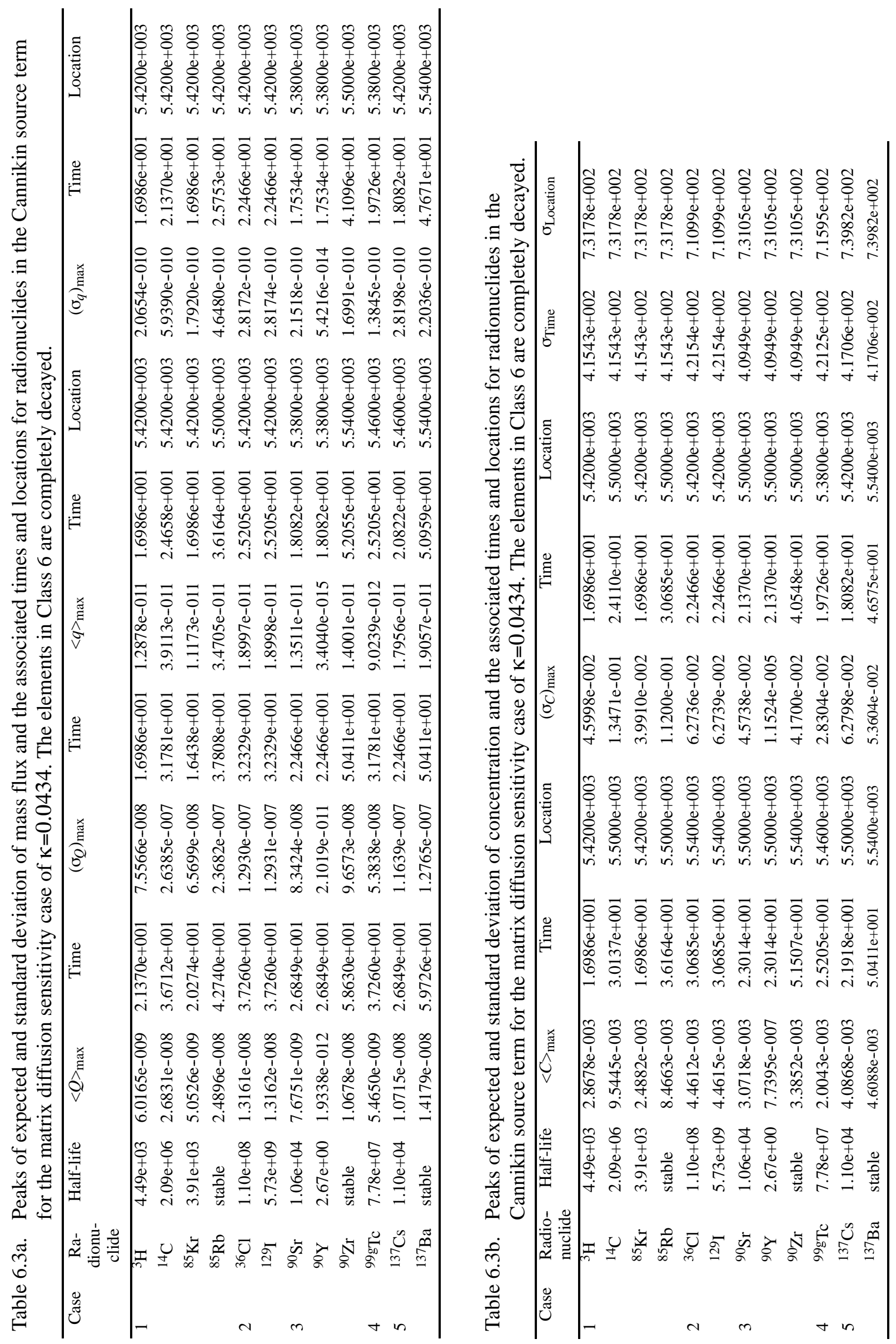
occurred and did not undergo sorption, they could induce an early breakthrough of plutonium, with the magnitude proportional to the proportion of plutonium fixed on the colloids. The IAEA (1999) emphasized that sampling at the atolls provided no evidence of the presence of natural colloids. In addition, they observed that "...the measured radionuclide concentrations in the waters of the cavity-chimney and the monitoring wells (Appendix V, Tables V.4, V.6 and V.11) as well as the $K_{d}$ values calculated from these measurements (Appendix V, Table V.10) do not support the hypothesis of an accelerated plutonium or ${ }^{241}$ Am transport by colloids."

Modeling to simulate colloid transport of radionuclides is essentially a simplification of the transport calculations performed previously; no retardation is included, either through sorption or matrix diffusion. The result of such a sensitivity is readily predictable: breakthrough will be faster and with higher mass than for situations including the retardation processes. As found by the IAEA, the impact will be directly proportional to the amount of radionuclide mass assumed to migrate on surfaces of colloidal particles and its release function. The amount migrating on colloids at Amchitka is unknown though reasonably expected to be quite small. The release apportioning assumed throughout the modeling here, that five percent of the refractory elements are available for immediate migration, is conservative and can be easily argued to be much smaller based on nuclear test studies.

Despite the lack of constraints on the sensitivity analysis, representatives of the State of Alaska Department of Environmental Conservation requested that transport calculations be performed that assume five percent of the mass of otherwise immobile radionuclides travels as colloids. The colloid-transport case was run for Long Shot because it was the only test displaying breakthrough of the Class 6 (refractory) radionuclides, though only for the matrix diffusion sensitivity case (see previous section). The results for ${ }^{151} \mathrm{Sm}$ are shown on Figure 6.13 for comparison with the matrix diffusion sensitivity case with ${ }^{151} \mathrm{Sm}$ breakthrough. The rare-earth elements have high boiling points, low solubilities, and high sorption to clays and zeolites. They have also already been implicated in colloid transport at the NTS (Buddemeier and Hunt, 1988) and as such are good analogs for plutonium and other actinides. ${ }^{151} \mathrm{Sm}$ is chosen over ${ }^{152} \mathrm{Eu}$ for its longer half-life (90 versus 13 years), as decay significantly impacts the effect of velocity variations and most of the radionuclides of interest for colloid transport are longer lived.

Comparing the peak mass breakthrough of ${ }^{151} \mathrm{Sm}$ for the low matrix diffusion sensitivity case with the case of no matrix diffusion or sorption shown here indicates an increase in peak mass of over 10 orders of magnitude for both the mean and standard deviation. Using a unit mass, the reasonableness of the State of Alaska scenario cannot be evaluated in terms of predicted concentration. However, once scaled by the classified data, the colloid concentrations resulting from this scenario can be evaluated in terms of solubility limits, colloid stability, and colloid concentration to determine if they are consistent with knowledge of radionuclide transport by colloids.

\subsubsection{Transient Responses to Sea Level Change}

As discussed in regard to the steady-state assumption of the conceptual flow model, the most significant transient process for the Amchitka groundwater system is the rise and fall of sea level in response to glacial cycles. These transients are documented as going in both directions: increases 

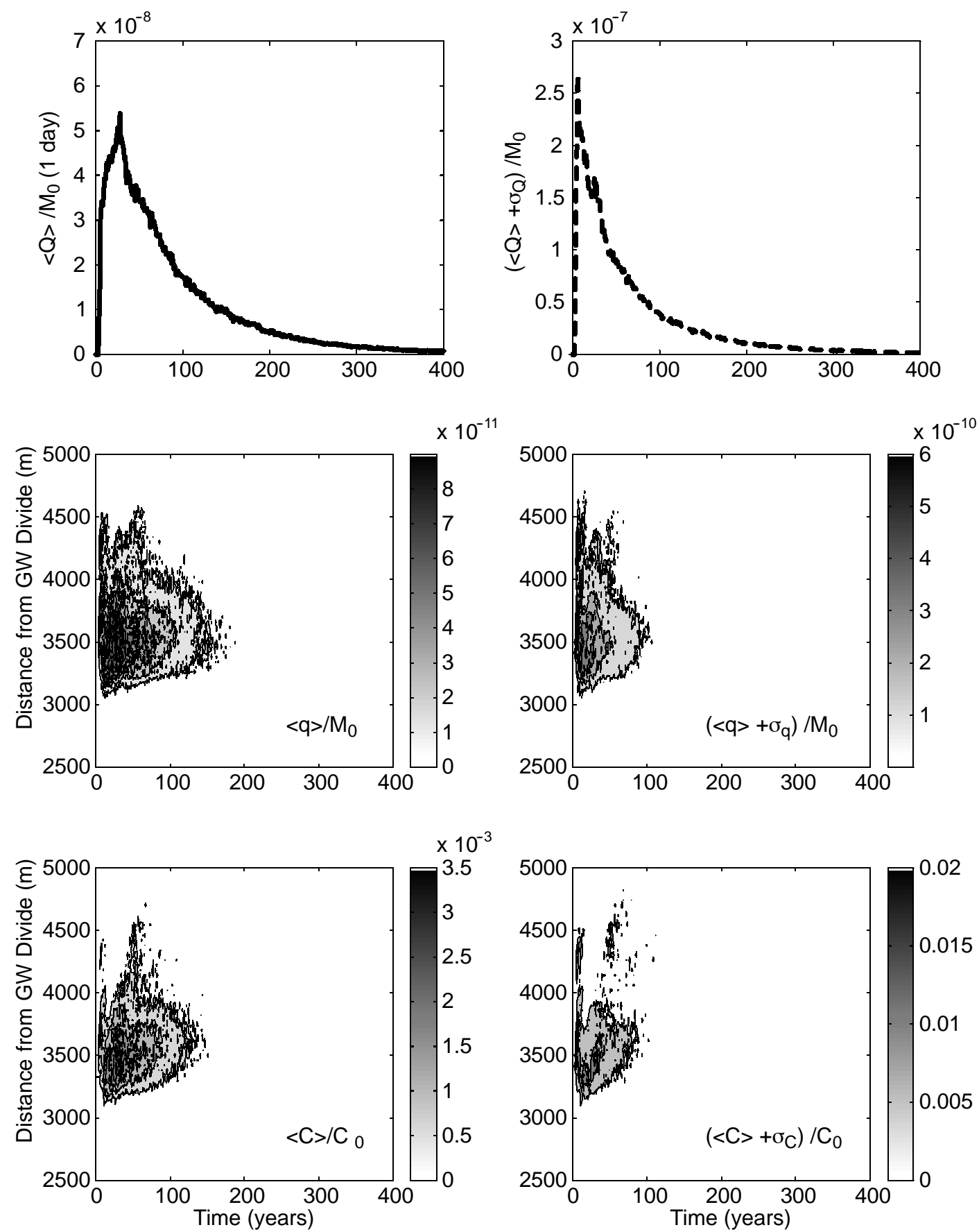

Figure 6.13. Results of simulating that five percent of the ${ }^{151} \mathrm{Sm}$ travels unretarded, simulating colloid-facilitated migration. 
in sea level of up to $76 \mathrm{~m}$ above current sea level and decreases of as much as $91 \mathrm{~m}$ below current sea level have been identified by mapping marine terraces (Gard, 1977). The last major regression is estimated to have ended about 127,000 years ago, whereas the last major transgression presumably peaked in late Wisconsinian time, on the order of 10,000 years ago (Gard, 1977). As a result, the scenario of concern is that of a mean sea level lower than that today, followed by a rise to current sea level, and the response of hydraulic head and groundwater chemistry to that sea level increase.

This sensitivity was performed for the Cannikin site, as it has the largest discrepancy between pressure and chemical data. A representative flow realization was selected and the modeling parameters held constant. Using the site's bathymetry, decreasing the sea level pressure boundary, and increasing the recharge area to include the area between the current shoreline and $30 \mathrm{~m}$ below current sea level, equilibrium head and chemical distributions were generated. Then the sea level was instantaneously increased to its present level and the system's reaction to this change monitored for 5,000 years.

The results show the large difference in the response times of the pressure and chemical systems that the conceptual model suggested. Within 100 years of the sea level rising $30 \mathrm{~m}$, the head in the freshwater lens and in the underlying seawater body are very close to their new equilibrium values (Figure 6.14 and Figure 6.15). Heads within the transition zone slowly approach their stable values over a couple of thousand years, but they differ from the equilibrium value by generally less than $10 \mathrm{~m}$. The transition zone heads actually move in a rebounding fashion, re-approaching the lower initial values after rapidly increasing from the pressure change. This reflects the impact of density on the environmental head as the salinity profile slowly changes. In contrast, after 100 years from the sea level rise, the chemical profile is a little different from that in equilibrium with the 30-m-lower sea level. The simulations do not approach a new equilibrium for at least 2,000 years across much of the transition zone. For example, the $\mathrm{Cl}$ concentration at a depth of about 2,000 $\mathrm{m}$ below land surface at the location of UAe-1 begins at a concentration of about 5,200 mg/L under the lower sea level condition. One hundred years after the sea level rises, it has increased to only $7,600 \mathrm{mg} / \mathrm{L}$, after 1,000 years it is about $12,600 \mathrm{mg} / \mathrm{L}$, and another thousand years brings it to 14,000 $\mathrm{mg} / \mathrm{L}$. After 5,000 years, the salinity is at about 15,600 $\mathrm{mg} / \mathrm{L}$.

This slow modeled response in the chemical system is probably overly rapid compared to reality because the process of matrix diffusion is not included in the simulation (it is simulated in the radionuclide transport calculations through the particle tracking). The equilibration presented in Figure 6.14 is a result solely of the varying velocity field. Presuming that the low sea level stand was of sufficient duration to equilibrate the matrix blocks as well as fractures with fresh water, the equilibration time as sea level rose would exhibit an even longer tailing as fresh water diffuses from the blocks and more saline water diffuses into them.

The significance of this sensitivity analysis is that it substantiates the conception that of the two sets of calibration data, the head data are more likely to be in equilibrium with the current conditions than the groundwater chemical data. Comparing the chemical data from UAe-1 to the simulation, many of the data appear representative of a much lower sea level condition than present, a situation consistent with the ${ }^{14} \mathrm{C}$ age dates in excess of 8,000 years. At Milrow, the large degree of vertical 

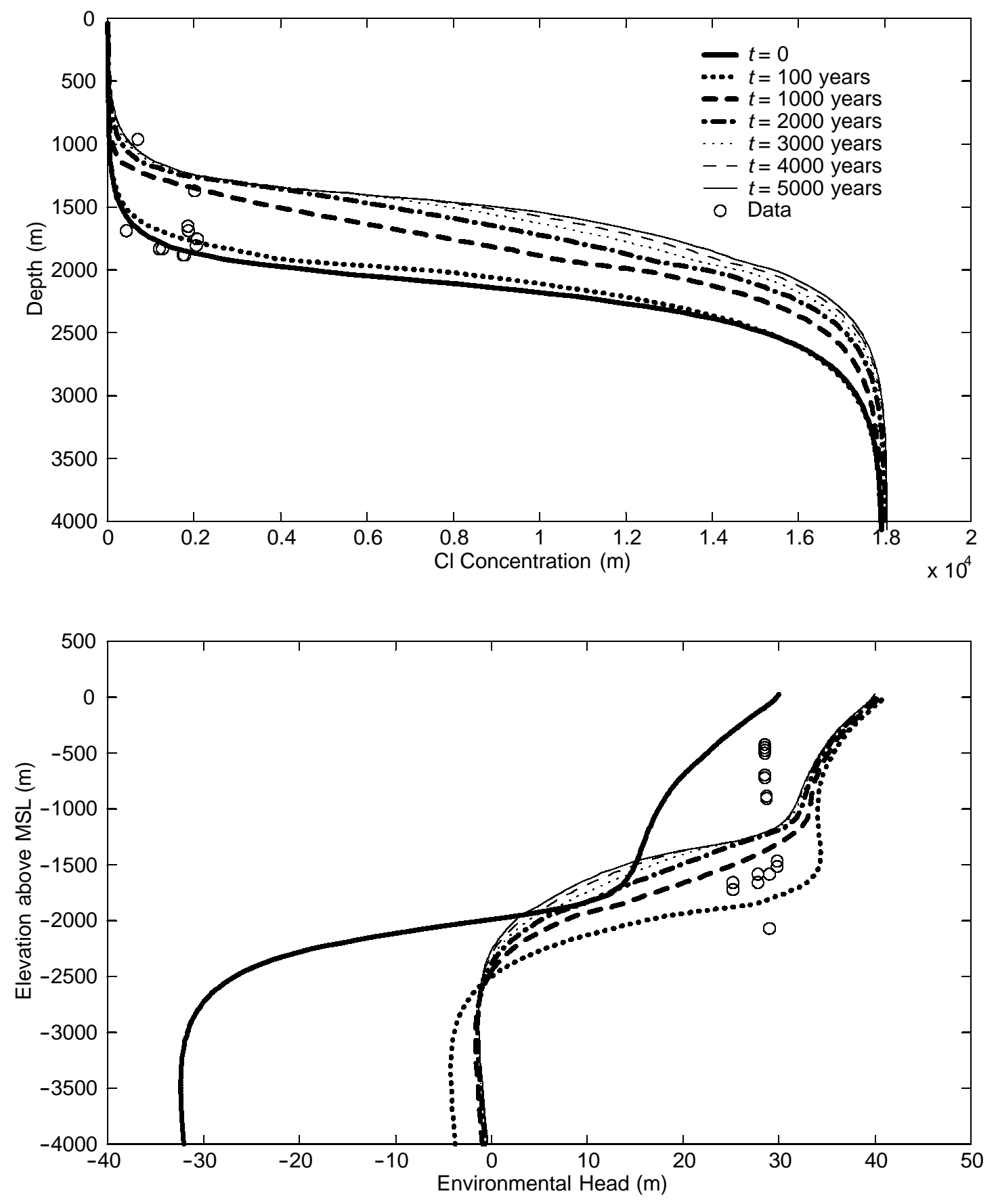

Figure 6.14. Changes in the concentration and head profiles at the UAe-1 location in response to a rise in sea level from an assumed glacial condition at $30 \mathrm{~m}$ below present sea level. 

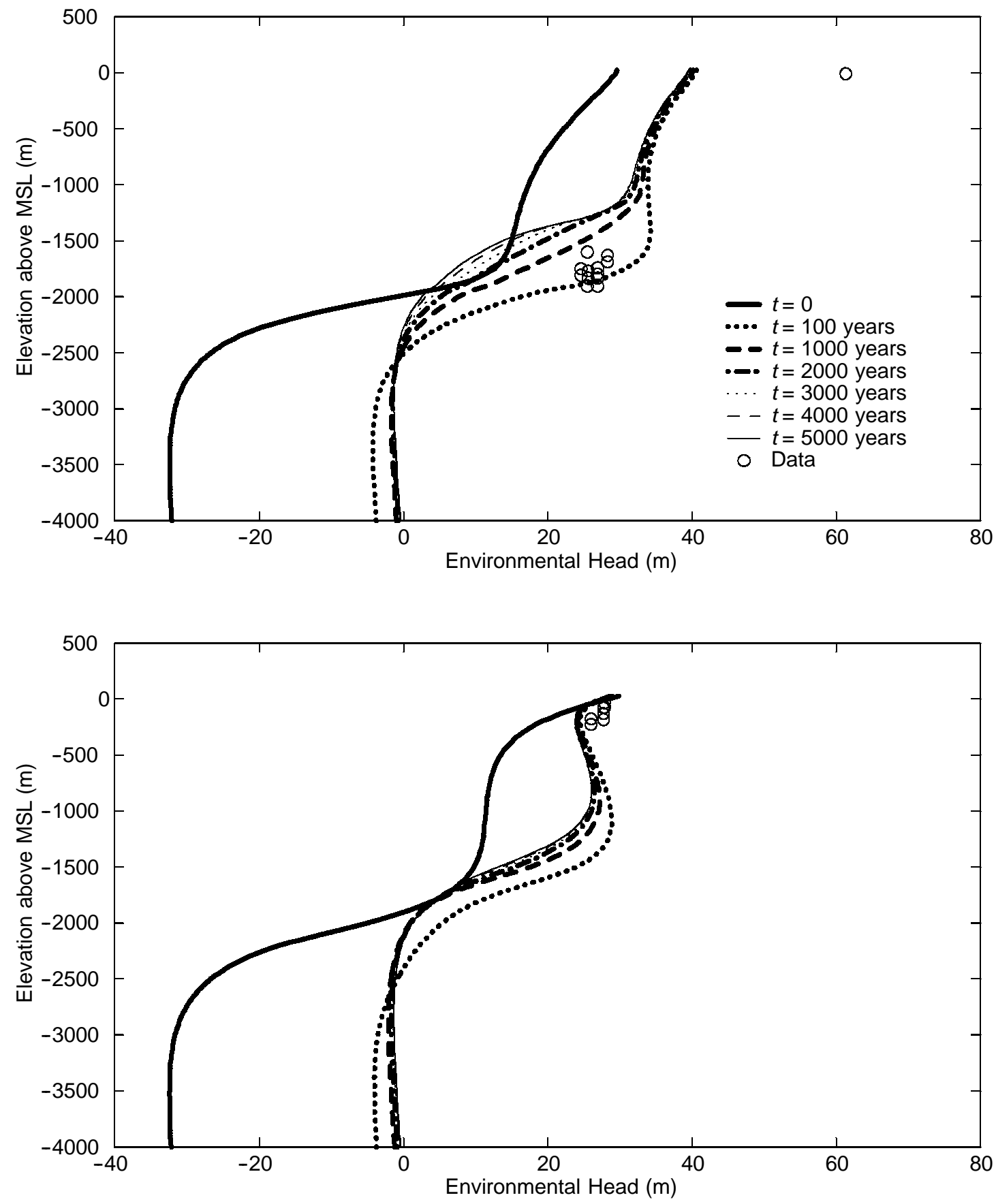

Figure 6.15. Changes in the head profiles at the UA-1 and HTH-1 locations in response to a rise in sea level from an assumed glacial condition at $30 \mathrm{~m}$ below present sea level. 
spreading evident for the transition zone in the groundwater chemical data may also be due to the slow chemical equilibration to sea level changes, again indicating that dispersion observed in the chemical profile represents a transient effect.

\section{$\underline{6.1 .5}$ Island Half-Width}

As discussed in Section 2.1.1, the conceptual model for groundwater flow at Amchitka assumes that a groundwater divide runs along the long axis of the island, separating flow to the Bering Sea on one side and flow to the Pacific Ocean on the other. The position of the divide is also assumed to coincide with that of the surface water divide. This assumption can be called into question due to the observation of asymmetry in the freshwater lens beneath the island (Fenske, 1972). This asymmetry is supported by the data analysis and modeling performed here, which suggests that the freshwater lens is deeper at Long Shot and Cannikin than at Milrow.

Not only is there uncertainty as to whether the groundwater and surface water divides coincide, there is additional uncertainty in the location of the surface water divide itself, as the topography of the island in the area of the nuclear tests is very subdued. The surface water divide was estimated using a detailed series of topographic maps at a scale 1:6,000 and with a 10-foot contour interval, created for Amchitka by the U.S. AEC (41 map sheets known as the Amchitka Island Map Atlas; Holmes and Narver, 1976). Despite this resolution, the distance between 10-foot elevation contours can reach over $100 \mathrm{~m}$ in places.

To understand the impact of this uncertainty on the groundwater modeling, several sensitivity cases were evaluated. In these, the island half-width was assumed to be 200 and $400 \mathrm{~m}$ wider than the estimate for Milrow, and also assumed to be 200 and $400 \mathrm{~m}$ narrower than used in the base-case model. For reference, the base-case half-width used at Milrow is 2,062 $\mathrm{m}$ so that plus and minus 10 and 20 percent differences are considered here. One realization was used for these calculations, one in which the cavity is located in the freshwater lens. It shows a 100 percent mass breakthrough and has the parameter values $K=2.34 \times 10^{-2} \mathrm{~m} / \mathrm{d}$, Rech $=1.82 \mathrm{~cm} / \mathrm{yr}$ and $\theta=1.62 \mathrm{cx} 10^{-4}$.

Varying the island half-width both affects the depth to the transition zone (through varying the land surface available for recharge) and the position of the cavity in the flow system (by virtue of changing the distance from the test to the no-flow boundary). These effects can be seen on Figure 6.16 and Figure 6.17. Reducing the island half-width decreases the depth of the transition zone, and cuts the distance between the cavity and the transition in half for the 400-m-shorter half-width. Conversely, the transition zone is deepened by an increasing half-width, increasing the distance from the cavity to the transition zone by a factor of two for the 400-m-wide island. The flowpath distance to the seafloor from the cavity is also affected, lengthening for a wider island and shrinking for a smaller one.

The impact of these various configurations on transport is shown in Figure 6.18. What is first obvious from the breakthrough curves is that a difference of $\pm 200 \mathrm{~m}$ in the island half-width has a limited influence on the breakthrough behavior, despite the transition zone moving up or down a couple of hundred meters. This sensitivity can be expected to be higher if the cavity is positioned closer to the transition zone than evaluated here. Once the half-width changes by 20 percent, 

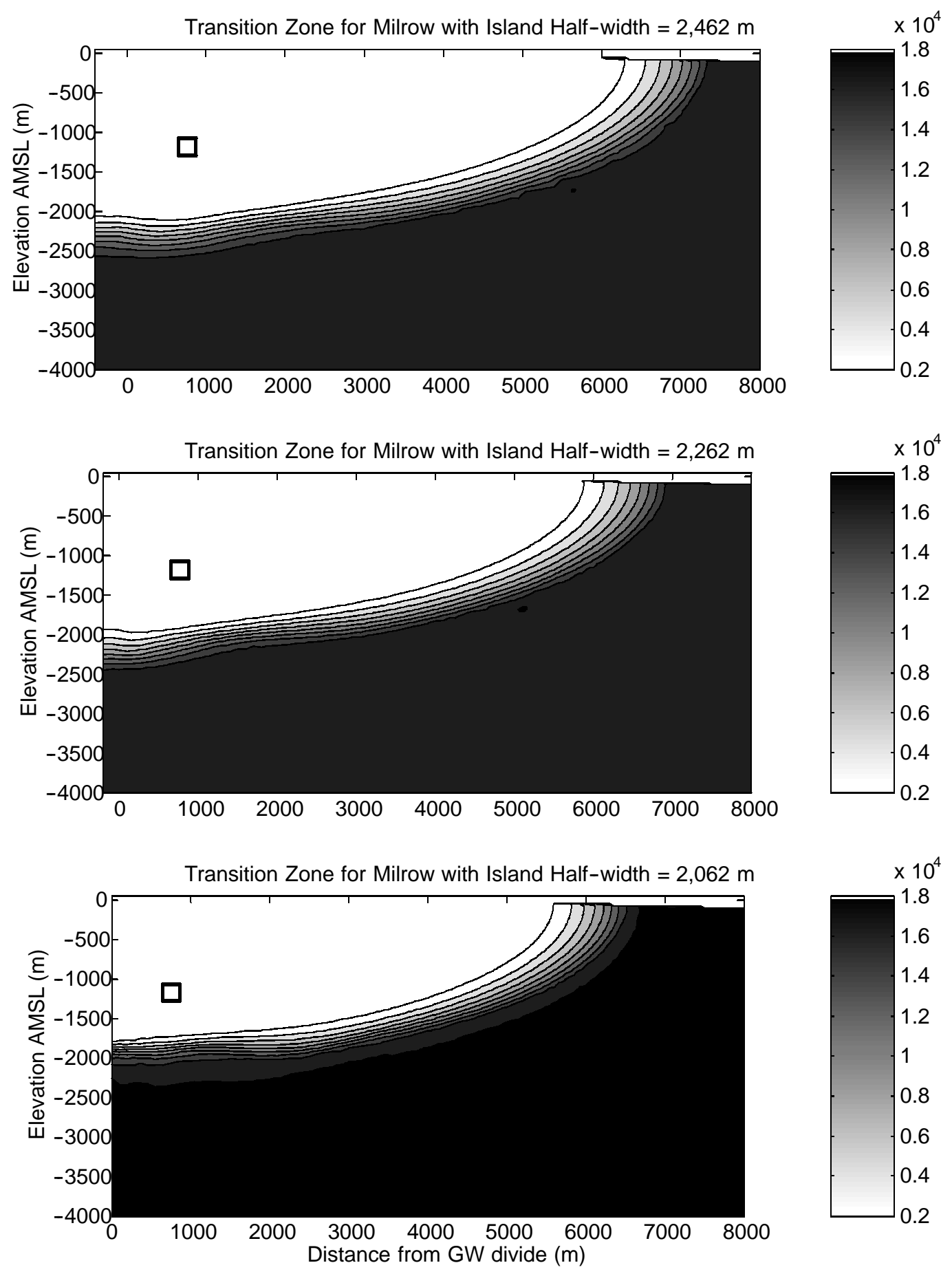

Figure 6.16. Variation in transition zone configuration for one realization of the Milrow model with the base-case island half-width $(2,062 \mathrm{~m})$ and 200 and $400 \mathrm{~m}$ wider. 

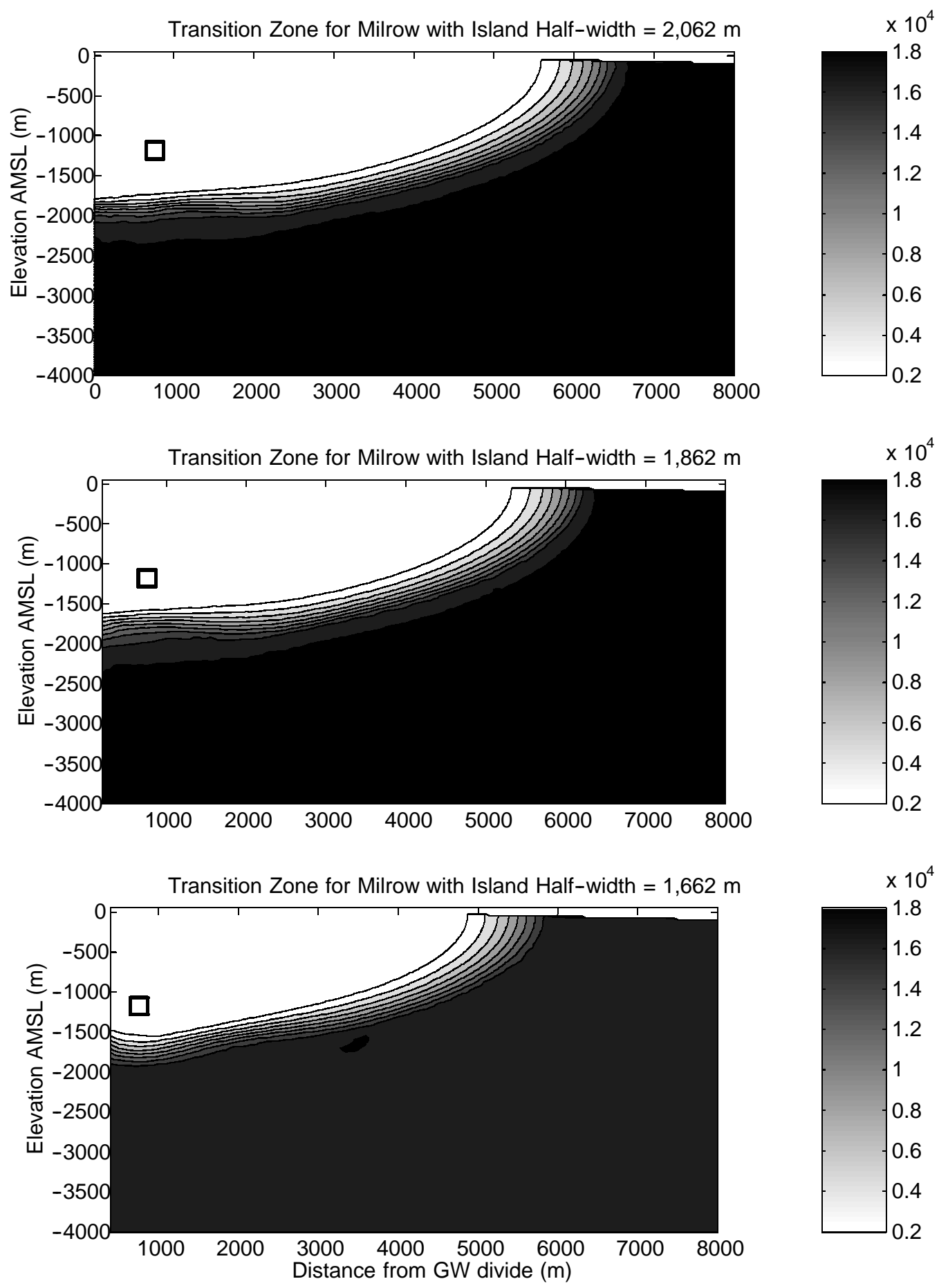

Figure 6.17. Variation in transition zone configuration for one realization of the Milrow model with the base-case island half-width $(2,062 \mathrm{~m})$ and 200 and $400 \mathrm{~m}$ shorter. 

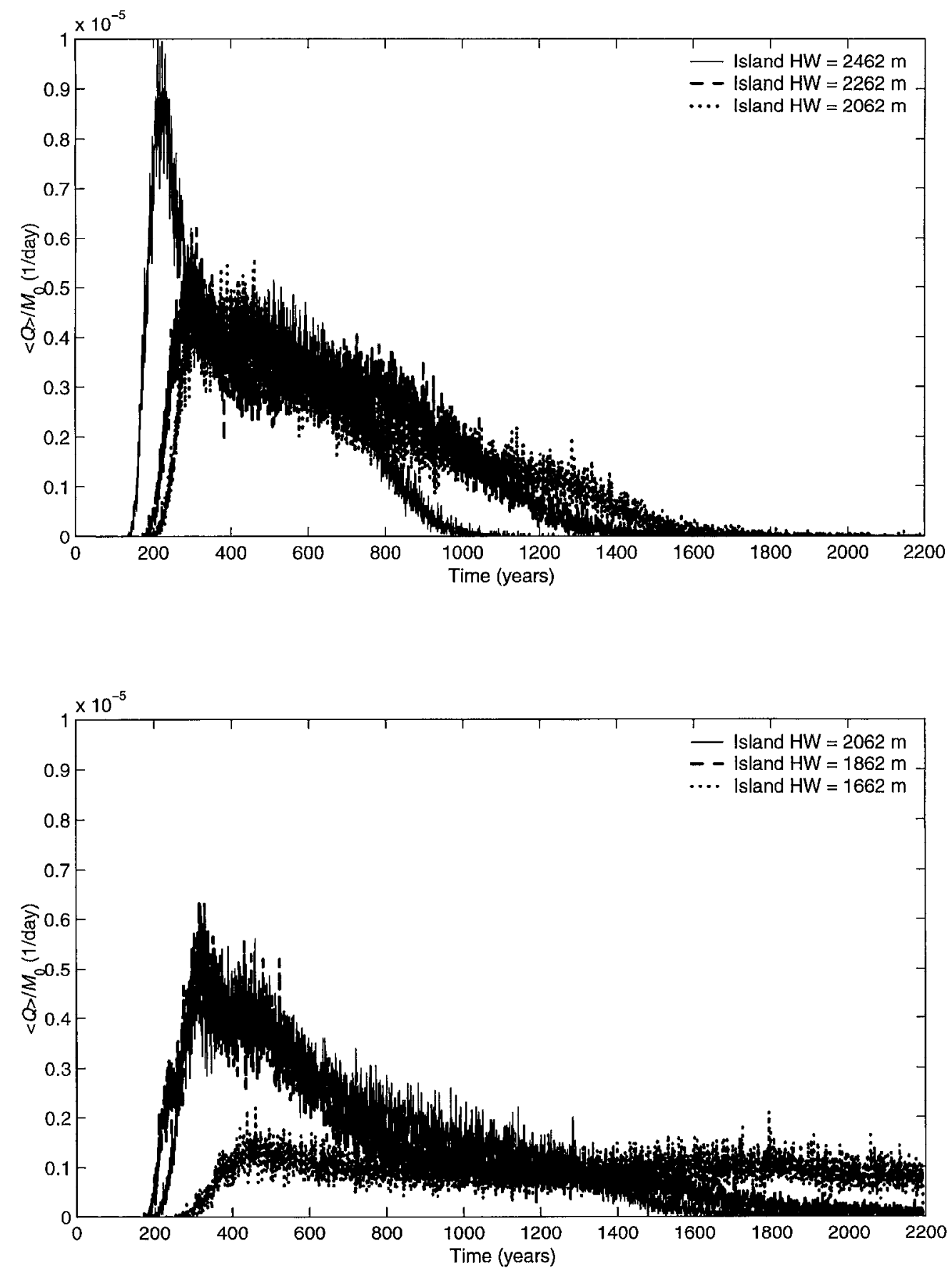

Figure 6.18. Undecayed, non-retarded breakthrough curves for one realization of the Milrow model under conditions of varying island half-width. The base case is $2,062 \mathrm{~m}$. 
however, a noticeable impact on the breakthrough is observed. A 400-m-longer half-width leads to an earlier breakthrough of mass at a peak flux about two times larger than the base case. A 400-m-shorter half-width results in a delay in breakthrough at a peak mass about five times lower than the base case.

If the half-width estimates are in error in the site models, the noted asymmetry in the freshwater lens can be used to infer the direction of the error. As the transition zone is more shallow at Milrow than the Bering-side sites, it is possible that the groundwater divide may be closer to the Pacific side of the island. If so, the Milrow breakthrough results in Section 5 would be too high and the Long Shot and Cannikin results too low. From the sensitivity runs, the magnitude of this potential error is probably on the order of a factor of two or three. It is important to note that the flat topography and ready availability of recharge do not support a groundwater divide largely different from the topographic divide. The asymmetry in the freshwater lens may be due to hydrogeologic factors other than the half-width, such as hydraulic conductivity, variations of which are accounted for in the site-specific calibrations.

\section{$\underline{\text { 6.1.6 Geothermal Heat }}$}

This Section describes the impacts of including geothermal heat in the Milrow model (referred to here as the geothermal model). The availability of hydraulic head, concentration, and temperature data sets and their high degree of confidence at Milrow make this site the most suitable for the sensitivity study of geothermal effects. These simulations are run using FEFLOW, and use the same two-dimensional finite-element mesh as the Milrow isothermal flow simulations described in Sections 2, 4, and 5. The geothermal model is configured to simulate pre-nuclear test conditions; therefore, the chimney is not included and $K$ and $\theta$ are treated as homogeneous properties throughout the domain. With the exceptions noted below, values of the groundwater flow parameters are the same as the values used in the calibrated flow model of Milrow (as described in Section 2.4.1). These values, as well as the values of the parameters required for the geothermal component are listed in Table 6.4. Fluid density and viscosity are dependent on both concentration and temperature, based on a nonlinear relationship of density to temperature incorporated in the FEFLOW code. The value of rock volumetric heat capacity, $c_{S} \varrho_{s}$, is estimated from a specific heat capacity, $c_{s}$, of $0.84 \mathrm{~J} / \mathrm{gm}-{ }^{\circ} \mathrm{C}$ determined from EH-1 core samples (Greene, 1965) and an average rock density, $\varrho_{s}$, of $2.3 \mathrm{gm} / \mathrm{cm}^{3}$ determined from laboratory derived dry bulk density values of core samples from UAe-1, UAe-2, UAe-3, and UAe-6 (Lee, 1969a, b, c, d) and the lithologic log of UAe-2 (Ballance, 1968). The value of rock thermal conductivity, $\lambda_{s}$, is estimated from laboratory tests of core samples from EH-1 (Greene, 1965). The volumetric heat capacity and thermal conductivity of water are FEFLOW default values.

Temperature profiles measured in several deep Amchitka Island boreholes (Sass and Moses, 1969) guide the choices of fixed temperature boundary conditions. UAe-2 displays the highest temperature gradient of all the Amchitka boreholes, a gradient of $3.2^{\circ} \mathrm{C}$ per $100 \mathrm{~m}$. This gradient is considerably higher than an average crustal value of $2.5^{\circ} \mathrm{C}$ per $100 \mathrm{~m}$ reported by Freeze and Cherry (1979), presumably as a result of volcanic activity along the Aleutian Ridge. Extrapolation of the UAe-2 profile to ground surface indicates a mean annual ground-surface temperature of about 
$4^{\circ} \mathrm{C}$ and this value is used for the temperature boundary along the upper surface of the model. This is consistent with the $3.9^{\circ} \mathrm{C}$ daily mean temperature noted for Amchitka (Armstrong, 1977). Likewise, the temperature of $125^{\circ} \mathrm{C}$ specified at the bottom boundary of the model is estimated by extrapolating the UAe-2 temperature profile to an elevation of $-4,000 \mathrm{~m}$ AMSL. Temperatures specified along the right (seaward) boundary vary linearly with depth from $4{ }^{\circ} \mathrm{C}$ at the top to $125^{\circ} \mathrm{C}$ at the base. The specified-recharge and concentration boundary conditions are the same as those used in the calibrated isothermal model, but the specified-head boundaries now account for the buoyancy effect imparted by the increased geothermal temperature at depth.

Table 6.4. Values of parameters used in FEFLOW for simulations incorporating geothermal heat.

\begin{tabular}{ll}
\hline \hline \multicolumn{1}{c}{ Parameter } & \multicolumn{1}{c}{ Value } \\
\hline Horizontal Hydraulic Conductivity, $K_{x x}$ & $6.77 \times 10^{-3} \mathrm{~m} / \mathrm{d}$ \\
Vertical Hydraulic Conductivity, $K_{z z}$ & $6.77 \times 10^{-4} \mathrm{~m} / \mathrm{d}$ \\
Specific Storage, $S_{S}$ & $1.0 \times 10^{-4}$ \\
Recharge, Rech & $1.125 \mathrm{~cm} / \mathrm{yr}$ \\
Fracture Porosity, $\theta$ & $5.0 \times 10^{-4}$ \\
Mass Longitudinal Macrodispersivity, $A_{L}$ & $100 \mathrm{~m}$ \\
Mass Transverse Macrodispersivity, $\mathrm{A}_{T}$ & $10 \mathrm{~m}$ \\
Mass Diffusion, $D^{*}$ & $1.0 \times 10^{-9} \mathrm{~m}^{2} / \mathrm{s}$ \\
Density Ratio & 0.025 \\
Rock Volumetric Heat Capacity, $\varrho_{\mathrm{s}} \mathrm{c}_{\mathrm{s}}$ & $1.9 \times 10^{6} \mathrm{~J} / \mathrm{m}^{3} \mathrm{C}$ \\
Water Volumetric Heat Capacity, $\varrho_{0} \mathrm{c}_{0}$ & $4.2 \mathrm{~J} / \mathrm{m}^{3} \mathrm{C}$ \\
Rock Thermal Conductivity, $\lambda_{\mathrm{s}}$ & $2.59 \mathrm{~J} / \mathrm{m}^{3} \mathrm{C}$ \\
Water Thermal Conductivity, $\lambda_{0}$ & $0.56 \mathrm{~J} / \mathrm{m}^{3} \mathrm{C}$ \\
Thermal Longitudinal Dispersivity, $B_{L}$ & $100 \mathrm{~m}$ \\
Thermal Transverse Dispersivity, $B_{T}$ & $10 \mathrm{~m}$ \\
Water Density and Viscosity, $\varrho_{0}$ and $\mu_{0}$ & 6 th order function of temperature \\
\hline \hline
\end{tabular}

The geothermal sensitivity run adds geothermal heat to the base-case Milrow model, with the values of all flow parameters unchanged from the base-case model. Thermally driven buoyant flow caused by the geothermal gradient in this case increases the vertical upward flux below the island and shifts the transition zone almost $200 \mathrm{~m}$ higher relative to the isothermal case (Figure 6.19). At the transition zone, this increased vertical flux is then directed seaward, resulting in higher velocities along the transition zone as compared to the isothermal case. Despite these differences, the overall patterns of flow are similar to the isothermal case.

The upward and left (toward the divide) components of velocities simulated below the transition zone are both larger due to the buoyancy-driven flow simulated in the geothermal model. Higher flow rates mean that velocities near the working point, which is located below the transition zone at Milrow, are higher when including the effects of geothermal heat (Figure 6.20). The vertical 

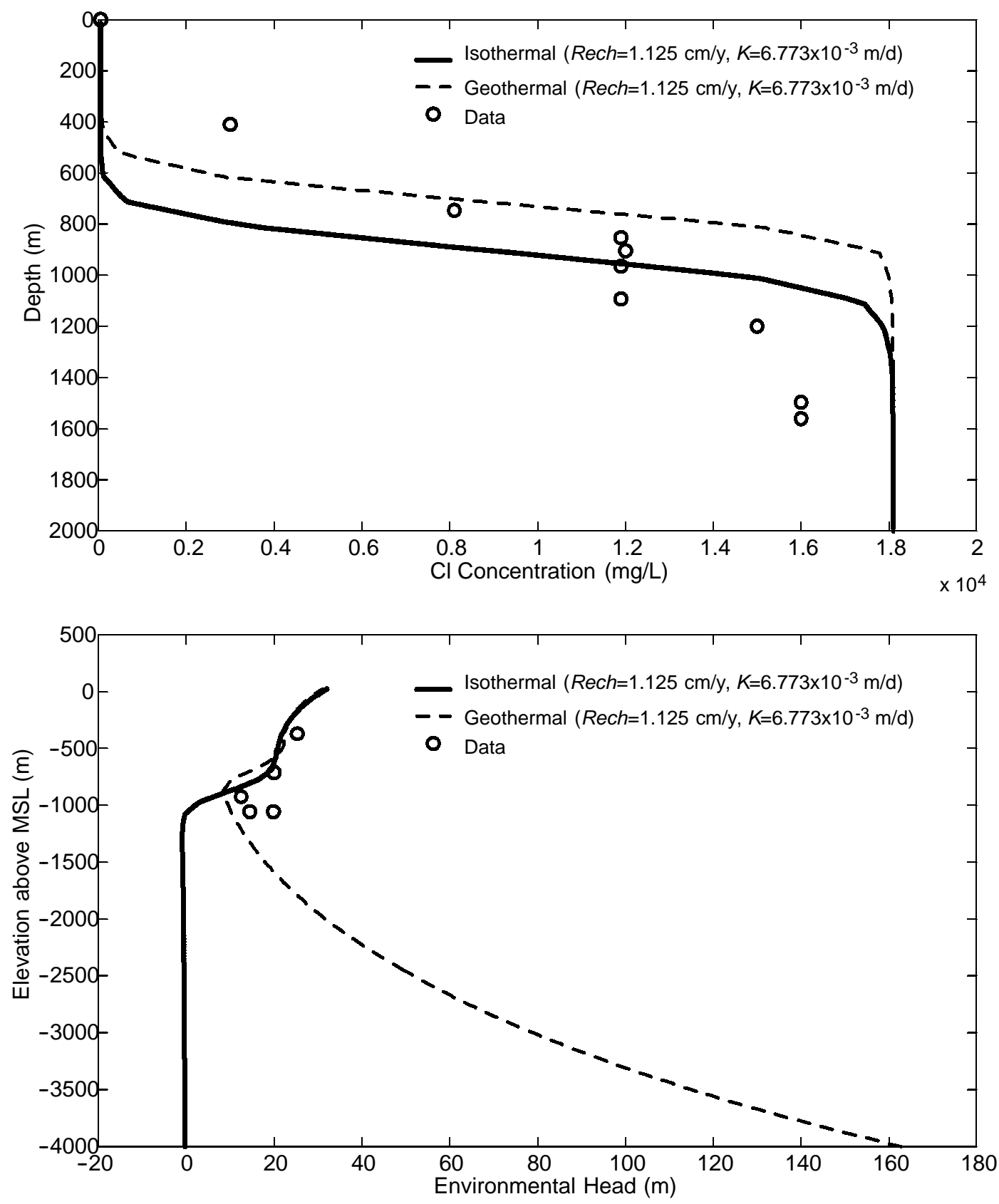

Figure 6.19. Comparison of profiles of head, concentration and temperature simulated by the isothermal and geothermal models, and values measured at UAe-2.

and horizontal velocities at the Milrow working point are about twofold higher in the geothermal model. Velocities higher than the isothermal model are generally maintained along the predicted flowpaths from the working point toward the sea, suggesting that inclusion of geothermal heat in the model simulations has the effect of reducing contaminant travel times for the Milrow and Cannikin sites where the working points are below the transition zone in many of the realizations considered. 

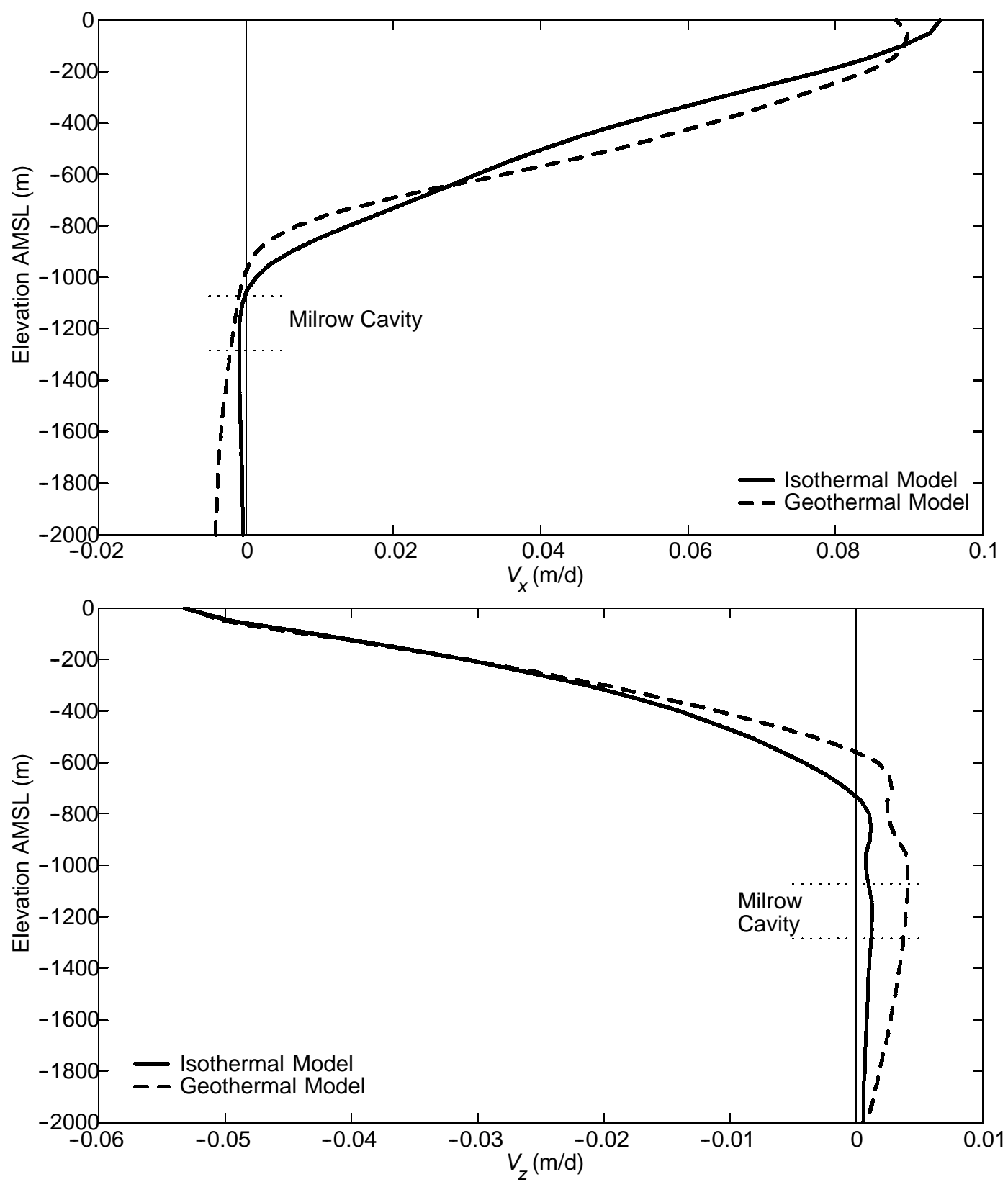

Figure 6.20. Comparison of velocity profiles along a vertical line through the working point of Milrow for isothermal and geothermal models.

The comparison of non-decayed, non-retarded breakthrough curves shows the impact of the higher velocities for the geothermal as compared to the isothermal case (Figure 6.21). The geothermal case exhibits more rapid breakthrough and a peak mass value between three and four times higher than in the isothermal simulation. Recall that this difference applies only when the transition zone is at or above the test cavity and that the impact of including geothermal heat is minimal above the transition zone as can be seen from the velocity profiles of Figure 6.20. 


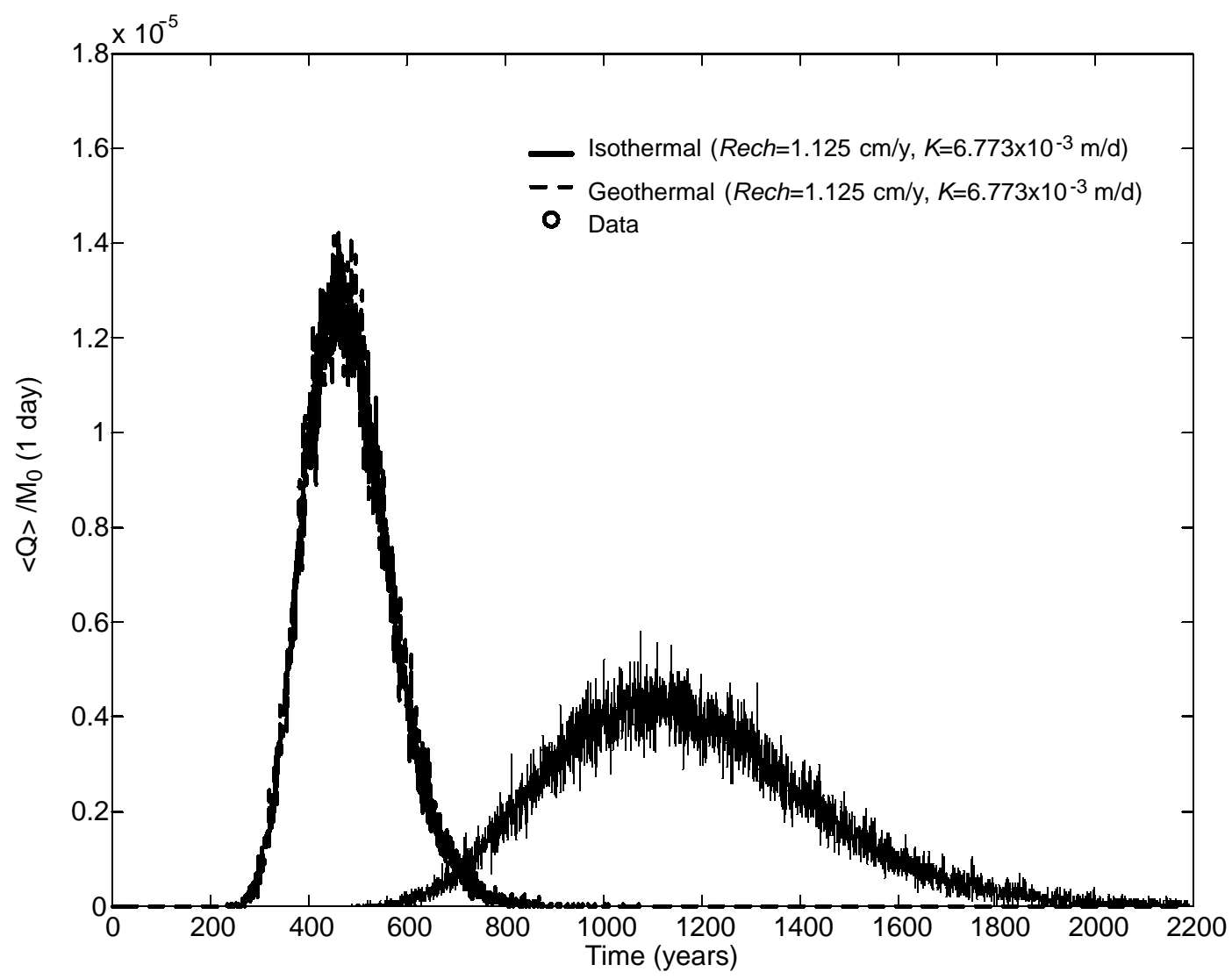

Figure 6.21. Comparison of mass breakthrough at the sea floor for non-decayed, unretarded, solutes under isothermal conditions and geothermal conditions.

\subsection{Three-Dimensional Sensitivity Studies}

The modeling presented thus far uses a two-dimensional (2-D) perspective to analyze the flow and transport problem. As discussed in Section 2.1.1, the island hydraulic environment lends itself to a 2-D approach. The 2-D vertical formulation of the base-case model relies on the assumption that groundwater flow is essentially perpendicular to the long axis and shoreline of the island, such that the mesh configuration is parallel to this flow. This simplifying assumption is considered reasonable for the conceptual model and is significantly more computationally efficient than a fully three-dimensional (3-D) formulation. However, there are several conceptual model assumptions that require a 3-D approach to analyze and this in turn causes an evaluation of the effect of neglecting the third dimension in the majority of modeling.

The 3-D density-dependent flow and mass transport simulations are run using the FEFLOW code. The coordinate directions of the models are such that $x$ and $z$ are the same as in the 2-D case and the third dimension of $y$ is the horizontal distance parallel to the shore. The finite-element mesh geometry of each vertical slice in the 3-D models is identical to the mesh geometry of the 2-D Cannikin model, with the addition of a width of each element in the $y$ direction (perpendicular to 
the axes of the 2-D model). Each slice is of uniform width such that there is no variation in model geometry across the overall width of the model.

All of the sensitivity studies presented here are applied to three realizations out of the 260 run for the Cannikin model in 2-D. The three realizations were chosen to span the gamut of breakthrough behavior observed in the simulations, ranging from about 28 percent to 60 percent to almost 100 percent breakthrough at the ocean floor (Figure 6.22). The 260 realizations were first categorized according to amount of breakthrough and porosity and three realizations were selected that spanned the breakthrough range but had virtually identical porosity (the realizations selected all have a porosity of about $2.67 \times 10^{-4}$ ). As already demonstrated, the velocity field is very sensitive to porosity, so it was held constant to reveal the impact of the sensitivity cases. The recharge-conductivity ratios of these three realizations were then used for the sensitivity modeling to derive the velocity field for particle tracking. Note that these ratios result in poor fits to the calibration data in some cases, but the objective here is simply to assess the possible impact on breakthrough. The three realizations encompass the variety of positions of the transition zone relative to the test cavity that result from the various parameter combinations.

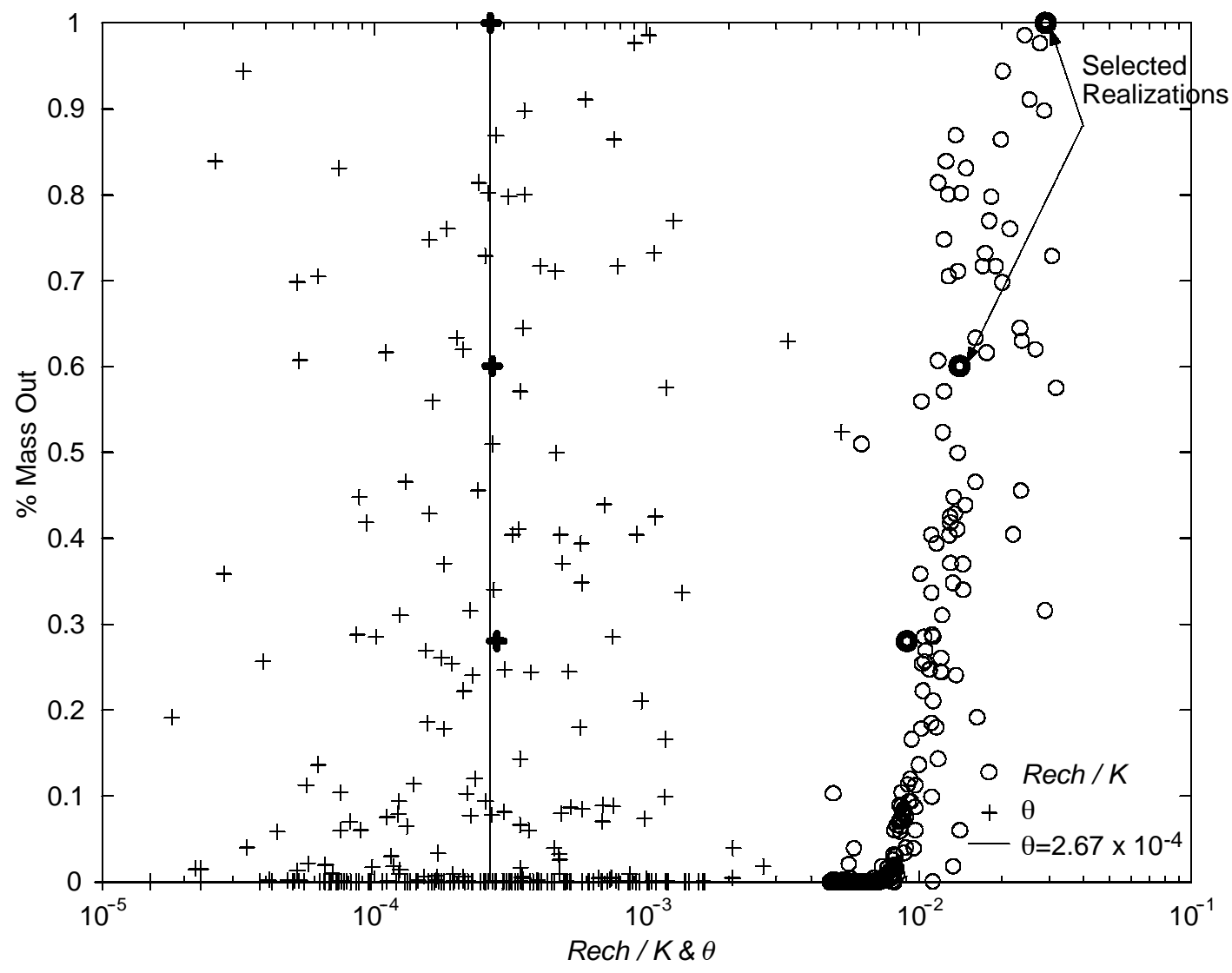

Figure 6.22. Selection of realizations for 3-D modeling. Three realizations were chosen from the Milrow simulations that covered the range of breakthrough behavior (percent mass breakthrough at the ocean floor), but that had very similar porosity values. The corresponding recharge-conductivity ratios were used in the 3-D modeling. 
The relative position of the transition zone to the Cannikin cavity for the three selected realizations can be seen in Figure 6.23. Though these realizations were selected from the Monte Carlo realizations generated for Cannikin, the various positions of the transition zone relative to the cavity allow them to represent flow fields possible for all three tests. The realization with the transition zone well below the cavity is representative of Long Shot. The realizations with the cavity within and below the transition zone are likely to be more representative of Milrow and Cannikin.

\subsubsection{Flow in the Rubble Chimney}

The rubble chimney formed in response to a nuclear explosion disrupts the natural state of the surrounding rock, creating heterogeneity in the spatial distributions of $K$ and porosity. Unlike the homogeneity assumed for the natural rock, the changes in $K$ and porosity are a limited local feature, centered over the working point of the nuclear test. The 2-D formulation correctly accounts for the vertical boundaries of the chimney only in the direction parallel to the mesh configuration (the x-axis of the model), i.e., parallel to the natural flow direction, and treats the chimney as extending infinitely in the lateral direction (perpendicular to the model mesh and perpendicular to the natural flow direction). The implication is that the 2-D model treats flow in the chimney as occurring in an infinitely wide feature (that is, wide in the direction perpendicular to the 2-D mesh). In reality, the chimney is only as wide perpendicular as it is parallel to natural flow, and can be treated realistically only in a 3-D model.

The geometry of the model representing 3-D flow in the rubble chimney is based on the Cannikin site to be consistent with the model incorporating heat derived from the Cannikin nuclear test (described in section 6.2.2 below). The model is comprised of 15100 -m-wide vertical layers of elements, giving a total model width of $1,500 \mathrm{~m}$ perpendicular to the natural flow direction (Figure 6.24). There are, therefore, 16 vertical layers of nodes separating these layers. The location and configuration of the chimney in the $x$ - $z$ plane is identical to the chimney in the 2-D Cannikin simulations, and extends across three slices, or $300 \mathrm{~m}$, in the center of the 3-D domain. The chimney is simulated as a vertical, rectangular column having a width in the $x-y$ plane of about two $R_{c}$, where $R_{c}$ is the cavity radius (estimated to be $157 \mathrm{~m}$ ). The hydraulic properties of the rock beyond this radius are considered to be not significantly affected by the nuclear explosion and are assigned the background values of $K$ and porosity. IAC (1998) modeled filling times of underground nuclear tests at Mururoa and Fangataufa atolls under several scenarios of fracturing beyond the cavity and concluded that observed filling rates are consistent with very little damage (fracturing) outside the cavity/chimney.

Boundary conditions and values of the groundwater flow and mass transport parameters for the three realizations are shown in Table 6.5. Conceptually, the rubble chimney acts as a conduit that promotes vertical flux, given the higher vertical conductivity in that region. Modeling the chimney in 3-D provides the geometry required to simulate groundwater entering the chimney from all radial directions, rather than the two directions allowed by the 2-D representation. Similarly, horizontal flow may exit the chimney at the transition zone in radial directions other than the seaward direction simulated in the 2-D model. 

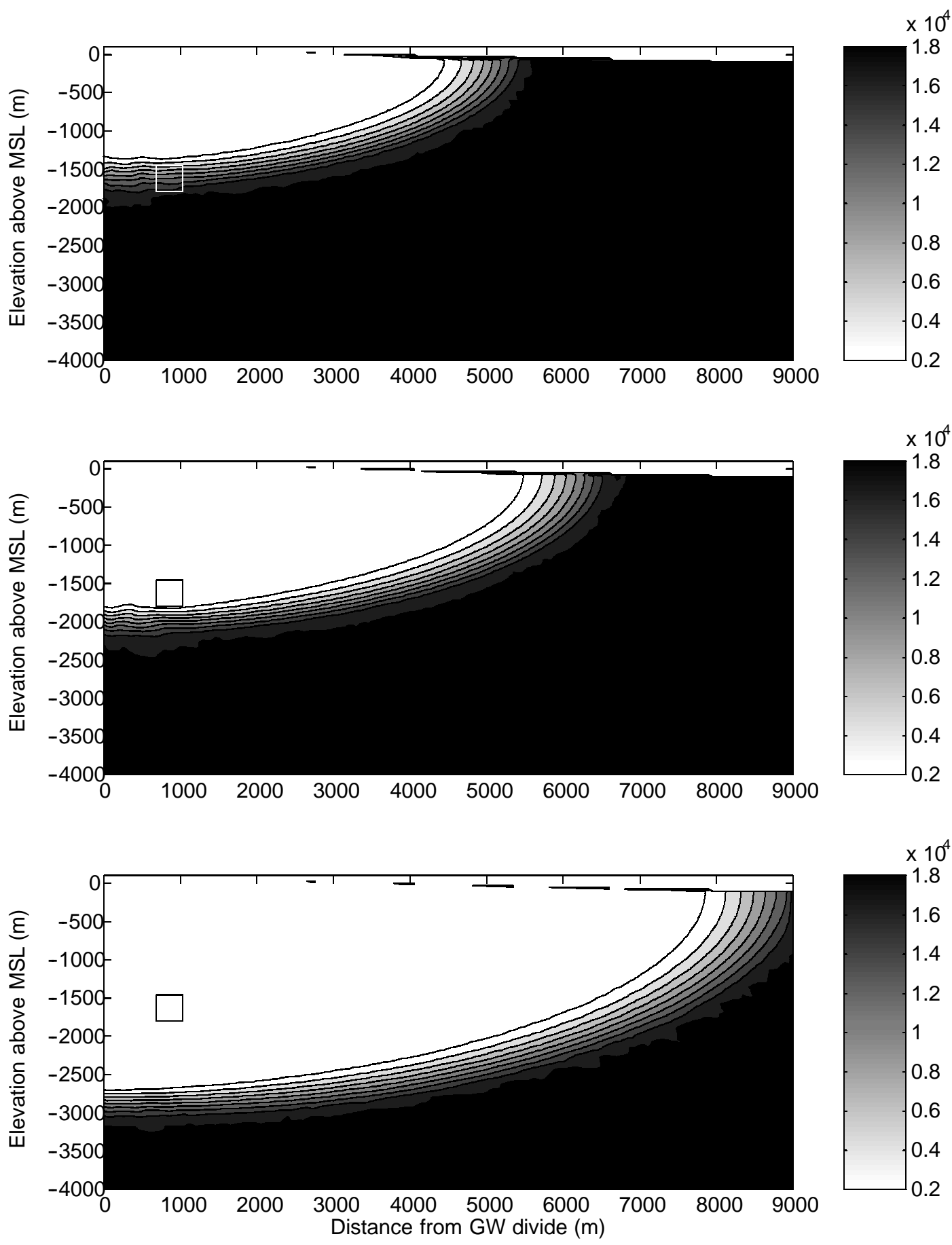

Figure 6.23. Salinity in the island groundwater system, expressed as concentration of chloride in $\mathrm{mg} / \mathrm{L}$, for the three realizations identified in Figure 6.22, as calculated in 2-D with the nuclear chimney included. 


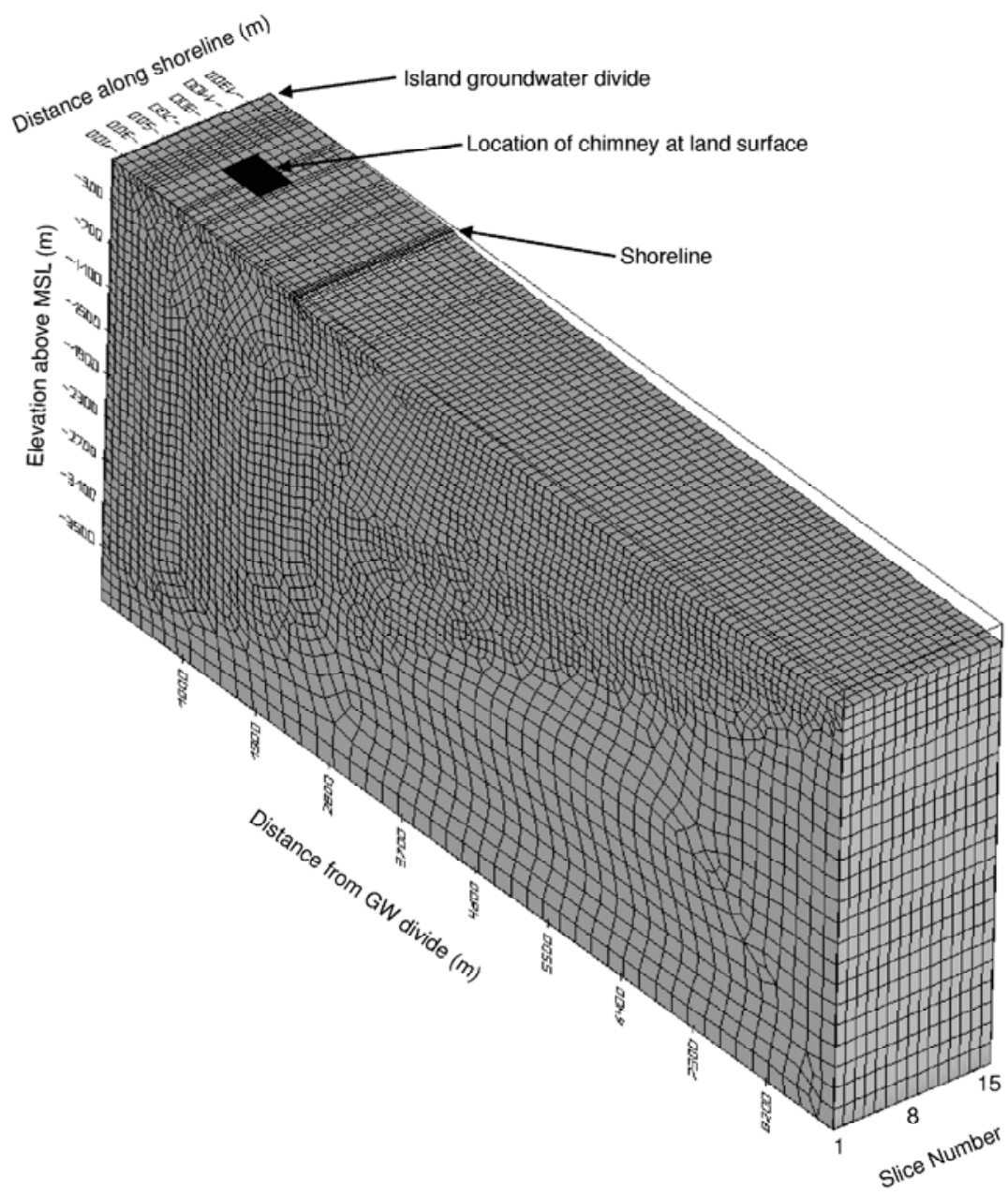

Figure 6.24. Design of finite-element mesh used for the 3-D model of flow in the Cannikin cavity and rubble chimney. All vertical layers are $100 \mathrm{~m}$ wide.

Table 6.5. Values of parameters used in three-dimensional simulations incorporating the rubble chimney.

\begin{tabular}{lcccc}
\hline \multicolumn{1}{c}{ Parameter } & Realization \#1 & Realization \#2 & Realization \#3 & All Cases \\
\hline Horizontal Hydraulic Conductivity, $K_{x x}$ and $K_{y y}$ & $1.86 \times 10^{-2} \mathrm{~m} / \mathrm{d}$ & $6.48 \times 10^{-3} \mathrm{~m} / \mathrm{d}$ & $1.78 \times 10^{-3} \mathrm{~m} / \mathrm{d}$ & \\
Vertical Hydraulic Conductivity, $K_{z z}$ & $1.86 \times 10^{-3} \mathrm{~m} / \mathrm{d}$ & $6.48 \times 10^{-4} \mathrm{~m} / \mathrm{d}$ & $1.78 \times 10^{-4} \mathrm{~m} / \mathrm{d}$ & \\
Cavity and Chimney, $K_{x x}, K_{y y}$ and $K_{z z}$ & $1.86 \times 10^{-2} \mathrm{~m} / \mathrm{d}$ & $6.48 \times 10^{-3} \mathrm{~m} / \mathrm{d}$ & $1.78 \times 10^{-3} \mathrm{~m} / \mathrm{d}$ & \\
Specific Storage, $S s$ & & & & $1 . \times 10^{-4}$ \\
Recharge, Rech & $6.13 \mathrm{~cm} / \mathrm{yr}$ & $3.33 \mathrm{~cm} / \mathrm{yr}$ & $1.89 \mathrm{~cm} / \mathrm{yr}$ & \\
Fracture Porosity, $\theta$ & $2.81 \times 10^{-4}$ & $2.71 \times 10^{-4}$ & $2.67 \times 10^{-4}$ & \\
Chimney Porosity & & & & 0.07 \\
Mass Longitudinal Macrodispersivity, $A_{L}$ & & & & 100 \\
Mass Longitudinal Macrodispersivity, $A_{T}$ & & & & 10 \\
Mass Diffusion, $D^{*}$ & & & & $1.0 \times 10^{-9} \mathrm{~m}^{2} / \mathrm{s}$ \\
Density Ratio & & & 0.025 \\
\hline
\end{tabular}


The impact of considering 3-D flow can be seen by comparing Figure 6.25 to Figure 6.23 . The 3 -D formulation results in the transition zone being simulated as shallower than in the 2-D case with the same parameter values. The magnitude of the change is largest for the highest recharge/conductivity ratio (the transition zone moves upward by about $500 \mathrm{~m}$ ). Despite this, the test cavity remains in the freshwater lens and thus flow velocities from the cavity are not impacted significantly. The lowest ratio recharge/conductivity case sees the transition zone move upward by about $100 \mathrm{~m}$, placing the cavity further into the low velocity saltwater zone.

The effect of the chimney on the transport results is larger in 3-D than in 2-D (Figure 6.26). In 2-D, the two realizations with the cavity in or below the transition zone experience more breakthrough of mass in the 2,200 year model timeframe ( 28 vs. 18 percent mass breakthrough for realization \#1, 52 vs. 33 percent for realization \#2). With the transition zone below the cavity, both the 2-D and 3-D calculations result in 100 percent breakthrough in the model time frame, but the breakthrough is later and spread over more time for the 3-D case. The result is that the 2-D model underestimates the effect of the chimney on slowing particle velocities, neglects dispersion in the third dimension, and results in slightly earlier breakthrough with higher mass than the 3-D case. This result is true for all three recharge/conductivity ratios and indicates that the use of the 2-D approximation for transport from the cavities is conservative.

The impact of the chimney on the flow field for the three cases of recharge/conductivity ratio is to cause the transition zone to be pushed deeper than in the base case that does not include the chimney (compare Figure 6.27 with Figure 6.25). The difference is on the order of a couple of hundred meters at most, and does not drastically alter the position of the transition zone relative to the cavity. Darcy velocities in the upper portion of the chimney are higher in the 3-D formulation, and are directed downward from ground surface toward the transition zone. Because the chimney is simulated as extending to ground surface, it captures a larger proportion of recharge through radial flow into the chimney than the 2-D formulation, and this may account for the resulting deeper transition zone.

The greater flux through the chimney causes lateral spreading of particles originating in the cavity, a process that does not occur in the 2-D model. Comparing particle trajectories and distribution for 3-D realization \#1 with and without the chimney (Figure 6.28) shows the plume width closely approximating the cavity size when the chimney is not included. With the chimney, lateral spreading (parallel to the shore) occurs, at least doubling the width of the plume. Some of the spread even occurs away from shore, toward the groundwater divide. The lateral spreading is due to the higher flux, induced by the high vertical conductivity, exiting in all directions from the chimney conduit. The net effect will be lower contaminant concentrations as the plume is diluted with a larger volume of groundwater.

The impact of the chimney on the transport results for the three cases is dramatic (Figure 6.29). Without the chimney, all three realizations experience breakthrough of 100 percent of the mass in the 2200-year model timeframe. When the chimney is included, only the case with the transition zone well below the cavity has complete breakthrough, and even then the breakthrough is spread over a much longer time. The large impact is not related to the relatively minor effect of the chimney 

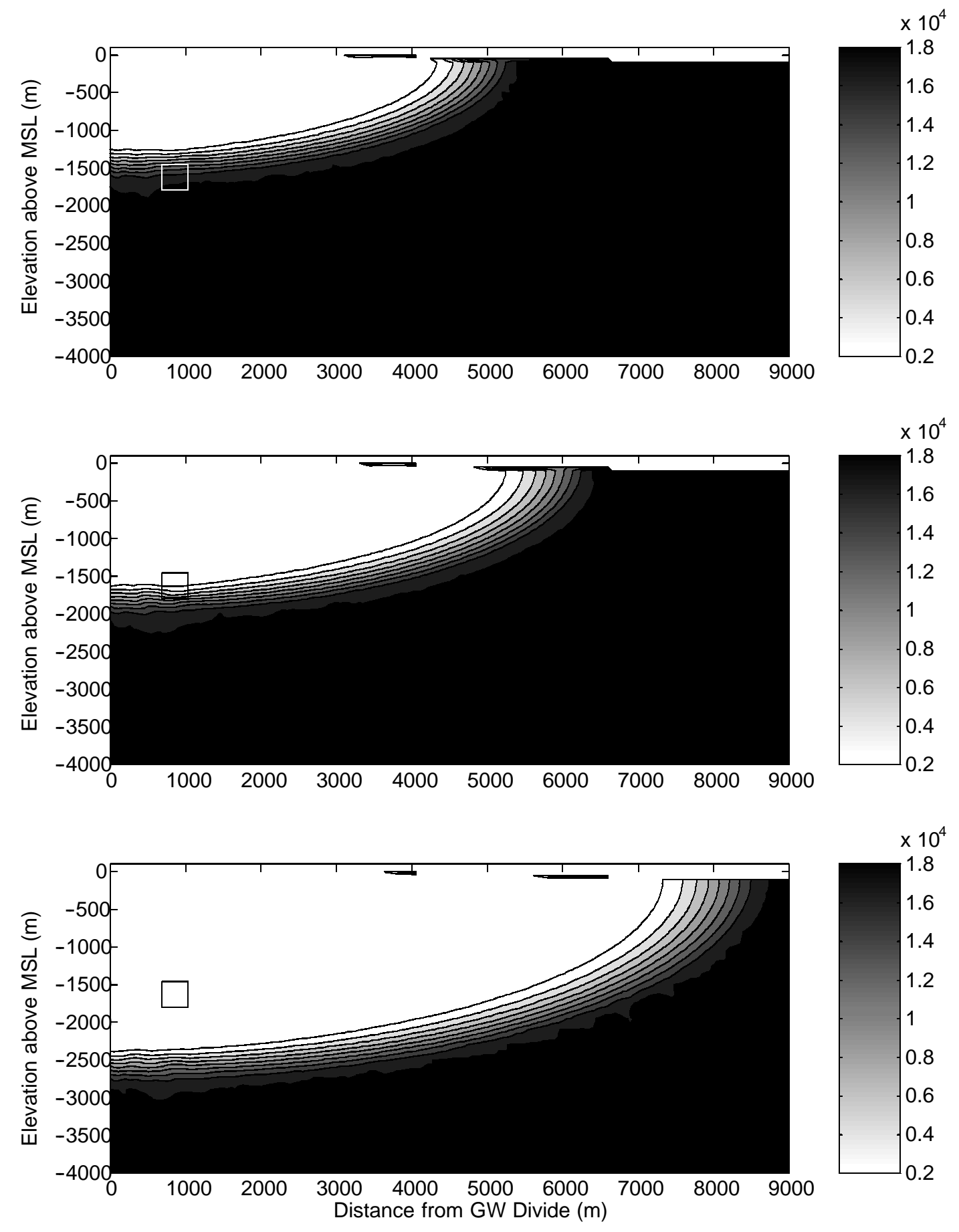

Figure 6.25. Salinity in the island groundwater system, expressed as concentration of chloride in $\mathrm{mg} / \mathrm{L}$, for the three select realizations, for the 3-D model including the nuclear chimney. Compared to the 2-D model (Figure 6.23), the transition zone is shallower. 

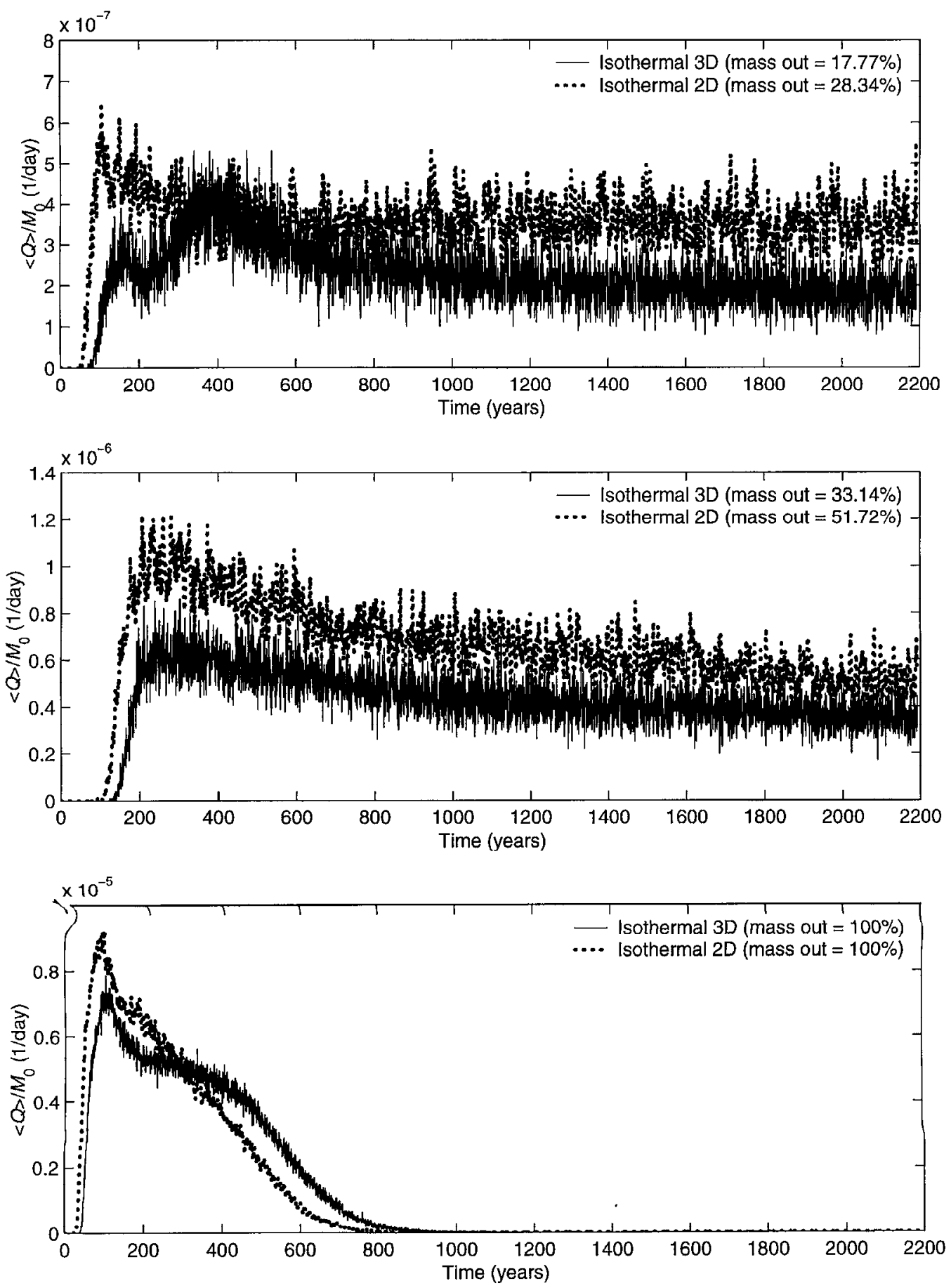

Figure 6.26. Breakthrough of undecayed, non-retarded particles in 2-D and 3-D domains with both including a nuclear chimney. Each graph represents a different case of recharge/conductivity ratio. 

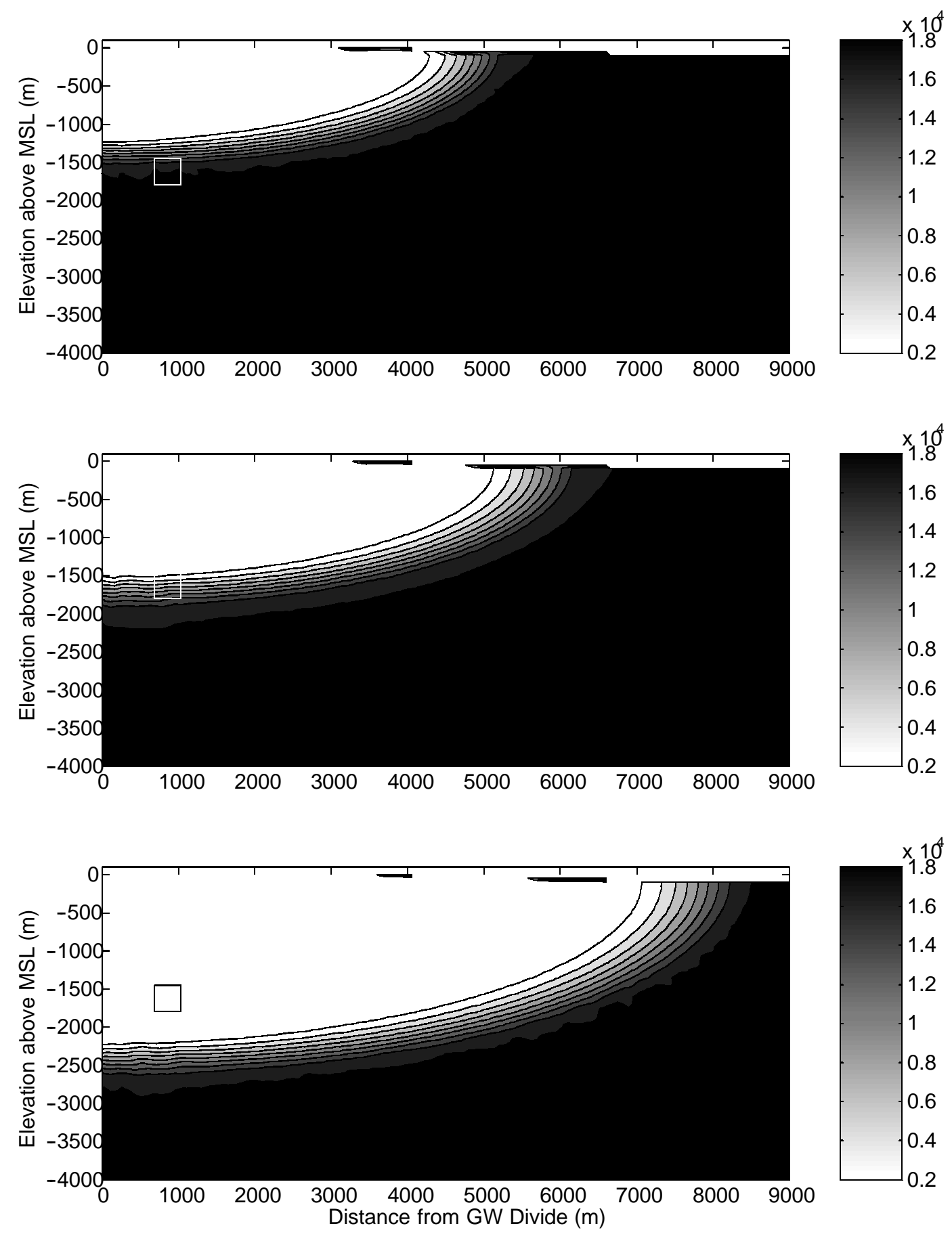

Figure 6.27. Salinity in the island groundwater system, expressed as concentration of chloride in $\mathrm{mg} / \mathrm{L}$, for the three sensitivity realizations in 3-D without incorporating the nuclear chimney. Compared to the 3-D case with the chimney (Figure 6.25), the transition zone occurs shallower. 


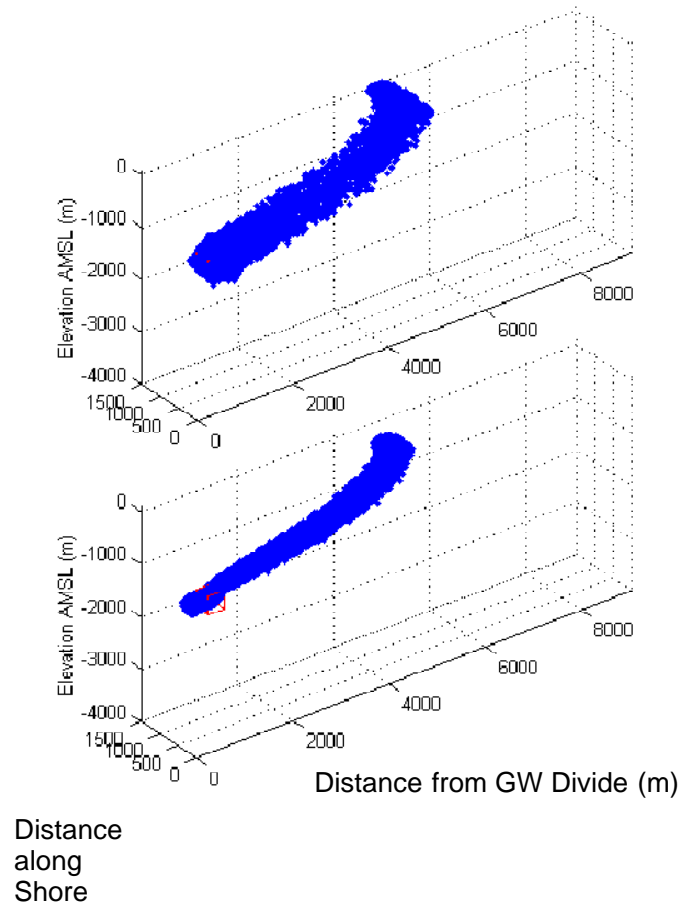

Isothermal

Model with

Chimney

\section{Isothermal \\ Model without \\ Chimney}

\section{SIDE VIEWS}
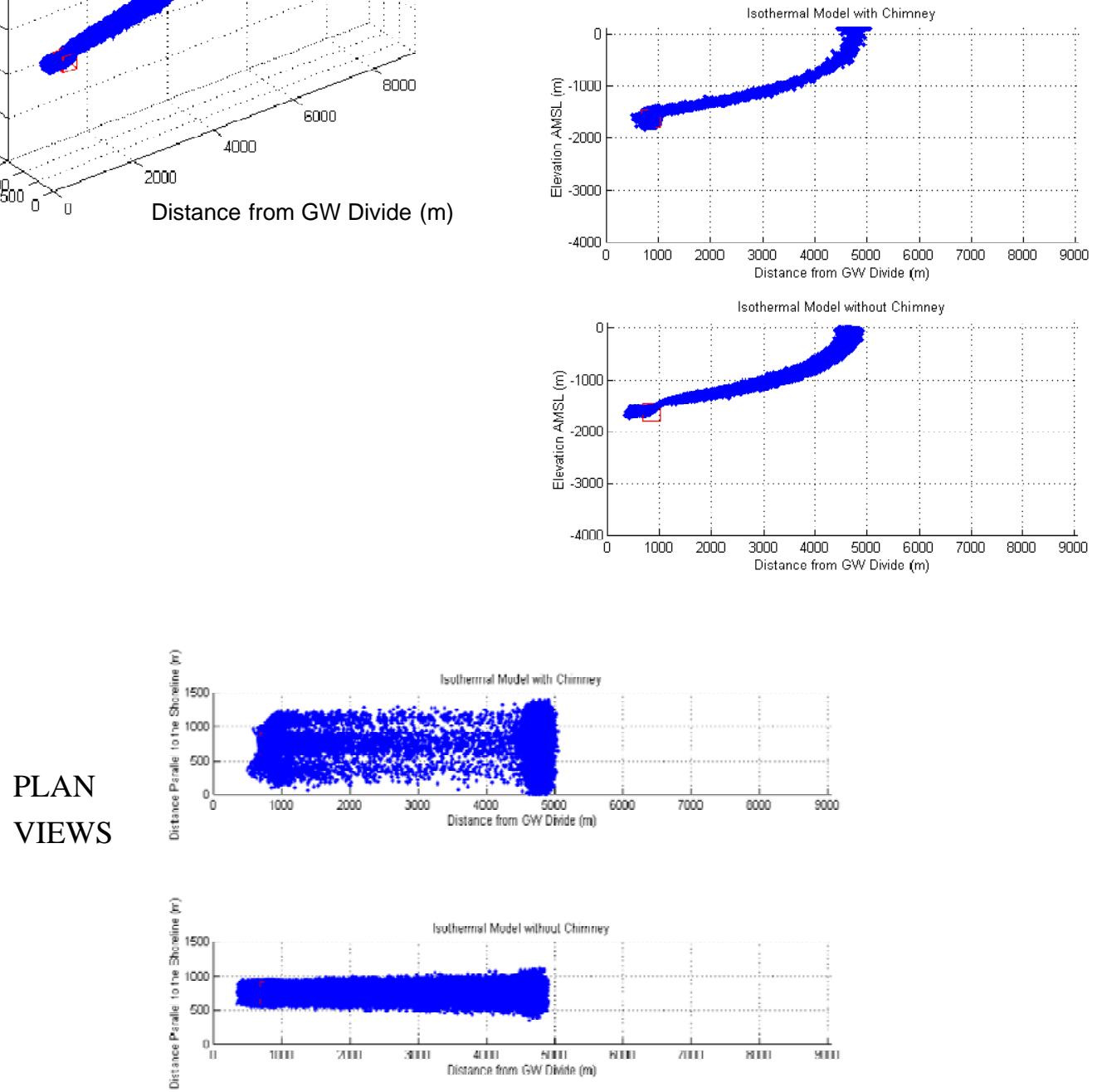

Figure 6.28. Particle trajectories for flow in the Cannikin domain with and without the nuclear chimney simulated, for 3-D realization \#1. 

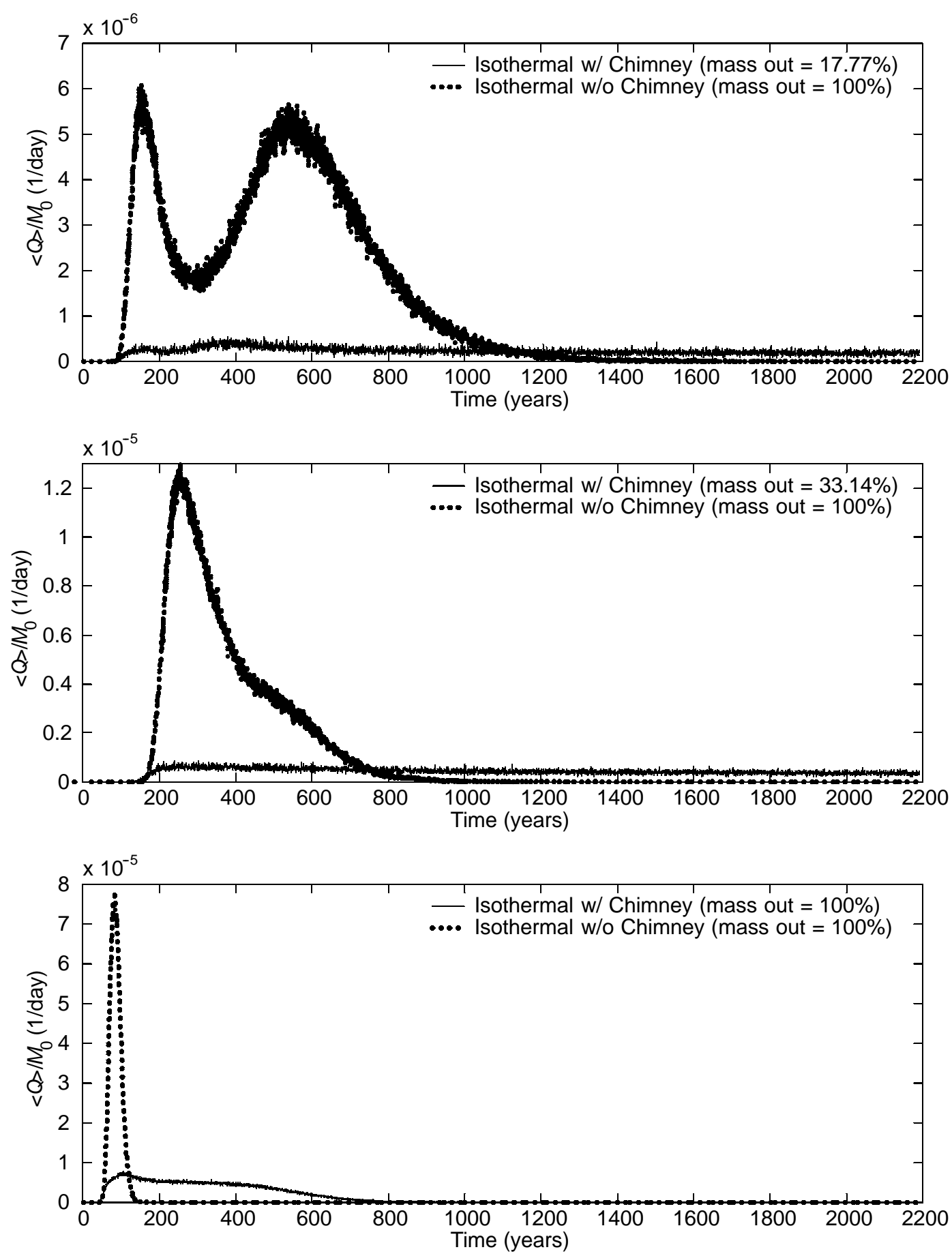

Figure 6.29. Breakthrough of undecayed, non-retarded, particles in a 3-D isothermal flow field with and without a nuclear chimney simulated. Each graph represents a different case of recharge/conductivity ratio for the three selected realizations. 
the transition zone, but rather is due to the large difference in effective porosity between the chimney and the aquifer. The chimney porosity is $7.0 \times 10^{-2}$, based on observations of infill behavior, whereas the aquifer porosity in these three realizations is $2.67 \times 10^{-4}$, simulating fracture flow. The time of initial and peak breakthrough is approximately the same for the chimney and non-chimney cases; this indicates that for the chimney case, it is those particles very near the cavity edge (which rapidly escape the cavity to enter the undisturbed aquifer) that account for the first breakthrough. The lower mass for the peak breakthrough in the chimney case reflects the small percentage of particles that have that position. The remainder of the mass is released over hundreds of years as it moves at slow velocity through the cavity and chimney.

\subsubsection{Cannikin Lake}

The Cannikin explosion cavity was created instantaneously by the nuclear test, and 38 hours later the overlying material collapsed into the void and chimneyed up to land surface. A closed depression was formed, but rather than a circular crater centered on ground zero as typically seen at the NTS, an asymmetric, roughly triangular-shaped collapse occurred, centered over a point about $360 \mathrm{~m}$ southeast of ground zero. The form of the sink is controlled in part by one northwest-trending and two east-trending faults (Morris and Snyder, 1972). The maximum amount of subsidence is about $12 \mathrm{~m}$ (Morris, 1973). Morris and Snyder (1972) suggest that the displacement of the sink relative to the cavity may be related to stoping normal to the lithologic bedding planes as the roof of the cavity failed along successive bedding surface during collapse.

Eighty-four percent of the White Alice Creek drainage area was temporarily transformed into a closed basin and nearly all the flow was diverted toward the cavity (Gonzalez, 1977). There was no visible filling of the depression for more than 10 months, a period interpreted as the time that the cavity and chimney were resaturating. Starting in September 1972, a lake began to form in the depression, and Cannikin Lake was filled in December 1972 when overflow into the lower reach of White Alice Creek occurred and on to the Bering Sea. The surface area of the lake is reported as $121,400 \mathrm{~m}^{2}$, with a maximum depth of $10 \mathrm{~m}$ (Dudley et al., 1977).

Though part of Cannikin Lake probably does not overlie the chimney directly, the relationship between the filling of the Lake and infill of the cavity and chimney (as reported by Claassen, 1978) demonstrates that there is some hydrologic connection between the features. The impacts of the formation of Cannikin Lake subsequent to the Cannikin nuclear test were investigated using an isothermal 3-D density-dependent flow and mass transport model utilizing the FEFLOW code. The 3-D model incorporating the rubble chimney was modified to include the lake as a zone of specified-head nodes on the top boundary. Other than this modification, the finite-element mesh geometry, the hydrogeologic features (including the chimney), and the other boundary conditions remained unchanged from the chimney model. As was done for the chimney model, the flow and mass transport model incorporating Cannikin Lake is comprised of three cases of recharge-conductivity ratio that cover the range of breakthrough behavior. The values of the parameters used in this flow and mass transport model are the same as those used in the 3-D model that included the rubble chimney. 
Cannikin Lake is represented as specified head nodes within a zone at ground surface having horizontal dimensions of $600 \mathrm{~m}$ by $200 \mathrm{~m}$ (surface area of $120,000 \mathrm{~m}^{2}$ ), with the long axis oriented parallel to the direction of natural groundwater flow toward the sea (Figure 6.30). Although there is uncertainty as to the nature of the hydraulic connection between the lake, the shallow groundwater system and the chimney itself, the model simulates the lake as covering two thirds of the chimney and being in direct hydraulic connection with it at ground surface. The hydraulic head specified for the lake is determined from the steady-state head simulated near ground surface at the inland edge of the chimney in each of the three cases of the rubble chimney model discussed in section 6.2.1. For each case, this head value is assigned to all boundary nodes on the top surface that are located within the zone of the lake. Under pre-lake steady-state conditions, the profile of hydraulic head at the top of the aquifer generally slopes toward the sea, interrupted only by a depression in head over the more permeable rubble chimney. With the addition of the lake, hydraulic heads (represented by

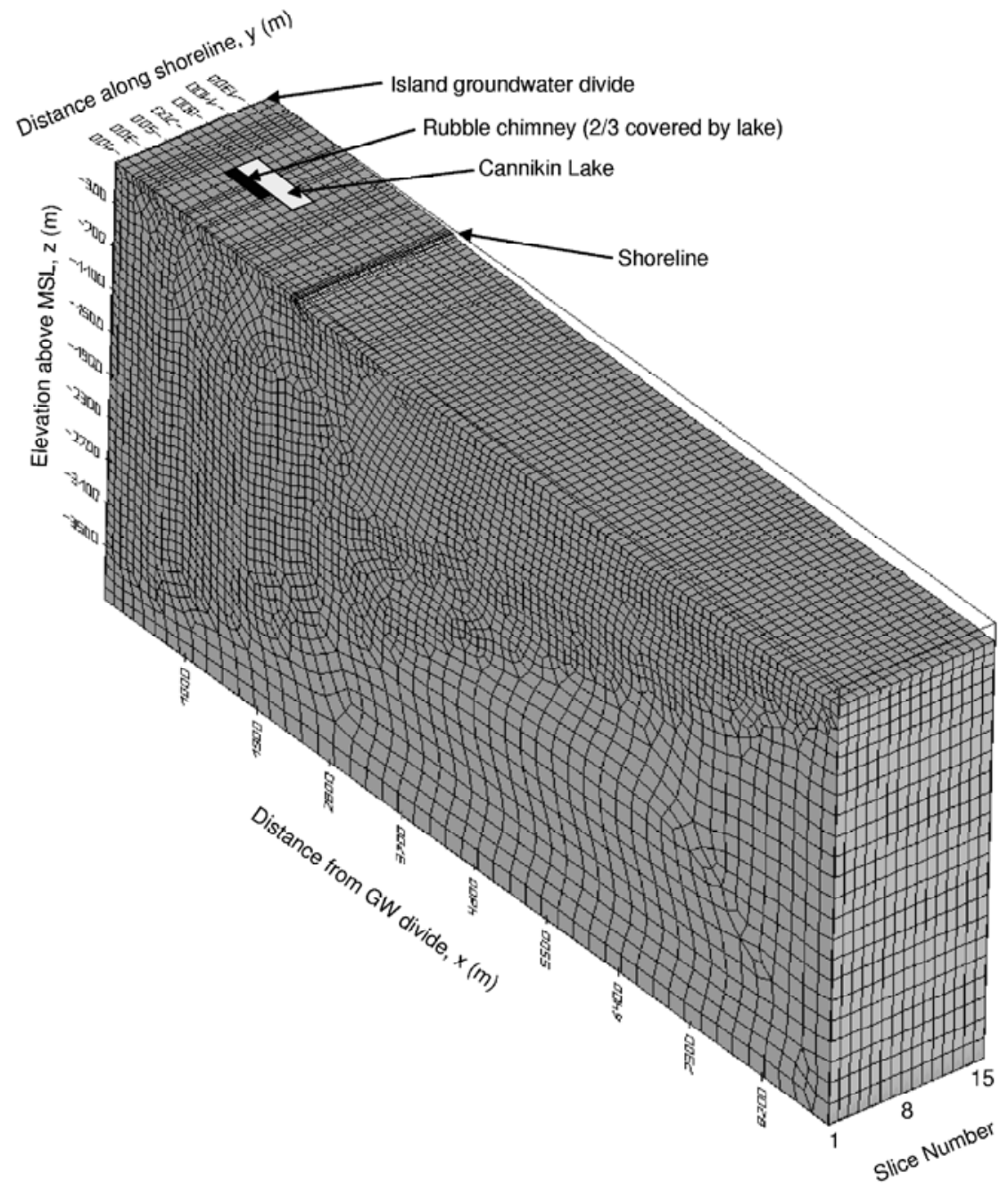

Figure 6.30. Design of finite-element mesh used for the 3-D model incorporating Cannikin Lake. All vertical layers are $100 \mathrm{~m}$ wide. 
the lake elevation) range between about eight and $16 \mathrm{~m}$ above heads in the pre-lake underlying aquifer on the seaward edge of the lake, depending on the recharge-conductivity case. This large head difference provides a very large source of recharge to the rubble chimney and surrounding shallow aquifer that is maintained throughout each simulation, and limited only by the conductivity of the chimney and aquifer materials. The flow and mass transport model of FEFLOW is run until steady state is reached and the effects of recharge from the lake are fully incorporated in the distributions of concentration, head, and velocity. At this point the velocities are saved and used as input for the radionuclide transport models.

Examination of undecayed, non-retarded mass transport for the three realizations shows little change in the breakthrough curves for the three realizations (Figure 6.31). The percentage of mass breaking through at the sea floor is slightly higher for realizations 1 and 2 (by two to three percent for the cases with the cavity below and in the transition zone). These results suggest that the impact of neglecting the lake on the flow and transport results in section 5 is minimal compared to other sources of uncertainty.

\subsubsection{Heat Derived from Nuclear Test}

The energy released by a nuclear detonation is partly consumed through ground motion, and vaporizing and melting rock, but also results in a large increase in temperature in the cavity. This thermal pulse dissipates with time by conduction through the geologic material and convection through groundwater. While temperatures in the cavity region remain above ambient, they affect the groundwater flow system and alter geochemical reaction rates that are temperature dependent. In their analysis of underground nuclear tests in the South Pacific, the International Atomic Energy Agency (IAEA, 1998) evaluated the thermal impact of the tests. It was found that the temperature difference with ambient temperature decays to zero over a period of about 500 years. The hydrologic impact was to create a vertically upward flowpath above the cavity-chimney, driven by thermal buoyancy. Thermal impacts of the Cannikin test are investigated here to address concerns about buoyancy-driven movement of water heated by the nuclear test.

The impacts on flow patterns and radionuclide transport caused by heat derived from the Cannikin nuclear test are addressed using a 3-D density-dependent flow and mass transport model. These simulations are run using the FEFLOW code and the same mesh geometry and hydrogeologic features as used for the 3-D simulations of flow in the rubble chimney (Figure 6.32).

In an analysis of subsurface hydraulic and chemical data collected from the Cannikin test, Claassen (1978) reports that hydraulic recovery occurred relatively rapidly, with chimney voids nearly filled within 280 days after the test. Rapid filling of the chimney with cooler water from surrounding aquifers also caused the chimney region to cool relatively rapidly; cavity temperatures had declined to about 35 to $40^{\circ} \mathrm{C}$ above pre-test ambient temperatures 280 days after the test, as measured in re-entry hole UA-1-p1. Although the South Pacific tests were of much smaller magnitude than the reported yield of Cannikin, the IAEA (1998) reports that nuclear explosions in basalt result in temperature increases between 25 and $50^{\circ} \mathrm{C}$, regardless of yield. IAEA (1998) also suggests that for the purposes of hydrologic modeling, the initial temperature increase is confined to a region within $1 R_{c}$ of the working point, because simulation of heat transfer by conduction 

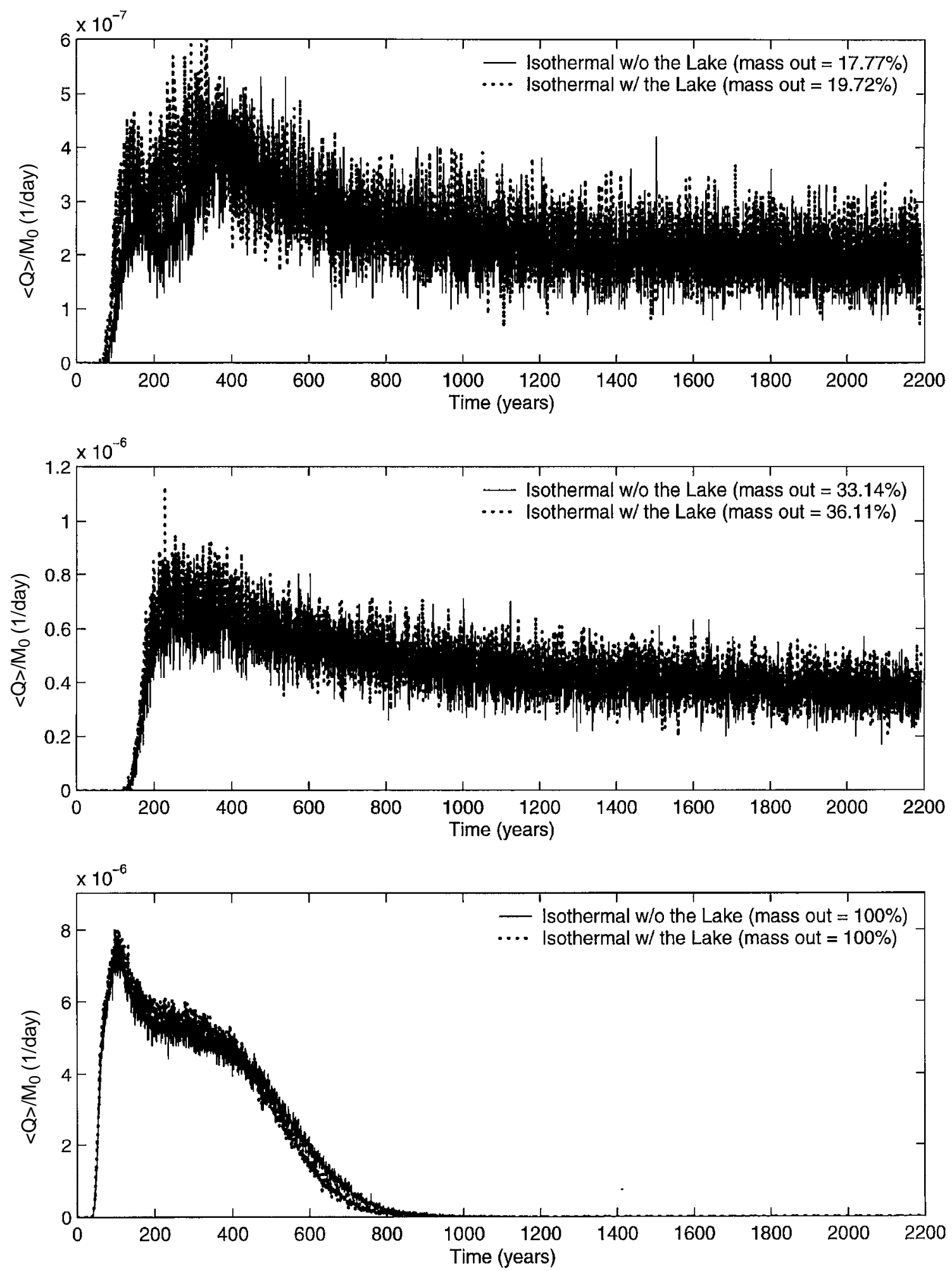

Figure 6.31. Breakthrough of a non-decayed, unretarded, solute using the steady velocity fields generated from isothermal simulations with and without including Cannikin Lake above the chimney. 


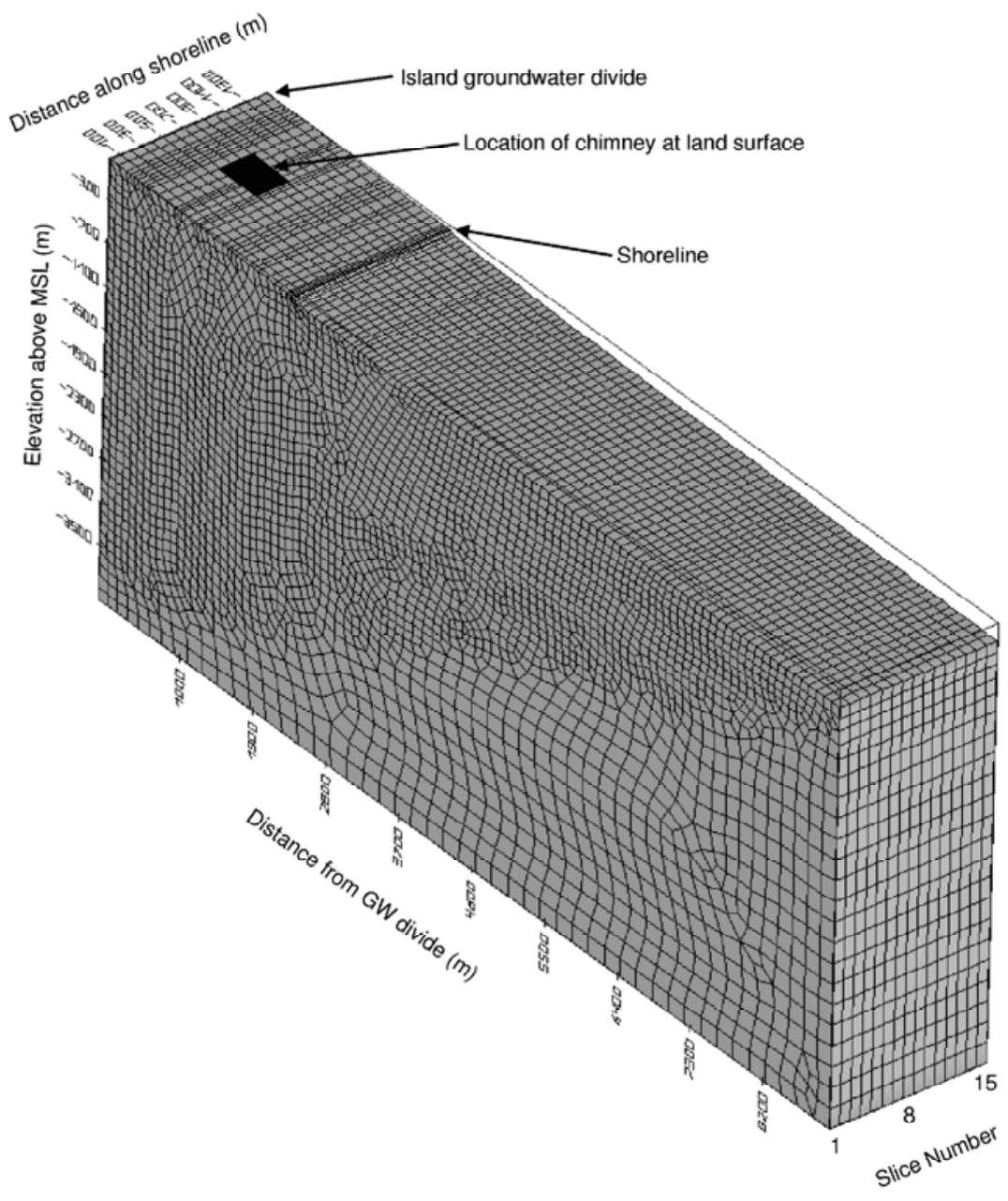

Figure 6.32. Design of finite-element mesh used for the 3-D model incorporating heat derived from the Cannikin nuclear test. All vertical layers are $100 \mathrm{~m}$ wide.

outside this radius will occur very slowly. In the present model, nodes within $1 R_{c}$ of the working point are assigned an initial temperature of $50^{\circ} \mathrm{C}$ above the pre-test ambient temperature. All other nodes are assigned an initial temperature of $4{ }^{\circ} \mathrm{C}$, the mean annual ground-surface temperature.

Three cases of the model are run, with values of the groundwater flow and mass transport parameters the same as the three cases of the 3-D chimney model, spanning the range of recharge/conductivity ratios included in the 2-D Monte Carlo analysis. The values of the thermal parameters are the same values used in the geothermal model (section 6.1.6). All of the values are shown in Table 6.6. Geothermal aspects would be overwhelmed by the large thermal pulse simulated here, so for reasons of computational efficiency, the geothermal process is not incorporated. Instead, the upper, lower, and right side temperature boundaries are assigned values of $4^{\circ} \mathrm{C}$. 
Table 6.6. Values of parameters used in three-dimensional simulations incorporating heat derived from the Cannikin test.

\begin{tabular}{lcccc}
\hline \multicolumn{1}{c}{ Parameter } & Realization \#1 & Realization \#2 & Realization \#3 & All Cases \\
\hline Horizontal Hydraulic Conductivity, & $1.86 \times 10^{-2} \mathrm{~m} / \mathrm{d}$ & $6.48 \times 10^{-2} \mathrm{~m} / \mathrm{d}$ & $1.78 \times 10^{-2} \mathrm{~m} / \mathrm{d}$ & \\
$K_{x x}$ and $K_{y y}$ & & & \\
Vertical Hydraulic Conductivity, $K_{z z}$ & $1.86 \times 10^{-3} \mathrm{~m} / \mathrm{d}$ & $6.48 \times 10^{-3} \mathrm{~m} / \mathrm{d}$ & $1.78 \times 10^{-3} \mathrm{~m} / \mathrm{d}$ & \\
Cavity and Chimney, $K_{x x}, K_{y y}$ and $K_{z z}$ & $1.86 \times 10^{-2} \mathrm{~m} / \mathrm{d}$ & $6.48 \times 10^{-2} \mathrm{~m} / \mathrm{d}$ & $1.78 \times 10^{-2} \mathrm{~m} / \mathrm{d}$ & \\
Specific Storage, $S s$ & & & & $1 . \mathrm{x} 10^{-4}$ \\
Recharge, Rech & $6.13 \mathrm{~cm} / \mathrm{yr}$ & $3.33 \mathrm{~cm} / \mathrm{yr}$ & $1.89 \mathrm{~cm} / \mathrm{yr}$ & \\
Fracture Porosity, $\theta$ & $2.81 \times 10^{-4}$ & $2.71 \times 10^{-4}$ & $2.67 \times 10^{-4}$ & \\
Chimney Porosity & & & 0.07 \\
Mass Longitudinal Macrodispersivity, $A_{L}$ & & & \\
Mass Longitudinal Macrodispersivity, $A_{T}$ & & & 100 \\
Mass Diffusion, $D *$ & & & 10 \\
Density Ratio & & & $1.0 \times 10^{-9} \mathrm{~m}^{2} / \mathrm{s}$ \\
Rock Volumetric Heat Capacity, $\varrho_{s} c_{S}$ & & & 0.025 \\
Water Volumetric Heat Capacity, $\varrho_{0} c_{0}$ & & & $1.9 \times 10^{6} \mathrm{~J} / \mathrm{m}^{3} \mathrm{C}$ \\
Rock Thermal Conductivity, $\lambda_{S}$ & & & $4.2 \mathrm{~J} / \mathrm{m}^{3} \mathrm{C}$ \\
Water Thermal Conductivity, $\lambda_{0}$ & & & $2.59 \mathrm{~J} / \mathrm{m}^{3} \mathrm{C}$ \\
Thermal Longitudinal Dispersivity, $\beta_{L}$ & & & $0.56 \mathrm{~J} / \mathrm{m}^{3} \mathrm{C}$ \\
Thermal Transverse Dispersivity, $\beta_{T}$ & & & $100 \mathrm{~m}$ \\
Water Density and Viscosity, $\varrho_{0}$ and $\mu_{0}$ & & & $10 \mathrm{~m}$ \\
Initial Temperature in Cavity & & & $6 \mathrm{th}$ order function \\
Initial Ambient Temperature & & & of temperature \\
\hline
\end{tabular}

The results show temperatures in the cavity region remain elevated above pre-test temperatures for hundreds of years (Table 6.7 and Figure 6.33). Within $2 R_{c}$ of the cavity, temperatures rise to no more than about $8^{\circ} \mathrm{C}$ above pre-test temperatures and show very slow declines to pre-test levels. Thermal effects are minor at distances greater than about $4 R_{c}$ from the working point.

Table 6.7. Locations of selected points around the Cannikin cavity and chimney where temperatures are presented in Figure 6.33.

\begin{tabular}{cl}
\hline Point No. & Location \\
\hline 1 & Working point $(\mathrm{WP})$ \\
2 & $3 \mathrm{R}_{\mathrm{c}}$ above $\mathrm{WP}$ \\
3 & $5 \mathrm{R}_{\mathrm{c}}$ above WP \\
4 & $5 \mathrm{R}_{\mathrm{c}}$ below $\mathrm{WP}$ \\
5 & $3 \mathrm{R}_{\mathrm{c}}$ above and $5 \mathrm{R}_{\mathrm{c}}$ seaward of WP \\
6 & $5 \mathrm{R}_{\mathrm{c}}$ above and $5 \mathrm{R}_{\mathrm{c}}$ seaward of $\mathrm{WP}$ \\
7 & $3 \mathrm{R}_{\mathrm{c}}$ above and $5 \mathrm{R}_{\mathrm{c}}$ parallel to shore of $\mathrm{WP}$ \\
8 & $5 \mathrm{R}_{\mathrm{c}}$ above and $5 \mathrm{R}_{\mathrm{c}}$ parallel to shore of $\mathrm{WP}$ \\
\hline
\end{tabular}



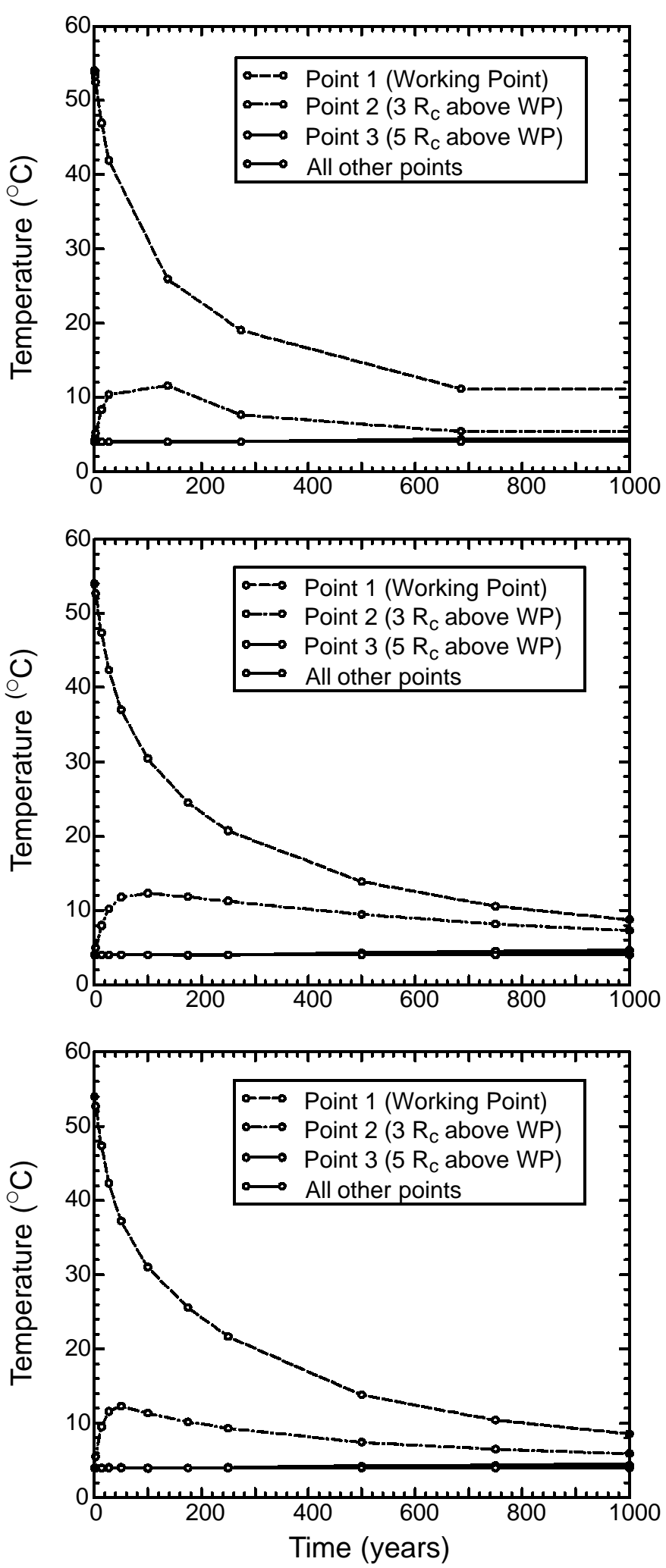

Figure 6.33. Variation of temperatures at selected points around the cavity and chimney, following addition of heat derived from the Cannikin test. Each graph represents a different case of recharge-conductivity ratio. 
The long-term elevated temperatures within the cavity cause thermally driven buoyant flow in the cavity region for several hundred years. With the exception of the center of the cavity, upward Darcy velocities within $2 R_{c}$ of the working point reach maximum values about fivefold higher than pre-test ambient values, followed by slow declines. Horizontal flow is enhanced as increased vertical flow in the cavity/chimney drives lateral flow into the base of the cavity and out of the chimney above the cavity. Though a maximum twentyfold increase in the vertical and horizontal components of Darcy velocity is simulated at the working point, other points within $2 R_{c}$ show less than fivefold increases. Within $2 R_{c}$, velocities return to near pre-test values within about 400 years. The effects of heat-driven buoyant flow are small beyond $4 R_{c}$ in both vertical and horizontal directions.

The addition of thermal energy from the nuclear test has a limited impact on the position of the transition zone for the three cases evaluated (compare Figure 6.34 and Figure 6.25). The simulations with thermal input have slightly shallower transition zones, presumably due to thermal buoyancy. Mixing induced by thermal convection cells is noticeable, however, when particle movement is tracked. Increased spreading in the y-axis direction (parallel to shore) is easily seen for realization \#2 (Figure 6.35) and is believed to result from thermally driven flow exiting radially from the chimney. The nuclear test heat drives some particles upgradient, thereby increasing their flowpath length to the sea (Figure 6.36). This increased spreading may result in some particles being effectively stranded in low velocity portions of the flow field once the heat pulse decays. This is not observed in the transport results here because transport was calculated for the velocity field at 100 days after the test, not on the transient velocity fields. As a result, some of the particles simulated at the seaward edge of the domain, particularly for realization \#3 (Figure 6.37), would not be expected to travel that distance in the transient flow field as they are located in the saltwater portion of the domain that will rapidly return to very slow velocities as the heat pulse decays. Indeed, the flow field directions return to near-steady state within 25 years of the test, so that particles forced counter to the steady-state gradient by the thermal pulse (particularly those moved into the saltwater portion of the domain) will then reverse, inducing a looping trajectory (Figure 6.38).

The impact of nuclear heat on the transport results varies greatly depending on the position of the cavity relative to the transition zone (and thus the recharge/conductivity ratio) considered. The evaluation of transport is performed for the velocity field at 100 days after the test, when the thermal impact is still very large; as such, it overestimates the impact of the thermal pulse by maintaining the high velocity field for the simulation time rather than allowing the velocities to decay. When the cavity is below the transition zone, the inclusion of the 100-day nuclear thermal effect causes a factor-of-three increase in the peak mass breakthrough, but the time of the peak breakthrough is considerably delayed over the isothermal case (Figure 6.39). Over the model period of 2,200 years, twice as much mass is calculated to discharge at the sea floor for the thermal case as compared to the isothermal calculations. The same general behavior is found when the cavity is within the transition zone, though the time delay between the isothermal and thermal peaks is greater and the difference in peak mass reduced to less than a factor of two. The overall increase in total mass discharged for the thermal case is one and one-half times the isothermal case. The impact of thermal conditions on transport when the cavity is above the transition zone is minimal compared to the 

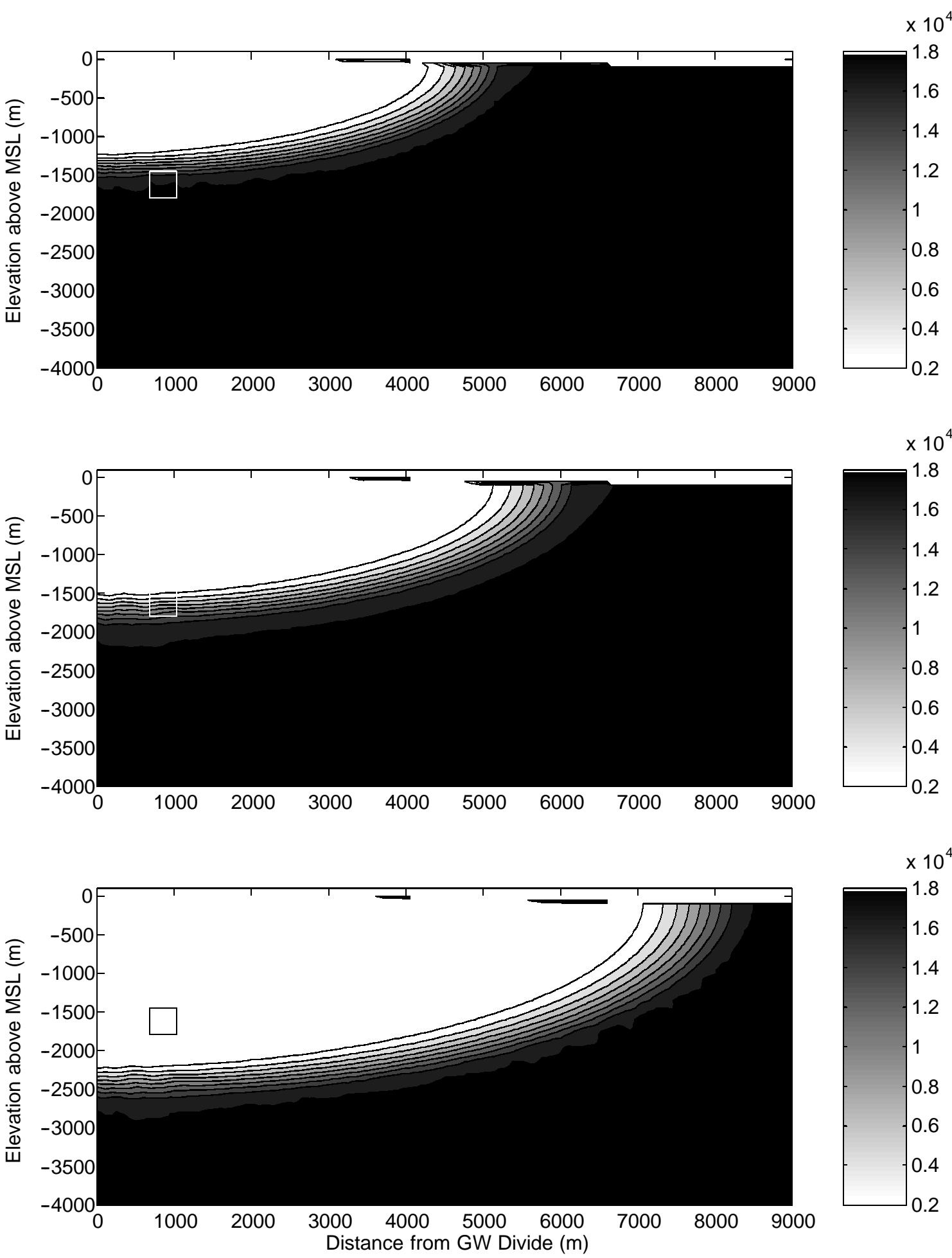

Figure 6.34. Salinity in the island groundwater system, expressed as concentration of chloride in $\mathrm{mg} / \mathrm{L}$, for the three select realizations, for the 3-D model including the nuclear chimney and heat from the nuclear test. 

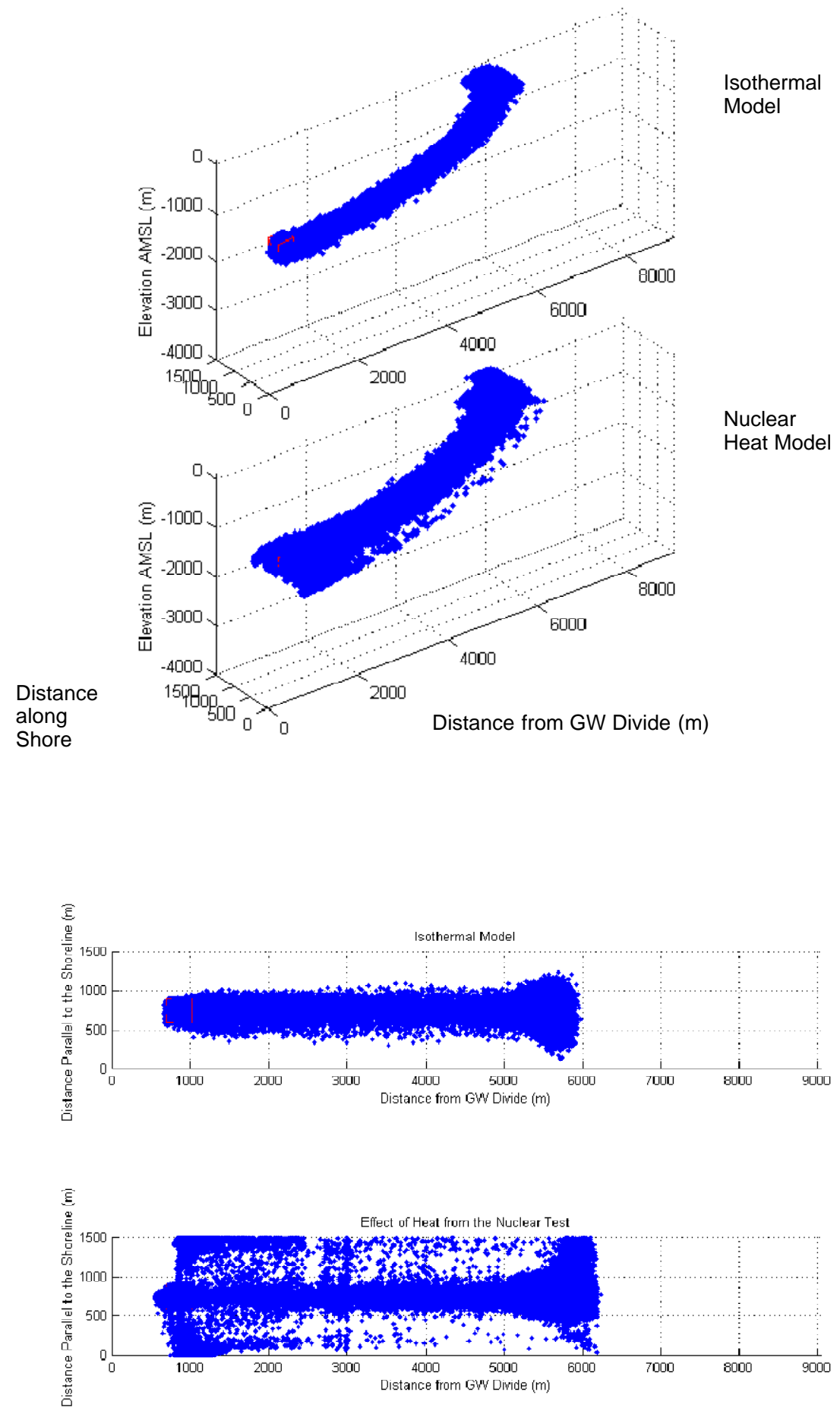

Figure 6.35. Particle trajectories from the Cannikin cavity with and without nuclear heat for realization \#2 (cavity within the transition zone). The velocity field is representative of 100 days after the test. 

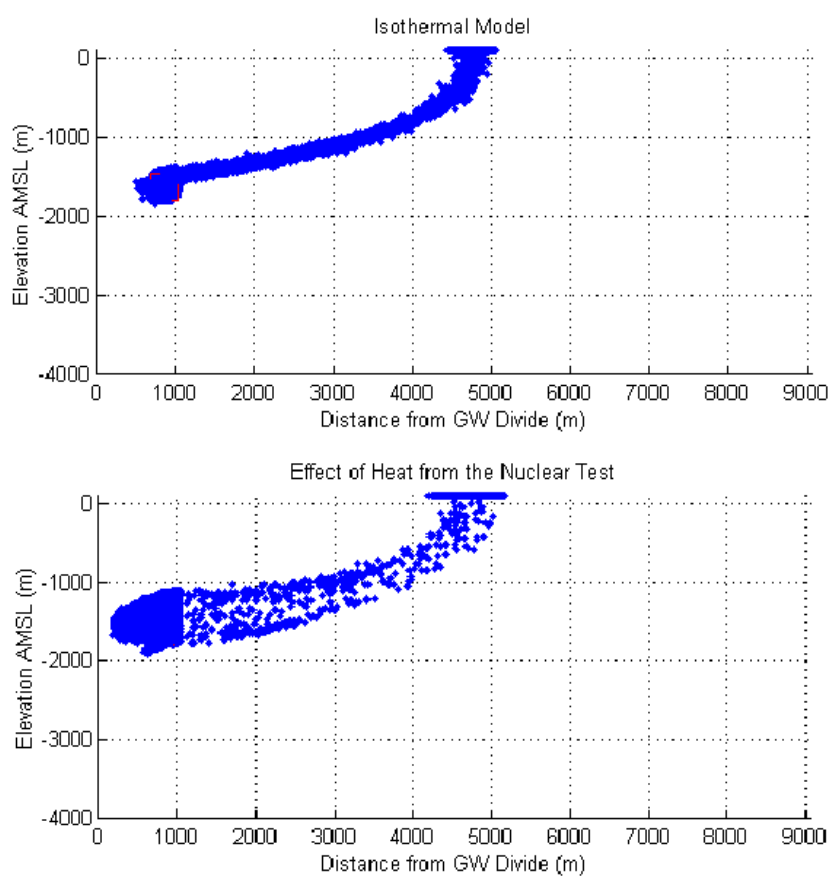

Figure 6.36. Cross section view of particle trajectories from the Cannikin cavity with and without nuclear heat for realization \#1 (transition zone above the cavity). The velocity field is representative of 100 days after the test.
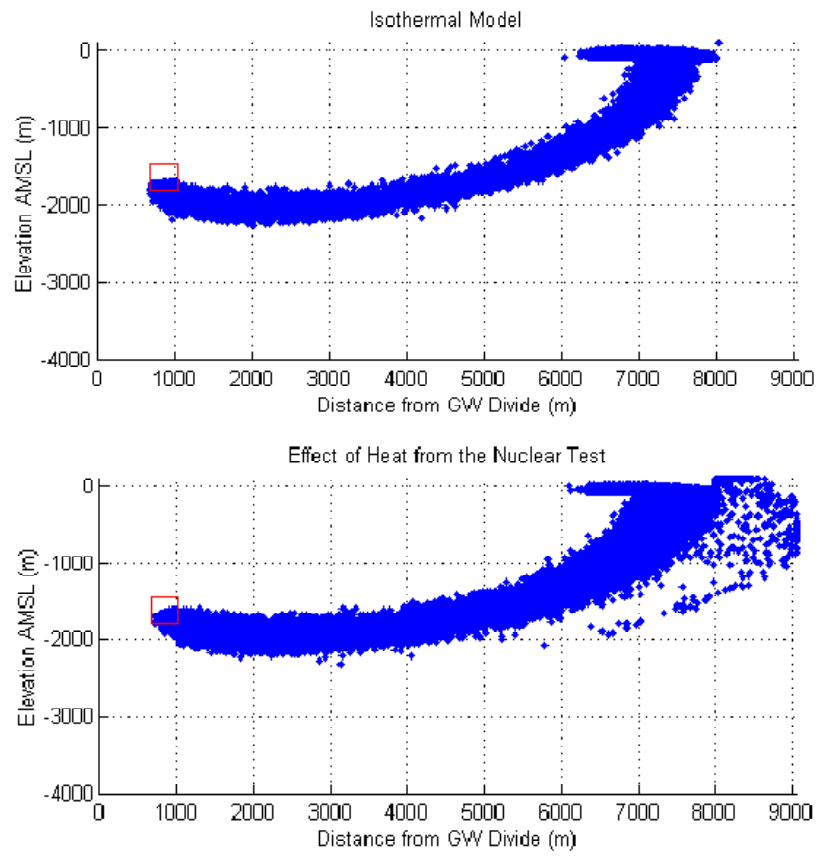

Figure 6.37. Cross-section view of particle trajectories from the Cannikin cavity with and without nuclear heat for realization \#3 (transition zone below the cavity). The velocity field is representative of 100 days after the test. 


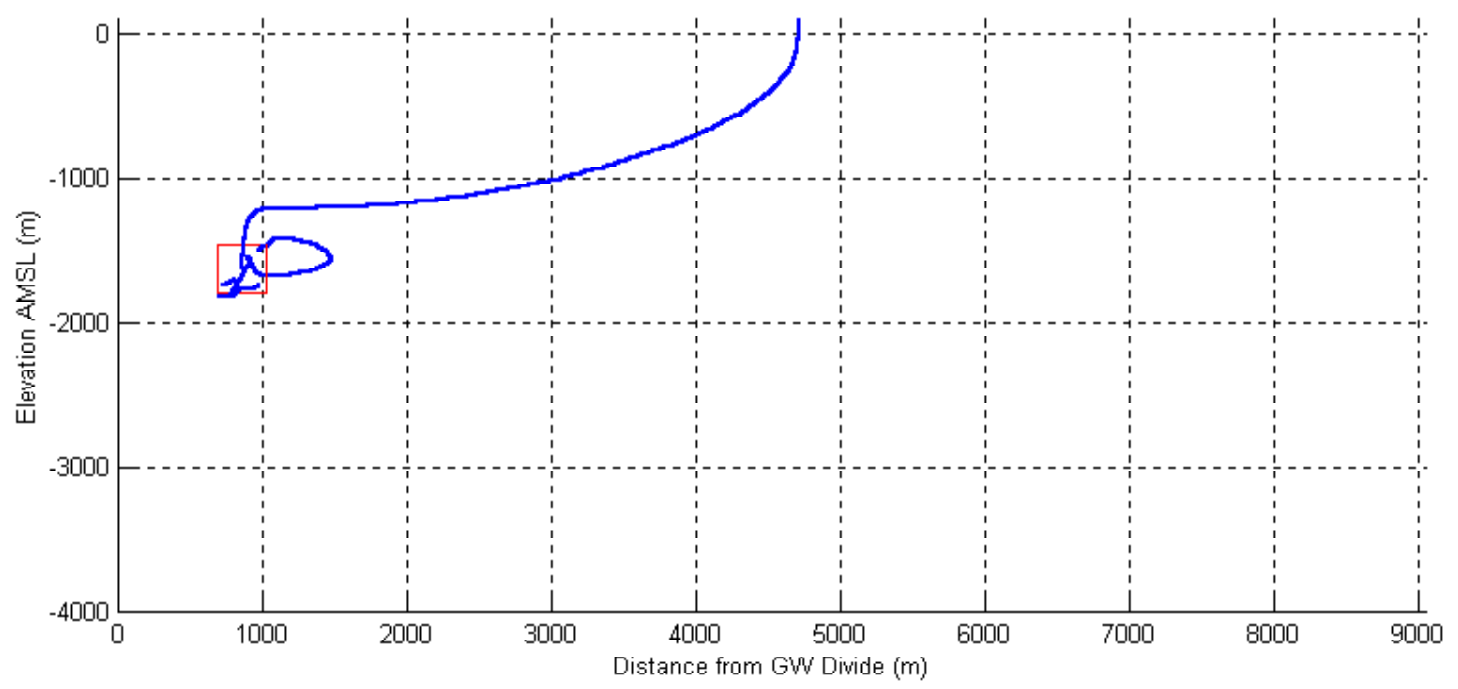

Figure 6.38. A vertical 2-D view of particle trajectories showing the looping pattern in the 3-D thermal model with nuclear heat.

isothermal situation; the thermal peak is very slightly delayed and of slightly lower magnitude than the isothermal case, and both scenarios exhibit 100 percent breakthrough.

The thermal sensitivity runs indicate that neglecting the test-induced thermal effects is not significant for Long Shot and indeed, it is more conservative to not include the thermal process. The net result of neglecting the thermal impact for Milrow and Cannikin will depend on the half-life of the radionuclide considered. If tritium is the nuclide of concern, the isothermal case will be more conservative as it allows an earlier peak. Despite the higher mass calculated at later time for a non-decaying solute under thermal conditions, a short-lived radionuclide mass will decay to negligible amounts by the time the thermal-scenario peak arrives at the sea floor. In contrast, for a long-lived radionuclide that experiences limited decay over 1,000-year time frames, the thermal case will result in more mass being released over the model period, and higher peak fluxes.

\subsubsection{Three-dimensional Formulation - Flow with Fault Zones}

Numerous fault zones have been identified on the island by mapping lineation features on aerial photographs (Carr et al., 1966) and by analysis of shipborne magnetometer and seismic surveys (von Huene et al., 1971). Most of these faults strike in the east-northeast direction, roughly perpendicular to the axis of the island (Figure 1.4), and dip steeply. Carr et al. (1966) report that the fault zones are composed of highly fractured rock and may be up to thousands of feet wide, although little is known about whether these zones increase or reduce the permeability of the rocks they transect. If the fault zones have significantly lower permeability than the intervening rock, the faults will act as barriers to groundwater flow, with flow oriented parallel to them toward the sea. This is the flow pattern modeled in the 2-D cross-sectional models. However, if the fault zones are significantly more permeable than the surrounding rock, groundwater will flow preferentially toward the faults. The U.S. Army Corps of Engineers and USGS (1965) suggest that fault zones in the Banjo Point 

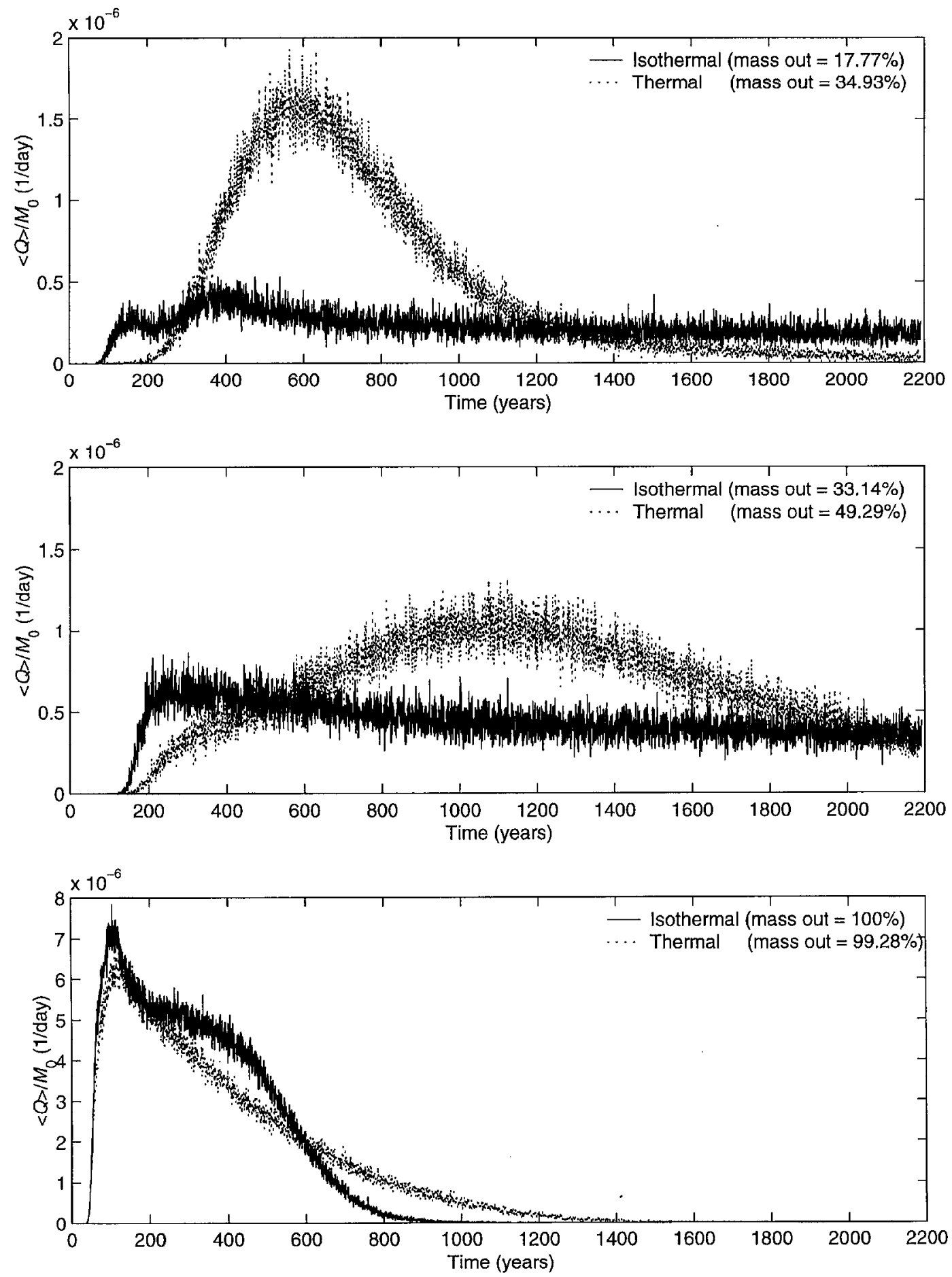

Figure 6.39. Breakthrough of undecayed, unretarded mass from a nuclear chimney with and without heat from the nuclear test. Each graph represents a different case of recharge/conductivity ratio for the three selected realizations. 
Formation in the vicinity of the Long Shot site are at least ten times more permeable than the bulk of the formation. If the permeability contrast is sufficiently high, this scenario might produce fast pathways for flow from the chimney toward the sea.

The impacts on flow patterns and radionuclide transport caused by permeable fault zones are addressed here using isothermal, 3-D, density-dependent flow and mass transport models. The simulations are run using the FEFLOW code and a mesh geometry and hydrogeologic features that are similar to those comprising the rubble chimney models. The differences are the addition of one 5-m-wide layer on each outside lateral face of the model, and the addition of four 100-m-wide layers inside the model. The 5-m-wide layers represent fault zones and in the first fault scenario are assigned fault hydraulic conductivity values ten times the values in the unfaulted rock. In the second fault scenario, the faults are assigned hydraulic conductivity values 100 times the values in unfaulted rock. The horizontal to vertical $K$ anisotropy ratio of 10 is maintained within the fault zones in both scenarios. The four additional 100-m-wide layers within the model increase the overall model width to $1,910 \mathrm{~m}$, which approximates the width of the unfaulted structural blocks near Cannikin (Engdahl, 1972). The cavity and chimney are positioned midway between the fault zones at a distance of $800 \mathrm{~m}$ from each. Thus, the 3-D models simulate flow and transport within a single structural block bounded on the lateral faces by permeable fault zones. The faults are considered here to be preferred pathways of flow to the sea and do not allow flow across them (Figure 6.40).

Three cases of each fault scenario are run, with boundary conditions and values of the groundwater flow and mass transport parameters the same as the three cases of the 3-D chimney model (Table 6.8). The only differences are the increased $K$ values in the fault zones, as previously described.

Table 6.8. Values of parameters used in three-dimensional simulations incorporating fault zones.

\begin{tabular}{lcccc}
\hline \multicolumn{1}{c}{ Parameter } & Realization \#1 & Realization \#2 & Realization \#3 & All Cases \\
\hline Horizontal Hydraulic Conductivity, & $1.86 \times 10^{-2} \mathrm{~m} / \mathrm{d}$ & $6.48 \times 10^{-2} \mathrm{~m} / \mathrm{d}$ & $1.78 \times 10^{-2} \mathrm{~m} / \mathrm{d}$ & \\
Unfaulted Structural Block, $K_{x x}$ and $K_{y y}$ & & & & \\
Vertical Hydraulic Conductivity, & $1.86 \times 10^{-3} \mathrm{~m} / \mathrm{d}$ & $6.48 \times 10^{-3} \mathrm{~m} / \mathrm{d}$ & $1.78 \times 10^{-3} \mathrm{~m} / \mathrm{d}$ & \\
Unfaulted Structural Block, $K_{z z}$ & & & & \\
$K_{z z}$ and $K_{y y}$ of Fault Zones, Scenario \#1 & $1.86 \times 10^{-1} \mathrm{~m} / \mathrm{d}$ & $6.48 \times 10^{-2} \mathrm{~m} / \mathrm{d}$ & $1.78 \times 10^{-1} \mathrm{~m} / \mathrm{d}$ & \\
$K_{z z}$ of Fault Zones, Scenario \#1 & $1.86 \times 10^{-2} \mathrm{~m} / \mathrm{d}$ & $6.48 \times 10^{-3} \mathrm{~m} / \mathrm{d}$ & $1.78 \times 10^{-2} \mathrm{~m} / \mathrm{d}$ & \\
$K_{z z}$ and $K_{y y}$ of Fault Zones, Scenario \#2 & $1.86 \mathrm{~m} / \mathrm{d}$ & $6.48 \times 10^{-1} \mathrm{~m} / \mathrm{d}$ & $1.78 \mathrm{~m} / \mathrm{d}$ & \\
$K_{z z}$ of Fault Zones, Scenario \#2 & $1.86 \times 10^{-1} \mathrm{~m} / \mathrm{d}$ & $6.48 \times 10^{-2} \mathrm{~m} / \mathrm{d}$ & $1.78 \times 10^{-1} \mathrm{~m} / \mathrm{d}$ & \\
Cavity and Chimney, $K_{x x}, K_{y y}$ and $K_{z z}$ & $1.86 \times 10^{-2} \mathrm{~m} / \mathrm{d}$ & $6.48 \times 10^{-2} \mathrm{~m} / \mathrm{d}$ & $1.78 \times 10^{-2} \mathrm{~m} / \mathrm{d}$ & \\
Specific Storage, $S s$ & & & & $1 . \times 10^{-4}$ \\
Recharge, Rech & $6.13 \mathrm{~cm} / \mathrm{yr}$ & $3.33 \mathrm{~cm} / \mathrm{yr}$ & $1.89 \mathrm{~cm} / \mathrm{yr}$ & \\
Fracture Porosity, $\theta$ & $2.81 \times 10^{-4}$ & $2.71 \times 10^{-4}$ & $2.67 \times 10^{-4}$ & \\
Chimney Porosity & & & & 0.07 \\
Mass Longitudinal Macrodispersivity, $A_{L}$ & & & & 100 \\
Mass Longitudinal Macrodispersivity, $A_{T}$ & & & & $1.0 \times 10^{-9} \mathrm{~m}^{2} / \mathrm{s}$ \\
Mass Diffusion, $D^{*}$ & & & & 0.025 \\
Density Ratio & & & & \\
\hline
\end{tabular}




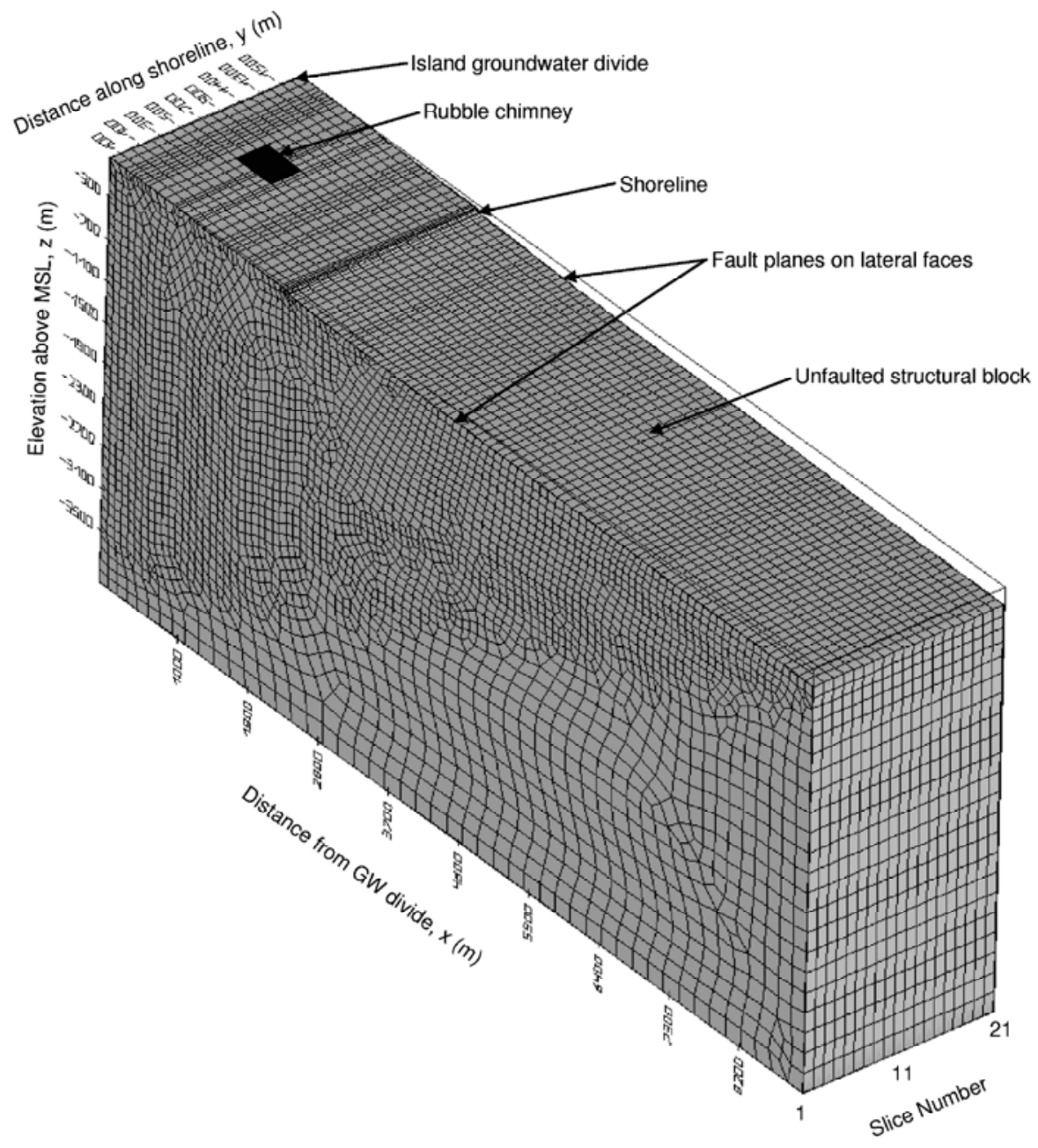

Figure 6.40. Design of finite-element mesh used for the the 3-D model incorporating fault zones near Cannikin. Layers 1 and 21 represent the 5-m-wide fault zones (but are too thin to be visible on this diagram). Layers 2 through 20 are $100 \mathrm{~m}$ wide and comprise the unfaulted structural block.

Inclusion of permeable faults is somewhat analogous to increasing $K$ uniformly throughout the model domain, although the magnitude of the response is considerably less due to the limited areal extent of the more permeable zones. In the density-driven flow system modeled here, an increase in $K$ generally causes the transition zone to be established at a higher elevation, as was shown previously for the 2-D case. Similarly, in the case of 3-D flow with fault zones, faults with $K$ values 10 times greater than the unfaulted rock result in a slightly higher location of the transition zone, although the difference is well within the uncertainty of the measurements. Increasing the fault $K$ further shows a greater impact on the transition zone; faults with $K$ values 100 times greater than rock $K$ start to dominate the flow pattern, causing the transition zone to be established at an elevation about $200 \mathrm{~m}$ higher (Figure 6.41 and Figure 6.42). The high contrast in $K$ also is reflected in the upper portion of the head profiles, which show about a 4-m difference in head between the center 

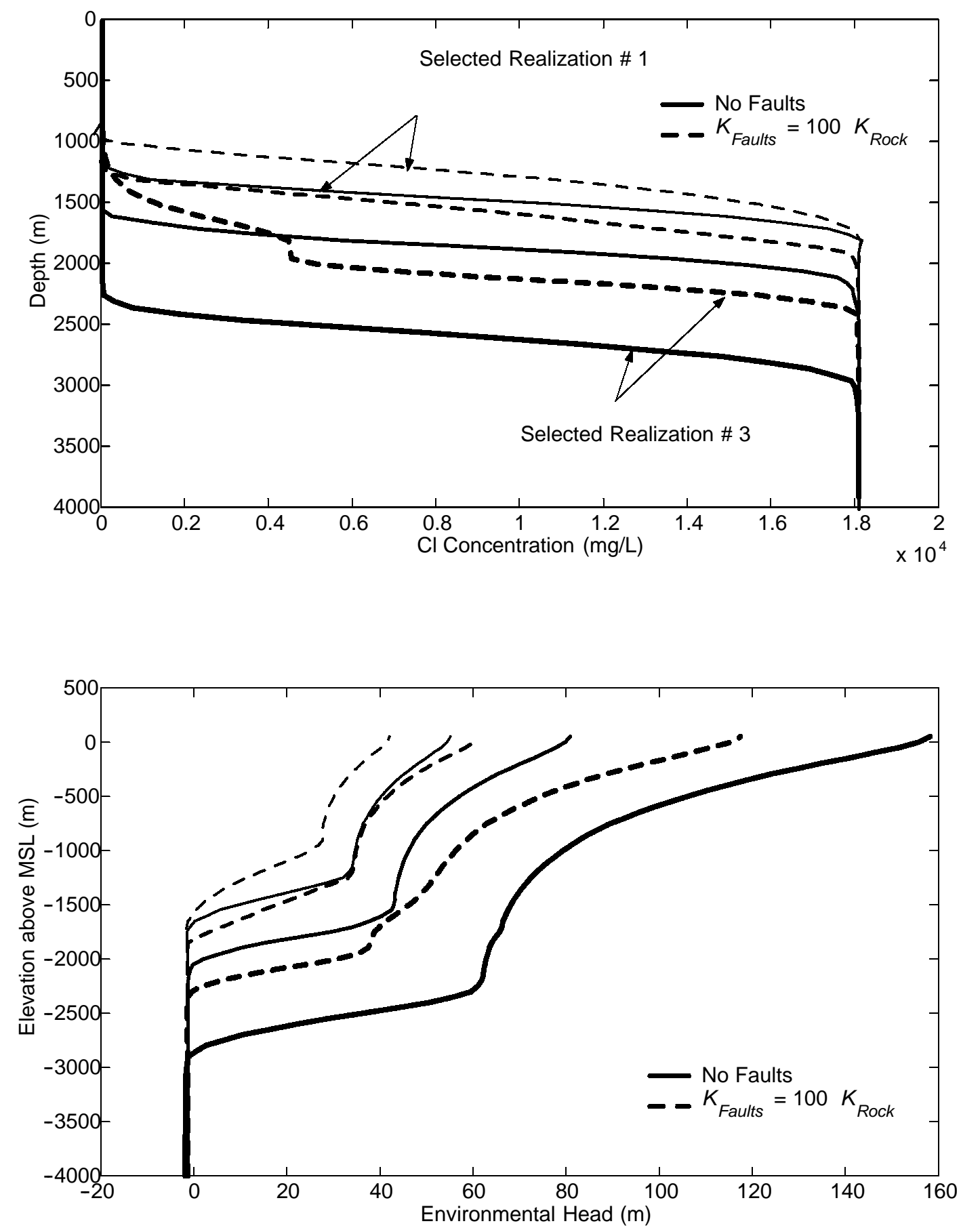

Figure 6.41. Profiles of concentrations and heads along a vertical line through the working point of Cannikin showing the effect of faults with $K$-ratio of 100 . 

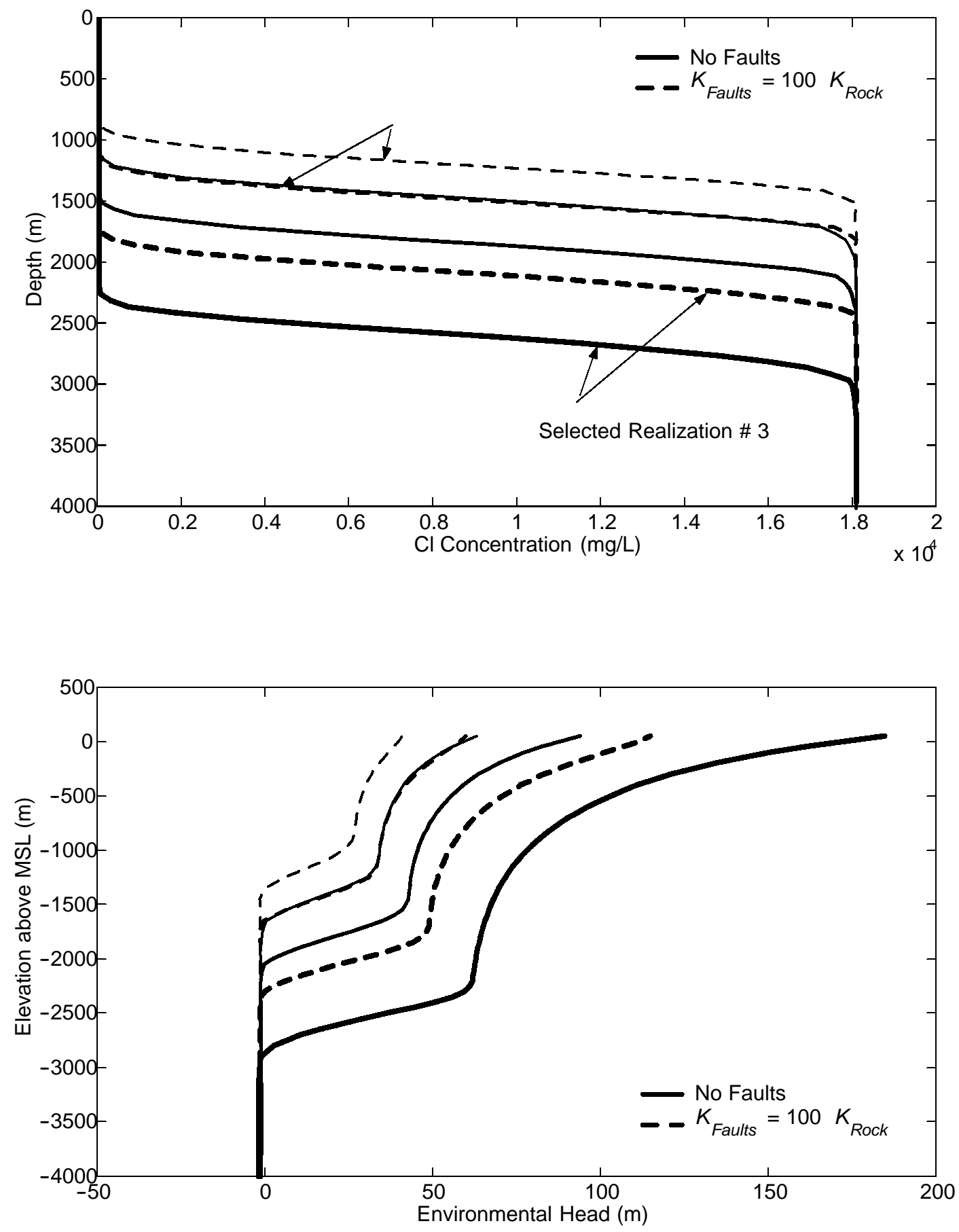

Figure 6.42. Profiles of concentrations and heads along a vertical line through the faults (at same $\mathrm{x}$ as the working point) showing the effect of faults with $K$-ratio of 100 . 
of the structural block and the edge. This head gradient has the effect of driving groundwater flow from the center of the model where the cavity is located, toward the faults.

The results of the flow model for the three selected realizations are analyzed in terms of transport of particles from the cavity to the seafloor. Figure 6.43 shows a snapshot of the particles' distribution at 2,200 years for selected realization \#2 comparing the three-dimensional model with and without fault zones. The faults are assigned a conductivity value 100 times higher than the unfaulted rocks. The impact of the shallower transition zone is apparent on the 3-D and the vertical views. Particles break through between 4 and $5 \mathrm{~km}$ from the island axis in the faulted system, but they break through between 5 and $6 \mathrm{~km}$ in the unfaulted scenario. In the plan view of Figure 6.43, the impact of fault zones is most apparent where a strong lateral (parallel to the shoreline) preferential flow drives a large number of particles toward the faults in both directions. These particles then migrate along the transition zone within and parallel to the faults until they reach the seafloor. This selected realization has the cavity within the transition zone and the shallower transition zone resulting from the effect of the faults leads to the cavity being below the transition zone. Particles thus move upward with the saltwater and then shoot outside the cavity in the four directions: toward the sea, toward the island axis and toward the two faulted blocks. When the recharge-conductivity ration is large and the cavity is located above the transition zone as in selected realization \#3, the impact of the faults on spreading the particles laterally is very minor as can be seen from Figure 6.45. This is to be expected since the dynamics of the freshwater lens and the velocity pattern therein are mainly controlled by the recharging freshwater. The high-K faults lead to a shallower transition zone and thus break through closer to the shoreline as compared to the unfaulted scenario.

The breakthrough curves for the three selected realizations and the comparison between the faulted and unfaulted cases are shown in Figure 6.45. Again, the impact of the faults depends on the location of the cavity with respect to the transition zone. The first realization shows an increase in the mass arriving to the seafloor and a higher peak of mass flux, but at a later time as compared to the breakthrough peak of the unfaulted scenario. The other two realizations (with cavity within or above the transition zone) show the same or lower mass arriving to the seafloor within 2,200 years and lower mass flux peak. As mentioned earlier, the significance of this impact depends on the radionuclide's half-life, with short-lived nuclides being more conservatively evaluated using the unfaulted scenario. 


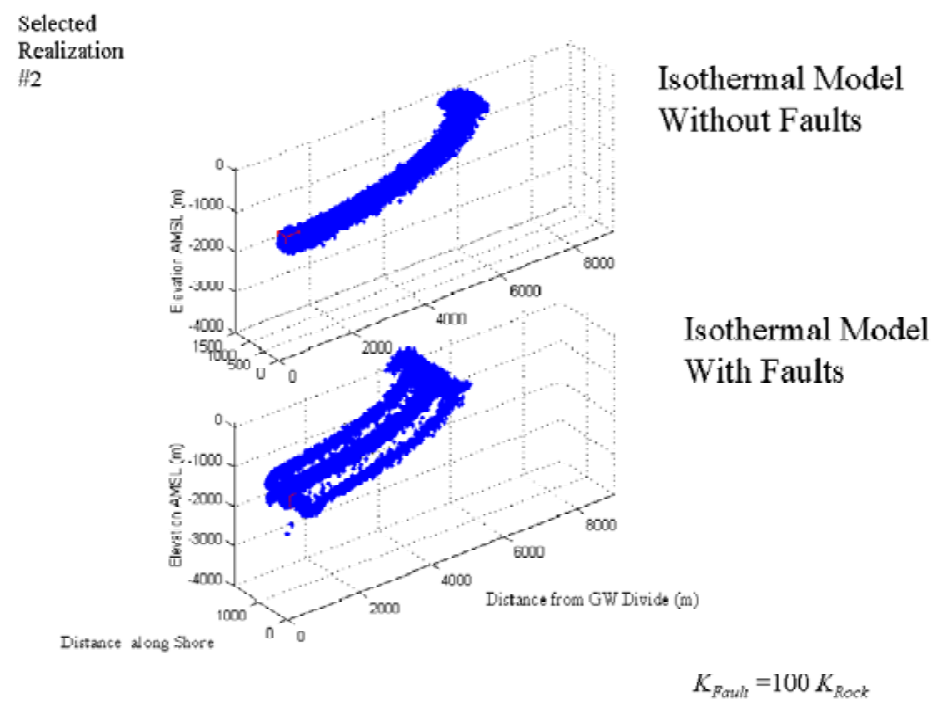

Selected

Realization
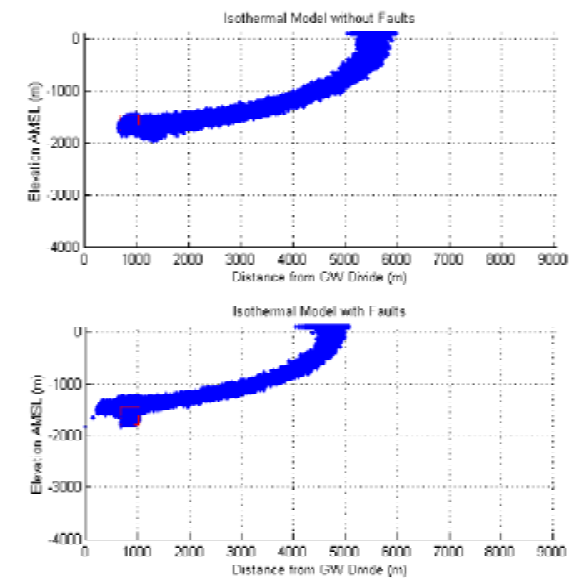

$$
K_{\text {Tault }}=100 K_{\text {Rock }}
$$
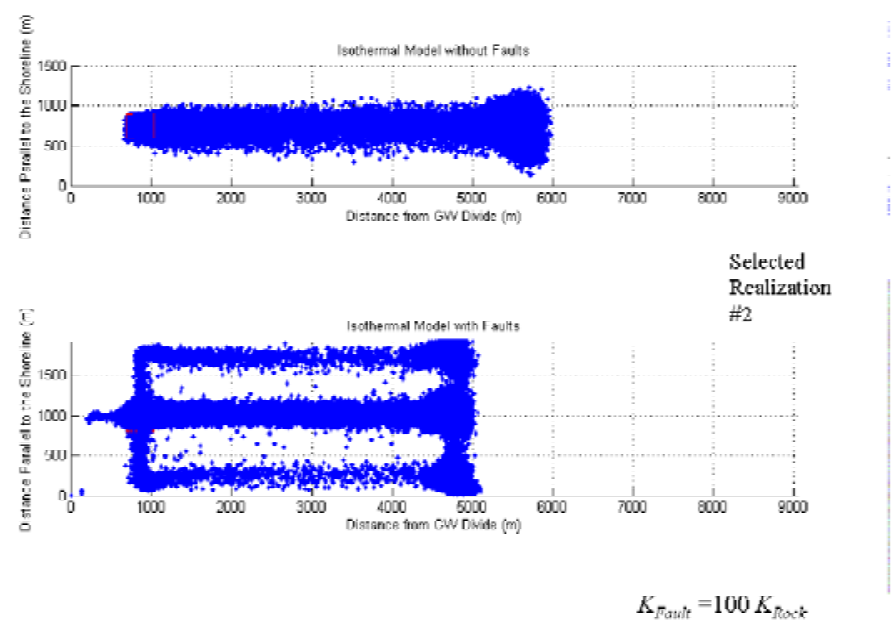

Figure 6.43. Particle distributions comparing faulted and unfaulted scenarios for Cannikin 3-D model for selected realization $\# 2$. 

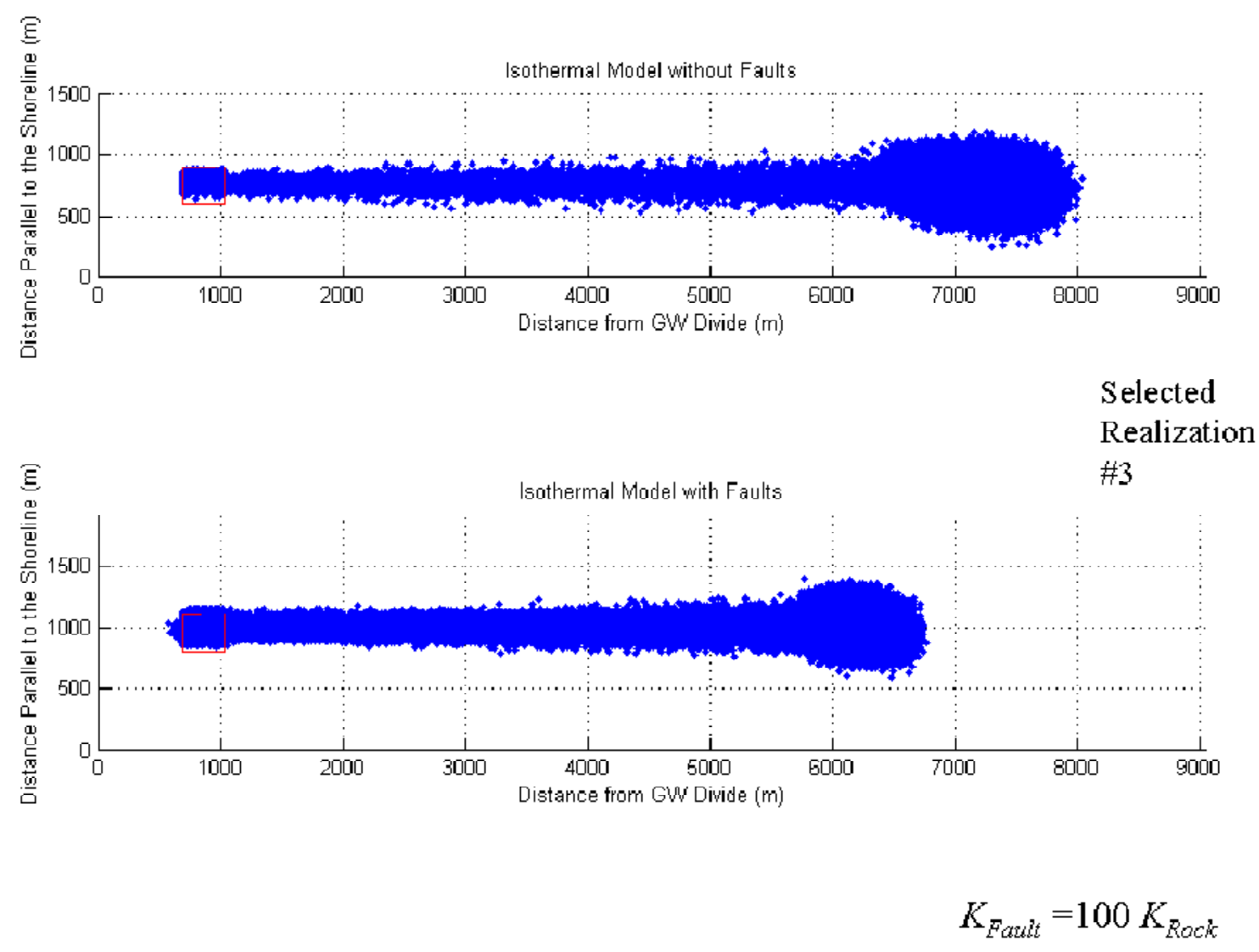

Figure 6.44. Plan view of particles' distribution for realization \#3 showing the effects of faults when the transition zone is below the cavity. 

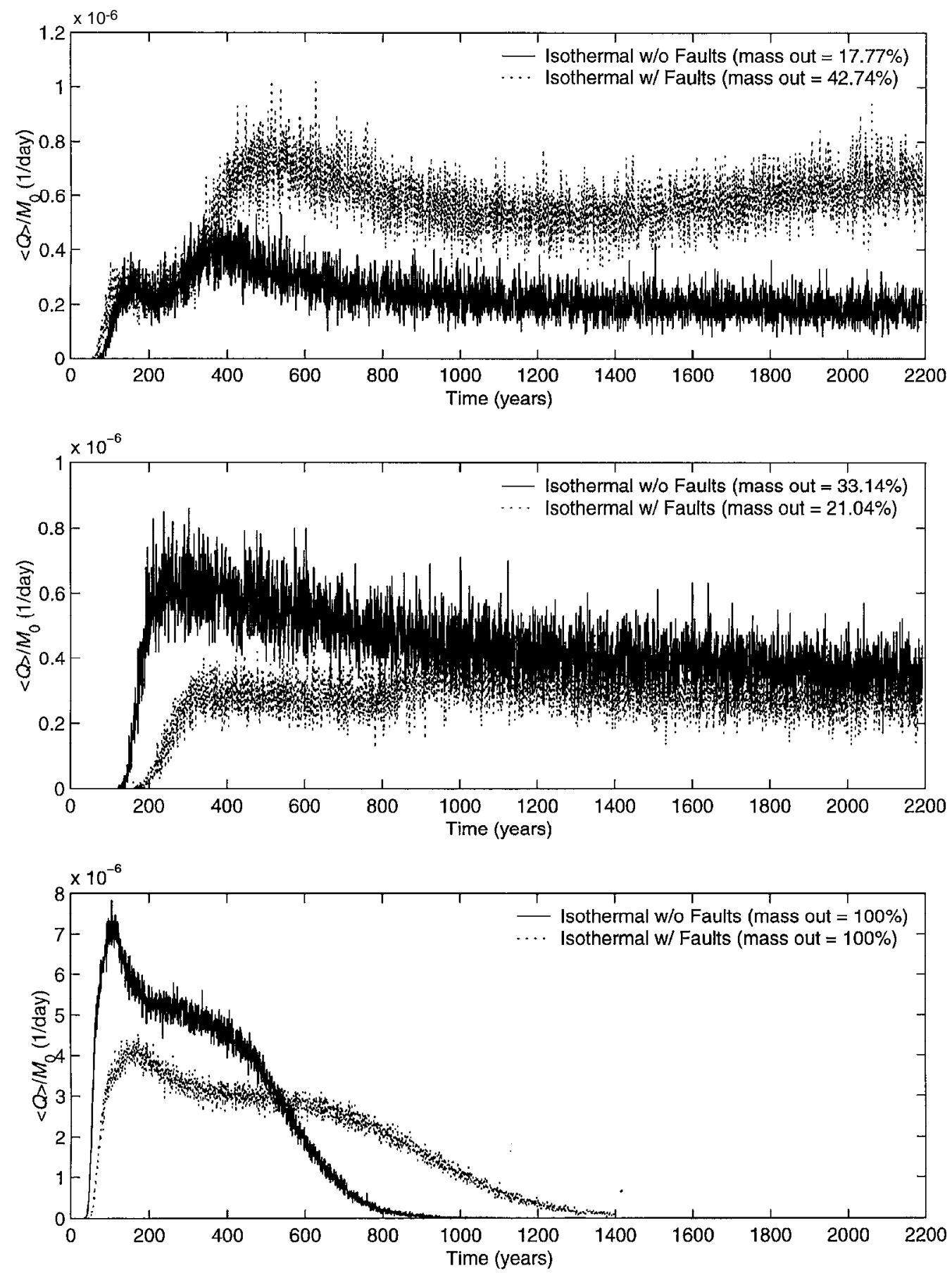

Figure 6.45. Breakthrough of undecayed, unretarded mass from Cannikin cavity with and without fault zones. Each graph represents a different case of recharge-conductivity ration for the three selected realizations. 


\subsection{Summary and Conclusions}

Modeling of Amchitka's nuclear tests encompasses two major processes: 1) the flow modeling, which includes density-driven flow due to saltwater intrusion, and 2) the transport modeling that is a combination of advection, dispersion, retardation, source term and glass dissolution, matrix diffusion and radioactive decay. Modeling each of the two processes is based on a certain conceptualization of the flow or the transport. There are many assumptions that are aimed at reducing the complexity of the studied processes or are a result of the scarcity of data available at the island. Many of the processes encountered are associated with difficulties determining the values of the parameters governing them, and in some cases the processes themselves are not well understood. The selected modeling approach and the results presented in this study represent an attempt to overcome these difficulties and address these uncertainties.

The flow and transport modeling is based on a two-dimensional conceptualization of the island's cross section, which is represented for each test by a transect from the island's centerline (divide) through the test location and then to the sea. The two-dimensional modeling relies on a homogeneous, anisotropic conductivity field with no spatial variability except at the cavity and chimney. Flow and transport through fractures is the fundamental scenario considered.

A calibration is performed for each test location using head data and groundwater chemistry data from nearby boreholes as calibration targets. Simultaneous, exact matches of these two independent data sets are not achieved at any site, though the uncertainty expressed by the standard deviation in the base-case flow models encompasses the observed data. The head data are considered to be more reliable than the chemical data and are given more weight in the calibration. The chemical data are subject to questions of their degree of representing in-situ conditions due to borehole mixing and incomplete purging of drilling fluids. In addition, the chemical data are more likely than the head data to be in disequilibrium with current hydraulic conditions as a result of the last sea level change, as demonstrated in a sensitivity analysis. The final calibrations depict a deeper transition zone on the Bering Sea side of the island as compared to the Pacific.

A parametric uncertainty analysis evaluated the effect of uncertainty in seven key parameters on the resulting uncertainty in the transport results. The parameters evaluated are hydraulic conductivity, recharge, macrodispersivity, fracture porosity, small-scale dispersivity, glass dissolution, and matrix diffusion. The end result of this modeling stage is the reduction of the list of uncertain parameters from seven parameters to only four parameters. Three parameters are excluded from the list because the uncertainties associated with the values of these parameters show minor effects on the uncertainties of the transport results in comparison with the remaining parameters. Of the remaining list of the uncertain parameters, hydraulic conductivity, recharge and fracture porosity are treated as uncertain in the flow and transport modeling, while the uncertainty in matrix diffusion is handled as a sensitivity.

The flow and transport modeling for each site solves the flow and transport problems using random realizations for the values of the three parameters in the uncertain list while keeping all other parameters at fixed values (as if they are known with certainty). The ensemble of realizations of the 
transport solutions is then analyzed for individual nuclides with different release and retardation characteristics. Transport results indicate that the radionuclide movement at Long Shot is much faster than at Milrow and Cannikin. That is due to the location of the cavity being very shallow as compared to the other two tests. The working point of Long Shot is at a depth of $700 \mathrm{~m}$, whereas the Milrow cavity is centered at about 1,218 $\mathrm{m}$ and that of Cannikin is at about 1,791 $\mathrm{m}$ below ground surface. Thus, Long Shot is above the transition zone in all realizations, whereas Milrow and Cannikin tend to be within or below the transition zone.

The location of the cavity relative to the varying location of the transition zone is an important factor influencing transport results. Below the transition zone, the generally toward-island-axis flow direction in the saltwater zone delays the particles' migration toward the breakthrough boundary by lengthening the flowpath. This is accentuated by much slower velocities in the saltwater section. If the location of the transition zone in a certain realization is causing the cavity to be located in the saltwater zone, transport is significantly delayed in that realization allowing for more radioactive decay. In comparing the transport results of the three tests, one can observe a certain pattern related to that factor. At Long Shot, for example, all of the realizations had mass flux breakthrough at the seafloor within the simulation time. At Milrow, 8 percent of the realizations did not break through at the seafloor within 2,200 years, while at Cannikin over 30 percent did not break through, even without considering the effects of retardation and decay. The same trend is evident in the percentage of mass breakthrough, when it does occur. Over 90 percent of the Long Shot realizations experienced 100 percent breakthrough, whereas percentage of breakthrough was typically much lower for the Milrow and Cannikin realizations that did reach the seafloor.

An explanation for these aspects is shown in Figure 7.1. The figure shows the three transition zones at the three sites and the corresponding cavity location. For each test, the vertical distribution of concentration (averaged over the MC realizations considered) at the right edge of the cavity is plotted (solid lines). The dotted lines in the figure indicate the elevation of the top and bottom of the cavity at the three sites. As can be seen in the figure, the Long Shot cavity is always located at the freshwater side and very far from the center of the transition zone. This leads to the direct movement of radionuclides from the cavity toward the seafloor. The Milrow cavity and that of Cannikin, on the other hand, are located at the saltwater side of the transition zone (on average). This means that in many realizations, the cavity comes in contact with the circulatory and very slow flow pattern occurring at the lower edge of the transition zone. This explains why 25 realizations at Milrow do not produce any mass breakthrough within 2,200 years. For Cannikin, the cavity is also located in the saltwater side of the transition zone (on average), and in addition is deeper. This results in a larger number of realizations coming in contact with the circulatory flow pattern, and longer flowpaths to the seafloor when they do.

The differences in cavities relative to the transition zone between the three sites are reflected in the breakthrough curves. Considering tritium, the earliest peak mean breakthrough occurs at Long Shot, in 25 to 30 years after the test at a normalized peak mean concentration of about $1.8 \times 10^{-4}$. Both Milrow and Cannikin have peak mean tritium breakthrough at about 100 years after each test, with peak normalized concentrations of $1.6 \times 10^{-8}$ for Milrow and $1.9 \times 10^{-9}$ for Cannikin. In all 


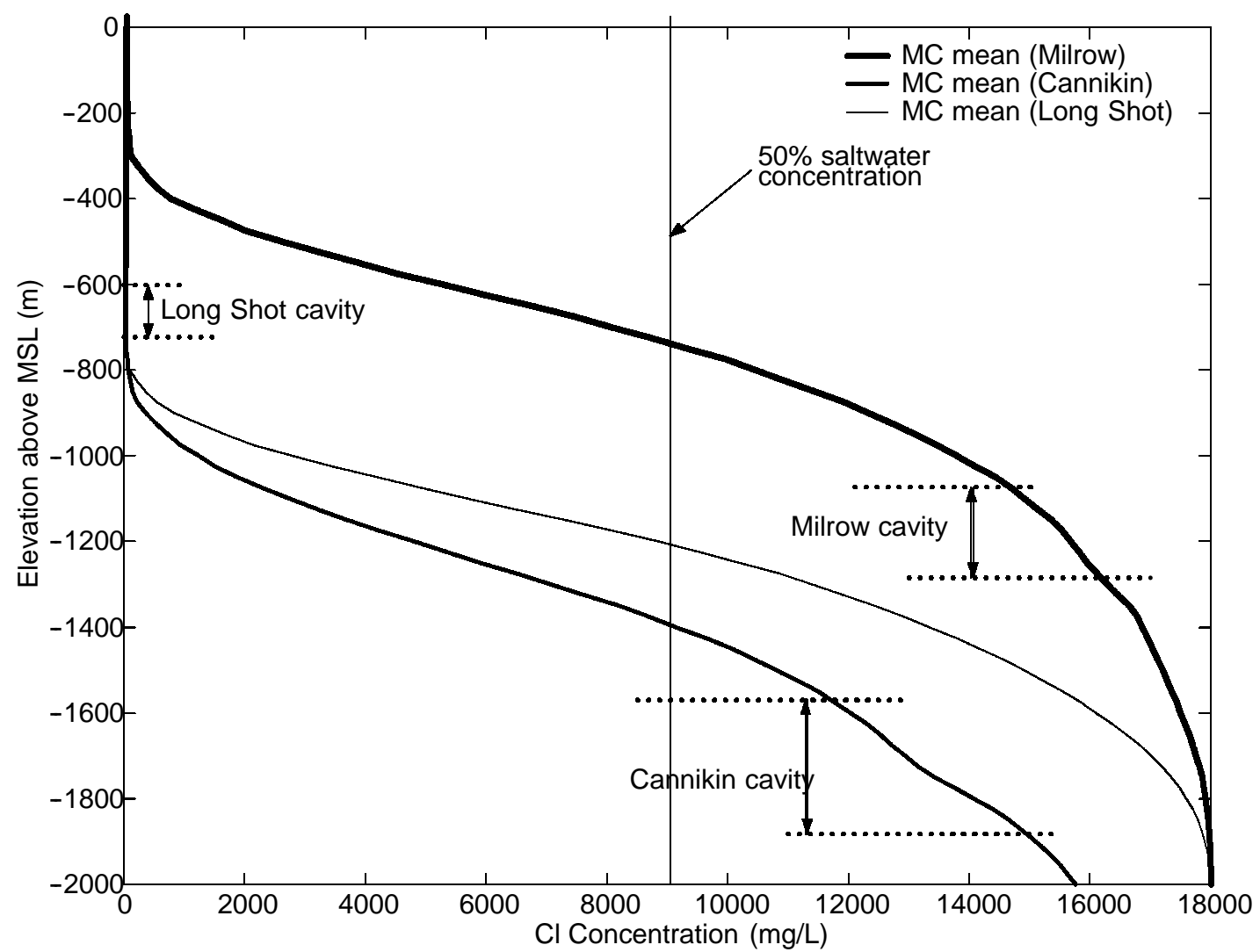

Figure 7.1. Cavity location relative to the expected transition zone profile for the three tests.

cases, adding one standard deviation increases the concentrations approximately one order of magnitude. The time and normalized mass for each radionuclide considered is a function of its radioactive half-life, as well as the flow and transport results. For example, the peak mean concentration of ${ }^{14} \mathrm{C}$ occurs at about 100 years at Long Shot, as the peak for tritium at 20 to 30 years is driven in large part by the short tritium half-life.

The incorporation of uncertainty in the transition zone location (through uncertainty in recharge and hydraulic conductivity), while consistent with the uncertainties from island data, leads to a large variation in transport results from one realization to the next. As described above, the transport calculated for a realization with the Milrow cavity intersecting the transition zone is dramatically different than for a realization with the transition zone below the cavity. For both Milrow and Cannikin, the early-time portion of the breakthrough curves is dominated by the realizations representing the transition zone at or below the cavities.

A variety of sensitivity studies are presented. With the exception of evaluating matrix diffusion, the alternate scenarios are performed on several realizations selected to be representative of the gamut of flow behavior. As a result, the sensitivity results are not directly comparable to the Monte Carlo results, but do allow identification of the general magnitude of impact that process uncertainty contributes. A variety of numerical solution issues, matrix diffusion, colloid transport, 
uncertainty in island half-width, sea level changes, and geothermal processes are evaluated using the 2-D models. The impact of the 2-D simplification, flow in the rubble chimney, Cannikin Lake, nuclear heat and flow in fault zones are all evaluated with 3-D models.

The presence of the nuclear chimney, with its high vertical conductivity, is found to dominate many of the other conceptualizations (the chimneys are included in the base-case Monte-Carlo calculations). Numerical solution issues, sea level changes, geothermal processes, the 2-D simplification, Cannikin Lake, and fault zones all have relatively limited impact on transport results for the realizations analyzed, or result in significantly less transport than the base-case. Matrix diffusion, colloid transport, island half-width, and nuclear heat are potentially more significant.

The impact of flow field conceptual processes (e.g., thermal processes, faults, the half-width, and Cannikin Lake) on transport varies strongly with cavity location in the domain relative to the transition zone. Variations in transport caused by these features are on the order of several times (larger and smaller), not orders of magnitude. Conversely, some of the base-case model parameters have uncertainties spanning many orders of magnitude that translate directly into velocities, and therefore they have greater impact on the results than the uncertainties in heat and 3-D flow evaluated here. In addition, the uncertainties in retardation properties, evaluated as the matrix diffusion parameter and colloids, can also affect results by orders of magnitude. Matrix diffusion uncertainty is conservatively evaluated here (only lower diffusion is evaluated, not higher), with data suggesting the process is larger and allowing much less transport than simulated.

Considering the supporting data as well as the modeling results, the most significant uncertain parameter is the porosity assigned to the fracture system. Not only does the porosity directly control travel times, it is uncertain through many orders of magnitude and there are no island-specific data to support a mean value nor distribution. It should be noted that this is a common problem for fracture-flow environments, and one that is not easily remedied. It should additionally be emphasized that the fracture flow approach taken here for a conceptual model is also an assumption. At the overburden pressures encountered at depths of thousand of meters, and given the abundant data supporting relatively high matrix porosity values, a porous medium assumption may be equally valid and would result in extremely long travel times (recall that only 29 of 100 realizations had breakthrough in 5.5 million years in a porous medium analysis for Milrow). Additional uncertain parameters are the matrix diffusion coefficient and glass dissolution rate, though the significance of their impact depends on the half-life of the radionuclide and the predicted flow velocities.

The quantification of uncertainty due to key model parameters, expressed as the standard deviation of the breakthrough curves, allows many of the uncertainties discussed above to be included in the risk assessment. The modeling results presented here are but one part of the risk assessment process that evaluates the potential hazard posed by the three underground nuclear tests on Amchitka. The results of the risk assessment will determine whether the uncertainties identified here are of potential significance or can be tolerated within an acceptable margin of safety. 


\section{REFERENCES}

Anderson, R.E., 1971. Tectonic setting of Amchitka Island, Alaska. U.S. Geological Survey, Report USGS-474-75, Rev. 1, 46p.

Andricevic, R., J. Daniels, and R. Jacobson, 1994. Radionuclide migration using a travel time transport approach and its application in risk analysis. Journal of Hydrology, 163:125-145.

Andrecevic, R. and V. Cvetkovic, 1996. Evaluation of risk from contaminants migrating by groundwater. Water Resources Research, 32(3):611-621.

Armstrong, R.H., 1977. Weather and Climate, in Merritt, M.L. and R.G. Fuller, editors, 1977. The Environment of Amchitka Island Alaska. Energy Research and Development Administration, Technical Information Center, pp.53-58.

Ballance, W.C., 1970a. Hydraulic testing of hole UAe-7h, Amchitka Island, Alaska. U.S. Geological Survey, Report USGS-474-84, 31p.

Ballance, W.C. 1970b. Hydraulic tests in hole UA-1 and water inflow into an underground chamber, Amchitka Island, Alaska. U.S. Geological Survey, Report USGS-474-72, 54p.

Ballance, W.C., 1972a. Hydraulic tests in drill hole UAe-1, Amchitka Island, Alaska. U.S. Geological Survey, Report USGS-474-102, 32p.

Ballance, W.C., 1972b. Hydraulic tests in hole UAe-6h, Amchitka Island, Alaska. U.S. Geological Survey, Report USGS-474-104, 27p.

Ballance, W.C. and G.A. Dinwiddie, 1972. Hydraulic testing of hole UA-1-HTH-1, Amchitka Island, Alaska. U.S. Geological Survey, Report USGS-474-144, 27p.

Ballance, W.C., 1973a. Hydraulic tests in hole UAe-2, Amchitka Island, Alaska. U.S. Geological Survey, Report USGS-474-103.

Ballance, W.C., 1973b. Hydraulic tests in hole UAe-3, Amchitka Island, Alaska. U.S. Geological Survey, Report USGS-474-26, Rev. 1, 30p.

Bath, G.D., W.J. Carr, L.M. Gard Jr. and W.D. Quinlivan, 1972. Interpretation of an aeromagnetic survey of the Amchitka Island Area, Alaska. U.S. Geological Survey, Professional Paper 707, $25 \mathrm{p}$.

Bath, G.D., C.H. Miller and W.D. Quinlivan, 1971. Interpretation of a gravity survey of Amchitka Island, Alaska. U.S. Geological Survey, Report USGS-474-93 (Amchitka-24), 54p.

Bear, J., 1972. Dynamics of Fluids in Porous Media. American Elsevier, New York.

Bedford, R.G. and D.D. Jackson, 1965. Volatilities of the fission product and uranium oxides. Lawrence Livermore National Laboratory, UCRL-12314, 37 p. 
Beetem, W.A., R.A. Young, C.L. Washington and L.J. Schroder, 1971. Chemical analyses of water samples collected on Amchitka Island, Alaska. U.S. Geological Survey, Report USGS-474-135 (Amchitka-29), 23p.

Borg, I.Y., 1975. Radioactivity trapped in melt produced by a nuclear explosion. Nuclear Technology, 26:88-100.

Borg, I.Y., R. Stone, H.B. Levy and L.D. Ramspott, 1976. Information pertinent to the migration of radionuclides in ground water at the Nevada Test Site, Part 1: Review and analysis of existing information. Lawrence Livermore National Laboratory, Report UCRL-52078 Part 1, 216 p.

Bourcier, W.L., S. Roberts, D.K. Smith, S. Hulsey, L. Newton, A. Sawvel, C. Bruton, C. Papelis, W. Um, C. Russell and J. Chapman, 2001. Determination of Reactive Surface Area of Melt Glass. In review with the U. S. Department of Energy, Nevada Operations Office.

Bredehoeft, J.D. and I.S. Papadopulos, 1965. Rates of vertical groundwater movement estimated from the Earth's thermal profile. Water Resources Research, 1(2):325-328.

Buddemeier, R.W. and J.R. Hunt, 1988. Transport of colloidal contaminants in groundwater: radionuclide migration at the Nevada Test Site. Appl. Geochem. 3:535-548.

Carr, W.J., L.M. Gard, G.D. Bath and D.L. Healey, 1971. Earth-science studies of a nuclear test area in the western Aleutian Islands, Alaska: An Interim Summary of Results. Geological Society of America Bulletin, 82:699-706.

Carr, W.J., L.M. Gard Jr. and W.D. Quinlivan, 1969. Geologic reconnaissance of Amchitka Island, Alaska, December 1966. U.S. Geological Survey, Report USGS-474-42 (Amchitka-3) (distributed in 1970 and reprinted in 1971), 15 p.

Carr, W.J. and W.D. Quinlivan, 1969. Progress report on the geology of Amchitka Island, Alaska. U.S. Geological Survey, Report USGS-474-44 (Amchitka-5) (revised), 15p.

Castagnola, D.C., 1969. Tritium anomalies on Amchitka Island, Alaska, Parts I and II. Teledyne Isotopes Report for the U.S. Atomic Energy Agency, Nevada Operations Office, NVO-1229-113 Part 1, 41p and 15p.

Claassen, H.C., 1978. Hydrologic processes and radionuclide distribution in a cavity and chimney produced by the Cannikin nuclear explosion, Amchitka Island, Alaska. U.S. Geological Survey, Professional Paper 712-D, 28p.

Cooper, H.J., J.D. Bredehoeft and I.S. Papadopulos, 1967. Response of a finite-diameter well to an instantaneous charge of water. Water Resources Research, 3(1):263-269.

Cvetkovic, V. and G. Dagan, 1994. Transport of kinetically sorbing solutes by steady random velocity in heterogeneous porous formations. Journal of Fluid Mech., 265, 189-215.

Cvetkovic, V., J. O. Selroos and H. Cheng, 1999. Transport of reactive tracers in rock fractures. Journal of Fluid Mech., 378, 335-356. 
Dagan, G., V. Cvetkovic and A. Shapiro, 1992. A solute flux approach to transport in heterogeneous formations, 1, The general framework. Water Resources Research, 28(5):1369-1376.

Diersch, J.J.G., 1998. Interactive, graphics-based finite-element simulation system FEFLOW for modeling groundwater flow contaminant mass and heat transport processes. FEFLOW Reference Manual, WASY Ltd., Berlin, 294 p.

Dudley, Jr., W.W., W.C. Ballance and V.M. Glanzman, 1977. Hydrology, in Merritt, M.L. and R.G. Fuller, editors, 1977. The environment of Amchitka Island, Alaska. Energy Research and Development Administration, Technical Information Center, pp.35-51p.

Dupuis, M., 1970. Distribution and evolution of radioelements after a nuclear explosion. Bull. Infor. Sci. Tech., 149: Lawrence Livermore National Laboratory, 1972, UCRL-Trans-10617-5.

Essington, E.H., P.R. Fenske and W.E. Nork, 1970. Radioactivity in Water, Project Milrow. Teledyne Isotopes report for the U.S. Atomic Energy Commission, Nevada Operations Office, NVO-1229-135, 49p.

Essington, E.H., E.J. Forslow and D.C. Castagnola, 1971. An interim summary of tritium data for STS “A,” Amchitka Island, Alaska, July 1, 1969 through June 30, 1970. Teledyne Isotopes Report, NVO-1229-157, 82p.

Essington, E.H. and J.V.A. Sharp, 1968. Some aspects of ground-water solution chemistry, underground nuclear explosion zones, Nevada Test Site. In Eckel, E.B., Nevada Test Site, Geological Society of America Memoir 110, pp. 263-273.

Faure, G., 1977. Principles of Isotope Geology. John Wiley and Sons, New York, 464p.

Fenix and Scisson, Inc., 1972. Abandonment of Drilled Holes, Amchitka Island Alaska. Report prepared for U.S. Atomic Energy Commission under contract AT(26-1)-38, 68p.

Fenske, P.R., 1972a. Event-related hydrology and radionuclide transport at the Cannikin Site, Amchitka Island, Alaska. Desert Research Institute, Center for Water Resources Research, Report 45001, NVO-1253-1, 41p.

Fenske, P.R., 1972b. Hydrology and radionuclide transport, Amchitka Island, Alaska. Desert Research Institute, Technical Report Series H-W, Hydrology and Water Resources Publication No. 12, 29p.

Freeze, R.A. and J.A. Cherry, 1979. Groundwater, Prentice-Hall, Inc., Englewood Cliffs, New Jersey, $604 \mathrm{p}$.

Frick, U., W. Alexander, B. Baeyens, P. Bossart, M.H. Bradbury, Ch. Bühler, J. Eikenberg, Th. Fierz, W. Heer, E. Hoehn, I.G. McKinley and P.A. Smith, 1991. Grimsel Test Site - The Radionuclide Migration Experiment - Overview of Investigations 1985-1990. National Cooperative for the Disposal of Radioactive Waste Technical Report 91-94. 
Garber, M.S., 1971. A method for estimating effective porosity in a rubble chimney formed by an underground nuclear explosion. U.S. Geological Survey, Professional Paper 750-C, pp. C207-C209.

Gard, L.M., 1977. Geologic History, in Merritt, M.L. and R.G. Fuller, editors, 1977. The environment of Amchitka Island, Alaska. Energy Research and Development Administration, Technical Information Center, pp.13-34p.

Gard Jr., L.M., 1972. Chemical analyses of igneous rocks from drill holes and outcrops, Amchitka Island, Alaska (Including Working-Point Rocks of Long Shot, Milrow and Cannikin Events). U.S. Geological Survey, Report USGS-474-140, 19p.

Gard Jr., L.M., 1971, Geological and hydrological considerations at the Cannikin Site. U.S. Geological Survey informal report.

Gard Jr., L.M. and W.E. Hale, 1964. Geology and hydrology of the Long Shot Site, Amchitka Island, Alaska. U.S. Geological Survey, Technical Letter Long Shot-1, 32p.

Gates, O., G.D. Fraser and G.L. Snyder, 1954. Preliminary report on the geology of the Aleutian Islands. Science, v.119, pp.446-447.

Gelhar, L.W. and C.L. Axness, 1983. Three-dimensional stochastic analysis of macrodispersion in aquifers. Water Resources Research, 19(3):1643-1644.

GeoTrans, Inc., 1995. A fracture/porous media model of tritium transport in the underground weapons testing areas, Nevada Test Site. Report prepared for the U.S. Department of Energy, 39 p.

Glasstone, S. and J. Dolan, 1977. The Effects of Nuclear Weapons, 3rd edition. U.S. Department of Defense and U.S. Department of Energy, 653p.

Goishi, W., J.W. Meadows, N. Namboodiri, D.K. Smith and J.F. Wild, 1995. Radionuclide inventory for U.S. nuclear tests conducted off the NTS and hydronuclear and safety experiments conducted on the NTS, Lawrence Livermore National Laboratory, UCRL-ID-121901.

Goishi, W., B. Esser, J. Meadows, N. Namboodiri, D. Smith, J. Wild, S. Bowen, P. Baca, L. Olivas, C. Geoffrion, J. Thompson and C. Miller, 1994. Total radionuclide inventory associated with underground nuclear tests conducted at the Nevada Test Site 1955-1992. Los Alamos National Laboratory, LA-CP-94-0222, 242 p.

Gonzalez, D.D., 1977. Hydraulic effects of underground nuclear explosions, Amchitka Island, Alaska. Ph.D. Dissertation, Colorado State University, Fort Collins, Colorado, 141p.

Gonzalez, D.D. and L.E. Wollitz, 1972. Hydrological effects of the Cannikin Event. Bulletin of the Seismological Society of America, 62(6):1527-1542.

Goode, D.J., 1990. Particle velocity interpolation in block-centered finite difference groundwater flow models. Water Resources Research, 26:925-940. 
Green, G.W., 1965. Some hydrological implications of temperature measurements in exploratory drillholes, Project Long Shot, Amchitka Island, Alaska. U.S. Geological Survey Technical Letter Geothermal-1, 8 p.

Hampton, C.M. and D.K. Bailey, 1984. Gas extraction experiments on volcanic glasses. Journal of Non-Crystalline Solids, 67:147-168.

Hess, K.M., S.H. Wolf and M.A. Celia, 1992. Large-scale natural gradient tracer test in sand and gravel, Cape Cod, Massachusetts, 3, Hydraulic conductivity variability and calculated macrodispersivities. Water Resources Research, 28(8):2011-2027.

Holmes and Narver, Inc., 1976. Amchitka Island Map Atlas. U.S. Atomic Energy Commission, Nevada Operations Office, Archive and Records Center, 41 sheets.

International Atomic Energy Agency (IAEA), 1998. The radiological situation at the Atolls of Mururoa and Fangataufa, Volume 4, Releases to the Biosphere of Radionuclides from Underground Nuclear Weapons Tests at the Atolls, IAEA, Austria, 270p.

IT Corporation, 1998. Report and analysis of the BULLION forced-gradient experiment. Prepared for DOE/NV. Report DOE/NV/13052-042. Variable paging. Las Vegas, NV.

Kersting, A.B., 1996. The state of the hydrologic source term. Lawrence Livermore National Laboratory, UCRL-ID-126557, 30 p.

Kinzelbach, W., 1988. The random walk method in pollutant transport simulation. In Groundwater Flow and Quality Modeling, edited by E. Custodio, A. Gurgui and J. P. Lobo Ferreira, 227-246, Norwell, Mass.

Kirkorian, O.H., 1981. Predictive calculations of volatilities of metals and oxides in steam-containing environments. Lawrence Livermore National Laboratory, UCRL-85553, 27 p.

Krefet, A. and A. Zuber, 1978. On the physical meaning of the dispersion equation and its solutions for different initial and boundary conditions. Chem. Eng. Sci., 33, 1471-1480.

LaBolle, E., J. Quastel, G. Fogg and J. Gravner, 2000. Diffusion processes in composite porous media and their integration by random walks: Generalized stochastic differential equations with discontinuous coefficients. Water Resources Research, 36:651-662.

LaBolle, E., G. Fogg and A.F.B. Tompson, 1996. Random-walk simulation of solute transport in heterogeneous porous media: Local mass-conservation problem and implementation methods, Water Resources Research, 32:583-593.

Lee, W.H. and L.M. Gard, Jr., 1971. Summary of the subsurface geology of the Cannikin Site, Amchitka Island, Alaska. U.S. Geological Survey, Report USGS-474-132, Amchitka 6-4, 24p.

Lee, W.H., 1969a. Some physical properties of rocks in drill hole UAe-2, Amchitka Island, Alaska. U.S. Geological Survey, Report USGS-474-5, 12p. 
Lee, W.H., 1969b. Some physical properties of rocks in drill hole UAe-1, Amchitka Island, Alaska. U.S. Geological Survey, Report USGS-474-48, 13p.

Lee, W.H., 1969c. Some physical properties of rocks in drill hole UAe-3, Amchitka Island, Alaska. U.S. Geological Survey, Report USGS-474-6, 11p.

Lee, W.H., 1969d. Some physical properties of rocks in drill hole UAe-6c, Amchitka Island, Alaska. U.S. Geological Survey, Report USGS-474-33, 13p.

Lee, W.H. and R.H. Morris, 1968. Preliminary lithologic log of drill hole UAe-1 from 5,000 to 7,000 feet, Amchitka Island, Alaska. U.S. Geological Survey, Report 474-47, 3p.

McKeown, F.A., D.D. Dickey and R.C. Bucknam, 1970. Ground displacement measurements, in U.S. Geological Survey, Geologic and Hydrologic Effects of the Milrow Event, Amchitka Island, Aleutian Islands, Alaska. U.S. Geological Survey, Report USGS-474-71 (Amchitka-20), pp.18-43.

McKeown, F.A., R.A. Young, W.P. Williams and G.E. Brethauer, 1967. Geologic Effects of the Long Shot Explosion, Amchitka Island, Alaska. U.S. Geologic Survey, Technical Letter, Long Shot-3, $73 \mathrm{p}$.

Merritt, M.L. and R.G. Fuller, editors, 1977. The environment of Amchitka Island, Alaska. Energy Research and Development Administration, Technical Information Center, 682p.

Merritt, M.L., 1977. Geographic setting, in Merritt, M.L. and R.G. Fuller, editors, 1977. The Environment of Amchitka Island Alaska. Energy Research and Development Administration, Technical Information Center, pp.1-11.

Merritt, M.L., 1973. Physical and biological effects, Cannikin. U.S. Atomic Energy Commission, Nevada Operations Office, Las Vegas, Nevada, report NVO-123, 106p.

Moreno, L., Y. Tsang, F. Hale, and I. Neretnieks, 1988. Flow and tracer transport in a single fracture: A stochastic model and its relation to some field observations. Water Resources Research, 24(12):2033-2048.

Morris, R.H. and L.M. Gard, 1970. Visible geologic effects, in U.S. Geological Survey, Geologic and Hydrologic Effects of the Milrow Event, Amchitka Island, Aleutian Islands, Alaska. U.S. Geological Survey, Report USGS-474-71, Amchitka-20, pp.3-17.

NAGRA (National Cooperative for the Disposal of Radioactive Waste), 1994. Kristallin-I Safety Assessment Report. National Cooperative for the Disposal of Radioactive Waste, Technical Report 93-22, 396p.

Nork, W.E. and P.R. Fenske, 1970. Radioactivity in Water - Project Rulison. U.S. Atomic Energy Commission, Nevada Operations Office, Report NVO-1229-131, 14p.

Nork, W.E., J.V.A. Sharp and C.L. Carnahan, 1965. Ground-water safety feasibility project Long Shot. Hazleton-Nuclear Science Corporation, Palo Alto, California, 49p. 
Ohl, J.P., 1973. Bibliography of published reports by U.S. Geological Survey personnel on the geology and hydrology of the Amchitka Supplemental Test Area, Aleutian Islands, Alaska, 1969-72. U.S. Geological Survey, Report USGS-474-164, 15p.

Peters, R.R., E.A. Klavetter, I.J. Hall, S.C. Blair, P.R. Heller and G.W. Gee, 1984. Fracture and matrix hydrologic characteristics of tuffaceous materials from Yucca Mountain, Nye County, Nevada. Sandia National Laboratories Report SAND84-1471.

Pohll, G., A. E. Hassan, J. Chapman, C. Papelis and R. Andricevic, 1999. Modeling groundwater flow and radioactive transport in a fractured aquifer. Groundwater, 37(5):770-784.

Pohll, G., J. Chapman, A. Hassan, C. Papelis, R. Andricevic and C. Shirley, 1998. Evaluation of groundwater flow and transport at the Shoal underground nuclear test: An interim report. Desert Research Institute, Water Resources Center, Publication \#45162, DOE/NV/11508-35, 123 p.

Pohlmann, K., J. Chapman, A. Hassan and C. Papelis, 1999. Evaluation of groundwater flow and transport at the Faultless underground nuclear test, Central Nevada Test Area. Desert Research Institute, Water Resources Center, Publication \#45165, DOE/NV/11508-41.

Pollock, D.W., 1988. Semianalytical computation of path lines for finite difference models. Groundwater, 26:743-750.

Rabb, D.D., 1970. Particle-Size Distribution Study: Piledriver Event. Proc. Symp. Engineering with Nuclear Explosives, CONF-700101, Vol. 2, pp. 888-908.

Rehfeldt, K., O. Crici, J. Renier and J. Marie, 1996. Hydrologic parameter data documentation package, underground test area subproject, Phase I Data analysis Task, Vol. IV. IT Corp., prepared for U.S. Department of Energy, Environmental Restoration Program, 21 p.

Sass, J.H. and T.H. Moses, Jr., 1969. Subsurface temperatures from Amchitka Island, Alaska. U.S. Geological Survey, Technical Letter, USGS-474-20 (Amchitka-16), 5 p.

Schafer-Perini, A.L. and J.L. Wilson, 1991. Efficient and accurate front tracking for two-dimensional groundwater flow models. Water Resources Research, 27:1471-1485.

Schwartz, L., A. Piwinskii, F. Ryerson, H. Tewes and W. Beiriger, 1984. Glass produced by underground nuclear explosions. Journal of Non-Crystalline Solids, 67:559-591.

Shapiro, A.M. and V. Cvetkovic, 1988. Stochastic analysis of solute arrival time in heterogeneous porous media. Water Resources Research, 24:1711-1718.

Smith, D.K. and W.L. Bourcier, 1999. The Production and Dissolution of Nuclear Explosive Melt Glasses at Underground Test Sites in the Pacific Region. International Atomic Energy Agency, Proceedings of Symposium on Marine Pollution, held in Monaco, 5-9 October 1998, IAEA-TECDOC-1094, IAEA-SM-354/81, pp.169-174.

Smith, D.K., B.K. Esser and J.L. Thompson, 1995. Uncertainties Associated with the Definition of a Hydrologic Source Term for the Nevada Test Site. Lawrence Livermore National Laboratory, UCRL-ID-120322, 21 p. 
Smith, D.K., 1995. Characterization of nuclear explosive melt debris. Radiochimica Acta, 69:157-167.

Smith, D.K., 1997. Radionuclides recommended by the UGTA Source and Transport Subcommittee of significance for remedial investigations at the Nevada Test Site. Memorandum from Lawrence Livermore National Laboratory to Janet Wille, IT Corporation, copied to Robert Bangerter, DOE, dated April 2, 1997.

Smith, D.K., A.B. Kersting, J.M. Kenneally, J.H. Rego and J.L. Thompson, 1997. Hydrologic resources management program FY 1996 Progress Report. Lawrence Livermore National Laboratory, UCRL-ID-126886, 40 p.

Snow, D.T., 1968. Rock fracture spacings, openings and porosities. Journal Soil Mech. Found. Div., Proc. Amer. Soc. Civil Engineers, 94, pp.73-91.

Snyder, R.P., 1969a. Preliminary lithologic log of UAe-2, from 0 to 3,580 feet, Amchitka Island, Alaska. U.S. Geological Survey, Report USGS-474-52, 2p.

Snyder, R.P., 1969b. Preliminary lithologic log of drill hole UAe-2, from 3,580 feet to 6,500 feet (TD). U.S. Geological Survey, Report USGS-474-53, 2p.

Stallman, R.W., 1965. Steady one-dimensional fluid flow in a semi-infinite porous medium with sinusoidal surface temperature. Journal of Geophysical Research, 70(12):2821-2827.

Stenhouse, M.J. and J. Pottinger, 1994. Comparison of sorption databases used in recent performance assessments involving crystalline host rock. Radiochemical Acta, 66/67:267-275.

Tompson, A. F. B. and L. W. Gelhar, 1990. Numerical simulation of solute transport in three-dimensional, randomly heterogeneous porous media. Water Resources Research, 26(10):2541-2562.

Tompson, A.F.B., C.J. Bruton and G.A. Pawloski (editors), 1999. Evaluation of the Hydrologic Source Term From Underground Nuclear Tests in Frenchman Flat at the Nevada Test Site: The Cambric Test. Lawrence Livermore National Laboratory report UCRL-ID-132300, 319p.

Triay, I.R., A. Meijer, J.L. Conca, K.S. Kung, R.S. Rundberg, B.A. Strietelmeier, C.D. Tait, D.L. Clark, M.P. Neu and D.E. Hobart, 1997. Summary and Synthesis Report on Radionuclide Retardation for the Yucca Mountain Site Characterization Project. Los Alamos National Laboratory, Report LA-13262-MS, 274 p.

Triay, I.R., K.H. Birdsell, A.J. Mitchell and M.A. Ott, 1993. Diffusion of sorbing and non-sorbing radionuclides. In Proceedings of the Fourth Annual International High Level Radioactive Waste Management Conference, Las Vegas, NV, April 26-30, Vol. 2. American Nuclear Society, pp.1527-1532.

U.S. Army Corps of Engineers and U.S. Geological Survey, 1965. Project Long Shot Amchitka Island, Alaska, Geologic and Hydrologic Investigations (Phase I). Unnumbered report. 
U.S. Atomic Energy Commission, 1967. Site-selection Report, Supplemental Test Site Program, Amchitka Island. Prepared by Holmes and Narver for U.S. AEC (no document number), 14p.

U.S. Department of Energy, 1982. Long-Term Hydrologic Monitoring Program, Amchitka Island, Alaska. Nevada Operations Office report NVO-242, 26p.

U.S. Department of Energy. 2000. United States Nuclear Tests July 1945 Through December 1992. DOE/NV-209 (Rev. 15), 162p.

U.S. Geological Survey, 1970. Geologic and hydrologic effects of the Milrow Event, Amchitka Island, Aleutian Islands, Alaska. U.S. Geological Survey, Report USGS-474-71 (Amchitka-20), $76 \mathrm{p}$.

U.S. Geological Survey, 1972. Geologic and hydrologic effects of the Cannikin underground nuclear explosion, Amchitka Island, Aleutian Islands, Alaska. U.S. Geological Survey, Report USGS-474-148 (Amchitka-33), 87p.

Voss, C. I., 1984. SUTRA - Saturated-unsaturated transport: A Finite-element simulation model for saturated-unsaturated, fluid-density-dependent groundwater flow with energy or chemically reactive single-species solute transport. U.S. Geological Survey, Water-Resources Investigations Report WRIP 84-4369 (revised 1990, 1997), 409p.

von Huene, R., W.J. Carr, D. McManus and M. Holmes, 1971. Marine geophysical study around Amchitka Island, Western Aleutian Islands, Alaska. U.S. Geological Survey, Report USGS-474-74 (Amchitka-22), 31p.

Walter, G.R., 1982. Theoretical and experimental determination of matrix diffusion and related solute transport properties of fractured tuffs from the Nevada Test Site. Los Alamos National Laboratory, Report LA-9471-MS.

Wheatcraft, S. W., 1995. Seawater intrusion model of Amchitka Island, Alaska. Desert Research Institute, Water Resources Center, Publication \#45127, DOE/NV/10845-59.

White, A.F., 1983. Surface chemistry and dissolution kinetics of glassy rocks at $25^{\circ} \mathrm{C}$. Geochim. et Cosmochim. Acta, 47:805-815. 


\section{APPENDIX A: HYDRAULIC ANALYSES}

Hydraulic tests were conducted on Amchitka Island by the United States Geological Survey (USGS) in the late 1960s and early 1970s to determine suitable zones for conducting nuclear tests and to characterize the hydrology of Amchitka Island. Most of the hydraulic tests were performed by either injecting (slug type) or swabbing (bail type) a known volume of water from the borehole followed by monitoring recovery of the fluid. Most of these tests were conducted in uncased boreholes using straddle packers to isolate specific zones. The length of the zones tested ranged from 18.3 to $485 \mathrm{~m}$, with an average length of $85 \mathrm{~m}$. Because of the high cost of rig time, these tests were only conducted for short periods of time, which often did not allow water to return to static conditions.

The USGS performed hydraulic tests in UAe-6H, UA-1, UA-1-HTH-1, UAe-7h, UAe-1, UAe-3, and UAe-2. The plots and analysis of these tests are reported in a series of publications released by the USGS (Ballance, 1970a, 1970b, 1972a, 1972b, 1972c, 1973b). The analysis of these data by the USGS produced results reported in relative specific capacities (RSC) as opposed to hydraulic conductivity or transmissivity (See Figure A1).

Because the groundwater modeling efforts on Amchitka Island required a description of the hydraulic conductivity with depth, the data presented in the USGS reports were reanalyzed using the method of Cooper et al. (1967). The analysis is conducted by plotting $\mathrm{H} / \mathrm{H}_{\mathrm{o}}$ vs. time, where $\mathrm{H}$ is the head change in the well at time ( $\mathrm{t}$ ), and $\mathrm{H}_{\mathrm{o}}$ is the instantaneous head change in the well. To facilitate comparison of the measured data to the type curves provided by Cooper et al. (1967), head ratio is plotted on an arithmetic scale, while time is plotted on a logarithmic scale. The type curves are then laid over the data plots keeping the y axis coincident (i.e., the value of $\mathrm{H} / \mathrm{H}_{\mathrm{O}}=1$ on both plots. The data are then matched to the type curve with a similar curvature by sliding the type curves along the $\mathrm{x}$-axis. Once curve matching is complete, the transmissivity $(\mathrm{T})$ can be calculated as

$$
T=\frac{r_{c}^{2}}{t_{1}}
$$

where $\mathrm{t}_{1}$ is the time on the data plot where $\frac{T t}{r_{c}^{2}}=1.0 ; \mathrm{r}_{\mathrm{c}}=$ radius of well casing; and $\mathrm{t}=$ time. The hydraulic conductivity is then determined by dividing the transmissivity by the length of the interval tested.

The following is an example of the calculation using the data presented in Figure A2. The diameter of the wells drilled on Amchitka Island were $0.062 \mathrm{~m}$. Overlaying the type curves, Figure A3 on the data plot (Figure A2), $t_{1}$ was determined to be 11 minutes. Putting these values in Equation (1) the transmissivity is $0.1258 \mathrm{~m}^{2} /$ day. Dividing by the length of the interval tested, $106 \mathrm{~m}$, the hydraulic conductivity is $0.0012 \mathrm{~m} /$ day. Figure 4 shows the data plots used to determine hydraulic conductivity for the various tested intervals from the hydrologic test holes on Amchitka Island. Figure 5 through Figure 11 shows the lithologic logs and all of the intervals tested by the USGS on Amchitka Island.

While reviewing the work the USGS performed, several issues became apparent. In some of the hydraulic tests, leaks occurred around the inflatable packers making those tests invalid. 
Swabbing test tended to give higher values for hydraulic conductivity, as it was suspected that injection of fluid tended to introduce fine material into the formation thus reducing the equilibration time and apparent hydraulic conductivity. Also tests were conducted for short time periods precluding full hydraulic equilibration.

\section{REFERENCES}

Ballance, W.C., 1970a. Hydraulic testing of hole UAe-7h, Amchitka Island, Alaska. U.S. Geological Survey report USGS-474-84, 31p.

Ballance, W.C., 1970b. Hydraulic tests in hole UA-1 and water inflow into an underground chamber, Amchitka Island, Alaska. U.S. Geological Survey report USGS-474-72, 54p.

Ballance, W.C., 1972a. Hydraulic tests in drill hole UAe-1, Amchitka Island, Alaska. U.S. Geological Survey report USGS-474-102, 32p.

Ballance, W.C., 1972b. Hydraulic tests in hole UAe-6h, Amchitka Island, Alaska. U.S. Geological Survey report USGS-474-104, 27p.

Ballance, W.C., 1972c. Hydraulic testing of hole UA-1-HTH-1, Amchitka Island, Alaska. U.S. Geological Survey report USGS-474-144, 27p.

Ballance, W.C., 1973a. Hydraulic tests in hole UAe-2, Amchitka Island, Alaska. U.S. Geological Survey report USGS-474-103.

Ballance, W.C., 1973b. Hydraulic tests in hole UAe-3, Amchitka Island, Alaska. U.S. Geological Survey report USGS-474-26, Rev. 1, 30p.

Cooper, H.J., J.D. Bredehoeft and I.S. Papadopulos, 1967. Response of a finite-diameter well to an instantaneous charge of water. Water Resources Research, 3(1):263-269.

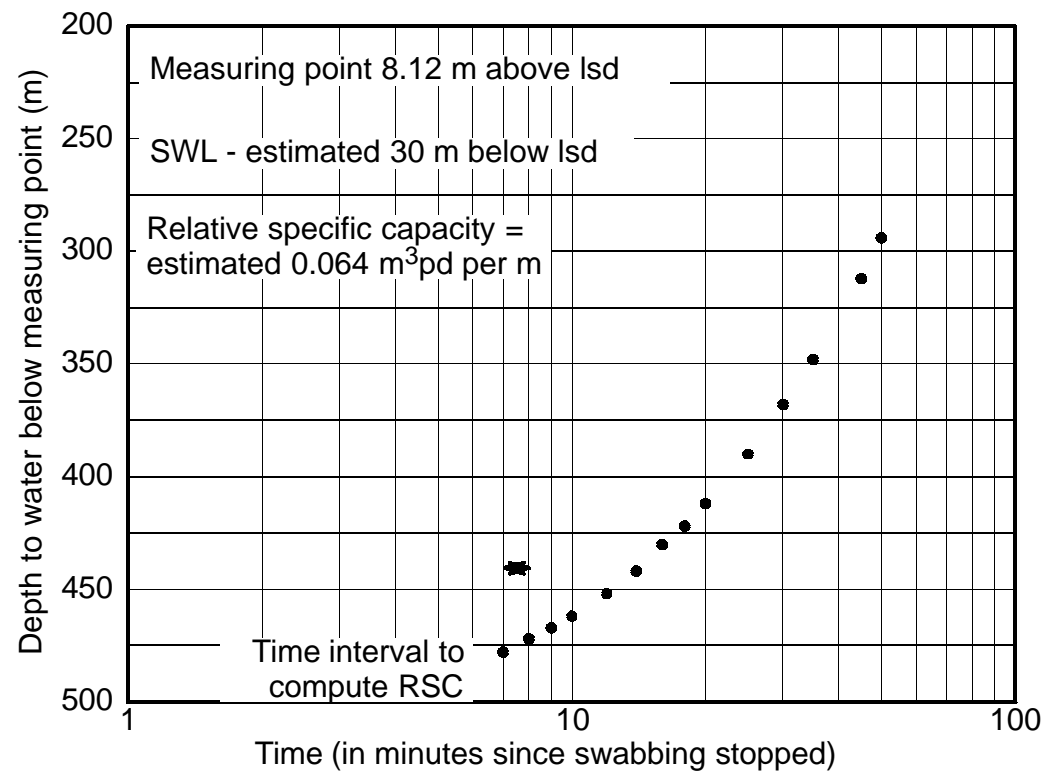

Figure A1. Swabbing recovery test from borehole UAe-2. Straddle packers were set to isolate the zone between $1,294.4$ to $1,352.7 \mathrm{~m}$. 


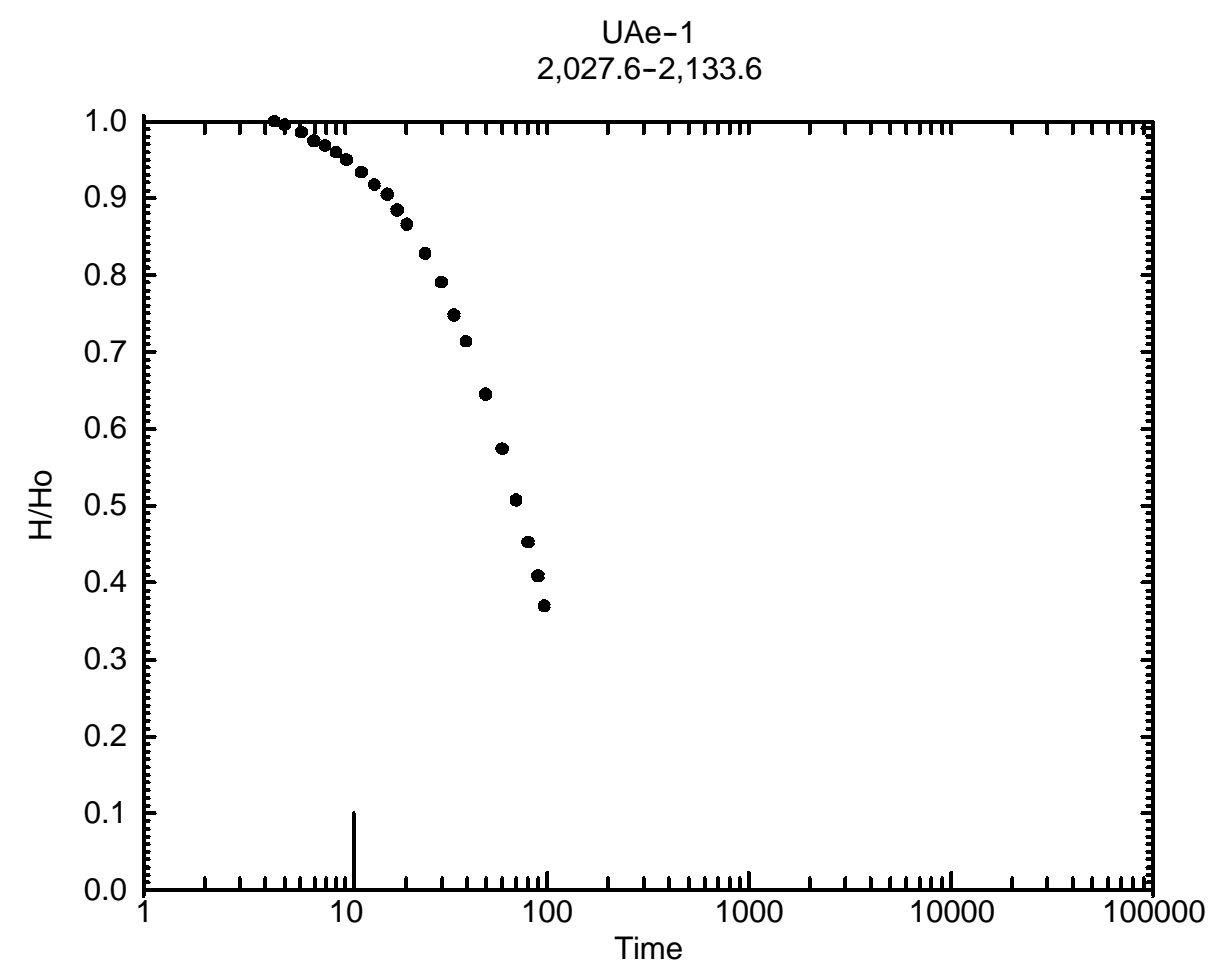

Figure A2. Plot of the ratio of measured head $(\mathrm{H})$ to the head after injection or swabbing $\left(\mathrm{H}_{0}\right)$ with respect to time after injection or swabbing in minutes.

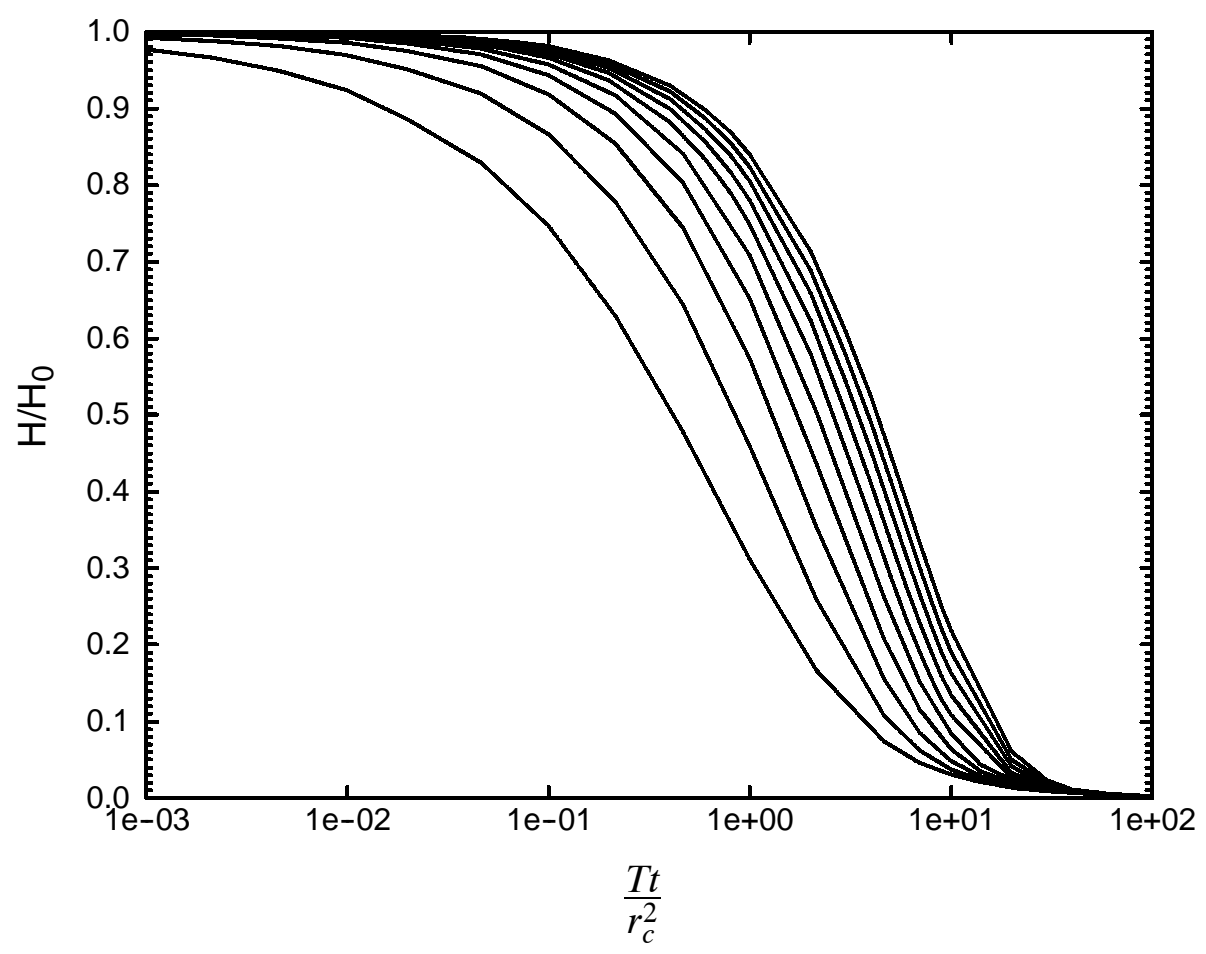

Figure A3. Type curves used in the analysis of data from Amichitka Island. $\mathrm{H}$ is the measured head above or below the static head, $\mathrm{H}_{0}$ is the measured head above or below the static head immedaitely after injection or withdrawal, $T$ is the transmissivity, $t$ is the time in minutes and $r_{c}$ is the radius of the well. 

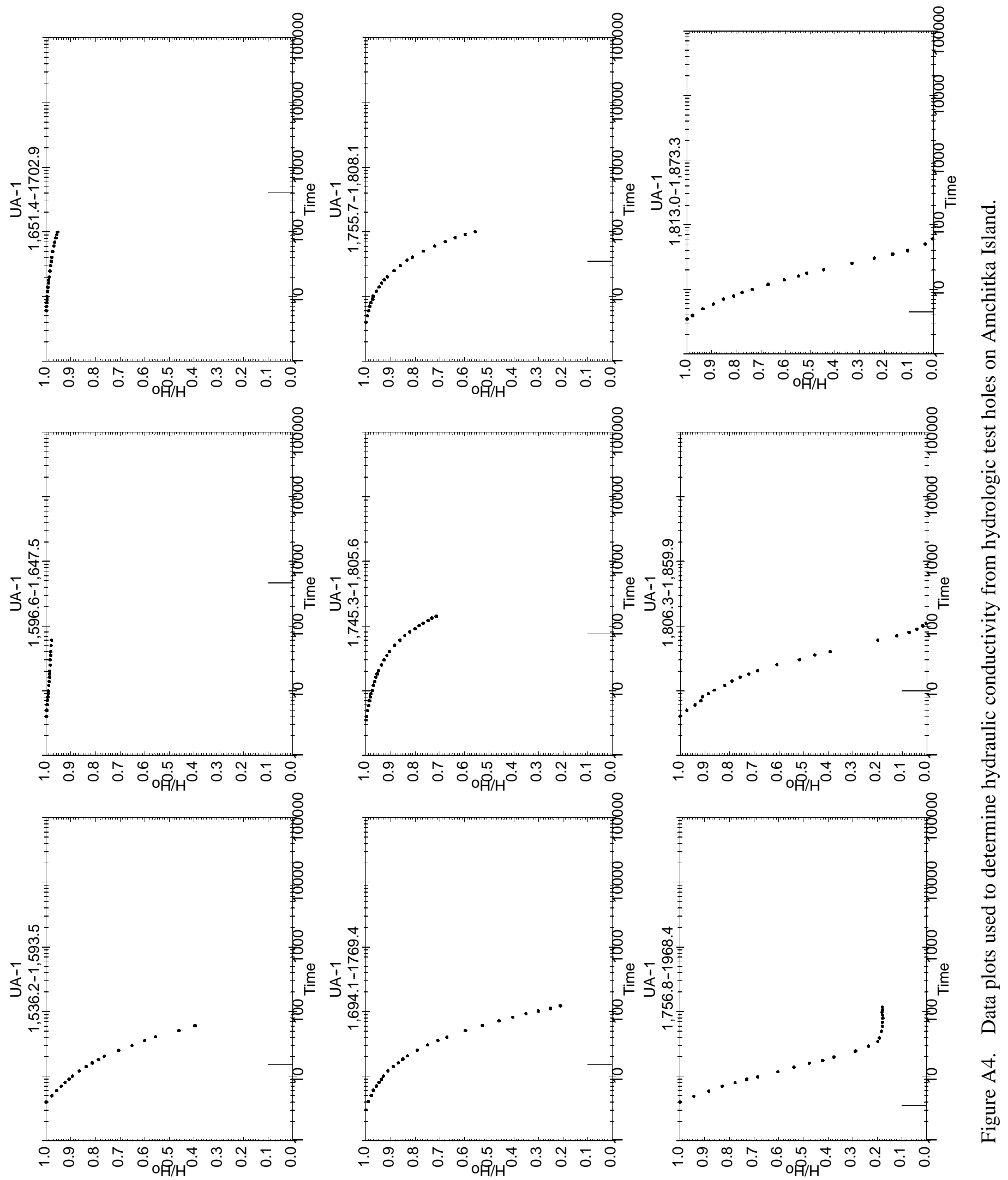

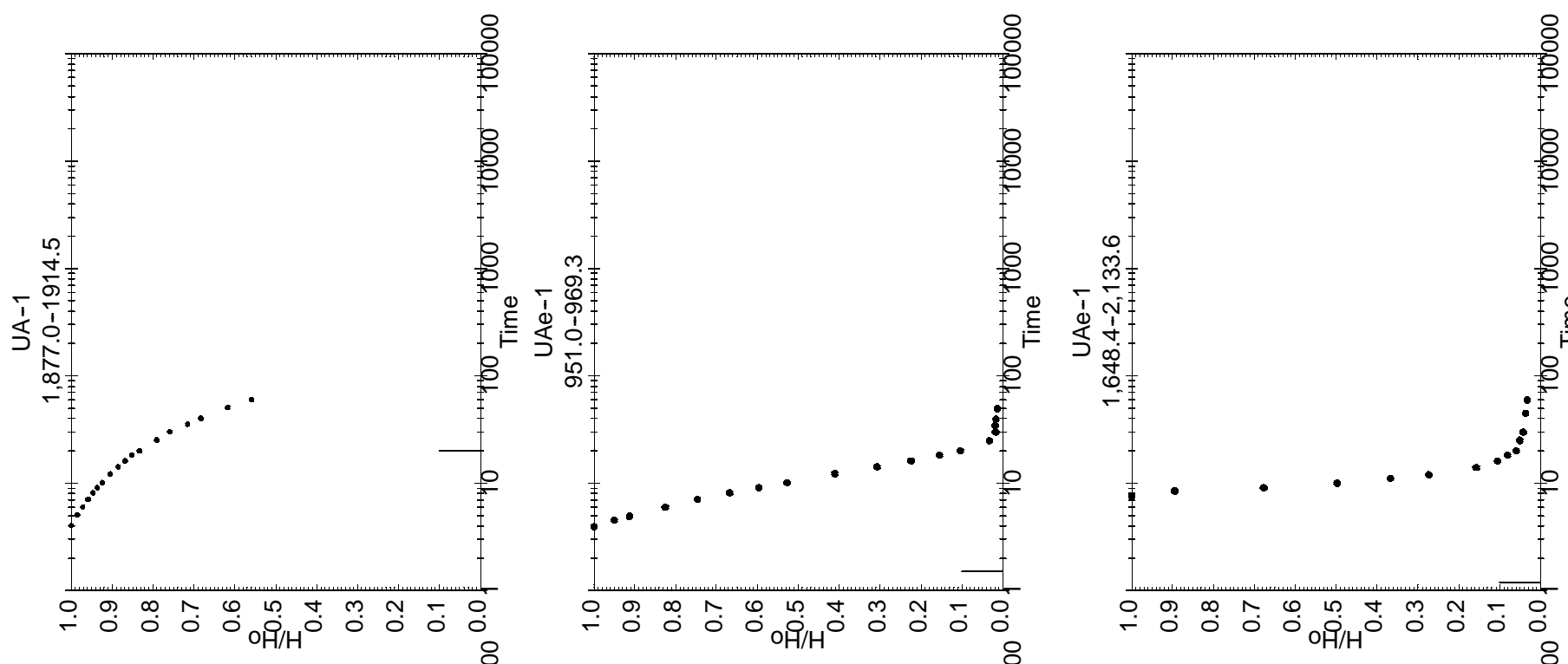

苍

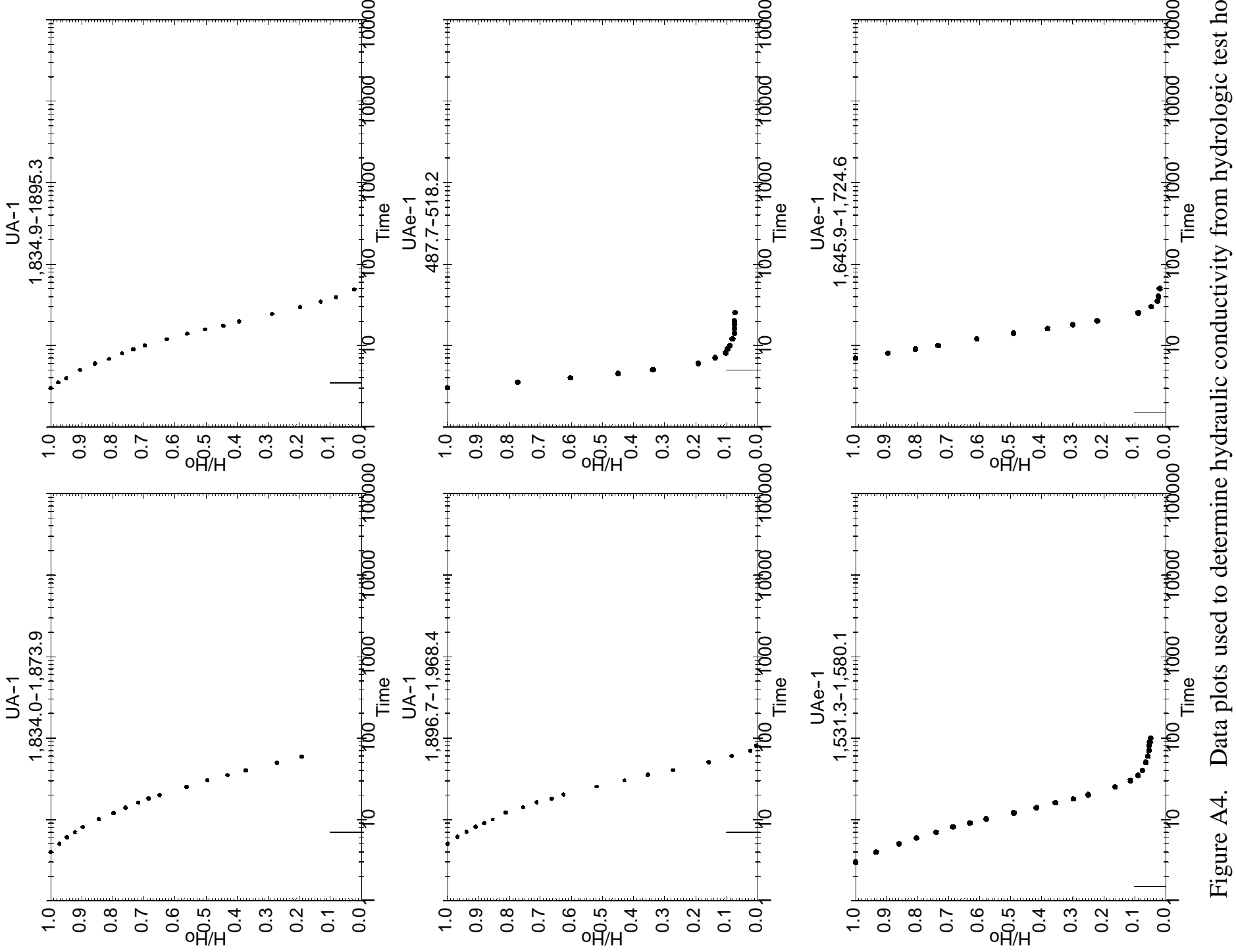



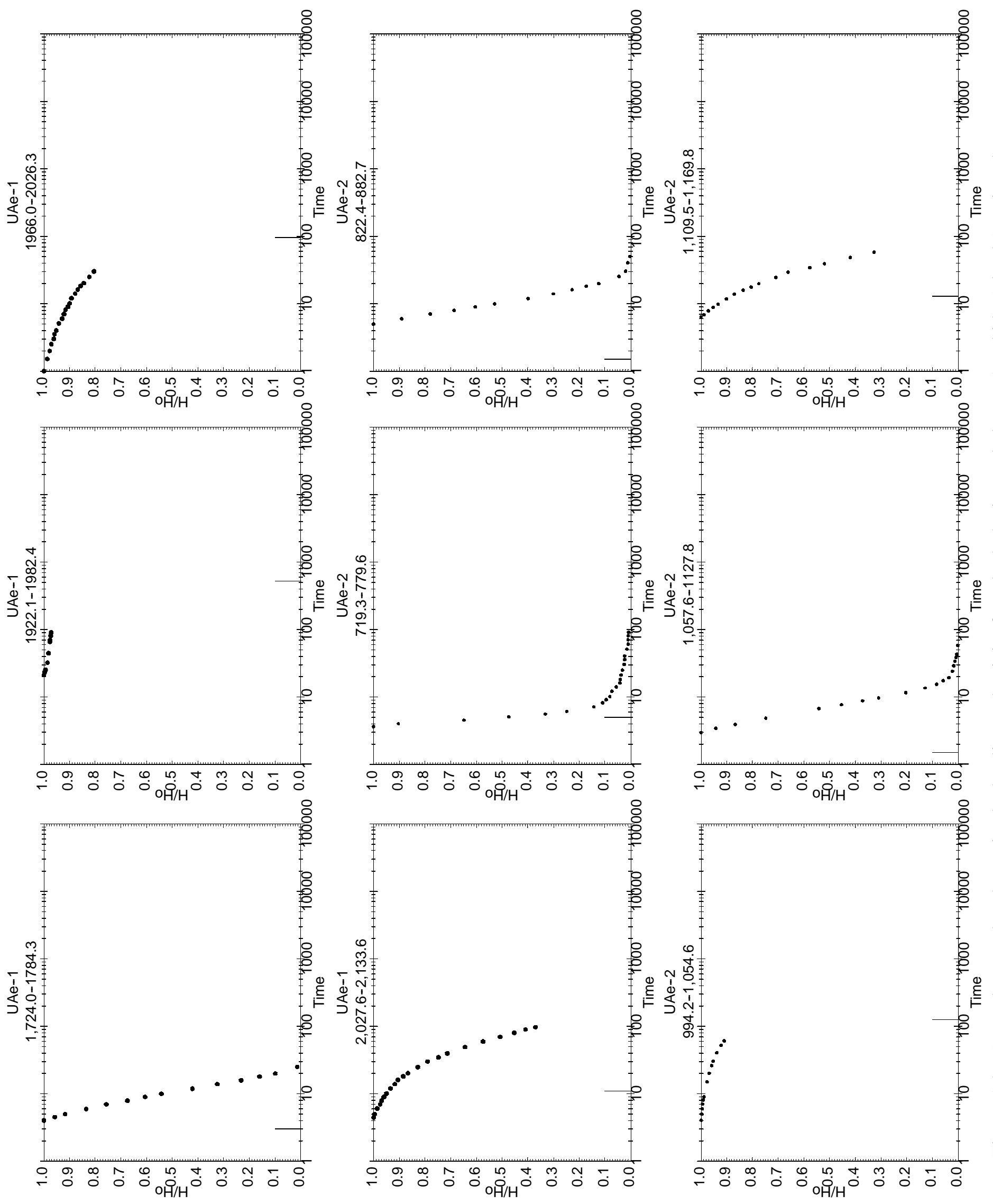

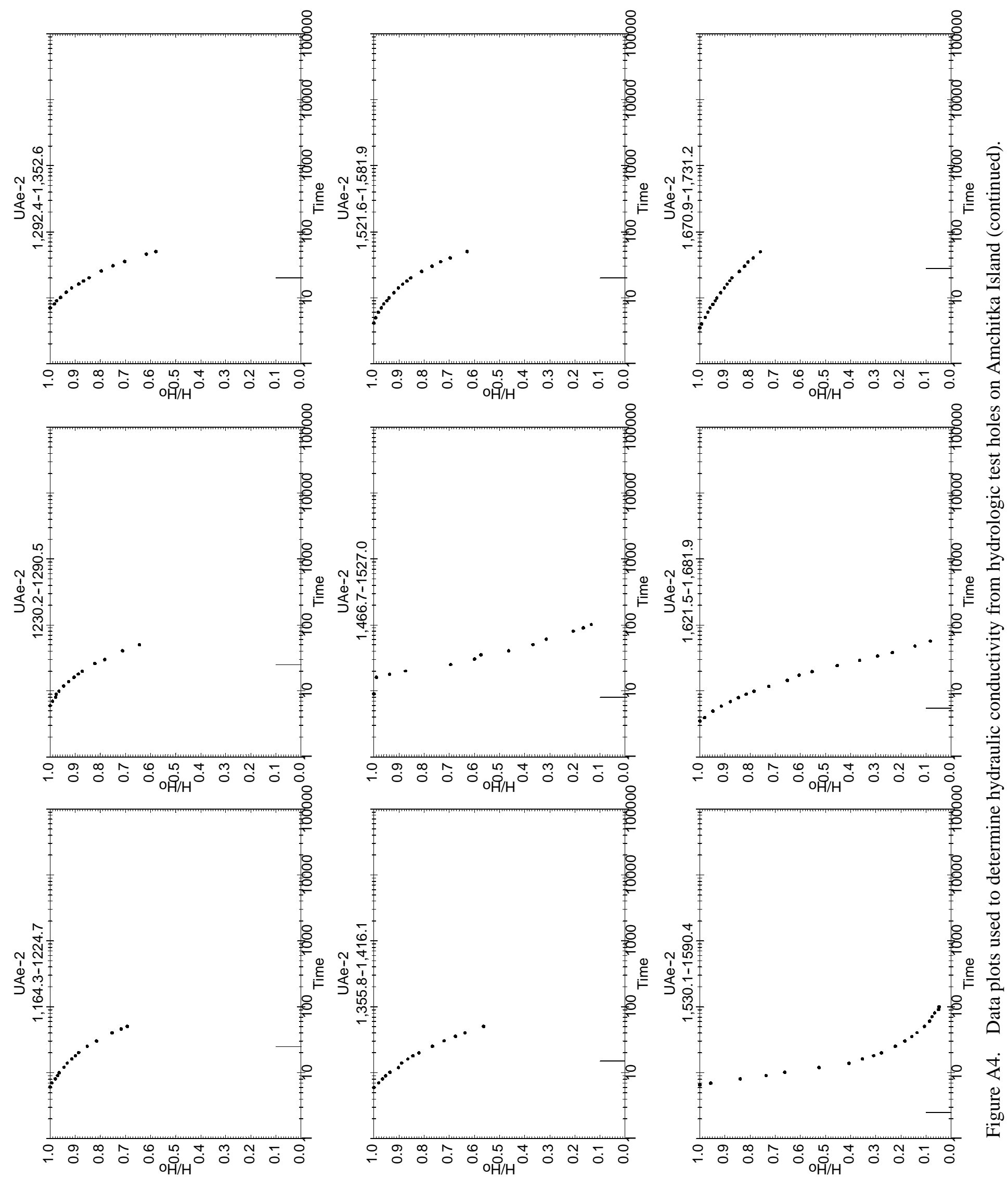


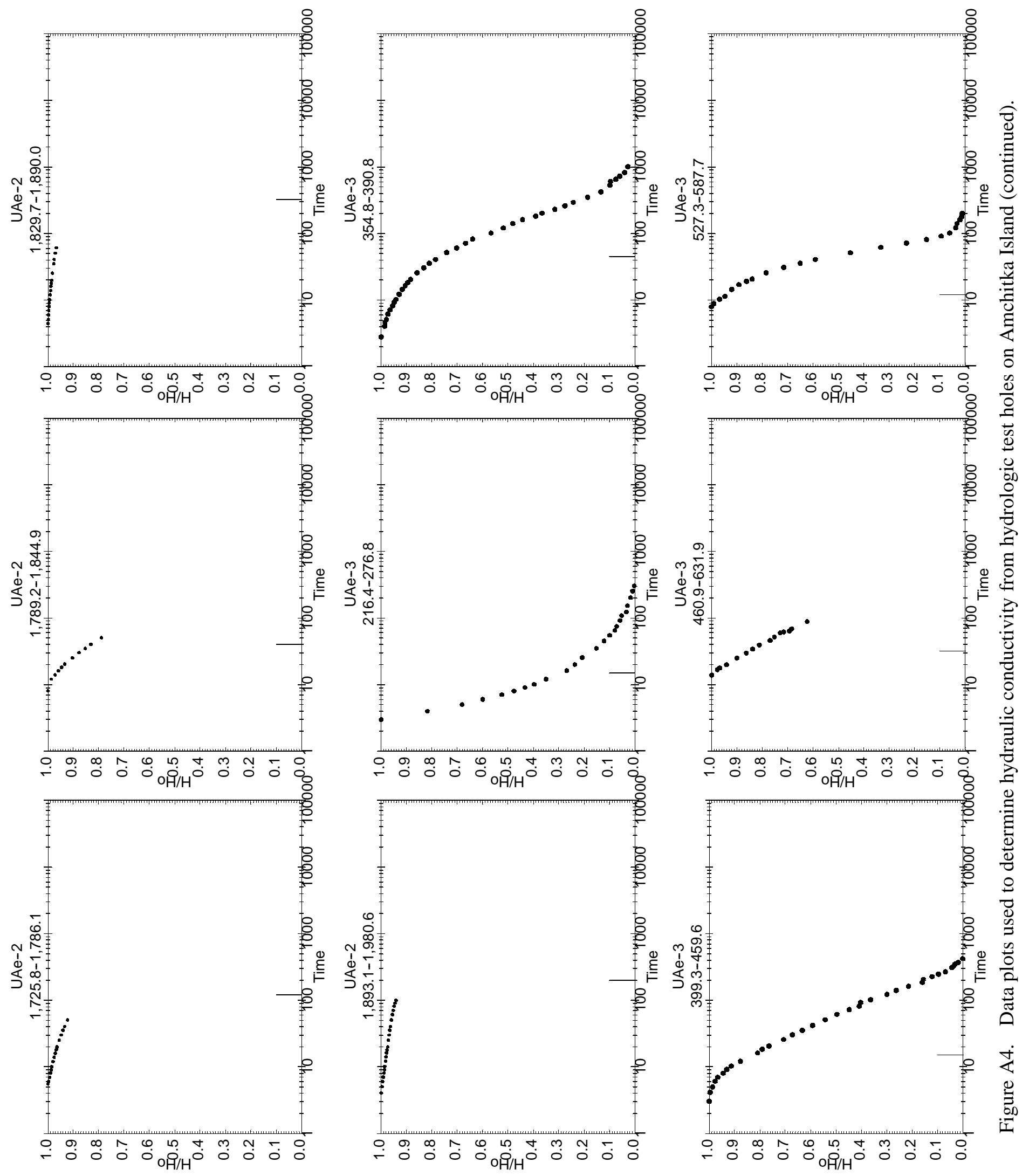




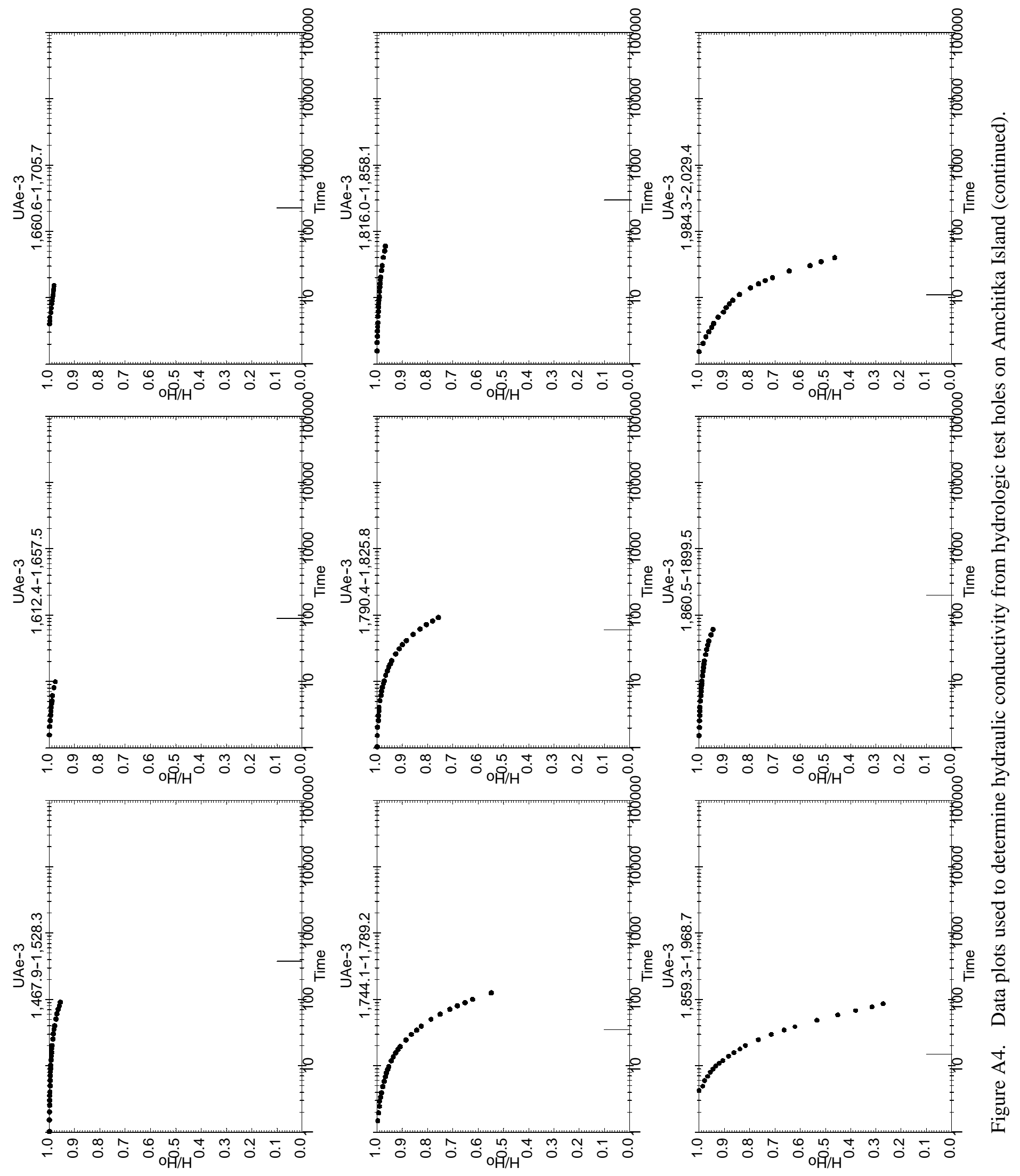



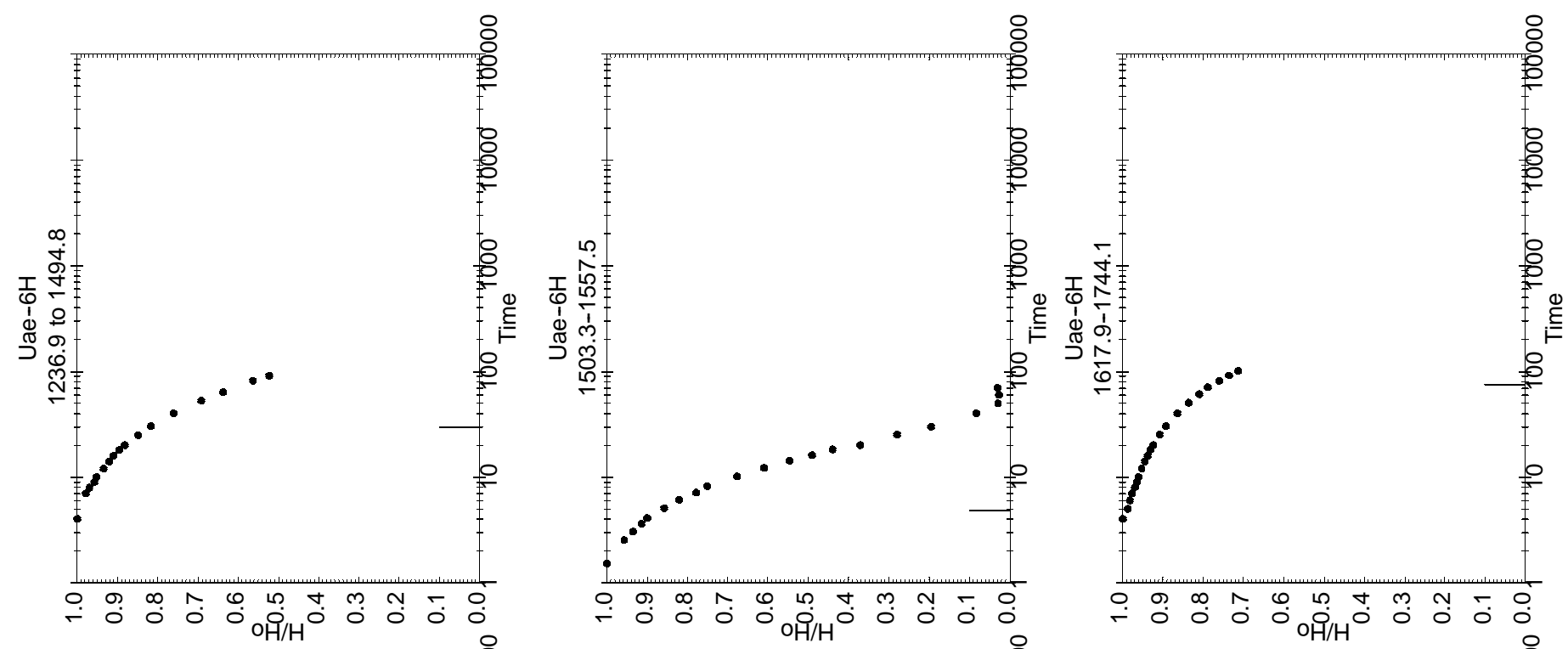

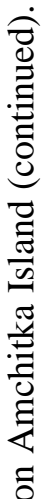
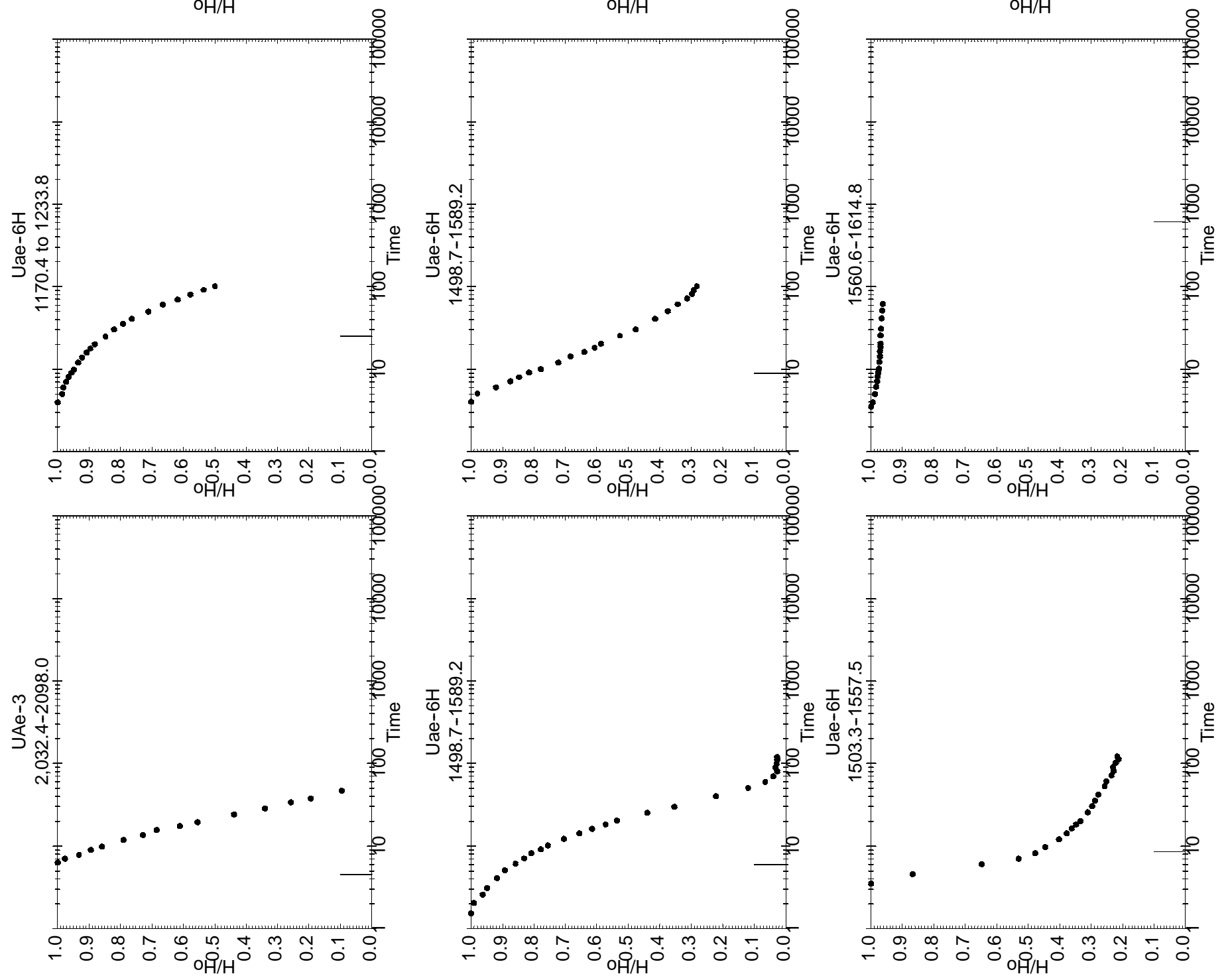

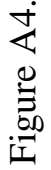



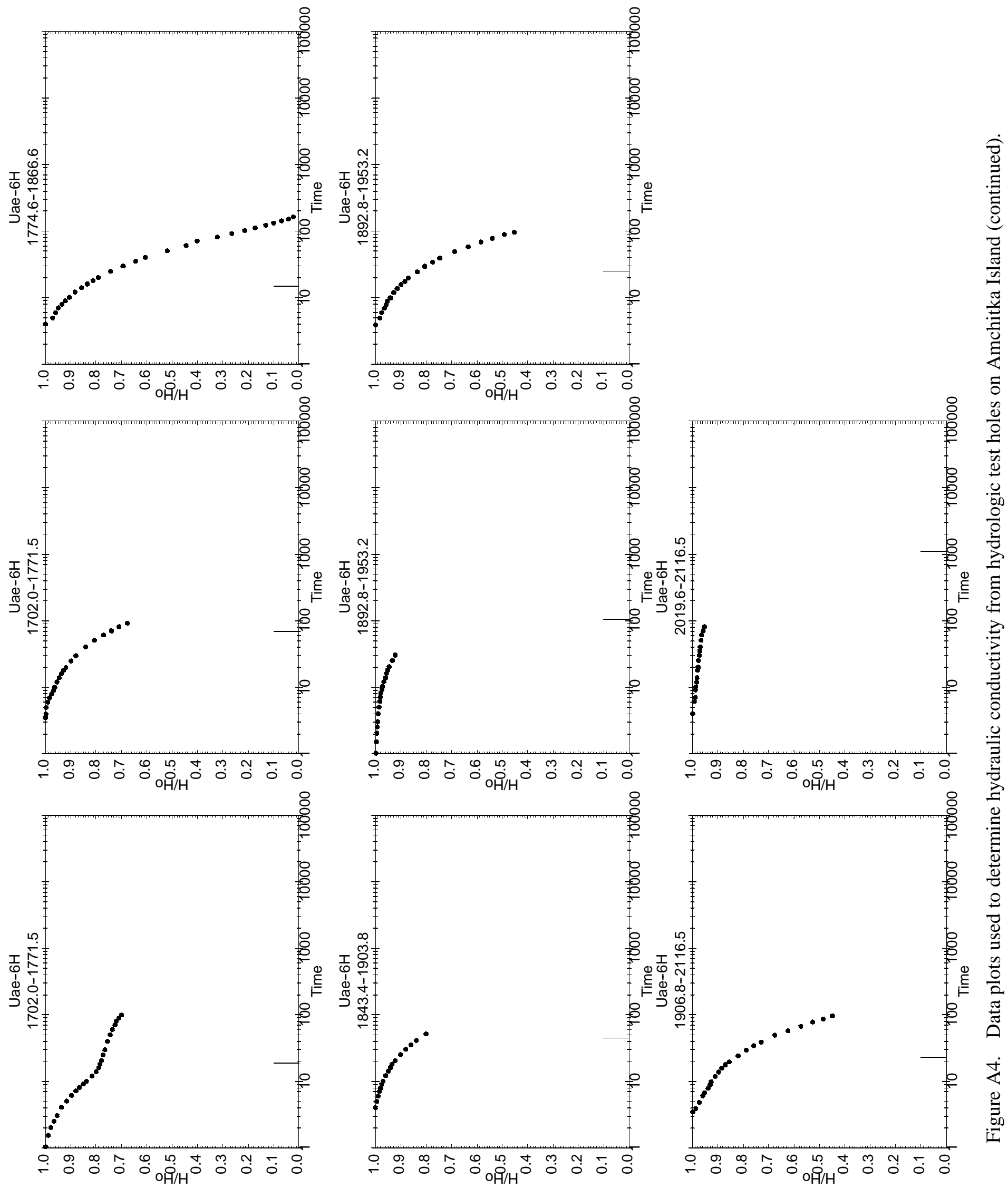


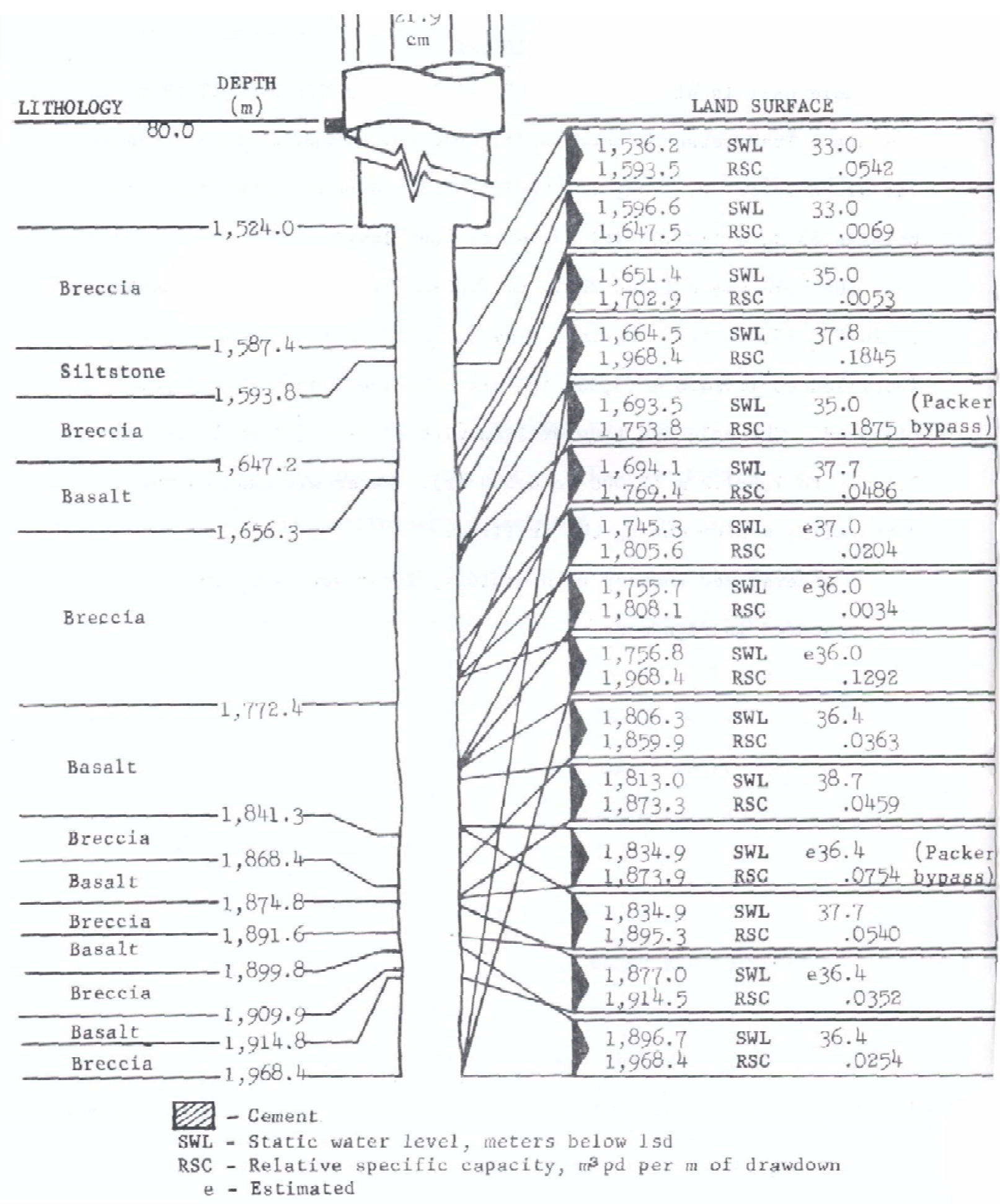

Figure A5. Construction diagram, lithologic log and summary of hydroloic tests, hole UA-1 (after Balance, 1970b). 


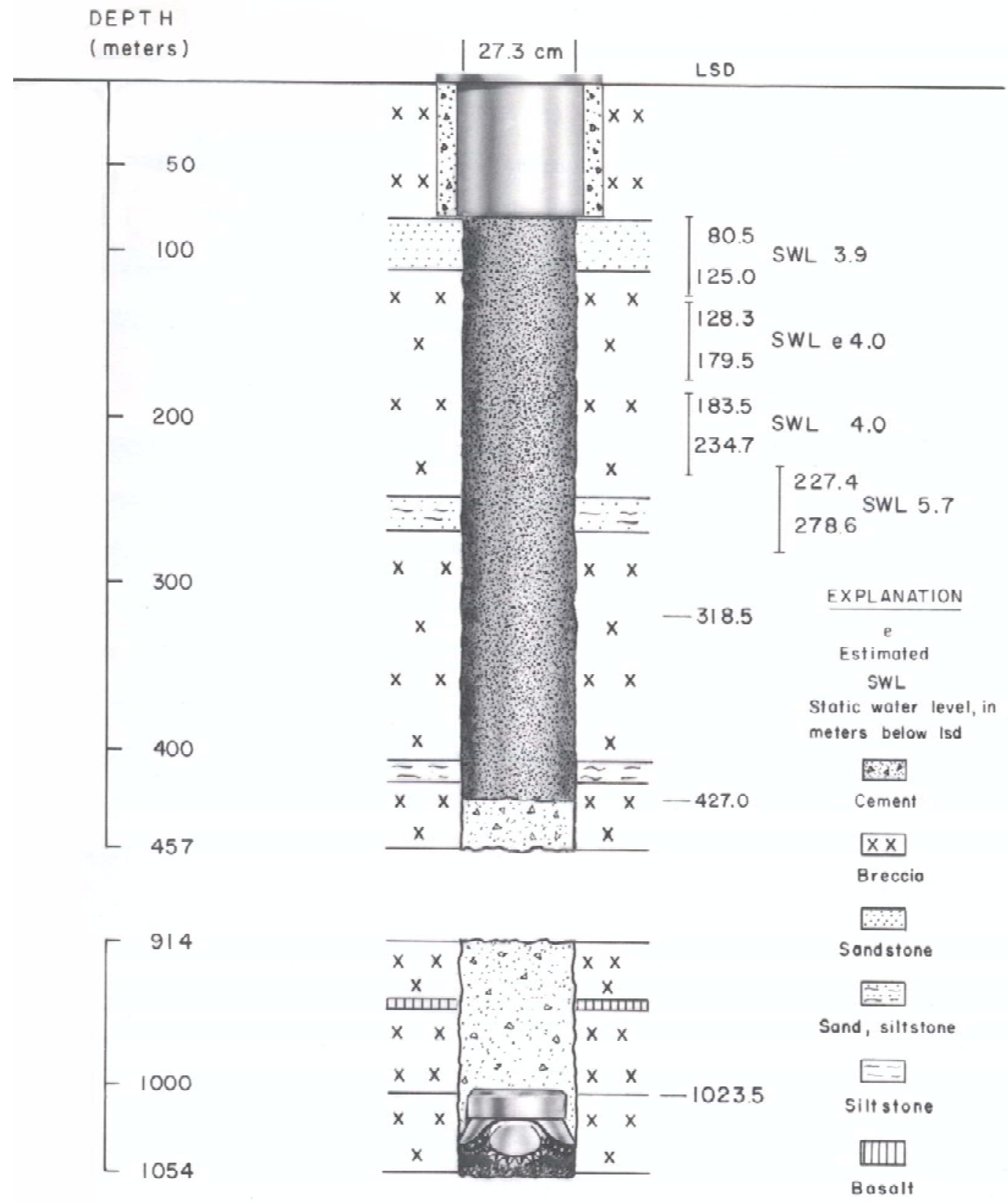

Figure A6. Construction diagram, lithologic log and summary of hydroloic tests, hole UA-1-HTH-1 (after Balance, 1972c). 


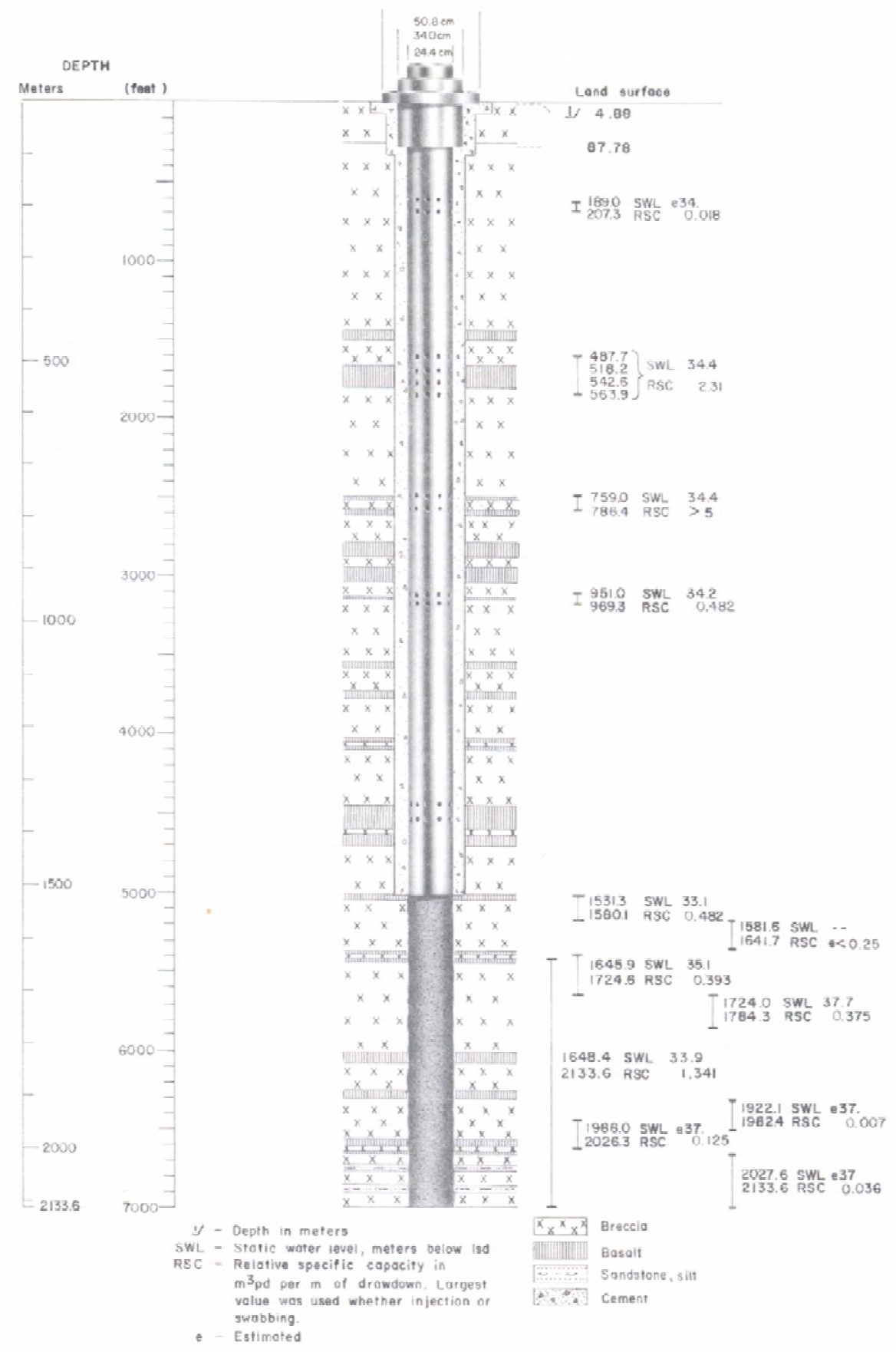

Figure A7. Construction diagram, lithologic log and summary of hydroloic tests, hole UAe-1 (after Balance, 1972a). 


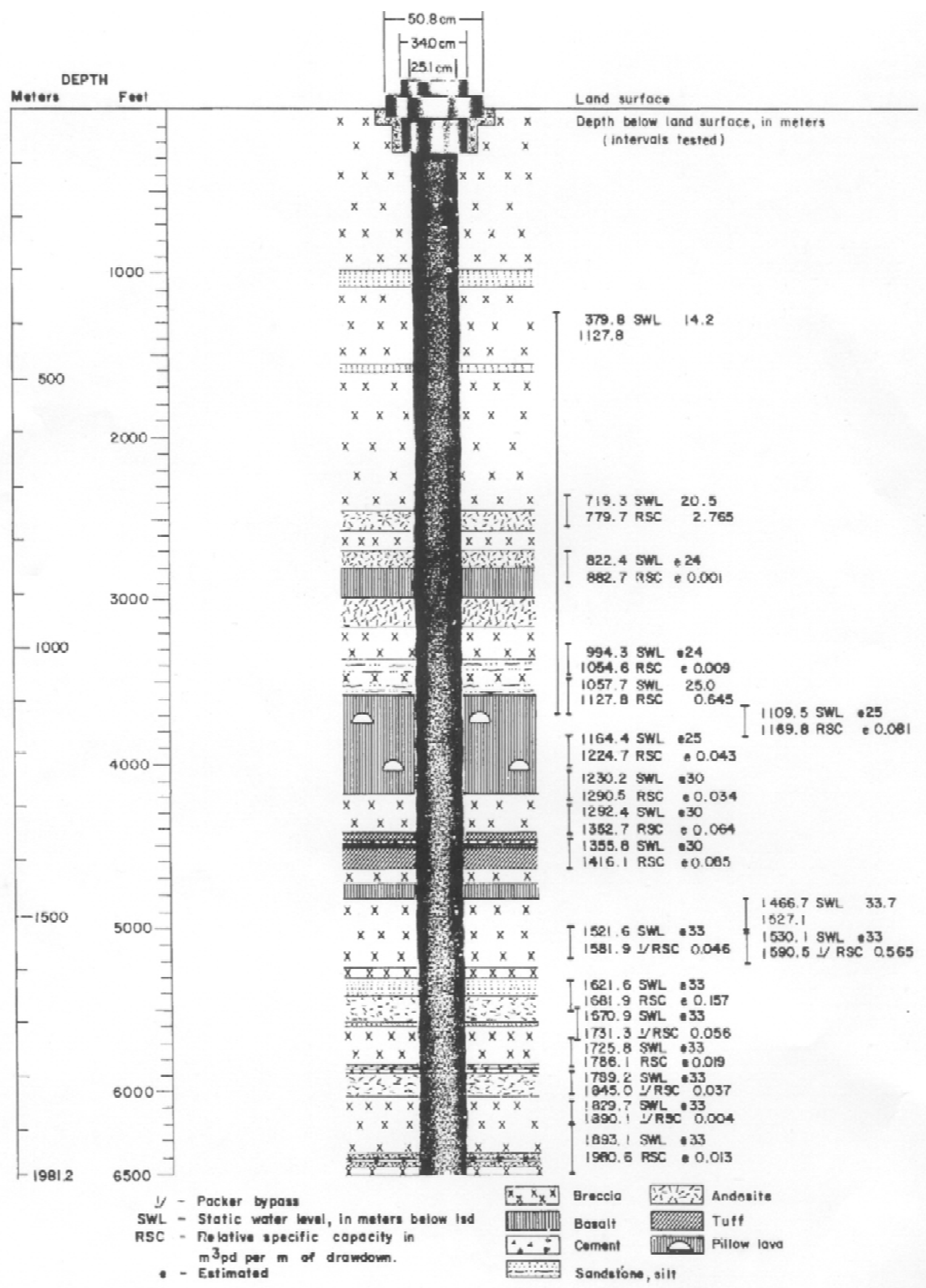

Figure A8. Construction diagram, lithologic log and summary of hydroloic tests, hole UAe-2 (after Balance, 1973a). 


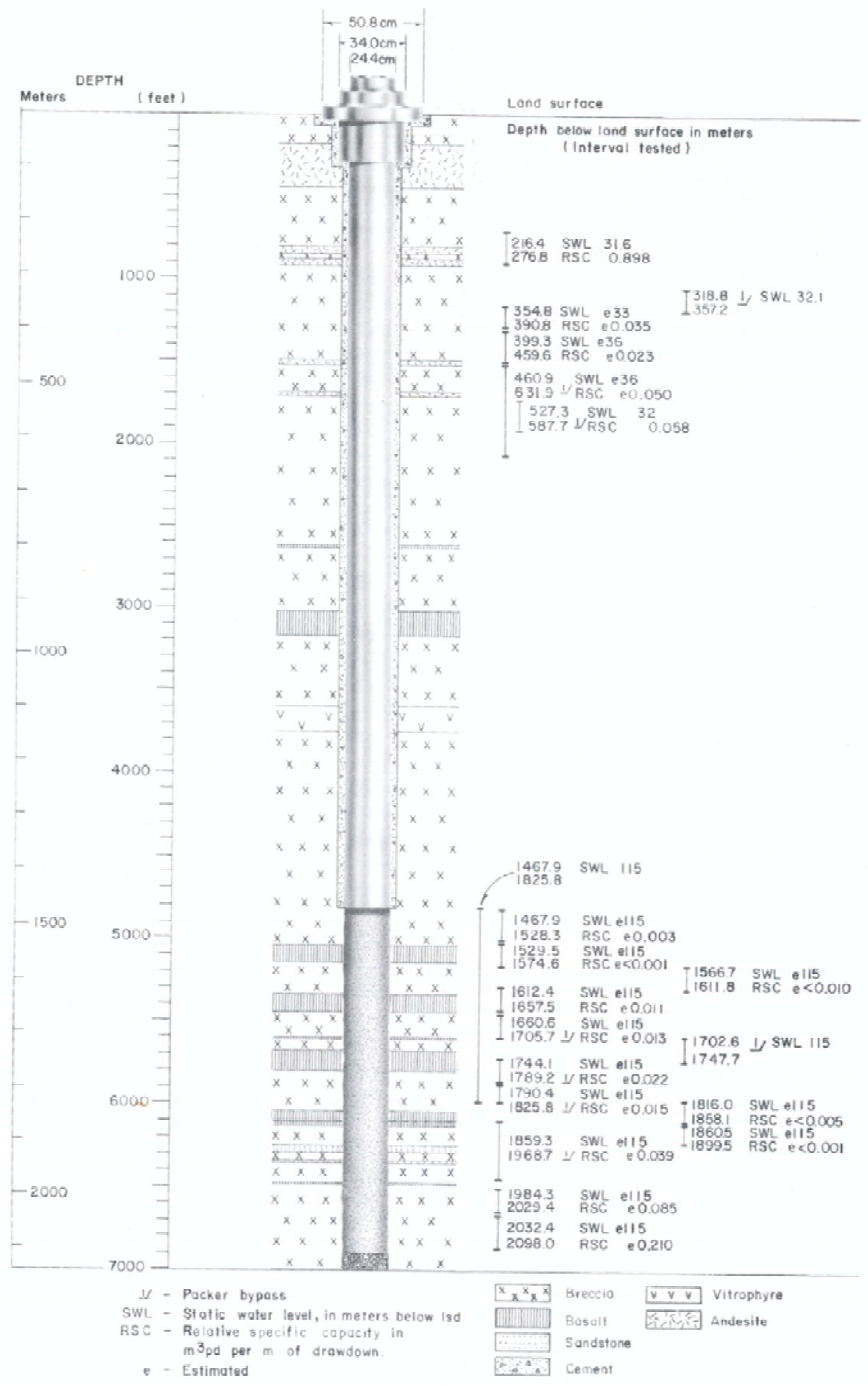

Figure A9. Construction diagram, lithologic log and summary of hydroloic tests, hole UAe-3 (after Balance, 1973b). 


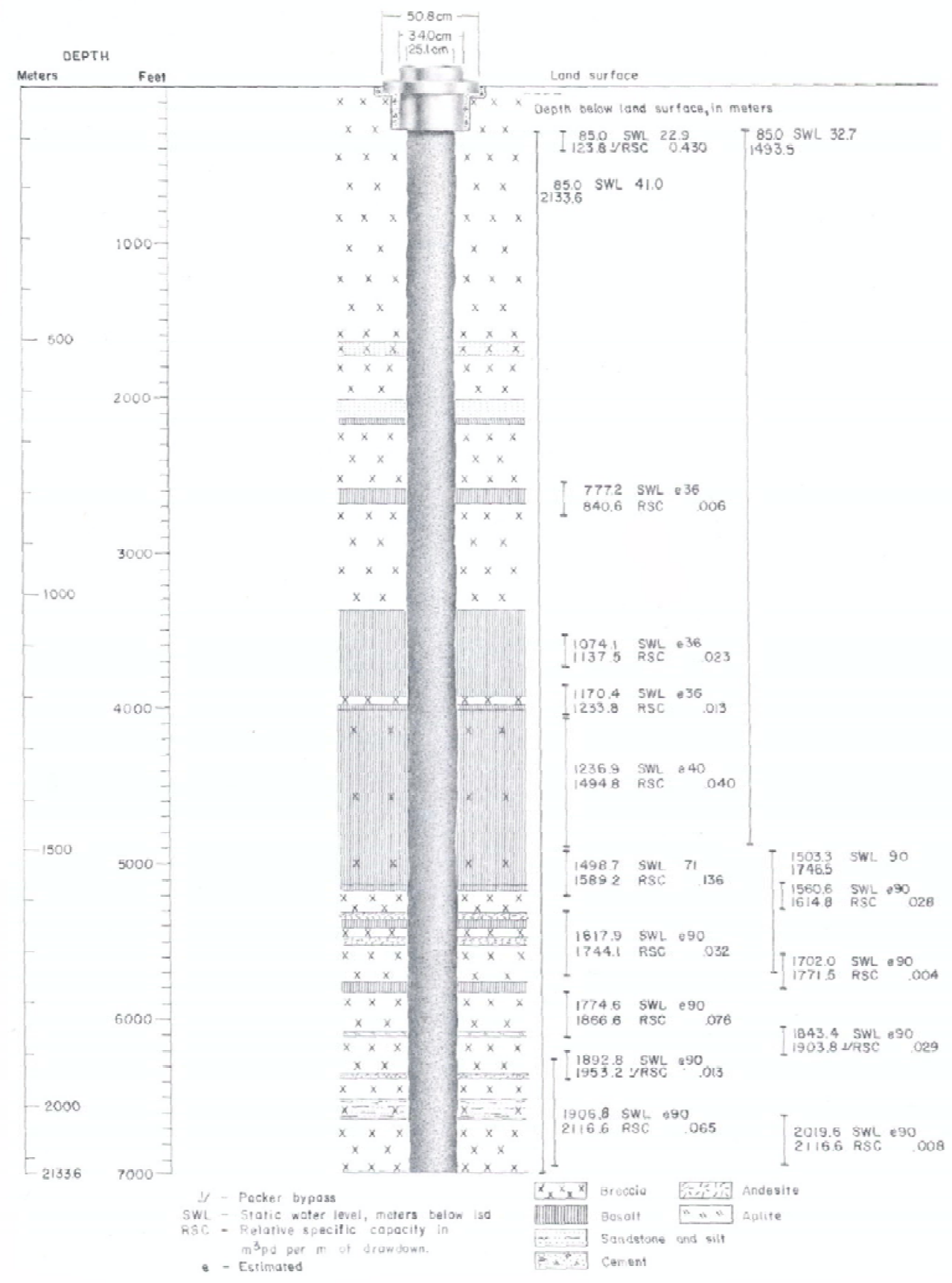

Figure A10. Construction diagram, lithologic log and summary of hydroloic tests, hole UAe-6h (after Balance, 1972b). 


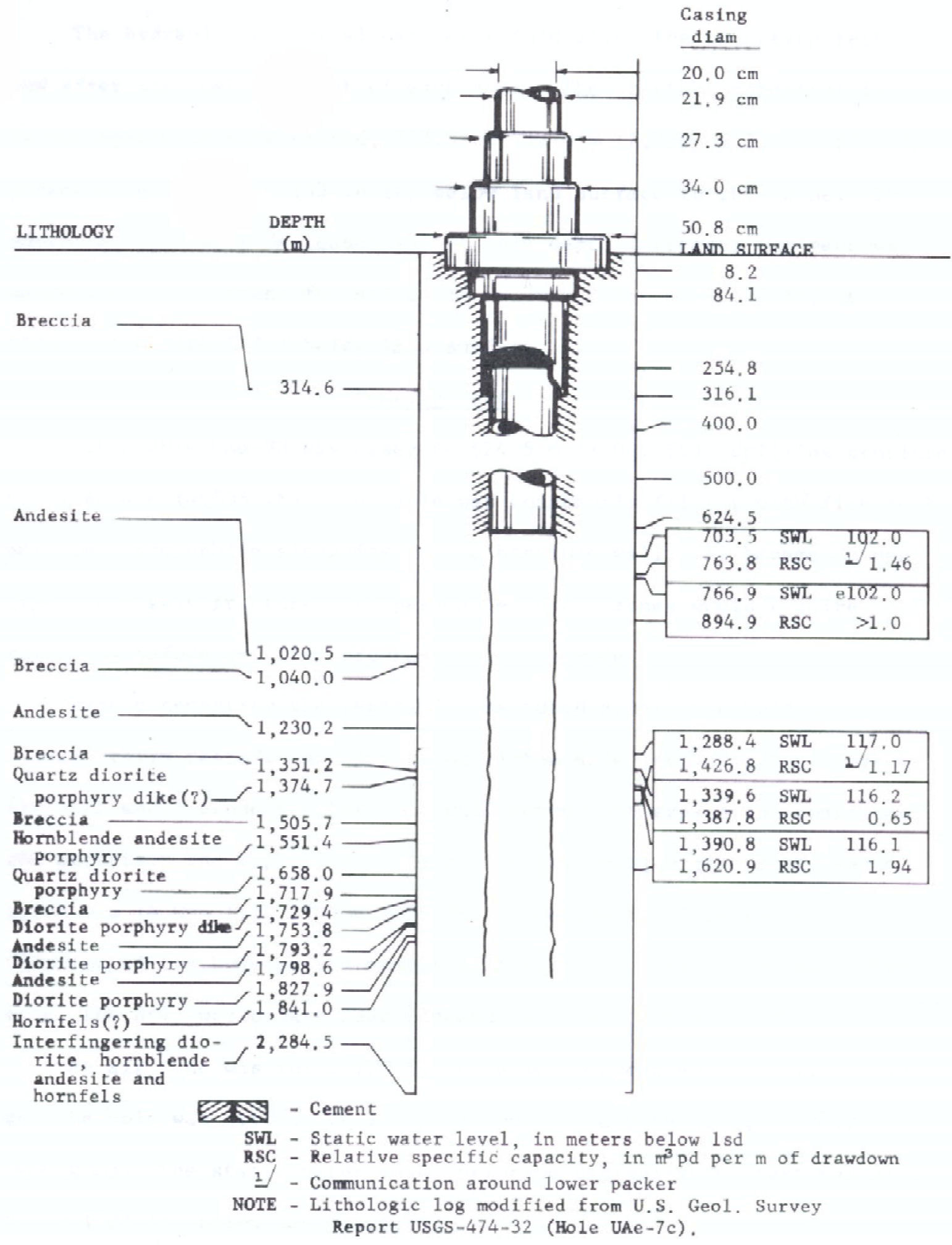

Figure A11. Construction diagram, lithologic log and summary of hydroloic tests, hole UAe-7h (after Balance, 1970a). 


\section{APPENDIX B: GLASS DISSOLUTION SOLUTION by Greg Pohll}

White (1983) gives the following linear mass transfer equation for glass dissolution, normalized by area

$$
\zeta=\zeta_{0}+k_{l} t
$$

where $\zeta$ is the cumulative mass dissolved per unit area $\left(\right.$ moles $\left./ \mathrm{cm}^{2}\right), \zeta_{0}$ is the initial dissolved mass per unit area $\left(\right.$ moles $\left./ \mathrm{cm}^{2}\right), k_{l}$ is the linear rate constant $\left(\right.$ moles $\left./ \mathrm{cm}^{2} \mathrm{~s}\right)$, and $t$ is the time $(\mathrm{s})$.

Taking the first derivative of Eq. B1 with respect to time determines the normalized rate of change (with respect to area) of the glass. Note also that the sign must be changed to account for a loss of mass from the glass, rather than a gain as was written in Eq. B1

$$
\frac{d}{d t}=-k_{l}
$$

To calculate the actual mass dissolution rate in gm/s, we must multiply Eq. B2 by the specific surface area, gram formula weight and the available mass of glass

$$
\frac{d M}{d t}=-k_{l} M A_{s p} G_{f w}
$$

where $M$ is the mass of glass at any time $t(\mathrm{gm}), A_{s p}$ is the specific surface area of the glass $\left(\mathrm{gm} / \mathrm{cm}^{2}\right)$, and $G_{f w}$ is the gram formula weight ( $\left.\mathrm{gm} / \mathrm{mole}\right)$.

Note that the units of $d M / d t$ are now gm/s. One could also remove the gram formula weight, which would produce moles/s. Now separate variables to solve for $M$

$$
\frac{d M}{M}=-k_{l} A_{s p} G_{f w} d t
$$

Integrating both sides gives

$$
\ln (M)=-k_{l} A_{s p} G_{f w} t+C^{\prime}
$$

where $C^{\prime}$ is the integration constant. For simplicity, lets define a new variable $k_{g}$, which will be defined as

$$
k_{g}=k_{l} A_{s p} G_{f w}
$$

which then simplifies Eq. B5 to

$$
\ln (M)=-k_{g} t+C^{\prime}
$$

Taking the exponents of both sides of Eq. B7 yields 


$$
M=C^{\prime} e^{-k_{g} t}
$$

The integration constant is simply the initial mass of the glass (at $t=0$ ), so Eq. B8 can be written as

$$
M=M_{0} e^{-k_{g} t}
$$

where $M_{0}$ is the initial glass mass $(\mathrm{gm})$.

Therefore, Eq. B9 defines the mass at any time $t$ for the glass structure. For modeling purposes, we are more interested in the amount of glass that is in solution, which can be described as

$$
M_{\text {soln }}=\left(M_{0}-\zeta_{0} A_{s p} G_{f w}\right)\left(1-e^{-k_{g} t}\right)+\zeta_{0} A_{s p} G_{f w}
$$

Eq. B10 also includes the small amount of mass that is lost instantaneously as defined in Eq. B1 by White (1983). This term was not included in Eq. B9, but can be easily added, by redefining (more correctly) the integration constant to include the mass lost at $t=0$

$$
M_{\text {solid }}=\left(M_{0}-\zeta_{0} A_{s p} G_{f w}\right) e^{-k_{g} t}
$$

For modeling purposes, the amount of glass lost to solution between any two time steps is important so the numbers of particles that should be released can be obtained. The algorithm is as follows:

1. Assume that $p$ is the percentage of mass released hydraulically, and thus $1-p$ represents the mass in the glass.

2. Next, one must address how much mass is lost due to the instantaneous dissolution $\left(\zeta_{0} A_{s p} G_{f w}\right)$. A problem is that this term is in real mass units, which makes it difficult to use a unit mass within the transport model. Rather than relying on classified data, which will remove much of the analysis from public review, the instantaneous dissolution term is ignored here. This is justified for two reasons. First, the mass involved in this term is very small relative to the total mass dissolved. The inclusion of this term is important for short-term experimental work but not for the long-term, total dissolution process considered here. Second, the process leading to this instantaneous dissolution is considered to be due to surface ion exchange, which is handled through the partioning of the radionuclides into both glass and surface deposits. The portion assigned to surface deposits (conservatively assumed to be $5 \%$ of the refractory nuclides, despite evidence that the actual percentage is closer to 1 or $2 \%$ ) is assumed instantaneously dissolved in groundwater, accounting for this term.

3. By ignoring the instantaneous dissolution term, then one can simply use Eq. 3.1 in the body of the main report. Note that Eq. 3.1 simplifies to $k_{g}$ as defined by Eq. B6 above, using the gram formula weight of $\mathrm{SiO}_{2}$ 


\title{
APPENDIX C:
}

Modeling the Transport of Reactive and Non-Reactive Solutes in Cores from the Cannikin Test Site, Amchitka Island, Alaska

\author{
by \\ N. Brown and C. Papelis \\ Division of Hydrologic Sciences \\ Desert Research Institute
}




\title{
MODELING THE TRANSPORT OF REACTIVE AND NONREACTIVE SOLUTES IN CORES FROM THE CANNIKIN TEST SITE, AMCHITKA ISLAND, ALASKA
}

\author{
Prepared by
}

Nicole Brown and Charalambos Papelis

Division of Hydrologic Sciences

Desert Research Institute

University and Community College System of Nevada

\section{Prepared for}

Nevada Operations Office

U.S. Department of Energy

Las Vegas, Nevada

September 1999 


\section{EXECUTIVE SUMMARY}

During the period of nuclear weapons production and testing, the United States government conducted a series of nuclear weapons tests at various sites throughout the United States and its territories. The nuclear testing performed at these sites resulted in subsurface contamination from contaminants such as radionuclides (e.g., the cesium radionuclide, ${ }^{137} \mathrm{Cs}$ ), organic compounds, toxic metals (such as lead, $\mathrm{Pb}$ ), hydrocarbons, drilling mud and residues from plastics, epoxies, and drilling instrumentation (U.S. DOE, 1996). Because of their toxicity or radioactivity, many of these contaminants are considered to be major health hazards and consequently pose a threat to organisms that are exposed to them (in particular, humans and wildlife). The fate, transport, and distribution of contaminants in the subsurface environment are significantly controlled by groundwater movement and the extent of interaction between the contaminants and surrounding rock matrix. Studies have shown that a number of chemical and physical mechanisms occurring within the subsurface may cause retardation of contaminants with respect to groundwater flow.

In an effort to estimate the migration of radionuclides and toxic compounds from the Cannikin Test Site, Amchitka Island, Alaska, this project component investigated the mobility of reactive (lead and cesium) and nonreactive (bromide) solutes through core samples obtained from the Cannikin site. Lead $(\mathrm{Pb})$ and cesium (Cs) were chosen because of their different reactive characteristics and because they may occur in the subsurface environment as by-products of the underground nuclear detonation that was performed at the site in November 1971. Bromide (Br) was chosen because of its nonreactive characteristics so that an assessment could be made to determine how the rate of solute transport varies between nonreactive and reactive species. Additionally, by using a nonreactive tracer, we could estimate how retardation is affected by diffusion only, since $\mathrm{Br}$ is not expected to sorb appreciably. Though chloride is often used as a nonreactive solute, analysis of the site's groundwater yielded a high chloride concentration $(1,920-16,000 \mathrm{mg} / \mathrm{L})$ so that the chloride ion would be an inappropriate tracer.

Experiments were conducted with Cannikin Test Site basalt and breccia core samples obtained from the U.S. Geological Survey Core Library at the Nevada Test Site. These samples were ground, characterized by a number of physiochemical methods, and subsequently used in equilibrium sorption experiments with $\mathrm{Pb}$ and $\mathrm{Cs}$. The remaining, intact materials were used in the diffusion experiments with $\mathrm{Br}$. With respect to the sorption experiments, $\mathrm{Pb}$ displayed a behavior typical of cation sorption on amphoteric surface sites, with fractional uptake increasing with increasing $\mathrm{pH}$, despite the high ionic strength of the synthetic groundwater solution used in these experiments. Such behavior is consistent with sorption on amphoteric surface sites as opposed to internal cation exchange sites. Experiments with Cs showed no sorption in the high ionic strength synthetic groundwater. It is thus expected that at high ionic strength, Cs would be highly mobile and exhibit no significant sorption on the solid materials.

Based on the experimental sorption data, parameters describing both linear and Freundlich isotherms were estimated for a variety of conditions. The results indicate that equilibrium partitioning at the solid-water interface is strongly $\mathrm{pH}$-dependent for $\mathrm{Pb}$ and virtually non-existent for $\mathrm{Cs}$ under field conditions. As a consequence, modeling the transport of these contaminants, $\mathrm{Pb}$ in particular, requires knowledge of or assumptions about the groundwater $\mathrm{pH}$. Under certain conditions, the isotherms for $\mathrm{Pb}$ were approximately linear. In most cases, however, deviations from linearity suggested that the use of the Freundlich isotherm would be more appropriate to accurately model the data.

The results of the diffusion experiments using a sodium bromide $(\mathrm{NaBr})$ tracer revealed two trends. First, the extent of diffusion varied significantly with respect to each sorbent. Second, the extent of diffusion

and the resulting diffusion coefficient varied with time. It was found that the basalt sample generally had 
lower effective diffusion coefficients than the breccia. The calculated tortuosity for the basalt (being inversely proportional to the effective diffusion coefficient) was therefore larger in all instances than the tortuosity calculated for the breccia by a factor of approximately $1.5-2$.

The results of the diffusion experiments indicate that, on average, ions in solution would most likely travel faster in the breccia than in the basalt. This is somewhat expected, as the breccia has a slightly higher porosity than the basalt, thereby providing additional pathways through which ions could travel.

The parameters determined in this study can be used to reduce the uncertainty in radionuclide transport modeling by accounting for retardation of radionuclides and other contaminants of concern due to sorption on, and diffusion through, subsurface materials. Finally, it cannot be overemphasized that the results reported here are specific to the conditions used and that, given the non-linearity of some of these systems, use of these parameters outside their range of applicability might result in significant errors. 


\section{CONTENTS}

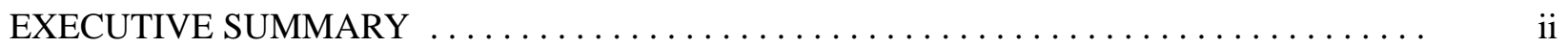

LIST OF FIGURES $\ldots \ldots \ldots \ldots \ldots \ldots \ldots \ldots \ldots \ldots \ldots \ldots \ldots \ldots \ldots \ldots \ldots \ldots \ldots \ldots \ldots$

LIST OF TABLES $\ldots \ldots \ldots \ldots \ldots \ldots \ldots \ldots \ldots \ldots \ldots \ldots \ldots \ldots \ldots \ldots \ldots \ldots \ldots \ldots \ldots \ldots \ldots$

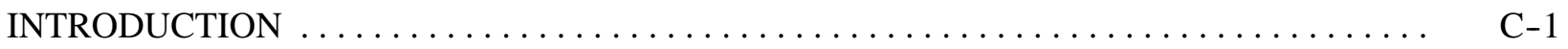

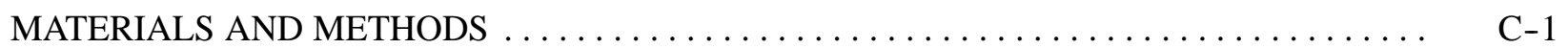

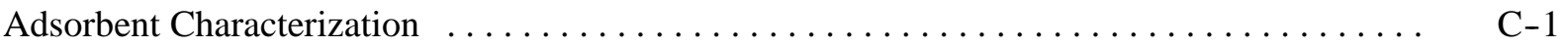

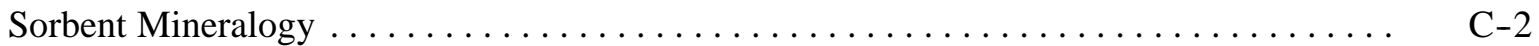

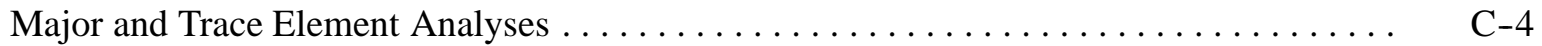

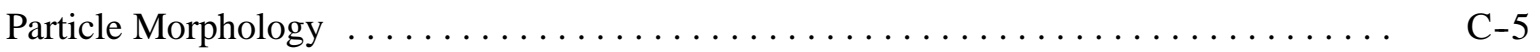

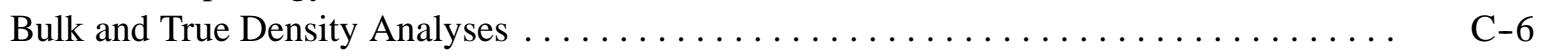

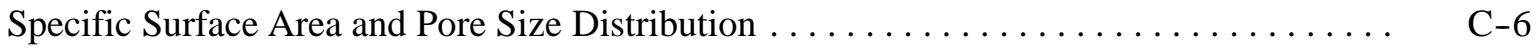

Soil Solution $\mathrm{pH}$ and Cation Exchange Capacity $\ldots \ldots \ldots \ldots \ldots \ldots \ldots \ldots \ldots \ldots \ldots$

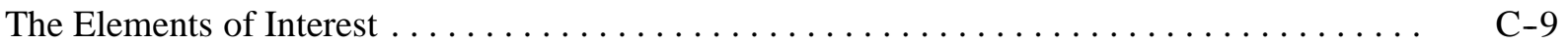

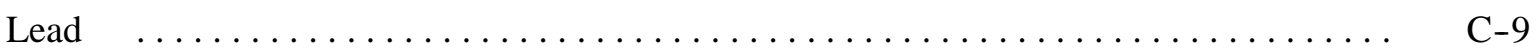

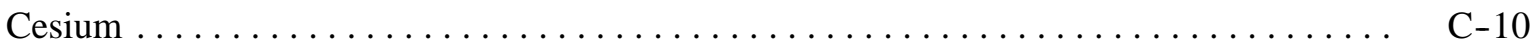

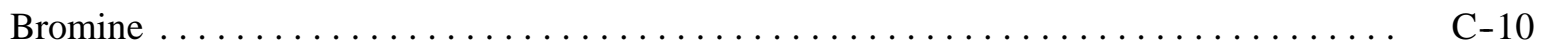

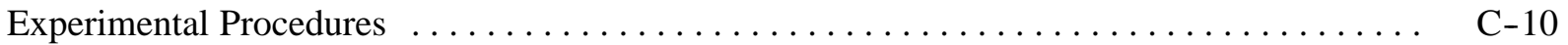

Batch Equilibrium Sorption Experiments with the Cannikin Site Core Samples . . . . . . C-10

Diffusion Experiments with the Cannikin Site Core Samples $\ldots \ldots \ldots \ldots \ldots \ldots \ldots \ldots$ C-12

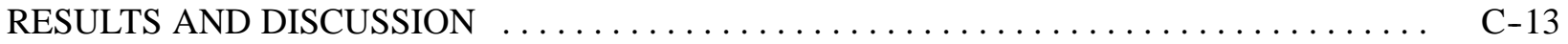

Sorption of $\mathrm{Pb}$ and $\mathrm{Cs}$ on Cannikin Basalt and Breccia $\ldots \ldots \ldots \ldots \ldots \ldots \ldots \ldots \ldots \ldots$

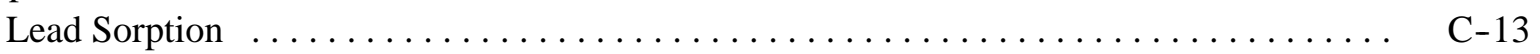

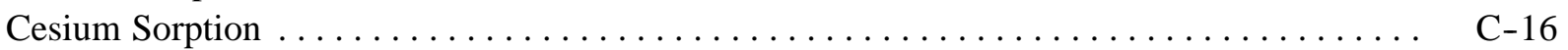

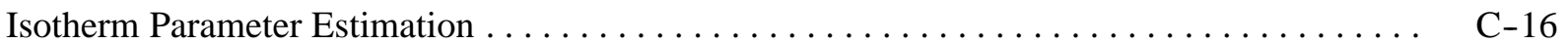

Diffusion of $\mathrm{Br}$ through Cannikin Basalt and Breccia $\ldots \ldots \ldots \ldots \ldots \ldots \ldots \ldots . . \ldots \ldots$

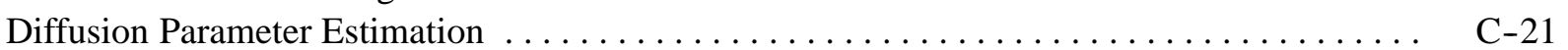

Solution to the Diffusion Equation for Nonreactive Solutes $\ldots \ldots \ldots \ldots \ldots \ldots \ldots \ldots \ldots$ C-23

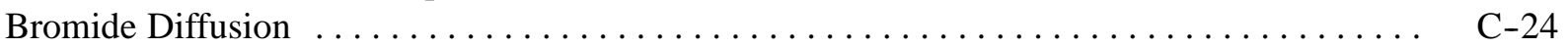

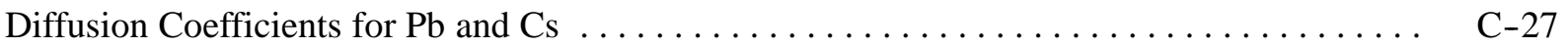

SUMMARY, CONCLUSIONS, AND RECOMMENDATIONS $\ldots \ldots \ldots \ldots \ldots \ldots \ldots \ldots$ C-28

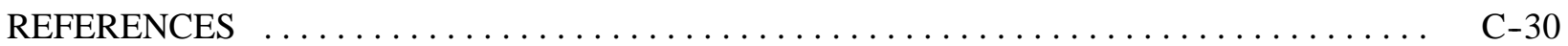




\section{LIST OF FIGURES}

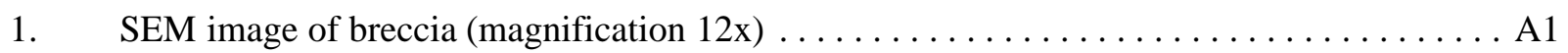

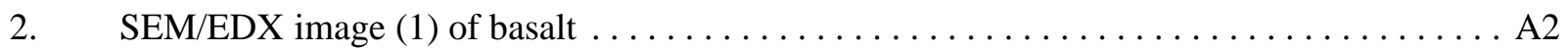

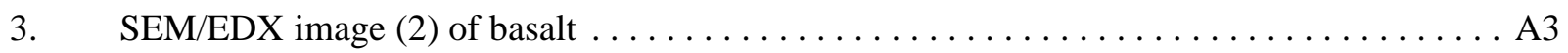

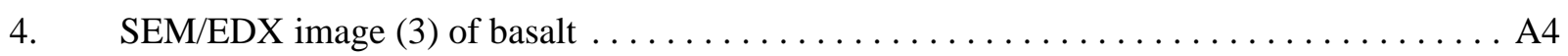

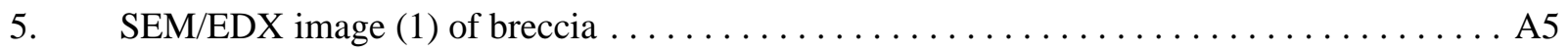

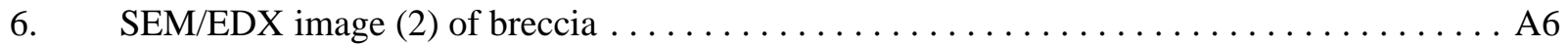

7. Isotherm of nitrogen adsorption/desorption on the basalt. $\ldots \ldots \ldots \ldots \ldots \ldots \ldots \ldots \ldots$ C-8

8. Isotherm of nitrogen adsorption/desorption on the breccia. $\ldots \ldots \ldots \ldots \ldots \ldots \ldots \ldots$ C-8

9. Experimental apparatus used in the diffusion experiments with $\mathrm{NaBr} . \ldots \ldots \ldots \ldots \ldots$ C 13

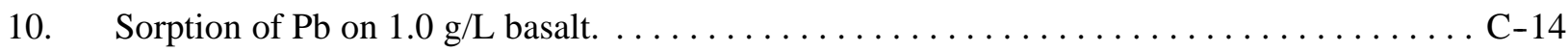

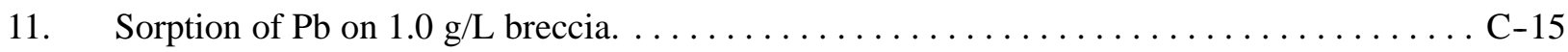

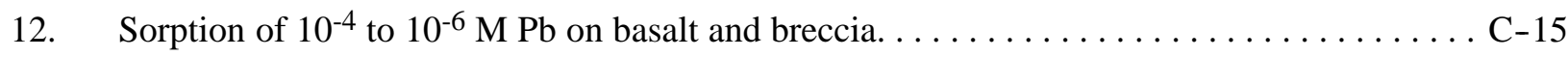

13. Comparison of sorption of $10^{-4}$ to $10^{-6} \mathrm{M} \mathrm{Pb}$ on larger and smaller size

14. Comparison of sorption of $10^{-4}$ to $10^{-6} \mathrm{M} \mathrm{Pb}$ on larger and smaller size

fractions of breccia. . . . . . . . . . . . . . . . . .

15. Sorption of $1 \times 10^{-6} \mathrm{M}$ Cs on $1.0 \mathrm{~g} / \mathrm{L}$ basalt and breccia. $\ldots \ldots \ldots \ldots \ldots \ldots \ldots \ldots \ldots$

16. Linear isotherms of $\mathrm{Pb}\left(\mathrm{NO}_{3}\right)_{2}$ sorption on basalt at $\mathrm{pH}$ values of $6,7,8$, and $9 . \ldots \ldots \ldots \mathrm{C}-20$

17. Linear isotherms of $\mathrm{Pb}\left(\mathrm{NO}_{3}\right)_{2}$ sorption on breccia at $\mathrm{pH}$ values of $6,7,8$, and $9 . \ldots \ldots \ldots \mathrm{C}-20$

18. Diffusion of $\mathrm{Br}$ out of a basalt core sample as a function of time. $\ldots \ldots \ldots \ldots \ldots \ldots \ldots$

19. Diffusion of $\mathrm{Br}$ out of a breccia core sample as a function of time. $\ldots \ldots \ldots \ldots \ldots \ldots$

21. Plot of experimental results and linear regression line of $\mathrm{Br}$ diffusion through breccia core. . . . . . . . . . . . . . . .

20. Plot of experimental results and linear regression line of $\mathrm{Br}$ diffusion through

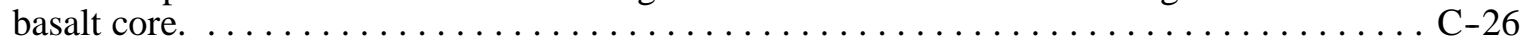




\section{LIST OF TABLES}

1a. Major element composition of the breccia and basalt. . . . . . . . . $\ldots \ldots \ldots$

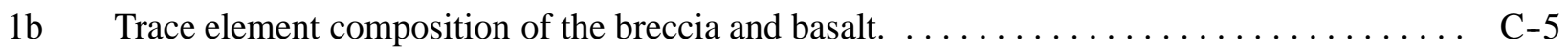

2. Measured specific surface areas of basalt and breccia sorbents. $\ldots \ldots \ldots \ldots \ldots \ldots$ C-7

3. Pore size measurements for the basalt and breccia. . . . . . . . . . . $\ldots \ldots \ldots$

4. Composition of site and synthetic groundwater. $\ldots \ldots \ldots \ldots \ldots \ldots \ldots \ldots \ldots \ldots \ldots \ldots$

5. Linear and Freundlich isotherm parameters for lead sorption. $\ldots \ldots \ldots \ldots \ldots \ldots \ldots \ldots$

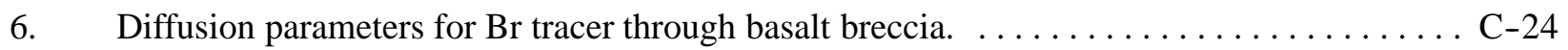

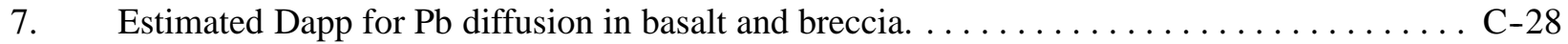

8. Estimated Deff for Cs diffusion in basalt and breccia. $\ldots \ldots \ldots \ldots \ldots \ldots \ldots \ldots \ldots$ 


\section{INTRODUCTION}

During the Cold War, the United States government conducted a series of nuclear weapons tests at various sites throughout the United States and its territories. The nuclear testing performed at these sites resulted in subsurface contamination from contaminants such as radionuclides (e.g., uranium, ${ }^{238} \mathrm{U}, \mathrm{Pu}, \mathrm{Am}$, and cesium, ${ }^{137} \mathrm{Cs}$ ), organic compounds, toxic metals (such as lead, $\mathrm{Pb}$ ), hydrocarbons, drilling mud and residues from plastics, epoxies, and drilling instrumentation (U.S. DOE, 1996). Because of their toxicity or radioactivity, many of these contaminants are considered to be health hazards (some, proven carcinogens) and consequently pose a threat to organisms that are exposed to them (including humans and wildlife). Thus, it is vitally important to assess the potential of these contaminants to reach the accessible environment where humans can ingest them-either by way of contaminated water supplies or through contaminated food chains.

Two factors primarily affect the transport and fate of contaminants in groundwater: (1) properties of the subsurface materials or the subsurface environment, and (2) physiochemical and biological properties of the contaminant (Knox et al., 1993). The degree to which contaminants interact with the soil matrix, therefore, will have a significant effect on the migration of such contaminants downstream. Conservative (nonreactive) ions and compounds, which are not affected by abiotic or biotic processes, essentially move with the velocity of the groundwater. Conversely, nonconservative (reactive) ions or compounds have the potential to be significantly retarded compared to groundwater flow if the proper conditions exist in the surrounding subsurface environment. Any attempt, therefore, to estimate the migration potential of contaminants requires that experimental studies be performed to evaluate the reactivity of these substances for the surrounding subsurface matrix through which the groundwater flows (Papelis, 1997).

The objective of this study was to estimate the rate of migration of reactive and nonreactive solutes (representative of inorganic contaminants found at underground nuclear test sites) through volcanic basalt and breccia from the Cannikin Test Site, Amchitka Island, Alaska. In an effort to predict the migration potential of these contaminants to reach surface waters (in particular the Bering Sea which lies approximately 1 mile away), batch equilibrium experiments were performed using $\mathrm{Pb}$ and $\mathrm{Cs}$ as reactive solutes and diffusion experiments were performed using bromide $(\mathrm{Br})$ as a nonreactive solute. Lead and Cs were selected for the study because of their different reactive characteristics and because they may occur in the subsurface environment at the Cannikin site either as a result of their use in shielding of the nuclear device or as byproducts of the test performed at the site in November 1971. Bromide was chosen because of its nonreactive characteristics to allow a comparison regarding the movement of nonreactive and reactive solutes.

The remainder of this report is organized as follows. The characterization of each adsorbent, a brief discussion of the ions of interest $(\mathrm{Pb}, \mathrm{Cs}$, and $\mathrm{Br})$ and the general experimental procedures are presented next. The results and discussion are presented subsequently, followed by a summary, conclusions and recommendations for further study.

\section{MATERIALS AND METHODS}

\section{Adsorbent Characterization}

Two adsorbents (hereafter referred to simply as sorbents) were used in this study: basalt and breccia. An extensive characterization was performed on each of these sorbents, which included mineralogy (solid structure), as determined by $\mathrm{x}$-ray diffraction (XRD), soil $\mathrm{pH}$ measurement, major 
and trace element analysis by $\mathrm{x}$-ray fluorescence (XRF), solid morphology and composition as determined by scanning electron microscopy (SEM) and energy dispersive $\mathrm{x}$-ray (EDX) spectroscopy, respectively, pore size distribution and specific surface area, as determined by nitrogen adsorption, porosity and density determination, and cation exchange capacity (CEC). This level of characterization is needed to define parameters that are important in the experimental design and that are required for the estimation of other geochemical transport parameters obtained from the experimental data.

A portion of each sorbent was first reduced in size, a step necessary for performance of small-scale batch equilibrium experiments. It should be noted that the sorption capacity of a solid is proportional to the total surface area available and the total surface area of nonporous particles is inversely proportional to the particle diameter. Thus, it is expected that higher sorption, per unit mass of sorbent, will occur as the particle size fraction is decreased. The size reduction and subsequent sieving resulted in nine size fractions, ranging in size from greater than $4 \mathrm{~mm}$ to less than $50 \mu \mathrm{m}$. The 600 to $354 \mu \mathrm{m}$ size fraction was mainly used in the sorption experiments, although a comparison of sorption behavior was made using the 833 to $600 \mu \mathrm{m}$ size fraction as well.

\section{$\underline{\text { Sorbent Mineralogy }}$}

The mineralogy of the basalt and breccia was determined by XRD after particle size reduction. Spectra were collected in the 5 to $60^{\circ} 2 \theta$-range using $0.03^{\circ} 2 \theta$ steps and $\mathrm{Cu} \mathrm{K} \alpha$ radiation $(\lambda=$ $1.54060 \AA$ ). Inspection of the spectra and an automated search of the peaks obtained is consistent with the presence of the following minerals for each sorbent: basalt-major: augite and laumontite; minor: analcime, augite, and magnesioferrite; breccia-major: plagioclase and chlorite; minor: laumontite, plagioclase, chlorite, and quartz. This composition agrees well with that given by Brown (1967) for basaltic rocks. All aforementioned minerals fall into one of the following major mineral groups: pyroxenes (augite), zeolites (laumontite, analcime), feldspars (plagioclase), chlorite, spinels (magnesioferrite), or quartz. A brief description of each of these mineral groups is provided below.

\section{Pyroxenes}

The pyroxene group is a broadly diverse mineral family whose various members constitute the most abundant and widespread of the ferromagnesian minerals in igneous rocks. In general, pyroxenes are defined as a group of dark, rock-forming silicate minerals, closely related in crystal form and composition with the general formula: $\mathrm{A}_{2} \mathrm{~B}_{2}\left[\mathrm{Si}_{4} \mathrm{O}_{12}\right]$, where $\mathrm{A}=\mathrm{Ca}, \mathrm{Na}, \mathrm{Mg}$, or Fe ${ }^{2+}$, and $\mathrm{B}=\mathrm{Mg}, \mathrm{Fe}^{2+}, \mathrm{Fe}^{3+}, \mathrm{Cr}, \mathrm{Mn}$, or $\mathrm{Al}$, with silicon sometimes replaced in part by aluminum (Jackson, 1997). Structurally, pyroxenes are all single-chain silicates (inosilicates) based on tetrahedral linkage. They are comprised of endless one-dimensional chains made up of $\mathrm{SiO}_{4}$ tetrahedra in which two apical oxygens are shared with adjacent tetrahedra. The individual chains are bound together by interstitial cations in roughly octahedral coordination (Blatt and Tracy, 1996). A structural subdivision divides the pyroxenes into clinopyroxenes, which crystallize in the monoclinic system and orthopyroxenes, which crystallize in the orthorhombic system. A detailed discussion on each of these subdivisions is not within the scope of this text and the reader is referred to Blatt and Tracy (1996), Jackson (1997), and Brown (1967) for further information. Augite, one of the minerals found in both the basalt and the breccia, falls into the clinopyroxene subgroup and is usually black, greenish black, or dark green. 


\section{Zeolites}

Zeolites are crystalline, hydrated aluminosilicates of alkali and alkaline earth cations that possess infinite, three-dimensional crystal structures (Ming and Mumpton, 1989). They are further characterized by their abilities to hydrate and dehydrate reversibly and to exchange some of their constituent cations, without major change of structure. As hydrous aluminosilicates, zeolites are analogous in composition to the feldspars, with $\mathrm{Na}, \mathrm{Ca}$, and $\mathrm{K}$ (rarely $\mathrm{Ba}$ or $\mathrm{Sr}$ ) as their primary cations (Jackson, 1997). They are classified as tectosilicates, meaning they consist of three-dimensional frameworks of $\mathrm{SiO}_{4}{ }^{4-}$ tetrahedra in which all oxygens of each tetrahedron are shared with adjacent tetrahedra. Such an arrangement reduces the overall Si:O ratio to 1:2, and if each tetrahedron were to contain $\mathrm{Si}$ as its central cation, the structure would be electrically neutral, as is quartz (Ming and Mumpton, 1989). In zeolite structures, however, some of the $\mathrm{Si}^{4+}$ is replaced by $\mathrm{Al}^{3+}$, giving rise to a net negative charge within the framework, which is balanced by the incorporation of cations, in particular $\mathrm{Ca}^{2+}, \mathrm{Na}^{+}, \mathrm{K}^{+}$or $\mathrm{Mg}^{2+}$, in the cage structure. In general, zeolites are either white or colorless, though they have been tinted red or yellow due to impurities. Two zeolites, laumontite and analcime, were identified as either major or minor minerals in the sorbents used in this study. Laumontite is a white, monoclinic zeolite mineral having the formula: $\mathrm{Ca}\left[\mathrm{Al}_{2} \mathrm{Si}_{4} \mathrm{O}_{12}\right] \bullet 4 \mathrm{H}_{2} \mathrm{O}$. This mineral can sometimes contain appreciable amounts of sodium and, on exposure to air, loses water, becomes opaque, and crumbles (Jackson, 1997). Analcime, the other identified zeolite, is a glassy, colorless to pink zeolite mineral with the general formula: $\mathrm{Na}\left[\mathrm{AlSi}_{2} \mathrm{O}_{6}\right] \cdot \mathrm{H}_{2} \mathrm{O}$. It is a cubic zeolite, commonly found in diabase and alkali-rich basalts. For further information on these minerals, or on zeolites in general, the reader is referred to Ming and Mumpton (1989), Gottardi and Galli (1985), and Mumpton (1981).

\section{Feldspars}

The feldspar group is unquestionably the most common mineral group in both the earth's crust and in igneous rocks. Feldspars are anhydrous tectosilicates of general formula: $\mathrm{M}\left[\mathrm{Al}(\mathrm{Al}, \mathrm{Si})_{3} \mathrm{O}_{8}\right]$, where $\mathrm{M}=\mathrm{K}, \mathrm{Na}, \mathrm{Ca}, \mathrm{Ba}, \mathrm{Rb}, \mathrm{Sr}$, or Fe (Jackson, 1997). Structurally, the feldspars are framework aluminosilicates consisting of a three-dimensional continuous framework of tetrahedrally coordinated silicon and aluminum. All four corner oxygens in each $\mathrm{SiO}_{4}$ or $\mathrm{AlO}_{4}$ tetrahedron are linked to adjacent tetrahedra (Blatt and Tracy, 1996). Feldspars are usually white or nearly white in color and are clear and translucent, although they may sometimes be colored due to impurities. Plagioclase feldspars, one of the minor minerals identified in both the basalt and breccia, are simply those feldspars that are rich in $\mathrm{Ca}$ and/or $\mathrm{Na}$, but with small amounts of $\mathrm{K}$, as opposed to alkali feldspars (such as orthoclase), which are rich in $\mathrm{K}$ and $\mathrm{Na}$, but have small amounts of $\mathrm{Ca}$ (Huang, 1989). For more information on feldspars, the reader is referred to Huang (1989) and Brown (1967).

\section{Chlorites}

Chlorites are defined as a group of platy, monoclinic, usually greenish minerals having the general formula: $\left(\mathrm{R}_{+2}, \mathrm{R}_{+3}\right)_{6} \mathrm{AlSi}_{2} \mathrm{O}_{10}(\mathrm{OH})_{8}$, where $\mathrm{R}_{+2}=\mathrm{Mg}^{2+}, \mathrm{Fe}^{2+}, \mathrm{Mn}^{2+}$, or $\mathrm{Ni}^{2+}$ and $\mathrm{R}_{+3}=$ $\mathrm{Al}^{3+}, \mathrm{Fe}^{3+}, \mathrm{Cr}^{3+}$ (Jackson, 1997; Barnhisel and Bertsch, 1989). There are four subgroups of this 2:1 layer clay mineral: trioctahedral chlorite (the most common chlorites), dioctahedral chlorite, di,trioctahedral chlorite, and tri,dioctahedral chlorite. Chlorites, being less stable than other clays when placed into acidic environments, have a high tendency to be altered. It is this tendency that accounts for significant amounts of $\mathrm{Mg}^{2+}$ and other cations that occupy exchange sites of clay minerals of such soils (Barnhisel and Bertsch,1989). Chlorites in soil are largely inherited as primary minerals found in metamorphic or igneous rocks, or they occur as alteration products from minerals such as hornblende, biotite, and other ferromagnesium minerals. The structure of the most common 
chlorite, trioctahedral chlorite, is composed of four sheets of polyhedra. Three of these sheets are chemically bound together to form a 2:1 layer that is structurally similar to mica, consisting of two tetrahedral sheets, one on each side of an ocathedral sheet. The fourth sheet has been described in the literature in several ways, but is commonly expressed as an interlayer hydroxide sheet. Further discussion on this material is beyond the scope of this report and the reader is again referred to Barnhisel and Bertsch (1989) for additional information.

Spinels and Quartz

The spinel group can be defined as a group of minerals of general formula: $\mathrm{B}_{2}\left[\mathrm{AO}_{4}\right]$, where A represents $\mathrm{Mg}, \mathrm{Fe}^{2+}$ and $\mathrm{Fe}^{3+}, \mathrm{Zn}$, or $\mathrm{Mn}$ or any combination of these, and is in tetrahedral coordination by oxides, and $\mathrm{B}$ represents $\mathrm{Al}, \mathrm{Fe}^{2+}$ and $\mathrm{Fe}^{3+}$, or $\mathrm{Cr}$ and is in octahedral coordination by oxides (Jackson, 1997). Magnesioferrite, a major mineral found in the breccia, is defined as a black, strongly magnetic, cubic mineral of the spinel group having the formula: $\mathrm{Fe}_{2}{ }^{3+}(\mathrm{Mg}, \mathrm{Fe})^{2+} \mathrm{O}_{4}$.

Quartz is a crystalline, rock-forming mineral of the general formula $\mathrm{SiO}_{2}$. This mineral is found in essentially all soils and parent materials and, next to feldspar, is the commonest mineral, occurring either in transparent hexagonal crystals (colorless, or colored by impurities) or in crystalline or cryptocrystalline masses (Jackson, 1997). A silicate mineral, quartz is classified as a tectosilicate comprised entirely of $\mathrm{SiO}_{4}$ tetrahedra in which each oxygen is linked to $\mathrm{Si}$ atoms of adjacent tetrahedra forming a three-dimensional framework structure.

\section{Major and Trace Element Analyses}

To further quantify the mineralogical composition of the basalt and breccia samples, the XRD analysis was complemented by estimation of bulk elemental composition, as determined by X-ray fluorescence (XRF) and energy dispersive X-ray spectroscopy (EDX). The XRF results are shown in Tables 1a and 1b. The major element composition (Table 1a) is presented as weight percentage in terms of oxides. An average chemical composition of basalt according to LeMaitre (1976) is also shown for comparison purposes. Inspection of Table 1a shows that our analysis was in close agreement with that presented in the literature. Trace element composition for each sorbent is presented in Table $1 \mathrm{~b}$.

Table 1a. Major element composition of the breccia and basalt.

\begin{tabular}{cccc}
\hline \hline Major Element* & Breccia & Basalt & Basalt according to LeMaitre (1976) \\
\hline $\mathrm{SiO}_{2}$ & 49.5 & 50.5 & 50.06 \\
$\mathrm{Al}_{2} \mathrm{O}_{3}$ & 16.4 & 16.1 & 15.94 \\
$\mathrm{TiO}_{2}$ & 1.13 & 1.07 & 1.87 \\
$\mathrm{Fe}_{2} \mathrm{O}_{3}$ & 13.0 & 11.5 & 11.4 \\
$\mathrm{CaO}$ & 7.11 & 11.8 & 9.70 \\
$\mathrm{~K}_{2} \mathrm{O}$ & 1.74 & 1.95 & 1.08 \\
$\mathrm{P}_{2} \mathrm{O}_{5}$ & 0.385 & 0.387 & 0.34 \\
$\mathrm{MnO}$ & 0.223 & 0.213 & 0.20 \\
$\mathrm{Na}$ & 4.05 & 1.40 & 2.94 \\
$\mathrm{MgO}$ & 6.44 & 5.14 & 6.98 \\
\hline \hline
\end{tabular}

* All data are given as percent weight and were normalized to account for losses on water molecules. 
Table 1b. Trace element composition of the breccia and basalt.

\begin{tabular}{ccc}
\hline \hline Trace Element & Breccia (ppm) & Basalt (ppm) \\
\hline $\mathrm{Rb}$ & 24.30 & 19.46 \\
$\mathrm{Sr}$ & 290.10 & 473.15 \\
$\mathrm{Y}$ & 25.58 & 22.64 \\
$\mathrm{Zr}$ & 63.95 & 77.55 \\
$\mathrm{Nb}$ & 7.03 & 4.06 \\
$\mathrm{Cr}$ & 64.71 & 61.41 \\
\hline \hline
\end{tabular}

As shown in Table 1a, both sorbents have very similar compositions. Additionally, the table reveals that $\mathrm{SiO}_{2}$ represents the majority of the sample by weight in both sorbents. This is somewhat expected because $\mathrm{SiO}_{2}$ would be present as quartz or as a component of any aluminosilicate. Other components found to be present in substantial quantities include $\mathrm{Al}_{2} \mathrm{O}_{3}, \mathrm{Fe}_{2} \mathrm{O}_{3}, \mathrm{CaO}, \mathrm{Na}_{2} \mathrm{O}$, and $\mathrm{MgO}$.

An examination of the bulk elemental composition using EDX was performed on the breccia sorbent only and the results were found to be very similar to those of the XRF analysis. Analysis of a general view of a breccia sample, shown in Figure 1 (Figures 1 through 6 are located at the end of this report), yielded the following component weight percentages: $\mathrm{Na}_{2} \mathrm{O}-3.82 ; \mathrm{MgO}-3.61$; $\mathrm{Al}_{2} \mathrm{O}_{3}-17.99 ; \mathrm{SiO}_{2}-48.15 ; \mathrm{CaO}-11.41$; and $\mathrm{Fe}_{2} \mathrm{O}_{3}-15.02$.

\section{Particle Morphology}

To obtain a better understanding of the morphology of the sorbents, each sample was examined by scanning electron microscopy (SEM). SEM is one of the most commonplace, powerful, and sophisticated techniques available for the examination of surface and near-surface characteristics of samples. In addition, an average composition of individual particles imaged with the SEM was determined using an energy dispersive $x$-ray (EDX) attachment to the SEM. A JEOL JSM-840A SEM/EDX was used to examine several areas of the sample under different magnifications.

An attempt was made to identify individual minerals in the sample by SEM/EDX. Analyses can be performed with a spatial depth resolution of about 1 to $2 \mu \mathrm{m}$ and an accuracy of 5 to 10 percent (Papelis and Sloop, 1997). This allows a semi-quantitative identification of individual mineral crystals based on the relative abundance of common elements in minerals. It should be noted here, however, that because several different minerals may have similar composition in terms of oxides, independent information on the types of minerals present, for example from XRD, may be required for unambiguous mineral identification. The advantage of the technique, however, lies in the fact that individual mineral grains can be examined, as opposed to analysis by XRD, which yields an average bulk composition.

Thin-section examination of both sorbents identified several minerals as shown in Figures 1 through 5. Figures 2, 3, and 4 correspond to the basalt sample and identify the presence of plagioclase (feldspar), zeolites, spinels, and pyroxenes. This is consistent with the XRD analysis, which identified augite (a pyroxene), laumontite (a zeolite), plagioclase, and chlorite. Figures 5 and 6 
correspond to the breccia sample and identify the presence of albite (a feldspar), plagioclase and orthoclase (feldspars), a zeolitic alteration product, pyroxene, and spinel. This, too, is consistent with the XRD analysis which identified analcime (a zeolite), augite, magnesioferrite (a spinel), laumontite, plagioclase, chlorite, and quartz. The advantage of the examination of thin sections is that the relative semiqualitative abundance of mineral groups can be determined.

\section{Bulk and True Density Analyses}

The bulk and true densities of the sorbents were estimated by using the intact core samples and the following procedure. First, the sample was dried at $100{ }^{\circ} \mathrm{C}$ in an oven for 24 hours. The dry weight, $\mathrm{w}_{\mathrm{d}}$, of the sample was then measured and recorded. The total volume, $\mathrm{V}_{\mathrm{T}}$, of the dried sample was measured by placing the sample in a graduated cylinder and measuring the change in level of a surrounding medium. In this method, the surrounding medium consisted of quality glass spheres having a diameter between 425 and $300 \mu \mathrm{m}$. This material was chosen so that a true measure of the total volume would be obtained rather than a skewed value, which might be obtained by using water (the dry sample might absorb water into the pore spaces, thereby yielding incorrect results). The size fraction chosen for the glass spheres allowed for an acceptable degree of compaction, yet prevented spheres from migrating into the pore spaces. Once the volume of the dry sample was determined, the bulk density $\left(\rho_{b}\right)$ could be obtained using Equation (1):

$$
\rho_{b}=\frac{\text { mass dry sample }}{\text { total volume dry sample }}=\frac{w_{d}}{V_{T}}
$$

The sample was then immersed in NANOpure ${ }^{\mathrm{TM}}$ water (high purity water with at least $18 \mathrm{M} \Omega$ $\mathrm{cm}$ resistivity) and placed in a sealed vacuum chamber at ambient temperature to achieve saturation. Once saturated, the surfaces were wiped off and the saturated weight determined. Assuming the water density is $1.00 \mathrm{~g} / \mathrm{cm}^{3}$ at $25^{\circ} \mathrm{C}$ (approximate water temperature) the total pore volume, $\mathrm{V}_{\mathrm{P}}$, of the rock was then determined as the difference between the dry and saturated sample weights divided by the density of the water. The true density was then determined as the dry weight divided by the volume of the solid $\left(\mathrm{V}_{\mathrm{T}}-\mathrm{V}_{\mathrm{p}}=\mathrm{V}_{\text {solid }}\right)$. Total porosity, $\varepsilon$, is the ratio of total pore volume to total sample volume and can therefore be determined by the following equation:

$$
\varepsilon=\frac{\mathrm{V}_{\mathrm{p}}}{\mathrm{V}_{\mathrm{T}}}
$$

The average bulk density measured for the basalt sample was $2.21 \mathrm{~g} / \mathrm{cm}^{3}$ and the average true density was $2.51 \mathrm{~g} / \mathrm{cm}^{3}$. The bulk and true densities for the breccia sample were $2.13 \mathrm{~g} / \mathrm{cm}^{3}$ and 2.46 $\mathrm{g} / \mathrm{cm}^{3}$, respectively. Likewise, it was determined that the porosity of the basalt sample was approximately 11 percent and that of the breccia was approximately 13 percent. These values are consistent with those reported by Freeze and Cherry (1979), who list an average porosity value of brecciated basalts as 10 percent and by Fetter (1994), who states that basalts generally have a porosity between 1 and 12 percent.

\section{Specific Surface Area and Pore Size Distribution}

The specific surface area and the pore size distribution of the sorbents were determined based on nitrogen adsorption measurements, using a Gemini 2370 Analyzer and the BET model (Brunauer et al., 1938). This method can be used to obtain an estimate of the specific surface area of sorbents

having surface areas from 1 to several hundred $\mathrm{m}^{2} / \mathrm{g}$ (using nitrogen adsorption). Although the 
method has several shortcomings, it continues to be the most widely used and general method for particle surface area estimation (Gregg and Sing, 1982). The measured specific surface areas for the two size fractions used for the sorption experiments are shown in Table 2.

The specific surface area of nonporous particles is inversely proportional to particle size, i.e., as the particle size increases, the specific surface area decreases. Inspection of Table 2 does indeed reveal a small dependence of specific surface area on particle dimensions for both sorbents. One should note, however, the relatively small change in surface area between the larger and smaller size fractions for the basalt material. Such behavior can most likely be attributed to the fact that the majority of the surface area is internal, in which case one would not expect to see much difference in specific surface area with size. The presence of zeolites, as determined by XRD analysis, is consistent with these findings because zeolites possess an internal cage-like framework structure giving them a large internal surface area. The small variations of surface area between particle sizes can most likely be attributed to decreased accessibility of internal pores with increasing particle size.

Table 2. Measured specific surface areas of basalt and breccia sorbents.

\begin{tabular}{ccc}
\hline \hline Sorbent & Size Fraction $(\mathrm{mm})$ & Surface Area $\left(\mathrm{m}^{2} / \mathrm{g}\right)$ \\
\hline Basalt & $833-600$ & 2.4024 \\
& $600-354$ & 2.537 \\
\multirow{2}{*}{ Breccia } & $833-600$ & 8.3936 \\
& $600-354$ & 9.432 \\
\hline \hline
\end{tabular}

Inspection of the table also reveals the differences in surface areas between the two sorbent types with that of the breccia being almost four times larger than that of the basalt. It is important to be aware of this because it enables normalization of solute sorption data to surface area and, ultimately, allows a meaningful comparison to be made regarding sorption of ions as a function of sorbent type. For example, the breccia would require roughly $1 / 4$ the solid concentration of the basalt to have roughly the same overall surface area.

The results of pore size analysis can be seen in Table 3. (Note: The results presented are for the 600-354 $\mu \mathrm{m}$ size fraction and are averaged values of duplicate analyses). As can be seen from the table, the average pore diameter (4V/A) is $205.18 \AA$ for the basalt, and $153.43 \AA$ for the breccia. Based on the average pore size diameter, these materials can be classified as mesoporous, referring to materials with pore size diameters between 20 and 500A. Figures 7 and 8 illustrate the adsorption and desorption branches of the nitrogen isotherms for the basalt and the breccia, respectively.

Table 3. Pore size measurements for the basalt and breccia.

\begin{tabular}{lcc}
\hline \hline & Basalt & Breccia \\
\hline BJH Adsorption Average Pore Diameter (4V/A) & $240.48 \AA$ & $158.75 \AA$ \\
BJH Desorption Average Pore Diameter (4V/A) & $122.52 \AA$ & $90.42 \AA$ \\
Average Pore Diameter (4V/A) & $205.18 \AA$ & $153.43 \AA$ \\
\hline \hline
\end{tabular}

Inspection of both figures shows the results of each duplicate experiment to be in close agreement with each other. Table 3 shows the average pore diameters (4V/A) calculated from the 


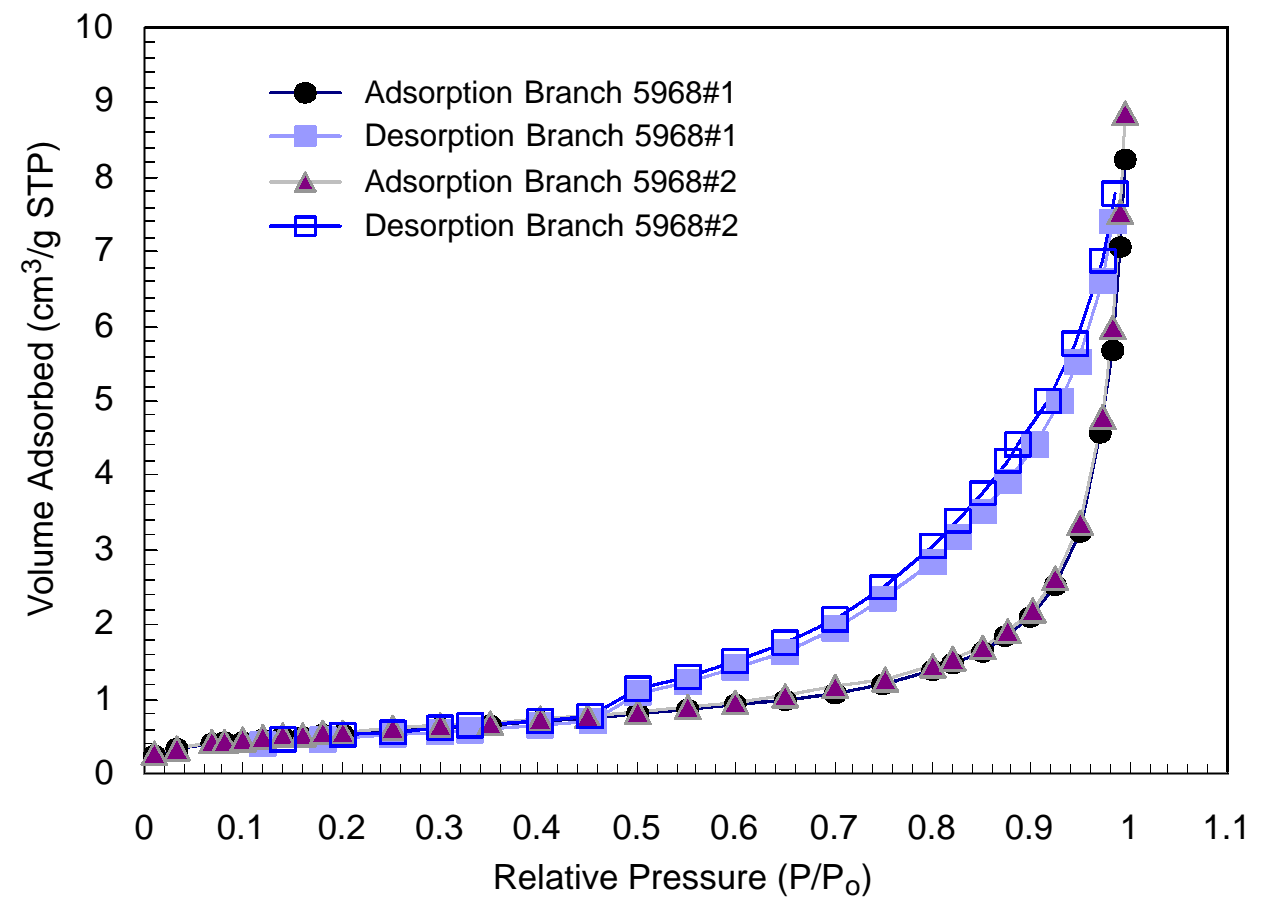

Figure 7. Isotherm of nitrogen adsorption/desorption on the basalt.

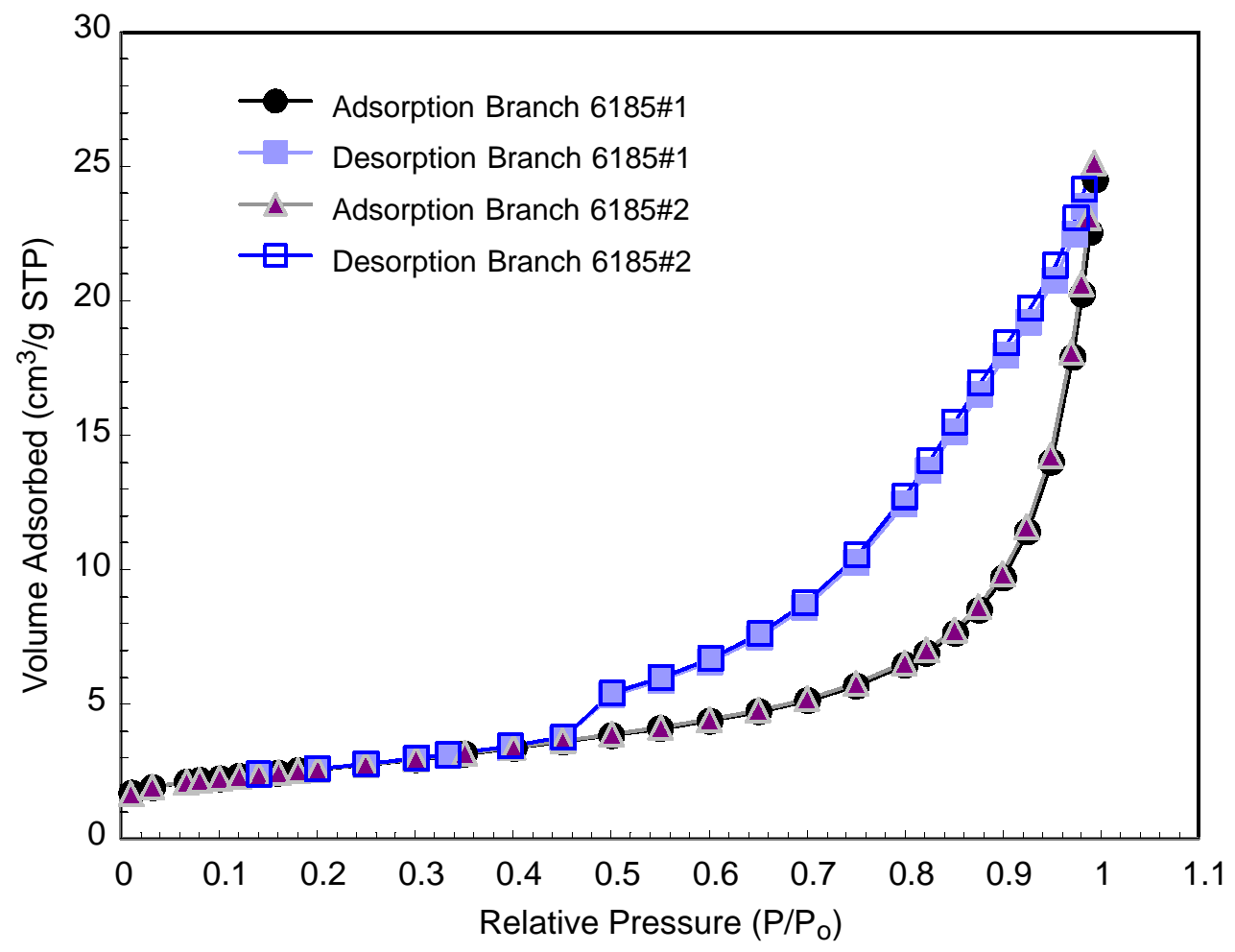

Figure 8. Isotherm of nitrogen adsorption/desorption on the breccia. 
adsorption and desorption branches of each sorbent. The average pore diameter estimated from the adsorption branch (as averaged from duplicate analysis) was $240.48 \AA$ and $158.75 \AA$ for the basalt and the breccia, respectively. The average pore diameter estimated from the desorption branch was $122.52 \AA$ and $90.42 \AA$ for the basalt and breccia, respectively.

In conclusion, it can be seen that the basalt has a somewhat larger average pore diameter than the breccia. This is consistent with the finding that the breccia has the higher specific surface area because, as previously mentioned, specific surface area in inversely proportional to size; thus the smaller pore sizes are expected to have larger surface areas.

\section{Soil Solution $\mathrm{pH}$ and Cation Exchange Capacity}

The soil solution $\mathrm{pH}$ was measured by suspending an amount of the sorbent in NANOpure ${ }^{\mathrm{TM}}$ water and allowing it to equilibrate for approximately 24 hours. The $\mathrm{pH}$ values obtained for solid concentration of $1 \mathrm{~g} / \mathrm{L}$ were 8.511 and 8.765 for the basalt and breccia, respectively. These results become important, as is discussed later in this report, when looking at the sorption of $\mathrm{Pb}$ on the sorbents. It is at a $\mathrm{pH}$ of approximately 8 that $\mathrm{Pb}$ sorption on each sorbent most closely resembles a linear isotherm.

The cation exchange capacity (CEC) was determined according to Busenberg and Clemency (1973). The measurements for each sorbent were performed in duplicate and the final value obtained was an average of the two individual experiments. The CEC of the basalt was $86.3 \mathrm{meq} / \mathrm{kg}$, and the CEC of the breccia was $183 \mathrm{meq} / \mathrm{kg}$. Note that the CEC of the breccia was approximately twice that of the basalt. This can most likely be attributed to the fact that the breccia has a higher surface area than the basalt, and potentially greater number of reactive sites for exchanging ionic species per unit mass of material. Thus, it is no surprise that the material with the higher surface area has the higher CEC.

\section{The Elements of Interest}

$\underline{\text { Lead }}$

Lead is perhaps the most common of the toxic heavy metal elements and is normally found in sulfides forming the common mineral galena, $\mathrm{PbS}$. The element occurs naturally in the earth's crust with an average concentration of 14 parts per million ( $\mathrm{ppm}$ ). In soils, concentrations can range from 2-200 parts per billion (ppb) for normal, unpolluted soils to as high as 1-30 ppm in polluted soils (Cox, 1995).

Lead is introduced naturally into the environment from the erosion of lead-containing rocks and through gaseous emissions during volcanic activity. In addition to natural emissions, anthropogenic sources of lead include lead smelting and refining, automobile emissions, lead-acid storage batteries, the production of alkyllead compounds for use as anti-knock agents in gasoline, roofing materials, pigments (white lead, $\left.\mathrm{Pb}_{3}\left(\mathrm{CO}_{3}\right)_{2}(\mathrm{OH})_{2}\right)$, pipes for domestic water systems, manufacturing of cable sheathings, sheet, pipe, foil and tubes, solders and alloys, ammunition, the production of various inorganic compounds, and protective shields for nuclear chemists, x-ray operators, and radiologists (Waldron, 1980; Cox, 1995).

Lead primarily affects the blood, the nervous system, and the kidney and symptoms of lead poisoning include anemia, anorexia, and abdominal pains, as well as neurological effects such as irritability, mood disturbance, and loss of coordination. The residence time of lead in the body is very long, one reason being that a significant amount is taken up in the bones where the $\mathrm{Pb}^{2+}$ replaces some $\mathrm{Ca}^{2+}$ in calcium phosphates (Cox, 1995). 


\section{$\underline{\text { Cesium }}$}

A rare Group IA element, Cs has little use, no known biological role, and is non-toxic. Chemically, cesium resembles rubidium and potassium, and is characterized as being a silvery-white, very soft metal which reacts rapidly with oxygen and explosively with water. Cesium occurs as the hydrated aluminosilicate pollucite, $\mathrm{Cs}_{4} \mathrm{Al}_{4} \mathrm{Si}_{9} \mathrm{O}_{26} \bullet \mathrm{H}_{2} 0$, but the world's only commercial source is at Bernic Lake, Manitoba, and Cs is mainly obtained as a byproduct of the lithium industry (Greenwood and Earnshaw, 1984; Emsley, 1989). It is not very abundant in the Earth's crust, there being only 7 ppm present. Detectable amounts are found in plant and animal organisms, mineral waters, and soils (Hart, et al., 1975).

Cesium metal is used in photoelectric cells, spectrographic instruments, scintillation counters, radio tubes, military infrared signaling lamps, and various optical and detecting devices. Cesium compounds are used in glass and ceramic production, as absorbents in carbon dioxide purification plants, as components of getters in radio tubes, and in microchemistry. Cesium salts have been used medicinally as antishock agents after administration of arsenic drugs (Hart, et al., 1975).

Although Cs is not known to be toxic, radioactive isotopes of cesium formed as fission products from uranium are indeed of environmental concern. Cesium-137 is a significant health hazard because its long half life of about 30 years allows it to persist in the environment as a highly radioactive element. Besides its persistence and high activity, ${ }^{137} \mathrm{Cs}$ has the further insidious property of being mistaken for potassium by living organisms and taken up as part of the fluid electrolytes, thereby becoming bioaccumulated through the food chain (Hammond, 1992). One positive function of the radioactive isotope, however, is its use in the treatment of cancer.

\section{Bromine}

Bromine is a rather rare element in the earth's crust and occurs exclusively as the bromide ion, $\mathrm{Br}^{-}$. Being chemically similar to chlorine, it exhibits many of the same characteristics, such as being very soluble and relatively abundant in the ocean. Most bromine used for industrial purposes is extracted from the sea water or other natural brines. In most cases, the element is not used in its elemental or ionic form, but is converted to organic bromine compounds such as ethylene dibromide, $\mathrm{CH}_{2} \mathrm{BrCH}_{2} \mathrm{Br}$, which is used as a fuel additive. Other organic bromides are used as pesticides or as fire retardants for synthetic fibers (Cox, 1995).

As the bromide ion, the element is universally present in life along with the similar chloride. It is not thought to be an essential element, though several bromide compounds have been found in marine organisms. Like chlorine, the elemental form $\mathrm{Br}_{2}$ is highly toxic. Likewise, elevated concentrations of $\mathrm{Br}^{-}$appear to have a depressive effect on the nervous system contributing to its use as a sedative and as an anti-convulsant for treating epilepsy.

\section{Experimental Procedures}

\section{Batch Equilibrium Sorption Experiments with the Cannikin Site Core Samples}

Batch equilibrium sorption experiments, using the reactive $\mathrm{Pb}$ and $\mathrm{Cs}$ solutes only, were conducted in individual 12-mL polypropylene centrifuge tubes. A specific amount of solid was added to the centrifuge tubes, the amount depending on the final solid concentration desired. Almost all experiments were performed using $1 \mathrm{~g} / \mathrm{L}$ solid. A variable amount of either $0.1 \mathrm{M} \mathrm{HNO}_{3}$ (nitric acid) or $0.1 \mathrm{M} \mathrm{NaOH}$ (sodium hydroxide) was added to adjust the $\mathrm{pH}$ to the approximate final $\mathrm{pH}$

value desired. The amounts of acid and base required for $\mathrm{pH}$ adjustment were determined by trial 
and error. Typically, a $\mathrm{pH}$ range between 5 and 9 was targeted. After the initial acid or base addition, the solution was allowed to equilibrate without further $\mathrm{pH}$ adjustments.

A set of nine individual centrifuge tube-reactors was set up at a time with varying target $\mathrm{pH}$ values. The first of these was a control tube to which no soil was added. Approximately $59 \mu \mathrm{L}$ of either $1.7 \times 10^{-5}, 1.7 \times 10^{-4}, 1.7 \times 10^{-3}$, or $1.7 \times 10^{-2} \mathrm{M}$ metal ion were added to the centrifuge tubes to achieve the desired final total metal concentration in the samples, ranging from $10^{-7}$ to $10^{-4} \mathrm{M}$. The adsorbate added was either $\mathrm{Pb}\left(\mathrm{NO}_{3}\right)_{2}$ (lead nitrate) or $\mathrm{CsNO}_{3}$ (cesium nitrate) depending on the experiment being performed. The necessary quantity of NANOpure ${ }^{\mathrm{TM}}$ water was added to result in a final solution volume of $10 \mathrm{~mL}$. All reagents used were of ACS grade quality grade or better. NANOpure $^{\mathrm{TM}}$ water was used exclusively for all solutions prepared.

The individual centrifuge tubes were allowed to equilibrate for at least 24-hours by end-over-end rotation at $8 \mathrm{rpm}$. Preliminary experimental work showed that this equilibration time was indeed adequate. Although true equilibrium, in a strict thermodynamic sense, was most likely not reached within the 24 hour equilibration period, the conclusions presented here are still valid, based on the much shorter time scale for the sorption processes described here, compared to processes such as solid solution formation and phase transformations, which would tend to shift the position of equilibrium.

Upon reaching equilibrium, the final $\mathrm{pH}$ of the suspension was measured using an Orion model $720 \mathrm{pH}$ meter with an Orion Ross glass combination electrode. The $\mathrm{pH}$ meter was calibrated daily before use with $\mathrm{pH} 4.00,7.00$, and 10.00 buffers. Immediately following the $\mathrm{pH}$ measurement, solid-solution separation was achieved using a Marathon K/R 21 centrifuge and centrifuging the samples at $9000 \mathrm{rpm}$ for 30 minutes. After centrifugation, a 2-mL aliquot was removed from the supernatant and acidified with $24 \mu \mathrm{L}$ of concentrated high purity $\mathrm{HNO}_{3}$ before analysis.

Ion concentrations of the aliquots were measured using a Perkin-Elmer $4110 \mathrm{ZL}$ atomic absorption spectrophotometer equipped with a graphite furnace and Zeeman background correction. The relative fractional uptake (percent sorbed) of the ions by the sorbent was determined by comparing the ion concentrations in the supernatant to the concentration of the control sample. The equation used to determine the percent sorbed is given by:

$$
\% \text { Sorbed }=\frac{\left(\mathrm{C}_{\mathrm{o}}-\mathrm{C}_{\mathrm{eq}}\right)}{\mathrm{C}_{\mathrm{o}}} \times 100
$$

where: $\mathrm{C}_{\mathrm{o}}=$ total concentration of metal added to sample $(\mathrm{mol} / \mathrm{L})$; and $\mathrm{C}_{\mathrm{eq}}=$ equilibrium concentration of metal remaining in the supernatant $(\mathrm{mol} / \mathrm{L})$

Most experiments were conducted in synthetic groundwater having a composition representative of that found in the field. This choice was made because use of partitioning coefficients to predict the fate and transport of inorganic contaminants in natural hydrogeological environments requires estimation of the coefficients under identical geochemical conditions to those found at the site being studied. Failure to do so may result in severe over- or underestimation of contaminant transport. An analysis of both, the site and synthetic groundwater can be found in Table 4. 
Table 4. Composition of site and synthetic groundwater.

\begin{tabular}{lccc}
\hline \hline Species & $\begin{array}{c}\text { Site Groundwater } \\
(\mathrm{mg} / \mathrm{L})\end{array}$ & $\begin{array}{c}\text { Site Groundwater } \\
(\mathrm{mol} / \mathrm{L})\end{array}$ & $\begin{array}{c}\text { Synthetic Groundwater } \\
(\mathrm{mol} / \mathrm{L})\end{array}$ \\
\hline $\mathrm{SiO}_{2}$ & $3.1-3.4$ & $5.66 \mathrm{E}-04-$ & - \\
$\mathrm{Al}^{3+}$ & - & - & - \\
$\mathrm{Fe}^{3+}$ & $<0.01$ & - & - \\
$\mathrm{Mn}^{2+}$ & $0.75-3.5$ & $6.19 \mathrm{E}-05$ & - \\
$\mathrm{Mg}^{2+}$ & $<0.1-170$ & $6.99 \mathrm{E}-03$ & $6.99 \mathrm{E}-03$ \\
$\mathrm{Ca}^{2+}$ & $260-1900$ & $4.74 \mathrm{E}-02$ & $4.74 \mathrm{E}-02$ \\
$\mathrm{Sr}^{2+}$ & $2.2-21$ & $2.28 \mathrm{E}-04$ & - \\
$\mathrm{Li}^{+}$ & $0.2-0.5$ & $7.20 \mathrm{E}-05$ & - \\
$\mathrm{Na}^{+}$ & $1980-8700$ & $3.65 \mathrm{E}-01$ & $3.65 \mathrm{E}-01$ \\
$\mathrm{~K}^{+}$ & $20-120$ & $3.07 \mathrm{E}-03$ & $3.07 \mathrm{E}-03$ \\
$\mathrm{HCO}_{3}{ }^{-}$ & $0-400$ & $7.05 \mathrm{E}-04$ & $7.05 \mathrm{E}-04$ \\
$\mathrm{CO}_{3}{ }^{2-}$ & 0 & $0.00 \mathrm{E}+00$ & $0.00 \mathrm{E}+00$ \\
$\mathrm{SO}_{4}{ }^{2-}$ & $890-2000$ & $1.87 \mathrm{E}-02$ & $1.87 \mathrm{E}-02$ \\
$\mathrm{Cl}^{-}$ & $3000-16000$ & $4.51 \mathrm{E}-01$ & $4.39 \mathrm{E}-01$ \\
$\mathrm{~F}^{-}$ & $<0.1-1.0$ & - & - \\
$\mathrm{NO}_{3}{ }^{-}$ & $<0.1-1.0$ & $3.23 \mathrm{E}-06$ & - \\
$\mathrm{PO}_{4}{ }^{3-}$ & $<0.1-5.4$ & - & - \\
$\mathrm{Note}^{-} \mathrm{pH}$ & & 6.9 & $\sim 7.8$ \\
\hline \hline
\end{tabular}

Diffusion Experiments with the Cannikin Site Core Samples

Diffusion experiments were conducted using small cores. The core (having typical dimensions no larger than $1 \frac{1 / 2}{2} \times 3 / 4$ " $x^{3 / 4}$ ") was cut from the full core sample using a water mill saw and the bulk density, true density, and porosity determined as described in the previous section. Once the bulk density, true density, and porosity of the sample were determined, the diffusion experiments were conducted as follows.

The core was first saturated in a $0.1 \mathrm{M}$ solution of sodium bromide $(\mathrm{NaBr})$ prepared using the synthetic groundwater. The saturation process was continued until no change in mass occurred. On average, saturation required approximately three weeks.

Prior to beginning the diffusion experiments, all but one outer surface of the sample were sealed with Varathane, a clear floor finish, to ensure that the bromide tracer was only able to diffuse out through the exposed end of the core. The experimental apparatus in which the diffusion experiments were conducted is shown in Figure 9. Each apparatus consisted of a one-liter mason jar having a tight-fitting screw-type lid. Each lid was equipped with a rubber septum for sampling and a threaded rod to which the core sample was attached and suspended above the underlying solution. The threaded rod allowed the height of the core sample to be adjusted to maintain constant contact with the underlying reservoir of solution. When using the bromide tracer, this underlying solution was $500 \mathrm{~mL}$ of NANOpure water. Each cell was also fitted with a 6-in long, 18-gauge 


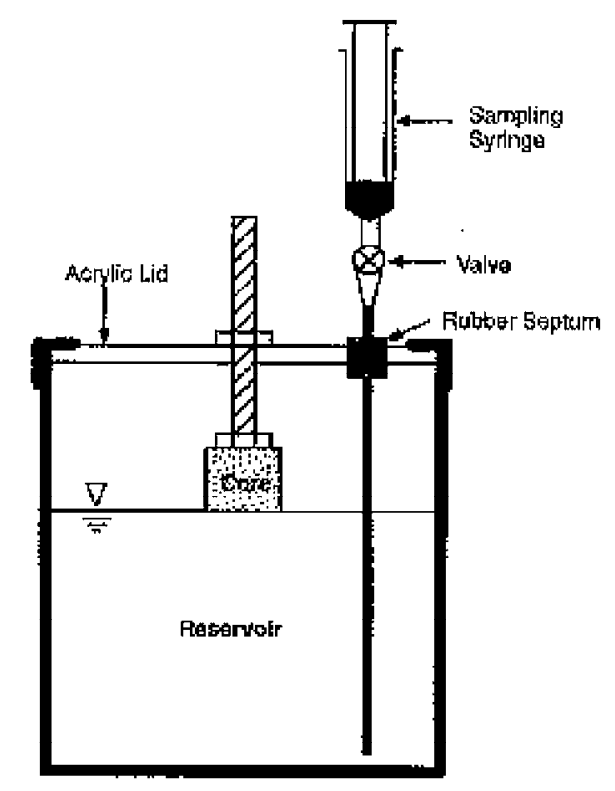

Figure 9. Experimental apparatus used in the diffusion experiments with $\mathrm{NaBr}$.

needle, permanently placed through the rubber septum. This allowed for the collection of 2-mL samples of reservoir solution. The collected samples were then analyzed using an Orion 94-35 bromide selective electrode and an Orion 90-02 double junction reference electrode to determine the relative change in $\mathrm{Br}$ concentrations with time. As a check, some samples were additionally analyzed by ion chromatography (IC) to test the accuracy of the ion selective electrode.

\section{RESULTS AND DISCUSSION}

The discussion of the results is divided into three sections. The first section presents a discussion of the results of the batch equilibrium sorption experiments for both the basalt and the breccia. This section is further subdivided into three parts: (1) lead sorption, (2) cesium sorption, and (3) isotherm parameter estimation. The second section presents the results of the diffusion experiments for both sorbents, followed by a discussion of the calculated diffusion parameters. Finally, the third section presents a comparison of the data for each sorbent where any similarities or differences are identified and discussed.

\section{Sorption of $\mathrm{Pb}$ and $\mathrm{Cs}$ on Cannikin Basalt and Breccia}

\section{Lead Sorption}

Sorption of $\mathrm{Pb}$ on $1.0 \mathrm{~g} / \mathrm{L}$ basalt at concentrations ranging from $10^{-4}$ to $10^{-6} \mathrm{M}$ in synthetic groundwater (ionic strength $\approx 0.5 \mathrm{M}$ ) is shown in Figure 10. Inspection of this figure shows that, in general, the fractional uptake is a function of $\mathrm{Pb}$ concentration, decreasing with increasing metal concentration. For example, sorption of $10^{-4} \mathrm{M} \mathrm{Pb}$ ranges from approximately 1 percent at a $\mathrm{pH}$ around 4 to 95 percent at a $\mathrm{pH}$ around 10 . Sorption of $10^{-6} \mathrm{M} \mathrm{Pb}$ at these same $\mathrm{pH}$ values is somewhat higher, approximately 18 percent at a $\mathrm{pH}$ around 4 to 96 percent at a $\mathrm{pH}$ around 10 . One should note that, although the fractional uptake decreases with increasing concentration (as a fraction of total metal concentration sorbed), the total metal sorbed is actually increasing. The behavior of $\mathrm{Pb}$ displayed in these graphs is typical for a cation sorbing on amphoteric sites, i.e., increasing sorption 


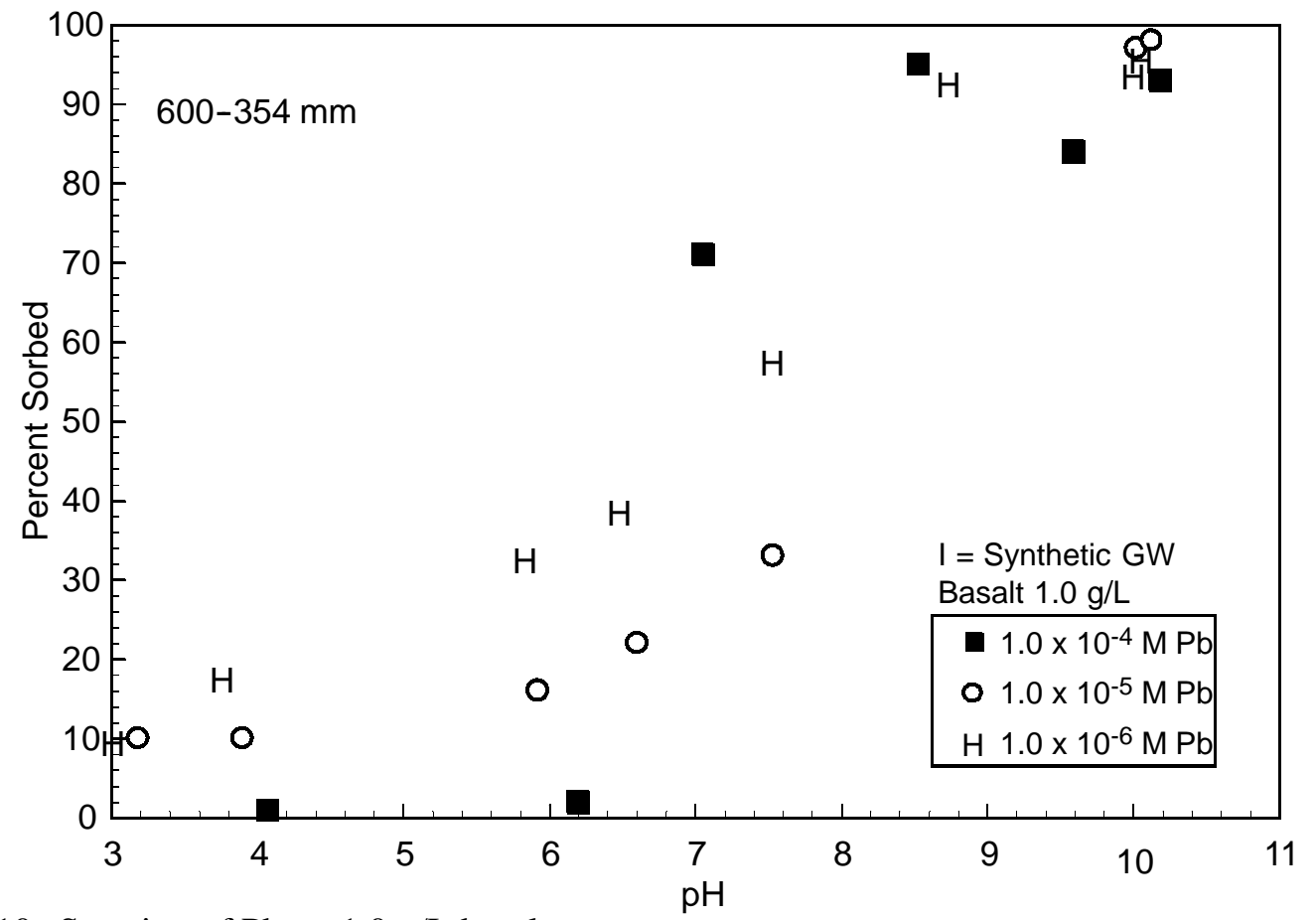

Figure 10. Sorption of $\mathrm{Pb}$ on $1.0 \mathrm{~g} / \mathrm{L}$ basalt.

with increasing $\mathrm{pH}$. For example, inspection of $\mathrm{Pb}$ sorption at $10^{-5} \mathrm{M} \mathrm{Pb}$ clearly shows the fractional uptake of $\mathrm{Pb}$ increasing from approximately 10 percent at a low $\mathrm{pH}$ of 3 to a fractional uptake of essentially 99 percent at a $\mathrm{pH}$ of approximately 10 . This $\mathrm{pH}$-dependent sorption behavior suggests that the $\mathrm{Pb}^{2+}$ sorption is limited to amphoteric sites. Internal, permanent charge, cation-exchange sites are apparently inaccessible at a high ionic strength such as that used in this experiment. Formation of $\mathrm{pH}$-dependent surface precipitates is also possible. Consideration of the sorption of $10^{-4} \mathrm{M} \mathrm{Pb}$ reveals a sharp increase in the percent $\mathrm{Pb}$ sorbed between $\mathrm{pH}$ of 6 and 7. Such an abrupt increase in slope is a good indication that $\mathrm{Pb}$ surface or bulk precipitates may be forming. Unfortunately, however, macroscopic studies alone cannot be used to distinguish between different types of sorption mechanisms. Additional spectroscopic experiments would be required to identify the mechanism as absorption, adsorption, or surface precipitation and, specifically, whether the ion is binding as an inner- or outer-sphere complex. The fact that $\mathrm{Pb}$ shows considerable sorption at such a high ionic strength is indicative that it is most likely forming a strong, inner-sphere complex. For more information regarding these binding mechanisms, see Papelis (1996).

Sorption of $\mathrm{Pb}$ on $1.0 \mathrm{~g} / \mathrm{L}$ breccia at concentrations ranging from $10^{-4}$ to $10^{-6} \mathrm{M}$ and using synthetic groundwater (ionic strength $\approx 0.5 \mathrm{M}$ ) is shown in Figure 11. Inspection of this figure shows a sorption pattern similar to that of $\mathrm{Pb}$ sorption on the basalt, i.e., decreasing fractional uptake with increasing metal concentration. Likewise, we see that sorption of $\mathrm{Pb}$ on the breccia follows a similar $\mathrm{pH}$-dependent behavior with percent $\mathrm{Pb}$ sorbed increasing from approximately 2 percent at $\mathrm{pH} 3$ to 98 percent at $\mathrm{pH} 10$ for the $10^{-5} \mathrm{M} \mathrm{Pb}$ concentration. This $\mathrm{pH}$-dependent sorption behavior, again, suggests that the internal cation-exchange sites are not accessible at the high ionic strength of the synthetic groundwater. Thus, $\mathrm{Pb}$ sorption on the breccia appears to be the result of sorption on external, $\mathrm{pH}$-dependent surface sites.

For comparison purposes, a plot was made showing the difference in sorption behavior of $\mathrm{Pb}$ between the basalt and the breccia. Inspection of Figure 12 shows, in general, higher sorption on the 


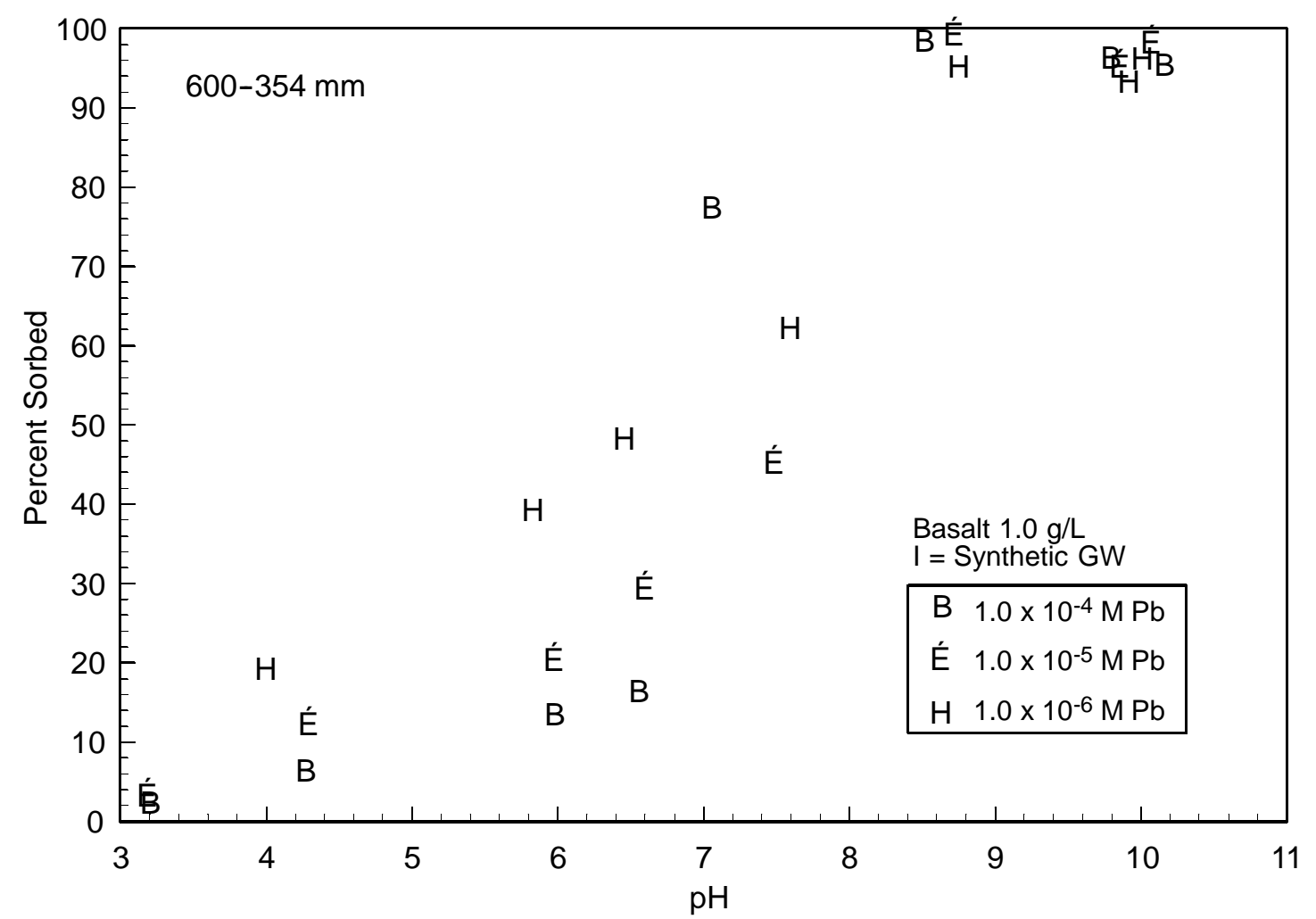

Figure 11. Sorption of $\mathrm{Pb}$ on $1.0 \mathrm{~g} / \mathrm{L}$ breccia.

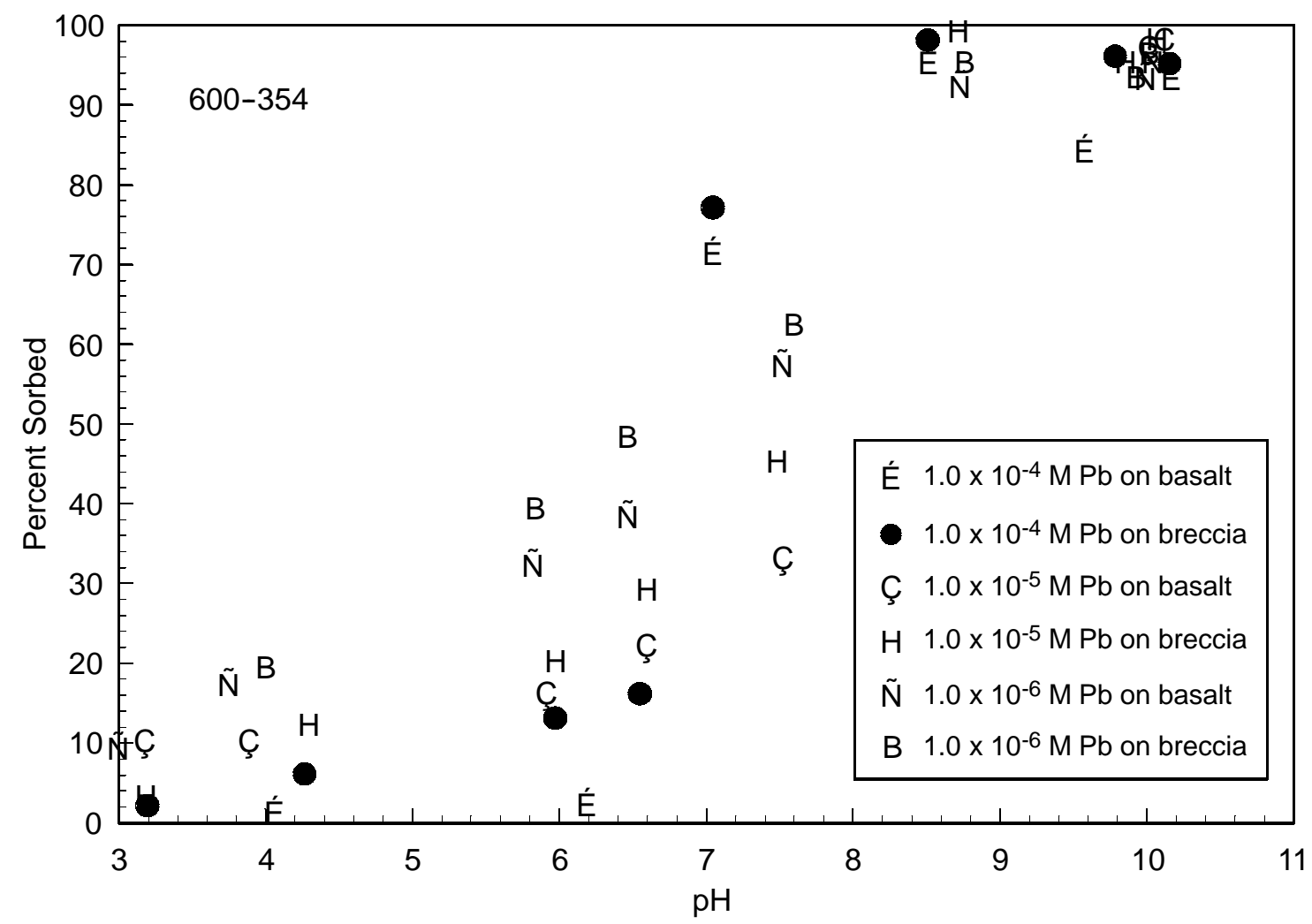

Figure 12. Sorption of $10^{-4}$ to $10^{-6} \mathrm{M} \mathrm{Pb}$ on basalt and breccia. 
breccia at all concentrations. This is expected because the breccia, having approximately four times the surface area of the basalt, would have a higher number of sorption sites available to which ions could bind.

To obtain an understanding of how the extent of metal sorption on each sorbent varied with particle size, experiments were performed using $\mathrm{Pb}$ and a slightly larger size fraction, i.e., 833 to $600 \mu \mathrm{m}$. The results of these experiments, using concentrations ranging from $10^{-4}$ to $10^{-6} \mathrm{M} \mathrm{Pb}$ can be seen in Figures 13 and 14 for the basalt and breccia, respectively. Inspection of these figures does show a slight increase in sorption as particle size decreases, which is expected as the smaller size fractions generally have a larger surface area. Because these size fractions are not very different, however, the difference in sorption is not significantly pronounced. Information regarding how the extent of sorption varies as a function of particle size is important because, at the actual field site, various types and scales of assemblages are present. Typically, as the scale increases, the reactivity of these assemblages decreases and it is thus important to keep this in mind when modeling solute transport.

\section{Cesium Sorption}

Unlike $\mathrm{Pb}$ sorption, $\mathrm{Cs}$ sorption on the basalt was essentially nonexistent when using the synthetic groundwater. This behavior indicates that, not only was Cs unable to compete effectively with other cations for internal cation exchange sites, but it was unable to bind to the amphoteric surface sites as well. Such behavior is somewhat expected because Cs is not readily hydrolyzable as is the $\mathrm{Pb}^{2+}$ cation and is thus not prone to making strong binding complexes with $\mathrm{pH}$-dependent surface sites. To test this hypothesis, the sorption behavior of Cs was also investigated using a $0.01 \mathrm{M}$ $\mathrm{NaNO}_{3}$ (sodium nitrate) background electrolyte concentration. Figure 15 shows the fractional uptake of $1 \times 10^{-6} \mathrm{M}$ Cs on $1.0 \mathrm{~g} / \mathrm{L}$ of basalt and breccia in $0.01 \mathrm{M} \mathrm{NaNO}_{3}$. It can be seen from this figure that $\mathrm{Cs}$ is able to sorb and that fractional uptake is weakly influenced by $\mathrm{pH}$ except at extremely low $\mathrm{pH}$. At such low $\mathrm{pH}$ values $\mathrm{Cs}$ is in competition with the $\mathrm{H}^{+}$ion, which is present in concentrations 2-3 orders of magnitude higher. In general, the behavior displayed suggests that sorption of Cs by both sorbents is primarily controlled by sorption on cation exchange sites. The dependence of Cs sorption on ionic strength is a good indication that it is forming outer-sphere sorption complexes, as expected for an alkali metal. Note, also, the slightly higher sorption occurring on the breccia which, again, results from it having the higher specific surface area.

\section{Isotherm Parameter Estimation}

The fractional uptake data obtained from the batch sorption experiments with $\mathrm{Pb}$ and $\mathrm{Cs}$ were used to construct sorption isotherms and to determine equilibrium partitioning coefficients. The amount of solute sorbed onto the soil can be calculated as the difference in mass of the solute in solution before and after reaction. As a result of the batch equilibrium experiments, it is possible to plot the mass sorbed per unit mass of soil, $\mathrm{S}$, as a function of the equilibrium concentration of solute remaining in solution, $\mathrm{C}_{\mathrm{eq}}$ (Fetter, 1994). This graphical representation is known as a sorption isotherm.

Several sorption isotherms have been developed and used over the years, however, the most commonly used are the linear, Freundlich, and Langmuir isotherms (Papelis, 1997). Because only the linear and Freundlich models were used in this study, they are discussed below. For more information on the Langmuir model, the reader is referred to Stumm and Morgan (1996), Drever (1997), Ruthven (1984), and Morel and Hering (1993). 


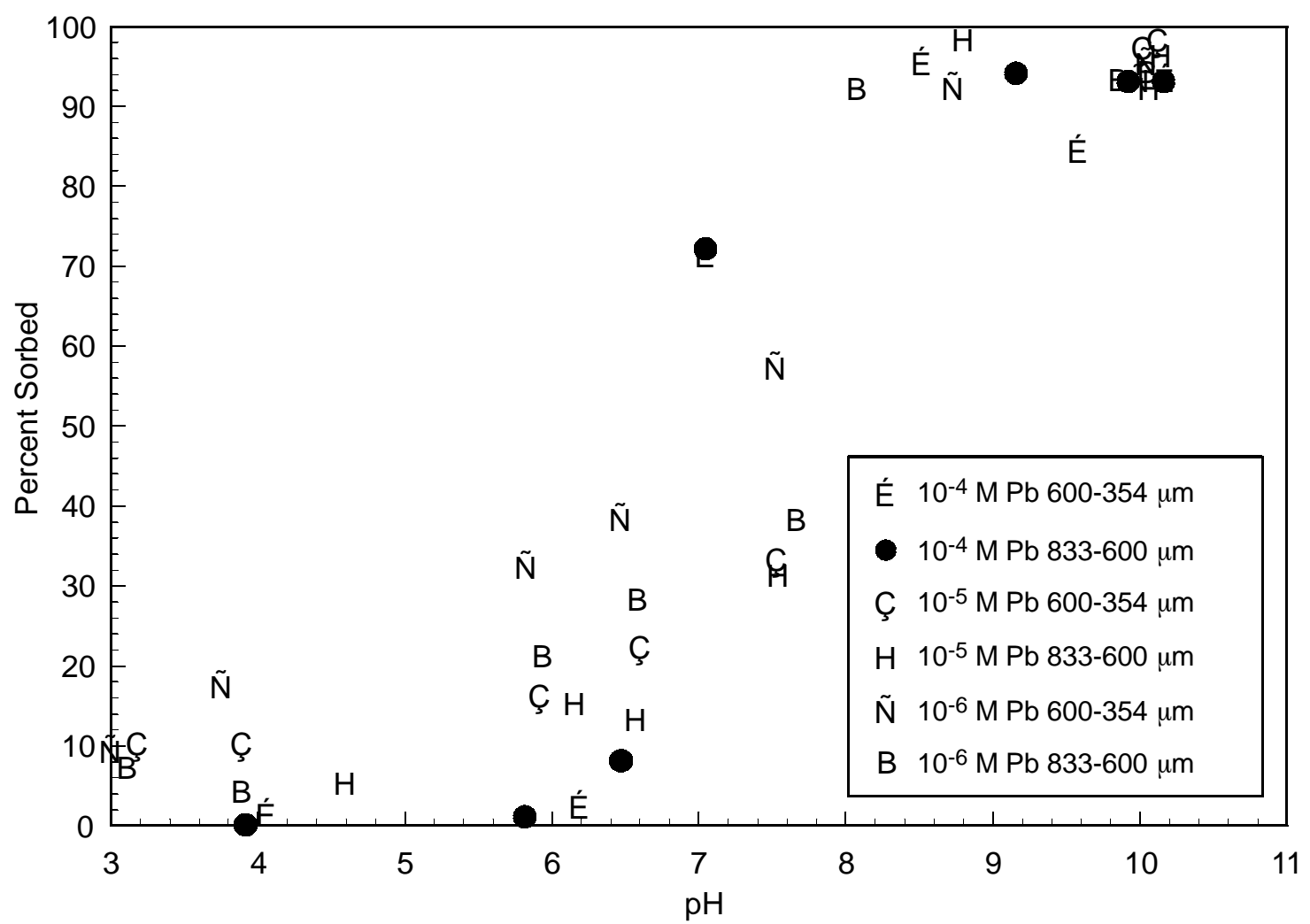

Figure 13. Comparison of sorption of $10^{-4}$ to $10^{-6} \mathrm{M} \mathrm{Pb}$ on larger and smaller size fractions of basalt.

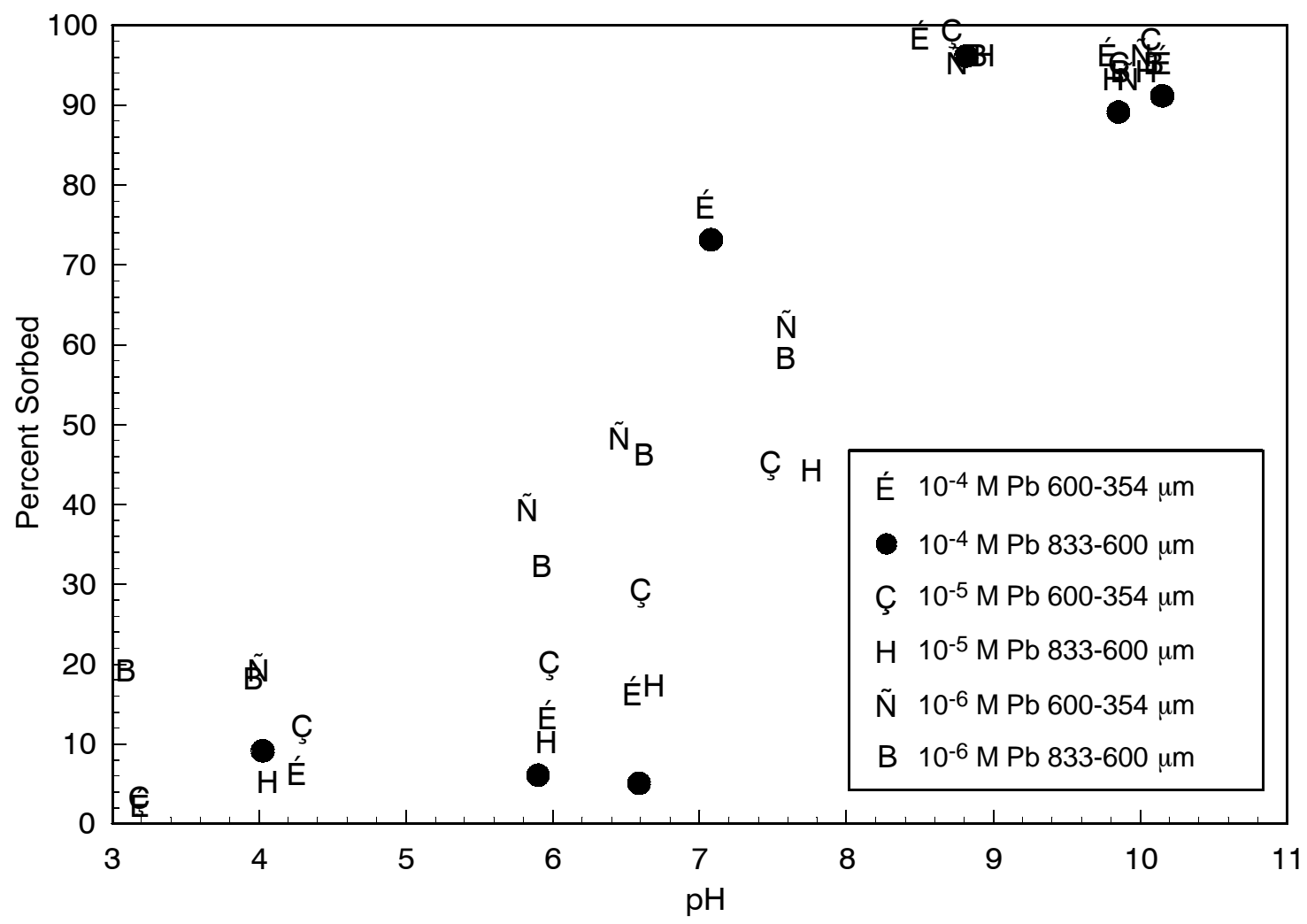

Figure 14. Comparison of sorption of $10^{-4}$ to $10^{-6} \mathrm{M} \mathrm{Pb}$ on larger and smaller sizes fractions of breccia. 


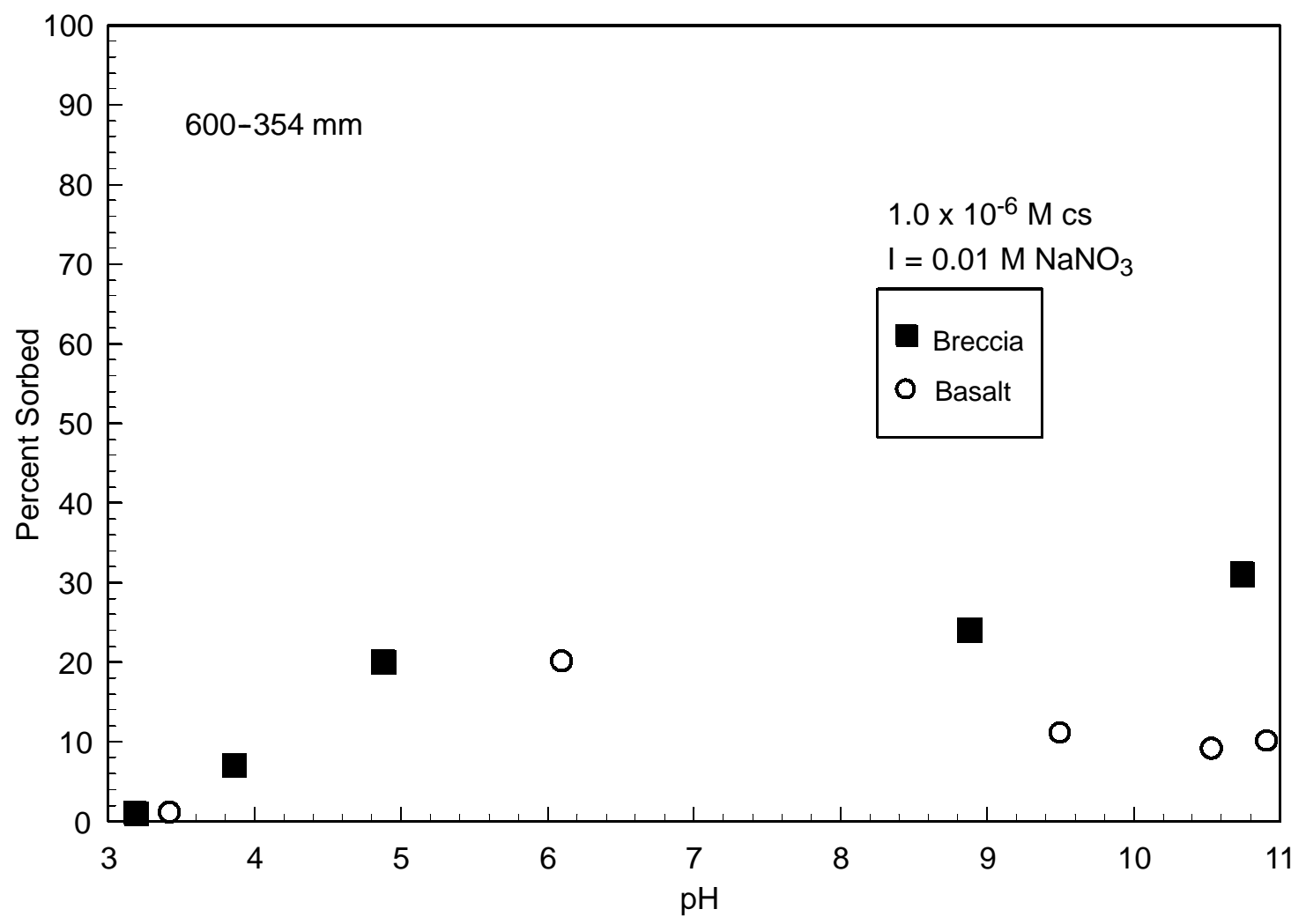

Figure 15. Sorption of $1 \times 10^{-6} \mathrm{M}$ Cs on $1.0 \mathrm{~g} / \mathrm{L}$ basalt and breccia.

The linear isotherm assumes that the amount of contaminant sorbed by the soil matrix is directly proportional to the concentration of the compound in solution (Travis and Etnier, 1981). The equation describing the linear isotherm is given as:

$$
\mathrm{S}=\mathrm{K}_{\mathrm{d}} \mathrm{C}_{\mathrm{eq}}
$$

where $\mathrm{S}=$ amount of solute sorbed ( $\mathrm{mol} / \mathrm{kg}$ solid), $\mathrm{C}_{\mathrm{eq}}=$ concentration of solute in solution (mol/L), and $\mathrm{K}_{\mathrm{d}}=$ distribution coefficient $(\mathrm{L} / \mathrm{kg})$.

In most instances, the $\mathrm{K}_{\mathrm{d}}$ value is the sought-after parameter and is used in various transport codes to model the migration of hazardous ions in the subsurface environment. The numerical value of the distribution coefficient is a function of the properties of the solid and the composition of the solution and thus cannot be easily transferred from one system to another. Futhermore, use of the $\mathrm{K}_{\mathrm{d}}$ assumes that the isotherm is truly linear and that the affinity of the sorbate for the sorbent remains the same for all levels of $\mathrm{C}_{\mathrm{eq}}$. Utilization of such a parameter when the above assumptions are not true may result in gross errors in sorption behavior predictions.

When sorption data do not exhibit a linear relationship, the Freundlich isotherm is often used instead. The Freundlich isotherm is the oldest of the nonlinear sorption isotherms and has been widely used to describe the sorption of solutes by soils (Travis and Etnier, 1981). The Freundlich isotherm is given as: 


$$
\mathrm{S}=\mathrm{K}_{\mathrm{f}} \mathrm{C}_{\mathrm{eq}} 1 / n
$$

where $\mathrm{S}=$ amount of solute sorbed ( $\mathrm{mol} / \mathrm{kg}$ solid), $\mathrm{C}_{\mathrm{eq}}=$ concentration of solute in solution (mol/L), $\mathrm{K}_{\mathrm{f}}=$ the Freundlich constant $\left((\mathrm{mol} / \mathrm{kg}) /\left((\mathrm{mol} / \mathrm{L})^{1 / \mathrm{n}}\right)\right)$, and $1 / n=$ the measure of nonlinearity (dimensionless).

The parameters $\mathrm{K}_{\mathrm{f}}$ and $1 / n$ represent the equivalent of $\mathrm{K}_{\mathrm{d}}$ and the exponent of the equilibrium concentration, respectively ( $1 / n$ is 1 , by definition, for the linear isotherm). The Freundlich isotherm applies very well to solids with heterogeneous surface properties because the $1 / n$ term takes into account that different sites have different binding energies, with molecules being sorbed at the sites with higher binding energies first, and at sites with lower binding energies later.

The linear and Freundlich parameters $\left(\mathrm{K}_{\mathrm{d}}\right.$ and $\mathrm{K}_{\mathrm{f}}$, respectively) calculated for $\mathrm{Pb}$ sorption on the basalt and breccia sorbents are presented in Table 5. The equilibrium data points used to construct the isotherms were obtained by hand fitting a best-fit curve to the fractional uptake data. Sorption isotherms for $\mathrm{Pb}$ contained a minimum of seven points and were constructed for sorption in synthetic groundwater at $\mathrm{pH}$ values of $6,7,8$, and 9. In all cases, $\mathrm{K}_{\mathrm{d}}$ and $\mathrm{K}_{\mathrm{f}}$ estimates were obtained by fitting a least squares line through the collected data points. The resulting $\mathrm{K}_{\mathrm{d}}$ graphs are shown in Figures 16 and 17.

Table 5. Linear and Freundlich isotherm parameters for lead sorption.

\begin{tabular}{cccccc}
\hline \hline $\begin{array}{c}\text { Background Electrolyte Used } \\
\text { (Synthetic Groundwater or } \\
\left.0.01 \mathrm{M} \mathrm{NaNO}_{3}\right)\end{array}$ & $\mathrm{pH}$ & $\begin{array}{c}\text { Sorbent } \\
\text { Type }\end{array}$ & $\begin{array}{c}\mathrm{K} \\
\left(\mathrm{m}^{3} / \mathrm{g}\right)\end{array}$ & $\begin{array}{c}\mathrm{K} \\
(\mathrm{g} / \mathrm{g})\left(\mathrm{g} / \mathrm{m}^{3}\right)^{1 / \mathrm{n}}\end{array}$ & $\begin{array}{c}1 / \mathrm{n} \\
(-)\end{array}$ \\
\hline Synthetic Groundwater & 6.0 & $\begin{array}{l}\text { Basalt } \\
\text { Breccia }\end{array}$ & $\begin{array}{l}2.14 \times 10^{-4} \\
3.17 \times 10^{-4}\end{array}$ & $\begin{array}{l}2.60 \times 10^{-4} \\
3.19 \times 10^{-4}\end{array}$ & 0.77 \\
& 7.0 & Basalt & $4.92 \times 10^{-4}$ & $5.75 \times 10^{-4}$ & 0.92 \\
& & Breccia & $5.80^{7} \times 10^{-4}$ & $5.25 \times 10^{-4}$ & 0.72 \\
& \multirow{2}{*}{8.0} & Basalt & $1.91 \times 10^{-3}$ & $2.28 \times 10^{-3}$ & 1.06 \\
& & Breccia & $1.66 \times 10^{-3}$ & $2.09 \times 10^{-3}$ & 0.96 \\
& \multirow{2}{*}{9.0} & Basalt & $1.59 \times 10^{-2}$ & $8.83 \times 10^{-2}$ & 1.53 \\
& & Breccia & $1.43 \times 10^{-2}$ & $3.28 \times 10^{-2}$ & 1.32 \\
\hline \hline
\end{tabular}

With respect to $\mathrm{Pb}$ sorption, several conclusions can be drawn by inspection of Table 5. First, the values of the isotherm parameters vary by orders of magnitude, a common phenomenon displayed by $\mathrm{pH}$-dependent sorption behavior. In general, both $\mathrm{K}_{\mathrm{d}}$ and $\mathrm{K}_{\mathrm{f}}$ values tend to increase with increasing $\mathrm{pH}$. This is expected because, as discussed earlier, an increase in $\mathrm{Pb}$ sorption is due to increased sorption on the amphoteric surface sites or increasing number or size of surface precipitates. Second, the isotherms do not exhibit true linearity as concluded by the fact that the Freundlich exponents are not equal to 1 , although the deviation from 1 is occasionally small. Because of the non-linearity of the isotherms, true distribution coefficients cannot be defined for this particular background electrolyte concentration. Observation of the table, however, shows that the Freundlich exponent comes quite close to 1 at $\mathrm{pH}$ 8. Because the measured groundwater $\mathrm{pH}$ was approximately 8 , the determined distribution coefficients may very well accurately describe the 


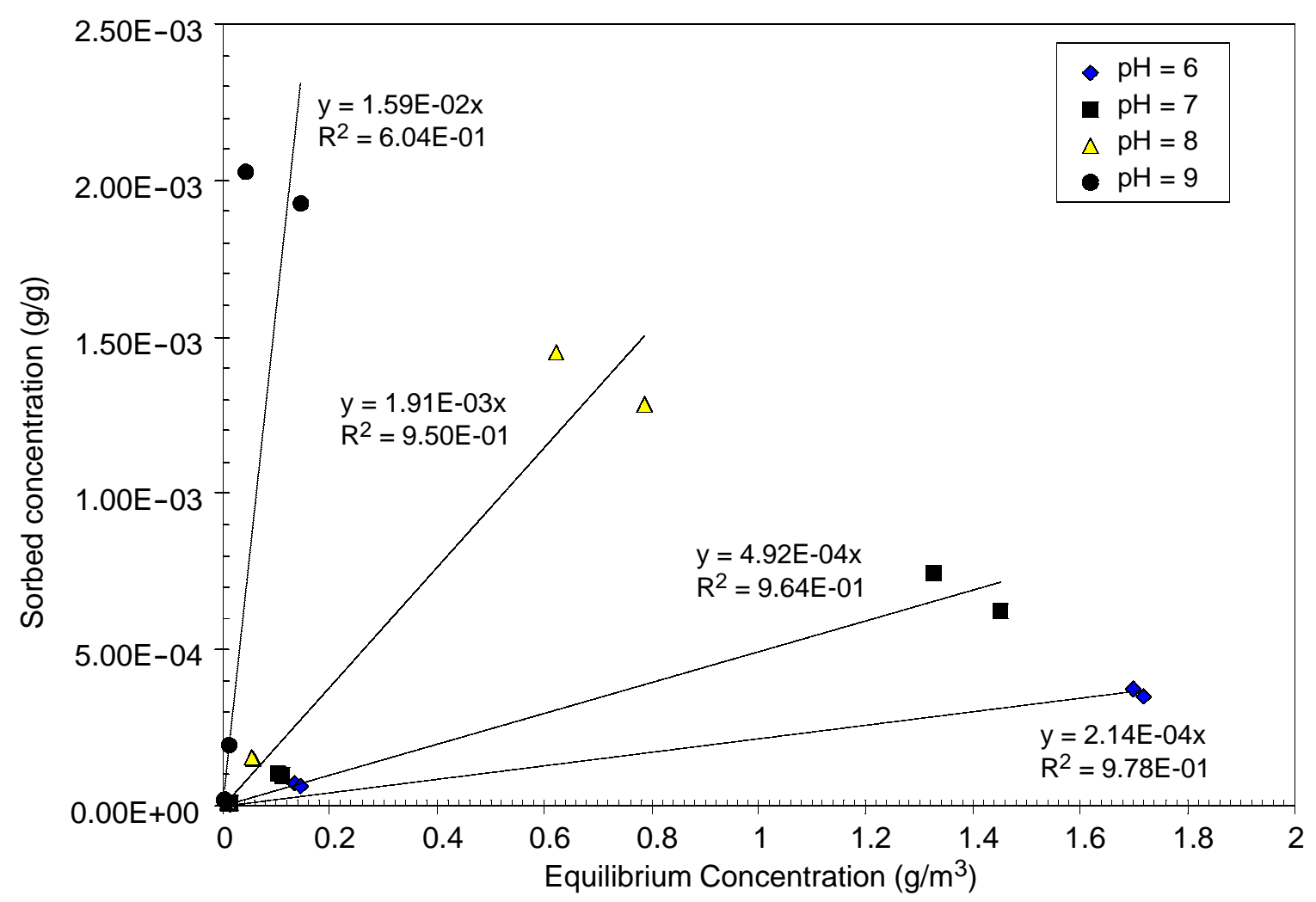

Figure 16. Linear isotherms of $\mathrm{Pb}\left(\mathrm{NO}_{3}\right)_{2}$ sorption on basalt at $\mathrm{pH}$ values of $6,7,8$, and 9 .

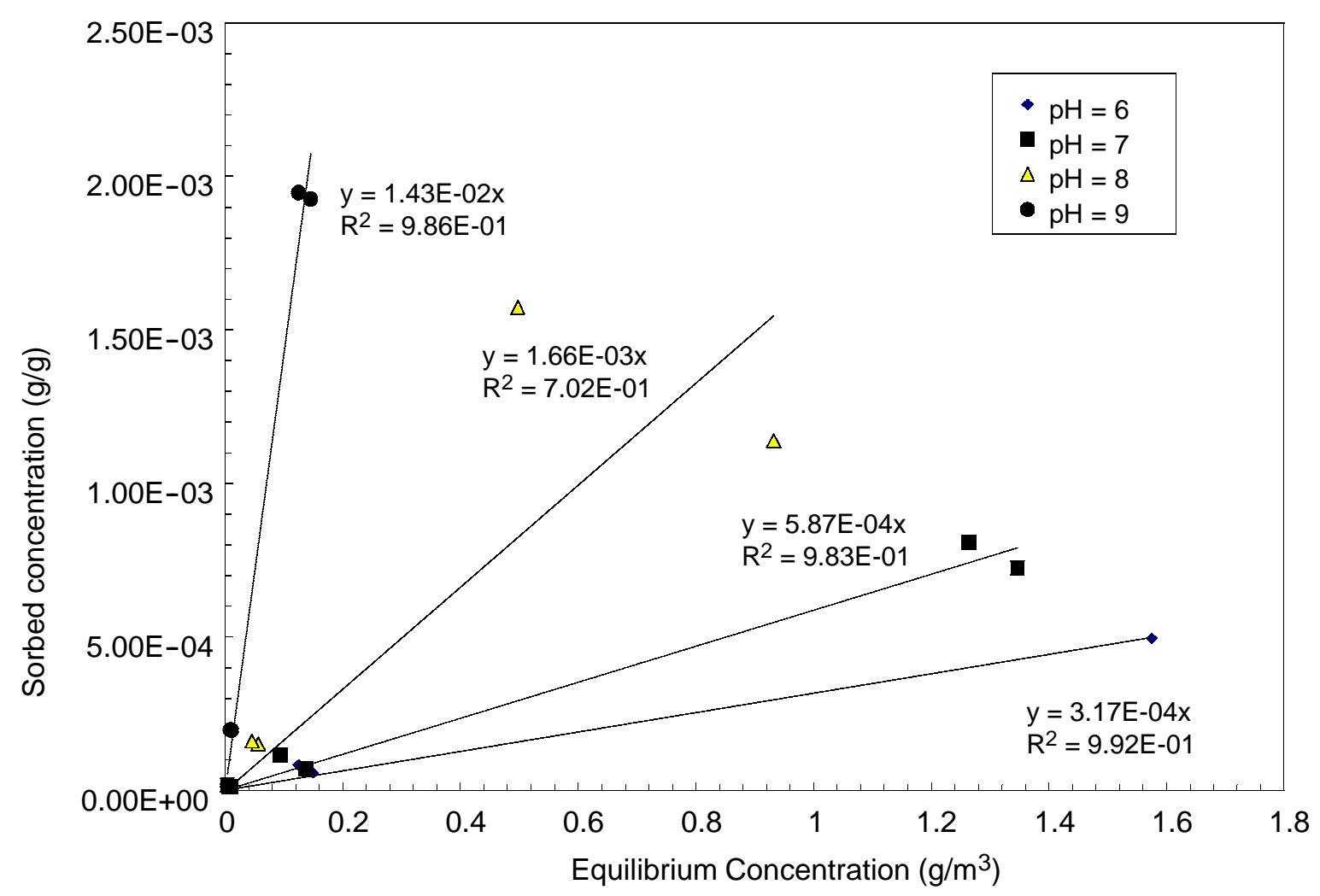

Figure 17. Linear isotherms of $\mathrm{Pb}\left(\mathrm{NO}_{3}\right)_{2}$ sorption on breccia at $\mathrm{pH}$ values of $6,7,8$, and 9 . 
migration of the $\mathrm{Pb}$ ion in this system. Otherwise, the calculated $\mathrm{K}_{\mathrm{f}}$ and $1 / n$ parameters can be used as an indication of the sorption capacity of the sorbent for the specific geochemical conditions at which the equilibrium data points were calculated.

Inspection of the table also reveals a trend with respect to the $1 / n$ values, in particular, the values increase with increasing $\mathrm{pH}$. This particular phenomenon indicates that $\mathrm{Pb}$ sorption is not occurring in a linear fashion and, as the deviation of the $1 / n$ value from one increases in the positive direction, there is actually an exponential increase in the amount of $\mathrm{Pb}$ being sorbed. Again, this may be an indication that $\mathrm{Pb}$ is forming precipitates at higher concentrations or $\mathrm{pH}$ values.

When comparing the $\mathrm{K}_{\mathrm{d}}$ and $\mathrm{K}_{\mathrm{f}}$ values of the two sorbents, it can also be seen that, at the lower $\mathrm{pH}$ values of 6 and 7, both values were higher for the breccia. This is expected because, as previously mentioned, the breccia, having approximately four times the specific surface area of the basalt, had more surface sites available on which sorption could occur. When comparing the $\mathrm{K}_{\mathrm{d}}$ and $\mathrm{K}_{\mathrm{f}}$ values of the two sorbents at the higher $\mathrm{pH}$ values of 8 and 9 , however, we see that these values are relatively close in most instances, suggesting that there was really no difference in the sorption behavior of $\mathrm{Pb}$ on the two sorbents. One possible explanation for this is because at these high $\mathrm{pH}$ values, nearly 100 percent sorption occurs on both sorbents resulting in partitioning coefficients that are quite similar.

In conclusion, it appears that the Freundlich isotherm best describes $\mathrm{Pb}$ sorption under the circumstances inherent to these experiments. Because the non-linearity of the isotherms is not extremely severe, however, linear distribution coefficients could be used as a starting point for estimating the migration of these ions in the subsurface environment as these are the parameters most commonly incorporated into transport models. Recognition of the limits of the applicability of this approach (concentration range and other experimental variables, however, is necessary before using the simpler linear isotherm, and it is once again noted that using these values beyond the experimental conditions can result in significant errors in sorption behavior prediction.

\section{Diffusion of Br through Cannikin Basalt and Breccia}

The following section discusses the results of the diffusion experiments performed with the Cannikin Site core samples and provides some background information regarding the underlying theory. A brief summary of the different types of diffusion parameters and how they are estimated is presented first, followed by the experimental results using the $\mathrm{Br}$ tracer. Calculations of diffusion coefficients for $\mathrm{Pb}$ and $\mathrm{Cs}$ are presented subsequently.

\section{Diffusion Parameter Estimation}

Diffusion experiments were conducted using intact pieces of the core samples and a $\mathrm{NaBr}$ tracer. The purpose of these experiments was to determine the extent of retardation that was attributable to matrix diffusion. In addition to sorption of solutes at the mineral-water interface, diffusion of ions into the rock matrix serves as an important retardation mechanism by removing ions from the flowing groundwater. Thus, it is important to take diffusion into account so that an accurate estimation of the migration of ions can be attained.

Specifically, the objective of performing the diffusion experiments was to arrive at values describing the diffusion of the $\mathrm{Br}$ ion through the core samples, including the effective and apparent diffusion coefficients, and the tortuosity. A brief discussion on each of these parameters and how they are determined is provided below. 
The diffusion of ions within the core sample was modeled using the analytical solution of the general diffusion equation:

$$
\frac{\partial C}{\partial t}=D \frac{\partial^{2} C}{\partial x^{2}}
$$

where $\mathrm{C}=$ concentration of diffusing species in solution $(\mathrm{mol} / \mathrm{L}), \mathrm{D}=$ diffusion coefficient $\left(\mathrm{m}^{2} / \mathrm{s}\right)$, $\mathrm{t}=$ time $(\mathrm{s})$, and $\mathrm{x}=$ distance in the direction of diffusion $(\mathrm{m})$.

The term "diffusion coefficient" in the above equation is used in a general sense and depending on the experimental conditions, it may take different meaning. When describing diffusion of a solute in bulk solution, the diffusion coefficient is referred to as the molecular diffusion coefficient, $\mathrm{D}_{\text {mol }}$. The molecular diffusion coefficient used in this experiment was determined by the Nernst-Haskell equation (Reid et al., 1977):

$$
D_{m o l}=\frac{R T}{F^{2}} \frac{1 / n_{+}}{1 / \lambda_{+}^{o}} \frac{+1 / n_{-}}{+1 / \lambda_{-}^{o}}
$$

where $\mathrm{D}_{\mathrm{mol}}=$ molecular diffusion coefficient $\left(\mathrm{m}^{2} / \mathrm{s}\right), \mathrm{T}=$ temperature $(\mathrm{K}), \mathrm{R}=$ gas constant $(8.314$ $\mathrm{J} / \mathrm{mol}-\mathrm{K}), \mathrm{F}=$ Faraday constant $(96485 \mathrm{C} / \mathrm{mol}), \lambda_{+}{ }^{\circ}, \lambda_{-}{ }^{\circ}=$ ionic conductivity at infinite dilution for cation and anion, respectively $\left(\mathrm{m}^{2} \mathrm{~S} / \mathrm{mol}\right)$, and $\mathrm{n}_{+}, \mathrm{n}_{-}=$valences of cation and anion, respectively (dimensionless).

In porous media, diffusion cannot proceed as fast as it can in a bulk solution because the ions must follow longer pathways as they travel in tortuous paths. To take this into account, an effective diffusion coefficient, $\mathrm{D}_{\text {eff, }}$, is used and is defined as:

$$
D_{e f f}=\frac{D_{m o l}}{\chi}
$$

where $\chi$ is the tortuosity (dimensionless), or the actual length of the flow path divided by the straight-line distance between the ends of the flow path of the diffusing species (Hershey and Howcroft, 1998; Fetter, 1994). The tortuosity factor (which accounts for pore structure effects on the length of the diffusion path) incorporates the effects of parameters such as particle size, porosity, and pore size distribution and has typical values ranging from approximately 1.5 to 10 (Papelis et al., 1995). The $\mathrm{D}_{\text {eff }}$ was determined by an analytical approach as described in the following section. Because there is no a priori method for tortuosity estimation, this value was estimated from Equation 8 .

If while flowing through the porous medium, the ions are sorbed onto the mineral surfaces or undergo any other reaction(s), the net rate of diffusion will obviously be reduced compared to that for nonsorbing species. In this case, the term apparent diffusion coefficient, $D_{a p p}$, is used to describe the diffusion of the solutes and is defined as:

$$
D_{a p p}=\frac{D_{m o l}}{\chi\left(1+\frac{\rho_{b} K_{d}}{\epsilon}\right)}
$$


where $\mathrm{D}_{\text {app }}=$ apparent diffusion coefficient $\left(\mathrm{m}^{2} / \mathrm{s}\right), \mathrm{D}_{\mathrm{mol}}=$ molecular diffusion coefficient $\left(\mathrm{m}^{2} / \mathrm{s}\right)$, $\chi=$ tortuosity (dimensionless), $\rho_{\mathrm{b}}=$ solid bulk density $\left(\mathrm{kg} / \mathrm{m}^{3}\right), \mathrm{Kd}=$ distribution coefficient $\left(\mathrm{m}^{3} / \mathrm{kg}\right)$, and $\varepsilon=$ porosity (dimensionless).

The apparent diffusion coefficient is a function of the solid structure, specifically its density, porosity, and tortuosity, and the specific sorbate-sorbent interactions. The distribution coefficient, $\mathrm{K}_{\mathrm{d}}$ can be estimated from batch equilibrium experiments. It should be noted here, however, that the use of Equation 9 assumes a linear distribution coefficient, $K_{d}$ and that, if such a value is not valid based on batch experiments, alternate methods would need to be employed.

It should also be noted here that the diffusion model requires the use of prescribed initial and time invariant boundary conditions (initial solute concentrations at $\mathrm{t}=0, \mathrm{C}_{\mathrm{o}}$, and the final solute concentration at equilibrium $\mathrm{C}_{\infty}$ ). Likewise, the diffusion was modeled assuming diffusion of fixed initial solute concentration out of the solid core into a well-stirred reactor of limited volume. The solution to Equation 6 would vary depending upon whether nonreactive and reactive solutes were being used due to sorption processes that may affect the latter. The solution for the case of a nonreactive tracer $(\mathrm{Br})$ is presented below.

\section{Solution to the Diffusion Equation for Nonreactive Solutes}

In the case of a nonreactive solute, and taking into account flow through a porous medium, the general diffusion equation becomes

$$
\frac{\partial C}{\partial t}=D_{e f f} \frac{\partial^{2} C}{\partial x^{2}}
$$

where all parameters are as defined in Equation 6. The solution to this equation (assuming no sorption and an independence of $\mathrm{D}_{\text {eff }}$ with concentration) is given by Crank (1975) as:

$$
C=C_{o} \operatorname{erft}\left(\frac{x}{2 \sqrt{D_{e f f}} t}\right)
$$

where erft is the error function, $\mathrm{C}=\mathrm{C}_{\mathrm{o}}$ at $\mathrm{t}=0$ for $\mathrm{x}<\mathrm{a} ; \mathrm{C}=0$ at $\mathrm{t}=0$ for $\mathrm{x}>\mathrm{a}$; and a is the length of the core. Taking the partial derivative, evaluating $\partial \mathrm{C} / \partial \mathrm{x} @ \mathrm{x}=0$ and simplifying this equation gives (Hershey and Howcroft, 1998):

$$
C_{\text {res }}=\left(\frac{2 A_{\text {core }}}{V_{\text {res }}}\right) \frac{C_{o} \epsilon \sqrt{D_{\text {eff }}}}{\sqrt{\pi}} t^{1 / 2}
$$

where $\mathrm{C}_{\text {res }}=$ solute concentration in reservoir $(\mathrm{mol} / \mathrm{L}), \mathrm{C}_{\mathrm{o}}=$ initial solute concentration of saturated core sample $(\mathrm{mol} / \mathrm{L}), \mathrm{A}_{\text {core }}=$ cross-sectional area of the core $\left(\mathrm{cm}^{2}\right), \mathrm{V}_{\text {res }}=$ volume of the reservoir $\left(\mathrm{cm}^{3}\right), \varepsilon=$ porosity (dimensionless), $\mathrm{D}_{\text {eff }}=$ effective diffusion coefficient $\left(\mathrm{m}^{2} / \mathrm{s}\right)$, and $\mathrm{t}=$ time $(\mathrm{s})$.

By plotting $\mathrm{C}_{\text {res }}$ vs. $\mathrm{t}^{1 / 2}$ and estimating the slope, $\mathrm{m}, \mathrm{D}_{\text {eff }}$ can be calculated by:

$$
\frac{C_{\text {res }}}{t^{1 / 2}}=m=\left(\frac{2 A_{\text {core }}}{V_{\text {res }}}\right) \frac{C_{o} \epsilon \sqrt{D_{\text {eff }}}}{\sqrt{\pi}}
$$


and rearranging to get:

$$
D_{\text {eff }}=\left[\left(\frac{V_{\text {res }}}{2 A_{\text {core }}}\right) \frac{m \sqrt{\pi}}{n C_{o}}\right]^{2}
$$

This solution was used to determine the $\mathrm{D}_{\text {eff's }}$ for $\mathrm{Br}$ through the basalt and breccia core samples. Once the $\mathrm{D}_{\text {eff }}$ was computed for each case, the tortuosity was then calculated using Equation 8. By combining the $\mathrm{D}_{\text {eff }}$, and the $\mathrm{K}_{\mathrm{d}}$ values determined from the batch equilibrium experiments for $\mathrm{Pb}$ and $\mathrm{Cs}, \mathrm{D}_{\text {app }}$ 's were calculated for the reactive solutes.

\section{Bromide Diffusion}

The results of the diffusion experiments showed two trends. First, the estimated diffusion coefficients varied significantly for the two sorbents. Second, the extent of diffusion and the resulting diffusion coefficient varied with time. Each of these findings is discussed in further detail below.

Diffusion of $\mathrm{Br}$ out of the basalt sample as a function of time is shown in Figure 18. As expected, the amount of $\mathrm{Br}$ in the reservoir increases with time as more $\mathrm{Br}$ diffuses out of the core. In the beginning, however, the steep increase in slope indicates that $\mathrm{Br}$ is diffusing out of the core rather quickly. This behavior is expected as the pores in closer contact with the reservoir solution (and hence having a shorter travel distance) release the bromide within them. As the duration of the experiment increases, the rate of concentration change decreases, indicating the system is approaching equilibrium. Though Br may still indeed be diffusing out of the core, it is not occurring as quickly as in the beginning of the experiment because the driving force is decreasing (i.e., there is a smaller difference in $\mathrm{Br}$ concentration between the core and the reservoir).

The same general behavior was observed for diffusion of Br out of the breccia samples, as can be seen in Figure 19. Again, we see the increase in $\mathrm{Br}$ concentration as a function of time as additional $\mathrm{Br}$ diffuses out of the core. To estimate the diffusion coefficients, a plot of concentration (mg/L) versus time $^{-1 / 2}$ is required. From this plot, the slope of the best-fit line as determined from regression analysis is then used to determine the $\mathrm{D}_{\text {eff }}$ as described by Equation 14. Figures 20 and 21 show these plots for each sorbent and the corresponding equations of the best-fit lines.

Table 6 lists the resulting effective diffusion coefficients and tortuosities determined for each sorbent type as a function of the duration of the experiment. As previously mentioned, two trends can be seen from the data: (1) $\mathrm{D}_{\text {eff }}$ decreases and tortuosity increases with time, and (2) $\mathrm{D}_{\text {eff }}$ for the basalt are smaller than those for the breccia.

Table 6. Diffusion parameters for $\mathrm{Br}$ tracer through basalt breccia.

\begin{tabular}{cccc}
\hline \hline Sorbent Type & Duration of Experiments (days) & Deff $\left(\mathrm{m}^{2} / \mathrm{sec}\right)$ & Tortuosity $(-)$ \\
\hline Basalt & 40 & $5.56 \times 10^{-10}$ & 2.92 \\
& 122 & $1.72 \times 10^{-10}$ & 9.43 \\
Breccia & 42 & $9.23 \times 10^{-10}$ & 1.76 \\
& 126 & $3.58 \times 10^{-10}$ & 4.54 \\
\hline \hline
\end{tabular}




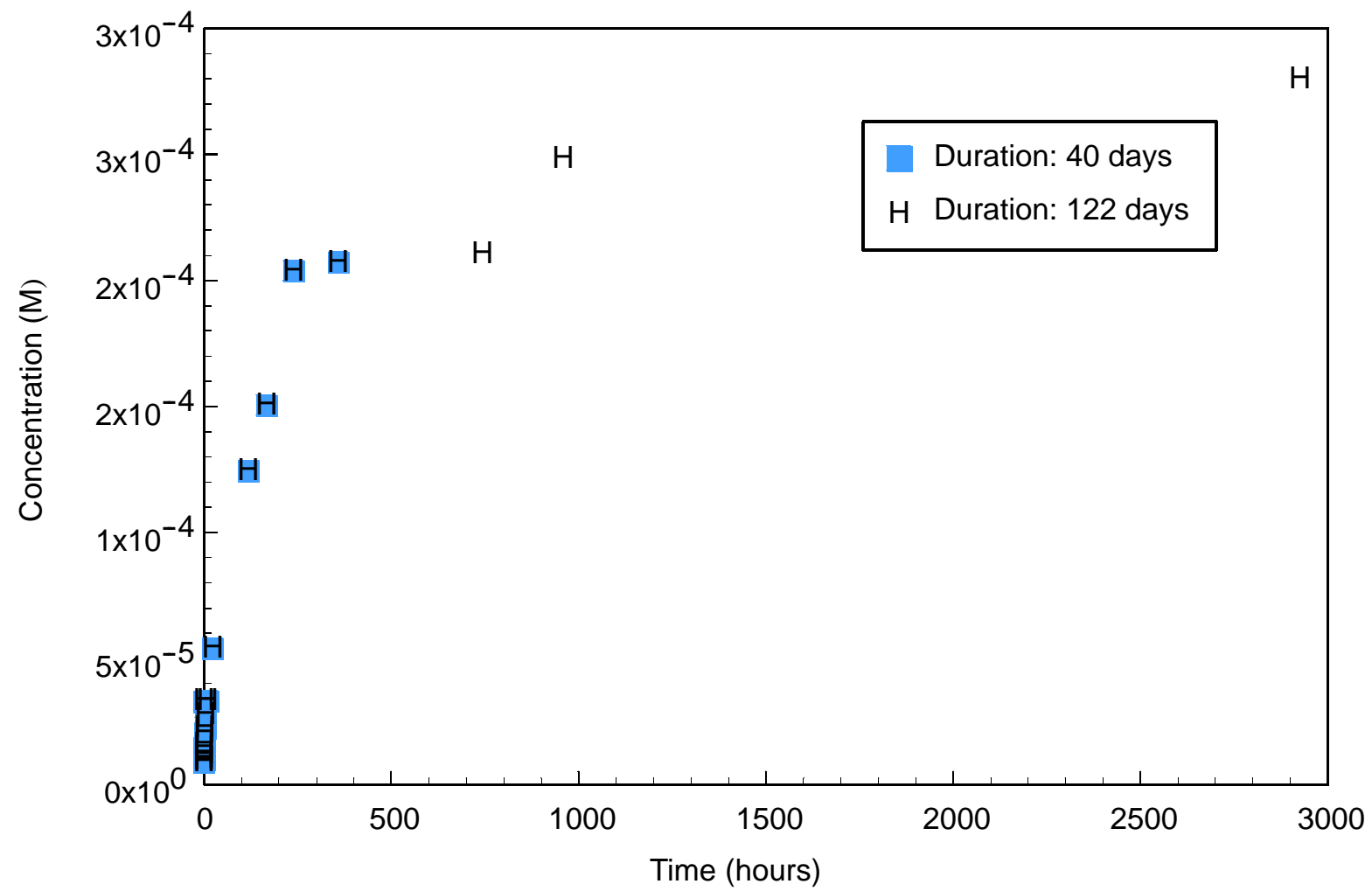

Figure 18. Diffusion of $\mathrm{Br}$ out of basalt core sample as a funtion of time.

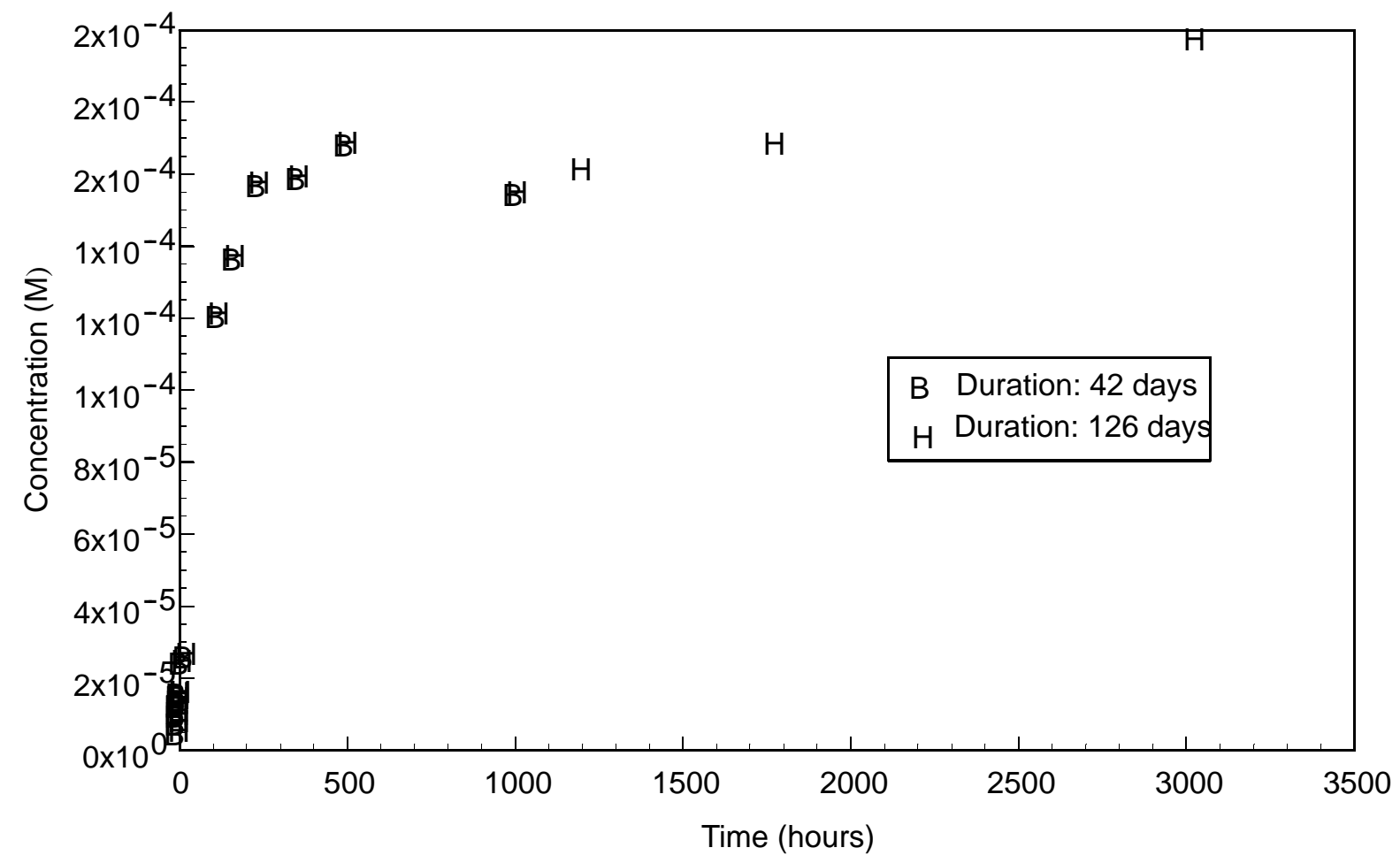

Figure 19. Diffusion of $\mathrm{Br}$ out of breccia core sample as a funtion of time. 


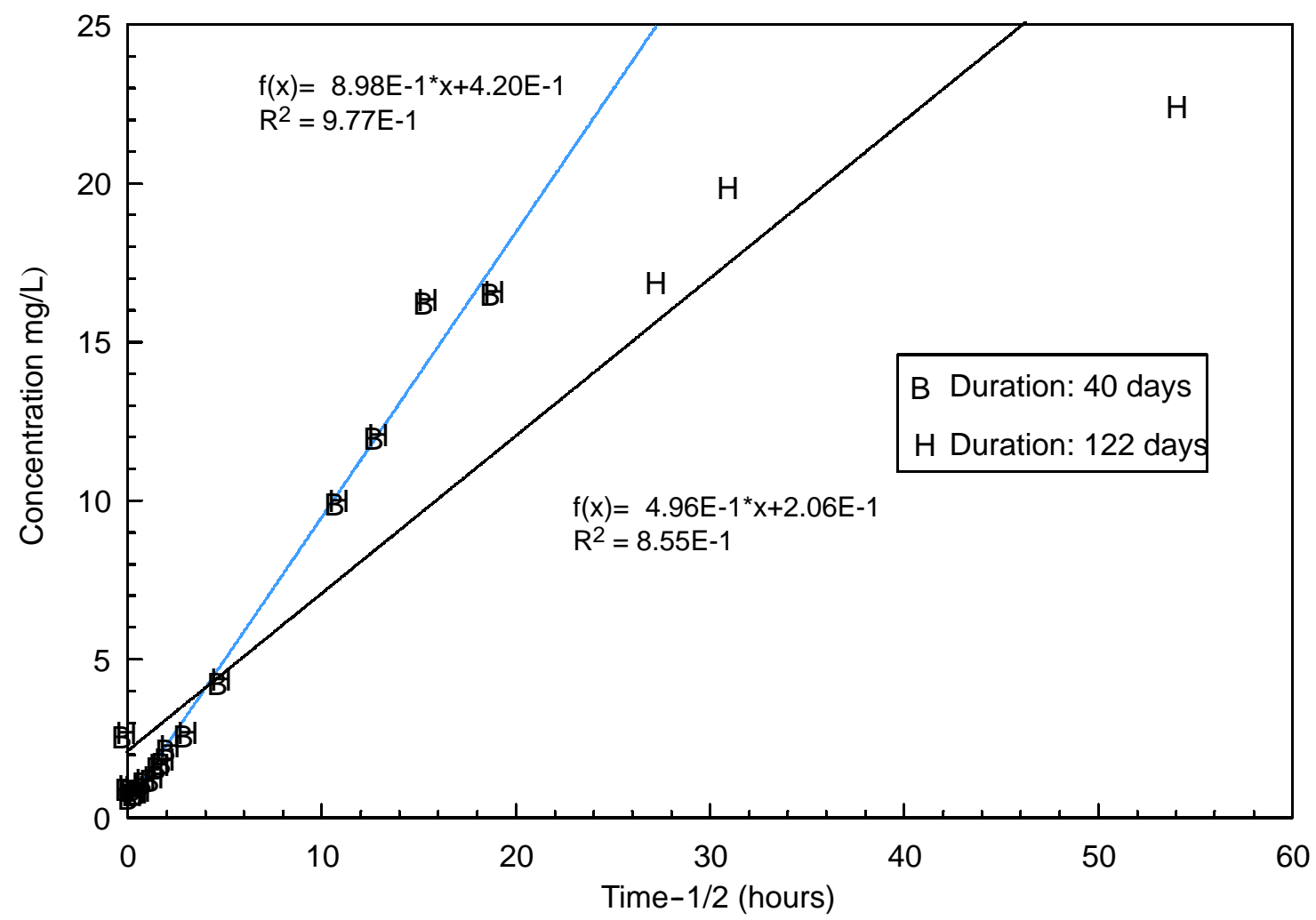

Figure 20. Plot of experimental results and linear regression line of $\mathrm{Br}$ diffusion through basalt core.

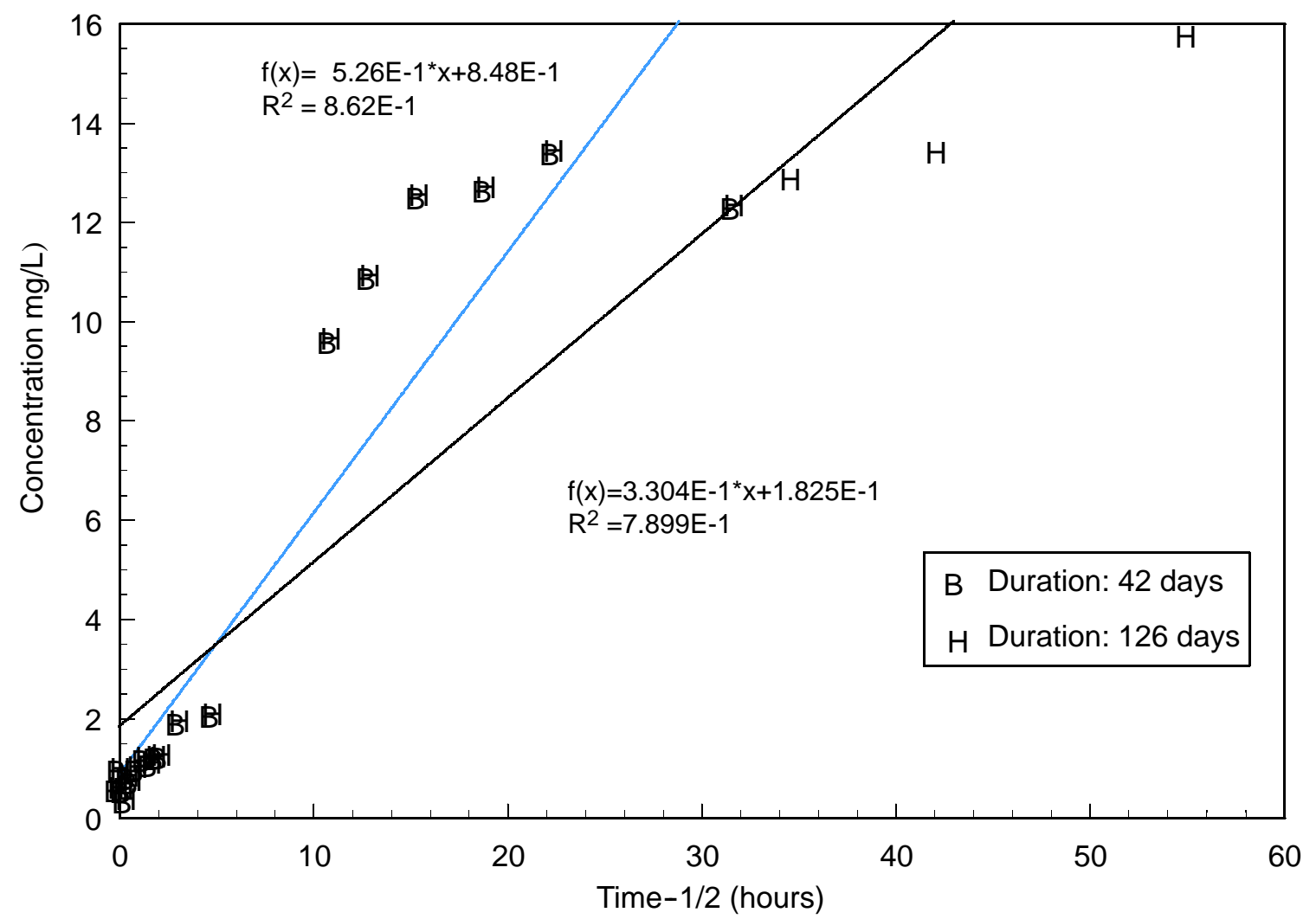

Figure 21. Plot of experimental results and linear regression line of $\mathrm{Br}$ diffusion through breccia core. 
The fact that the tortuosity increased with time is somewhat expected and can be explained as follows. The longer the experiment was allowed to run, the greater the distance $\mathrm{Br}$ would have to travel to reach the reservoir solution, i.e., the longer the paths within the core sample would be. Thus, $\mathrm{Br}$ diffusing from longer, more tortuous paths would require longer travel times to arrive at the outset. The porosity of the sample would also play a role in that, a material having a large porosity, would be able to transmit ions in solution more easily. The fact that the breccia had the higher porosity and lower tortuosity demonstrates this point quite well.

It can be seen from the table that, for each duration, the basalt had the lower effective diffusion coefficient between the two sorbent types. Thus, on average, it is expected that a diffusing $\mathrm{Br}$ ion would take longer to travel through the basalt compared to the breccia. This is consistent with the fact that the basalt does have the lower surface area and the lower porosity, both of which are factors in transmitting ions in solution.

\section{Diffusion Coefficients for $\mathrm{Pb}$ and $\mathrm{Cs}$}

With the data provided from the equilibrium sorption and the diffusion experiments, it is possible to estimate an apparent diffusion coefficient for $\mathrm{Pb}$ through the use of Equation 9. It is important to note here that, because each $\mathrm{K}_{\mathrm{d}}$ value calculated for $\mathrm{Pb}$ is dependent upon $\mathrm{pH}$, the resulting $\mathrm{D}_{\text {app }}$ values will be $\mathrm{pH}$-specific as well. The results of these calculations can be seen in Table 7.

As can be seen from the table $D_{\text {app }}$ values range from $4.72 \times 10^{-16} \mathrm{~m}^{2} / \mathrm{s}$ to $1.13 \times 10^{-13} \mathrm{~m}^{2} / \mathrm{s}$ for the basalt and from $1.34 \times 10^{-15} \mathrm{~m}^{2} / \mathrm{s}$ to $1.62 \times 10^{-13} \mathrm{~m}^{2} / \mathrm{s}$ for the breccia, depending on $\mathrm{pH}$ and reaction time used. From these data, we can conclude that $\mathrm{Pb}$ in solution would travel faster through the breccia than through the basalt. This is consistent with the results of the Br experiments in which $\mathrm{Br}$ appeared to have diffused through the breccia core more quickly than through the basalt core. One might expect $\mathrm{Pb}$ to travel faster through the basalt as the extent of retardation due to sorption on this material is less (as determined through the lower $\mathrm{K}_{\mathrm{d}}$ value). Inspection of Equation 9, however, reveals that the $D_{\text {app }}$ is a function of several factors in addition to the linear distribution coefficient, including the $\mathrm{D}_{\text {mol }}$, tortuosity, bulk density, and porosity. Thus, the fact that the basalt had the higher tortuosity, bulk density, and lower porosity is consistent with the finding that the $\mathrm{Pb}$ ion diffused slower through this material. 
Table 7. Estimated $\mathrm{D}_{\mathrm{app}}$ for $\mathrm{Pb}$ diffusion in basalt and breccia.

\begin{tabular}{|c|c|c|c|c|c|}
\hline Sorbent Type & $\begin{array}{c}\begin{array}{c}\text { Duration } \\
\text { (days) }\end{array}\end{array}$ & $\mathrm{pH}$ & $\begin{array}{c}\mathrm{K}_{\mathrm{d}} \\
\left(\mathrm{m}^{3} / \mathrm{kg}\right)\end{array}$ & $\chi$ & $\begin{array}{c}\mathrm{D} \\
\left(\mathrm{m}^{2} / \mathrm{s}\right)\end{array}$ \\
\hline Basalt & 40 & 6 & 0.214 & 2.92 & $1.13 \mathrm{E}-13$ \\
\hline Porosity $=0.11$ & & 7 & 0.492 & 2.92 & $4.93 \mathrm{E}-14$ \\
\hline \multirow[t]{6}{*}{ Bulk density $=2210 \mathrm{~kg} / \mathrm{m}^{3}$} & & 8 & 1.91 & 2.92 & $1.27 \mathrm{E}-14$ \\
\hline & & 9 & 15.9 & 2.92 & $1.52 \mathrm{E}-15$ \\
\hline & 122 & 6 & 0.214 & 9.43 & $3.51 \mathrm{E}-14$ \\
\hline & & 7 & 0.492 & 9.43 & $1.53 \mathrm{E}-14$ \\
\hline & & 8 & 1.91 & 9.43 & $3.93 \mathrm{E}-15$ \\
\hline & & 9 & 15.9 & 9.43 & $4.72 \mathrm{E}-16$ \\
\hline Breccia & 40 & 6 & 0.305 & 1.76 & $1.62 \mathrm{E}-13$ \\
\hline Porosity $=0.13$ & & 7 & 0.573 & 1.76 & $8.60 \mathrm{E}-14$ \\
\hline \multirow[t]{6}{*}{ Bulk density $=2130 \mathrm{~kg} / \mathrm{m}^{3}$} & & 8 & 1.52 & 1.76 & $3.24 \mathrm{E}-14$ \\
\hline & & 9 & 14.3 & 1.76 & $3.45 \mathrm{E}-15$ \\
\hline & 122 & 6 & 0.305 & 4.54 & $6.27 \mathrm{E}-14$ \\
\hline & & 7 & 0.573 & 4.54 & $3.34 \mathrm{E}-14$ \\
\hline & & 8 & 1.52 & 4.54 & $1.26 \mathrm{E}-14$ \\
\hline & & 9 & 14.3 & 4.54 & $1.34 \mathrm{E}-15$ \\
\hline
\end{tabular}

Note: $\mathrm{D}_{\mathrm{mol}}=1.422 \mathrm{E}-09$.

Because no sorption of Cs occurred when simulating field conditions (i.e. synthetic groundwater), Cs is expected to act essentially as a nonreactive species and hence only an effective diffusion coefficient can be calculated using Equations 7 and 8. The results of these calculations can be seen in Table 8. Inspection of the table again shows Cs is expected to travel more quickly through the breccia than through the basalt for the same reasons as stated earlier in the discussion regarding diffusion of $\mathrm{Br}$ through the samples.

Table 8. Estimated $\mathrm{D}_{\text {eff }}$ for Cs diffusion in basalt and breccia.

\begin{tabular}{lcccc}
\hline \hline Sorbent Type & Duration (days) & $\chi$ & $\begin{array}{c}\mathrm{D}_{\text {mol }} \\
\left(\mathrm{m}^{2} / \mathrm{s}\right)\end{array}$ & $\begin{array}{c}\mathrm{D}_{\text {eff }} \\
\left(\mathrm{m}^{2} / \mathrm{s}\right)\end{array}$ \\
\hline Basalt & 40 & 2.92 & $1.98 \mathrm{E}-09$ & $6.77 \mathrm{E}-10$ \\
& 122 & 9.43 & $1.98 \mathrm{E}-09$ & $2.10 \mathrm{E}-10$ \\
Breccia & 42 & 1.87 & $1.98 \mathrm{E}-09$ & $1.12 \mathrm{E}-09$ \\
& 122 & 4.54 & $1.98 \mathrm{E}-09$ & $4.35 \mathrm{E}-10$ \\
\hline \hline
\end{tabular}

\section{SUMMARY, CONCLUSIONS, AND RECOMMENDATIONS}

During the period of nuclear weapons production and testing, the United States government conducted a series of nuclear weapons tests at various sites throughout the United States and its territories. These tests resulted in subsurface contamination from contaminants such as radionuclides (eg. the cesium radionuclide, ${ }^{137} \mathrm{Cs}$ ), organic compounds, toxic metals (such as lead, $\mathrm{Pb}$ ), hydrocarbons, drilling mud and residues from plastics, epoxies, and drilling instrumentation (U.S. DOE, 1996). Because of their toxicity or radioactivity, many of these contaminants are 
considered to be major health hazards and consequently pose a threat to organisms which are exposed to them. The fate and transport of dissolved contaminants are largely determined by the degree of contaminant interaction with the soil matrix. Studies have shown both, sorption of these ions at the solid-water interface, and diffusion through the porous matrix to be two important factors that may serve as retardation mechanisms.

The objective of this project component was to estimate the rate of migration of reactive $(\mathrm{Pb}$ and $\mathrm{Cs}$ ) and nonreactive (Br) solutes (representative of inorganic contaminants found at underground nuclear test sites) through volcanic basalt and breccia from the Cannikin Test Site, Amchitka Island, Alaska. This site hosted an underground nuclear test conducted in November, 1971. Batch equilibrium sorption and diffusion experiments were performed to estimate isotherm parameters (linear and Freundlich) and diffusion (effective and apparent) coefficients.

The two sorbents used in this study were basalt and breccia. An extensive characterization was performed on each of these sorbents which included mineralogy (solid structure), as determined by $\mathrm{x}$-ray diffraction (XRD), soil $\mathrm{pH}$ measurement, major and trace element analysis by $\mathrm{x}$-ray fluorescence (XRF), solid morphology and composition as determined by scanning electron microscopy (SEM) and energy dispersive x-ray (EDX) spectroscopy, respectively, pore size distribution, surface area, porosity and density determination, and cation exchange capacity (CEC).

Sorption experiments were conducted in synthetic groundwater which had an ionic strength of approximately $0.5 \mathrm{M}$. Because Cs showed no sorption at this high ionic strength, additional experiments were conducted in $0.01 \mathrm{M} \mathrm{NaNO}_{3}$.

Lead displayed a typical cation sorption behavior (on amphoteric surface sites) with fractional uptake increasing with increasing $\mathrm{pH}$, despite the high ionic strength of the synthetic groundwater solution used in these experiments. The fact that $\mathrm{Pb}$ was able to sorb in such a high ionic strength solution indicates the formation of strong, inner-sphere coordination complexes on these mineral surfaces. Sorption experiments using the high ionic strength synthetic groundwater resulted in no appreciable Cs sorption. It is thus expected that under these conditions, Cs would be highly mobile and exhibit no significant sorption on the solid materials. At the lower ionic strength, however, Cs was able to sorb and demonstrated a sorption behavior that was weakly influenced by $\mathrm{pH}$. Such behavior suggests that sorption of Cs by both sorbents is primarily controlled by sorption on the internal, permanent-charge, cation-exchange sites. The dependence of Cs sorption on ionic strength is a good indication that it is forming outer-sphere ion pair complexes, as expected for an alkali metal.

Based on the experimental data, linear and Freundlich isotherm parameters $\left(\mathrm{K}_{\mathrm{d}}\right.$ and $\mathrm{K}_{\mathrm{f}}$, respectively) were calculated for $\mathrm{Pb}$ sorption on the basalt and breccia sorbents. The results indicate that equilibrium partitioning at the solid-water interface is strongly $\mathrm{pH}$-dependent for $\mathrm{Pb}$. As a consequence, realistic modeling of the transport of $\mathrm{Pb}$ in the system would require knowledge of, or assumptions about, the groundwater $\mathrm{pH}$. No parameters were calculated for Cs because of its inability to sorb under field conditions.

The degree of linearity of the isotherms also varied as a function of $\mathrm{pH}$. It was determined (by inspection of the Freundlich exponent) that the isotherm most closely resembled a linear isotherm at a $\mathrm{pH}$ of approximately 8 . Because the $\mathrm{pH}$ of the synthetic groundwater was determined to be approximately 8 , the use of linear distribution coefficients may accurately model the migration of $\mathrm{Pb}$ through the system. 
The results of the diffusion experiments using a sodium bromide $(\mathrm{NaBr})$ tracer showed two particular trends. First, the estimated diffusion coefficients varied significantly for the two sorbents. Second, the extent of diffusion and the resulting diffusion coefficient varied with time. It was found that, the basalt sample generally had a lower effective diffusion coefficient than the breccia when comparing the values after approximately equal times of duration. Thus, it is expected that ions traveling through the basalt would move slower than if traveling through the breccia.

Apparent diffusion coefficients were estimated for $\mathrm{Pb}$ diffusion through each sorbent. Like the $\mathrm{D}_{\text {eff }}$ using the $\mathrm{Br}$ tracer, the $\mathrm{D}_{\text {app }}$ using $\mathrm{Pb}$ was lower for the basalt sorbent. This is somewhat expected as the basalt does have a smaller porosity and specific surface area, and a larger bulk density, all of which play a role in the diffusion of ions through the material. Thus, although sorption of $\mathrm{Pb}$ was stronger on the breccia, it is generally expected that the retardation of $\mathrm{Pb}$ by diffusion through the porous matrix would be greater for the basalt sorbent.

Finally, effective diffusion coefficients were calculated for Cs diffusion through each sorbent. Although Cs is a reactive solute, under the conditions of this experiment it was unable to sorb due to the high ionic strength of the synthetic groundwater. Thus, only a $D_{\text {eff }}$ was estimated. The results again showed Cs would travel slower through the basalt sample as indicated by the lower $D_{\text {eff }}$.

The parameters determined in this study can be used to reduce the uncertainty in radionuclide transport modeling by accounting for retardation of such contaminants due to sorption at the solid-water interface and matrix diffusion. In order to obtain more accurate estimates of the diffusion coefficients, additional diffusion experiments using $\mathrm{Pb}$ and $\mathrm{Cs}$ as tracers would allow the evaluation of ion-specific effects. Finally, it cannot be overemphasized that the results presented here are specific to the conditions used and that application of the reported parameters to other systems might result in significant errors.

\section{REFERENCES}

Barnhisel, R.I. and P.M. Bertsch. Chlorites and Hydroxy-Interlayered Vermiculite and Smectite. in Minerals in Soil Environments. 2nd ed. (Co-edited by J.B. Dixon and S.B. Weed, eds.). Madison, WI: Soil Science Society of America. (1989): 729-789.

Blatt, H. and R.J. Tracy. Petrology: Igneous, Sedimentary, and Metamorphic. $2^{\text {nd }}$ ed. New York: W.H. Freeman. (1996): 529 pp.

Brown, G.M. Mineralogy of Basaltic Rocks. in Basalts: The Poldervaart Treatise on Rocks of Basaltic Composition (Edited by H.H. Hess and A. Poldervaart). New York: John Wiley \& Sons. (1967): 103-162.

Brunauer, S., Emmett, P.H., and E. Teller. Adsorption of Gases in Multimolecular Layers. J. Am. Chem. Soc. 60 (1938): 309-363.

Busenberg, E. and C.V. Clemency. Determination of Cation Exchange Capacity of Clays and Soils Using an Ammonia Electrode. Clays and Clay Minerals 21 (1973): 213-217.

Cox, P.A. The Elements on Earth. New York: Oxford University Press. (1995): 113-189.

Crank, J. The Mathematics of Diffusion. $2^{\text {nd }}$ ed. Oxford University Press, London. (1975): 414 pp.

Drever, J.I. The Geochemistry of Natural Waters: Surface and Groundwater Environments. $3^{\text {rd }}$ ed. Upper Saddle River, NJ: Prentice Hall. (1997): 436 pp. 
Emsley, J. The Elements. New York: Oxford University Press. (1989): 256 pp.

Fetter, C.W. Applied Hydrogeology, $3^{\text {rd }}$ ed. Englewood Cliffs, NJ: Prentice Hall. (1994): 691 pp.

Freeze, R.A. and J.A. Cherry. Groundwater. Englewood Cliffs, NJ: Prentice Hall. (1979): 604 pp.

Gottardi, G. and E. Galli. Natural Zeolites. New York: Springer-Verlag. (1985): 409 pp.

Greenwood, N.N. and A. Earnshaw. Chemistry of the Elements. Tarrytown, NY: Pergamon Press. (1984): $1543 \mathrm{pp}$.

Gregg, S.J. and K.S.W. Sing. Adsorption, Surface Area, and Porosity. 2nd ed. Orlando, FL: Academic Press, Inc. (1982): 303 pp.

Hammond, C.R. The Elements. in CRC Handbook of Chemistry and Physics. 80th ed. (David R. Lide, Editor in Chief). New York, NY: CRC Press. (1995): 4.1-4.34.

Hart, W.A. et al. The Chemistry of Lithium, Sodium, Potassium, Rubidium, Cesium, and Francium. in McGraw-Hill Encyclopedia of Chemistry. 2nd ed. (S.P. Parker, Ed.). New York, NY: McGraw-Hill, Inc. (1992): 1236 pp.

Hershey, R.L. and W.D. Howcroft. "Results of Laboratory Experiments Measuring the Tortuosity of Granite from the Shoal Site, Nevada. Desert Research Institute Report. (1998): 9 pp.

Huang, P.M. Feldspars, Olvines, Pyroxenes, and Amphiboles. in Minerals in Soil Environments. 2nd ed. (Co-edited by J.B. Dixon and S.B. Weed). Madison, WI: Soil Science Society of America. (1989): 975-1051

Jackson, J.A. Glossary of Geology. $4^{\text {th }}$ ed. Alexandria, Virginia: American Geological Institute. (1997): 769 pp.

Knox, R.C., Sabatini, D.A. and L.W. Canter. Subsurface Transport and Fate Processes. Boca Raton, FL: Lewis Publishers. (1993): 430 pp.

Lee, W.H. and L.M. Gard. Summary of the Subsurface Geology of the Cannikin Site, Amchitka Island, Alaska. United States Deparment of the Interior Geological Survey Report \#USGS-474-132. (1971): 24 pp.

LeMaitre, R.W. "Some Problems of the projection of chemical data into mineralogical classifications. Contrib. Mineral. Petrol., 56 (1976): 181-189.

Ming, D.W. and F.A. Mumpton. Zeolites in Soils. in Minerals in Soil Environments. 2nd ed. (J.B. Dixon and S.B. Weed, eds.). Madison, WI: Soil Science Society of America. (1989): 873-911.

Morel, F.M. and J.G. Hering. Principles and Applications of Aquatic Chemistry. New York: John Wiley \& Sons, Inc. (1993): 588 pp.

Mumpton, F.A. Natural Zeolites. in Mineralogy and Geology of Natural Zeolites. (Edited by F.A. Mumpton). Reviews in Mineralogy 4. Chelseas, MI: Mineralogical Society of America. (1981): $1-17$.

Papelis, C and D.A. Sloop. Equilibrium Studies of Lead, Cesium, Strontium, Chromate, and Selenite Sorption on Granite from the Project Shoal Test Site, Fallon, Nevada. Desert Research Institute Report. (1997): 51 pp. 
Papelis, C., Equilibrium Studies of Lead, Strontium, Chromate, and Selenite Sorption on Granite from the Project Shoal Test Site, Fallon, Nevada. Desert Research Institute Report. (1997): 24 pp.

Evaluation of Cobalt Mobility in Soils from the Nevada Test Site. Desert Research Institute Report, (1996): 40 pp.

P. Roberts, and J. Leckie. Modeling the Rate of Cadmium and Selenite Adsorption on Micro- and Mesoporous Transition Aluminas. Environmental Science \& Technology 29, no. 4 (1995): 1099-1108.

Reid, R.C., J.M. Prausnitz, and T.K. Sherwood. The Properties of Gases and Liquids. $3^{\text {rd }}$ ed. New York, NY: McGraw-Hill. (1977): 688 pp.

Ruthven, D.M. Principles of Adsorption and Adsorption Processes. New York: John Wiley \& Sons. (1984): 433 pp.

Stumm, W.S. and J.J. Morgan. Aquatic Chemistry: Chemical Equilibria and Rates in Natural Waters. New York, NY: John Wiley \& Sons. (1996): 1022 pp.

Travis, C.C. and E.L. Etnier. "A Survey of Sorption Relationships for Reactive Solutes in Soil. Journal of Environmental Quality 10, no. 1 (1981): 8-15.

U.S. Department of Energy, Office of Strategic Planning, 1996, The 1996 Baseline Environmental Management Report. Volume II, Alaska-New Jersey. (1996): 484 pp.

Waldron, H.A., ed. Metals in the Environment. San Francisco, CA: Academic Press. (1980): 333 pp. 


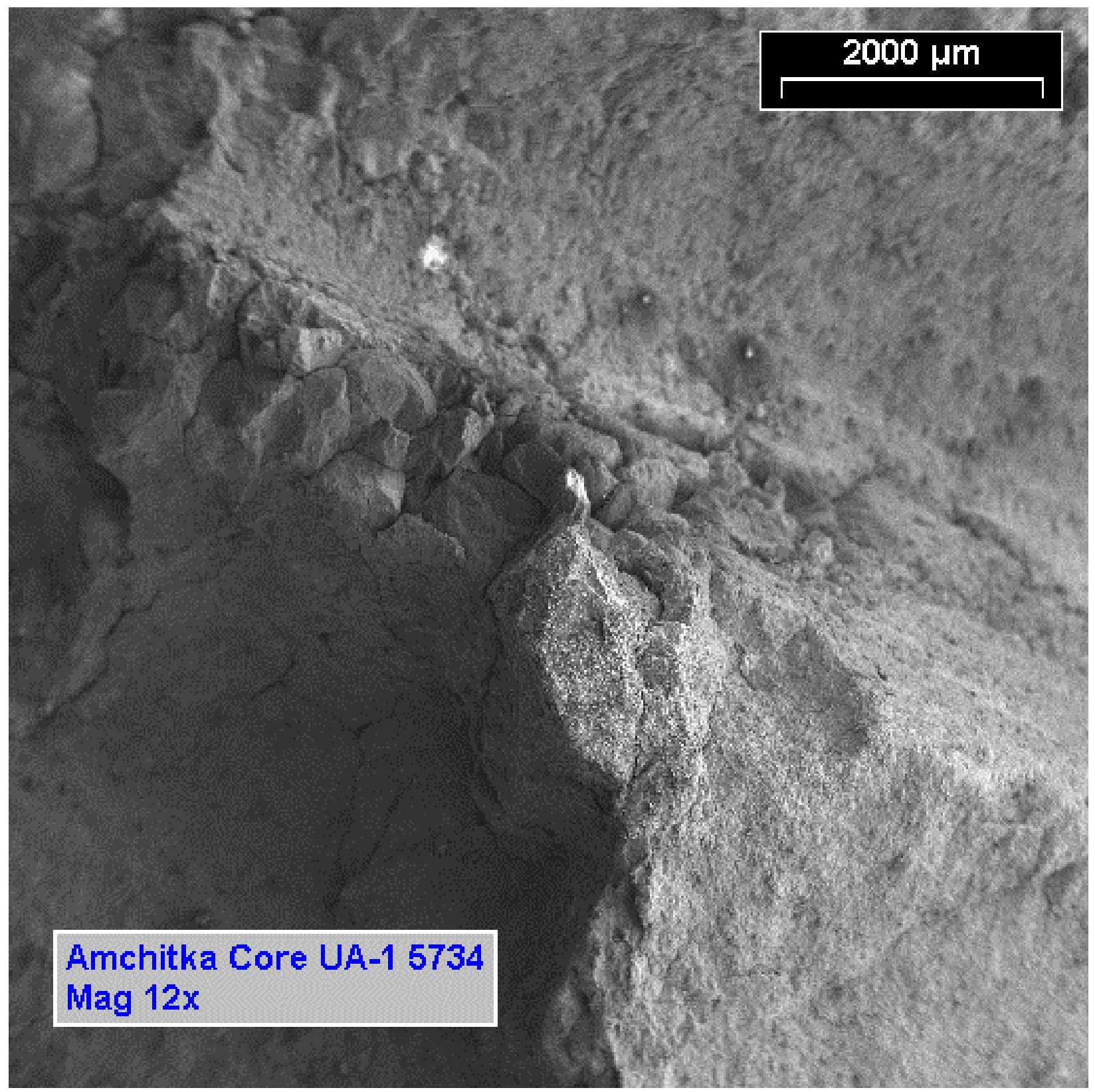

Figure 1. SEM image of breccia (magnification 12x). 


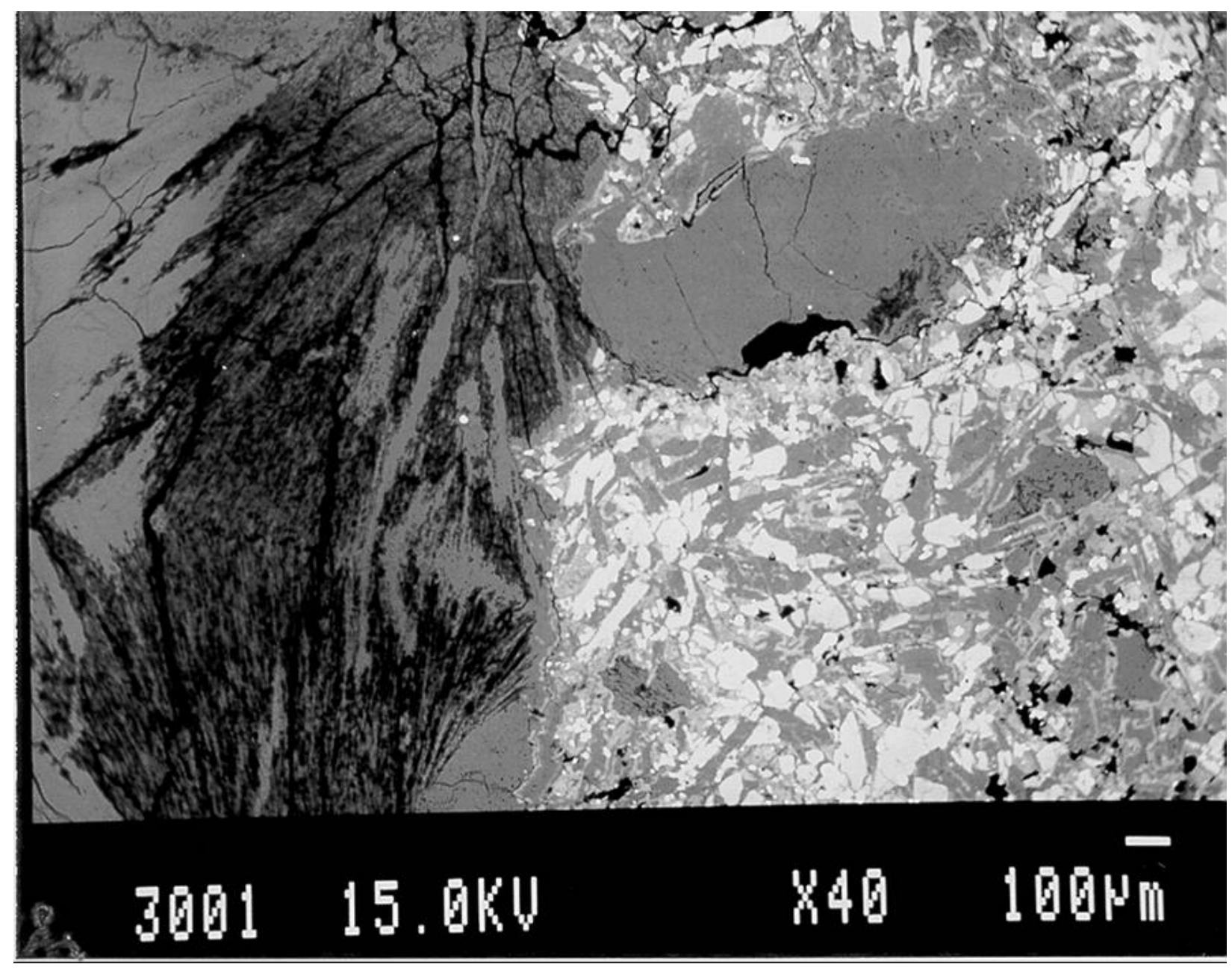

Figure 2. SEM/EDX image (1) of basalt. 


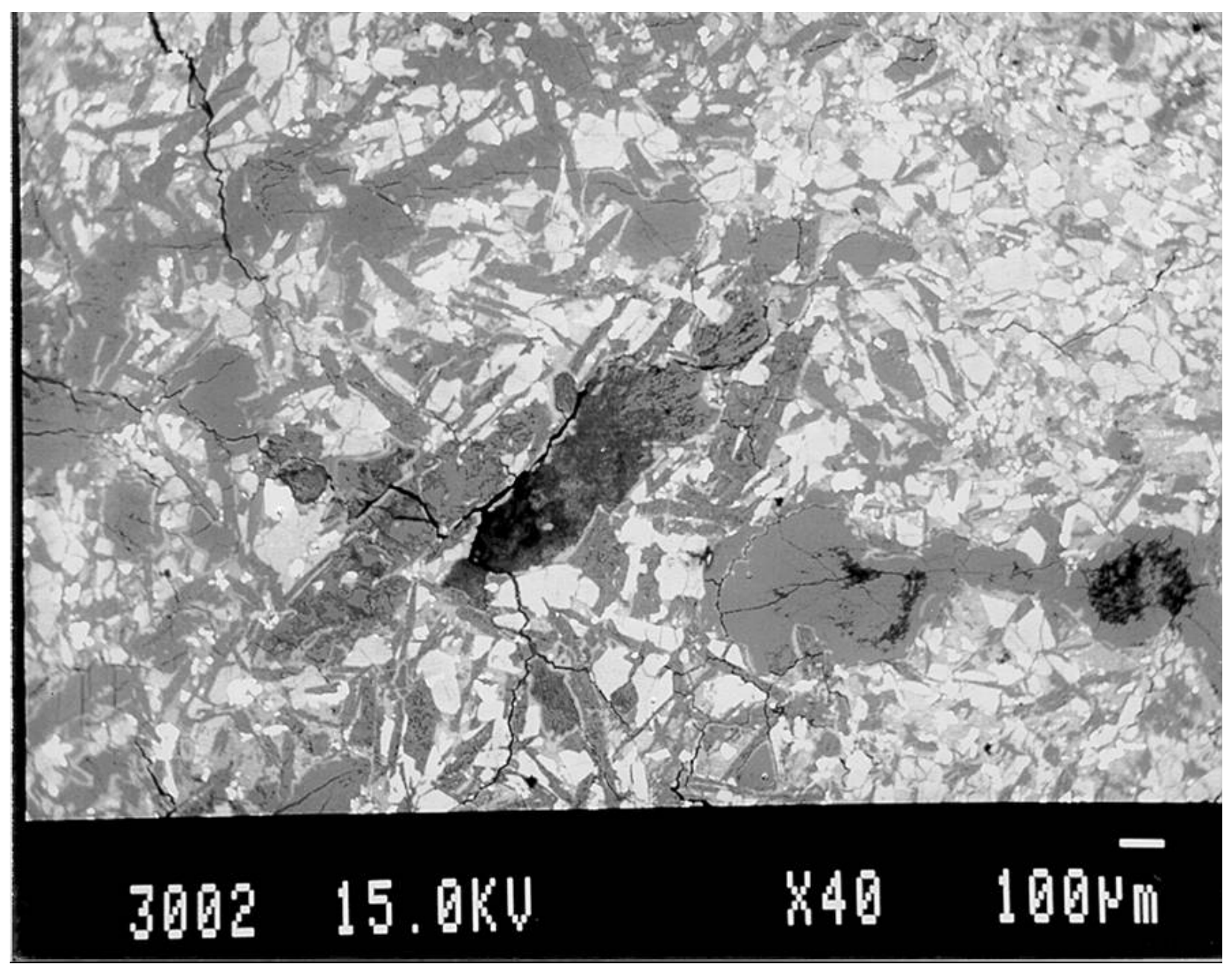

Figure 3. SEM/EDX image (2) of basalt. 


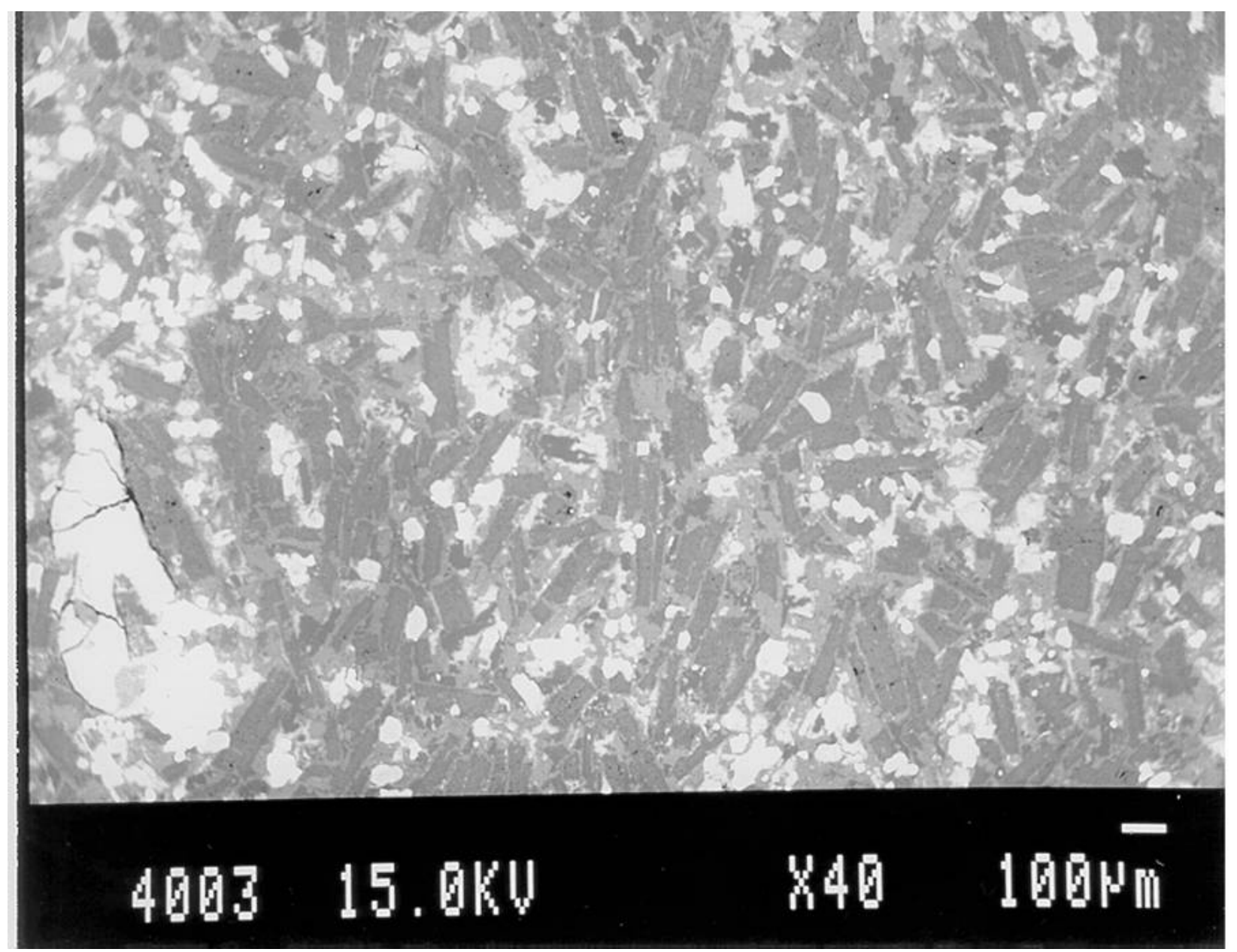

Figure 4. SEM/EDX image (3) of basalt. 


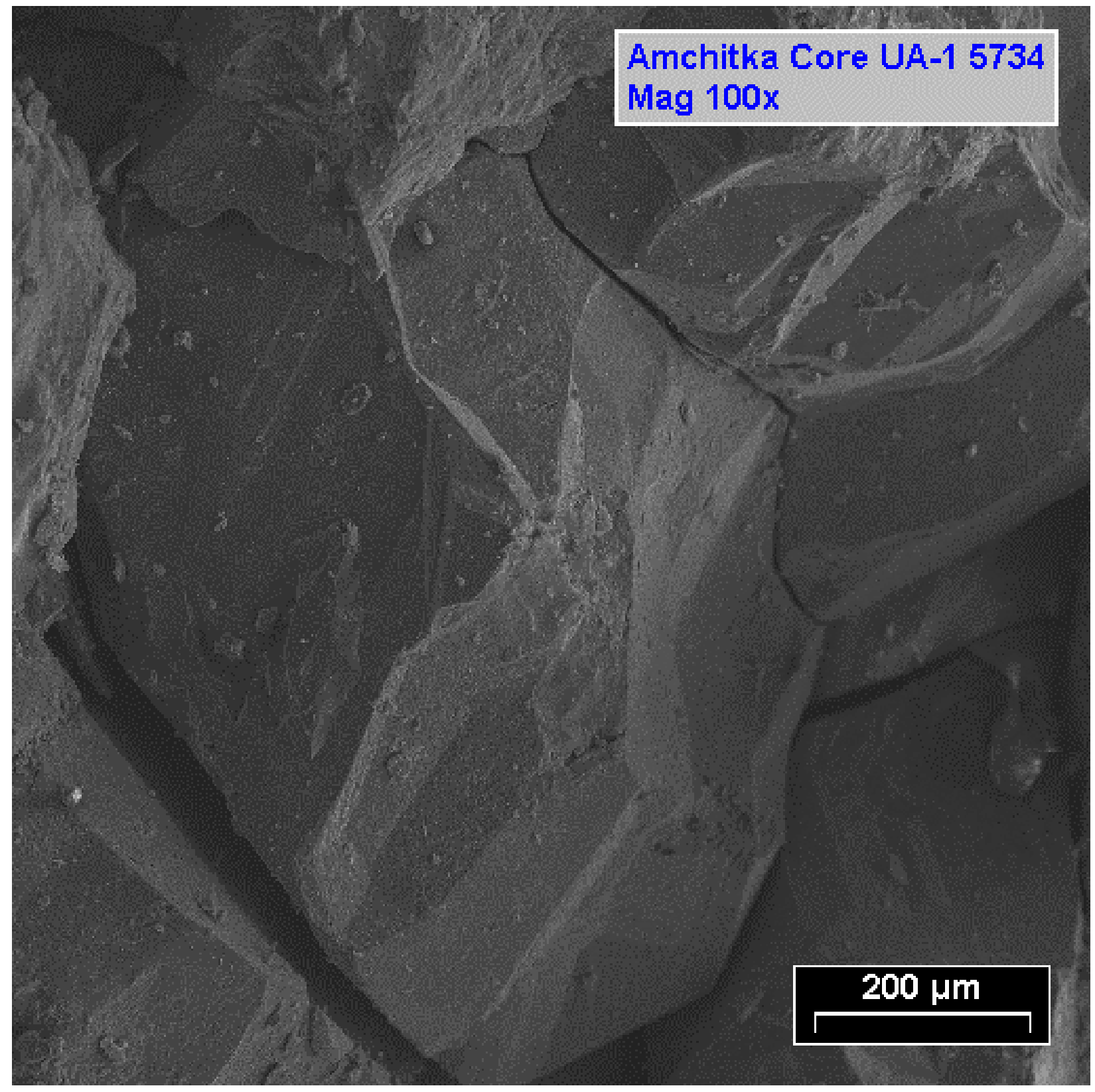

Figure 5. SEM/EDX image (1) of breccia. 


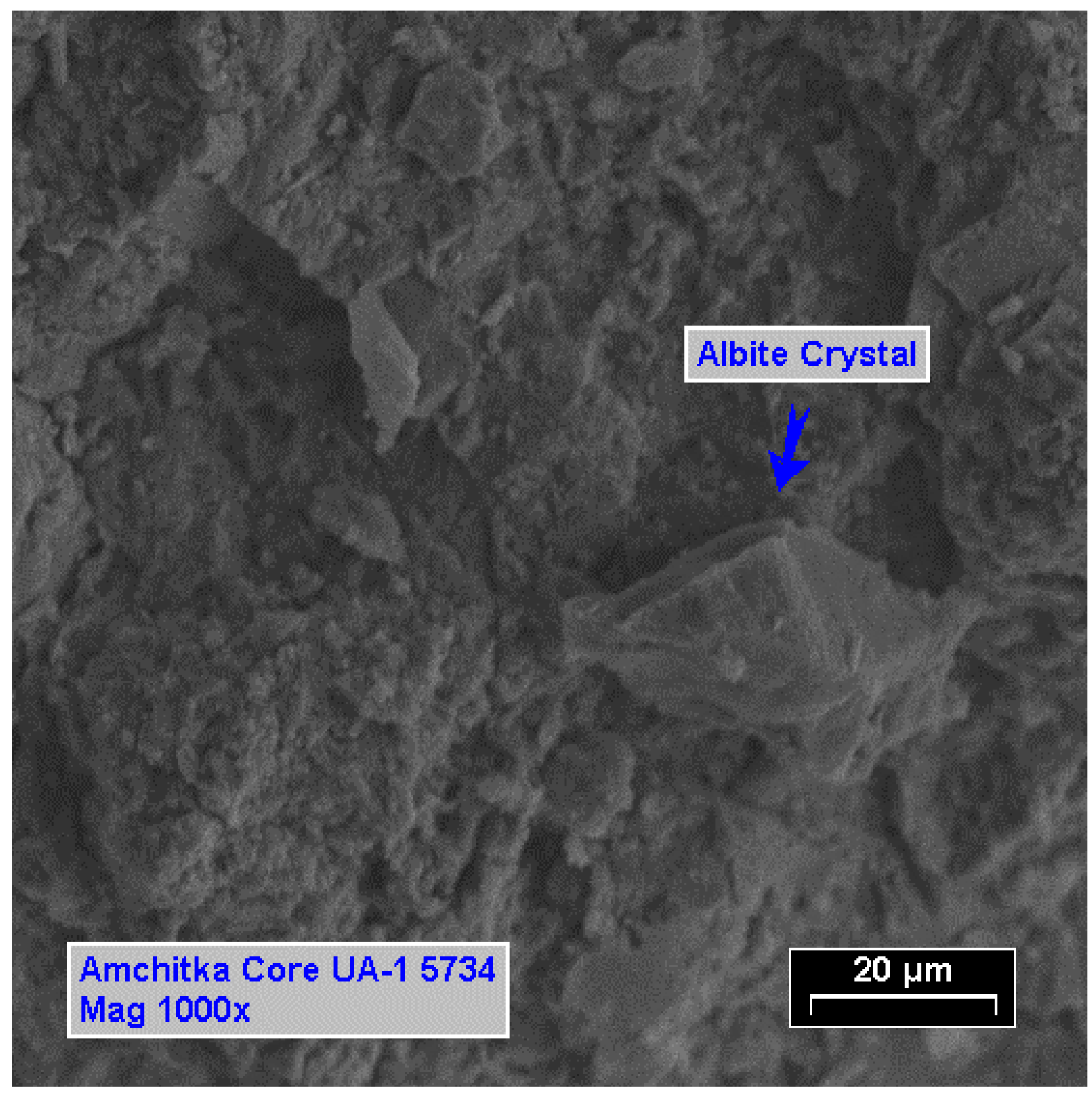

Figure 6. SEM/EDX image (2) of breccia. 